UC - NRLF

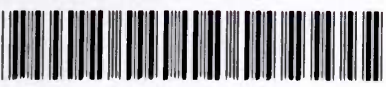
B 3563181 





THE ANIMAL PARASITES OF MAN. 


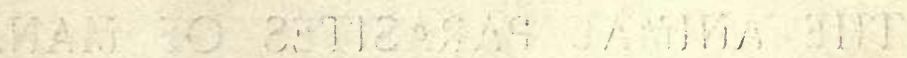


THE

\section{ANIMAL PARASITES OF} MAN

\section{A HANDBO0K FOR STUDENTS AND MEDICAL MEN}

BY

\section{Dr. MAX BRAUN}

Professor of Zoology and Comparative Anatomy, and Director of the Zoological Museum of the University of Konigsberg, Prussia

THIRD ENLARGED AND IMPROVED EDITION

With 294 illustrations in the text

Translated from the German by PAULine FALCKE

BROUGHT UP TO DATE BY

LOUIS W. SAMBON, M.D. (Naples)

Lecturer at the London School of Tropical Medicine; Honorary Member of the Manila Medical Society; Member of the Société de Médicine Tropicale, Paris; The Royal Medical and Chirurgical Society, \&્c.

AND

FRED. V. THEOBALD, M.A.

Vice-Principal and Economic Zoologist to the South Eastern Agricultural College; President of the Association of Economic Biologists, \&ंc.

N E W Y O R K

WILLIAM WOOD AND COMPANY

MDCCCCVIII 
PUBLIC BRALTH IIB.

Catolog for Publi Heath 


\section{PREFACE TO THE ENGLISH EDITION.}

Braun's work on Human Parasites is so well known and has been so much appreciated that it has already reached a third German edition. Thanks to the present publishers an English translation appears which is sure to be welcomed by the AngloSaxon race.

The great importance of parasitology is becoming more marked every day. It is especially in warm climates that this subject is of such interest medically; but, nevertheless, the practitioner in temperate and cold regions is constantly brought face to face with some parasitic infestation.

The rapid strides made in parasitology make it necessary that such works as this should be constantly revised. In this edition a considerable amount of fresh matter has been incorporated, bringing it up to date. The original text has been followed as closely as possible; additional mätter is enclosed in brackets.

The revision of the Protozoa, Cestodes and Nematodes has been undertaken by Dr. Sambon; the Trematodes, Arthropoda, \&c., by myself. A large amount of fresh matter has been added to the Arthropoda especially dealing with Mosquitoes, Tsetse Flies, Ticks, and other disease-carriers.

The translation has been made with much patience and skill by Miss Falcke, to whom the editors are much indebted for the trouble and time she spent over the work.

FRED. V. THEOBALD.

Wye Court, Wye,

November, I905. 



\section{CONTENTS.}

ON PARASITES IN GENERAL

Occasional and Permanent Parasitism

Epizoa, Entozoa, Helminthes

Hermaphroditism ...

Transmigration

Parasites, Messmates, Mutualists

Incidental and Pseudo-parasites

The Influence of Parasites on the Host

Origin of Parasites...

Derivation of Parasites

Change of Host

Literature

THE ANIMAL PARASITES OF MAN

A. Protozoa (Primitive Creatures) ..

General Characteristics of the Protozoa

Classification of the Protozoa

Class I. RHizopodA

Order I. Amabina

Gen. I. Amaba, Ehrbg. ...

Sp. I. Amaba coli, Loesch
2. Amoba gingivalis, Gros.
3. Amaba buccalis, Sternberg
4. Amoba ientalis, Grassi
5. Amoba pulmonalis, Artault
6. Amoba urogenitalis, Baelz
7. Amøba kartulisi, Dofl.
8. Amcba miurai, Ijami ...
9. Leydenia gemmipara, Schaud.

Class II. Flagellata (Mastigophora)

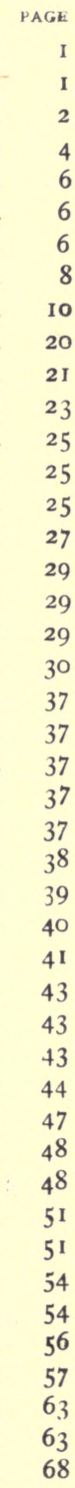


The Animal Parasites of Man-contd.

Protozoa-contd.

PAGE

History

Occurrence of the Coccidiida

Development (Schizogony, \&c.)

Classification of the Coccidia

The Coccidia observed in Man

Gen. Coccidium, R. Lkt....

I. Coccidium cuniculi (Riv.) ..

2. Coccidium hominis (Riv.) ...

3. Coccidium bigeninum, Stiles

Doubtful Species

I. Eimeria hominis ...

2. Coccidioides immitis

...

3. Coccidia of Dura Mater and Excretory Organs

4. Psorosperm Cysts ...

5. Severi's "Monocystide Gregarines"...

Order 3. Hamosporidia

History

The Hæmosporidia of Man

1. Plasmodium malaria (Laveran)

2. Plasmodium vivax (Grassi and Fel.)

3. Plasmodium, sp. ...

4. Doubtful Species ..

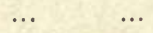

5. The Sporogony of the Malaria Plasmodia

Prophylaxis of Malaria

Hæmatozoa in Beri-beri

Hæmamœbæ in Leucæmia

...

...

The Hæmosporidia in Birds, Reptiles, Amphibia and Fishes

Order 4. Myxosporidia, Bütschli

History

Structure and Development

Order 5. Microsporidia, Balbiani

Order 6. Sarcosporidia, Balbiani

History

Structure and Development

The Sarcosporidia observed in Man

Appendix to the Sporozoa

Class IV. InfusoriA

General Observations

... $\quad$...

.. $\quad \ldots$

$$
\text { ... }
$$$$
\text { ... }
$$

Gen. I. Balantidium, Clap. et Lachm.

I. Balantidium coli (Malmst.)

2. Balantidium minutum, Schaud.

Gen. 2. Nyctotherus, Leidy Nyctotherus faba, Schaud. ..

Appendix to the Infusoria

B. Platyhelminthes (Flat-worms)

Classification of Platyhelminthes $\quad$..

Class I. Trematoda, Rud.

Structure and Development $\quad .$.

Biology

Classification of the Trematodes

The Trematodes observed in Man

Fam. I. Paramphistomida (Fischoed)

Gastrodiscus hominis...

Fam. 2. Fasciolida, Raill.
68

72 
The Animal Parasites of Man-contd.

Platyhelminthes-contd.

Gen. I. Fasciola, L...

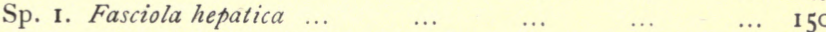

Distomum oculi humani, Amm. ... . ... $\quad \ldots \quad$ I 56

Monostomum lentis, v. Nordm. $\quad \ldots \quad \ldots \quad \ldots \quad \ldots \quad$ i 56

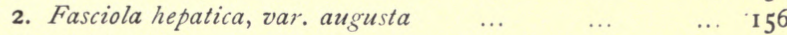

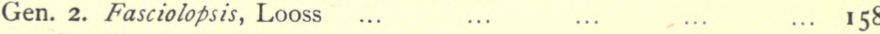

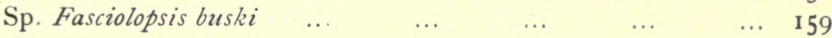

$\begin{array}{lllllll}\text { Distomum rathoutisi ... } & \ldots & \ldots & \ldots & \ldots & \text { I } 59\end{array}$

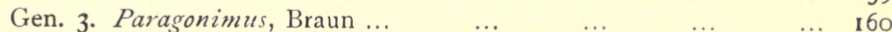

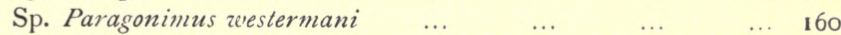

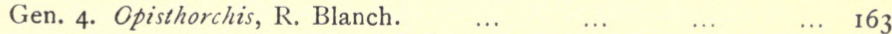

Sp. I. Opisthorchis felineus, Riv. ... $\quad \ldots \quad \ldots \quad \ldots \quad \ldots \quad 163$

Metorchis truncatus (Rud.) $\quad$.. $\quad \ldots \quad \ldots \quad \ldots \quad 166$

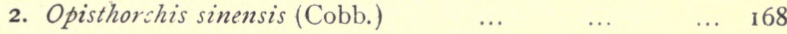

3. Opisthorchis noverca, Braun... $\quad \ldots \quad \ldots \quad \ldots \quad \ldots \quad$ I70

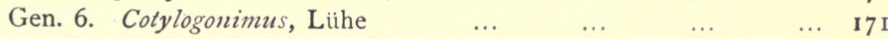

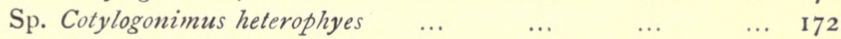

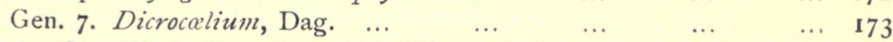

Sp. Dicrocalium lanceatum, Stiles and Hass. $\quad \ldots \quad \ldots \quad \ldots \quad 174$

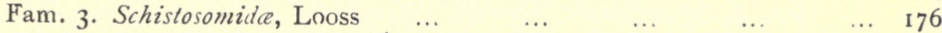

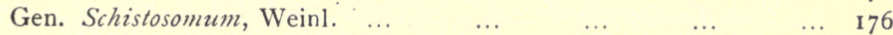

$\begin{array}{llllll}\text { Sp. Schistosomum hcematobium } & \ldots & \ldots & \ldots & \ldots & \text { I76 }\end{array}$

$\begin{array}{lllllll}\text { Schistosomum japonicum } & \ldots & \ldots & \ldots & \ldots & \mathbf{I} 8 \mathbf{I}\end{array}$

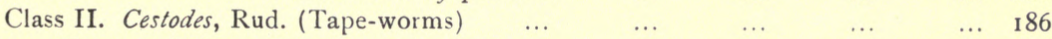

$\begin{array}{llllll}\text { Characteristics and External Conditions } & \ldots & \ldots & \ldots & \ldots & \text { I } 86\end{array}$

$\begin{array}{lllllllll}\text { Anatomy of the Cestodes } & \ldots & \ldots & \ldots & \ldots & \ldots & \ldots & \mathbf{1} 90\end{array}$

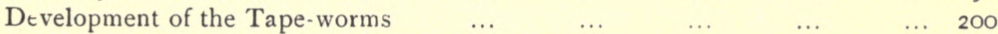

$\begin{array}{llllllllll}\text { Biology } & \ldots & \ldots & \ldots & \ldots & \ldots & \ldots & \ldots & \ldots & 209\end{array}$

$\begin{array}{lllllllll}\text { Abnormalities and Malformations } & \ldots & \ldots & \ldots & \ldots & \ldots & 2 \text { II }\end{array}$

$\begin{array}{llllllll}\text { Classification of the Cestodes } & \ldots & \ldots & \ldots & \ldots & \ldots & \ldots & 2 \text { I } 2\end{array}$

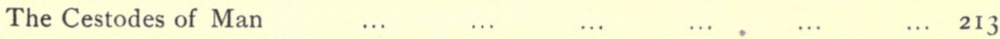

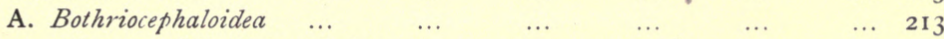

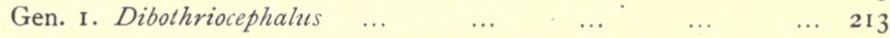

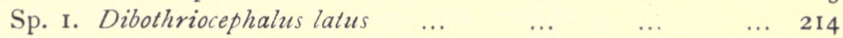

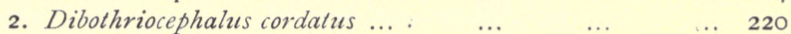

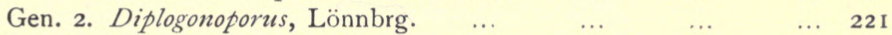

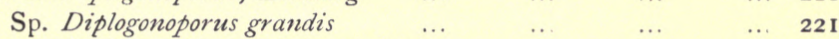

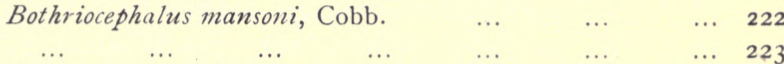

$\begin{array}{lllllll}\text { Gen. 3. Dipyliinum, R. Leuck. } & \ldots & \ldots & \ldots & \ldots & \mathbf{2 2 3}\end{array}$

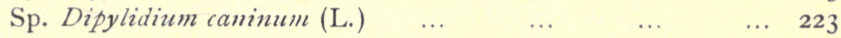

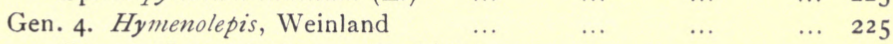

Sp. I. Hymenolepis nana (v. Lieb.) $\quad \ldots \quad \ldots \quad \ldots \quad \ldots 26$

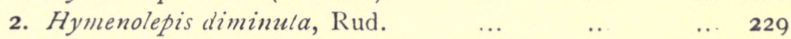

3. Hymenolepis lanceolata, Bloch. $\quad \ldots \quad \ldots 2 \quad \ldots 230$

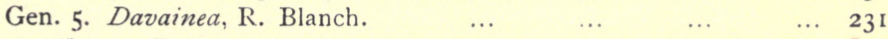

Sp. I. Davainea madagascariensis... $\quad \ldots \quad \ldots \quad \ldots \quad \ldots 232$

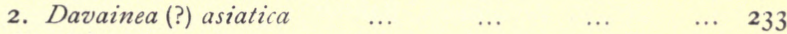

$\begin{array}{llllllllll}\text { Gen. 6. Tenia, L. } & \ldots & \ldots & \ldots & \ldots & \ldots & \ldots & \mathbf{2} 33\end{array}$

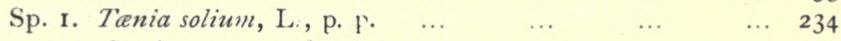
$\begin{array}{lllllll}\text { Cysticercus acanthotrias } & \ldots & \ldots & \ldots & \ldots & 240\end{array}$

2. Tania marginata, Batsch. ... $\quad \ldots \quad \ldots \quad \ldots \quad \ldots 242$

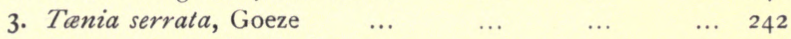

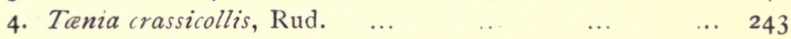


The Animal. Parasites of Man-contel.

Platyhelminthes-conld.

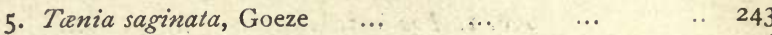

6. Tenia africana, v. Linstow,... $\quad \ldots \quad \ldots \quad \ldots \quad 246$

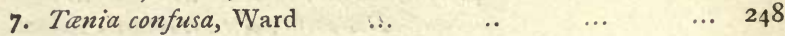

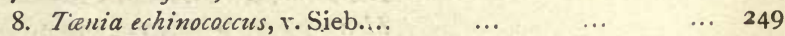

Structure and Devolopment of Echinococcus ... $\quad \ldots \quad 252$

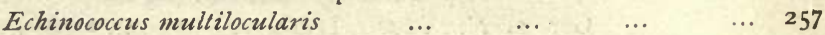

$\begin{array}{cccccc}\text { Tania hominis, v. Lstw. ... } & \ldots & \ldots & \ldots & \ldots & 26 \mathrm{I} \\ \end{array}$

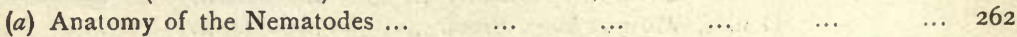

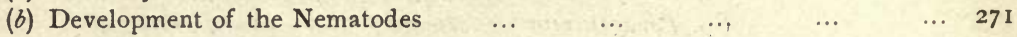

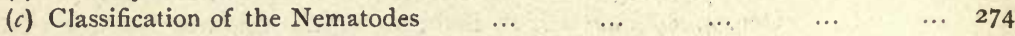

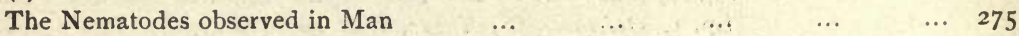

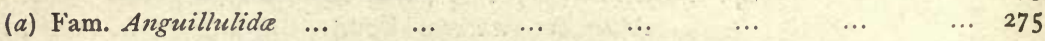

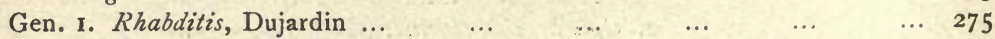

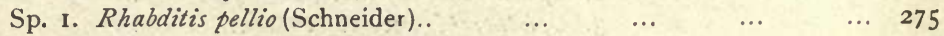

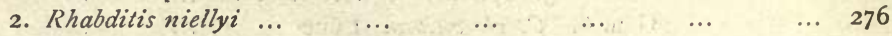

Gen. 2. Anguillulina, Gervais and Beneden $\quad \ldots \quad \ldots \quad \ldots \quad \ldots \quad \ldots \quad \ldots 276$

Sp. Anguillulina putrefaciens, Kühn $\quad \ldots . \quad \ldots . \quad \ldots \quad \ldots 276$

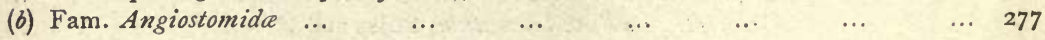

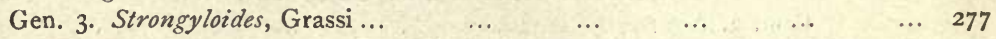

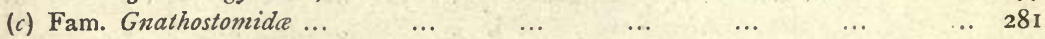

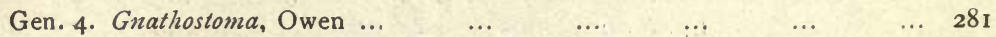

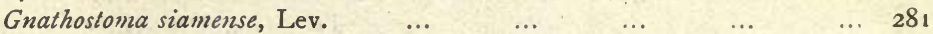

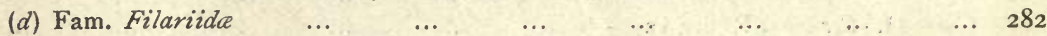

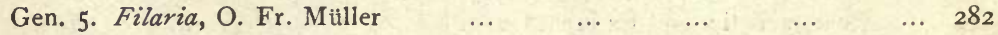

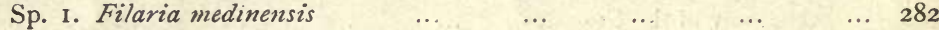

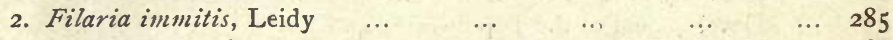

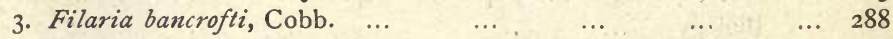

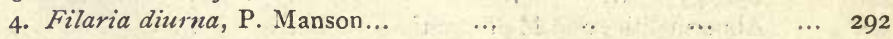

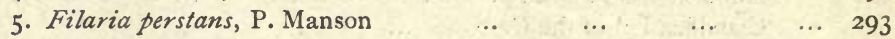

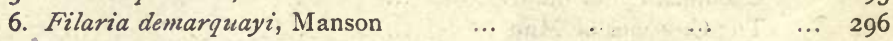

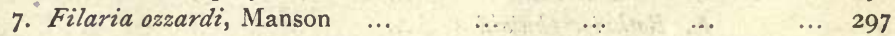

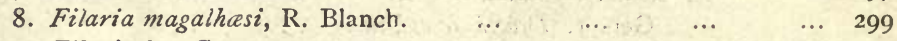

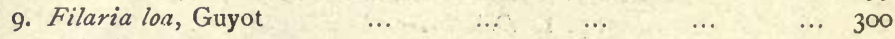

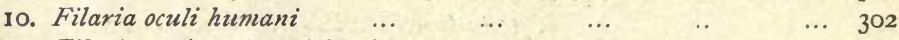

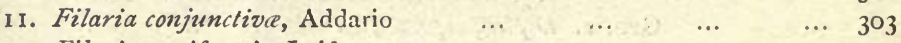

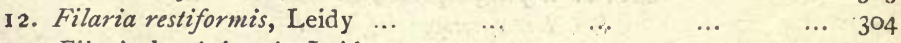

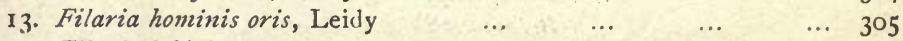

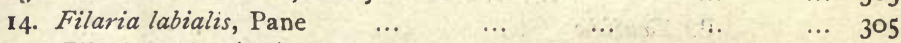

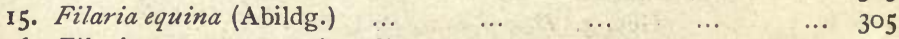

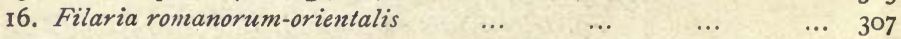

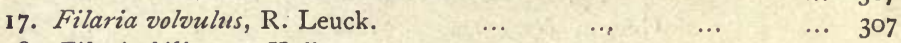

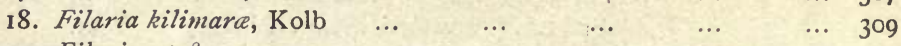

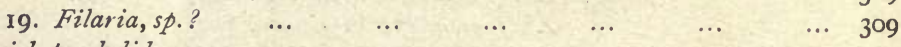

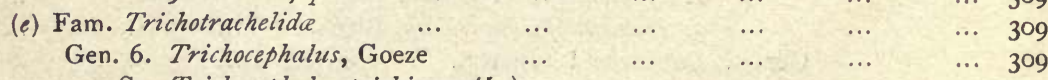

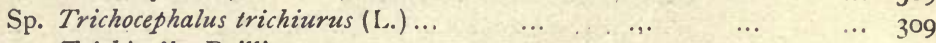

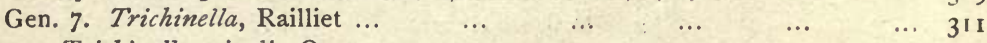

$\begin{array}{llllllll}\text { Trichinella spiralis, Owen } & \ldots & \ldots & \ldots . & \ldots & \ldots & \ldots & 3 \mathrm{II}\end{array}$

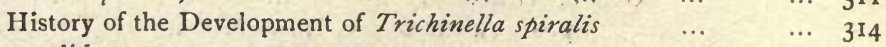

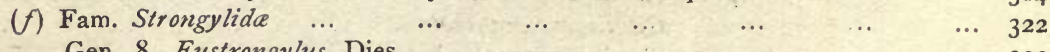

Gen. 8. Eustrongylus, Dies. $\ldots \begin{array}{llllllll} & \ldots & \ldots & \ldots & \ldots & \ldots & 322\end{array}$

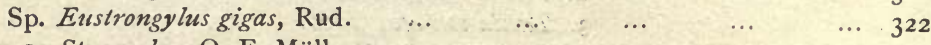

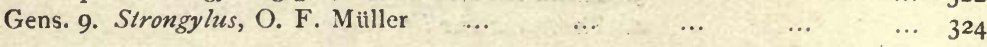


The Animal Parasites of Man-contd.

Nematodes-contd.

Sp. Strongylus apri, Gmelin

Gen. 10. Ankylostoma, Dubini

Sp. Ankylostoma duodenale Uncinaria americana, Stil.

Gen. II. Physaloptera, Rud.

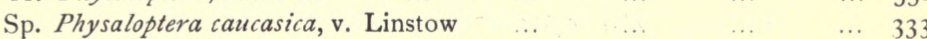

$\begin{array}{llllllll}\text { (g) } \text { Fam. Ascaride } & \ldots & \ldots & \ldots & \ldots & \ldots & \ldots & \ldots\end{array}$

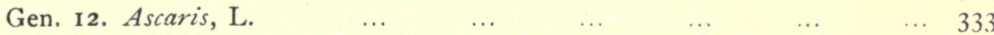

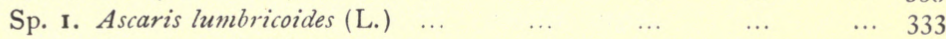

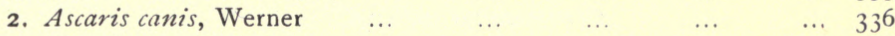

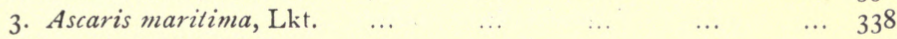

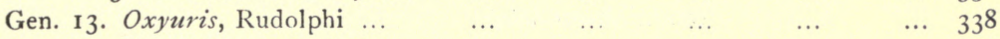

$\begin{array}{llllllll}\text { Sp. Oxyuris vermicularis } & \ldots & \ldots & \ldots & \ldots & \ldots & 338\end{array}$

Gordiacea ...

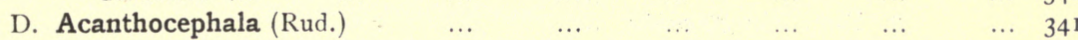

$\begin{array}{lllllllll}\text { Structure and Development } & \ldots & \ldots & \ldots & \ldots & \ldots & \ldots & 34 \text { I }\end{array}$

$\begin{array}{llllllll}\text { Species of Acanthocephala in Man } & \ldots & \ldots & \ldots & \ldots & \ldots & 344\end{array}$

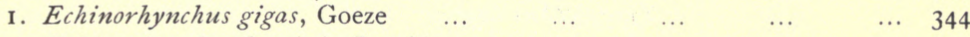

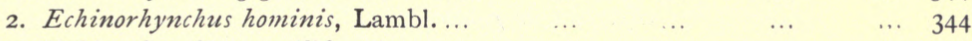

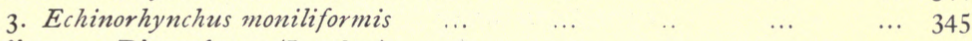

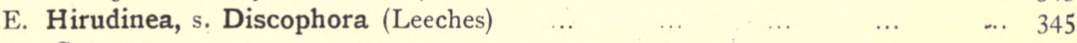

$\begin{array}{lllllllllll}\text { Structure } & \ldots & \ldots & \ldots & \ldots & \ldots & \ldots & \ldots & \ldots & 345\end{array}$

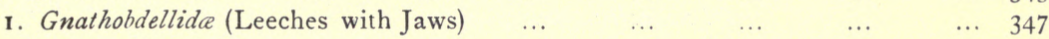

$\begin{array}{llllllllll}\text { Gen. Hirudo, L. } & \ldots & \ldots & \ldots & \ldots & \ldots & \ldots & \ldots & 347\end{array}$

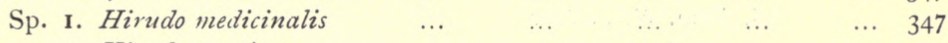

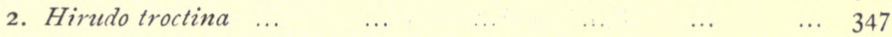

$\begin{array}{llllllllll}\text { Gen. Limnatis } & \ldots & \ldots & \ldots & \ldots & \ldots & \ldots & \ldots & 348\end{array}$

$\begin{array}{lllllllll}\text { Sp. 3. Limnatis nilotica } \ldots & \ldots & \ldots & \ldots & \ldots & \ldots & \ldots & 348\end{array}$

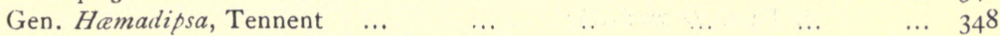

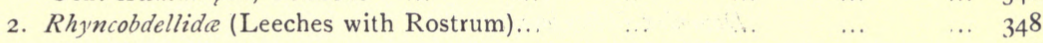

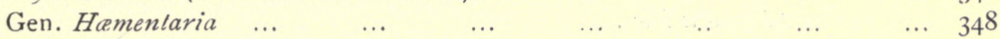

$\begin{array}{lllllllll}\text { Gen. Placobdella } & \ldots & \ldots & \ldots & \ldots & \ldots & \ldots & \ldots & 348\end{array}$

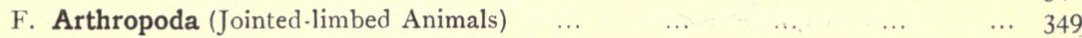

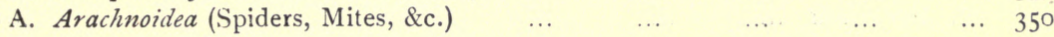

$\begin{array}{lllllllll}\text { Order Acarina } & \ldots & \ldots & \ldots & \ldots & \ldots & \ldots & \ldots & 350\end{array}$

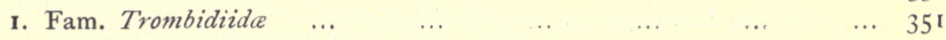

$\begin{array}{lllllllll}\text { Leptus autumnalis, Shaw } & \ldots & \ldots & \ldots & \ldots & \ldots & 35 \mathrm{r}\end{array}$

$\begin{array}{llllllll}\text { Trombidium thalsahuate } & \ldots & \ldots & \ldots & \ldots & \ldots & \ldots & 353\end{array}$

$\begin{array}{llllllll}\text { Akamushi or Kedani... } & \ldots & \ldots & \ldots & \ldots & \ldots & 354\end{array}$

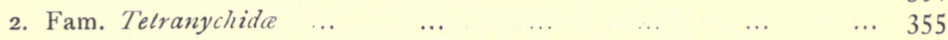

$\begin{array}{llllllll}\text { Tetranychus molestissimus } & \ldots & \ldots & \ldots & \ldots & \ldots & \ldots & 355\end{array}$

$\begin{array}{lllllll}\text { Tetranychus telarius... } & \ldots & \ldots & \ldots & \ldots & \ldots & 355\end{array}$

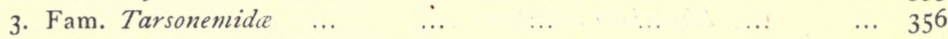

$\begin{array}{lllllllll}\text { Pediculoides ventricosus } & \ldots & \ldots & \ldots & \ldots & \ldots & & \ldots 56\end{array}$

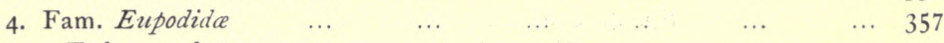

$\begin{array}{llllllllll}\text { Tydeus molestus } & \ldots & \ldots & \ldots & \ldots & \ldots & \ldots & \ldots & 357\end{array}$

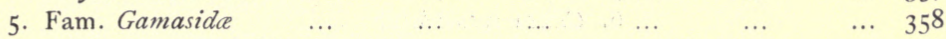

$\begin{array}{lllllllll}\text { Dermanyssus gallina } & \ldots & \ldots & \ldots & \ldots & \ldots & 358\end{array}$

$\begin{array}{lllllllll}\text { Dermanyssus hirundinis } & \ldots & \ldots & \ldots & \ldots & \ldots & 358\end{array}$

$\begin{array}{llllllll}\text { Holothyrus coccinella... } & \ldots & \ldots & \ldots & \ldots & \ldots & 359\end{array}$

$\begin{array}{llllllll}\text { 6. Fam. Ixodida } & \ldots & \ldots & \ldots & \ldots & \ldots & \ldots & 360\end{array}$

$\begin{array}{lllllllll}\text { Classification } \text { of Ixodidce } & \ldots & \ldots & \ldots & \ldots & \ldots & 362\end{array}$

$\begin{array}{lllllllll}\text { Synopsis of Genera } & \ldots & \ldots & \ldots & \ldots & \ldots & \ldots & 363\end{array}$ 
The Animal Parasites of MAN-conli.

Arthropoda-contd.

Ixodes reduvius ...

PAGE

Ixodes hexagonus

Amblyomma cayennense

Hyalomma agyptium

Hamaphysalis punctata

Dermacentor reticulatus.

Rhipicephalus sanguineus...

Argas reflexus ... ...

Argaspersicus ... ...

Argas chinche ...

Ornilhodorus savignyi

Ornithodorus turicala

Ornithodorus talaje

Ornithodorus tholozani

Ornithodorus négnini

7. Fam. Tyroglyphida

Sp. Tyroglyphus farince

Tyroglyphus siro

Tyroglyphus longior

Glyciphagus prunorum ...

Glyctphagus cursor ...

Glyciphagus buski

Rhizoglyphus parasiticus

Histiogaster spermaticus

Cheyletus mericourti, Lab.

8. Fam. Sarcoptide

Sp. Sarcoptes scabiei

Sarcoptes minor

Nephrophages sanguinarius

9. Fam. Demodicidle ... ...

Demodex folliculorum $\quad$...

Order Lingualulide...

Linguatula rhinaria ..

Porocephalus constrictus

B. Myriapoda

C. Insecta

Structure, Development and Classification

I. Rhyncola

(a) Rhynchola aptera, s. parasilica...

Fam. Pediculide

Sp. I. Pediculus capitis

2. Pediculus vestimenti

3. Phthirius inguinalis

(b) Rhynchota hemiptera ...

Fam. Acanthiade

Sp. 4. Cimex leclularius

5. Cimex ciliatus

6. Cimex rotundatus

Fam. Reduviida

Sp. 7. Conorhinus sànguisuga

8. Conorhinus, sp. novum

9. Conorhinus rubrofascialus

I0. Conorhinus renggeri

II. Conorhinus variegalus
. 364

... 366

.. 367

... 367

.. 368

.. 368

.. 369

... 369

... 371

.. 372

... 372

... 373 .

.. 373

.. 373

.. 374

.. 374

... 375

.. 375

... 375

.. 377

.. 377

.. 377

.. 378

.. 378

.. 379

.. 379

.. 380

.. 383

.. 384

... 385

.. 386

... 387

... $3^{87}$

.. 390

... 390

.. 390

.. 39 I

.. 394

.. 394

... 394

.. 395

... 396

.. 396

.. 397

.. 397

.. 397

.. 398

.. 398

... 398
.. 398

... 398

.. 399

.. 399

... 400

... 400 
The Animal Parasites of Man-cont .

Arthropoda-contd.

12. Conorhinus nigrovarius ...

PAGE

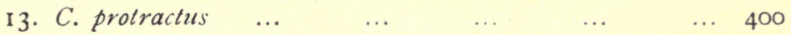

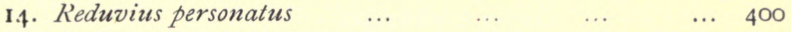

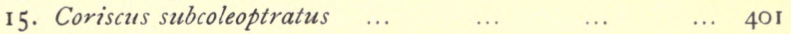

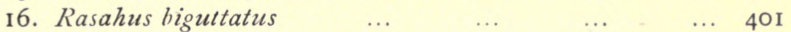

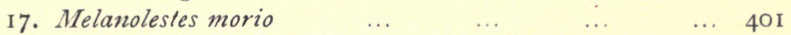

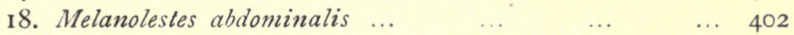

$\begin{array}{llllllll}\text { Fam. Lygaide } & \ldots & \ldots & \ldots & \ldots & \ldots & \ldots & 402\end{array}$

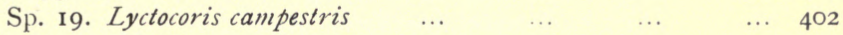

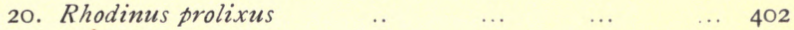

$\begin{array}{llllllllll}\text { II. Coleoptera } & \ldots & \ldots & \ldots & \ldots & \ldots & \ldots & \ldots & 403\end{array}$

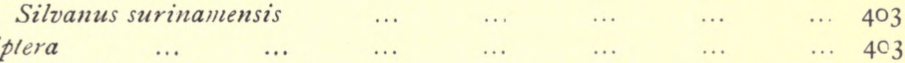

$\begin{array}{llllllll}\text { (a) Aphaniptera... } & \ldots & \ldots & \ldots & \ldots & \ldots & \ldots & 403\end{array}$

$\begin{array}{llllllll}\text { Sp. I. Pulex irritans } & \ldots & \ldots & \ldots & \ldots & \ldots & 403\end{array}$

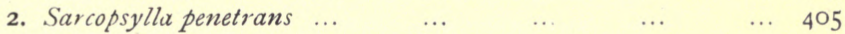

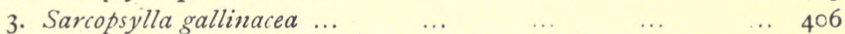

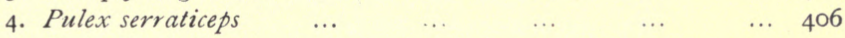

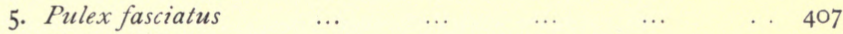

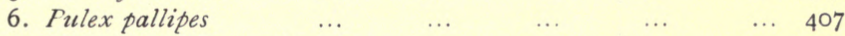

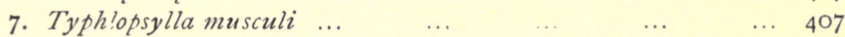

Systematic, Anatomical, and Biological Remarks on Mosquitoes ... $\quad . .407$

$\begin{array}{lllllllll}\text { Culicidæ or Mosquitoes } & \ldots & \ldots & \ldots & \ldots & \ldots & \ldots & \ldots & 415\end{array}$

$\begin{array}{llllllllll}\text { Classification of Culicida } & \ldots & \ldots & \ldots & \ldots & \ldots & \ldots & \ldots & 42 \mathrm{I}\end{array}$

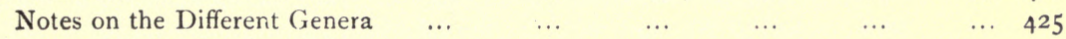

$\begin{array}{llllllll}\text { Sub-family Anophelina } & \ldots & \ldots & \ldots & \ldots & \ldots & \ldots & 425\end{array}$

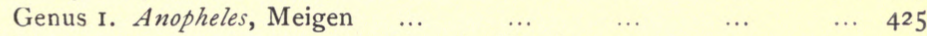

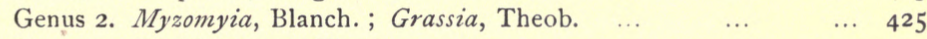

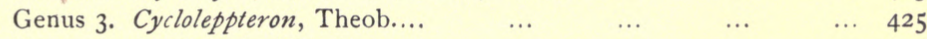

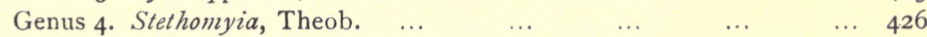

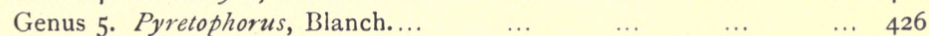

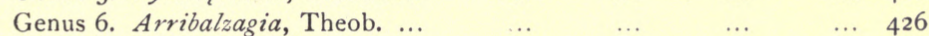

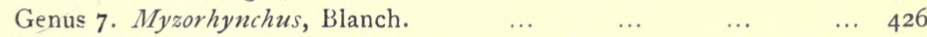

Genus 8. Nyssorhynchus, Blanch. $\quad \ldots \quad \ldots \quad \ldots \quad \ldots \quad \ldots 426$

$\begin{array}{llllllll}\text { Genus 9. Cellia, Theob. } & \ldots & \ldots & \ldots & \ldots & \ldots & 427\end{array}$

$\begin{array}{llllllll}\text { Genus ro. Aldrichia, Theob. } & \ldots & \ldots & \ldots & \ldots & \ldots & 427\end{array}$

$\begin{array}{lllllllll}\text { Sub-family Megarhinina } & \ldots & \ldots & \ldots & \ldots & \ldots & & \ldots & 427\end{array}$

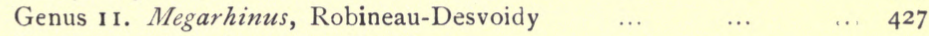

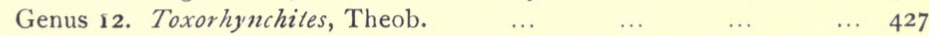

$\begin{array}{lllllllll}\text { Sub-family Culicina } & \ldots & \ldots & \ldots & \ldots & \ldots & \ldots & 427\end{array}$

$\begin{array}{llllllll}\text { Genus Mucidus, Theob. } & \ldots & \ldots & \ldots & \ldots & \ldots & 427\end{array}$

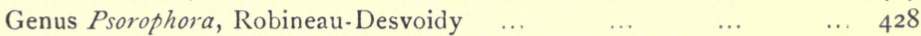

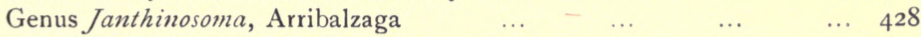

$\begin{array}{lllllllll}\text { Genus Stegomyia, Theobald } & \ldots & \ldots & \ldots & \ldots & \ldots & 428\end{array}$

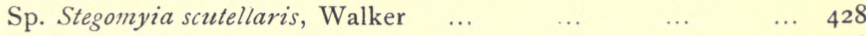

$\begin{array}{llllllll}\text { Genus Theobaidinella, Blanch. } & \ldots & \ldots & \ldots & \ldots & \ldots & 428\end{array}$

Sp. Theobaldinella anmulata, Meigen... $\quad \ldots \quad \ldots \quad \ldots \quad \ldots \quad 429$

$\begin{array}{llllllll}\text { Genus Culex, Linnæus ... } & \ldots & \ldots & \ldots & \ldots & \ldots & 429\end{array}$

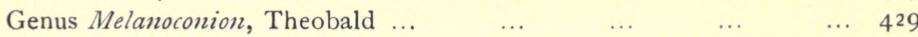

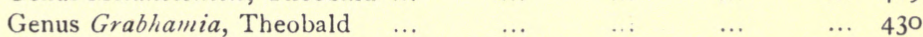

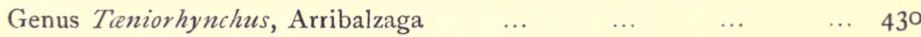

$\begin{array}{lllllllll}\text { Genus Mansonia, Blanch. } & \ldots & \ldots & \ldots & \ldots & \ldots & 430\end{array}$

Genus Acartomyia, Theobald $\quad \begin{array}{lllllllll} & \ldots & \ldots & \ldots & \ldots & \ldots & 43 \mathrm{I}\end{array}$

$\begin{array}{lllllllllll}\text { Other Nematocera } & \ldots & \ldots & \ldots & \ldots & \ldots & \ldots & \ldots & \ldots & 43 \text { । }\end{array}$ 
Other Nematocera - cont $d$.

Sandflies or Simutida

Simulium maculatum, Meigen

Family Chironomida

Genus Ceratopogon

Psychodida ...

Brachycera (Flies)

I. Phora rufipes, Meig. ..

2. Piophila casei (L.)

3. Teichomyza fusca, Macq.

4. Anthomyia canicularis, Meig. ...

5. Homalomyia scalaris, Fabri.

6. Musca domestica, L.

7. Lucilia macellaria (Fabri.)

8. Lucilia nobilis, Meig. ...

9. Lucilia cesar, Limm. ...

I0. Sarcophaga carnaria (L.)

II. Sarcophaga magnifica ...

12. Ochromyia anthropophaga

13. Auchmeromyia depressa

14. Auchmeromyia luteola, Fabr.

15. Hypoderma bovis

16. Hypoderma diana

17. Gastrophilus, sp.

18. Dermatobia cyaniventris

19. Dermatobia noxialis

Biting-mouthed Brachycera ...

Family Tabanida, or Gad-flies

Family Asilida, or Wolf-flies

Family Muscida (in widest sense) Glossina (Tsetse-flies)

Pupipara, or Eproboscida 


\section{LIST OF ILLUSTRATIONS.}

Fig. I. Amoba coli, Loesch.

2. Encysted intestinal amœba. (After Grassi.)

3. Amoeba coli, Loesch. (After Kovacs.)

4. Amaba coli from a Cat. (After Kovacs.)

5. Amaba kartulisi, Dofl. (After Kartulis.)

6. Amoba miurai, Ijima.

7. Leydenia gemmipara, Schaudinn.

8 \& 9. Trichomonas vaginalis. (After Künstler.)

IO. Trichomonas intestinalis, Lkt. (After Grassi.)

I I. Lamblia intestinalis. (After Grassi and Schewiakoff.)

12 \& I3. Cercomonas hominis. (After Davaine, Lambl.)

I4. Monas pyophila, R. Blanch. (After Grimm.)

15. Bodo urinarius, Künstler.

16. Flagellata observed by Barrois.

17. Trypanosoma lewisi, Kent. (After Kempner and Rabinowitch.)

18. Trypanosoma carassii, Mitrophanow.

19. Monocystis agilis. (After v. Stein.)

20. Xiphorhynchus firmus, Léger.

21. Clepsidrina munieri, Schneid. (After Schewiakoff.)

22. Conjugation stages of Clepsidrina blattarum. (After Bütschli.)

23. Sporulation stage of, Clepsidrina ovata. (After Schneider.)

24. Monocystis sp. of earth-worms. (After Bütschli.)

25. Spores of various gregarines. (After Léger.)

26. Clepsidrina longa. (After Léger.)

27. Coccidium cuniculi. (Riv.)

28. Spores of Coccidium cuniculi. (After Balbiani.)

29. Swarm cysts of Coccilium. (After R. Pfeiffer.)

30. Development of Coccidium schubergi, Schaudinn.

3I \& 32. Coccidium cuniculi (Riv.). (After Balbiani.)

33. Coccidium hominis. (After Riek.)

34. Coccidium bigeminum, Stiles.

35. Eimeria hominis, R. Blanch. (After Künstler.)

36. Quartan parasite. (After Mannaberg or Golgi.)

37. Tertian parasite. (After Mannaberg.)

38 \& 39. Pernicious parasite. (After Mannaberg.)

40. Development of pernicious parasites in the intestine of Anopheles maculipennis. (After Grassi.)

4I. Ookinets of pernicious parasites. (After Grassi.)

42. Cysts of pernicious parasites. (After Grassi.)

43. Four stages of sporulation of malaria parasites from $A$. maculipennis. (After Grassi.)

44. Sporoz ites of pernicious parasites. (After Grassi.)

45 \& 46. Hamogregarina stepanowi. (After Danilewsky.)

47. Myxosporidia, \&c. (After J. Müller.)

48. Myxobolus mülleri, Bütschli. 
FIG. 49. Myxidium lieberkïhnii, B. (After Bütschli.)

50. Spore of Myxobolus. (After Doflein.)

51. Myxidimum lieberkühnii. (After L. Cohn.)

52. Myxoproteus ambiguus, \&c. (After Doflein.)

53. Spores of Myxosporidium. (After Bütschli.)

54 \& 55. Nosema bombycis. (After Balbiani, Thélohan.)

$56,57 \& 60$. Sarcocystis miescheriani. (Kühn, Bertram.)

58 \& 59. Sarcocystic tenella. (After Bertram.)

6I. Spores of S. tenella, Raill. (After Laveran and Mesnil.)

$62 \& 63$. Balantidium coli. (Leuckart, Casagrandi and Barbagallo.)

64. Balantidium minutum. (After Schaudinn.)

65. Nyctotherus faba, Schaudinn.

66. Polystomum integerrimum of frog. (After Zeller.)

67. Fasciola hepatica, L.

68. Harmostomum leptostomum. (Olss.)

69. Anterior of Distomum hepaticum.

70. Allocreadium isoporum (Looss).

71. Terminal cells of Cotylogonimus heterophyes. (After Looss.)

72 \& 73. Male and female genitals of Opisthiogylphe endoloba. (After Looss.)

74. Ovum of Fasciola hepatica.

75. Miracidium of Distomum hepaticum. (From Leuckart.)

76. Cercaria of Echinostomum sp.

77. Development of Fasciola hepatica, L. (From Leuckart.)

78. Redia of liver fluke. (After Leuckart.)

79. Redia of Cercaria echinata.

80. Cercaria of liver fluke. (After Leuckart.)

81. Encysted Fasciola hepatica. (After Leuckart.)

82. Gastrodiscus hominis. (After Leuckart.)

83,84 \& 85. Fasciola hepatica.

86. Egg of Fasciola hepatica, L.

87. Limnous minutus: (From Leuckart.)

88. Young Fasciola hepatica. (From Leuckart.)

89. Fasciola hepatica, var. angusta, Raill. (After Stiles and Hassall.)

90. Fasciolopsis buski (Lank.). (After Odhner.)

9I. Distomum rathouisi (Poir). (After Claus.)

92 \& 93. Paragonimus westermani (Kerb.).

94. Egg of Paragonimus westermani (Kerb.).

95 \& 98. Opisthorchis felineus, Riv.

96. Egg of Opisthorchus felineus.

97. Distomum siliricum. (After Winogradoff.)

99. Metorchis truncatus, Rud.

100 \& 101. Opisthorchis sinensis, Cobb.

102. Uterine egg and miracidium of Opisthorchis sinensis.

103. Opisthorchis noverca, Mihi. (After Leuckart.)

I04. Distomum conjunctum, Cobb.

105. Cotylogonimus heterophyes (v. Sieb.). (After Looss.)

106. Dicrocalium lanceatum (Stiles and Hassall.)

107. Eggs of Dicrocalium lanceatum (Stiles and Hassall).

108. Miracidia of Dicrocalium lanceatum.

109. Schislosomum hamalobium, Bilh. (After Looss.)

I10, III \& I12. Schistosomum hamatobium.

113. Ovum of Schistosomum hamatobium, Bilh.

114. Schistosomum japonicum.

II5. Section if vessel, showing schistosomes.

116 \& 117. Section of appendix, showing ova.

118. Transverse section of Ligula. (After Blochmann.) 
FIG. II9. Section through proglottis of Tinia crassicollis.

I 20 \& I 2I. Rostellum and head of Dipylidium caninum.

122. Section of head of Tania crassicollis.

123. Young Acanthobothrium coronatum, v. Ben.

124. Scolex of cysticercoid from Arion. (After Pintner.)

125. Proglottis of Tenia saginata.

126. Proglottis of Dibothriocephalus latus. (From Claus.)

127. Section through proglottis of $T$. crassicollis.

128. Section through proglottis of Dibothriocephalus latus.

129. Egg of Diplogonoporus grandis. (After Kurimoto.)

130. Uterine egg of $T$. saginata, G. (After Leuckart.)

131. Oncospheres of $T$. africana. (After von Linstow.)

132. Plerocercus of Tetrarhynchus.

133. Young cysticerci of Tenia saginata, G. (From Leuckart.)

134. Cysticercoid of Arion ater.

135. Section through piece of Canuris cerebralis.

136. Median section through Cysticercus. (After Leuckart.)

I37. Cysticercus pisiformis.

138. Chains of segments of Dibothriocephalus latus.

139. Section of head of Dibothriocephalus latus.

I40. Proglottis of Dibothriocephalus latus.

141. Egg of Dibothrioiephalus latus.

142 \& 143. Oncosphere of Dibothriocephalus latus. (After Schauinsland, Leuckart.)

144. Plerocercoid of Dibothriocephalus latus.

145. Plerocercoid of D. latus in a Lota vulgaris.

146. Cephalic end of $D$. cordatus. (After Leuckart.)

I 47 \& I48. Diplogonoporus grandis. (After Kurimoto.)

149. Cephalic end of Bothr. mansoni, Cobb. (After Leuckart.)

I50 \& 151. Dipylidium caninum. (After Diamare.)

152. Cysticercoid of Dipylidium caninum. (After Grassi and Rovelli.)

153 \& I54. Hymenolepis nana (v. Siebold).

I55. Villus of rat with cysticercoid of Hymenolepis murina. (After Grassi and Rovelli.)

156 \& 157 . Hymenolepis diminuta.

158. Ovum of Hymenolepis diminuta. (After Grassi.)

159. Hymenolepis lanceolata. (After Goeze.)

I6o. Scolex of Davainea madagascariensis. (After Blanchard.)

I6I \& I62. Tania solium.

163. Hooks of $T$. solium. (After Leuckart).

ז64. Ovum and embryo of $T$. solium.

165. Mature proglottides of $T$. solium.

I66. Hooklets of $T$. marginata. (After Leuckart.)

I67 \& 168. Tania saginata.

169. Muscle of ox with Cysticercus bovis. (After Ostertag.)

170, I7I \& I72. Tania africana. (After v. Linstow.)

I73 \& I74. Tania confusa.

175. Tania echinococcus.

176. Section through an Echinococcus cyst.

177 \& 178. Echinococcus veterinorum.

I79. Echinococcus hominis.

I80. Hooklets of Echinococcus.

I8I. Echinococcus multilocularis. (After Ostertag.)

182, 184, 189 \& 217. Ascaris lumbricoides.

183 \& 185 . Ascaris megalocephalus. (After Nassonow.)

I86 \& 188. Rhabditis form of Rhabdonema nigrovenosum.

187. Transverse section through Ascaris mystax.

I90. Muscle of pig with capsules containing Trichinx. 
xviii.

FIG.

191 \& 192. Strongyloides intestinalis.

193. Gnathostoma siamense. (After Levinson.)

194, 194a \& 194b. Guinea-worm or Filariı medinensis. (After Leuckart.)

195. Filaria immitis. (After Railliet.)

196. Mouth organs of mosquito piercing skin of dog. (After Noè).

197. Larvæ of Filaria bancrofti. (After Railliet.)

198. Filaria magalhãesi. (After v. Linstow.)

199 \& 200. Filaria loa. (After R. Blanchard.)

201 \& 202. Filaria conjunctiva. (After Addario, Grassi.)

203 \& 204. Filaria equina. (After Railliet).

205. Trichocephalus trichiurus.

206. Trichinella spiralis. (After Claus.)

207. Trichiniella. (After Hertwig-Graham.)

208 \& 209. Calcification of Trichinella.

2 ro. Eustrongylas gigas. (After Railliet.)

2II. Eggs of Eustrongylas gigas. (After Railliet.)

212. Strongyhus apri. (After Railliet.)

213, 214 \& 216. Ankylostoma duodenale.

215. Ovum of Ankylostoma ducodenale. (After Parona and Grassi.)

217. Ascaris lumbricoides. (From Claus.)

218. Ovum of Ascaris lumbricoides.

219. Section through head-part of Ascaris canis. (After Leuckart.)

220. Ovum of Ascaris canis.

221 \& 222. Oxyuris vermicularis.

223. Echinorhynchus angustatus.

224. Echinorhynchus acus. (After Wagener.)

225. Egg of Echinorhynchus gigas. (After Leuckart.)

226. The internal organs of the leech. (After Kennel.)

227. Hirudo medicinalis. (After Claus.)

228 \& 229. Leptus autumnalis.

230. The Kedani mite. (After Tanaki.)

231. Tetranychus telarius, var. russeolus, Koch. (After Artault.)

232. Pediculoides ventricosus. (After Laboulbène and Mégnin.)

233. Tydeus molestus. (After Moniez.)

234. Dermanyssus gallina. (After Berlese.)

235. Dermanyssus hirundinis. (After Delafond.)

236 \& 237. Ixodes ricinus. (After Pagenstecher.)

238. Argas reflexus. (After Pagenstecher.)

239. Argas persicus. (After Mégnin.)

240. Tyroglyphus farina. (After Berlese.)

24I. Tyroglyphus longior, Gerv. (After Fum. and Robin.)

242. Rhizoglyphus parasiticus. (After Dalgetty.)

243 \& 244. Sarcoptes scabiei. (After Fürstenberg.)

245. Sarcoptes minor. (After Railliet.)

246 \& 247. Nephrophages sanguinarius. (After Miyake and Scriba.

248. Demodex folliculorum of the dog. (After Mégnin.)

249 \& 250. Linguatula rhinaria.

25I \& 254. Pediculus vestimenti, Burm.

252. Ovum of the head-louse.

253. Head-louse, male.

255. Phthirius inguinalis, Leach.

256. Head of the bed-bug.

257. Pulex irritans.

258. Larva of flea. (After Railliet.)

259. Pulex serraticeps.

260 \& 26I. Sarcopsylla penetrans. (After Moniez.) 
Fig. 262. Head of male and female Anopheles. (After Giles.)

263. Head of male and female Culex. (After Giles).

264. Mouth-parts of $A$. claviger. (After Grassi.)

265. Anopheles maculipennis. (After Nuttall and Shipley.)

266. Longitudinal section of an Anopheles. (After Grassi.)

267. Anopheles maculipennis, Meigen. (After Grassi.)

268. Larva of $A$. maculipennis, Fabr. (After Grassi.)

269. Larva of Culex. (After Grassi.)

270. Pupa of $A$. maculipennis, Meig. (After Grassi.)

27I. Neuration of wing. (Theobald.)

272. Heads of Culex and Anopheles. (After Daniels.)

273. Eggs of various mosquitoes.

274. Diagram of structure of typical mosquito. (Theobald.)

275. Types of scales; head and scutellar ornamentation; forms of clypeus. (Theobald.)

276. Wing of Anopheles maculipennis, Meigen.

277. Wing of a Culex.

278. Wing of Simulium.

279. Wing of Chironomus.

280. A Ceratopogon or Midge.

28I. An owl midge (Phlebotomus, sp.). (Giles.)

282. Larva of Anthomyia canicularis.

283. Larvæ of Musea vomitaria.

284. Larva of Lucilia macellaria.

285. The Screw-worm fly (Compsomyia macellaria). (After Conel.)

286. Green bottle-fly (Lucilia casar, Linn.)

287. Larva of Ochromyia. (After Blanchard.)

288. Larva of Dermatobia cyaniventris. (After Blanchard.)

289. Larva of Dermatobia cyaniventris. (After Blanchard.)

290. Dermatobia noxialis, Goudot.

291. Ox gad-fly (Tabanus bovinus, Linn.).

292. The Brimp (Hamatopota pluvialis, Linn.).

293. Stinging fly (Stomoxys calcitrans, Linn.).

294. Tsetse-fly (Glossina morsitans) (Westwood). 


\section{ON PARASITES IN GENERAL.}

By the term PARAsites is understood living organisms which, for the purpose of procuring food, take up their abode, temporarily or permanently, on or within other living organisms. There are both plants and animals (Phytoparasites and Zooparrasites) both of which lead a parasitic life in or upon other plants and other animals.

Phytoparasites are not included in the following descriptions of the forms of parasitism, but a very large number of animal parasites (zooparasites) are described; the number of the latter, as a rule, are very much under-rated. How great a number of animal parasites exist may be gathered from the fact that with the exception of the Echinodermata and the Tunicata, which, so far as we know at present, do not harbour living parasites, all other classes of animals are subject to them; some of the larger classes, such as Sporozoa, Cestodes, Trematodes and Acanthocephala, consist entirely of parasitic species, and parasitism even occurs amongst the vertebrates (Myxine). It therefore follows that the characteristics of parasites lie, not in their structure, but in the manner of their existence.

Parasitism itself occurs in various ways and degrees. According to R. Leuckart, we should distinguish between ocCAsional (temporary) and PERMANENT (stationary) PARASITISM. Occasional parasites, such as the flea (Pulex irritans), the bed-bug (Cimex lectularia), the leech (Hirudo medicinalis), and others only seek their "host" to obtain nourishment and find shelter while thus occupied, but without being bound to the host, they usually abandon the latter soon after the attainment of their object (Cimex, Hirudo), or they may remain on the body of their host throughout their entire development from the hatching of the egg (Pulex). It follows from this mode of living that the occasional parasites become sometimes distinguishable from free-living relatives, though only to a slight extent. It is, therefore, never difficult to assign the systematic position of temporary parasites from their structure. 
In consequence of their mode of life all these forms live on the external surface of the body of their host, though more rarely they take up their abode in cavities easily accessible from the exterior, such as the mouth, nose and gills. They are therefore frequently called Epizoa or Ectoparasites; but these designations do not only cover the temporary parasites, because numerous epizoa (as for instance the louse) are parasitic during their entire life.

In contradistinction to these temporary parasites, the permanent parasites obtain shelter as well as food from their host for a long period, sometimes during the entire course of their life; they do not seek their host only when requiring nourishment, but always remain with him, thus acquiring essential protection. The permanent parasites, as a rule, live within the internal organs, preferably in those which are easily accessible from the exterior, such as the intestine, with its appendages; nevertheless, permanent parasites are also found in separate organs and systems, such as the muscular and vascular systems, hollow bones, brain, \&c.: some live on the outer skin. Here, again, the terms ENTOzOA and endoparasites do not include all stationary parasites; to the latter, for instance, appertain the lice, which pass all their life on the surface of the body of their host, where they find shelter and food and go through their entire development. The ectoparasitic trematodes, numerous insects, crustaceans, and other animals live in the same manner.

All "Helminthes," however, belong to the group of permanent parasites. This term is now applied to designate certain low worms which lead a parasitic life (intestinal worms); but they are not all so termed. For instance, the few parasitic TuRbellaria are never classed with the helminthes, although closely related to them. The turbellarians, in fact, belong to a group of animals of which only a few members are parasitic, whereas the helminthes comprise those groups of worms of which all species (Cestodes, Trematodes, Acanthocephala), or at least the majority of species (Nematodes), are parasitic. Formerly the Linguatulidæ (Pentastomum) were classed with the helminthes because their existence is also endoparasitic, and because the shape of their body exhibits a great similarity to that of the true helminthes; but since the study of the development of the Linguatulidæ (P. J. van Beneden, I848, and R. Leuckart, I858) has demonstrated that they are really degenerated arachnoids, they have been separated from the helminthes.

It is hardly necessary to emphasise the fact that the helminthes or intestinal worms do not represent a systematic group of animals, but only a biological one, and that the helminthes can only be dis- 
cussed in the same sense as one speaks of land and water animals, i.e., without conveying the idea of a classification in such a grouping. It is true that formerly this was universally done, but very soon the error of such a classification was recognised: still, until the middle of last century, the helminthes were regarded as a systematic group, although C. E. v. Baer (I827) and F. S. Leuckart (I827) strenuously opposed this view. Under the active leadership of J. A. E. Goeze, J. G. H. Zeder, J. G. Bremser, K. A. Rudolfi and F. Dujardin, the knowledge of the helminthes (helminthology) developed into a special study, but unfortunately it lost all connection with zoology. It required the intervention of Carl Vogt to disestablish the helminthes as one class of animals, by uniting the various groups with those of the free-living animals most closely related to them (Platyhelminthes, Nemathelminthes).

Permanent parasitism has, in the course of time, caused creatures adopting this mode of life to undergo considerable, sometimes even striking, bodily changes, permanent ectoparasites having as yet undergone least alteration. The latter sometimes bear so unmistakably the likeness to that group to which they belong that even a superficial knowledge of their structure and appearance often suffices for the recognition of their systematic position. For instance, though the louse has, like many decidedly temporary parasites, lost-a characteristic of insects-its wings in consequence of parasitism, yet nobody would deny its insect nature (Cimex, Pulex). On the other hand, however, the changes in a number of permanent ectoparasites (such as parasitic Crustacea) are far more considerable, and correspond with the changes that have taken place in permanent endoparasites.

These alterations depend, partly on retrogression and .partly on the acquisition of new peculiarities; in the former case the change consists in the loss of those organs which have become useless in a permanent parasitic condition of existence, such as wings in the louse, and the articulated extremities seen in the larval stage of parasitic crustaceans. The loss of these organs goes hand in hand with the cohesion of segments of the body that were originally separate, and alterations in the muscular and nervous systems. In the same manner another means of locomotion is lost-the ciliated coat-which is possessed by many permanent parasites during their larval period, and which is, to all appearances, not secondary and recently acquired, but represents a primary character inherited from free-living progenitors, and still transmitted to the altered descendants, because of use during the larval stage (the 
larvæ of a great many Trematodes, the oncospheres of some Cestodes). Amongst the retrogressions, the loss of the organs of sense may be mentioned, particularly the eyes, which are still present, not only in the nearest free-living forms but also in the free-living larvæ of true parasites; it is only quite exceptionally that the eyes are subsequently retained; as a rule they are lost. Lastly, in a great many cases the digestive system also disappears, as in parasitic crustaceans, in a few nematodes and trematodes, in all cestodes and acanthocephala. There remains at most the rudiments of the muscles of the foregut, but these are adapted to entirely different uses.

The new characters which permanent parasites may acquire are, first of all, the remarkably manifold CLASPING and CLINGING ORGANS, which are seldom (as in parasitic crustaceans) directly joined on to already existing structures. In those instances in which organs for the conveyance of food are retained, these likewise frequently undergo transformation, in consequence of the altered food and manner of feeding; such alterations consist, for instance, in the transformation of a masticating mouth apparatus into the piercing and sucking organs of parasitic insects.

Hermaphroditism (as in Trematodes, Cestodes, and a few Nematodes) is a further peculiarity of many permanent parasites; moreover, the living together in couples that occurs, especially in trematodes, may lead to complete cohesion and, exceptionally, also to re-separation of the sexes. In many cases the females only are parasitic, while the males live a free life, or there may be in addition the so-called complementary males. Occasionally the male alone is parasitic, and in that case lives within the female of the same species, which may live free, like certain Gephyrea (Bonellia), or the female also may be parasitic, as Trichosomum crassicaudum, which lives in the bladder of the sewer rat (Mus decumanus).

We have numerous proofs that demonstrate how considerably the original features of many parasites have become changed. We need only draw attention to the aforementioned Linguatulidæ, also to many of the parasitic crustaceans belonging to various orders. In all of these a knowledge of the larval stages-in which there is no alteration, or at most only a slight degree of change-serves to determine their systematic position, i.e., the nearest conditions of relationship.

The most remarkable changes are observed in those groups that contain only a few parasitic members, the majority leading a free life. A striking instance is afforded by a snail, the well-known Entoconcha mirabilis, Müller. This mollusc consists merely' of an elongated 
sac living in a Holothurian (Synapta digitata), which possesses none of the characteristics of either the gastropods or any molluscs, and in the interior of which there is nothing to be observed but the organs of generation and the embryos. Nevertheless, the Entoconcha is decidedly a parasitic snail, as is clearly proved by its larvæ, but it is a snail which, in consequence of parasitism, has lost all the characteristics of molluscs in its mature condition, but still exhibits them in the early stages of development.

Certain nematodes show very clearly to what devious courses parasitism may lead. The Atractonema gibbosum, the life-history of which has been described by $\mathrm{R}$. Leuckart, and which lives in the larvæ and pupæ of a dipterous insect (Cecidomyia), exhibits, in its early stage, the ordinary characteristics of other threadworms. A few weeks later-the males having died off immediately after copulation-the females are transformed into spindle-shaped bodies, the mouth and anus of which are closed. They carry with them an irregularly shaped appendage, in which the segmenting ova are situated and in which the further conditions of life of the Atractonema are accomplished. A minute examination has demonstrated that this appendage is the prolapsed and enlarged vagina of the creature which has become merely a supplementary attachment. The conditions present in the Sphaerularia, the nematoid nature of which was long undiscovered, are still more remarkable. It was only when Siebold proved that typical nematodes were hatched from their eggs that their nature was recognised. The nematodes thus produced have not the slightest resemblance to the parent.

The researches of Lubbock, A. Schneider, and more particularly of $\mathrm{R}$. Leuckart, have shown that what we call Sphaerularia bombi is not an animal but merely an organ - the vagina - of a nematode worm. This vagina at first grows, sac-like, from the body of the tiny nematode ; it gradually assumes enormous dimensions, $(2 \mathrm{~cm}$. in length) ; it contains the sexual organs and parts of the intestine; the remaining portion of the actual creature then becomes small and shrivelled; it may be easily overlooked, being but an appendage to the vagina with its independent existence, and it finally disappears altogether.

The GREAT FERTILITY of parasites is another of their peculiarities, though this may be also the case to a certain degree with some of the free-living animals, the progeny of which are likewise exposed to enormous destruction.

More remarkable, however, is the fact that the young of the endoparasites only very exceptionally grow to maturity by the side of their parents; for they always sooner or later leave the organ 
inhabited by the latter, almost always reach the open, and after a shorter or longer period of free existence seek new hosts. During their free period, moreover, a considerable growth may be attained, or metamorphosis may take place, or even procreation. In the exceptional cases in which the young remain within the same host, they nevertheless always quit the organ inhabited by the parents. They likewise NEVER attain maturity within the host inhabited by the parents, but only, as in other cases, after having gained access into fresh hosts.

These transmigrations play a very important rôle in the natural history of the internal parasites, but they frequently conceal the cycle of development, for sometimes there are INTERMEDIARY GENERATIONS, which themselves invade intermediary hosts. Even when there are no intermediary generations, THE SYSTEM OF THE INTERMEDIARY HOSTS is frequently maintained by the endoparasites.

According to the kind of food partaken of by parasites, it has recently become usual to separate the true parasites from those creatures that feed on the superfluity of the food of the host, or on products which are no longer necessary to him, and to call the latter MESSMATES or commensals. As examples, the Ricinidæ are thus designated, because, like actual lice, they dwell amongst the fur of mammals or the plumage of birds; they do not, however, suck blood, for which their mouth apparatus is unsuited, but subsist on useless epidermal scales. These epizoa, according to J. P. van Beneden, are, to a certain extent, useful to their hosts, by removing deciduous materials which under certain circumstances might become harmful to them. ${ }^{1}$ This investigator, who has contributed so greatly to our knowledge of parasites, assigns the Ricines to the MUTUALISTS, under which term he comprises animals of various species which live in common, and confer certain benefits on one another. The mutualists are usually intimately connected in a mutually advantageous association known as "symbiosis."

Incidental and Pseudo-parasites.-In many cases the parasites are confined to certain hosts, and may therefore be designated as specific to such hosts. Thus, hitherto, Tania solium and Tania saginata in their adult condition have only been found in man; Tania crassi-

1 The Ricinidæ are by no means advantageous to their hosts. These Hemipterous parasites give rise to an intolerable itching which may cause loss of rest, emaciation, and sometimes even death. Birds suffering from phthiriasis of the Ricines are usually in bad health. - L. W S.

${ }^{2}$ For further information on these conditions, see Die Schmarotzer des Thierreichs, by P. J. van Beneden, Leipzig, I876; and Die Symbiose, by O. Hertwig. 
colis only in the cat; Distomum turgidum and D. ovocaudatum only in Rana esculenta, and so forth. In many other cases, however, certain species of parasites are common to several, and sometimes many, species of hosts; Tenia cucumerina s. elliptica is found in the domestic cat as well as in the dog; Distomum hepaticum is found in a large number of herbivorous mammals (ninet`en species), Amphistomum subclavatum in numerous urodela and anuric amphibia, Holostomum variabile in about twenty-four species of birds, and so on. In these cases the hosts are almost invariably closely related, appertaining, as a rule, to the same family or order, or at any rate to the same class. Trichina spiralis, which is found in man, and in the bear, pig, rat, mouse, cat, fox, polecat and marten, and is capable of being artificially cultivated in the dog, rabbit, sheep, horse and in other mammals, and even in birds, is one of the most striking exceptions.

Some parasites are so strictly confined to one species of host that, even when artificially introduced into animals very closely related to their normal host, they do not thrive, but sooner or later, often very quickly, die off, and very rarely establish themselves. For example, repeated attempts have been made to rear the adult Tania solium in the dog, or to rear Cysticercus cellulose in the ox, or Cysticercus Tania saginata in the pig, but they have always proved unsuccessful; only exceptionally has it been possible to transfer Conurus cerebralis, the larval stage of a tapeworm of the dog (Tania conurus), from the brain of the sheep to that of the domestic goat. On the other hand in the case of the Trichinæ transference into a different host is easily accomplished.

Under natural conditions it is not uncommon for certain kinds of specific parasites to occur occasionally in unusual hosts; they there stand to the latter as "INCIDENTAL PARASITES." Thus Echinorhynchus gigas, a specific parasite of the pig, is only an incidental parasite of man ; Distomum hepaticum and Distomum lanceolatum are specific to numerous kinds of mammals, but may be found incidentally in man; on the other hand, Bothriocephalus latus, a specific parasite of man, may occasionally take up its abode in the dog, cat and fox. As a rule all those parasites of man that are only rarely met with, notwithstanding that human beings are constantly being observed and examined by medical men, are termed INCIDENTAL PARASITES OF MAN. In many cases we are acquainted with the normal or specific host of these parasites. Thus we know the specific host of Balantidium coli, Coccidium oviforme, Distomum hepaticum, T.enia cucumerina, \&c. ; in others it is as yet unknown to us. In the latter case the question 
partly relates to such forms as have been so deficiently described that their recognition is impossible, partly to parasites of man in various regions of the earth, the Helminthes and parasites of which are totally unknown or only slightly known, or finally to early developmental stages that are difficult to identify. Creatures that usually live free, and exceptionally become parasitic, may likewise be called incidental parasites. In this category are included a few Anguillulida that have been observed in man; also Leptodera appendiculata, which usually lives free, but may occasionally become parasitic in black slugs (Arion empiricorum): when parasitic it attains a larger size, and produces far more eggs than when living a free life. In order to avoid errors, the term "incidental parasites" should be confined to true parasites which, besides living in their normal host, mayalso live in other hosts. Leuckart speaks of FACULTATIVE PARASITISM in such forms as Leptodera. ${ }^{1}$ L. Oerley succeeded in artificially causing Rhabditis pellio to assume facultative parasitism by introducing these worms into the vagina of mice, where the parasites remained alive and multiplied. Rhabditis pellio dies in the intestines of mammals and man; it remains alive in frogs, but always escapes into the open with the fæces.

Recently the incidental parasites of man have also been called "Pseudo-parasites" or "Pseudo-helminthes"; formerly, however these terms were applied not only to living organisms that do not and cannot live parasitically, and that only exceptionally and incidentally get into man, but also to any foreign bodies, portions of animals and plants, or even pathological formations that left the human system through the natural channels, and the true nature of which was misunderstood. Frequently these bodies were described as living or dead parasites and labelled with scientific names, as if they were true parasites. A study of these errors, which formerly occurred very frequently, would be as interesting as it would be instructive. It is better not to use the expression pseudo-parasites for incidental parasites, but to keep to the original meaning, for it is not at all certain that pseudo-parasites are not described, even nowadays.

The Influence of Parasites on the Host.-In a great many cases we are not in a position to state anything regarding any marked influence exercised by the parasite on the organism and on the conditions of life of the host. Most animals and many persons exhibit no signs of such influence. As a general rule, the parasite, which is always smaller and weaker than its host, does not attempt to

\footnotetext{
'Oerley, L., Die Rhabditiden und ihre medicinische Bedeutung, Berlin, I886, p. 65.
} 
endanger the life of the latter, as simultaneously its own existence would be threatened. The parasite, of course, robs its host, but usually in a scanty and sparing manner, and the injuries it inflicts can hardly be taken into account. There are, however, numerous cases in which ${ }^{1}$ the situation of the parasites or the nature of their food, added to their number and movements, may cause more or less injury, and even threaten the life of the host. It stands to reason that a Cysticercus cellulose situated in the skin is of but slight importance, whereas one that has penetrated the eye or the brain must give rise to serious disorders. A cuticular or intestinal parasite is, as a rule, less harmful than a blood parasite. A helminth, such as an Ascaris lumbricoides or a tapeworm, that feeds on the residues of foodstuffs within the intestine, will hardly affect its host by depriving it of this material. The case is different when the parasites are very numerous, especially when the heavily infested host happens to be a young individual needing all it ingests for its own requirements, and therefore unable to sustain the drain of numerous guests in the intestine. Disturbances also set in more rapidly when the intestinal helminthes are blood-suckers, such as Anchylostoma duodenale, the injury to the host resulting from the kind of food taken by the parasite.

Generally, the disorders caused by loss of chyle are insignificant when compared with those induced by the GROWTH and agglomeration of the helminthes; the latter may cause chiefly obstructions of small vessels or symptoms of pressure in affected or contiguous organs, with all those complications which may arise secondarily, or they may even lead to the complete obliteration of the organ attacked. Of course the symptoms will vary according to the nature of the organ attacked.

In consequence, also, of the Movements of the parasites, disorders are set up that may tend to serious pathological changes of the affected organs. The collective migrations, undertaken chiefly by the embryos of certain parasites (trichinosis, acute cestode tuberculosis), are still more harmful, as are also the unusual migrations of other parasites, which, incidentally, may lead to the formation of so-called worm abscesses or to abnormal communications (fistulæ) between organs that are contiguous but possess no direct connection.

Recently, several authors have called attention to the fact that the helminthes produce MATERIALS that are TOXIC to their host ; and

' Lühe, M., "Ueber d. Fix. d. Helm. a. d. Darmwand ihrer Wirthe u. die dadurch verursachten path.-anat. Veränderungen d. Wirthsdarmes," Trans. of the IV. Intern. Zool. Congr., Berlin, I901. 
the effects of such poisons explain the pathology of helminthiasis far more satisfactorily than the theory of reflex action.

In a number of cases these toxic materials (leucomaines) have been isolated and their effects on living organisms demonstrated by actual experiments. It also appears that the absorption of materials formed by the decomposition of dead helminthes may likewise cause toxic effects. However, our knowledge of these conditions is as yet in its initial stage. ${ }^{1}$

Nearly all the symptoms caused directly or indirectly by parasites are of such a nature that the presence of the parasites cannot be diagnosed with any certainty, or only very rarely; the most that can be done is to deduce the presence of parasites by the exclusion of other causes. Fortunately, however, there are sufficient means by which we may confirm the diagnosis in a great many cases. Such means consist not only in a minute examination of the patient by palpation, percussion and local inspection, but also in the microscopical examination of the natural secretions and excretions of the body, such as sputum, nasal mucus, urine and fæces. Though such examinations may entail loss of time, they are necessary in the interest of the patient. It appears to me, moreover, that quackery, which has gained considerable ground even in the treatment of the helminthic diseases of man, can thus be considerably limited.

Origin of Parasites. - In former times, when the only. correct views that existed related to the origin of the higher ailimals, the mode of procreation of the parasites as well as of other low animals was ascribed to SPONTANEOUS GENERATION (generatio aquivoca), and this opinion prevailed throughout the middle ages; the writers on natural science merely devoted their time to the interpretation of the views of the old authors, and perpetuated the opinion of the ancients on questions which even in those days could have been correctly explained merely by observation.

It was only when observations were again recommenced, and the microscope was invented, that the idea of spontaneous generation became limited; not only did the microscope reveal the organs of generation or their products (eggs) in numerous animals, but, Redi succeeded in proving that the so-called Helcophagi (flesh maggots) are

1 Moursson, et Schlagdenhauffen, "Nouv. rech.clin. et phys. sur quelq. liquides organ.," C. R. Ac., Paris, 1882, p. 791 ; Debove, "De l'intox. hydat.," Bull. et Mém. soc. míd. des hôpit., I 888 ; Linstow, v., "Ueb. d. Giftgehalt d. Helm.," Internat. Monatsschr. $f$. A nat. u. Phys., xiii., I 896 ; Peiper, "Z . Symptomatol. der thier. Paras.," Deutsche med. Wochenschr., I897, No. 40; Mingazzini, P., "Ric. sul. veleno d. elm. int.," Rass. intern. d. med. modern. Ann., ii., I901, No. 6 ; Vaullegeard, A., "Etud.exp. et crit. sur l'action d. helm.," Bull. soc. Linn. de Normandie, 5, Ser. T. vii., 1901, p. 84, and others. 
only the progeny of flies, and never appear in the flesh of slaughtered animals when fully developed flies are prevented from approaching and depositing their eggs on it. Swammerdam likewise knew that the "worms" living in the caterpillars of butterflies were the larvæ of other insects (Ichneumon flies) which had laid their eggs in their bodies; he also discovered the ova of lice. The two authors mentioned were, however, unwilling to see the experience they had gained regarding insects applied to the helminthes, while Leeuwenhoek vehemently opposed the theory of a spontaneous generation, maintaining that, on a basis of common sense, eggs, or at all events germs, must exist, even though they could not be seen.

The use of the microscope also revealed a large number of very small organisms in the water and moist soil, some of which undoubtedly resembled helminthes. Considering the wide dissemination of these minute organisms, it was natural to conjecture that after their almost unavoidable introduction into the human system they should grow into helminthes (Boerhave, Hoffmann). Linnæus went even further, for he traced the descent of the liver-fluke of sheep from a free-living planaria (Dendroccelum lacteum), the Oxyuris vermicularis, from freeliving nematodes, and the Tania lata (i.e., Bothriocephalus latus) from a tapeworm (Schistocephalus solidus) found free in the water. Linnæus' statements met with general approval. However, we must bear in mind that at that time the number of helminthes known was very small, and many of the forms that we have long ago learned to differentiate as specific were then regarded as of ONE SPECIEs. Linnæus' statements were partly supported by similar discoveries by other investigators, such as Unzer, and partly also by the discovery of eggs in many helminthes. It was believed that the eggs hatched out in the outer world gave birth to free-living creatures, and that these, after their introduction into the intestine, were transformed into helminthes. By means of these eggs the old investigators tried to explain the HEREDITARY TRANSMISSION of the intestinal worms, which was universally believed until the commencement of the last century; some authors went so far as to regard the intestinal worms as congenital or inherited; they maintained the possibility of direct transmission, as in suckling, and denied that the eggs reaching the external world had anything to do with the propagation of the parasites.

The more minute comparison between the supposed free-living stages of the helminthes and their adult forms, and the impossibility of finding corresponding free forms for the ever-increasing number of parasitic species, revealed the improbability of Linnæus' state- 
ments (O. Fr. Müller). It was the latter author also who recognised the origin of the tapeworms (Schistocephalus, Ligula) found free in the water. They originate from fishes which they quit spontaneously.

Nevertheless, and in spite of the fact that van Doeveren and Pallas correctly recognised the significance of the eggs in the transmission of intestinal worms, these statements remained disregarded, as did Abildgaard's observation, experimentally confirmed, that the (immature) cestodes from the abdominal cavity of sticklebacks become mature in the intestines of aquatic birds. However, at the end of the eighteenth and the commencement of the nineteenth centuries, and after helminthology had been raised to a special branch of study by the successful results of the investigations of numerous authors, (Goeze, Bloch, Pallas, Müller, Batsch, Rudolphi, Bremser), many of whom experienced a "divine joy" in searching the intestines of animals for helminthes, some authors reverted to generatio aquivoca, without, however, entirely denying the existence of organs of generation and eggs. The fact that a few nematodes bore living progeny -a fact of which Goeze was already aware-had no influence on the erroneous opinion, as in such cases it was considered that the young continued to develop beside the old forms; there were also many helminthes known that never developed sexual organs and never produced eggs, and which therefore were referred to generatio aquivoca. People were convinced that the intestinal mucous membrane or an intestinal villus could transform itself into a worm. either in a general morbid condition of the body, or in pathological changes of a more local character. The appearance of helminthes was even regarded as useful and as a means for the expulsion of injurious matter.

These views, firmly rooted and supported by such eminent authorities as Rudolphi and Bremser, could not easily be overthrown. First, a change took place in the knowledge of the trematodes. In I773 O. Fr. Müller discovered the Cercarice living free in the water; he regarded them as independent creatures and gave them the name that is still used at the present time. Nitszch, who also minutely studied these creatures and who recognised the resemblance of the anterior part of their bodies to a Distomum, did not, however, arrive at a correct conclusion; he regarded the combination rather as that of a Distomum with a Vibrio, for which he mistook the characteristic tail of the cercaria; he also noticed the encystment (transformation into the pupa) on foreign bodies of many species of these creatures, but was of opinion that this process signified only the termination of life. 
Considerable attention was attracted to the matter when Bojanus first published a paper entitled "A Short Note on Cercaria and their Place of Origin." He pointed out that the cercaria creep out of the "royal yellow worms," which occur in freshwater snails (Linnaus paludina), and are probably generated in these worms.

Oken, in whose journal, Isis, Bojanus published his discovery, remarks in an annotation, "One might lay a wager that these cercaria are the embryos of distomes." Soon after (I827), C. E. v. Baer was able to confirm Bojanus' hypothesis that the cercaria as a "heterogenous brood" originated from spores in parasitic tubes in snails (germinating tubes). Moreover, Mehlis (Isis, I83I, p. Igo) not only discovered the lids of the ova of distomes, but likewise saw an infusorian-like embryo slip out of the eggs of Monostomum flavum and Distomum hians. A few years later (I835) v. Siebold observed the embryos (miracidia) of the Monostomum mutabile, and discovered in their interior a cylindrical body that behaved like an independent being (" necessary parasite"), and was so similar in appearance to the "royal yellow worms" (Bojanus) that Siebold considered the origination of the latter from the embryos of trematodes as at all events possible. Meanwhile, v. Nordmann (Helsingfors) had in I832 seen the miracidia of distomes provided with eyes swimming in water; v. Siebold (I835) had observed the embryos, or oncospheres, of tape-worms furnished with six hooklets in the so-called eggs of the tænia; while Creplin (I837) had discovered the "infusorial" young of the Bothriocephalus ditremus, and conjectured that similar embryos were to be found in other cestodes with operculated eggs. The fact was, at all events, established that the progeny of the helminthes appears in various forms and is partly free-living. The researches of Eschricht (I84I) were likewise of influence, as they elucidated the structure of the Bothriocephali, and proved that the encysted and sexless helminthes were merely immature stages.

J. J. Steenstrup (I842) was, however, the first to furnish explanations for the numerous isolated and uncomprehended discoveries. Commencing with the remarkable development of the Cœlenterata, he established the fact that the Helminthes, especially the endoparasitic trematodes, multiply by means of alternating and differently formed generations. Just as the polyp originating from the egg of a medusa represents a generation of medusæ, so does the germinal tube (royal yellow worm) originating from the ciliated embryo of a distomum, \&c., represent the cercaria; these were consequently regarded as the progeny of trematodes, and Steenstrup, guided by his observations, conjectured that the cercaria, whose entrance into 
the snails he had observed accompanied by the simultaneous loss of the propelling tail, finally penetrate into other animals, in which they become distomes.

Part of this hypothetical cycle of development was erroneous, and in other particulars positive observation was lacking, but the path pursued was in the right direction. Immediately after the appearance of Steenstrup's celebrated work, v. Siebold expressed his opinion that the encapsulated distomes certainly had to travel, i.e., to be transmitted with their bearers into other hosts, before becoming mature. This view was experimentally confirmed by de Filippi, La Valette St. George (I855), as well as by Pagenstecher (I857), while the metamorphosis of the ciliated embryo of distoma into a germinal tube was first seen by G. Wagener ( 1857 ) in Distomum cygnoides of frogs. All that we have subsequently learned from the works of numerous investigators about the development of endoparasitic trematodes has certainly increased our knowledge in various directions, and, apart from the deviating development of the Holostomides has, as a whole, confirmed the briefly sketched cycle of development.

Steenstrup's work on the cestodes did not attract the same attention as his work on trematodes. Steenstrup always insisted on the "nurse" nature of the cysticerci and other bladderworms. Abildgaard (I790), as well as Creplin (I829 and I839), had already furnished the information that certain sexless cestodes (Schistocephalus and Ligula) from the abdomen of fishes only become mature after their transference into the intestine of aquatic birds, and these passive migrations were confirmed in an entire series of other cestodes, particularly by v. Siebold (I 844 , $\mathrm{I} 848, \mathrm{I} 85^{\circ}$ ) and E. J. van Beneden (I849), not by actual experiment, but by undoubted observation.

It was conjectured correctly that the ova or oncospheres penetrate into certain intermediate hosts, in which they develop into unsegmented larvæ. Here they remain until, with their host, they are swallowed by some predacious animal; they then attain the intestine freed from the surrounding membranes through the process of digestion, and settle themselves there to form the adult chain of proglottides. Though some few scientists, such as P. J. van Beneden and Em. Blanchard, deduced from these observations that the bladderworms (Cystici), which had hitherto been regarded as a separate class of helminthes, were only larval tæniæ, this correct view was not at first universally accepted; the foundation was too slight, and $v$. Beneden was of opinion that the cysticerci were not necessary, but only appeared incidentally. 
v. Siebold was a strenuous opponent to this theory, notwithstanding his experiences on the change of hosts of the Tetrarhynchus. Together with Dujardin he conjectured that the tæniæ underwent a deviating cycle of development (I850); he was of opinion that the six-hooked oncospheres left the intestine, in which the older generation lived, and were scattered about with the fæces, and finally re-entered per os (i.e., with water and food) a host similar to the one they had left, in the intestine of which they were directly transformed into tapeworms. A changing of host in the sense of the other cestodes was not supposed to occur (the history of the cestodes was at this time not entirely established). As the oncospheres of the tænia are enveloped in one calcareous or several softer coverings which they cannot leave actively, and as, in consequence of this condition, innumerable oncospheres cannot. penetrate into an animal, and others cannot reach the proper animal, v. Siebold conceded, at least for the latter, the possibility of a further development; but this was only supposed to occur because they had either invaded wrong hosts, or, having reached the right hosts, had penetrated organs unsuitable to their development; and had thus gone astray in their travels, and had become HYDROPICALLY DEGENERATED TÆNIÆ. This was v. Siebold's explanation of bladder-worms. Naturally, v. Siebold himself conjectured that a recovery of the diseased tapeworm might occur, in a few exceptional cases, after transmission into the correct host, as, for instance, in the Cysticercus fasciolaris of mice, the host of which is the domestic cat, and in which there is a seemingly normally developed piece of tapeworm situated between the caudal vesicle and the cysticercus head.

Guided by correct views, F. Küchenmeister undertook in Zittau the task of confirming the metamorphosis of Cysticercus pisiformis of hares and rabbits into tapeworms in the intestine of the dog, by means of feeding experiments. The first reports on the subject, published in $\mathrm{I} 85 \mathrm{I}$, were not likely to meet with universal approval, because Küchenmeister first diagnosed the actual tapeworm he had been rearing as Tania crassiceps, afterwards as Tania serrata, and finally as Tania pisiformis, n. sp. However, in any case Küchenmeister, by means of the reintroduction of experimental investigation, rendered a great service to helminthology.

The publication of Küchenmeister's works induced v. Siebold to undertake similar experiments (I852 and I853), which were partly published by his disciple Lewald in 1852 . But the positive results obtained hardly changed Siebold's opinion, for 
although he no longer considered the bladder-worms as hydropically degenerated tapeworms, he still regarded them as tæniae that had strayed. This change of opinion was partly due to an important work of the Prague zoologist, v. Stein (I853), who was able to examine the development of a small bladder-worm in the larvæ of the well-known meal-worm (Tenebrio molitor), and to demunstrate that, as Goeze had already proved in the case of Cysticercus fasciolaris of mice, first the caudal vesicle is formed and then the scolex, whereas Siebold believed that in bladder-worms the posterior end of the scolex was formed first, and that this posterior end underwent a secondary hydropic degeneration.

In opposition to v. Siebold, Küchenmeister successfully proved the necessity of the bladder-worm stage by rearing tapeworms in dogs from the Cysticercus tenuicollis of domestic mammals and from the Conurus cerebralis of sheep. He, and simultaneously several other investigators independently, succeeded, with material provided by Küchenmeister, in rearing the Conurus cerebralis in sheep from the oncospheres of the Tania conurus of the dog (I854). R. Leuckart obtained similar results in mice by feeding them with the mature proglottides of the Tania crassicollis of cats (I854).

Küchenmeister also repeatedly reared the Tania solium of man from the Cysticercus cellulose of pigs (I855), and from the embryos of this parasite P. J. van Beneden succeeded in obtaining the same Cysticercus in the pig (I854). As Küchenmeister had taught to distinguish the Tania mediocanellata, known to Goeze as Tania saginata, amongst the large tæniæ of man (I85I), it was not long before $R$. Leuckart (I862) succeeded in rearing the cysticercus of the hookless tapeworm in the ox. It is particularly to this last-named investigator that helminthology is indebted more than to any other author. He followed the gradual metamorphosis from oncospheres to cystic worms in all its details.

In view of all the researches that were made and which are too numerous to mention individually, the idea that bladder-worms are abnormal or only incidental forms had to be abandoned. Everything points to the fact that in all cestodes the development is divided between two kinds of animals; in one-the host, the adult tapeworm is found; while in the other, the intermediary host, we find some form or other of an intermediate stage (cysticercus in the broadest sense). The practical application of this knowledge is self-evident. If no infected pork or beef is partaken of, no 
tapeworm can be acquired, and also the rearing of cysticerci in one's own body is prevented by avoiding the introduction of the eggs of tapeworms.

Though these results were definitely proved by numerous researches, yet they have been repeatedly challenged, notably by J. Knoch (I862) who, on the 'basis of experiments, sought to confirm a direct development without an intermediary host and ciliated stage, at all events as regards Bothriocephalus latus. However, the repeated communications of this author met with but little favour from competent persons, partly because the experiments were conducted very carelessly, and partly because their repetition on dog and man ( $R$. Leuckart) had no results (I863). It was only in I883 that I was able to prove that the developmental cycle of Bothriocephalus latus is similar to that of the other cestodes. The results obtained in other places by Parona, Grassi, Ijima and Zschokke render any discussion of Küchenmeister's conclusions unnecessary. Long after Knoch a French author, P. Mégnin, also pleaded for the direct development of some cestodes, and especially some tæniæ; he also sought to prove a genetic connection between the hookless and armed tapeworms of mammals (I879), but the arguments he adduced, so far as they rest on observations, can be easily refuted or attributed to misinterpretation. Only one of these arguments is correct, namely, that the number of the species of tæniæ with which we are acquainted is far larger than that of the corresponding cystic forms; but this disparity alone cannot be taken as a proof of direct development. We can only say that our knowledge in this respect is deficient; as a matter of fact, we have during recent years become acquainted with a large number of cystic forms hitherto unknown appertaining to tæniæ which have long been known. It must also be borne in mind that no man in his lifetime can complete an examination for bladder-worms of the large number of insects, for instance, which may destroy an entire generation of an insectivorous species of bird within a small district.

Naturally it does not follow that direct development in the cestodes is altogether lacking, but the arguments so far advanced point only to its being possible. Indeed, communications from Grassi ( 1889 ) have furnished us in Tania murina with an example which shows that development may take place without an intermediary host, notwithstanding the retention of the cystic stage. We can no longer doubt that the oncospheres of this species, introduced into rats of a certain age, after a time grow into tapeworms without 
leaving the intestine, but not directly, for they bore into the intestinal wall, where they pass the cystic stage, the cysts afterwards falling into the intestinal lumen, where they develop into tapeworms.

Important observations were soon made on the remaining groups of helminthes. The discussion on the origin of parasites soon became confined to the helminthes. Amongst the Nematodes, it had long been known that encapsulated forms existed that had at first been regarded as independent species, but very soon they were pronounced to be immature forms, in consequence of their lack of sexual organs. Though Dujardin and also v. Siebold regarded them as "strayed" animals, v. Stein (I853) very promptly demonstrated that the progeny of the nematodes were destined to travel by discovering a perforating organ in the larval nematodes of the mealworm. This was. first experimentally confirmed (I860) by R. Leuckart, R. Virchow and Zenker, all of whom succeeded not only in bringing to maturity the muscle trichinæ (known since I830) in the intestine of the animals experimented upon, but were likewise able to follow the migrations of the progeny. Of course, the encapsulating brood remained in the same organism, and in this respect deviated from the broods of other helminthes which escape into the outer world and find their way into other animals, but the encapsulated nematodes could no longer be regarded as the result of straying. Subsequently, R. Leuckart, more or less completely, worked out the history of the development of numerous nematodes, or pointed out the way in which further investigations should be made. We have learnt that in nematodes, far more frequently than in other helminthes, the typical course of development is subject partly to curtailment and partly to complications, which sometimes considerably increase the difficulties of investigation and have hitherto prevented us from reaching a definite conclusion, though the way to it is now clear.

In a similar manner the works of $\mathrm{R}$. Leuckart have cleared up the development of the Acanthocephala and Pentastomes. Of course, much still remains to be done; so far, we do not even know all the helminthes of man and of the domestic animals in all their phases of life, and still less is known of those of other animals. We are indebted to the discoveries of the last fifty years for the knowledge arrived at, though comparatively few names are connected with it; the gross framework is revealed, but the gaps only have been filled up here and there. However, 
we may trustfully leave the completion of the whole to the future, without fear that any essential alterations will take place.

The deductions to be drawn are as follows: That the helminthes like the ectoparasites multiply by sexual processes, that the entire course of development of the helminthes is never gone through in the same host as is the case with several ectoparasites, that the progeny at an earlier or later stage of development, as eggs, embryos or larvæ, quit the host inhabited by the older generation, and almost always attain the outer world : only in Trichinella does the development take place directly in the definite host. Where the eggs have not yet developed they go through the embryonic evolution in the outer world, and the young larvæ are transmitted, either still enclosed within the egg or embryonic covering, into the intermediary host-more rarely they are transferred straight into the final host-or they hatch out from their envelopes, and after a longer or shorter period of free life, during which they may partake of food and grow, they, as before, penetrate, usually in an active way, into an intermediary host, or at once invade the final host. Exceptionally (Rhabdonema), during the free life there may be a propagation of the parasitic generation, and in this case only the succeeding generation again becomes parasitic, and then at once reaches its final host. The young forms which have invaded the final host become mature in the latter, or after a longer or shorter period of parasitism again wander forth (as the (Estrides, Ichneumonides, \&c.), and reach the adult stage in the outer world. The young stages, during which they undergo metamorphoses or are even capable of producing one or several intermediate generations, are passed in the intermediary hosts until, as a rule, they are passively carried into the final host and there complete their cycle of development with the formation of the organs of generation. This manner of development, the spending of life in two different kinds of animals (intermediary and final host), is typical of the helminthes. This is manifested in the acanthocephala, the cestodes, the majority of the endoparasitic trematodes, a number of the nematodes, and the linguatulidæ; there are now and then exceptions, however, in which, for instance, the host and intermediary host exchange order (Trichinella, Tania murina).

Parasites are hardly ever inherited amongst animals. According to a few statements, however, Trichinella and Conurus are supposed to be transmissible from the infected mother to the fœtus; 
otherwise all animals acquire their parasites, especially the entozoa, from without, the parasites penetrating either actively, as in animals living in the water, or passively with food and drink. A particular predisposition to worms is not more likely than a spontaneous origin of parasites.

Derivation of Parasites.-Doubt now no longer exists as to the derivation of the temporary and of many of the stationary ectoparasites from free-living forms. This conclusion is founded on the circumstance that not only are there numerous intermediate degrees in the manner of living and feeding between predacious and parasitic animals, but that there is more or less uniformity in their structure. The differences that exist are easily explained as consequences of altered conditions of life. The case is more difficult in regard to groups that are exclusively parasitic (Cestoda, Trematoda, Acanthocephala, Linguatulide, and Sporozoa), or groups that are chiefly parasitic (Nematoda), because in these cases the gulf that divides these forms from free-living animals is wider. It is true that we know that the nearest relatives of the Linguatulida are found amongst the Arachnoidea, and indeed in the Acarina; that, moreover, the structure and development of the Sporozoa refers them to the Protozoa, and allows them to be regarded as the descendants of the lowest Rhizopoda. We know that the Trematoda, and through these the Cestoda, are closely related to the Turbellaria, from which they may be traced; the Nematoda, however, and still more the Acanthocephala, stand quite apart. This is less evident however, in the Nematoda, for there are numerous free-living kinds of these from which it is possible that the parasitic species may have descended. Indeed, this seems more than probable if one takes into consideration such examples as Leptodera, Rhabdonema and Strongyloides, as well as the conditions of life of free-living nematodes. These mostly, if not exclusively, spend their lives in places where decomposing organic substances are present in quantities; some species attain maturity only in such localities, and there propagate very rapidly. Should the favourable conditions for feeding be changed the animals seek out other-localities, or they remain in the larval form for some time until more favourable conditions set in. It is comprehensible that such forms are very likely to adopt a parasitic manner of life which at first is facultative (Leptodera, Anguillula), but may be regarded as the transition to true parasitism. The great advantages attached to a parasitic life consisting not only 
in protection, but also in the supply of suitable food, and consequently in the easier and greater production of eggs, fully account for the gradual passage of facultative parasitism into true parasitism. In many forms the young stages live free for some time (Strongyloides), in others, as is the case in Rhabdonema, parasitic and free-living generations alternate; in others, again, the free period is limited to the egg stage or entirely suppressed.

Though it is possible thus to connect the parasitic with the free-living nematodes, also by taking their manner of life into account, this matter presents greater difficulties in regard to other helminthes. It is true that the jointed cestoda may be connected with and traced from the less known and interesting singlejointed cestoda (Amphilina, Archigetes, Caryophyllaus, Gyrocotyle), but trematodes are all parasites, with the exception of one form, Temnocephala, a peculiarly shaped creature, several species of which live on the surface of the body of crustaceans and freshwater turtles. Temnocephala is, nevertheless, a predacious animal; it feeds on infusoria, the larvæ of small insects and crustaceans. So far as is known it does not nourish itself on parts of its host; it belongs to the group of commensals, or more correctly, to that of the SPACE PARASITES, which simply dwell with their host and do not even take a portion of the superfluity of his food. However, space parasitism may still be regarded as the first stage of commensalism, which is again to be regarded as a sort of transition to true parasitism.

It is possible that parasitism came about in this way in the trematodes, in which connection we must first consider the turbellaria-like ancestors of the trematodes. Much can be said in favour of such a genetic relationship between turbellaria and trematodes and hardly anything against it; it should also be remembered that amongst discs or suctorial pores, and which are only differentiated from the few parasitic turbellaria there are some that possess clinging ectoparasitic trematodes by the possession of a ciliated integument, which is found only in the larval stages of the latter.

The Acanthocephala occupy an isolated position. Most authors certainly regard them as related to the nematodes; in any case. however, the connection is not a close one, and the far-reaching alterations which must have occurred prevent a clear view. Perhaps the free original forms of acanthocephala are no longer in existence, but that such must have existed is a foregone conclusion.

An explanation of the CHANGE OF HOST so frequent in parasites is more difficult than that of their descent. R. Leuckart is of 
opinion that the present intermediary hosts, which belong principally to the lower animals, were the original hosts of the parasites, and fostered both their larval and adult stages. It was only in course of time that the original hosts sank to the position of intermediary hosts, the cause for this alteration being that the development of parasites, especially of the helminthes, through further development and differentiation extended over a larger number of stages. The earlier stages remained in their original hosts, but the later stages sought out other hosts (higher animals). To prove this Leuckart points out that the mature stages of the helminthes, with but few exceptions, occur only in the vertebrates which appeared later in the development of the animal kingdom, while the great majority of intestinal worms of the lower animals only represent young stages, which require transmission into a vertebrate animal before they can become mature. The few helminthes that attain maturity in the lower animals (Aspidogaster, Archigetes) are therefore regarded by Leuckart as. primitiveforms, and he compares them with the developmental stages of helminthes, Aspidogaster going through a change of host with Redia, Archigetes with Cystercoidea. He classes the nematodes that become mature in the invertebrates with Anguillulida, i.e., with saprophagous nematodes from which the parasitic species descend.

Leuckart therefore regards the change of host as secondary, so does Sabatier. The latter, however, adduces other reasons for this (lack of clinging organs and the necessity to develop them in an intermediary stage); but in this connection he only considers the Cestoda. In opposition to Leuckart, R. Moniez, however, is convinced that the migrations of the helminthes, as well as the system of intermediary hosts, represent the original order of things. Moniez traces all Entozoa from saprophytes, but only a few of these were able to settle directly.into the intestine and there continue their development. These are forms that at the present day still lack an intermediary host, such as Trichocephalus, Ascaris and Oxyuris. In most other cases the embryos, however, consisted of such saprophytes as were, in other respects, suitable to become parasites but were incapable of resisting the mechanical and chemical influences of the intestinal contents; they were therefore obliged to at once leave the intestine, and accomplished this by penetrating the intestinal walls and burrowing in the tissues of their carriers. In this position, assisted by the favourable conditions of nutrition, they could attain a relatively high degree of development. Mechanical reasons pre- 
vented a return into the intestines, where the eggs could be deposited. Most of them doubtless died off, as parasites at present, as also their young stages do when they penetrate wrong hosts. A part of them, nevertheless, passively reached the intestine of beasts of prey. Many were destroyed in the process of mastication; for a small part, however, there was the chance of reaching the intestine of a beast of prey undamaged, and there, having become larger and more capable of resistance, maturity was attained. By means of this incidental coincidence of various favourable circumstances, these processes, according to Moniez, have been established by heredity and have become normal.

This is not the place to express an opinion either for or against the various hypotheses advanced, but the existence of these diametrically opposed views will alone show the great difficulty of the question. Independently, however, it appears more natural to come to the conclusion that parasitism as well as change of hosts were gradual transitions.

As a conclusion to this introductory chapter, I append a list of the most important works on the helminthology of man and animals.

\section{LITERATURE.}

GoezE, J. A. E. Versuch einer Naturgeschichte der Eingeweidewürmer thierischer Körper. Blankenburg, I782. 4to, 47 I pp., with 44 plates.

ZEDer, J. G. H. Erster Nachtrag zur Naturgeschichte der Eingeweidewürmer, von J. A. E. Goeze. Leipzig, I 800. 4to, with 6 tables.

RUdolPhI, C. A. Entozoorum sive vermium intestinalium historia naturalis. I., Amstelod., I 808 ; ii., I 809 . $8 \mathrm{vo}$, with I 8 piates.

Rudolphi, C. A. Entozoorum synopsis. Berol., I8I9. 8vo, with 3 plates.

Bremser, J. G. Ueber lebende Würmer im lebenden Menschen. Wien, I8rg. 8vo, with 4 plates.

Bremser, J. G. Icones helminthum, systema Rudolphii entozoologicum illustrantes. Viennae, I 824 . Fol. (Paris, I 837 ).

DUjardin, F. Histoire naturelle des helminthes ou vers intestinaux. Paris, I845. $8 \mathrm{vo}$, with I 2 plates.

Diesing, C. M. Systema helminthum. 2 vols. Vindobonae, I850, I851. 8vo. Supplements by the same author: Revision der Myzhelminthen (Report of the Session of the Imp. Acad. of Science. Wien., xxxii., 1858); with addendum (ibid., xxxv., 1859) ; Revision der Cephalocotyleen (ibid., xlix., I864, and xlviii., 1864); Revision der Nematoden (ibid., xlii., 186I); Supplements (ibid., xliii., I 862 ).

Beneden, P. J., van. Mémoire sur les Vers intestinaux. Paris, I858. 4to, with I $2 \mathrm{pl}$.

KüchenMeISTer, F. Die in und an dem Körper des lebenden Menschen vorkommenden Parasiter. Leipzig, I 855 . 8vo, with I4 plates.

Leuckart, R. Die menschlichen Parasiten und die von ihnen herrührenden Krankheiten. I., Leipzig, 1863; II., Leipzig, 1876. 8vo.

CobBold, T. Sp. Entozoa; an Introduction to the Study of Helminthology. London, I 864 . 8vo. Supplement, London, I 869 .

Davaine, C. Traité des entozoaires et des maladies vermineuses de l'homme et des animaux domestiques. 2nd edit. Paris, I877. 8vo. 
Linsrow, O. v. Compendium der Helminthologie, ein Verzeichniss der bekannten Helminthen, die frei oder in thierischen Körpern leben, geordnet nach ihren Wohnthieren, unter Angabe der Organe, in denen sie gefunden sind, und mit Beifügung der Litteraturquellen. Hannov., 1878. 8vo. Supplement, including the years $1878-1888$, Hannov., 1888 .

СоввоLD, T. Sp. Parasites; a Treatise on the Entozoa of Man and Animals, including some Account of the Entozoa. London, I879. 8 vo.

Leuckart, R. Die Parasiten des Menschen und die-von ihnen herrührenden Krankheiten. 2nd edit. Leipzig, 1879. The Protozoa, Cestodes, Trematodes and Hirudinei have hitherto appeared (continued by Brandes).

Bürschlı, O. Protozoa in Bronn's Klass. u. Ordn. d. Thierreichs. Vol. i., Leipz., I880I889. $8 \mathrm{vo}$, with 79 plates.

Braun, M. Trematodes in Bronn's Klass. u. Ordn. d. Thierreichs. Vol. iv., I, Leipz., 1879-1893. 8vo, with 33 tables. (The first thirteen sheets, comprising the history of the worms up to 1830 , were compiled by H. Pagenstecher.)

Z ËRN, F. A. Die thierischen Parasiten auf und in dem Körper unserer Haussäugethiere, sowie die durch erstere veranlassten Krankheiten, deren Behandlung und Verhütung. 2nd edit. Weimar, 1882. 8vo, with 4 plates.

Coвbold, T. Sp. Human Parasites; a Manual of Reference to all the Known Species of Entozoa and Ectozoa. London, 1882. 8vo.

Küchenmeister, F., and F. A. ZÜRn. Die Parasiten des Menschen. 2nd edit. Leipzig, I 888 . 8vo, with is plates.

Blanchard, R. Traité de zoologie médicale. I., Paris, 1889; II., I89o. 8vo.

NeumanN, L. G. Traité des maladies parasitaires non microbiennes des animaux domestiques. 2nd edit. Paris, 1892. 8 vo.

Looss, A. Schmarotzerthum in der Thierwelt. Leipzig, 1892. 8vo.

RaIlliet, A. Traité de zoologie médicale et agricole. 2nd edit. I., Paris, I893. 8 vo.

Parona, C. L'elmintologia italiana da' suoi primi tempi all' anno, I890. Genova, I 894. 8 vo.

Braun, M. Cestoda in Bronn's Klass, u. Ordn. d. Thierreichs. Vol. iv., 2, Leipzig, 1894-1900. $8 \mathrm{vo}$, with 24 plates.

Mosler, F., und E. Peiper. Thier Parasit. (Spec. Path. u. Ther. v. H. Nothnagel. Vol. vi.) Wien, I 894 . 8vo, with 124 illustrations.

Laveran et R. Blanchard. Les hématozoaires de l'homme et des anim. Paris, 1895. 12mo, with 30 figs.

Siuiter, C. R. De dierl. paras. v. d. mensch en van onze huisdier. Haag, 1895. 8vo.

BlAnchard, R. Malad. parasit., paras. animaux, paras. végét. à l'exclus. des bactér. (Traité de pathol. gén. de Ch. Bouchard T., vol. ii.) Paris, I895. 8vo, with 70 figs.

Huber, J. Ch. Bibliographie der klin. Helminthol. München, I895. 8vo. With Suppl., 1 898, and continued as Bibl. d. klin. Entomol. München, 1899-1900.

Moniez, R. Traité de parasitol. anim. et végét. appl. à la médecine. Paris, 1896. $8 \mathrm{vo}$, with II 6 figs.

Weichselbaum. Parasitologie (Weil's Handb. d. Hyg.). Jena, I898. 8vo, with 78 illustrations.

Kraemer, A. Die thierischen Schmarotzer des Auges (Gräfe and Sämisch's Handb. d. ges. Augenheilk.). Leipzig, I899. 8vo, with I6 illustrations.

Cholodkowsky, N. A. Icones helm. hominis. St. Petersburg, 1898-99. Fol. (atlas, with 15 plates).

Journals. - Besides the zoological and medical journals, the following are of

Centralblatt fïr Bacteriologie und Parasitenkunde, edited by Loeffler, Pfeiffer and Braun; and

Archives de Parasitologie, edited by R. Blanchard.

The following book is of importance to medical men :-

Ostertag, R. Handbuch der Fleischbeschau. 4th edit. With 260 illustrations. Stuttgart, I902. 


\section{THE ANIMAL PARASITES OF MAN.}

MAN is one of those organisms in which a whole host of parasites find conditions suitable for their existence: Protozoa, Plathelminthes, Nematodes, Acanthocephala, Hirudinea, and a large number of Arthropoda, Arachnida, as well as Insects, all include members which are parasites of man. These creatures either live on the external surface of the body or within the intestine and its appendages; yet other organs and systems are not quite free from foreign guests-we are acquainted with parasites in the bones, in the circulatory system, in the brain, in the muscles, in the excretory and genital organs, and even in the organs of sense.

Although it is possible in a 'way, and perhaps might be advantageous, to arrange and describe the parasites of man according to the situations in which they are found (parasites of the skin, intestinal parasites, \&c.), their description in the various stages of development would doubtless be disturbed when, as is generally the case, the different stages are passed in different organs, and a work which treats more fully of the natural history of the parasites than of the local disorders they give rise to would suffer thereby.

I therefore prefer to describe the parasites of man in their systematic order, and to mention their different anatomical stations in man in describing each species.

\section{A. PROTOZOA (Primitive Creatures).}

Ali those animal organisms which throughout their entire life never rise above the unicellular stage, or merely form simple, loose colonies of similar unicellular creatures, are grouped under the term Protozoa, as the simplest types of animal life. All the vital functions of these, the lowest forms of animals, are carried out by their bodily substance, the SARCODE (protoplasm); often particular parts possess particular functions; but the limits of a cell are never over-stepped thereby; these special parts of the cells are called "cell-organs" ; recently they have been termed "organelles."

The living protoplasm has the appearance of a finely granular, viscid substance which, as a rule, when not surrounded by dense investing membranes or skeletons, exhibits a distinct kind of movement, which has been termed AMÆBOID; according to the species, processes of various forms and various numbers called pseudopodia are projected and withdrawn, and with their assistance these tiny creatures glide along, one might almost say flow along, over the surface. In most protozoa two layers of plasma may be recognised, and distinguished by their appearance and structure, namely, 
the superficially situated, viscid, and quite hyaline ECTOSARC or ectoplasm, and the more fluid and always granular ENDOSARC (endoplasm) which is entirely enveloped by the ectoplasm. The two layers have different functions, the movements originate from the ectosarc, which also undoubtedly fulfils the functions of breathing, introduction of food and excretion; the endosarc, which in some forms (Radiolaria) is separated from the ectosarc by a membrane, undertakes the digestion of the food. To this apportionment of functions to various layers of plasma is due the development of particular cellular organs, such as the appearance of cILIA (filaments), FLAGELLA (whips), sUctorial tUBULes (in the Suctoria) and the myophanes, contractile parts of the ectosarc in infusoria and gregarines, differentiated by striation. In many cases (Flagellata, Ciliata), a place is formed for the ingestion of food (oral part, cytostom) to which, not rarely, there is added a straight or curved opening (cytopharynx), through which the food reaches the endosarc; the indigestible residue is either cast off through the oral part or excreted by a special anal part (cytopyge). In rare cases, organs sensitive to light, the so-called pigment or optic spots (Euglena), are developed. In the case of infusoria the endosarc circulates slowly, and agglomerations of fluids (FOOD VACUOLES) sometimes appear around each bolus of food; in these vacuoles the food is digested under the action of certain materials (ferments). Even in the lowest protozoa fluids to be excreted are, as a rule, gathered into one, or, more rarely, several " conTRACTILE VACUOLES," which regularly discharge their contents; this action, however, is to a certain extent governed by the temperature of the surrounding medium. In some infusoria a tube-like gap in the plasm is joined to the contractile vacuole which usually occupies a certain position ; this forms a sort of excretory duct, and there are also supply-canals leading to these cellular organs.

Very frequently various substances are deposited in the endosarc, such as fatty granules, drops of oil, pigment granules, bubbles of gas or crystals. More solid skeletal substances are secreted in or on the ectosarc. To the latter belong the cuticles of the sporozoa and infusoria, the chalky shells containing one or several chambers of the Foraminifera, the siliceous and very ornamental framework of the Radiolaria, and the chitinous integument of many Flagellata, Infusoria, \&c. Some forms, such as the Amœbinæ, make use of foreign bodies found in their surroundings, such as grains of sand and so on, to build their shelters.

The FOOD consists of small animal or vegetable organisms and of organic waste ; it is usually introduced in toto into the endosarc. On the other hand, the suctoria extract the substance from their prey by means of their suctorial tubes. Many parasitic species also ingest solid food, others feed themselves by endosmosis.

In all cases ONE NUCLEUS at least is present. It is true that the existence of non-nucleated protozoa, the Monera, is still insisted upon, but some of these have already proved to be nucleated, and the presence of nuclei in the others will no doubt be established. Very often the number of nuclei increases considerably, but these multi-nucleated stages are always preceded by mononucleated stages. In the infusoria, in addition to the larger or principal nucleus (macronucleus) there is usually a smaller accessory or deputy nucleus (micronucleus): 
The form and structure of the nucleus vary exceedingly in different species; there are elongated, kidney-shaped, or even ramified nuclei as well as spherical or oval ones; in addition to vesicular-shaped nuclei with a distinct nucleolus and incidentally also with a nuclear framework, we also frequently come across homogeneous and more solid formations. The nuclei are always differentiated from the protoplasm by their reactions, particularly in regard to certain stains.

The nucleus plays the same part in the life of the single celled organisms as it does in the cells of the metazoa and metaphytes; it appears to influence in a certain manner all, or at least most of, the processes of life, such as motility, regeneration, growth, and apparently also digestion; its principal influence, however, is exercised in the propagation of the cells, as this is always brought about by the nucleus.

The PROPAGATION of the protozoa is effected either by division or by means of direct budding. In division, which is preceded by direct or indirect (mitotic) division of the nucleus, the body separates into two, several, or even a great many segments; in this process the entire substance of the body is involved, or a small residual fragment may be left which does not undergo further division and finally perishes. In the budding method of multiplication a large number of buds are formed either on the surface or in the interior of the creature. Where divisions or buddings follow one another rapidly, without the segments separating immediately after their production, numerous forms develop, which are unlike the parental forms, and these are termed swarming spores or spores. Divisions imperfectly accomplished lead to the formation of protozoal colonies.

Sometimes encystment ${ }^{1}$ takes place previous to division; frequently, also, sexual processes appear, such as the union of two similar (isogamia) or dissimilar (anisogamia) individuals; the union may be permanent (copulation), the process being comparable to the fecundation of the ovum by a spermatozoon, or the union may be transient (conjugation); after the exchange of portions of the nucleus the couple separate, to multiply independently of each other. Sometimes there is an ALTERnation of GenERATION, through there being several methods of propagation combined in the same species, either-conjugation or copulation-being practised; the different generations may thus differ considerably in certain cases.

Protozoa inhabit salt water as well as fresh water; they are also found on land in very damp places, and invade animals as parasites.

\section{Classification of the Protozoa.}

Class I.-Rhizopoda (Sarcodina). Protozoa, the body substance of which forms pseudopodia; most of them are capable of developing chitinous, chalky, or gravelly coverings or frameworks, which, however, permit the protrusion of the pseudopodia either over the entire periphery or at certain points. They possess one nucleus or several.

${ }^{1}$ Independently of propagation, many protozoa protect themselves from death by encystment when the water in which they are living dries up; in this condition the wind may carry them over wide tracts of land. 
Order I.-Amobina (Lobosa) naked or with a simple shell, sometimes formed of a foreign substance; the pseudopodia may be lobulated or finger-shaped; there is a contractile vacuole; generally only one nucleus. They live in fresh or salt water, in the soil, and also parasitically.

Order 2.-Foraminifera (Reticularia). Mostly provided with a chalky shell, usually consisting of several chambers, and allowing the protrusion of the pseudopodia either at the periphery or only at the opening. The pseudopodia are filamentous and frequently anastomosed; there is no contractile vacuole; there are usually several nuclei. Marine.

Order 3.-Heliozua. Naked, with a chitinous or simple radial chalky framework; the pseudopodia are filamentous, and are frequently supported by firmer axis filaments, which exhibit no tendency to anastomosis: there is a contractile vacuole; one or several nuclei. Live in fresh water.

Order 4.-Radiolaria. The body has radially-placed filamentous pseudopodia, and the nucleus is hidden in the central capsule; there is almost always a silicious framework, consisting of pieces arranged radially, tangentially, or lattice-like; there is no contractile vacuole; but there are always vesicular vacuoles in the peripheral sarcode. Marine.

Class II.-Flagellata (Mastigophova). Protozoa with one or several long flagella used for locomotion and for acquiring food; in stationary forms their only function is to draw in food; cytostom common, contractile vacuole always present. May be either naked or provided with shells and shelters; one nucleus only. They live either in fresh or salt water, or may be parasitic.

This class is again divided into several sub-classes or orders, of which only the Euflagellata, with the Monadines and Polymastigodes, are of interest here.

Class III.-Sporozoa. Protozoa that only live parasitically in the cells, tissues, or organs of other animals; they ingest liquid food by osmosis ; the surface of the body is covered with an ectoplasmatic layer, or cuticle; have no cilia in the adult state, and rarely form pseudopodia; flagella occur, but only on the male propagating individuals. There may be one or numerous nuclei, but no contractile vacuole. Propagation by means of spores, mostly provided with shells, is characteristic; division and budding seldom occur, but alternation of generations is frequent.

Sub-class I.-Telosporidia (Cytosporidia) are usually of one constant form, rarely amœboid; are always mononuclear in the mature state; they live within cells in the first stage. Sporulation at the end of life.

Order 1.-Gregarinida. Body of a constant, usually elongated form, surrounded by a cuticle. In the early stage they lead an intracellular existence; in the mature stage they live within the intestine or abdomen of invertebrate animals, especially the arthropoda, and, like intestinal parasites, are provided with clinging organs. Fecundation isogamic; the spores have shells, no polar bodies, and usually contain several minute germs (sporozoites).

Order 2.-Coccidiida (Coccidiomorpha). Body of uniform spherical or oval shape; intracellular life, but are not freely motile in cavi- 
ties of the body. Fecundation anisogamous; spores have shells without polar bodies, mostly with several sporozoites.

Order 3.-Hamosporidia. Parasites of the blood corpuscles of vertebrate animals ; they exhibit amœboid movements ; present alternation of generations and hosts; spores naked.

Sub-class 2.-Neosporidia. They are polynucleated in the adult state; the form of the body varies exceedingly; sporulation commences even before the completion of growth.

Order I.-Myxosporidia. The spores have shells, with or without caudal appendages, with two, rarely four, polar capsules. They live free in such organs as the gall or urinary bladder, but are chiefly found in connective tissue, and especially in fishes.

Order 2.-Microsporidia. Spores with shells; no caudal appendage, with one polar capsule. They usually live in the tissues of the arthropoda.

Order 3.-Sarcosporidia. Elongated parasites of the muscular fibres of amniotic vertebrate animals, on rare occasions they occur also in the connective tissue; the spores are naked, have no polar bodies (?) ; kidney- or sickle- shaped.

Class IV.-Infusoria (Ciliata). The body is generally uniform in shape, with cilia, contractile vacuole, frequently also with cytostom; usually has macro- and micro- nucleus; live free in water and also parasitically.

The orders Holotricha, Heterotricha, Hypotricha and Peritricha are classified according to the arrangement of the cilia.

Class V.-Suctoria are bodies with suctorial tubes, contractile vacuoles, macro- and micro- nucleus, no cytostom. They generally invade aquatic animals as space parasites, yet also attack plants; early stage ciliated. Live frequently as parasites in infusoria.

\section{LITERATURE.}

Besides the zoological works (compare Buitschli and A. Lang) and those already alluded to, the following may be noted :-

Pfeiffer, L. Die Protoz. als Krankheitserreger. 2nd edit. Jena, 189i. Supplements, Jena, 1895.

SchneidemühL, G. Die Protoz. als Krankheitserreger der Menschen u. der Hausthiere. Leipzig, I 898.

Doflein, F. Die Protoz. als Parasiten und Krankheitserreger. Jena, I901; and the and edit. of the book.

\section{Class I. Rhizopoda.}

Order I. Amobina.

Gen. I. Amába, Ehrbg.

The body of the amœba, which is always naked, frequently exhibits the differentiation of the ecto- and endo- sarc very distinctly; the ectosarc is viscid and hyaline, the endosarc is liquid and granular, and in addition contains food-particles (free in the plasma or enclosed in vacuoles), fatty granules; incidentally also crystals. It contains, moreover, the compact or vesicular nucleus, which occurs singly in nearly all species, and the contractile vacuole which discharges its watery contents with acid reaction to 
the exterior, and in some species into the surrounding plasma. Movements are effected by means of pseudopodia, processes of the protoplasm which may be projected and retracted from any part of the body. Notwithstanding the fact that this causes a continuous change of shape, the form, number and arrangement of the finger-like or lobulate pseudopodia are characteristic of each species, and together with the size, which fluctuates between 0.01 and $0.5 \mathrm{~mm}$, and the structure, as well as the number of nuclei and the constitution of the protoplasm, serve to distinguish the species. The food, consisting of the tiniest organisms (bacteria, algæ, protozoa) or residues; is ingested by. the body, with the assistance of the pseudopodia, i.e., is ingulfed by the protoplasm.

Propagation takes place by means of segmentation, after previous direct or mitotic division of the nucleus. After the completion of encystment and after the successive segmentation of the nucleus into many parts, there occurs a division into numerous segments, each containing a nucleus. The division either involves the entire plasm or leaves a residual body. After leaving the cell-membrane the segments assume an amoboid or flagellated form, and in this condition they are capable of propagation through longitudinal division. Finally, they give up flagellate movement, sink to the bottom, and continue to move by the means of pseudopodia.

The amœbæ live chiefly in stagnant fresh water, creeping about at the bottom of puddles or on plants; a few species are marine, others live in moist soil, and a number are parasitic. In no case has there been satisfactory evidence to prove whether the amœbæ are facultative or true parasites.

All the amœba-like beings one comes across in the open, or in infusions or cultures, are not independent organisms, but developmental forms of other animal, or particularly vegetable, organisms; this, perhaps, is also the case in some of the parasitic forms: the task of distinguishing the latter from body cells is very often difficult.'

\section{Amoeba coli, Loesch, I875.}

Form, roundish or pear-shaped; size fluctuates between 0.008 and $0.05 \mathrm{~mm}$. The ectosarc can hardly be recognised in the quiescent creature, but is distinctly visible in the pseudopodia; the endosarc is more or less finely granular, and usually contains white and red blood corpuscles taken up for food; it may also contain eosinophile cells, bacteria, epithelial cells and particles of fæcal matter; the pseudopodia are broad, lobose, one or two being protruded at a time. The activity of the movement depends on the temperature and on the constituents of the surrounding medium: when the contents of the intestine have an

1 The literature on this subject is found in Bütschli, 1.c. in R. Behla, Die Amøben vom paras. und culturell Standpunkt (Berlin, I898, 8vo, with one plate); also in A. Lang, Lehrb. der vergl. Anat. der wirbellosen Thiere, 2nd edit. (Jena, I901, 8vo, with 259 illustrations) Compare also Feinberg, "Ueber Amoeben u. ihve Unterscheidung von . Körperzellen (Fortschritte der Medic., I899, xvii., p. I21). 
acid reaction the intestinal amœbæ die off; a low temperature retards the amœboid movement, and finally causes it to cease. The number of vacuoles varies; they rarely change form. A nucleus is always present, though it cannot always be seen in the living animal; after death, or through the addition of reagents (acetic acid, sublimate), it shows clearly; its form is spherical,

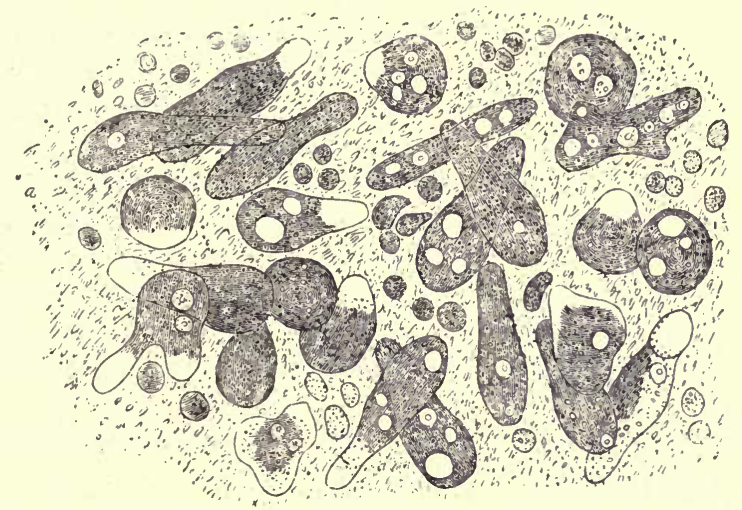

FIG. I. - Amoeba coli, Loesch, in the intestinal mucus, containing blood and pus corpuscles. (After Loesch.)

and it is of the same size as the vacuoles $(0.006 \mathrm{~mm}$.). According to some authors the nucleolus is easily detected, others state that it is only exceptionally visible.

The propagation of the amoba takes place in the intestine by simple division (it has been observed by Casagrandi and Barbagallo ${ }^{1}$ as well as by Harris ${ }^{2}$ ). The transmission to other hosts is appar-
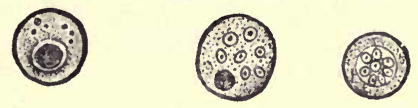

FIG. 2.-Encysted intestinal amœba in the act of propagation. (After B. Grassi.)

ently effected exclusively by encysted forms, the protoplasm of which, after repeated division of the nucleus, separates itself into. as many parts as there are new nuclei (Casagrandi and Barbagallo), by arranging itself round each new nucleus. According

\footnotetext{
'Casagrandi, O., and Barbagallo, P., "Sull' amoeba coli" (Boll. Accad. Gioenea, sc. nat. Catania, I895).

"Harris, H. F., "Some Observations on a Method of Multiplication of the Amoeba dysenteria" (Med. News, 1894, lxv., No. 21, p. 567).
} 
to Grassi, ${ }^{1}$ the propagation is effected by amœbæ, the protoplasm of which is still entire, but which probably will divide later. Calandruccio ${ }^{2}$ succeeded in infecting himself by swallowing encysted intestinal amœbæ; twelve days after ingestion amœbæ appeared in his fæces. Quincke and Roos obtained the same result in experiments on cats, whereas the transmission by means of non-encysted amœbæ proved negative.

Amobæ have frequently been seen in the fæces evacuated by healthy persons and in those of patients suffering from the most varied intestinal disorders. They were first discovered by $\mathrm{Lambl}^{3}$ at Prague in I859, in the evacuations of a child suffering from dysentery, but this discovery was of little value in itself, as the author stated that he had also found Difflugia and Arcella. At a later date Lewis $^{4}$ and Cunningham ${ }^{5}$ observed amoboid organisms in the stools of patients suffering from cholera and other diseases. We owe the first detailed description and the determination of the species to Lösch, who found amøeb in great numbers, as well as pus and blood corpuscles, in the stools of a patient in St. Petersburg who exhibited dysenteric symptoms (fig. I). Lösch was also the first observer who 'sought to confirm the pathogenic action of intestinal amobæ by means of experiment. $\mathrm{He}$ introduced small quantities of fæces containing amœbæ into four dogs per os et anum, and eighteen days later, at the autopsy of one of the animals that had already passed sanguineous masses of mucus with amobæ soon after the experiment, he found several ulcers in the rectum containing numerous amœbæ. As the three other dogs remained healthy, Lösch expressed the opinion that the amobæ should not be regarded as a cause of disease, but that probably they prevented the healing of intestinal ulcers previously present, thus increasing the original inflammatory conditions.

The occurrence of intestinal amœbæ in man has been reported from a great many regions. We hear of them in Germany (Pfeiffer, Schuberg, Behla, Quincke and Roos, Roemer, Boas, Jaeger), in Austria (Cahen, Epstein, Manner, Hlava, Sorgo), in Russia (Lösch, Massiutin, Ucke), in Roumania (Babes and Zigura), in Bosnia (Schardinger), in Greece (Kartulis), in Italy (Grassi, Calandruccio, Fenoglio, Casagrandi and Barbagallo, Vivaldi), in France (Peyrot and Roger), in Algeria (Gasser), in Egypt (Sonsino, Kartulis, Koch, Kruse and Pasquale), in Abyssinia (Grassi), in India (Lewis, Cunningham, Harold, Manson, Ross), in Hong Kong (Normand), in Tonquin (Laveran), in the Philippines (Flexner), in Sumatra (Kovacs), in Saghalian

'Grassi, B., "Protoz. paras. e spec. quelli che sono nell' uomo" (Gazz. med. ital.lomb, I879, No. 45); "Int. ad alc. prot. endop." (Atti soc. ital. sc. nat., I882, xxiv., p. I); "Morf. e sist. di alc. prot. par." (Atti Acc. Lincei Rend, iv., I, p. 5) ; "Signif. patol. d. prot. par. dell' uomo" (ibid., p. 33 ).

2 Calandruccio, "Anim. par. dell' uomo in Sicilia" (Att. Acc. Gioen., I89o, ii., p. 95).

${ }^{3}$ Lambl, A. d. Franz-Josephs-Kinderspit. i. Prag., I 860, i., p. 362.

${ }^{4}$ Lewis, Sixth Ann. Rep. San. Comm. Government of India, Calcutta, I87o.

${ }^{5}$ Cunningham, D., Seventh Ann. Rep. San. Comm. Gov. of India, Calcutta, I87o.

"Lösch, F., "Massenh. Entw. v. Amoeb. i. Dickdarm" (Virchow's Arch. f. Path., I 875 , lxv., p. 196). 
(Lobas), in North and South America (Musser, Stengel, Councilman, Howard, Osler, Dock, Lutz, Fajardo, Roemer).

The interest aroused in the intestinal amœbæ of man is to be ascribed not so much to their world-wide distribution as to the fact that they are supposed to be connected with a serious disease to which man is subject, namely, dysentery. The Commission despatched to Egypt and India in 1883 to investigate cholera ${ }^{1}$ not only succeeded in discovering the bacillus of cholera, but also collected information regarding dysentery. In Egypt, Koch performed autopsies on five fatal cases of dysentery. In four of these, in addition to bacteria, he found amœbæ at the bottom of the ulcers (on sections); in the fifth case the ulcers in the large intestine were nearly or entirely cicatrised. During the life of these patients amœbæ could not be found in the stools. The same author made similar observations in India. At about the same time Kartulis, in Alexandria, discovered amœba-like bodies in the stools of six persons suffering from chronic inflammation of the bowels, or diarrhœa, and he described these as "giant amœbæ."' Encouraged by Koch's researches, Kartulis $^{3}$ continued his studies on dysentery, and was able to confirm the presence of amœbæ in every case of undoubted dysentery (more than I50 cases), whereas they were entirely absent in other bowel complaints; he also succeeded in demonstrating amœbæ in sections from the large intestine, but only in cases of dysentery, and not in other intestinal diseases involving ulceration of the bowel. Further researches on over 500 cases confirmed the previous observations. Living amœbæ were likewise found in the pus of liver abscesses, which frequently follow tropical dysentery, the parasites presumably passing from the intestine to the liver by way of the blood-vessels. R. Koch's (l.c.) researches

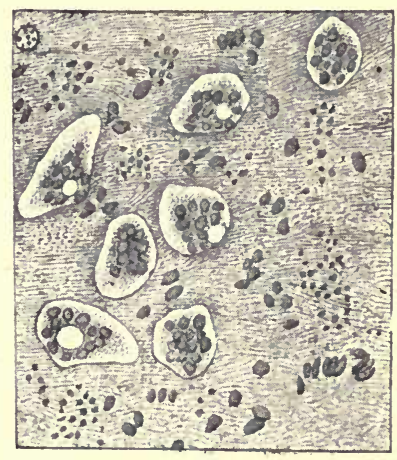

Fig. 3.-Amoeba coli, Lïsch, in the mucus of a dysenteric stool, with red blood corpuscles. (After Kovacs.) would lead one to form the same conclusion. Finally, Kartulis ${ }^{4}$ was able to
confirm by experiments similar to those of Lösch, which were so widely disputed, that animals, especially cats, injected with dysenteric fæces or pus containing amœbæ easily developed a disease resembling endemic dysentery. In reply to the objection raised, that in such experiments impure material was used; and that the disease in the animals experimented upon was due to other agents (bacteria, \&c.), Kartulis communicated a successful experiment in which the infection had been conveyed by pus free of bacteria, but containing amœbæ.

Koch, R., and G. Gaftky, "Ber ii. d. Thit. d. z. Erforsch. d. Cholerabac. ents. Commiss." (Arb. a. d. Kais. Gesundheitsamte, 1887, iii., Berl., 1887).

"Kartulis, "Ueber Riesenamaben (?) bei chron. Darmentz. d. Aegypt." (Virchow's Arch., 1885, xcix., p. I45).

${ }^{3}$ Kartulis, "Z. Etiol. d. Dysent." (ibid., 1886, cv.); "Z. Etiol. d. Dys. i. Aeg." (C. f. B. u. P. 1887, V., p. 745); "Ueb. trop. Leberabs. u. ihr Verh. z. Dys." (Virchow's Arch., I889, cxviii., p. 97); "Einiges iib. d. Pathog. d. Dysenterie-Amaeb." (Centralbl. f. B. u. P., 1891, ix., p. 365 ).

"Kartulis, "Dysenterie" (Spec. Path. und Ther. von H. Nothnagel, v., 3, Wien, 1806). 
Kartulis' views, which are briefly stated here, are also considered by the author to hold good for endemic (tropical) dysentery. They have met partly with assent, and partly with vehement opposition. The authors who support Kartulis, such as Councilman and Lafleur,' Quincke and Roos, ${ }^{2}$ Kruse and Pasquale, ${ }^{3}$ Kovacs, ${ }^{+}$and others, ${ }^{5}$ for the most part agree on the grounds of their own very extensive researches, but also on account of the irrefutable arguments adduced by Kartulis, and they are more or less convinced of the pathogenic action of Amoba dysenterica, and agree in regarding the parasite as the sole, or at least the primary, agent in the causation of endemic (tropical) or amœbic dysentery or amœbic enteritis. They are also of opinion that the bacteria which always accompany the amceba are not specific, but possess pathogenic qualities and play a part in the morbid process induced by the amœba.

The opponents base their opinion on the fact that in various places intestinal amœbæ are either invariably absent in cases of true endemic dysentery, or are very scarce, as, for instance, in Japan, Algeria, the Philippines; moreover, that they are found in the evacuations in other infectious and non-infectious intestinal diseases (typhus, cholera, colitis, proctitis, acute and chronic intestinal catarrh, \&c.), and that they are even present in perfectly healthy persons. ${ }^{6}$ The experimental infection produced in animals to prove the pathogenic nature of the Amœbæ of the intestine is not considered above reproach. Apart from the circumstance that all the experiments were not followed by positive results, in one case, undoubtedly, impure material was used; and in those cases where test cultures proved that the material was free from bacteria, no absolute proof of this condition was given. Moreover, it is also possible to cause a dysenteric disease in mammals (cats were mostly used) when the amœbæ in the evacuations used for injection have been killed off by the addition of water or by heating, or even when ordinary garden mould diluted with water is used for the injection. It is also emphasised that the order of the experiments is entirely reversed, because the infection of man

'Councilman, W. P., and H. A. Lafleur, "Amoebic Dysentery" (Johns Hopk. Hos. Rep., I891, ii., p. 395).

"Quincke and Roos, "Ueb Amoeb.-Enteritis" (Berl. klin. Wchschrift., I 893, xxx., No. 45, p. 1089); Roos, E. Z., Kenntniss der Amobenenteritis (Arch. für exp. Path. und Pharm., 1894, xxxiii., p. 389).

${ }^{3}$ Kruse, W., and Pasquale, "Eine Exped. n. Egypt." (Dtsch. med. Wchschrft., 1893, No. 15, p. 354; No. 16, p. 378); "Unters. üb. Dy's. u. Leberabsc." (Ztschr. f. Hyg., 1894, xvi., p. 1).

4 Kovacs, F., "Benb. u. Vers. "̈z. d. sog. Amoeben-Dys." (Zeitschr. f. Heilkde., 1892, xiii., p. 500).

"Compare also the following literature: Schuberg, A., "Die paras. Amceben $d$. menschl. Darms (C. f. B., u. P., I893, xiii., pp. 598,654, 701); Janowski, W., "Z. Aetiol. d. Dys." (C. t. B., P. u. I., 1897, xxi., pp. 88, 15 1, 194, 234).

${ }^{6}$ Schuberg, A. (C. f. B. und P., 1893, xiii., p. 598); Casagrandi, O. G. V., and P. Barbagallo (Boll. Accad. Gioenea sc. nat. Catania, 1885); Celli, A., and R. Fiocca, "Ueb. d. Aetiol. d. Dys." (C. f. B. u. P., 1895, xvii., p. 309); Grassi, B. (l.c.); Massiutin, "Amoeb. als Paras. d. Dickdarms" (Wratsch, 1889, No. 25, Ref. in C. f. B. u. P., 1889, vi., p. 45I) ; Laveran, "Etiol. de la dys." (Sem. mid., 1893, p. 508; C. R. soc. biol., 1893, v., p. 875 ).

"Gasser, I., "Note sur la cause de la dys." (Arch. mid. exp. et d'anat. pathol., i895, p. 198). 
certainly does not take place per anum.' Moreover, some authors" who have received intestinal amœbæ from various sources state that there is no morphological difference between the amœbæ of tropical and European dysentery; and that a bacterium of which there are apparently several varieties is the cause of dysentery in the temperate as well as in the tropical and subtropical zone. ${ }^{3}$ The specific nature of these bacteria is proved above all by the agglutination which the blood serum effects on the
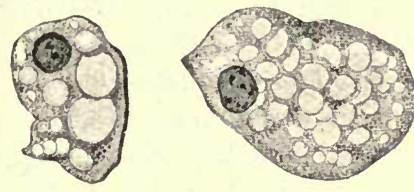

FIG. 4. - Amøba coli from the section of the intestine of a cat which had been infected with the intestinal amœba of a man. Stained with alum - carmine. (After Kovacs.)

bacteria in persons ill with or recovered from the infection, the serum of healthy persons not causing agglutination. Those forms of dysentery caused by bacteria and in which amœbæ are either not found or very rarely, are excluded from the discussion, and further proofs will be necessary in order to gain general recognition for the etiology of the so-called amœbic enteritis or amœbic dysentery. It must, however, be mentioned that Kartulis endeavoured to test the methods of Celli and Fiocca (killing the amœbæ by warming) and of Casagrandi and Barbagallo (killing the amœba with distilled water), but was unable to confirm their results. Kartulis, by means of test cultures on various media, assured himself of the absolute purity of the abscess-pus containing amœbæ which he used for his experiments.

A few authors take up an intermediate position, in so far as they admit of the existence of various species of parasitic amœbæ in man. One of these they consider innocuous, because it is found more or less frequently in healthy persons, and comes under observation in very different intestinal disorders, while another they believe to be the cause of amœbic enteritis. Councilman and Lafleur do not agree with this view; they designate the amœba of dysentery plainly as Amoeba dysenterice. Kruse and Pasquale use the same designation, and reserve the old term, Amceba coli, Lösch, for the non-infectious species. Quincke and Roos distinguish three species:

'Janowski, l.c., \&c., and others.

"Roemer, F., "Amoeb. bei Dys. u. Enteritis" (Munch. med. Wchschr, 1898, xlv., No. 2, p. 4I).

${ }^{3}$ Celli, A., and R. Fiocca, l.c. ; Laveran, l.c.; Zancarol, "Pathog. d. abcès du foie" (Rev. d. chirurg., 1893, xiii., p. 671; Ret. in C. f. B. u. P., 1893, xiv., p. 638); Arnaud., "Rech. sur l'étiol. de la dys, aigue. d. pays chaud" (Ann. Inst. Pasteur., I 894, viii.); Silvestri, E., de "Contrib. allo stud. del l'etiol. $d$. dissent.," Torino, 1895; Celli, A., "Eziol.d. diss." (Ann. d'igien: sperim, 1896, vi., p. 204) ; Shiga, K., "Ueb. d..Dysenterie bacillus" (C. f. B., P. u. I., 1898, xxiv., pp. 817, 870, 912); Celli, A., and G. Valenti, "Nochm. iib. d. Aet. d. Dys." (C. /. B., P. u. I., 1899, xxv., p. 48I); Escherich, Z., "Aet.d. Dys." (ibid., r 899, xxvi., p. 385) ; Flexner, G., "The Etiology of Tropical Dys entery" (ibid., 1900, xxviii., p. 625) ; Kruse, W., "Ueb. d. Ruhr, also Volkskrkht. u. ihr Erreger" (Dtsch. med. Wchschr., I900, xxvi., p. 637); "Weit. Unters. ub. d. Ruhr u.d. Ruhrbacillen" (ibid., $190 \mathrm{I}$, xxvii., pp. 370, 386) ; Volagussa, F., "Aetiol. u. Serum ther. der Kinderdys" (Ann. d'igien. sper., I901, x.) ; Centralbl. fiir B., P. und I., I90 I, xxix., p. 639); Lavkowiz, X., "Enterococc. als Ruhrerreg." (ibid., p. 635).

'The reason that Raph. Blanchard, who in 1885 had already mentioned the amœba of dysentery as a special species ("A maba intestinalis," in Traite de Zool. mid., vol. i., Paris, I 885, p. I 5), is not included here, is that the author himself changed his views, and only recognises one species of amoba, the Amocha coli, in the intestine of man ( $\mathrm{Mal}$. paras., Evc:, I895, p. 658). 
a small species (0.025 mm.), finely granular, the Amoeba coli, Lösch, which is pathogenetic to man and the cat; a larger one $(0.040 \mathrm{~mm}$.$) , coarsely$ granular, the Amoba coli mitis, which is pathogenetic to man but not to the cat; and a species of similar appearance, the Amoeba intestini vulgaris, which is innocuous both to man and cat. Celli and Fiocca' even go a step further, differentiating, as they do, the following species in the intestine of man: (I) Amoba lobosa, with var. guttula (i.e., Amoeba guttula, Duj.), var. oblonga (i.e., A. oblonga, Schm.), and var. coli (i.e., A. coli, Lösch); (2) Amoeba spinosa, n. sp. (in the vagina as well as in the intestine of persons suffering from diarrhœa and dysentery); (3) Amcba diaphana, n. sp. (in the human intestine in cases of dysentery); (4) Amoeba vermicularis, Weisse (in the vagina and in the intestine in dysentery); and (5) Amoba reticularis, $\mathrm{n}$. sp. (in the intestine in dysentery). These authors state that they have also found all these species free in the soil or in the ooze of waters, and have cultivated them in pure cultures. It is, however, probable that in all these experiments it was not a question of exclusively animal organisms, as the existence of the latter depends on food very different to that which was used in the pure cultures"; it is therefore advisable to take up an expectant standpoint in this connection.

Of the species differentiated by Quincke and Roos, two ( $A$. intestini vulgaris and $A$.coli mitis) may be regarded as identical, because no morphological differences have been described, and because the statement that their effect on man is different is, to say the least, doubtful. ${ }^{3}$ It is therefore reasonable to infer that two species were under discussion, one pathogenic and the other harmless. The possibility of a morphological difference between the two forms has, however, not hitherto been proved, and has recently been again denied, notably by Roemer (I898). In spite of the numerous works published within recent years on the intestinal amœbæ of man, no definite conclusion has yet been arrived at. Notwithstanding this, at the present time medical men strictly differentiate bacillary dysentery from amœbic dysentery or amœbic enteritis ; the former occurs in Germany in the dysentery district (Kruse, I900, 190I), the latter particularly in East Prussia (Jaeger, ${ }^{4}$ 1902).

'Celli, A., and R. Fiocca, "Beitr. z. Amoebenforsch, II." (C. f. B. u. P., I894, xvi., p. 329); "Ric. int. alla biol. d. Amobe" (Bull. Accad. med. Roma, 1894-95, xxi., p. 285); Ref. in C.f. B., P. u. I., 1897, xxi., p. 290.

${ }^{2}$ It is quite different with the experiments of Frosch (C. f. B., P. u. I., I $897, \mathrm{p}$. 926); Tsujitani (ibid., xxiv., p. 666); and Schardinger (Stzgsb.d. K. Acad. d. Wiss. Wien. Math.-mt. Cl., 1899, cviii., part 1, p. 7 I3), who fed their nurslings with suitable bacteria: they do not, however, concern us here, being free-living species.

"Compare also Quincke, "Ueb. Protozoën-Enteritis" (Berl. klin. Wchschr., 1894, Nos. 46 and 47).

${ }^{4}$ Jaeger, H., in C.. . B., P. u. I., xxxi., Orig., p. 551 . 
2. Amceba gingivalis, Gros.

3. Amoba buccalis, Sternberg. ${ }^{2}$

4. Amceba dentalis, Grassi. ${ }^{3}$

Of these three species the last mentioned may certainly be eliminated, as its describer has himself suggested the possibility of having mistaken salivary corpuscles for amœbæ; the other two species are supposed to live in the tartar on teeth. They have not again come under observation, and, on the other hand, Celli and Fiocca distinctly state that they have never found amœba-like organisms in the oral cavity.

\section{Amceba pulmonalis, Artault. ${ }^{4}$}

The author discovered a few amœboid formations with nucleus and vacuole in the contents of a lung cavern. In the fresh condition they were distinguishable from leucocytes by their remarkable capacity of light refraction; they were also much slower than the latter in staining with methylene blue or fuchsine; their movements became more lively in a strong light. Water and other tgents killed them, and then, even when stained, they could not be distinguished from leucocytes.

\section{Amøba urogenitalis, Baelz. ${ }^{5}$}

This species was found in masses in the sanguineous urine as well as in the vagina of a patient in Japan, aged 23, in whom, shortly before death caused by pulmonary tuberculosis, hæmaturia with severe tenesmus of the bladder had set in. The amoba, which showed great motility, and had a diameter of about $0.050 \mathrm{~mm}$. when quiescent, exhibited a granular plasma and a vesicular nucleus. Baelz is of opinion that these parasites were introduced into the vulva with the water used for washing the parts, and thence penetrated into the bladder and vagina.

Similar cases are also reported by other authors: Jürgens, ${ }^{3}$ Kartulis,

' Gros, G., "Fragm. d'helm. et de phys. microsc." (Bull. soc. Imp. d. Natural. de Moscou, I 849, I and 2, p. 555).

${ }^{2}$ Sternberg, in Zeitschr. f. newere Med., I862, Nos. 20-24, published by Walter, in Kiew, and issued in the Russian language.

${ }^{3}$ Grassi, B., in Gazz. med. ital. lomb (8), 1879, i., No. 45, p. 445.

"Artault, St., "Flore et faune d. cav. pulmon." (Arch. de parasit., I 898, i., p. 275).

"Baelz, E., "Ueb. einig. neue Paras. d. Mensch." (Berl. klin. Wochenschr., I883. p. 237).

'Jürgens, Deutsch. med Wochenschr., 1892, p. 454.

" Kartulis, "Pathog. Protoz. b. Mensch." (Zeitschr. f. Hyg., 1893, xiii., p. 2, Anm. 2) 
Posner,' and Wijnhoff.". Jürgens found small mucous cysts, filled with amœboid bodies, in the bladder of an old woman suffering from chronic cystitis; they were also met with in the vagina. The amœbæ observed by Kartulis in the sanguineous urine of a woman, aged 58 , suffering from a tumour of the bladder, measured $0.012-0.020 \mathrm{~mm}$., and exhibited slow movements by protruding short pseudopodia. The vacuoles and nucleus became visible only after staining with methylene blue.

Posner's case related to a man, aged 37 , who had hitherto been quite healthy and had never been out of Berlin. Suddenly, after a rigor, he passed urine tinged with blood, in which were found, besides red and white blood corpuscles and hyaline and granular casts, large granular bodies (about $0.050 \mathrm{~mm}$. in length and $0.028 \mathrm{~mm}$. in breadth), which slowly altered their shape, and contained red blood corpuscles in addition to other foreign matter. These bodies exhibited one or several nuclei and some vacuoles. From the course of the disease, which extended over a year, and during which similar attacks recurred, Posner came to the conclusion that the amœbæ which had originally invaded the bladder penetrated into the pelvis of the kidney, where they probably settled in a cyst, and thence induced the repeated attacks.

Wijnhoff observed four cases of amœburia in Utrecht. ${ }^{3}$

\section{Amceba kartulisi, Dofl. ${ }^{4}$}

Kartulis ${ }^{5}$ observed the following case: An Arab, aged 43 , developed an abscess as large as an orange on the right lower jaw, with a fistulous opening secreting a thick pus. In the pus, as well as on pieces of bone that were extracted, amœbæ of

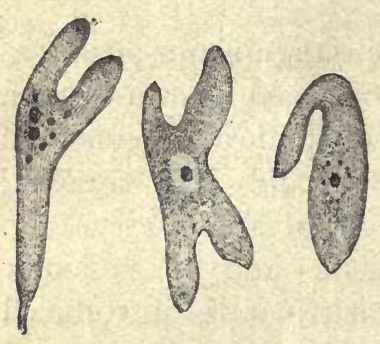

FIg. 5.-A moeba Kartulisi Dofl., from the pus of a submaxillary abscess, in various stages of motility. (After Kartulis.)

$0.030-0.038 \mathrm{~mm}$. in diameter were found in addition to bacteria. The movements of these amœbæ were more lively than those of the amøbæ of dysentery; their coarsely granular protoplasm contained pus and blood corpuscles; the long finger-like pseudopodia were very rapidly protruded, and usually appeared singly; as a rule, the very small nucleus was visible only after staining, and in like manner the vacuoles also escaped observation.

A case observed by Flexner $^{6}$, also deserves mention. It relates to a man, aged 62 , with

'Posner, C., "Ueb. Ameeb. i. Harn" (Berl. klin. Wochenschr., 1893, xxx., No. 28, p. 674).

2Wijnhoff, J. A., "Over amceburie" (Nederl. Tijdschr. v. Geneeskde, 1895, p. 107).

${ }^{3}$ The amoba-like formations found by Doria on the floor of the glands in endometritis chronica (Arch. f. Gynäkol., 1894, xlvii., p. I) are regarded by Pick (Berl. klin. Wochenschr., 1895, Nos. 22 and 23) as altered epithelial cells.

'Doflein, F., Die Protoz. als Par. u. Krankheitserr., Jena, 1901, p. 30.

"Kartulis, "Ueb. pathog. Prot.b. Mensch." (Zeitschr. f. Hyg., I893, xiii., p. 9).

"Flexner, "Amoeba in an Abscess of the Jaw" (Johns Hopk. Hosp. Bull., No. 25 , I892! ; ref. in C. f. B. u. P., xiv., 1893, p. 288. 
an abscess on the floor of the oral cavity, from which pus was artificially evacuated. The pus in addition to many different kinds of bacteria also contained amœbæ. These amœbæ were larger than leucocytes, and exhibited granular plasm and vacuoles; the nucleus could not be distinctly made out.

The pseudopode formation, which ceased at a low temperature, could again be brought into play by warming the slide.

Doflein "conjectures that in both the cases quoted it was a question of dysenteric amœbæ, though there was no history of previous dysentery in either case. It has long been known that Amoba dysenterica appears in dysenteric hepatic abscesses and in the secondary pulmonary abscesses that occasionally follow. An observation by Nasse,' who operated on a dysenteric hepatic abscess, shows that the amœbæ may also penetrate still further. In this case gangrene of the wound subsequently set in, and the amœbæ were found not only in the hepatic abscess, but subsequently also in the wound, in the skin, and even in the muscular system.

The "amœbæ" found by Berndt" in the pus from a hepatic abscess (after typhus) appear to be entirely problematical formations.

\section{Amœeba miurai, Ijima."}

Under this term the author describes protoplasmatic bodies which Miura, in Tokyo, found in the serous fluid of a woman, aged 26 , who had died from pleuritis and peritonitis endotheliomatosa; two days before death these same forms had also appeared in the hæmorrhagic fæces of the patient. The bodies were usually spheroid or ellipsoidal, and at one pole carried a small protuberance beset with filamentous short pseudopodia, resembling the appendages possessed by free-living amœbinæ. Their size varied between 0.015 and $0.038 \mathrm{~mm}$.; the plasma was finely granular, and no difference was observable in the ectoand endo-sarc, only the villous appendage was lighter; the plasma contained vacuoles more or less numerous, none of which were contractile. After the addition of acetic acid one to three nuclei could be distinguished, 0.008 to 0.015 in size. Actual movements were not observed. Taking everything into consideration, the independent nature of

'Nasse, "Ueb. ein. Amobenfund b. Leberabsc. u. Dys." (Dtsch. med. Wochenschr. 3 89 I, p. 88 I).

${ }^{2}$ Berndt, F., “Protoz. in ein. Leberabsc." (Dtsche. Zeitschr. f. Chir., 1895, xl., p.163).

"Ijima, J., "On a New Rhizopod Parasite of Man" (Annot. zonl. japon, I898. ii. . 3, p. 85$)$; ref. in C. f. B., P. u. I., I 899, xxv., p. 885 . 
these bodies is, to say the least, doubtful, ${ }^{1}$ although it cannot be denied that they possess a certain similarity to the marine Amoba Amida, Grïber or Greeff, and to a few other species.

\section{Leydenia gemmipara, Schaud.2}

In the fluid removed by puncture from two patients suffering from ascites in the first medical clinic in Berlin, cellular bodies with spontaneous movement were found which Leyden and Schaudinn regard as distinct organisms. They remained alive without the use of the heated object table for four or five hours, the external temperature being 24 to $25^{\circ}$ C. In a quiescent condition they were of a spherical or irregular polygonal form; their surface was rarely smooth, being beset with
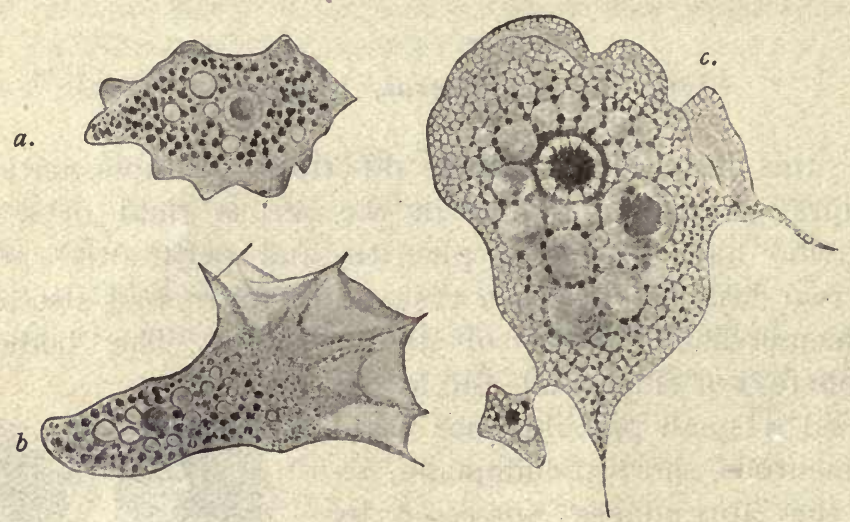

FIG. 7.-Leydenia gemmipara, Schaud. : (a) In a quiescent condition, $1,000 / \mathbf{1} ;(b)$ in the act of moving, $\mathrm{I}, 000 / \mathrm{I} ;(c)$ a preserved specimen with bud, $\mathrm{I}, 500 / \mathrm{I}$.

protuberances and excrescences. The substance of the body was solid and permeated with light refracting nuclei with a yellowish shimmer. The hyaline ectosarc was rarely seen distinctly. All sizes from 0.003 to $0.036 \mathrm{~mm}$. in diameter were observed. The movements were rather sluggish, the ectosarc in the meantime appearing in the form of one or several large lamellæ in which also strings of the granular endosarc appeared, and frequently protruded over the border of the hyaline pseudopod. The

${ }^{1}$ Lühe considers A moeba miurai to be "exudation cells" (C. . B., P. U. I., I902, xxi., ref., p. 207).

2Leyden, E. v., and F. Schaudinn, "Leydenia gemmipara, ein neuer $i$. d. Ascites Fliiss. d. leb. Mensch. get. amcebenähnl. Rhizopode" (Sitzungsber. d. K. Pr. Acad. d. Wiss. Berl., 1896, xxxix., p. 95 I). 
tendency for the conjunction of several individuals by means of their pseudopodia, was so marked that associations ensued similar to those known in free-living rhizopods.

The plasma enclosed blood corpuscles as well as numerous vacuoles, one of which pulsated slowly (every quarter of an hour), and a vesicular nucleus the diameter of which was about equal to one-fifth of the entire body.

Propagation took place by means of division and budding, after previous direct division of the nucleus. The buds are supposed to repeatedly divide soon after their appearance, thus giving rise to minute formations of $0.003 \mathrm{~mm}$.

There was a suspicion in both cases that the ascites was associated with malignant neoplasms in the abdomen, and autopsy verified this view in one case.

Notwithstanding the fact that after this publication the ascites fluid in analogous cases has been diligently examined for Leydenia, only two confirmatory reports exist hitherto, according. to my knowledge. One is due to Lauenstein,' the other to Leyden." The latter first of all mentions the fact that the second case of the two mentioned above also came to the post-mortem room and confirmed the correctness of the diagnosis. $\mathrm{He}$ also reports that in a large number of cases the fluid drawn from numerous ascites patients was examined, and the same remarkable cells with amœboid motion were repeatedly found. According to Leyden these bodies are so characteristic of carcinomatous ascites that he succeeded a few times by means of their presence in correctly giving a decision in cases of doubtful diagnosis.

Other observers regard the Leydenia as abnormally altered body-cells, such as are apt also to appear in the exudations of other diseases. L. Pfeiffer ${ }^{3}$ has even now come to look upon the amœboid forms, which he and others have observed in the vesicles of variola, vaccine, varicella, herpes, \&c., in pus and pleuritic effusion, and hitherto regarded as parasites, as merely "exudation cells." +

\section{Class II. Flagellata (Mastigophora),}

During the motile part of their life the Flagellata possess one or more flagella which serve for locomotion, and in many cases also for the capture of food; a few groups (Euglenoidince, Choanoflagellata) have only one flagellum, others two or several of about equal length (Isomastigoda), or of various lengths (Monadina, Heteromastigoda, Dinoflagellata). The long

'Lauenstein, C., "Ueb. cin. Befund von 'Leyd. gemmip.", (Deutsch. med. Wochenschr., 1897, xxiii., p. 733).

"Leyden, E. v., "Z. Aet. d. Carcin." (Zeitschrift f. kl. Med., I90i, xliii., p. 4).

"Pfeiffer, L., "ref. "ib. die Leyden-Schaudinn'sche Arbeit" (Mïnch. med. Wochenschr., I 896, xliii., p. 894).

'Lühe expresses his conviction that the Leydenia are of an independent nature (C. f. B., P. U. I., 1902, xxxi., ref., p. 207). 
flagellum is called the principal flagellum; the smaller ones on the same creature are called accessory flagella. The flagella directed backwards, which occur in the Heteromastigodes and are used for clinging, are termed trailing flagella. At the basis of the flagella, which are almost always at the anterior end, the Choanoflagellata possess a plasmatic funnel-shaped neck. In the parasitic forms an undulating membrane is frequently present.

The body of the Flagellata is usually small, generally elongated, and of unchangeable form; it is frequently covered by a distinct cuticle, and, in certain groups, by a solid armature, or it may be more or less loosely enveloped by a gelatinous or membranous covering. An ectosarc layer is not usually observable. The granular plasm contains a varying number of vacuoles, one of which in most cases is always contractile, and is generally situated at the place from which the flagella arise, that is, at the anterior extremity. The plasm, moreover, contains the nucleus, which is nearly always single; and in many species there are, besides, yellow, brown, or green chromatophores of various shapes, such as occur in plants. Some species feed after the manner of green (holophytic) plants, or of plants free from chlorophyll (saprophytic); others, again, ingest solid food, and for this purpose usually possess a cytostom; the latter, however, in a few forms is not used for its original function, but is connected with the contractile vacuole. A few species, such as Trichocysts, present eye-spots with or without light-refracting bodies.

Propagation takes place by means of division, mostly longitudinal division, and after previous division of the nucleus, eventually of the neck and the chromatophores. The flagella during this process appear to be regularly cast, so that each daughter-individual must develop fresh flagella, as is the case with the cytostom. Division may take place in the free motile condition, or, in the encysted state, eventually within the capsule. Divisions imperfectly accomplished give rise, to colonies. Copulation from time to time amongst individuals of the same or different form is very general amongst the flagellata. The product of copulation, the zygote, becomes parent to the free motile generation by means of successive divisions; this affords an alternation of generations, as the latter multiply without previous copulation.

Most Flagellata live free in fresh and salt water; they like stagnant water, and are found in waters rich in organic products of decomposition, such as puddles, swamps and pools. Those forms developing shells and colonies are as a rule, adherent. A number of species are parasitic in man and animals, living mostly within the intestine or in the blood.

It is usual to classify the Flagellata into four orders: Euflagellata, Dinoflagellata, Choanoflagellata, and Cystoflagellata, of which only the Euflagellata are of interest to us. This is a group comprising numerous species. for the further classification of which the number and position of the flagella are utilised.

The Euflagellata observed in man closely approach to the Protomonadines as well as to the Polymastigines; the former possess either only one or two similar flagella, or one principal and one or two accessory flagella, whereas the Polymastigines possess at least three flagella of equal size, or four to eight of unequal size, inserted at different points. An undulating membrane may be present in members of both groups; during rapid motion it conveys the impression of a row of cilia and has often been mistaken for the latter. 
It must also be pointed out that unicellular organisms with one or several flagella are not always classified with Flagellates, for such forms occur in Rhizopods as well as transiently in the lower plants. In addition the examination of the Flagellates, especially the parasitic species, is very difficult on account of their diminutive size and great activity; thus it happens that certain forms cannot with certainty be included in the group because their description is insufficient.

\section{LITERATURE.}

BüțSchli, O. Protozoa in Bronn's Cl. u. Ord. d. Thierr, I880- 97.

Klebs, G. Organisation einig. Flagellatengrupp. (Unters. a. d. bot. Inst. Tübing, I 883 , i., 2 ; Z. f. wiss. Zool., I 892, lv.

Bıochmann, F. Mikrosk. Thierw. des Süsswassers. 2nd edition, I 89 5.

KENT, S. Manual of the Infusoria. London, I880-81, i.

\section{A.-Polymastigina, Blochm.}

The Flagellata parasitic in man, and best known, belong to the Polymastigines, and to two genera that are easily distinguishable.

Gen. I. Trichomonas, Donné, I837.

The body is generally pyriform, the anterior part usually rounded, the posterior part pointed ; there are at the anterior extremity three or four equally long flagella that are sometimes fused together; in addition there is an undulating membrane that commences at the anterior extremity and proceeds obliquely backwards. The nucleus is situated at the anterior extremity, and behind it are one or more vacuoles, none of which seem to be contractile. These flagellates are parasitic in vertebrate and invertebrate animals, and live chiefly in the intestine.

\section{Trichomonas vaginalis, Donné.}

Form of body very variable, elongated, fusiform or pear-shaped, also amœboid; the length varying between $0^{\circ} 015$ and $0^{\circ} 025$ mm., and the breadth between $0^{\circ} 007$ and 0.012 . The posterior extremity is drawn out to a point and is about half the length of the remainder of the body. Cuticle very thin; the body substance finely granular. At the anterior extremity there are three - some say four ${ }^{1}$ - flagella of equal length which are frequently united together, at least at the base, and easily fall off.

There is an undulating membrane which runs spirally across the body, arising from the place of insertion of the flagella, and terminating at the base of the caudal process. Cytostom seldom

1 To explain this discrepancy it is stated that the border of the undulating membrane can raise itself off in the form of an independent flagellum. 
recognisable. Nucleus vesicular, elongated, situated at the anterior extremity. ${ }^{1}$

Propagation takes place by division (Marchand); encysted forms are unknown.

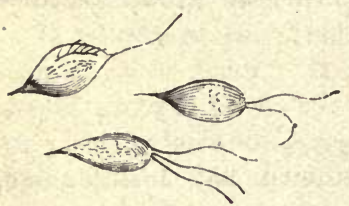

FIG. 8. - Trichomonas vaginalis (enlarged).

Trichomonas vaginalis lives in the vaginal mucus of women of various ages; not in normal mucus, but in mucus of acid reaction. It is found in menstruating females as well as in females that have passed the menopause; it is found in pregnant and nonpregnant women, even in very young girls, provided always that they have a vaginal catarrh with acid reaction of the secretion. Should the acid reaction change, as, for instance, during menstruation, the parasites disappear, as they do likewise on injection

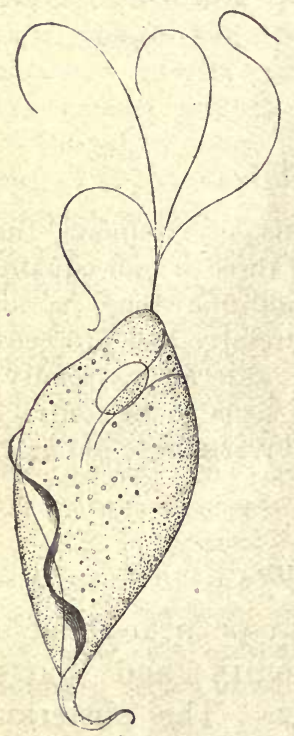

FIG. 9.-Trichomonas vaginalis, $D$., high mag$\mathrm{n}$ ification. (After Künstler.) of any alkaline fluid into the vagina; a low temperature (below $+15^{\circ} \mathrm{C}$.) is also fatal to the parasites.

Trichomonas vaginalis appeared to be a parasite specific to the female organs and not transmissible to man. Recently, however, several observations have been made that confirm the occurrence of this species in the urethra of the male. The infection apparently takes place through coitus when changes are present in the urethral mucous membrane ; in any case the three cases observed point to this circumstance. ${ }^{2}$

Experimental transmission to rabbits, guineapigs and dogs failed (Blochmann, Dock). So far the manner in which women become infected is unknown.

\section{Trichomonas intestinalis, R. Lkt.}

Now several authors believe that a second trichomonade inhabiting man, Trichomonas intes-

1 According to Marchand, the nucleus is connected with a line, which becomes visible on addition of acetic acid, terminates at the posterior extremity, and does not correspond to the line of insertion of the undulating membrane. This formation probably is the same as the one known as the "quill" in Trichomonas batrachorum, Perty. Blochmann also mentions two longitudinal rows of granules, which commence at the same plane as the nucleus and converge towards the back.

2 Donné, A. Rech. sur la nature du mucus, Paris, I837; Scanzoni, F. W., Beitr. z. Gbrtskde, I855, ii., p. I 31 ; Scanzoni, F. W., and A. Kölliker, "Quelq. rem. sur le 
tinalis, R. Lkt., is identical with Trichomonas vaginalis, Donné. Leuckart's species ${ }^{1}$ was based on the discoveries of Marchand" and Zunker, ${ }^{3}$ who state that according to all appearances, and in their opinion, it is the same as Cercomonas intestinalis, Lambl, I875 (nec I859), which they found in the fæces of patients suffering from intestinal disorders. The organism is described by them as being $0.01-0.015 \mathrm{~mm}$. in length; the posterior extremity terminates in a point, while a row of twelve or more cilia commence at the anterior end and extend over the body. Leuckart states that this parasite placed by the two authors with the Cercomonas, is a Trichomonas, that they mistook the undulating membrane for cilia, and overlooked the flagella. Notwithstanding its striking similarity with $T r$. vaginalis it is distinguishable from this species by the considerably larger number of parts (cilia) composing the ciliated crest (undulating membrane). Lambl's Cercomonas intestinalis ${ }^{4}$ (of 1875 ) which corresponds with Cercomonas hominis, Davaine ${ }^{5}$ (I854), is regarded by Leuckart as a true Cercomonade (characterised by a flagellum

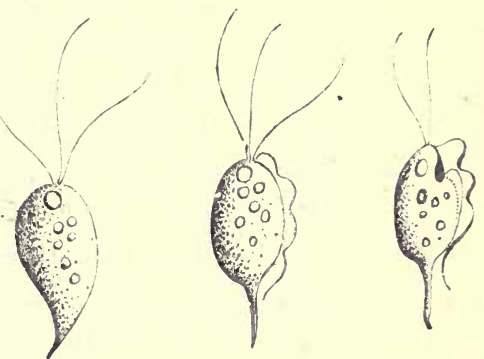

FIG. IO.-Trichomonas intestinalis, Lkt. (after Grassi). and the absence of an undulating membrane) thus generically distinct from Trichomonas.

The correctness of Leuckart's judgment in regard to Mar-

Trich. vag." (C. R. As. sc., Paris, I 868, xl., p. ro76) ; Hausmann, Die Paras. d. weibl. Geschlechtsorg, Berlin, I870 ; Blochmann, F., "Bem. ïb. einig. Flagell." (Z. $f$ w. Z., I 884, xl., p. 42) ; Künstler, J., "Trichom. vagin., D." (Journ. d. microgr., i 884, viii. p. 3 I7) ; Marchand, F., "Ueb. d. Vork. v. Trich. im Harne eines Mannes " (C. f. B. u. P. I 894, xv., p. 709); Miura. K., "Trich vag. im frisch gelass. Urin eines Mannes" (ibid., I 894, xvi., p. 67) ; Marchand, F., "Bem z. d. vorsteh. Arbeit" (ibid., p. 74); Dock, G., "Flag. Protoz. in the Freshly Passed Urine of a Man" (Med. News, I894, lxv., p. 640) ; Dock, G., "Trichom. as a Paras. of Man" (Am. Journ. Med. Sc., I896, p. I) ; Lavéran, A., and E. Mesnil. "Sur la Morph. et la syst. d. Flag., a membr. ondul." (C. R. Ac. sc., Paris, I90 I, exxxiii., p. I 3 I). 3 I 5 ).

'Leuckart, R., Die Parasiten d. Mensch. (L.pzg. I879-86, i., 2nd edition, p.

"Marchand, "Ein Fall von Infusorien im Typhusstuhl" (Virchow's Arch. f. path. Anat., x 875, ixiv., p. 293).

3 Zunker, "Ueb. d. Vork. d. Cercom. intestinalis im Digestionscanal des Menschen" Deutsch. Ztschr. f. pract. Med., I878, p. 1.)

1 Under the term Cercomonas intestinalis, Lambl in different years has described two entirely distinct flagellata, namely, in I859 (Mikr. Unters. d. Darm-Excrete. Prag Vierteljahrsschr. f. prakt. Hlkde., lxi., p. 5 I ; and Lambl A.d. Franz-Josephs-Kinderspitale in Prag., Prag., I860, i., p. 360), a form that we at the present day term Lamblia i.ntes. tinalis; and in 1875 (in the Russian Medical Report, No. 33), a species identical with Cercomonas hominis, Dav.

"Davaine, C., "Sur les anim. infus. trouv. dans les selles d. malad. atteints du cholira ot d'aitr. malad." (C. R. soc. binl., I 854, ii., p. I29). 
chand-Zunker's Flagellate was soon demonstrated by Grassi's ${ }^{1}$ researches, accounts of which were published soon after. In about roo cases of bowel complaints in North Italy and Sicily, Grassi found Flagellata in the stools, which he first named Monocercomonas and Cimanomonas, but later, however, termed Trichomonas. However, in opposition to Leuckart, Grassi has also classified Davaine's Cercomonas hominis (= Cerc. intestinalis, Lambl, 1875) as Trichomonas, and most authors have followed his example. It is only recently that, through Janowski, ${ }^{2}$ the former standpoint has again been taken up. After a thorough review of the literature, the occurrence of Cercomonades in the intestine of human beings, in addition to Trichomonades, is considered by the author to have been proved, and he adds a minute description of the Trichomonades. According to this, as well as according to the statements of earlier authors, all morphological distinction between Trichomonas vaginalis, Donné, and T. intestinalis, Leuckart, disappears. No importance can any more be attached to the greater number of the cilia which, according to Leuckart, were nothing more nor less than an impression conveyed by the movements of the undulating membrane; therefore Leuckart's designation must give way to Donnés older term, and the Trichomonade occurring in the intestine of man must be called Trichomonas vaginalis, Donné.

In the same way other names applied to this species become synonyms, the following, for instance: Protoryxomyces coprinarius, Cunn., I88I ; ${ }^{3}$ Monocercomonas hominis, Grassi, I882; Cimanomonas hominis, Grassi, I882 ; Trichomonas hominis, Grassi, I888; Cercomonas coli hominis, May, I89I ; ${ }^{4}$ Monocercomonas hominis, Epstein. ${ }^{5}$

It therefore follows that the species here discussed is found not only in the vagina of women, in the urethra of men, and in the small and large intestines of healthy ${ }^{6}$ and sick persons, but

' Grassi, B., "Int. ad. alc. prot. entopar." (Atti soc. ital. sc. nat. Milano, I882, xxiv., p. 135): "Signific. pathol. dei protoz. par. dell" uomo" (Atti R. Accad. d. Lincei. Rendic., iv., 1888, p. 83): "Sur quelq. prot. endop. . . " (Arch. ital. de biol., 1882, ii., p. 402 ; I883, iii., p. 23).

2Janowski, W., "Flagell. i. d. menschl. Faces" (Zeitschr. f. klin. Med., 1887, xxxi., p. 442).

${ }^{3}$ Cunningham, D. D., "On the Development of Certain Microscopical Organisms Occurring in the Intestinal Canal" (Quar. Journ. of Micros. Sc., 1880, 2, xxi., p. 234; Zeitschr. fiir Biolog., 1882, viii., p. 251).

' May, "Ueber Cercom. coli hom." (Dtsch. Arch. f. klin. Med., I89I, xlix., p. 5I).

"Epstein, A., "Beob. ilber Monocerc. hom. u. Amoba coli" (Prag. med. Wochenschr., I 893, Nos. 38-40).

"Schuberg, A," "Die paras. Ameeb. d. menschl. Darmes" (C. f. B. u. P., I893, xiii., p. 598); Boas, Dtsch. me.d. Wochenschr., 1896, p. $2-4$. 
has also been observed in the stomach and in the oral cavity: in the stomach by Strube, ${ }^{1}$ in the oral cavity of a typhoid patient and in that of a healthy person by Rappin, ${ }^{2}$ as well as by Zunker in one of his patients. The Trichomonades that have been observed by Steinberg ${ }^{3}$ in the oral cavity of man, and which he regards as belonging to three different species ( $T$. elongata, $T$. caudata, and $T$. Alagellata, and perhaps also his Cercomonas biflagellata), are certainly specimens of $T$. vaginalis, s. $10^{4}$ The same may be said of the flagellata observed in the lung or in the expectoration, and which have received the name of

\section{Trichomonas pulmonalis.}

Two authors make use of this designation, A. Schmidt and St. Artault $;^{6}$ the former found the Trichomonades exclusively in the so-called Dittrich's grafts, together with various bacteria; the latter found the parasites in the contents of a large vomica. In this connection we may refer to an old communication of Leyden and Jaffe," who likewise observed "infusoria" in the putrid sputum of persons suffering from gangrene of the lungs and putrid bronchitis (compare p. 53 as to the occurrence of Cercomonades in gangrene of the lungs).

It is evident, therefore, that Trichomonas vaginalis finds the conditions necessary to its existence in various organs of man that are accessible from the outside. It has not yet been established in what condition and by which means the parasites are able to find entrance into man. Transmission to mammals (per os) has proved negative. Their occurrence in the oral cavity, and, still more, their presence in the lungs, seems to point to the air as the vehicle, and their presence in the intestine does not contradict this view. Others incriminate drinking water, and an observation of Epstein (l.c.) seems to support this opinion. In a room in Epstein's

\footnotetext{
'Strube, G., Trich. hom. im Mageninhalt bei Carcinoma cardice" (Berl. klin. Wochenschr, 1898, p. 708).

"Rappin, G., Contrib. à l'itude des bact. de la bouche à l'état norm. et dans la fièvre typhoide, Thèse, Paris, I881.

${ }^{3}$ Steinberg, Kieqer Ztschr. $f$. neuere Med., I 862.

+ It appears that Höffle (Chem. u. Mikrosk. am Krankenbett, Erl., I850, p. 6I) and Langeraux (Traité d'an. path., i., p. 777) long ago observed Trichomonades in the oral cavity.

sSchnidt, A., "Ueb. paras. Protoz. i. Auswurf" (Münch. med. Wchschr., I895, No. 5 I).

"Artault, St., "Flore et faune d. Cavern. pulm." (Arch. d. parasit., I898, i., p. 2 I 7 ).

7 Leyden and Jaffe, "Ueb. putr. (foet.) Sputa nebst einig. Bemerk. ùb. Lungenbrand u. putr. Bronchitis" (Dtsch. Arch.f. klin. Med., I867, p. 488).
} 
clinic occupied by four children, three who partook of the general diet as well as of water fell ill of diarrhœea with Trichomonades, whereas the fourth child, who did not drink water, remained well. When, however, this child, as a matter of experiment, was twice given $250 \mathrm{c} . \mathrm{cm}$. of the same water that the other children had had, he likewise became ill. According to another opinion the Trichomonades are innocuous inmates of the intestines of many healthy persons, and appear alive in the fæces whenever, from any cause, there is increased peristaltic action of the bowels. It is, however, not beyond the bounds of possibility that in intestinal disturbances the Trichomonades, by increasing rapidly, may aggravate, or at least protract, the morbid process.

May, Roos, ${ }^{1}$ and Schürmayer $^{2}$ state that they have seen encysted forms, but it is not certain whether these really belong to Trichomonas.

Kunstler has published an account of the more minute structure of the Trichomonades (Observ. sur le Trich. intest. in Bull. scientif. de la France et de la Belg., I898, xxxi.).

\section{Gen. 2. Lamblia, R. Blanch., I888.}

Syn., Dimorphus, Grassi, I879, nec Haller, I878; Megastoma, Grassi, I88I, nec de Blainville.

The body is pear-shaped, with a hollow on the inferior surface directed to the front. It has four pairs of flagella directed backwards, of which three pairs lie on the borders of the hollow, and the fourth arises from the pointed posterior extremity.

\section{Lamblia intestinalis (Lambl), I889.}

Syn., Cercomonas intestinalis, Lambl, 1859 (nec 1875); Hexamitus duodenalis, Davaine, I875; Dimorphus muris, Grassi, I879; Megastoma entevicum, Grassi, I88I ; Megastoma intestinale, R. Blanch., I886.

Length, 0.OI-0.02I mm.; greatest breadth, 0.005-0.0I2; flagella of about equal length (0.009-0.0I4 mm.).

The body is finely granular and has a very thin cuticle, which does not entirely prevent changes of form of the body;

'Roos, E., "Ueb. Infus.-Diarrhoe" (Dtsch. Arch. f. klin. Med., 1893, li., p. 505).

"Schürmayer, B., "Ueb. d. Vork. d. Flagell. i. Darmk. d. Mensch." (C. t. B. u. P., I 895, I, xviii., p. 324). For further literature see Janowsky (l. c.). To Schürmaver the credit is due of rediscovering the Trichomonade of the human intestine, although in the single work which he consulted, Leuckart's Trichomonas intestinalis is mentioned a few lines before the place he referred to, and on the same page (Leunis, Svnops. bearb. v. H. Ludwig, 1886, ii., p. II25). Fortunately chance led our author to use the same name for his apparently new species, although in it he did not find the undulating membrane. 
the very motile tail-like appendix in the frontal plane is flattened. The excavation at the anterior extremity, which is directed obliquely forward and with its border projecting backwards and interrupted, no doubt corresponds to the peristoma and serves as a clinging organ. The first pair of flagella (anterior flagella) arise from its anterior edge, the second and third pairs (lateral and median flagella) from the posterior edge, whereas the tail flagella are inserted at the posterior end of the tail. In life the anterior and lateral flagella sway only with the thinner part projecting beyond the body; in the rest of their course they appear to be almost attached to the body; the median and tail flagella are quite free. There are knob-like formations at their origin. The entire flagellate apparatus appears to be connected with the nucleus.
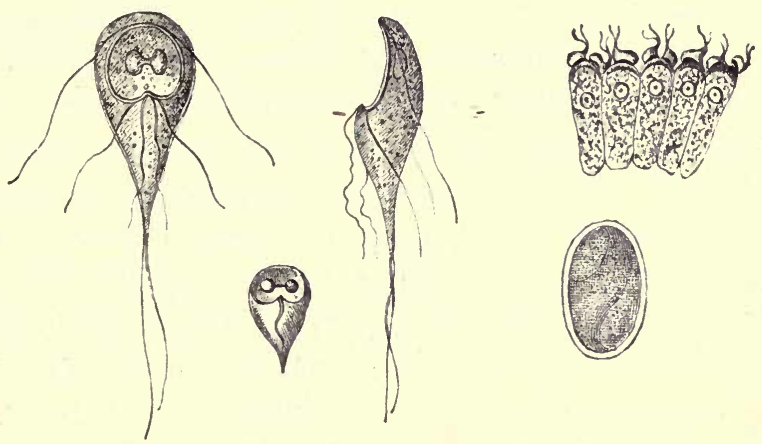

Fig. I r.-Iamblia intestinalis, from the surface, from the side, on intestinal epithelium cells, dead and encysted. (After Grassi and Schewiakoff.)

The nucleus is of a dumb-bell shape, has a nucleolus in each half, and lies anteriorly in that part of the body that is excavated. Division forms have not been observed, but there are encysted stages. The oval cysts (fig. II) measure o.oI $\mathrm{mm}$. in length by $0.007 \mathrm{~mm}$. in breadth, they are surrounded by a fairly thick hyaline layer, through which the contour of the creature can sometimes be seen quite distinctly.

Lamblia intestinalis inhabits the anterior part of the small intestine of various mammals (species of Mus and Avvicola, rabbit, domestic dog and cat, sheep) and of man. Encysted forms are found in the colon and in the fæces. If there is increased intestinal peristaltic movement the free forms also appear in the evacuations, in which, however, they perish if kept long, especially if the temperature is lowered to $0^{\circ} \mathrm{C}$. or raised above $40^{\circ} \mathrm{C}$. Although they frequently appear in large numbers they cause no disorder; at all events, hitherto no stringent reasons have been brought forward to cause the Lamblia to be considered pathogenetic. On the other 
hand, the fact that they are observed not only in persons suffering from intestinal disorders, but also in other diseases, as well as in perfectly healthy persons, proves their innocuousness.

The infection occurs by ingesting the encysted forms, a fact which Grassi confirmed on his own person. Cereals, or food prepared from cereals, polluted with Lamblia by animals living in the vicinity of human dwellings (mice, rats), are probably the vehicles by which they are introduced into man.

The parasite under discussion was first observed by $\mathrm{Lambl}^{1}$ in the mucous evacuations of children. He regarded the parasite as a Cercomonade and termed it Cercomonas intestinalis, which name as a rule is applied to Cercomonas hominis, Davaine, although Stein $^{2}$ had already pointed out the difference of the two species. Grassi observed this species first in mice (Dimorphus muris), and subsequently in human beings in Upper Italy, and named it Megastoma entericum..$^{3}$ Bütschli ${ }^{4}$ and Blanchard ${ }^{5}$ then laid stress on the identity of this species with Lambl's Cercomonas intestinalis (I859), and consequently called it Megastoma intestinale. Lastly, Blanchard ${ }^{6}$ drew attention to the circumstance that the specific name (Megastoma) chosen by Grassi had already been used four times, to specify various kinds of animals, and proposed the denomination Lamblia. Accordingly Lamblia intestinalis is the only term that holds good, and should be generally adopted.

In Upper Italy the parasite in the encysted condition has also been seen by Perroncito ${ }^{7}$ in man. At the same time, Grassi and Schewiakoff ${ }^{8}$ undertook a new examination of specimens from mice and rats. In Germany, Lamblia intestinalis was found by Moritz and Hölzl, ${ }^{9}$ Roos, ${ }^{10}$ Schuberg ${ }^{11}$ and Salomon ${ }^{12}$ and Moritz and Hölzl

'Lambl, "Unters. d. Darmexcrete" (Vierteljahrsschr. f. prakt. Hlkde., Prag., 1859, Ixi., p. 51; Aus d. Franz-Jos.-Kinderspit. in Prag., i., Prag., 1860, p. 360).

2 Stein, F. v., Der Org. d. Infus., III. D. Org. d. Flagell, 1878, i., p. 80.

"Grassi, B., "Dei protoz. par. e. spec. di quelli che sono nell' uomo" (Gazz. med. ital. lomb., Milano, 1879, No. 45); "Di un nuovo paras. dell' uomo (Meg. enter.)" (Gaz\%. degli. ospit., I881, ii., Nos. I3-I 5); "Interno ad alc. prot. endop." (Atti soc. ital. sc. nat., 1882, xxiv.); "Sur quelq. prot. endop." (Arch. ital. de biol., 1882, ii., p. 421).

4 Bütschli, O., Protozon in Bronn's Cl. $u$. Ord. d. Thierr., 1884, p. 843.

- Blanchard, R., Traité de Zool. méd., Paris, I885, 1, i., p. 9 1.

- Blanchard, R., "Rem. sur le Mégast. int." (Bull. soc. zool., France, I 88s, xiii., p. 18).

"Perroncito, E., "Ueber d. Einkaps. d. Megast. intest." (C. f. B. u. P., 1887, ii., p. 738 ), and Giorn. R. Accad. med., Torino, 1887.

"Grassi, B., and W. Schewiakoff, "Beitr. z. Kcnntn. d. Meg. ent." (Z. f. wiss. Zool., I 888, xlvi., p. 143).

9 Moritz, E., and Hölzl, "Ueb. Hüuf. u. Bedeut. d. Vork. d. Meg. enter. i. Darmk. d. Menschen" (Minch. med. Wochenschr., 1892, xxxix., No. 47 ; Sitz.-Ber. d.Artzl., , Ver. in Münch., 1893, ii., p. 89).

10 Roos, "Ueb. Infus.-Diarrh." (Dtsch. Arch. f. klin. Med., I893, li., p. 505).

"Schuberg, A., "Ref. "iber die Arbeit von Moritz u. Hölzl" (C. f. B. u. P., I893, xiv., p. 85 ).

12 Salomon, H., "Ueb. ein. Fall von Infusorien-Diarrh." (Berl. Klin. Wochenschr., 1899, No. 46); Quincke, H., “Ueb., Protozoèn-Enteritis" (ibid., Nos. 46-47). 
confirmed the relative frequency of the species. In Königsberg, Prussia, a student found encysted Lamblia in his fæces. One case is reported from Finland by Sievers, ${ }^{1}$ another case from Scandinavia by Müller. ${ }^{2}$ Frshezjesski " reports cases from Russia, but I have not had the opportunity of reading his article on the subject. Jaksch ${ }^{4}$ announces the occurrence of the parasite in Austria; Piccardi ${ }^{5}$ mentions their presence again in Italy; and we hear of them in Egypt from Kruse and Pasquale. ${ }^{6}$ Finally, the structure of Lamblia intestinalis has been recently described by Metzner. ${ }^{7}$

\section{B. Protomonadina, Blochm.}

The diminutiveness of the Protomonadines and their less superficial situation than the Polymastigines, is the cause that, at least in regard to the species occurring in man, they are very little known. As regards parasitical species, this group may be divided as follows, according to the number of flagella and the presence or absence of an undulating membrane :-

(1) Cercomonadida, with one flagellum at the anterior extremity, without an undulating membrane.

(2) Bodonida, with two flagella, without an undulating membrane.

(3) Trypanosomida, with one flagellum and an undulating membrane along the entire length of the body.

\section{Cercomonas hominis, Davaine, I854.}

Davaine ${ }^{8}$ found Flagellata in the evacuations of cholera patients. They had pear-shaped bodies elongated to a point posteriorly. Their length averaged from 0.010-0.012 mm., and a flagellum

'Sievers, "Balant. coli, Meg. ent. u. Bothr. latus bei ders. Pers." (Ztschr. f. klin. Med., I 896, xxxiii., p. 25).

2 Müller, E., "Cercom. intest. $i$. jejunum fran männ. " (Nord. med. ark. I889, xxi., No. 21) ; Förhdlg. biol. Fören., Stockholm, 1890, ii., p. 42 ; ref. in C. \%. B. u. P., I 890 , viii., p. 592.

3 Frshezjesski, "Ueb. d. Rolle d. Meg. enter. bei chronisch. Darmcatarrh." (Russk. Arch. Patol., klin. Med. i. Bakt., 1897, ii.).

+ Jaksch, v., "Ueb. d. Vork. v. thier. Paras. in d. Freces d. Kind" (Wien. kl. Wachenschr., I 888, No. 25, p. 5 I I).

s Piccardi, "Alc. prot. delle feci del l'uomo" (Giorn. R. Accad. med., Torino, 1895, lviii., I) ; Prngr. mêdical, 1895, No. 23, p. 377.

"Kruse, W., and A. Pasquale, "Unters. üb. Dysent. u. Ieberabscess" (Ztichr. $f$. Hyg., I894, xvi., p. I9).

"Metzner, R., "Unters. an Meg. enter. a. d. Kaninchendarm" (Ztschr. f. w. Zoo., 1901, lxx., p. 299).

8 Davaine, C., "Sur des animalcules infus. trouv. dans les selles d. mal. att. du chol, ct d'autres mal." (C. R. soc. biol., Paris, I 854,2 , i., p. I 29). 
twice as long as the body was carried at the rounded extremity; a nucleus was barely recognisable; occasionally a longish formation (cytostom?) appeared at the anterior extremity. The creatures moved with remarkable activity, they also attached themselves by means of their posterior extremity and swung about around the point of attachment. Davaine found a smaller variety in the dejections of a typhoid patient (fig. I2, $b$ ).

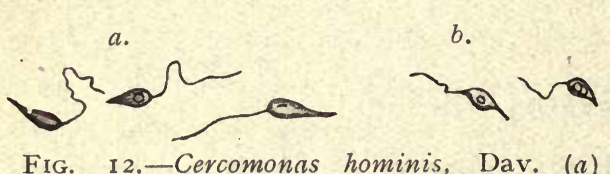

FIG. 12.-Cercomonas hominis, Dav. (a) Larger, (b) smaller variety. Enlarged (after Davaine).

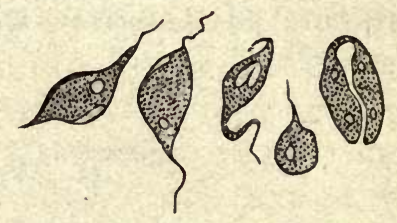

FIc. I 3.-Cercomonas hominis, Dav. From an Echinococcus cyst (after Lambl).

The Flagellata observed by Eckerkrantz ${ }^{1}$ in the intestine of man belong to this form-at least to the larger variety - and Tham " reported fresh cases soon after. Lambl's publication ${ }^{3}$ of 1875 , which was written in Russian, and became known through Leuckart's work $^{4}$ on parasites, also alludes to apparently typical cercomonades, which, however, were discovered, not in the intestine, but in an Echinococcus cyst in the liver. The elliptical, fusiform, rarely pear-shaped or cylindrical bodies of the parasites measured $0.005-0.014 \mathrm{~mm}$. in length, and were provided with a flagellum at one extremity, while the other extremity usually terminated in a long point. An oral aperture existed at the base of the flagellum, and there were one or two vacuoles about the posterior extremity. Longitudinal division was also observed (fig. 13).

As already mentioned, this form, which Lambl termed Cercomonas intestinalis, differs considerably from the form found by the same author in 1859 , which received the same designation (cf. Lamblia intestinalis), but it corresponds with Cercomonas hominis, Davaine. The latter, as well as Cercomonas intestinalis, Lambl, I879, are usually classed with the Trichomonades, but, as has already been remarked (cf. Trichomonas intestinalis), this cannot be considered correct, as only one flagellum is present.

According to Janowski, typical Cercomonades have also been

1 Eckercrantz, "Bidr. t. känned. om de i mennisk. tarmkan. förek. infus." (Nord, med. Ark., I869, i., No. 20 ; Virchow-Hirsch's Jahresber., I869, i., p. 202).

"Tham, P. V. S., "Tvänne fall of Cercom." (Upsala läkareför. förhalg., I 870, v., p. 691 ; Virchow-Hirsch's Jahresb., I870, i., p. 314).

${ }^{3} \mathrm{Lambl}$ " Cercomonas et Echinococcus in hepate hominis" (Medic. Wjestnik., I 875 , No. 33).

+ Second edition, vol. i., p. 308. 
observed in the intestine of man by Escherich, also by Cahen, ${ }^{1}$ Massuitin, ${ }^{2}$ Fenoglio, ${ }^{3}$ Councilman and Lafleur, ${ }^{4}$ Dock, ${ }^{5}$ Kruse and Pasquale, ${ }^{6}$ Zunker, ${ }^{7}$ as well as Quincke and Roos. ${ }^{8}$ However, it is an open question whether the Flagellata observed by Roos ${ }^{9}$ in one of his cases belonged to Davaine's species, the size shows some deviation (0.014-0.0r6 mm.). In this, as in many other cases, doubts have been raised as to whether the Flagellates found in the stools had actually lived in the intestine, or had subsequently appeared in the fæces: for this a surprisingly short time only is necessary. Salomon also appears to have observed Cercomonades (Berl. klin. Wchschr., I899, No. 46).

As with Trichomonas vaginalis so with Cercomonas hominis, it appears that the parasite settles not only in the intestine but also in the air-passages; this is demonstrated by the statements of Kannenberg ${ }^{10}$ and Streng ${ }^{11}$ of the occurrence of Monades and Cercomonades in the sputum and putrid expectoration in gangrene of the lungs, which no doubt apply to Cercomonas hominis (ct. also Artault). ${ }^{12}$ Possibly also the Flagellata observed in the pleural exudation by Litten ${ }^{13}$ and Roos ${ }^{14}$ may be here included; this is the more probable in Roos's case, as here the process ensued in the pleura after the breaking through of a vomica. Perroncito ${ }^{15}$ and Piccardi ${ }^{16}$ describe the encysted stages of the Cercomonades.

"Cahen, "Ueber Protoz. in kindl. Stuhl" (Deutsch. med. Wochenschr., I891, No. 27, p. 853$)$.

2 Massuitin, “A Amoeben als Parasiten des Dickdarms." (Wratsch., I 889, No. 25 ; Centralbl. fiir B. und P., I 889 , vi., p. $45 \mathrm{I}$ ).

3 Fenoglio, "Entérocolite par Amøba coli" (Arch. ital. d. méd., r 89o, xiv., p. 62).

+ Councilman and Lafleur, "Amabic Dysentery" (Johns Hopk. Hosp. Rep., ii., p. 395).

"Dock, "Observations on Amceba coli in Dysentery," (Daniels' Texas Med. Journ., I 89 I, p. 4I9).

"Kruse, W., and Pasquale, "Unters. ub. Dys." (Ztschr. f. Hyg., I 894, xvi., p. I).

"Zunker, "Ueb. d. Vork. v. Cerc. int. im. Dig. d. Mensch." (Dtsch. Ztschr. f. pr. Med., I 878 , p. I).

${ }^{8}$ Quincke and Roos, "Ueb. Amoeb.-Enter." (Berl. kl. Wchschr., 1893, p. 1089).

- Roos, E. “Ueh. Infus.-Diarrhoe" (Dtsch. Arch. f. kl. Med., 189.3, li., p. 505).

1. Kannenberg, "Ueb. Infus. im Sputum" (Virchow's Arch. f. path. Anat., I879, lxxv., p. 47 I ; Zitschr. f. kl. Med., I 880, i., p. 228).

"Streng, W., "Infus. i. Sput. bei Lungengangrän" (Fortschr. der Med., I892, x., p. 757 ).

12 Artault, St., “Flore et faune d. cav. pul." (Arch. de paras., I 898, i., p. 278).

"3 Litten, "Ueb. Hydropneumothorax" (Verh. d. Congr. f. inn. Med., i 886, p. 4I7).

14 Roos, E., "Ueb. Infus.-Diarrhoe" (Dtsch. Arch. f. kl. Med., I893, li., p. 505).

is Perroncito, E., "Ueb. d. Art d. Verbreitg. d. Cerc. intest." (C. f. B. u. P., I $88 S$, iv., p. 220 ; Arch. ital. d. biol., I888, x., p. 257 ; Ann. R. Acc. d'agric., Torino, I889, xxxii.).

16 Piccardi, "Alc. prot. d. feci dell" uomo" (Giorn. R. Acc. d. med., Torino, I 895 , Iviii., I ; Progr. méd., 1895, p. 377). 
2. Monas pyophila, R. Blanch, I895.

R. Blanchard ${ }^{1}$ thus designates a Flagellate that Grimm ${ }^{2}$ found in the sputum, as well as in the pus of a pulmonary

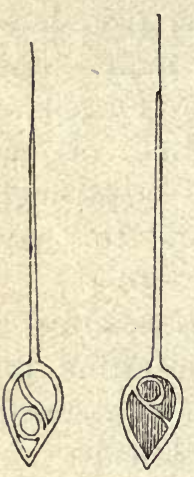

FIG. I4. -

Monas pyophila, R. Blanch. (after Grimm). and hepatic abscess, in the case of a Japanese woman living in Sapporo. The parasites resemble large spermatozoa. The body, measuring $0.030-$ $0.060 \mathrm{~mm}$., has the shape of a heart or a myrtle leaf, and is surrounded by a thick cuticle which is supposed to continue in the interior of the body, dividing it into three parts. There is a long appendix at the rounded pole covered over its greatest extent by the cuticle; the extremity, however, is free and resembles a flagellum. The parasites were very agile, frequently changed their shape, and were able to retract the long appendix within the body, which then assumed a round form.

\section{3.-Cercomonades in the urine.}

As far back as 1859 Hassall $^{3}$ described a flagellated infusorium which he called Bodo urinarius. It was found in alkaline urine a short time after exposure to the air. About fifty samples of urine from different persons were collected and specimens exposed to the air, and the results proved decisively that Bodo urinarius had only settled in the urine subsequently. This communication would not have been included here had not Künstler ${ }^{4}$ in 1883 announced the occurrence of a flagellate designated Bodo urinarius in the freshly passed urine of a patient, and at once conveyed the impression that it was a parasite originating from the urinary passages. This form has been variously criticised. Blanchard ${ }^{5}$ sets it up as a distinct parasite, and, as he considers that it differs from Bodo urinarius, Hass, he calls it Cystomonas urinaria. However, as the generic name of Plagiomonas already existed for Protomonadines with two flagella

' Blanchard, R., "Malar. Paras., Ec.," I 895, p. 690.

2 Grimm, F., "Ueb. ein. Leber-u. Lungena3sc. mit Protoz." (Arch. f. Chir., I 894, xlviii., p. 478 ).

${ }^{3}$ Hassall, "On the Development and Significance of Vibriolineola, Bodo urinarius - . in Alkaline and Albuminous Urine" (The Lancet, I859, ii., p. 503).

"Künstler, "Analyse micr. des urines d'un malade atteint de pyélite chron. conséc. à une opér. de taille" (Bull. soc. d'an. et de phys. norm. et path., Bordeaux, I 883 , iv., p. 2 I 5).

${ }^{5}$ Blanchard, R., Traité de Zucil. méd., Paris, I 885, i., p. 78. 
at the anterior extremity, $\mathrm{I}^{1}$ suggested the denomination of Plagiomonas urinaria. Blanchard regarded Trichomonas irregularis, Slsb., as synonymous, and in accordance with this opinion he recently $^{2}$ named the species Plagiomonas irregularis (= Bodo urinarius, Kunstl. nec Hass). This at the time and even now does not appear to me to be justified, as Salisbury ${ }^{3}$ found Trichomonas irregularis not only in the urine, but also in the vagina of the same person, and therefore a confusion with Trichomonas vaginalis is quite possible. On the other hand, Th. Barrois ${ }^{4}$ considers Hassall's and Künstler's Bodo urinarius to be identical, and the latter not a parasite of man. He bases this opinion on his own experience. In the freshly-passed urine of a patient, a physician in Lille found a number of flagellates, and Barrois confirmed their presence; however, as the urine was opaque, had an alkaline reaction, and contained innumerable and various bacteria in addition to the flagellates, Barrois doubted the freshness of the material; when, subsequently, the urine of the same patient was examined immediately after evacuation, no trace of flagellates could be found; of course the urine first examined had not stood long, so that it must be conjectured that the germs of the flagellates were only present periodically in the atmosphere of the sick room. At all events this observation demonstrates how careful one must be in the judgment of flagellates appearing in the secretions and excretions of man.

As, moreover, decomposition had set in in the urine examined by Künstler, and numbers of various bacteria were present in addition to the flagellates, Barrois does not
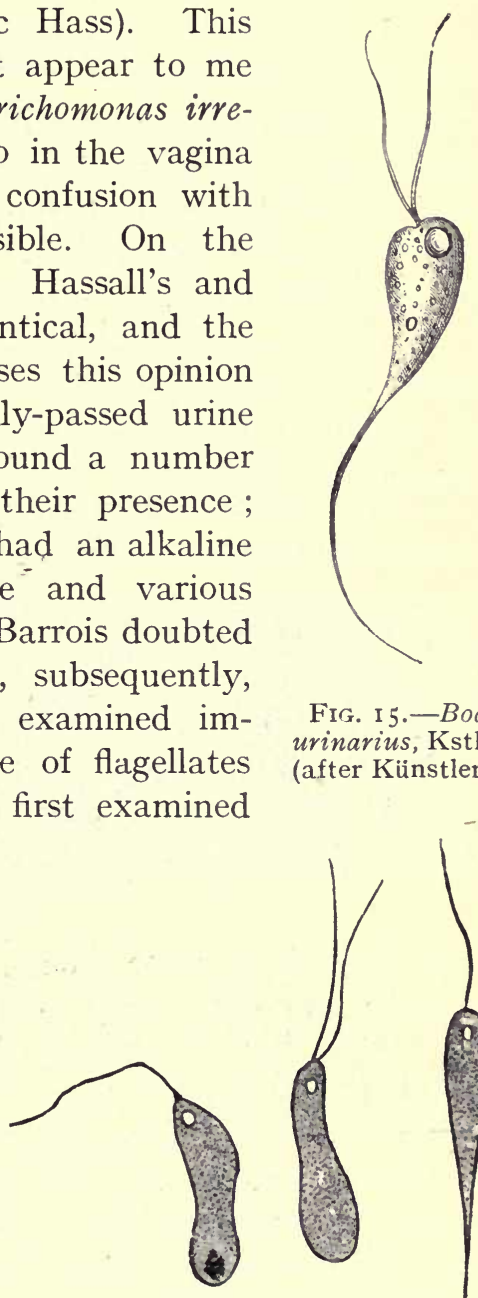

FIG. I 5.-Bodo urinarius, Kstlr. (after Kïnstler).

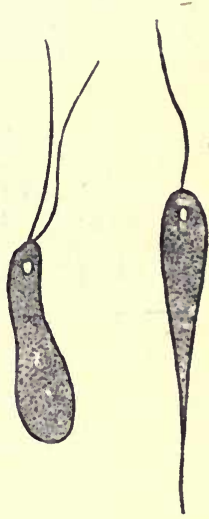

FIG. I6. - Flagellata observed by Barrois in the urine of a man (after Barrois).

' Braun, M., Die thier. Par. d. Mensch., 2nd edition, I895, p. 108.

${ }^{2}$ Blanchard, R., Mal. paras. . . . Paris, I 895, p. 691.

${ }^{3}$ Salisbury, "On the Parasitic Forms developed in Epithelial Cells of the Urine - and Genital Organs" (Amer. Journ. med. sc., I 868.)

4 Barrois, Th., "Quelq. obs. au sujet du B. urin." (Rev. biol. nord. France, 1894-95. vii., p. I65). 
consider that this case either is convincing. As a matter of course the appearance of cercomonades in the urine of man cannot be disputed, but hitherto no proof has been adduced to show that they live in man.

4.-Trypanosoma, Gruby, I843.

Since the 'forties we have. known through Valentin, Gluge, Remak, \&c., of flagellates in the blood of fishes and amphibia, and soon afterwards these parasites were found in the blood of rats and marmots. The species living in European frogs was called Trypanosoma sanguinis by Gruby. ${ }^{1}$

At the present date we distinguish a larger number of species which live, some of them, in the blood of various vertebrates, and some of them in the intestine of vertebrate and invertebrate animals. A few forms have acquired great importance from the

(a)

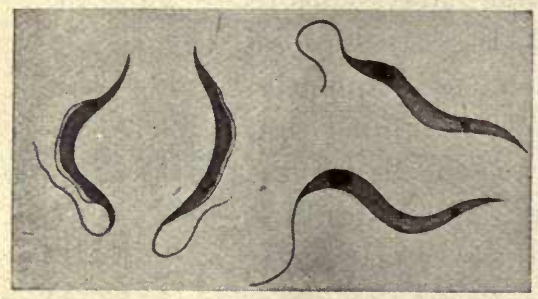

(b)
Fig. 17.-Trypanosoma Lewisi, Kent. From the blood of a rat; $0.008-0.010 \mathrm{~mm}$. in length; $(a)$ fresh; $(b)$ preserved; the nucleus is at the flagellated end. (After Kempner and Rabinowitch.)

fact that they cause more or less serious diseases in domestic animals, and that their presence not only endangers the lives of the latter, but frequently decimates them. Thus Trypanosoma brucei, Plimm and Bradf., is known to be the cause of the dreaded Tsetse fly disease (nagana), occurring in various parts of Africa; $T$. evansi (Steel) induces the disease known as surra, which occurs in Southern Asia; while $T$. equiperdum, Dofl., plays a part in dourine, a disease observed in N. Africa, the south of France, and Spain.

According to a report from Nepveu, ${ }^{2}$ trypanosomes also occur in the blood of man, but this seemed doubtful, as the observations were made in Algiers in patients suffering from malaria, and it was not unreasonable to surmise that developmental stages of

'Gruby, "Sur une nouv. esp. d'hematoz." (C. R. Ac., Paris, 1843, xvii., p. I1 34 ; Ann. sc. nat. zool., 1844, i., p. IO4).

${ }^{2}$ Nepveu, C. R., soc. biol., Paris, I 898 (I0), p. I I 72. 
malarial parasites had been mistaken for trypanosomes. The

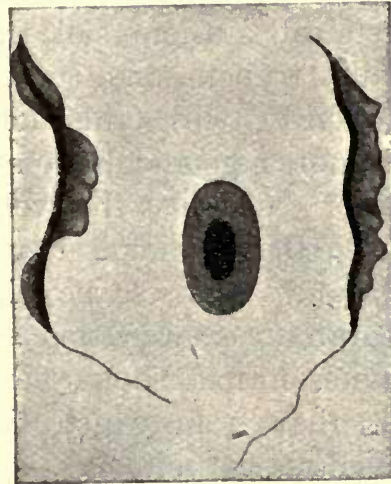

Fic. I 8.-Trypanosoma carassii, Mitr. Fron the blood of the crusian (Carassius vulgaris), drawn with a blood corpuscle from the host for comparison of size. (After Mitrophanow.)

statement has, however, acquired new importance from the fact that Dutton ${ }^{1}$ has observed trypanosomes in the blood of a European.

Trypanosomes are flagellates of elongated shape, which, nevertheless, are capable of changing their form. They bear an undulating membrane on one side along the entire length of the body, and in most cases possess a flagellum at one extremity.

Transmission is effected in the same species by blood-sucking arthropoda; $T$. bruce i is conveyed by the tsetse fly (Glossina morsitans), T. lewisi by fleas; the carrier, however, for most species is still unknown. ${ }^{2}$

\section{Trypanosoma.}

The discovery of a trypanosome in sleeping sickness, by Dr. Aido Castellani, in I902, has given great pathological importance to the genus Trypanosoma. It is therefore necessary to supplement the author's brief mention of this group of parasites with a summary of the most recent information on the subject.

Trypanosomes, as usually seen in the blood of man and cattle, are elongated, unicellular bodies provided with a kind of fin-fold, the undulating membrane, which runs along the dorsal edge of the body, forming frill-like folds, and terminates in a free whip-like filament, the flagellum, which may vary greatly in length. Stained specimens show very clearly a large nucleus, usually about the middle of the body, and a much smaller chromatin mass placed more or less near one pole. This small mass of chromatin has been. variously termed blepharoplast, micro-nucleus, centrosome. I will use the term blepharoplast as the most appropriate. In fact, it is from this small chromatin mass that arises the flagellum. The extremity of the body which encloses the blepharoplast is the anterior extremity; it varies greatly in shape at different stages of

'Laveran, A., and Mesnil, F., "Du mal. à trypanos. leur répart. à la surface du globe " (Janus, 1902, vii.).

1. 1 2 Other species of Glossina besides Glossina morsitans carry Trypanosoma brucei. Sleeping sickness (Trypanosoma gambiense) is carried by Glossina palpalis. Surra must be carried by some other biting flies, as Glossinae do not occur in Asia. (F.V.S.). 
development; it may be pointed or obtuse. The opposite end is the posterior extremity; it always tapers to a point and is con- tinued by the free end of the flagellum. Most authors call the posterior extremity anterior, because, as a rule, trypanosomes move more rapidly and, apparently, more frequently with this end foremost; but the direction of locomotion is not a good argument, otherwise we should have to call the posterior extremity the welldeveloped head of Cephalopods, simply because these animals move more rapidly with the tail end foremost, and thus escape the animals that prey upon them. A comparative examination of the flagellates, and especially of the free-living forms, shows very clearly that the true anterior extremity is that from which the flagellum arises. In most genera the flagellum is not only an organ of locomotion, but also an important means for the capture of food. In such forms as Euglena the anterior extremity is provided with an oral cavity which opens at the base of the flagellum. In Euglena the flagellum is entirely free and sways in front of the head of the creature, like a proboscis, and, indeed, it was called proboscis by Ehrenberg. In trypanosoma, the flagellum bends directly backwards and is attached, for a considerable portion of its length, to the body by a thin web of body plasma. The flagellum is composed of chromatin. In certain stages it is cast off. It is easily reproduced by the blepharoplast. When cast it may continue to move independently for some time. Adjoining or surrounding the blepharoplast is a clear area called the vacuole; it probably represents the contractile vesicle of other flagellata. Sometimes the plasma of stained specimens is beset with a variable number of dark-staining granules; these granules represent reserve material and are called chromatophores.

By examining large numbers of trypanosomes during the course of a trypanosoma infection, one soon notices that the parasites vary considerably in size and shape. A more careful study enables us to group these various forms into three distinct types, corresponding to the well-known forms of the Hamamobida found in the blood of malaria patients.

The most frequent form is the asexual form, which multiplies very rapidly by simple longitudinal division. It is usually seen in the process of division. This process begins most frequently with the division of the blepharoplast, which elongates and then divides. The nucleus divides almost simultaneously, sometimes before the blepharoplast. The division of the blepharoplast brings 
about the division of the flagellum, and the division of the flagellum is followed by the division of the whole body. The duplication of the flagellum begins at the point of origin and terminates at the free end; the duplication of the body proceeds dorso-ventrally, but the division forms do not separate along the ventral border until the newly-formed flagellum has entirely parted from the old one, thus the separation of the division forms proceeds from the tail end forwards. One frequently sees parasites still adhering by their anterior extremities. The division forms are of about equal size and slightly smaller than the parent form. Amongst these asexual forms we occasionally find some larger forms which are analogous to the macrogametes of the malaria parasites; as a rule, these forms do not divide until after copulation, which probably in most species takes place in the body of an alternative host. They are characterised by a larger size, which may be more than double that of the asexual forms, by a stumpy shape, by a short flagellum and by the presence of numerous chromatophores. Sometimes vacuoles are found in the plasma of these forms. They end by becoming almost round and losing entirely their flagellum. By the side of these female forms we meet some very slender hyaline forms with very long: flagellum, with comparatively large nucleus and large blepharoplast. They are the male forms or microgametes. The number of the sexual forms varies greatly in different slides. At times they are quite numerous.

The life-history of the trypanosomes is very superficially known. Quite recently Dr. Fritz Schaudinn has studied the entire life cycle of Trypanosoma noctua, a trypanosome of the little owl (Athence noctua), the gametes of which were described in I89I by Celli and Sanfelice under the name of Hamoproteus (= Halteridium) noctuce. I will give a brief sketch of the lifehistory of Trypanosoma noctuce as a guide to the study of the bionomics, of other species. Trypanosoma (= Halteridium) noctuce, like Hamamceba relicta (Proteosoma), insures the continuancy of its existence by an alternation of generative processes and by a change of hosts. Its intermediary host is the little owl (Athence noctuce), its definitive host is Culex pipiens.

When first introduced into the blood of the bird, the parasites have the form of trypanosomes, but they are as a rule very small. They attach themselves to the erythrocytes, discard their flagella and assume the well-known halteridium form. After about twenty-four hours, granules of pigment begin to appear in their 
plasma. The period of growth lasts six days, but the parasite does not remain attached to the erythrocyte the whole time; as a rule it leaves the corpuscle at night, assumes the trypanosoma form and moves about freely in the plasm until the next morning, when again it attaches itself to a red blood corpuscle in order to absorb nutriment. These alternating periods of movement and rest follow one another until full growth is attained. Then a multiplication stage sets in and the parasites multiply by consecutive longitudinal divisions until the products of division have attained a minimum size. The small flagellates then attach themselves once more to the erythrocytes, and the alternating. stages of growth and multiplication continue until the blood literally swarms with parasites.

By examining the blood of the owl one sees the asexual forms of different sizes and in different stages of division, but one distinguishes also other forms with coarsely granular plasma and fine pigment, which contain a small nucleus adjacent to the blepharoplast, likewise quite small. These forms are the macrogametes, they penetrate the erythrocytes and grow more gradually, accumulating more and more reserve material in their plasma. They appear to change their host cells more rarely, and towards the end of their growth are no longer able to assume the form of trypanosomes. The mature macrogametes are quite unable to leave their host cells, and are found surrounded by a pale residue of the erythrocyte, the nucleus of which is then situated quite at the periphery.

The macrogametes are the only forms which persist at the end of the acute stage of the halteridium disease, and after long intervals they are capable of bringing about a relapse by reproducing parthenogenetically the asexual forms. The macrogametes arise from the asexual forms, and can be recognised even in their earliest stages. The fertilisation of the macrogametes takes place at the moment in which the parasites leave their intermediary host.

The microgametocytes also arise from the asexual forms, and their nature may likewise be recognised in the earliest stages. They are characterised by pale plasma, coarse pigment, large nucleus, large blepharoplast. The mature microgametocytes give rise to eight microgametes which develop as soon as the blood is abstracted, but invariably perish within their mother cells when left in the circulatory system of the bird. As soon as the macrogamete makes its exit from the avian host it becomes globular, 
bursts out of the remains of the enclosing erythrocyte, and undergoes a series of nuclear changes preparatory to fertilisation. Then a microgamete penetrates the macrogamete, aided by a cone of attraction which is produced on the latter at the spot where the female nucleus lies. The macrogamete thus becomes the ookinet, it assumes an elongated form and becomes motile. When the blood begins to separate within the midgut of the mosquito, the ookinets migrate towards the anterior portion and here give rise to trypanosoma forms, both sexual and asexual. The asexual and female forms multiply by longitudinal division as in the blood of the bird, the male forms by multiple division. The small division forms attach themselves to the epithelial cells of the midgut by means of their flagella, which become short clinging structures. The attachment of the parasites coincides with the end of digestion when the midgut remains empty. Should the mosquito feed a second time, the parasites again become motile. Some of the resting parasites penetrate between the cells or even between the cells and the tunica elastico-muscularis. Usually in these situations they become globular and their flagella disappear altogether. When the latter forms again become free, they develop once more their flagella from the blepharoplasts. The female forms may grow to about three times the size of the asexual ones and become laden with reserve material. They seem unable to multiply by longitudinal division and can only accomplish sluggish contraction movements. They are no longer capable of transforming themselves into trypanosomes. These gregarine-like resting forms of female trypanosomes have a remarkable power of withstanding adverse conditions. When the mosquitoes after the first meal are obliged to fast for a long period, the asexual and male forms die off, but the female forms persist, they lie between the epithelium and the tunica elastico-muscularis, and greatly resemble the zygotes of malaria parasites, although lacking in pigment. These forms lose entirely their flagellum, the blepharoplast lies close to the nucleus, the reserve material is gradually used up, and large vacuoles appear in the plasma. If, after a long fast, the mosquito again feeds, the female forms which have survived reproduce the asexual forms by parthenogenesis (a kind of auto-fertilisation).

The zygotes which give rise to male forms are somewhat smaller than those which develop into femaie forms, their plasma is almost hyaline and coarsely vacuolar, the nucleus is relatively larger, and is very rich in chromatin. Having undergone certain nuclear changes the microgametocyte becomes globular and breaks 
up into eight small trypanosomes. These microgametes are distinguished from the other forms not only by their diminutive size, but by the development of their locomotor apparatus. They have large blepharoplasts and very - long flagella, which render them exceedingly motile.

When the blood has been entirely digested and the midgut remains empty, the parasites attach themselves to the epithelial cells lining the posterior part of the stomach about the valve in front of the malpighian tubes. Here they agglomerate in large clusters. When very numerous the parasites may greatly injure the walls of the midgut and thus cause the death of the mosquito. If the infection is followed by a long fast, all the asexual and male forms die off, the female forms alone persisting. When the mosquito again sucks blood the parasites detach themselves, distribute themselves in the blood, and then pass into the narrow anterior portion of the midgut, where they form a large cluster. At the time of the next feed the whole cluster is pushed back by the inrushing blood right through the midgut into the ileum, thence, by the peristaltic contractions of the intestine, the cluster is passed into the colon as far as Basili's curvature, the narrowest section of the intestine. On account of the nature of the epithelium in this part, the parasites are able to penetrate through the intestinal wall. Thus they reach the circulation, and through the dorsal vessel some are carried forwards into the lacunoma round the pumping organ, others are carried to the ovaries. Those carried forwards come to rest between the pumping organ and the pharyngeal valve; here they form a thick cluster, and by injuring the tunica elastico-muscularis, which is very delicate at this part, they pass into the pharynx. They are thence passed into the blood of the alternative host during the evacuation of the sucking reservoirs. The entire period of the migration of the parasites from their entry into the body of the mosquito to their exit from the latter, occupies a period of from seven to eight days.

The parasites that attain the ovaries penetrate the youngest eggs, and the macrogametes go to rest within the vitellus. The latter remain in the gregarine condition during the entire development of the embryo. They subsequently pass into the larva, and are found also in the perfect insect. The mosquito recently emerged from its pupa case does not seem able to transmit the infection by means of its first bite. According to Schaudinn's observations it can infect birds only at the time of its third feed. 


\section{Class III. Sporozoa.'}

Since the year I879 a number of isolated uni-cellular parasites that produce spores covered with shells are, according to $\mathrm{R}$. Leuckart, included with the gregarines, and this large group of protozoa is termed Sporozoa. The sporozoa comprise the so-called psorosperm tubes ( $\mathrm{J}$. Müller), i.e., Myxosporidia, Bütschli ; the oval or round Psorospermia (Eimer), i.e., Coccidia, Lkt., and Rainey's, or Miescher's tubes, i.e., Sarcosporidia, Bütschl. Later the Microsporidia and the Hamosporidia were also classed with the sporozoa.

\section{Order I. Gregarinida.}

Although hitherto the gregarinida have not been observed either in human beings or vertebrate animals, they must not be entirely omitted here, because they belong to the oldest known sporozoa, and our knowledge of them at the present time is less complete-at any rate, in regard to the history of development-than that of other groups (Coccidia, Hamosporidia).

Their bodies, which are usually elongated and frequently tape-like, and the length of which varies according to the species between 0.01-16 mm., may consist of a single cell, as in the Monocystidea, inhabiting the body cavity of echinodermata, annelida, \&c., or may be divided into two or three consecutive sections (Polycystidea, which invade the intestine, particularly of arthropoda).

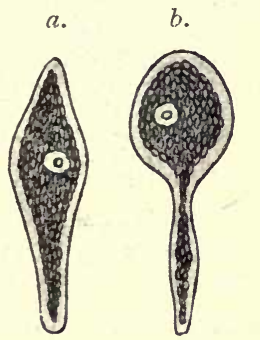

FIG. 19. - Monocystis agilis, St. From the vesicula seminalis of earthworms; $250 / \mathbf{1}$ (After. v. Stein).

(a) Quiescent; (b) moving.

The most anterior section, epimerit, is a variously-shaped organ that is used by the parasite to cling to the intestinal epithelial cells of its host; it is generally sunk within or between the cells, and when this condition (cephalin, cephalont) is given up the epimerite is cast off, tricystic forms thereby becoming dicystic. The next section, protomerit, is separated from the principal section, the deutomerite, by an ectoplasmatic transverse partition; the large vesicular nucleus (figs. 20, 26), which is provided with a usually round nucleolus (caryosoma), is situated in the deutomerit.

The surface of the body is formed by a hyaline cuticle, which, however, is not always so stiff as to prevent changes of form of the body. Beneath the cuticle (fig. 2I) there is a jelly-like mass that plays a part in the

'Bütschli, O., "Sporozoa in Bronn's Cl. u. Ordn. d. Thierr., 1 882, i., p. 479. Balbiani, G., Leçons sur les sporoz., Paris, I884. Wasielewski, "Sporozoenkunde," Jena, I896. Labbé, A., "Sporozon," 5th Edition of "Thierveichs," Berl., 1899. Hagenmïller, P., "Bibliographie gén. et spéc. des trav. conc. les. Sporoz." (Ann. Mus. hist. nat. Marseille, I 899, 2, i., Suppl.). I.̈̈he, M., “Ergebn. d..neuer. Sporozoenforsch., Jena, I900. 
gliding movement as well as in the encystment. The thin ectosarc then follows, and this also forms the transverse partition between the protomerit and deutomerit, its deepest part frequently exhibiting circular rows of muscles (myophane, myoneme) on both sections. The principal mass of the body consists of the very granular endosarc, the large or small, and usually round, granules being composed of paraglycogen, fats and other materials.

Some of the gregarines perform peristaltic or worm-like movements, even

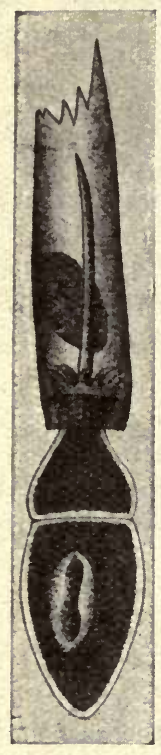

Fig. 20. - Xiphorhynchus firmus, Lég. With the epimerit fixed in an intestinal epithelial cell; host Dermestes lardarius; enlarged.

(After Léger.) in the mature condition (fig. 19), others glide along in the contents of the intestine without any visible change of form-like diatoms in water. According to Schewiakoff,' this is effected by the secretion of a slimy matter which soon stiffens at the posterior end of the body, adheres to the surface on which the creature rests and propels it forward. It is likewise this secretion, originating from the slime-secreting layer, which enables the gregarines (clepsidrinidæ) living free in the intestine, to adhere one to the other in rows.

Propagation of the gregarines may be effected in two ways. Sporula-

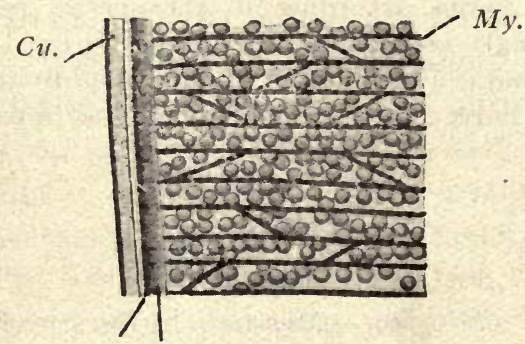

G. $E$.

FIG. 21. - Clepsidrina munieri, Schneid.; from Chrysomela hamoptera. Section of the surface, I,500 times enlarged. (After Schewiakoff). Cu. = Cuticle ; E. = Ectosarc. G. = Gelatinous layer. My. = Myophane. tion, which takes place during encystment, has long been known. Moreover, at all events in a few simpler forms, the so-called schizogonia may take place within the same host, the entire body (after division of the nucleus) separating into several nucleated segments (merozoites), each one of which becornes a gregarine directly.?

Sporulation is generally brought about by the fusing together of two contiguous gregarines and their consecutive encystment (fig. 22). Encystment in Ceratospora is said to be omitted or may be confined to one individual (as in Actinocephalus dujardini); in exceptional cases three individuals may

"Schewiakoff, "Ueb. d. Ursache d. fortschreit. Beweg. d. Gregar" (Z. f.w. Z., 1894, Iviii., p. 340).

"Cf. Schneider, A., "Ophryocystis bütschlii" (Arch. Zool. exp., 1884, 2, ii., p. II I ; "Ophr. trancesci" (Tabl. zool., 1885, i., p. I). Caullery et Mesnil., "Sur une Grég. coelom. prés. dans son cycle évolut. une phase de multipl. asporulée" (C. R. Ac. sc., Paris, I898, cxxvi., p. 262 ; C. R. soc. biol., Paris, 1898, v., p. 65). Léger et Hagenmüller, "Morph. et évolut. de l'Ophryoc. schneideri" (Arch. Zool. exp., 1900, 3, viii ; Notes No. 3). Léger, "Nouv. Sporoz. des larv. d. Dipt." (C. R. Ac. sc., Paris, 1900, cxxxi., p. 722.) Caullery and Mesnil, " Parasit. intracell. et la multiplic. asexuéc d. grég." (C. R. soc. biol., Paris, 1901, liii., p. 84). 
be: encysted together, and in one species (Pyxinia frenzeli) this is as frequent as the encystment of two.'

The fusion is effected with synonymous layers, thus being different from the above-mentioned association (adherence), which can always be relinquished or broken up.

Hitherto it has been inferred that the two encysted individuals (sporonts) conjugate because, as a rule, they sooner or later merge into one another; this opinion is, moreover, supported by the statements of Wolters" and Robóz, ${ }^{3}$ the former believing that he has actually witnessed the fusion of the nuclei of the two encysted individuals that sets in after the reduction of the nucleated substance and the expulsion of one part, whereas the latter has, at all events, observed the expulsion of portions of nucleus. This latter phenomenon has also been confirmed by recent research ${ }^{4}$; but, on the other hand, this observation has by no means proved even transient union of the reduced nuclei of the two sporonts, and accordingly there can be no question of the conjugation of the two individuals encysted together; their large vesicular nucleus rather dissolves, the greater part disappears in the substance of the body, or is sometimes ejected, and a new, though very small, nucleus is formed of the residue, and divides mitotically. The daughter nuclei

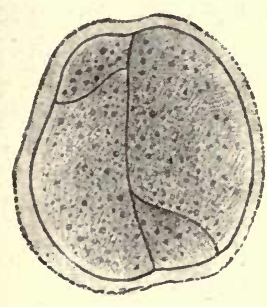

a.

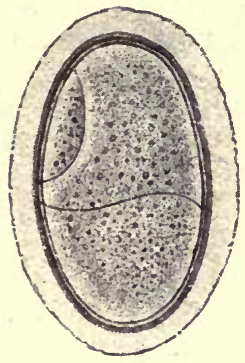

$i$

FIG. 22.-Two so-called conjugation stages of Clepsidrina blattarum. (After Bütschli).

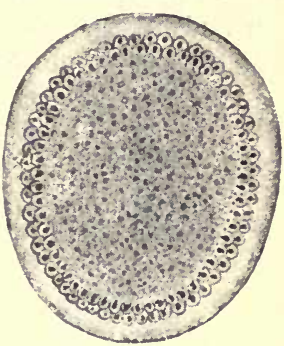

FIG. 23.-Sporulation stage of Clepsidrina ovata, schematised. (After A. Schneider.)

(livide again - a circumstance we have long been acquainted with-and this process is repeated until a large number of nuclei have formed in each sporont, which at the commencement of this process rounded off and encysted themselves. Sooner or later, the cuticle surrounding the two encysted parasites dissolves, and the nuclei crowd to the periphery of the united masses of

'Laveran et Mesnil, "Sur quel. particul. de l'evol. d'une grég." (C. R. soc. biol., Paris, 1900, lii., p. 554).

${ }^{2}$ Wolters, M., "Die Conjug. u. Sporenbildung bei Greg." (Arch. f. mikr. An., I89 I, xxxvii., p. 99).

${ }^{3}$ Math. Ber. aus Ungarn., I887, iv., p. I46; and Journ. R. Micr. Soc., London, I887, p. 769 .

+ Cuénot, S., "Evolut. d. grég. colom. du Grillon dom." (C. R. Ac. Sc., Paris, I 897, cxxv., p. 52); "Sur la prét. conjug. d. Grég." (Bibl. Anat., I899, p. 70) ; " Rech. sur l'évol. d. Grég." (Arch. de hiol., I 901 , xvii., p. 58I). Siedlecki, M., "Geschl. Vermehr. d. Monoceptis ascidia" (Bull, intern. de l'Ac. d. sc. d. Cracovie, I 809. p. 5 I 5 ). Mrazek, 1., "Studia o sporozoich" (Vestn. Krăl. Ceskê spolěcnosti náuk, I 899). 
protoplasm. A small portion of the protoplasm gathers round each nucleus, and a number of small cells, hitherto called sporoblasts, are formed (fig. 23) on a large unused residue of protoplasm (residual body, sporophor). As, however, these formations coalesce in pairs, as has been discovered by Siedlecki and Cuénot, they must be called gametes. They

a.

b.

c.

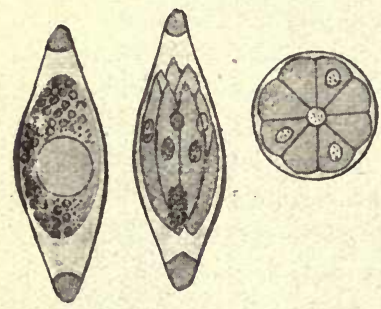

FIG. 24. -Monocystis sp. from the vesicula seminalis of earth-worms I400I. (a) Spore with spore cuticle developed; (b) mature spore with sporozoits and residual bodies ; (c) optical transerve section of mature spore (after Bütschli).

appear to be completely alike, but it is very probable that each one of the couple is the product of one of the sporonts ; in accordance herewith the conjugation or copulation would be isogamous. The designation sporoblast hitherto in use may be applied to the product of amalgamation. They are transformed into spores, assuming a more fusiform shape, and they secrete a covering of the same shape, within which the enclosed cells, after repeated mitotic division of the nucleus, divide -up into a certain number (usually

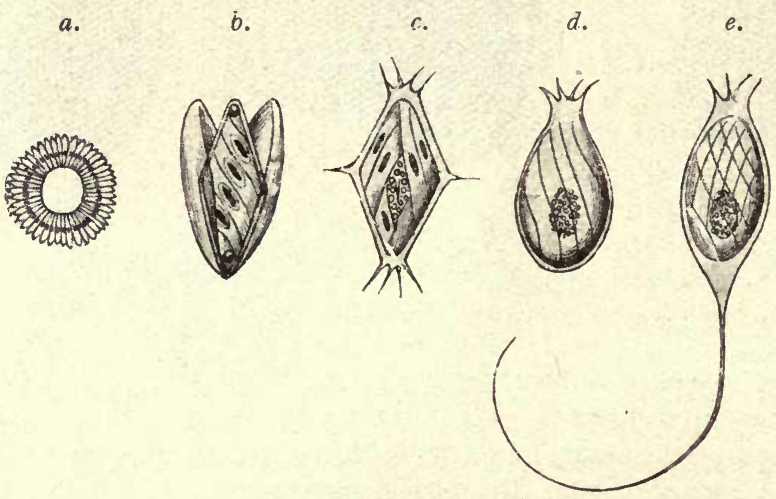

FIG. 25.-Spores of various gregarines. (a) of Porcspora: (b) of Xiphorhynchus ; (c) of Ancyrophora ; (d) of Gonospora; (e) of Ceratospora. (After Léger.)

eight) of elongated fusiform, or sickle-shaped little bodies, the sporozoites. Even in this process a small residual body remains, around which the sporozoites are grouped (fig. 24),

The development of a covering for the spores is lacking in Porospora;

' The Amphimixia here instanced cannot, however, take place in the cases in which one gregarine alone is encysted, or in which one of the two encysted individuals dies off, and the other then sporulates alone. Accordingly Amphimixia is not necessarily connected with the conjugation of the gametes. 
which is also the only genus that forms more than eight sporozoites fig. $25, a)$. The form and size of the spores vary considerably according to the species, and afford a valuable means for their distinction (figs. 25, b-e).

The development of the spores within the cysts generally takes place outside the host in the open, and may occupy very variable times. The cysts discharge their contents-the spores-either by simple bursting of the envelope of the cyst, or with the assistance of the swelling residual body, or by means of particular invertible sporoducts, one or several of which appear on the envelope of the cysts.

The ingestion of liberated spores, or also of mature cysts, causes infection. The sporozoites are actually only young gregarines, which become free through the bursting of the spores, acted upon by the intestinal juice, and in many cases bore into the epithelial cells of the invaded intestine by means of peculiar movements, which, however, are not amœboid.' In

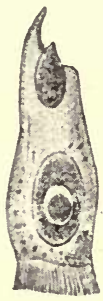

$b$.

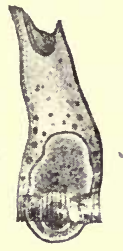

c.

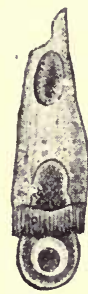

$d$.

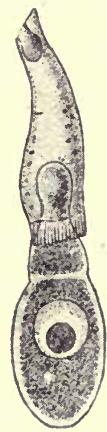

e.

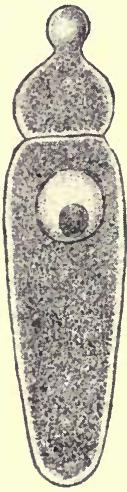

FIG. 26.-Development of Clepsidrina longa. (a) Occupying the enithelial cell; $(b, c)$ gradually coming out; (d) attached by the clinging apparatus; $(e)$ fully developed. (After Léger.)

this situation they increase in size, and grow beyond the epithelial cells occupied by them; the nucleus then lies in that part of the body extending from the cells into the intestinal lumen; the posterior extremity of the parasite, the deutomerite, is then separated from the anterior extremity by a transverse partition, and this part is finally divided into the epiand proto-merit (fig. 26). In the gregarines inhabiting the abdominal cavity an intra-cellular stage is wanting, as the sporozoites, which have become free in the intestine, travel through the intestinal epithelium without staying there; but a few species inhabiting the intestine depart from the

1 The infected epithelial cells are mostly not visibly altered; recently, however, cases have become known in which they have become hypertrophied and have finally perished.-Laveran and Mesnil, "Sur quelq. particul. de l'evol. d'une gríg." (C. R. soc. biol., Paris, I900, lii., p. 554). Siedlecki, M., "Sur les rapp. d. gr'́g. avec l'épith. intest. (ibid., I90r, liii., p. 81). Siedlecki, M., "Contrib. à l'etud. d. chang. cellul. prov. p. l. grég." (Arr.h. d'an. micr., I901, iv., p. 87). Léger et Dubosq., "Not. sur les grillons. III. Gregarina Davini" (Arch. Zool. exp., I 899, iii., ser. 7 ; not. et revue, p. 38). 
usual condition, in so far as the sporozoites likewise do not penetrate into the epithelial cells, but only fasten themselves on the latter by one pole, which ultimately becomes the epimerite. Finally, the intra-cellular phase may be of short duration, and multiplication by schizogony may take place during the same.

For the classification of the gregarinidia refer to the literature as follows :-

\section{LITERATURE.}

Dufour, L. Note sur la grég. (Ann. sc. nat., 1828, I, xiii., p. 366).

Koelliker, A. Beitr. z. Kenntn. nied. Th. I. Ueb. d. Gttg. Gregarina (Z. f. w. Z., I 848 , i., p. I).

Stein, F. v. Ueb. d. Nat. d. Greg. (Arch. f. An. u. Phys., I848, p. 182).

Lieberkühn, N. Evol. d. Grég. (Mém. cour. et mém. d. sav. étrang. Acad. belg., I 855, xxvi).

Sснміdт, A. Beitrag zur Kenntniss der Gregarinen und ihrer Entwickelung (Abhdl. d. Senckenb. naturf. Ges. in Frankf. a. M., I 854, i., p. I6I).

Beneden, E. v. Rech. sur l'évolution des Grégarines (Bull. Acad. roy. belg., I87r, 2; $x \times x i$., p. 325).

GiarD, A. Contribution à l'hist. nat. des Svnascidies (Arch. d. Zool. exp. et gén., I 872 , ii., p. 84 I).

SchNeIDER, A., in Arch. de Zool. exp. et gén., I873, ii., p. 515 ; 1875, iv., p. 493; I882, x., p. $423 ; 1884,2$, ii., p.I; and the zoological tables issued by the same author).

Bütschli, O. Kleine Beitr. z. Kenntniss d. Gregarinen (Z. f. w. Z., I88I, xxxv., p. 384).

LÉGER, L. Rech. sur les grégarines (Tabl. zool., I892, iii., p. I).

FRENZEL, J. Ueber einige in Seethieren lebende Gregarinen (Arch. f. mikr., An. I 885, xxiv., p. 545). Argentin. Gregarinen (Jen. Zeitsch. f. Naturwiss, I 892, xxvii., p. 233).

LÉger, L. Nouv. rech. sur les cyst. Polyparas. d. Arthrop. terr. (Ann. de la Fac. d. sc. de Marseille, I899. vi., No. 3. Sur un nouv. sporozoaire des larves de diptèr (C. R. Ac. sc., Paris,"T., 1900, cxxxi., p. 722).

\section{Order 2. Coccidiida.}

Hake (i) first saw the formations we now term Coccidia during his investigations on the so-called coccidial nodules of rabbits. The opinions as to the nature of these peculiar formations were very diverse; the discoverer considered them to be a sort of pus corpuscle; Nasse(2) took them for epithelial cells of the biliary passages, others for helminthes, especially the ova of trematodes (Dujardin, Küchenmeister, Gubler, \&c.). Remak(3) was the first to draw attention to their relation to the Psorospermia (Myxosporidia), and this investigator found them also in the small intestinal appendix of rabbits. Lieberkühn (4), who not only examined the coccidia of rabbits, but found similar forms in the kidneys of frogs, likewise calls them outright psorospermia; and to differentiate Müller's psorospermia, which are found in fishes, from those of rabbits, \&c., the latter were called oval or globular (Eimer) (5), until R. Leuckart (6) named them "Coccidia" and placed them in a group of the sporozoa analogous to that of the Gregarinida, Myxosporidia, \&c. Numerous works confirmed the occurrence of coccidia, not only in all classes of vertebrate animals, but also in invertebrates (mollusca, myriapoda, annelida, \&c.), and numerous genera and species have in the course of time been described which inhabit the epithelium of the intestine and

' Compare Caullery and Mesnil, “Le paras. intracell. et la multipl. asexue d. grég." (C. R. soc. biol., Paris, I901, liii., p. 84.) 
its appendages by predilection, but are also found in other organs (kidneys, spleen, ovaries, vas deferens, testicles); some also live in the connective tissue of various organs, more particularly of the intestine.

The knowledge of the development of the coccidia was of particular importance in determining their classification. By means of encysted coccidia from the liver of rabbits, Kauffmann (7) first confirmed the fact that the cystic membrane, which was filled, or partly filled, with granular contents, divided into three or four pale bodies after a long sojourn in water; Lieberkühn, however, observed the same process in the host in the case of coccidia of the kidney of the frog. Stieda(8) studied more minutely the alterations that take place within the encysted coccidia of the liver of rabbits after the death of the host; he discovered that what we at the present day call "spores" were oval formations pointed at the one pole, and surrounded by a delicate membrane, which exhibited a certain thickness at the pointed extremity and enclosed a slightly bent rodlet, expanding at either end into a strongly light-refracting globule; a finely granulated globule also lay in the concavity of the bent rodlet. Waldenburg (9) saw the appearance of the same phenomenon in coccidia from the epithelium of the villi and Lieberkühn's glands from the intestine of the rabbit; but the process in this case took place in a much shorter time.

Fig. 27.-Coccidium cuniculi (Riv.), from the liver of the rabbit, in various stagres of develop. ment.

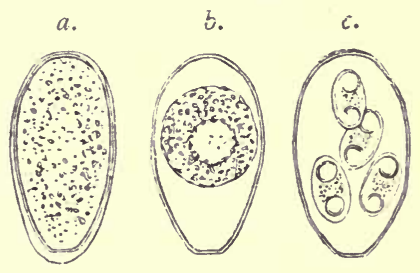

According to the discovery of Kloss (IO), the spores of the coccidia of the urinary organ of the garden snail are formed in far greater numbers; the round spores also harbour several (five to six) rodlets, which after the bursting of the spore-envelope become free. Eimer's researches have made us acquainted with a coccidium from the intestine of the mouse, which was transformed in toto into a "spore," with sickle-shaped little bodies; the fact was, moreover, established that the little bodies left the delicate envelope already in the intestine, made crossbow movements, and were finally transformed into amœboid beings, which apparently penetrated the epithelial cells; at all events, similar bodies of various sizes were seen in these cells. Taking the immense number of these parasites into account and the lack of any other cause, Eimer attributed the sudden death of his mice to the Gregarina falciformis, as the parasite was then called, just in the same way as a few years previously Reincke (II) ascribed the acute intestinal catarrh of rabbits leading to their death to the invasion of intestinal coccidia.

All that had become known about coccidia up to 1879 was then compiled by Leuckart, and completed by his own observations on the liver coccidia of the rabbit. Experimental infections had already been conducted by Waldenburg with intestinal coccidia of rabbits, and by Rivolta (12) with the coccidia of the fowls, which experiments confirmed the importance of the spores, or 
bodies, enclosed in them in the transmission of the parasites to other animals. Accordingly, it may be assumed that after the importation of the spores into the intestine the sporozoites are set free, actively penetrate into the intestinal cells, where they grow into coccidia, and finally become encysted. The further development, i.e., the formation of spores, takes place outside in these cases; in other cases (Kloss, Eimer) it takes place within the host. Although much regarding the cycle of development was still hypothetical, the theories coincided with the observations, and were therefore universally regarded as confirmed. Further research confirmed this view in numerous new forms.
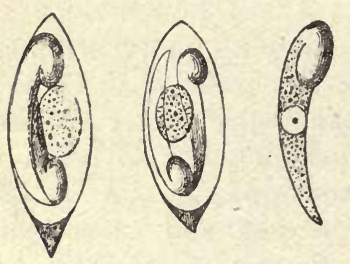

FIG. 28.- Spores of the Coccidium cuniculi, (Riv.), with two sporozoits and residual bodies: to the right a free sporozoit. (After Balbiani.)

L. Pfeiffer's statements (13) on the part that certain coccidia or their sporozoites played, or seemed to play, as causes of disease furnished renewed impetus for the investigation of the coccidia. The ingestion of even very numerous spores did not appear to account for the mass infection so frequently observed, even after Balbiani (15) had confirmed the fact that there were two, not one, sporozoites confined in every spore of the coccidia of rabbits (fig. 28). The hypothesis was therefore advanced that the sporozoites or young coccidia were able to divide themselves once more before again sporulating. The question was finally solved quite differently. R. Pfeiffer (14) first confirmed the fact that in addition to the well-known method of
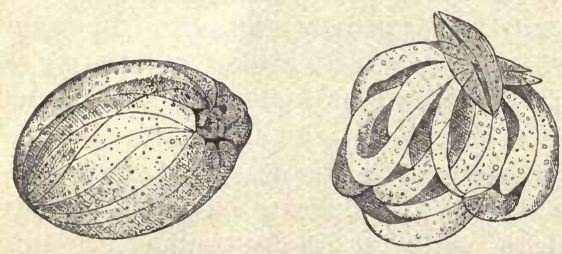

FIG. 29.- So-called swarm cysts of the Coccidium of the rabbit. (After R. Pfeiffer.)

sporulation in the coccidia of the rabbit that causes the infection of fresh hosts ("exogenous sporulation"), an enormous increase may follow in the already infected host in a manner that Eimer first observed in the coccidia of the intestine of the mouse ("endogenous sporulation"). Whereas it had hitherto been believed that some of the species of coccidia increased like Coccidium oviforme and others, like Eimeria falciformis, and this difference had been made the foundation of the classification. R. Pfeiffer was successful in observing the occurrence of both kinds of development in the same species, and expressed the opinion that endogenous sporulation, which takes place within the host, was the cause of the mass-infection that is mostly accompanied by serious consequences (fig. 29). L. Pfeiffer sought, 
above all, to demonstrate the correctness of this view as regards other species of coccidia also, and for this purpose he utilised the experiences already published. Coccidia were known to exist in a number of different hosts, and to propagate in some according to the Coccidium type, in others according to the Eimeria type; it therefore stands to reason that in this case it was not the question of two species belonging to different genera living side by side, with a different manner of development, but of one species, in the life of which both manners of development occur alternately,

This interpretation of facts was combated especially by A. Schneider (I6) and by Labbé (17), but has, nevertheless, proved true, apart from the circumstance that Schuberg (I8) succeeded in discovering the hitherto unknown Coccidium form in the intestine of the mouse ; and that, moreover, Léger confirmed the fact that there are no arthropoda in which Eimeria are not found together with coccidia. The question was finally settled by experiments made by Léger (19) with the coccidia of Scolopendra cingulata, by Schaudinn and Siedlecki (20) with those of Lithobius forcipatus, and by Simond (2I) with the coccidia of the rabbit. On Simond's suggestion the sickle-shaped germs correspond. ing to the sporozoites, which are formed by endogenous sporulation, are universally termed MERozorTs ; and in accordance with Schaudinn's suggestion, those individuals which form merozoites are termed Schizonts, and those which produce shelled spores are called Sporonts. In contradistinction to sporogony (exogenous sporulation), one therefore speaks of schizogony (endogenous sporulation).

The more minute examination of these processes at last led to the discovery of SEXUAL DIMORPHISM, of copulation and alternation of generation in the coccidia. Schuberg was the first to consider the possibility of copulation in coccidia; in addition to the formations which now are termed merozoites, he observed very diminutive bodies (" microsporozoites") in the coccidia of the intestine of the mouse, which were able eventually to perform copulation. Labbé confirmed this observation in some of the species, and Simond (2I) expressed the opinion that "chromatozoites" occurred in all coccidia. Copulation itself was then observed by Schaudinn and Siedlecki. The copulating bodies are termed gametes: as, however, they differ considerably one from the other, the males are called microgametes (i.e., the microsporozoites of Labbé and the chromatozoites of Simond) and the females macrogametes. After copulation is completed sporogony takes place, and in the cycle of development of one species this regularly alternates with schizogony (asexual propagation).

The recognition of this unsuspected complicated process was bound to effect reforms in the classification of the coccidia; and all the forms that had been regarded as developmental stages (Eimeria, \&c.) had to be eliminated from the system.

\section{LITERATURE.}

(1) HAKE. A Treat. on Varic. Capill. as constit. the Structure of Carcinom. of the Hep. Ducts, with an Account of a New Form of the Pus Globule. London, I 839.

(2) Nasse, H. Ueb. d. eiförn. Zellen d. tuberkelähnlichen Ablagerungen in d. Galleng. d. Kaninchen (Arch. f. An. u. Phys., I 843, p. 209).

(3) Remak, H. Diagn. u. pathogen. Unters. Berlin, I 845.

(4) Lieberküh, N. Ueb. d. Psorospermien (Arch. f. An. u. Phys., I854, p. I). Evol. des Grég. (Mém. cour et Mém: d sav. étrang. Ac. d. Belg., 1855, xxvi. 
(5) Eimer, Th. Ueb. d. ei- u. kugelförm. Psorsp. d. Wirbelth. Würzb., 1870.

(6) Leuckart, R. Die Paras. d. Menschen, \&c., 1879, ii., 2nd edition, p. 248.

(7) Kauffmann, W. Anal. ad tubercul. et entoz. cognitionem. Diss. in Berol., 1847.

(8) Stieda, S. Ueber d. Psorosp. d. Kaninchenleber (Virchow's Arch. f. path. An., I 865 , xxxii., p. I 32 ).

(9) Waldenburg, L. De struc. et origine cystidum verminos. Diss in Berol, I660. (Virchow's Arch. f. path. An., I862, xxiv., p. 149).

Zur Entw. d. Psorosp. (ibid., 1867, xl., p. 435).

(10) Kloss, H. Ueb. d. Paras. d. Niere von Helix (Abhand1. d. Senclienb. naturf. Ges. Frankf. a. M., 1855 , i., p. 189).

(I I) Reincke. Nonnulla quaed. de psorosp. cuniculi. Diss. in Kiliae, I866.

(12) Rivolta, G. Psorospermi i psorospermosi negli anim. dom. (Med. veter., i 860, 3, iv.).

(13) Pfeiffer, L. Beitr. z. Kenntn. d. pathol. Greg. ; II. Ueber Gregarinose, ansteckendes Epitheliom u. Flag.-Diphth. d. Vögel (Zeitschr. f. Hyg. u. Inf., I 889 , v., p. 363).

Die Protozoën als Krankheitserr. Ist edition, Jena, I 890 ; 2nd edition, I892.

( 4 ) Pfeiffer, R. Beitr. z. Protozoënforsch. I. Die Coccidienkrankh. d. Kaninchen Berlin, I 892 .

( I 5) Balbiani, G. Leç. sur les Sporoz. Paris, i 884, p. IO4.

(i6) Schneider, A. Le cycle évolut. d. Cocc. et M. L. Pfeiffer (Tabl. zool. ii., p. IO5).

(17) Laвbé, A. Rech. zool., cytol. et biol. sur les Cocc. (Arch. Zool. exp., i 896, 3, iv., p. 5 I6).

(18) Schuberg, A. Die Coccid. aus Darm der Maus (Verh. nat.-med. Ver. Heidelberg. N. F., I895, v., p. 369).

(19) Líger, L. Le cycl. évol. d. Cocc. chez. les arthrop (C. R. soc. biol., Paris, I 897. 10, iv., p. $3^{82}$ ).

Cocc. nouv. du tub. dig. d. Myriap. (C. R. Ac. sc., Paris, I897, cxxiv., p. 9or).

(20) Schaudinn; F., and M. Siedlecki. Beitr. z. Kenntn. d. Cocc. (Verh. d. D. zool. Ges., I 897, vii., p. I92).

Schatidinn, F. Unters. üb. d. Generationswechsel bei Cocc. (Zool. Jahrb. An., I 900 ; part 13, p. I97).

(2i) Simond, P. L. L'évol. d. sporoz. du genre Coccidium (Ann. Inst. Pasteur, i 897, xi., p. 545).

Occurrence of the Coccidiida. - The Coccidiida in their mature condition usually live within the epithelial cells of various organs, and by predilection inhabit those of the intestine and of its dependent organs; they also occur frequently in the excretory organs of the mammalia, birds, amphibia, molluscs, arthropoda, and may also be found in the scrotum and vas deferens, but the statement that they live in hen's eggs, as well as in the oviducts of fowls, has not been confirmed. ${ }^{1}$ Some species inhabit the nucleus, others live in the connective tissue, but their presence in the latter situation is probably only secondary, that is, they have only reached it from the epithelium of the affected organs.

Notwithstanding the progress made during the last decades, the ova of helminthes and more particularly of trematodes, have been mistaken for coccidia. Thus Poschinger (Zool. Anz., I 885, ix., p. 47 I) and Gebhard (Virchow's Arch., 1897, No. I47, p. 536) mistook the ova of Distomum turgidum, Brds., for coccidia. Podwyssotzki (Centralbl. f. allg. Path., 1890, i., p. 135) made a similar error with the ova (and vitelline sacs) of a species of Prosthogonimus (Dist. ovatum of the authors); von Willach (Arch. $f$. wiss $u$. prakt., Thierheilk, 1892 , xviii., p. 242) took the ova of a nematode for coccidia. These errors are merely alluded to as a warning. A closer examination of the objects and a knowledge of such mistakes will ensure their avoidance. 


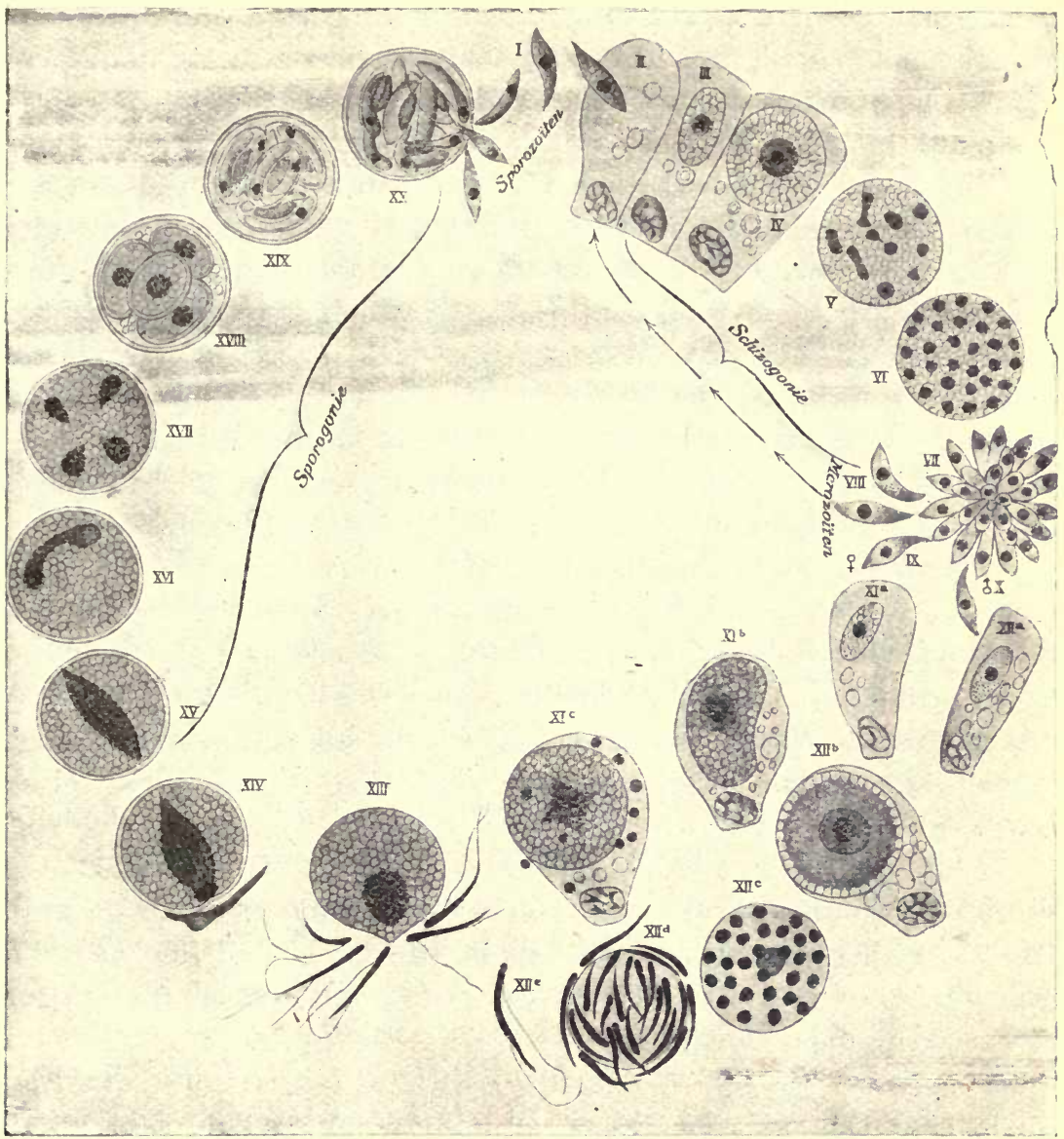

FIG. 30.-Scheme of the development of Coccidium schubergi, Schaud. (fronı the intestine of Lithobius). (After Schaudinn.) The infection is caused by a cyst (xx.), containing spores, which invades the intestine of a Lithobius, where it bursts and discharges the sporozoites (I.). II., A sporozoit invading an intestinal epithelial cell; III., intestinal epithelial cells with young coccidia; IV., intestinal epithelial cells with a globular schizont; v., nuclear segmentations within the schizont; vi., the daughter nuclei arranging themselves superficially; vir., formation of the merozoites; viII., merozoites that have become free, and which, penetrating into other epithelial cells of the same intestine, repeat the schizogony (II.-VIII.); IX. and x., merozoites which, likewise invading the epithelial cells of the same intestine, become individually sexually differentiated; xıa., adolescent macrogamete; xıb., older macrogamete; xic., mature macrogamete (discharging particles of nucleus); xiIa., young microgametocyte; xIIb., older microgametocyte; xIIc., increase of nuclei in the microgametocyte; xiId., the globular residual body around which numerous microgametes have formed; xile., an isolated microgamete; xill., the mature macrogamete surrounded by numerous microgametes and forming a fecundating prominence; XIV., the nucleus of a microgamete that has penetrated amalgamated with the nucleus of the macroganete (fecundation)-the latter casts off a membrane and becomes a sporont (oocyst); XV., XVI., XVII., nuclear segmentation in the sporont; XviII., sporont with four sporoblasts; xix., the sporoblasts transformed into spores; $\mathbf{x x}$., the cysts introduced in to the intestine that has liberated the sporozoites by bursting. 
The SIZE OF THE COCCIDIIDA, corresponding as a rule to the habitat, is usually small, but there are species that attain a diameter of I mm. Their FORM is globular, oval, or elliptical. External appendages are lacking, at least during the vegetative period of their life, which is spent in epithelial cells, within which they increase in size; as a rule only one is present in each cell, rarely more. The BODY SUBSTANCE is composed of a more or less finely granulated or distinctly alveolar protoplasm which exhibits no differentiation in ecto- and endo-sarc. All species possess a nucleus that enlarges with their growth; sometimes it only shows through the plasma as a lighter spot, or may even be quite concealed. It is vesicular in shape, and besides containing very delicate threads of chromatin in the light coloured nuclear juice, it contains generally only one large nucleolus (caryosoma).

The affected epithelial cells degenerate sooner or later as the parasite feeds on them. After having had their form changed by the growing parasite they finally perish. The cellular membrane then alone surrounds the coccidia, which, at least in the species sufficiently known, begin to propagate by an asexual process (ScHIZOGONY); hereby the parasites themselves become schizonts, as the initial stage is usually called. They differ from later stages (sporonts), which resemble them in form, by the absence of granulations in the plasma, as well as by the vesicular nucleus. The form is not always alike, for in some cases, at least, many schizonts assume a globular form.

Schizogony (fig. 30) commences with a division of the nucleus, which nevertheless takes place in different ways in the different species, and finally leads to the formation of numerous daughter nuclei which become smaller and smaller, and which collect beneath the surface of the schizonts, but in some species collect only at one half. A part of the protoplasm of the periphery now divides around each daughter nucleus, the remaining part (residual body) being left in the centre or on one side. The segments of the divided plasm, each containing a nucleus, assume a fusiform shape and become merozoits, which very soon gain their freedom and quit the residual body (fig. 30, VII.).

The merozoits move in a manner similar to that of the sporozoites, from which they are, however, distinguished by a somewhat different shape and the form of their nucleus. The movements consist either of slow incurvations with subsequent straightenings, or annular contractions along the entire extent of the body; in addition, there are gliding movements similar to 
those of many gregarines, and brought about in a like manner by the secreting at the posterior extremity of a gelatinous filament that stiffens rapidly. The merozoits do not gain the open in the usual way, but are destined to still further infect the same host by actively penetrating into other epithelial cells of the affected organ; here they continue their growth and may again and again undergo schizogony. In the Infusoria the repeated segmentations finally cease and are again renewed only after a conjugation; this is likewise the case with the coccidia, with the difference that in the latter the two uniting individuals (gametes) are differently constituted one from the other, whereas in the infusoria they are almost always similar.

When the schizogony ceases, the merozoits that had penetrated the epithelial cells and there grown consist of two kinds of beings differently constituted; one kind possessing a light plasm (fig. 30, xir.), the other an opaque plasm richly granulated, while both possess a vesicular nucleus with caryosoma (fig. 30, XI.). In order to continue their development the dark individuals must copulate, and are therefore termed either female gametes or, on account of their size, macrogametes. The hyaline individuals, the male individuals (microgametes) necessary to conjugation, are formed in greater numbers. They are slender bodies consisting chiefly of nuclear substance, which in most species bear two flagella of unequal length directed backwards, and the place of insertion of which varies according to the species (fig. 30, xxe.).

While the development of the microgametes is rapidly advancing a change of the nucleus occurs in the macrogametes, parts of the caryosoma (nucleolus) are extruded, and the nucleus loses at the same time its vesicular shape. By this time the macrogametes are capable of conjugation, and the process takes place within the host, generally, however, outside the affected and degenerated host cells. The microgametes that have now become free, leaving a very large residual body, crowd around the mature macrogametes, which project a small prominence (fecundating protuberance) for their reception (fig. 30, xiIr.). As soon as a microgamete comes into touch with this and penetrates into the plasm of the macrogamete, the latter surrounds itself with a membrane which prevents the intrusion of other microgametes. The nucleus of the microgamete that has gained entry amalgamates with the nucleus of the macrogamete, which is then capable of forming the well-known spores with shells; it is therefore called sporont (also oocyst or copula). 
The reduced nucleus of the macrogamete expands itself on the entry of the microgamete; and becomes a spindle to which the nuclear parts of the microgamete become attached (fig. 30, XIV. and Xv.). Thereupon the spindle divides into two daughter nuclei which assume a round shape. The protoplasm at this stage may at once divide, or another segmentation of the daughter nuclei may previously occur. In the former case the two halves divide again, so that finally four nucleated segments, the sporoblasts, are formed, whereas in the other case the four sporoblasts appear simultaneously. In both cases a residual body of varying size is separated from the protoplasm of the sporont. As a rule, in the meantime, the encysted sporonts have already been discharged outwardly, and there, and in the manner described above, form the sporoblasts after a longer or shorter period of incubation. The sporoblasts are originally naked, but they soon secrete a homogeneous membrane in which they become enveloped (fig. 30, XviII.). After the segmentation of the nucleus their contents divides into two sickle-shaped sporozoits, in addition to which there is generally also a residual body (fig. 30, xIx.).

This terminates the development; the spores are intended for the infection of other hosts. If they attain the intestine of suitable hosts, free or enclosed in the cystic membrane of the sporont, the actions of the intestinal juices cause them to open and permit the sporozoites to escape. The latter move exactly like the merozoites and soon make their way into epithelial cells, where they become schizonts.

Although our knowledge of the development of the coccidia is but of recent date, yet it already extends to a large number of species, which exhibit varying deviations from the cycle of development described above. The most important deviation is the simplification by the omission of schizogony, as in Legeria octopiana, which lives in the submucosa of the intestine of cuttlefish. In these the sporozoites that have invaded the epithelial cells are transformed direct into macrogametes or microgametocytes, which, after the disintegration of the cells of the host, reach the submucosa, where they continue their transformation, copulate and sporulate. Yet in this species auto-infection of the host is not lacking, at all events it has been stated that if the oocyts furnished with numerous spores penetrate from the submucosa into the intestinal lumen, they find themselves in the same condition as if they had been introduced per os, that is to say, the spores open themselves and their sporozoites infect other cells. 
In order to systematically classify the coccidia the form and number of the spores and the number of sporozoites are taken into account. Accordingly the following are differentiated :-

I.-Disporea, forming only two spores.

(I) Cyclospora, Schndr., each with two sporozoites.

(2) Isospora, Schndr., each with four sporozoites.

II.-Tetrasporea, forming four spores.

(3) Coccidium, Lckt., each with two sporozoites; spores globular or oval.

(4) Crystallospora, Labbé, each with two sporozoites; spores in the shape of a double pyramid.

III.-Polysporea, forming more than four spores.

(a) Oocysts, with sporoducts.

(5) Gymnospora, Mon. (probably a Gregarinida).

(b) Oocysts, without sporoducts.

(6) Barrouxia, Schndr., spores with one sporozoite.

(7) Adelea, Schndr., spores with two sporozoites.

(8) Legeria, R. Blanch. (=Benedenia, Schndr., nec Dies.), spores globular, with three sporozoites.

(9) Klossia, Schndr., spores round, with four sporozoites.

(Io) Hyaloklossia, Labbé, spores oval, with two or four sporozoites.

IV.-Asporocystidea, forming numerous naked sporozoites.

(I I) Legerella, Mesn.

\section{The Coccidia Observed in Man.}

Gen. Coccidium (R. Lckt. I879).

Spores of a fusiform, oval, or globular form, in each of which there are two sporozoites, in addition to a roundish residual body. The species live in the intestine, liver and kidney of vertebrate and invertebrate animals; a few give rise to epidemic diseases, more particularly in domestic animals.

\section{Coccidium cuniculi (Rivolta, I878).}

Syn. Psorospermium cuniculi, Riv., I878; Coccidium oviforme, R. Lckt., I 879 .

In this species the fertilised sporont stage (oocyst) has been known the longest and is found in the coccidium nodules so common in the liver of rabbits. It is oval, 0.033-0.049 $\mathrm{mm}$. in length, 0.015-0.028 mm. in breadth, and surrounded by an integument with a double outline which, according to some statements, has an opening at the pointed pole (fig. $3 \mathrm{I}, a, b$ ). The plasm, which is somewhat coarsely granular, entirely fills the integument or is gathered together into a round central mass. At this stage the parasites are evacuated in the natural way 
and sporulate in the open within a fortnight or three weeks. The fully-developed spores are of a broad fusiform shape and measure $0.012-0.015 \mathrm{~mm}$. in length, with a breadth of 0.007 $\mathrm{mm}$. They contain two sporozoites, broad at one end, pointed at the other, which lie in such a position that they form a bent dumb-bell-shaped body (fig. 32). A granulated residual body lies in the concavity. In sporulation the whole of the plasm of the sporont is taken up, and therefore in the oocyst there is no residual body.
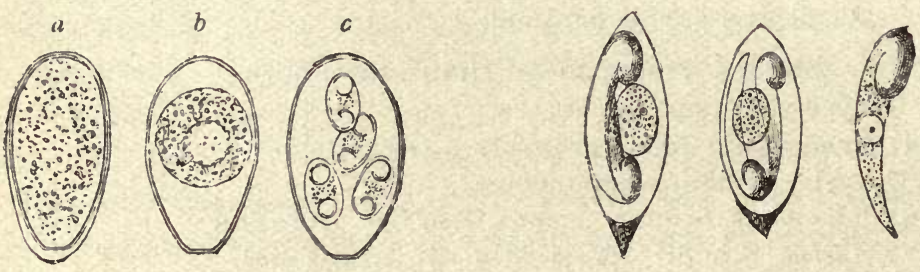

Fig. 31.-Coccidium cuniculi (Riv.), from the liver of the rabbit, sporulating (a) Entirely occupying the integument (oocyst); (b) gathered together in a nucleated ball ; (c) divided into four spores.

is FIG. 32. - Spores of the Coccidium cuniculi (Riv.), with two sporozoites and residual body: a free sporozoite to the right (after Balbiani).

The development of this species does not deviate from the course sketched above. Infection occurs through swallowing spores or oocysts containing spores. ${ }^{1}$ The gastric juice, as already stated by Rieck, causes the spores to open and the sporozoites to become free; the latter then utilise the ductus choledochus to reach the biliary ducts, where they penetrate the epithelial cells and propagate by means of schizogony. ${ }^{2}$

According to the number of spores taken up there ensues, sooner or later, at those parts of the biliary ducts that are attached, inflammation with proliferation of the epithelium and connective tissue of the passages, which become greatly thickened at the expense of the substance of the liver. ${ }^{3}$ Finally, irregular

\footnotetext{
' Pianese's statement (Arch. d. parasit., 1899, ii., p. 397) that the ingestion of oocysts before they have sporulated causes infection still lacks confirmation. It cannot, indeed, be denied that the animals experimented on finally became infected, but the necessary assumption that the oocysts developed further in the intestine is highly improbable. I consider it much more probable that the oocysts ingested were passed through the intestine, sporulated outside, and were then again .taken up by the animals experimented on.

${ }^{2}$ Podwyssotzki, W., "Z. Entw. d. Cocc. ovif. als Zellschmarotzer" (Bibl. med. Cassel, 1895, part D., ii., No. 4); Pianese, G., "Le fasi di svil. del Cocc. ovif." (Arch. de paras., 1899, ii., p. 397).

"Felsenthal and Stamm, "Veränd. in Leber u Darm. b. d. Coccidienkrankh. d, Kaninch." (Virchow's Arch. f. path. Anat., I 893, cxxxii., p. 36).
} 
or roundish thick-walled nodules, more or less isolated, and containing a caseous material, are formed; this material consists of detritus, pus cells, epithelial cells and coccidia in various stages of development, according to the time that has elapsed from the moment of infection. In originally severe infection which increases rapidly in consequence of schizogony, the inflammation of the liver is great and leads to serious illnesses and frequently to death; in other cases auto-division finally sets in, as schizogony cannot continue indefinitely, though the coccidia nodules persist.

The transmission of Coccidium cuniculi to man occurs very rarely, at all events the number of cases known are few. The following cases are probably correct:-

(I) Gubler's Case. A stone-breaker, aged +5 , was admitted to a Paris hospital suffering from digestive disturbances and severe anæmia. On examination the liver was found to be enlarged and presented a prominent swelling, which was regarded as echinococcuss. At the autopsy of the man, who succumbed to intercurrent peritonitis, twenty cysts were found averaging $2-3 \mathrm{~cm}$. in diameter, and one measuring $12-15 \mathrm{~cm}$. The caseous contents consisted of detritus, pus corpuscles, and oval-shelled formations, which were considered to be distomum eggs, but which, in accordance with Leuckart's conjecture, proved to be coccidia (Gubler, A., "Tumeurs du foie determ par des ceufs d'helm . . . ." [Mém. soc. biol., Paris, 1858, v., 2 ; and Gaz. méd. de Paris, 1858, p. 657); Leuckart, R., Die menschl. Paras., I863, ist edition, i., p: 49, Anm.].

(2) Dressler's Case (Prague). Relates to three cysts, varying from the size of a hemp-seed to that of a pea, and containing coccidia, found in a man's liver (Leuckart, R., Die menschl. Paras., I863, ist edition, I., p. 740).

(3) Sattler's Case (Vienna). Coccidia were in this case observed in the dilated biliary duct of a human liver (Leuckart, R., Die thier. paras. d. Mensch., i879, ist edition, ii., p. 281).

(4) Perls ${ }^{\circ}$ Case (Giessen). Perls discovered coccidia in an old preparation of Sömmering's agglomerations (Leuckart, R., ibid., p. 282).

(5) Silcock's Case (London). The patient, aged 50, who had fallen ill with serious symptoms, exhibited fever, enlarged liver and spleen, and had a dry, coated tongue. At the autopsy numerous caseous centres, mostly immediately beneath the surface, were found, while the contiguous parts of the liver were inflamed. The microscopical examination demonstrated numerous coccidia in the hepatic cells as well as in the epithelium of the biliary ducts. A deposit of coccidia was likewise found in the spleen, which the parasites had probably reached by means of the circulation of the blood ' (Silcock, "A Case of Parasit. by l'sorospermia" (Trans. Path. Soc., London, I890, xxi., p. 320).

Other cases are more or less dou $\therefore$ I, such as Virchow's (Arch. $f$.

${ }^{1}$ Pianese has confirmed the fact that coccidia actually occur in the blood of the hepatic veins of infected rabbits. 
path. An, 1860, xviii., p. 523), in which a thick-walled tumour, measuring 9-I I mm., was found in the liver of an elderly woman. Long oval formations surrounded by two membranes, measuring $0^{\circ} 056 \mathrm{~mm}$. in diameter, and containing a number of small roundish bodies were found in the tumour. Virchow is of opinion that these foreign bodies were developmental forms of the ova of pentastomes ${ }^{1}$ rather than coccidia.

The coccidia which Podwyssotzki states that he found in the hepatic cells and in their nuclei are also problematical (Podwyssotzki., "Ueb. $d$. Bedeut. d. Coccid." in d. Path. d. Leber d. Menschen, C. f. B. $u$ P., I889, vi., p. 4I). The parasite is termed Caryophagus hominis.

An observation by Thomas, of the presence of "Coccidium oviforme" in a cerebral tumour the size of a pea, and surrounded by' a bony substance, occurring in a woman, aged 40 , must admit of another explanation. (Thomas, J., "Case of Bone Formation in the. Human Brain due to the Presence of Cocc. ovif." Journ. Boston Soc. Med. Sc., I899, iii., p. 167; C. f. B., P.u. J., I900, p. xxviii., I882).

\section{Coccidium hominis (Rivolta, I878).}

Syn. : Cystospermium hominis, Riv., I878; Coccidium perforans, R. Lckt., 1879.

Remak was the first observer to confirm the fact that this species inhabits the intestinal epithelial cells of rabbits, giving. rise to severe diarrhoa, which usually causes death. A few later authors consider that the parasite is identical with Coccidium cuniculi, but there are differences between the two forms which justify the formation of a separate species.

Apart from its habitat, the difference consists in the smaller size of the oocysts $\left(0^{\circ} 024-0.026-0^{\circ} 035 \mathrm{~mm}\right.$. in length, and 0.0128 - $0.014-0.002 \mathrm{~mm}$. in breadth), in its more rounded form, and in the residual body that is always present after sporulation and absent in Coccidium cuniculi. Moreover, the time employed for the segmentation of the globular cystic contents into sporoblasts differs in the two species; in Coccidium hominis the time taken is three or four days, in Coccidium cuniculi three or four weeks. In other particulars the two species agree.

As Railliet and Lucet have demonstrated, infection is brought about by the ingestion of mature spores. In consequence of the schizogony such a severe auto-infection follows within a few days that the entire small intestine is affected. Even with the naked eye whitish spots may be observed in the mucous membrane caused by the wholesale colonisation of schizonts and sporonts in the cellular epithelium as well as in Lieberkühn's glands. The

1 Compare trematodes of man. 
intestinal lumen is sometimes entirely filled with free parasites, and frequently more than one schizont is met with in each epithelial cell. In such severe cases death occurs after a few days, in milder cases the diseased animals sink gradually, or may spontaneously recover.
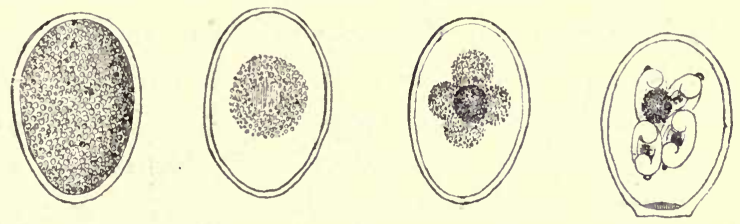

FIG. 33.-Coccidium hominis (Riv.) in sporulation. (After Riek.)

The coccidia observed in the intestine of the horse, goat, ox, sheep, pig, mole, marmot, guinea-pig and weasel are generally regarded as varieties of Coccidium hominis, i.e., C. perforans.

Eimer found the intestinal epithelium of two cadavers of human beings of the Pathological Institute in Berlin permeated with coccidia (Die ei. u. kugelf. Psorosp. 7. Wirbelth., I870, p. I6). Railliet and Lucet's case was undoubtedly attributable to intestinal coccidia. In this case a woman and her child had both been suffering from chronic diarrhœa for a long time, and coccidia were found in the fæces of both (Railliet, Trait Zool. med. et agric., I893, 2nd edition, p. I4O). In other cases (Grassi, Rivolta) in which only the occurrence of coccidia in the fæces is reported, the origin of the parasiteswhether from the intestine or liver-remains doubtful, and likewise also the species to which they belong.

\section{Coccidium bigeminum, Stiles, I89I.}

Syn: Cystospermium villorum intestinalium canis et felis, Rivolta, I874.

This species has been known since 1854 (Finck, Sur la phys. de l'épith. intest., Thèse, Strasburg, p. I7); it lives in the intestinal villi of dogs, cats and the pole-cat (Mustela putorius, L.), and is distinguished by its small size and its constant appearance in pairs. According to Stiles, ${ }^{1}$ the oocyst divides into two equal portions which become encysted and then form four spores. The oocysts of this species attain a length of $0.012-0^{\circ} 0 \mathrm{I} 5 \mathrm{~mm}$. and a breadth of $0.007-0.010 \mathrm{~mm}$. in the dog, only $0.008-0^{\circ} 010$ by $0.007-0.009 \mathrm{~mm}$. in the cat, and $0.008-0.012$ by $0.006-0.008 \mathrm{~mm}$. in the pole-cat.

'Stiles, Ch. W., "Notes on paras.," No. I I (Journ. of Comp. Med. and Vet. Arch., I892, xiii., p. 517 ). 
Coccidium bigeminum appears to occur also in man, at all events Virchow published a case which was communicated to him by Kjellberg, and attributes the disturbance to this parasite (Arch. f. path. An., I860, xviii., p. 523). Possibly also it would be more correct to ascribe the observation of Railliet and Lucet, which is mentioned under Coccidium hominis, to this species, as the coccidia in that case were distinguished by their diminutive size (length o.or $5 \mathrm{~mm}$., breadth o.oro $\mathrm{mm}$.). The case communicated by Grunow may also probably refer to Cocc. bigeminum (Grunow, "Ein Fall von Protozoën [Coccidien?] Erkrankung des Darmes" [Arch f. exper. Path. und P.harm., Igor, xlv., p. 262]).

a.

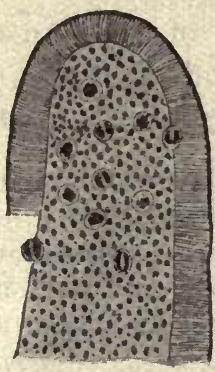

$b$.

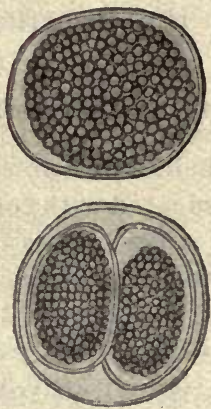

d. c.

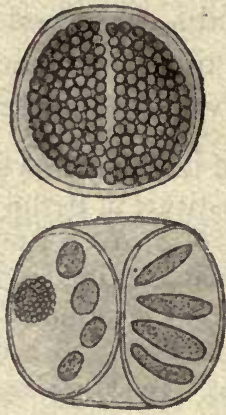

e.

FIG. 34.-Coccidium bigeminum, Stiles (from the intestine of a dog). (a) Piece of an intestinal villus beset with coccidia, slightly enlarged; (b) Cocc. bigeminum (0.01 5 $\mathrm{mm}$. in diameter), shortly before division; (3) divided; (d) each portion encysted; (e) four spores in each part, on the left seen in optical section, and a residual bodystrongly magnified. (After Stiles.)

\section{DoubTful. Species.}

There are numerous reports in literature on the occurrence of coccidialike organisms in man, which are, however, open to considerable doubt. It may prove useful to mention here a few such doubtful forms.

(I) Eimeria hominis, R. Blanch., 1895.-This is the designation applied to foreign bodies found in Bordeaux by J. Künstler and A. Pitres in the purulent pleural exudation of a man removed by tapping. The patient, who had been employed on a ship plying between Bordeaux and Senegal, felt a sensation of pressure on the left side of the thorax, and suffered from a dry cough and dyspnœa: there were neither night-sweats nor fever. The foreign bodies consisted of nucleated fusiform organisms of varying size (0.018-0.020-0.060-0.100 in length) and large round or oval cysts, which either contained the above-mentioned little bodies exclusively, or exhibited, in addition, an irregular residual body with numerous nuclei. Further observations could not be made. Blanchard regards the fusiform bodies as merozoites and the cysts as schizonts of a coccidium; whereas Moniez is of opinion that 
they represent parts of echinorhynchus (ova and floating ovaries). (Künstler, J., and Pitres, A.; "Sur une psorospermie trouvée dans une humeur pleur" [Journ. d. microgr., I 884, viii., p. 469] ; Blanchard, R., "Les Cocc. et leur rôle pathog." [Caus. scientif. soc. zool., France, 1900, "No. 5] ; Moniez, R., Traité de parasitol., Paris, I 896, p. 52).
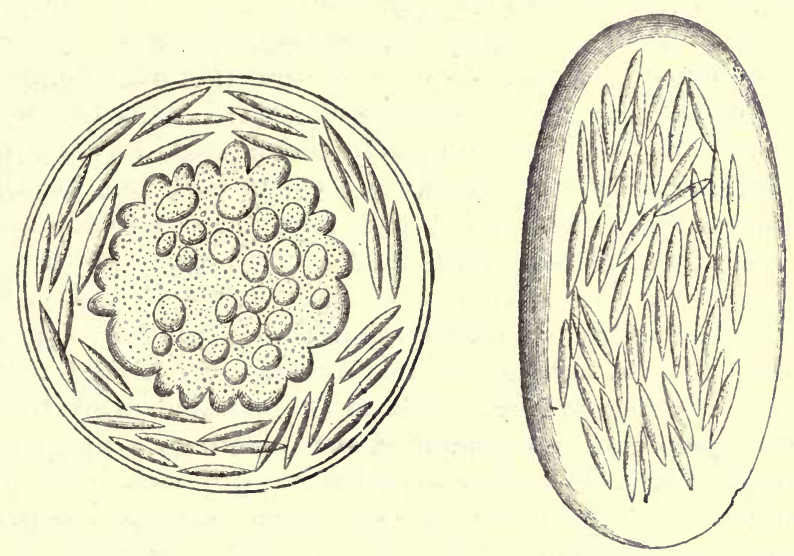

FIG. 35.-Coccidia (?) from the pleural exudation of a man=Eimeria hominis, R. Blanch. (After Künstler.)

(2) Coccidioides immitis and Cocc. pyogenes, Rixf. et Gilchr.-R. Wernicke describes round bodies, with shells $0^{\circ} \mathrm{OO}_{3}-\mathrm{O}^{\circ} \mathrm{O} 3 \mathrm{O} \mathrm{mm}$. in diameter, discovered by his pupil, A. Posada, to the number of ten, in the giant cells of granular proliferations situated in the corium. The patient, a native Brazilian soldier, exhibited a great many uneven protuberances on the skin of the face which were diagnosed as mycosis fungoides. In the case of an apparently identical cutaneous disorder in a man, aged 40, whose disease had already persisted for eight or nine years, Rixford and Gilchrist performed the autopsy and found similar bodies not only in the nodules, but in the lungs, liver, kidneys, genitals and lymphatic glands. They measured $0.016-\mathrm{O}^{\circ} \mathrm{O} 3 \mathrm{O} \mathrm{mm}$. in diameter, and in their developed state were sur. rounded by a capsule with double outline, and had granular protoplasmatic contents, but exhibited no nucleus. The coccidial nature of these foreign bodies appears somewhat more probable from the fact that the author states that he saw as many as Ioo merozoites in each schizont. In a second case, of a man, aged 33, the disease started with an eruption on the forehead; soon nodules appeared in the skin, and after only two months the lymphatic glands were affected. The patient died three months after the commencement of the disease. On examination, coccidia-like bodies, $0.020-0^{\circ} 035 \mathrm{~mm}$. in diameter, some of which were in the act of schizogony, were also found in the nodules. The authors consider that the parasites of the one case differ specifically from those of the other case, and therefore give them different names; whether, however, they related to coccidia or sporozoa, it may be surmised that in all three cases only onE species came under observation. (Wernicke, R., Uber einen Protozoënbefund bei Myc. fung. [C. f. B. u. P., 
1892, xii., p. 859]. Posadas, A., "Psorospermiosis infest. generalizada" [In.Diss., Buenos-Aires, I 894] ; "Ensayo sobre una nuova neoplasia del hombre . . . " Buenos-Aires, 1897-98. Rixford, R., and T. C. Gilchrist, "Two Cases of Protozoan [Coccidial] Infection of the Skin and other Organs " [Johns Hopkins Hosp. Rep., 1897, i., pp. 209, 269, 291] ; ref. in C. f. B., P. u. I., 1897, I, xxi., p. 812. Also Blanchard, R., Les coccid. et leur rôle pathog., Paris, 1900).

(3) An observation of Jürgens appears to me to be still less attributable to coccidia. At the autopsy of a patient who died in the Charite in Berlin, greyish-yellow growths were found on the dura mater cerebralis and spinalis, as well as on the cauda equina; the walls of the calices and renal pelvis were thickened and similarly discoloured, but not those of the ureters and bladder. In the neoplasms, which were but slightly vascular, various shining bodies were found, of which some resembled myelin and some starch grains, and some of which had shells. A few experimental inoculations were undertaken on rabbits, several of which soon died from pleuropneumonia; one exhibited after four months a rapidly-growing proliferation of the left eye. At the autopsy of this animal, which died a month later, medullary tumours were found not only in the eye and orbit, but also in the lungs, kidneys, epididymis and glands of the mesentery; the peritoneum was greatly affected. The little bodies regarded as protozoa were not lacking; but in consequence of their very diverse shape they can hardly be looked upon as independent organisms, but they probably appertain to those products of the organism which frequently occur in proliferations, and have been repeatedly described as parasites (Jürgens, "Ueber Erkrank. d. Protoz. b. Menschen." [Berl. klin. Wochenschr., I895, xxxii., p. 33I]).

(4) It is advisable to mention here that the "psorosperm cysts," mentioned in the last edition of this book (p. 8I), and which are supposed to play a part in the diseases of the urethra and the pelvis of the kidney, have been assigned to their proper place, especially by Lubarsch and Ribbert; they are metarmophoses of cells of the epithelial nests, which are present normally, especially in the urethra (cf. Radtke, E., "Beitr. z. Kenntn. d. Uret. cystica," in Diss. Königsberg i. Pr., I900).

(5) Severi's "Monocystide Gregarines." The pulmonary parenchyma of a stillborn child was found by Severi to be infiltrated with numerous oval, reddish little bodies, the size of which varied in length between 0.003 and $0.030 \mathrm{~mm}$., and in breadth between 0.0015 and $0.015 \mathrm{~mm}$. They were surrounded by a thin investing membrane, and mostly lay free in the tissue ; the smallest ones lay also in the epithelial cells and in the bloodvessels. The largest parasites exhibited a granular plasm, and occasionally an eccentrically situated nucleus the size of a red blood corpuscle (Severi, A., "Gregarinosi polmon. in Infante natomorto" [Rif. med., 1892, ii., p. 54; Boll. Accad. med. Genova, 1892, vii., No. 2]).

\section{Order 3. Hamosporidia.}

In the same manner as our knowledge of the development of the coccidia has advanced during recent years, so the same has occurred with the Hæmosporidia. The first communications (I) respecting the parasites inhabiting the blood or rather the blood corpuscles of vertebrates, remained 
unheeded, although they confirmed the occurrence of foreign bodies, compared by Lankester (1) to pseudo-navicella (spores of gregarines), in the blood of amphibia. It was only after Gaule (2) had rediscovered the "little blood-worms" (cytozoa) that more general attention was directed to the matter, perhaps because of the interpretation given by the author to his discoveries, and they were declared io be normal constituents of animal cells.

In contradiction, Ray Lankester (3) declared that the cytozoa were of a parasitical nature and gave the name of Drepanidium ranarum to the species observed in the frog, which Chaussat ${ }^{1}$ had called Anguillula minima. In this case he considered the parasite to represent a developmental stage of a still unknown gregarine. Their independent nature was finally confirmed by the works of Danilewsky (4); this investigator discovered analogous forms in the blood of lizards (Lacerta viridis and L.agilis) and of tortoises (Emys lutaria), and he described their development, which takes place in the blood.

Several years previously a French military doctor in Constantine, by name A. Laveran (5), had observed hyaline pigmented forms in the fresh blood of malarial patients- clinging to the-red blood corpuscles. On noticing the appearance of "flagclla" on these organisms which suddenly made lively movements, the thought occurred to him that they were the parasites (first termed Oscillavia malarice and later Hamatozoon malaria of malaria, intermittent fever, ague). Although Richard (6) soon after confirmed Laveran's discovery and extendec it by finding the still unpigmented early stages, these communications were subjected to lively opposition, because at this period it was generally believed that malaria was caused by a bacillus (Klebs, Tommasi-Crudelli). The investigators who afterwards pursued the subject (Marchiafava, Celli, \&c.), asserted that the objects seen were merely evidences of degeneration of the red blood corpuscles, the hæmoglobin of which was changed into melanin without the intervention of a parasite. However, when Marchiafava and Celli (7) saw the amoboid movements of Laveran's parasites they fully recognised their animal nature. The name Plaswodium malaria, usually given to the malarial parasites, emanated from these authors, and although unsuitable, according to the rules of nomenclature, it replaces the older and valueless term Oscillaria, and is still in use.

On the abandonment of the opposition to Laveran's doctrine, numerous authors commenced a careful study of the malarial parasites, so that by the beginning of the 'nineties certain conclusions had been arrived at. We had learned to know the difference of the parasites that caused the various forms of malaria, as well as their development in the blood, and confirmed the fact that the blood of malarial patients inoculated into healthy persons produced in the latter malaria of the same type as that from which the patient suffered (Gerhardt (8) Bignami and Bastainelli (9) and others). After Danilewsky (10) discovered the occurrence of disease-producing endoglobular

'Neither the name of the genus nor species can be retained, the former because already in 1869 it was given to an infusorium by Ehrenberg, and the latter because the species had already been named by Chaussat in 1850 . Labbé has, therefore, given to Drepanidium, Jank., the name of Lankestevella; the correct designation of the species is therefore Lankesterella minima (Chauss.). 
parasites in birds, investigators directed their attention to the study of the hæmosporidia of birds, Grassi and Feletti (II), Celli and Sanfelice (I2), Kruse (I3), Labbé (14). The last-mentioned author also demonstrated the existence of analogous forms in reptiles and amphibious animals in a masterly way.

Several authors gained great credit in collecting and compiling the scattered and fragmentary knowledge contained in a great quantity of literature. Amongst the works of these authors (I 5), Mannaberg's (16), which includes his independent personal researches, is highly commendable, as is also Ziemann's book (17). These works should be consulted for the literature not mentioned here.

The conclusions arrived at, however, still left many important questions unanswered. Nobody was in a position to state with any certainty in what manner the infection of man (apart from that of animals) was brought about, nor were tîtere any well-grounded demonstrations of how the cause of malaria, according to analogy with other parasites, left the body of the host, nor what was its subsequent fate. Neither of the theories advanced explain the matter; for even conceding the existence of malarial germs in the air and their invasion of the human body by way of the air passages, it remained an enigma why the germs should only occur at a slight elevation above the soil, or should only exist in certain compartments of many houses, or why they were not distributed in all directions by currents of air, \&c., \&c.

The last few years have thrown light on this subject. Several investigators, working almost simultaneously and partly quite independently, have come to the conclusion that blood-sucking animals play a part in malaria. For certain reasons a few blood-suckers could be rejected at once, others, such as mosquitoes, appeared to be particularly suspicious. ${ }^{1}$ Manson (18) was the first to call attention to the mosquito, knowing from his own experience the part played by these insects in the further development of the filariæ of the blood of man. Here, as in malaria, the mosquitoes are supposed to suck up the parasites with the blood of human beings and to void them ultimately into the water, so that hereby there is at least the possibility of infection of other hosts. Bignami (19) was of an exactly opposite opinion as to the rôle of the mosquito, which had been, in Italy, brought in to connection with malaria ages since, a belief which, according to Koch (20), was also shared by the natives of Africa. Supported by the experimental inoculations first undertaken and subsequently repeated by Gerhardt, Bignami gave it as his opinion that mosquitoes having themselves become infected by a still unknown stage of malarial parasites occurring in the open, inoculated them into man with their bite. This opinion, which was supported by the part played by ticks (Boophilus bovis) " living on cattle in the transmission of the agent of Texas fever (Piroplasma bigeminum), seemed to explain many obscure points, but the experiments conducted by Bignami and Dionisi to substantiate this view gave negative results.

R. Koch (20) combined the respective theories of Manson and Bignami,

${ }^{1}$ Nuttall, G. H. F., "Die Mosquito-Malariatheorie" (C. $f$. B., P. u. I., ז899, xxv., pp. I61, 209, 245, 285, and 337 ).

${ }_{2}^{2}$ The correct name of this Tick is Rhipocephalus annulatus (Say). The disease is called Redwater in Africa, and is known by this name in other places. In Africa the carrier is $R$, decoloratus (Koch), in Germany Ixodes reduvius acts as carrier. (F.V.T.). 
and referred also to the analogy of the trypanosomiasis of cattle which is transmitted by the tsetse-fly; nevertheless, Koch likewise could furnish no proof.

Ross (2I), inspired by Manson, first succeeded in following the development of the plasmodia that had reached the stomach of the mosquito with the blood of malarial patients, especially after he had made Proteosoma (Hamoproteus) living in birds the subject of his investigations. $\mathrm{He}$ found that the proteosoma in the stomach of the mosquito penetrate into the intestinal wall, grow into large cysts and produce innumerable rodshaped spores, which are set free in the body cavity of the mosquito by the bursting of the cysts, and then make their way into the salivary glands. When Ross allowed mosquitoes to suck the blood of infected birds, and about nine days later fed on healthy birds the infected mosquito that had been kept isolated, proteosoma were discernible in the blood of the birds five to nine days later.

These researches confirmed the mosquito-malaria theory, at all events as regards the malaria of birds, and its application to human malaria became more evident. At this stage Italian investigators, especially Grassi, took up the subject, and this scientist succeeded not only in demonstrating that certain species of the genus Anopheles, especially A. claviger, Fabr. $=A$. maculipennis, Meig., ${ }^{1}$ inoculate malaria to man by means of their bite just like species of the genus Culex are the carriers of proteosoma infection amongst birds, but he also followed the development of the parasites in the body of the mosquito more carefully than had hitherto been done (22). The commissions" despatched for the study of malaria on the spot and numerous independent scientists, gathered fresh knowledge, so that the literature on the subject has acquired enormous dimensions, notwithstanding the short time that has elapsed since the investigation of malaria began. The researches as to the structure and habits of mosquitoes and the methods recommended for the prevention of malaria are continually being extended. Although it is most gratifying to note the large number of workers engaged in the solution of the problem of malaria, which is one of great importance to mankind, the occasional premature conclusions arrived at, and which lead to the publication of immature work, is to be deplored, as they frequently mislead more sober investigators.

After all these works, the following facts may be briefly stated in regard to the malaria parasites. What had hitherto been known of them related to their schizogony and a few erroneously understood stages, which were actually related to sporogony (crescents, spheres, polymitus-form). By means of their bite certain species of mosquitoes introduce the crescents and spheres into their bodies with the blood. If the atmospheric temperature is sufficiently high, these forms become sexually differentiated, and after the females

The name claviger (Fabricius) used in Italy cannot stand. Fabricius had no type of claviger. (F. V. T.).

" "Ergebn. d. viss. Exped. d. Geh. Rath Koch nach Italien z. Erf. d. Malaria" (Dtsch. med. Wochenschr., 1899, p. 69); i.-v. "Ber. ub. d. Thütigk. d. Malaria-Exp." (ibid., p. 601, 1900, Nos. 5, 17, 18, 25, 34, and 46); "Zusammenfass. Darst. d. Ergebn. d. MalariaExp." (ibid., Nos. 49, 50). Ray, Annett and Austen, "Report on the Mal. Exp. of the Liverpool School of Tropical Medicine," Liverpool, 1900. 
(macrogametes) have been fertilised by the males (microgametes) they sporulate. The sporozoites ultimately collect in the salivary glands of the mosquitoes, and are inoculated into the blood of man or bird by means of the bite; here they again multiply by schizogony and thereby cause the disease.

Accordingly, certain species of mosquitoes are the definitive hosts of the malaria parasites, because the adult stage is passed in them; and warm-blooded animals are the intermediary hosts.

Hæmosporidia, in addition to their incidence in man and birds, also occur in monkeys [Kossel (23)] and bats, [Dionisi (24)], the alternative hosts, however, of these species are not yet known. It is doubtful whether the parasites causing the Texas fever of cattle (Piroplasma bigeminum, Smith), which Babes discovered and on which Celli and Santori recently reported (C. t. B. P. u. I., I897, xxi., p. 56r), are real Hæmosporidia. According to Babes, Laveran and Nicolle, analogous forms occur in sheep; according to Piana, Galli-Valerio, Leblanc, Marchoux, Nocard and Almy, they are found in dogs. (The two last-mentioned authors, in fact, suggest that ticks play a part in the piroplasma infection of dogs), according to Laveran they occur in horses, and according to Lignières several species of Piroplasma live in cattle.'

The development of the Hæmosporidia of cold-blooded animals, reptiles, amphibia and fishes, seemed amply known through Labbé's great work (I4); later works did not with certainty disclose any other circumstances, though in consequence of the discoveries concerning the malaria parasites of warm-blooded animals we began to doubt the completeness of our knowledge of the Hæmosporidia of cold-blooded animals. These doubts have been fully justified by the appearance of the only book treating of Lankesterella minima (= Drepanidium ranarum) by Hintze (25), for in these parasites there is an alternation of generations, without, however, a change of hosts. Schizogony and sporogony, according to the author, go on simultaneously within the same host, and the oocysts filled with sporozoites, which mature in the intestinal epithelium of the host, make their escape with the contents of the intestine into the open, whence they cause the infection of other hosts, probably per os.

\section{LITERATURE.}

(I) Chaussat. Des hénatozoaires. Thèse, Paris, 1850.

Ray LANkester. On Undulina the Type of a New Group of Infus. (Quart. Journ. Micr. Sc., I871, xi., p 387 ). 
Osler, W. An Account of Cert. Org. Occurr. in the Liquor Sanguinis (Proc. Roy. Soc., London, 1874, xxii., p. 391).

Bütschli, O. Einige Bemerk. über d. rothen Blutk. d. Frosches (Abh. d. Senckenb. nat. Ges. Frankf. a. M., I876, p. 49).

LEWIS. (Quart. Journ. Micr. Sc., I879, xix., p. IO9).

(2) Gaule, J. Ueb. Würmchen, welche a. d. Froschblutkörp. auswandern (Arch. f. An. u. Phys., phys. Abth., I880, p. 57).

Die Beziehungen d. Cytozoën zu d. Zellkernen (ibid., I 88I, p. 297).

Kerne, Nebenkerne u. Cytozoën (Centralbl. f. d. med. Wiss., i88 I, p. 56r).

(3) Ray Lankester. On Drep. vanarum . . . (Quart. Journ. Micr. Sc., 1882, xxii., p. 53).

(4) Danilewsky, B. Die Hæmatozoën d. Kaltblüter (Arch. f. mikr. An., I885, xxiv., p. 588).

Matér. pour servir à la paras. du sang (Arch. slav. de biol. I886, i., pp. 89, 364; I 887, ii., pp. 33, I 57 and 370 ; Biol. Centralbl., 1885, v., p. 529).

(5) Laveran, A. Note sur un nouv. paras. trouvé dans le sang de plus. mal. atteints de fièvre pal. (Bull. Ac. méd., 1880, Nov. 23 and Dec. 28).

Nat. paras. des accid. de l'impaludisme, Paris, I $88 \mathrm{I}$.

Des paras. du sang dans l'impalud. (C. R. Ac. sc. Paris, I882, xcv., p. 737).

(6) Richard, E. Sur le paras. de la malaria (C. R. Ac. sc. Paris, I882, 20, ii.).

(7) Marchiafava and Celli. Fortschr. d. Medicin. I885. Nos. I i and 24.

Nuove ric. sulla inf. malar. (Arch. p. le sc. med., I886, ix. ; 1888 , xii. ; I 889 , xiv.).

Nouv. ét sur l'infect. mal. (Arch. ital. de biol., I887, viii., p. I31).

(8) Gerhardt. Ueber Intermittens-Impf. (Zeitschr. f. klin. Med., I 884, vii.).

(9) Bignami and Bastanielli. Stud. s. inf. mal. (Boll. R. Ac. med. Roma, i893-94, $\mathrm{xx}$.).

(io) Danilew'ský, B. Zur Parasitol. d. Blutes (Biol. Centralbl., i 885-86, v., p. 529).

La parasitol. comp. du sang., Charkow, 1889. (Russ.).

Développ. d. paras. malariques dans les leucocytes d. oiseaux (Ann. Inst. Pasteur, 1890, p. 427).

Sur les microb. d'infect. malarique aiguë et chron. chez les oiseaux et chez l'homme (ibid., p. 753).

Contrib. à l'étud. de la microbiose malarique (ibid., I89I, p. 758).

Ueb. d. Polymitus malariae (C. f. B. u. P., I 89I, ix., p. 397).

(II) Grassi, B., and R. Feletti. Malariaparas. in d. Vögeln (C. f. B. u. P., i89i, ix., pp. 403, 429, 46r).

Weiteres zur Malariafrage (ibid., I89I, x., pp. 449, 48I, 5 I 7 ).

Contribuz. allo stud. dei parass. malarici (Atti Accad. gioenia sc. nat. Catania, I $892[4]$, v.).

(12) Celli, A., and F. Sanfei.ice. Sui parass. d. globulo rosso nel nomo e negli anim. (Ann. istit. d'igiene esperim., Roma. N. S. I., I89I, and Fortschr. d. Med., I 891, Nos. I2-1 5$)$.

(13) Kruse, W. Ueb. Blutparas. (Virchow's Arch. f. path. An., I890, cxx., p. 45 I, and cxx., p. I 359).

(14) LABbE, A. Rech. zool. et biol. sur les paras endogl. du sang des Vertébrés (Arch. zool. exp. et gén., I 894 [3], ii., p. 55).

(1 5 ) Spener, C., in Biol. Centralbl., xi., p. 390.

LAVERAN in Report of the XII. Internat. Congr. for Hyg.-Demogr., \&c., London.

BARBACcI in Centralbl. f. allg. Path., I893, iii., p. 49.

(16) Mannaberg, J. Die Malariaparasiten. Vienna, I893.

(i7) Ziemann, H. Ueb. Malaria-u. andere Blutparas. Jena, I898.

(I8) Manson, P. The Goulstonian Lecture on the Life-history of the Malarial Germ outside the Human Body (The Lancet, I896, i., pp. 695, 75 I, 83 I).

Hypotheses as to the Life-history of the Malarial Parasite outside the Human Body (ibid., 1896, ii., p. I7I5).

(19) Bignami, A. Hypotheses as to the Life-history of the Malarial Parasite outside the Human Body (The Lancet, I896, ii., pp. I 363 , I44I).

(20) Косн, R. Aerztl. Beob. in d. Tropen (Verh. d. deutsch. Colonial-Ges. Abth. Berlin-Charlottenberg, 1897-98. No. 7, p. 280).

Reiseberichte über Rinderpest. Berlin, I 898.

(21) Ross, R. On some Peculiar Pigmented Cells found in Two Mosquitoes Fed on Malarial Blood (Brit. Med. Journ., I 897, ij., p. 1786).

The Rôle of the Mosquito in the Evolution of the Malaria Parasite (The Lancet, I 898 , ii., p. 488).

Report on the Cultivation of Proteosoma in Grey Mosquitoes. Calcutta, I898. 
(22) Grassi, B. Several Notes in the Rendic. R. Acc. Lincei. Roma, Ser. 5, vols. vii. and viii., 1898 .

Le recente scoperte sulla malaria esposte in forma popolare. Milano, I899.

Studi di un zoologo sulla malaria (Atti R. Acc. Lincei. Mem. Cl. sc. fis. Ser. 5, vol. iii., Ann. ccxcvi., I900); in and edition, Rome, I90I; translated into German and entitled Die Malaria, Stud. eines Zool. Ist edition, Jena, I900; 2nd edition; Jena, I901.

Bastianell, Bignami, Celli, Dionisi and others either participated in Grassi's labours or worked independently: the works of these authors appeared partly in the Rendic. R. Acc. Lincei, Roma, partly in the "Atti soc. per gli. stud. della malaria," and partly independently.

(23) Kossel, H. Ueber ein. malariaähnl. Blutparas. bei Affen (Zeitschr. f. Hyg. u. Inx́., I 899, xxxii., p. 25).

(24) Dionisi, A. La Malaria di alcune specie di pipistrelli (Ann. d'igiene sperim, N. S., ix., I899).

(25) Hintze, R. Lebensweise u. Entw. d. Lankesterella minima (Zool. Jahrb. An., 1902, part xv., p. 693; also during the In.-Diss, Berlin, I901.

\section{The HæMOSPORIDIA OF MAN.}

The disease induced in man by Hæmosporidia (MALARIA, INTERMITTENT FEVER, AGUE OR CHILL-FEVER) is, apart from waterless deserts and the polar regions, distributed over the entire surface of the globe, but not equally, and it appears in various forms. The rhythmical course of the fever is characteristic; it sets in suddenly with a sensation of cold or with a rigor, in a few hours the temperature rises to 40 or $4 \mathrm{I}^{\circ} \mathrm{C}$., and remains at this for some hours, during which time the patient himself feels the increased bodily temperature (dry tongue, heat, headache); then the temperature falls rapidly, often to below normal, accompanied by profuse perspiration. There is, moreover, sensitiveness to pressure in the region of the spleen, and the spleen itself is enlarged. After the attack, the patient feels somewhat languid, but otherwise he is quite well until another attack supervenes. The attacks may recur daily (febris quotidiana), or one day may be free (febris tertiana), or two days may elapse between the attacks (febris quartana); thus the fever appears only on the third, fifth and seventh day, or the fourth, seventh, tenth day, and so on, respectively. Two types of tertian fever are clinically differentiated: the mild "spring tertian fever" that appears in the spring, and the severe "æstivo-autumnal fever," which is identical with "tropical malaria." This fever is also termed the malignant or pernicious form, because its paroxysms being protracted approach each other more, and thus give rise to a continuous or subcontinuous fever. Not infrequently combinations occur; we thus hear of febris tertiana duplex, when the attacks certainly occur daily, but are distinguished from one another either by the different time at which they commence, or by different duration, different degree of the 
fever, \&c. The paroxysm of the first day with the same peculiarities then sets in only on the third and fifth days; the paroxysm of the second day is repeated only on the fourth and sixth days, and so on. In a similar manner two or three quartan fevers may combine, and there may be a febris quartana duplex or triplex.

In order to demonstrate the combinations of analogous fevers the following table, taken from Mannaberg's work, may prove useful :-

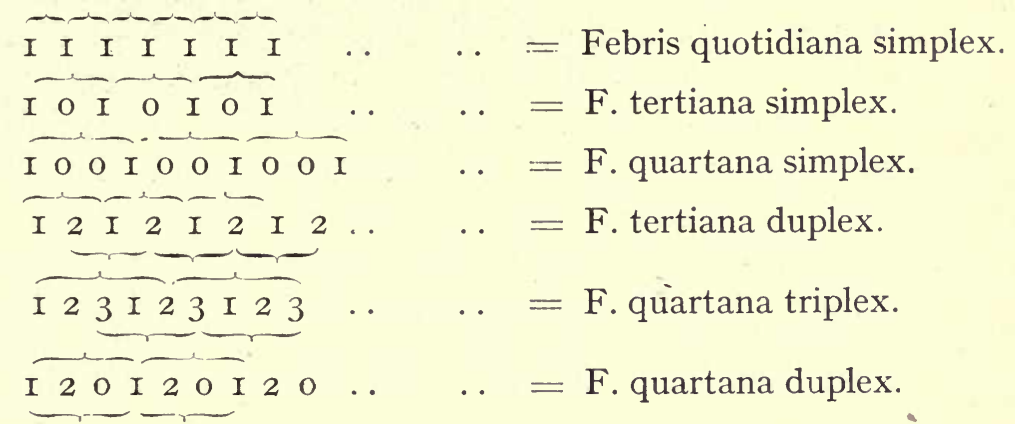

The equivalent figures connected by brackets represent the separate paroxysms of fever, whilst the o represents the afebrile day.

It has not yet been quite determined whether the so-called BLACKWATER FEVER belongs to the group of malarial fevers, but according to Plehn's statements this appears to be the case, as, at all events at the commencement of the disorder, Hæmosporidia are met with in most of the cases: they certainly, however, disappear very soon, in consequence of the enormous disintegration of blood corpuscles that takes place in this disease.

Finally, we speak of "MASKED FORMS of malaria" when there are disturbances of the general health that have a periodical character and yield to quinine. Nevertheless, only those cases should be reckoned as malaria the diagnosis of which is confirmed by the examination of the blood, i.e., by the discovery of Hæmosporidia.

Different Hæmosporidia correspond to the different types of malaria, and may be regarded either as varieties of one species or as distinct species $;^{1}$ the latter view appears to be in accordance with the present condition of our knowledge.

1 In addition to the literature mentioned above, the following may be cited: Golgi, C., "Sull' inf. malar." (Arch. p. le. sc. med., r886, x., p. I04) ; " Ancora sull inf. mal." (Gaz. d. ospid., 1886, No. 53); "Sul ciclo evelutivo dei par. mal. . . ." Arch. p. le sc. med., 1889, xiii., p. 173, and Fortschr. der Med., r889, No. 3); Mar- 


\section{Plasmodium malaria (Laveran).}

Syn.: Oscillaria malaria, Laveran, I883; Plasmodium, var. quartana, Golgi, I890; Hamamoba malaria, Grassi and Feletti, I892; Hamamceba laverani, var. quartana, Labbé, I894 ; Plasmodium malaria quartanum, Labbé, I 899.

This species is the cause of quartan fever, and is therefore also frequently termed the oUARTAN PARASITE. Soon after the paroxysm a small unpigmented body with sluggish amoboid movement is found on the red blood corpuscles. Whilst gradually growing the parasite penetrates within the blood corpuscle, and about twentyfour hours after the attack it commences to form the first fairly coarse grains of melanin, which are mostly situated at the periphery. As the pigment increases and the parasite grows-forty-eight hours after the attack it measures from one-half to two-thirds the size of the blood corpuscle-the movements become more sluggish and are finally entirely arrested. Sixty hours after the first paroxysm and twelve hours before the next one the plasmodia, which resemble discs, completely fill the blood corpuscles and only a
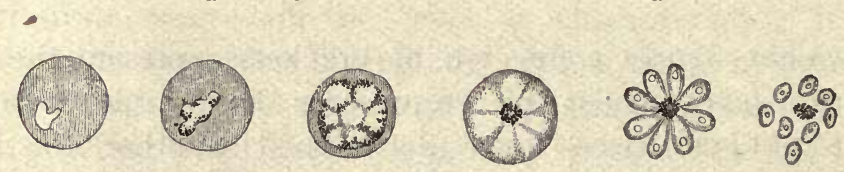

FIG. 36. - The development of the quartan parasite in the red blood corpuscles of man. (After Mannaberg or Golgi).

narrow rim is left, which later on also disappears. Schizogony then commences (six hours before the paroxysm); the grains of melanin are arranged radially, and then all crowd towards the centre of the disc, the peripheral part of which thereby becomes pigmentless, and one observes a spoke-like design, which indicates the radial segmentation of the disc; this becomes more and more distinct and finally leads to the segmentation of nine to twelve pear-shaped bodies placed wheel-like-the merozoites. These finally separate from the central heap of melanin and from each other, and by attacking fresh blood corpuscles induce the subsequent paroxysm of fever. The melanin grains are taken up by the leucocytes and are mostly deposited in the spleen, though also

chiafava and Bignami, "La quotid. e la terz. est.-aut." (Rif. med., I891, No. 217); "Le febre mal. est.-aut." (Boll. R. Acc. med. Roma, 1892, xvii ; Dtsch. med Wochenschr., 1892, No. 51. Grassi and Feletti, "Contrib. allo stud. d. par. mal." (Atti Acc. Gioen. Catania, 1892 [4], v., p. I ; Bastianelli and Bignami, " Sulla strutt. d. par. mal.

(Atti soc. stud. d. ma!., I 899, i.). Further literature by Mannaberg; Grassi, Celli, Labbé, Lühe, Ziemann, \&c. 
sometimes in the bone marrow, \&c.; this is therefore the cause of the well-known pigmentation of the spleen in persons who have suffered from malaria.

The entire increase by schizogony takes place in the circulating blood and occupies seventy-two hours. The blood corpuscles attacked become neither enlarged nor pale. If suitable methods for staining are used one succeeds in demonstrating in all stages the nucleus in the plasmodium as well as the stages of segmentation of the nucleus in schizogony.

It is very seldom that in examining the blood of persons suffering from quartan fever one comes across other forms (spheres, polymitus).

The appearance of quartana duplex or triplex is explained by the circumstance that two or three generations of parasites, with a difference of twenty-four hours in their development, are present in the blood. Irregularities in the duration of the development of the parasites obscure the regular character of the disease.

\section{Plasmodium vivax (Grassi and Fel.).}

Syn .: Hamamoba vivax, Gr. et Fel., I 892 ; Plasmodium, var. tertiana, Golgi, I889; Hamamceba Laverani, var. tertiana, Labbé, I894 ; Plasmodium malarice tertianum, Labbé, I 899.

This species is the cause of spring tertian fever; it is distinguished from Plasmodium malaria first, by the shorter period (forty-eight hours) occupied in schizogony; secondly, by the greater activity of the amœboid movements which do not even cease on being exposed to room temperature, and by the fact that many of the melanin-bearing stages are visible; moreover, the affected blood corpuscles become enlarged and lose their colour.' The stages of schizogony are rarely found in the circulating blood, but frequently occur in the spleen. During the process there is no wheellike arrangement of the merozoites, which lie in a roundish heap about the pigment residue; they are smaller than those of Plasmodium malaria and are fifteen to twenty in number. The spheres that come under observation in this type attain a size double that of a red blood corpuscle, and are plentifully supplied with coarse

\footnotetext{
${ }^{1}$ On staining according to Romanowsky's method a peculiar stippling of the affected blood corpuscles appears (Schüffner, Deutsch. Arch. f. kl. Med., 1899, lxiv.. p. 428 ; Maurer, C. f. B., P. $\because$ I., I900, xxviii., p. II 4 ).
} 
and even rod-shaped pigment granules, which are actively turmoiled. The polymitus form may be observed in the moist chamber.

Irregularities sometimes occur also in the schizogony of this species. The occurrence of two generations separated by about twenty-four hours brings about tertiana duplex.

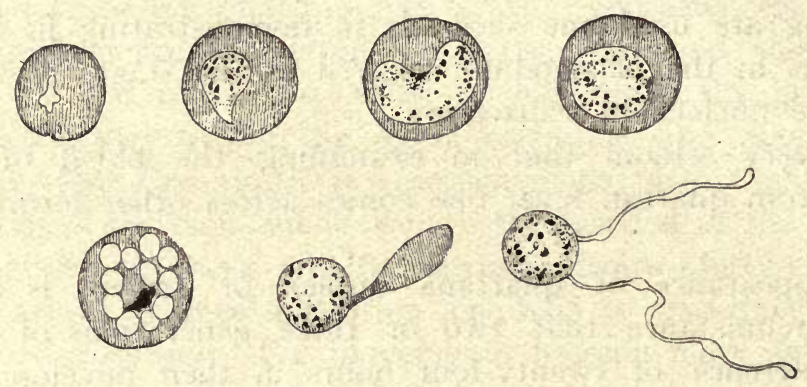

Fig. 37.-The development of the tertian parasite in the red blood corpuscles of man; to the right a "polymitus." (After Mannaberg.)

\section{Plasmodium, $s p .^{1}$}

Syn.: Laverania malaria, Gr. and Fel., I890; Hamamaba malaria pracox Grassi and Feletti, 1892, nec. Ham. pracox, Gr. and Fel., I890.

This parasite is the cause of æstivo-autumnal or tropical fever (also termed febris perniciosa s. maligna, tertiana maligna, febris tropica, febris bidua, also febris quotidiana). The parasite is very small and at most only occupies the third part of a blood corpuscle; it is, moreover, very active; its pigment is very finely granular; very frequently also, at all events more frequently than in other plasmodia, it assumes an annular form, the bodily substance in the centre becoming attenuated and finally tearing through. The development by schizogony normally occupies a period of forty-eighty hours, but the corresponding stages are seldom seen in the peri-

The correct terminology of this species is still unsettled. Grassi and Feletti have certainly called it Laverania malaria, but I see no reason that a particular species should be set up. Besides, this species belongs to the genus Plasmodium. Within this genus there already exists a species, "malariæ" (Laveran), the quartan parasite, and consequently the Grassi-Fcletti denomination of species cannot again be used in the same genus. For this reason other authors, such as Doflein, use the special term of "præcox," which also originates from Grassi and Feletti, combined with Hamamoeba. But in the same work (Boll. mens. Accad. Gioenia sc. nat. Catania, 1890, and C. f. B. u. $P ., 1891$, ix.) they term Hamam man. As the identity, however, of these forms has not been proved, and is not even probable, the term Hamamoba pracox can only be applied to one or the other, and should hold gcod for the hæmosporidium of birds as being the first mentioned in the text. Neveu Lemaire (Les hématoz. du paludisme, Paris, Igor) uses the most practical term, i.e., Hamatozoon falciparum, Welch. 
pheral blood as they are gone through in the spleen, liver, bonemarrow and cerebral capillaries. The latter, indeed, are frequently crowded with plasmodia undergoing schizogony, thereby explaining the severe cerebral symptoms. The number of small merozoites, arranged spoke-like, average from seven to twelve, rarely more.

In this type of fever, Laveran's sickles or so-called crescents, are more frequently met with than in other fevers.
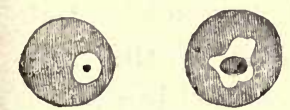

FIG. 38-The "pernicious parasite " in the red blood corpuscles of man. (After Mannaberg.)
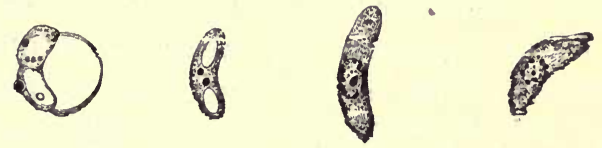

Fig. 39.- The crescents (Laverania) of the pernicious parasite. (After Mannaberg).

\section{Doubtful Species.}

The independence of the three foregoing species that are distinguished one from the other by their morphological and biological characteristics, has also been proved by the results obtained after inoculation of the blood of malaria patients into healthy persons; this can even be accomplished with very small quantities. After varying periods those inoculated always acquire malaria which is of the same type as that of the case from which the blood is taken.

According to Celli, and in opposition to the views of many authors, an actual quotidian fever occurs in summer and autumn, the agent of which is closely related to the Plasmodium of Tropical fever. The quotidian parasite is, however, smaller, has granules of pigment that are scarcely perceptible, and completes its cycle of development in the blood in twenty-four hours. Another very rare form has been observed by Celli and Marchiafava in Italy, and by Marchoux in the Tropics; it develops in less than twentyfour hours, without transforming the hæmoglobin into melanin. The independence of these two forms is questionable; they are mostly regarded as varieties of the plasmodia of tropical fever. ${ }^{2}$

\section{The Sporogony of the Malaria Plasmodia.}

Forms have already been mentioned in the above description of the malaria parasites of man that are incidentally met with, besides the stages of schizogony; these are the so-called SPHERES and CRESCENTS, or SiCKLes (fig. 39). They were found in blood just

${ }^{1}$ Celli, A., Die Malaria nach den neuesten Forsch., translated by Kerschbaumer, Berlin, Vienna, I900 (Celli, A., La malavia sec.le nuove ricerche., 2 nd edition, Rome, I900).

2 The same may hold good for Laverania limnhemica, the malaria parasite of the Cubans (Coronado, O. V., in Crónica med quir. de la Habana, I897, No. 6; and C. $f$ B., P. U. I., I 897 , xxii., p. 558). 
extracted from the body, not, however, in entirely fresh cases, but only after the illnes's has persisted for several days. Experience has also demonstrated that the crescents, which are only observed in malignant tertian fever, increase greatly if the disease is of long duration, and finally are the only forms present ; they also do not retain their shape, but become shortened to ovals, and at last become spheres. This process can be regularly induced by the addition of distilled water [Marshall (I)], or by breathing on the slide [Manson (2)]. Frequently also one may observe that some of the spheres (in abstracted blood) develop "flagella" that actively lash about and thus become the "polymitus": the flagella detach themselves, leaving behind an immovable lump of protoplasm with grains of melanin.

As all these processes were found to take place outside the circulating blood and to lead to final disintegration, and as nuclei were not visible, most investigators regarded the spheres, sickles and polymites as forms of degeneration of the malaria parasites. Only Mannaberg (3) stated that having seen indications of the union of two crescents he regarded these at any rate as representing conjugation forms.

The assumption of the absence of the nucleus was, however, erroneous. Sacharoff (4) first demonstrated the nucleus in spheres from the blood of crows, and also showed that the entire nuclear substance passes into the flagella when polymitus formation takes place. The experiments also undertaken by Ross on Manson's suggestion were very important; they demonstrated that crescents sucked up by mosquitoes from the blood of a man soon turned to spheres in the stomach, and about half of them were transformed into polymites. MacCallum (5) recognised the significance of the "flagella" in the Hæmosporidia of crows; he, like Opie (6) before him, found that there were two kinds of spheres, one kind with a coarsely granular protoplasm which became a vivid blue when stained with methylene blue, the other hyaline and scarcely stainable: the latter only becoming polymites. $\mathrm{He}$ observed that the actively moving flagella which detached themselves penetrated into the coarsely granular spheres, and thus the enigma was solved. The "flagella" whose origin and composition Bignami and Bastianelli ( 7 ) had traced in the plasmodium of the æstivo-autumnal fever are, accordingly, microgametes; the spheres are partly macrogametes, partly, so far as they become polymites, microgametocytes; and the polymitus is a microgametocyte at the moment of the development of the microgametes. 
Numerous works then followed, mostly relating to the sporulation of the plasmodium which takes place in the body of the mosquito" (Ross, "The Proteosoma of Birds in Species of Culex"; Grassi, "The Plasmodia of Man in Species of Anopheles" ; Bignami and Bastianelli (8), "The Tertian Parasites"; also Koch and others). Schaudinn (Io) pointed out the analogy with the development of the coccidia.

Schizonts alone are found in the blood of malaria patients in fresh infections. It is only after a certain time that, in addition, the gametes (crescents, sickles, or spheres) appear in gradually . increasing numbers. The difference between male and female individuals (microgametocytes and macrogametes) in the plasmodia of human malaria is not so great as is the case in the proteosoma of birds or in the coccidia.

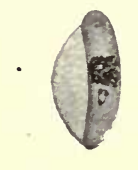

$a$.

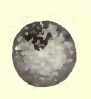

$h$,

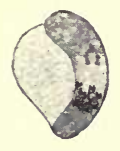

c.

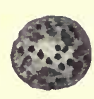

$d$.

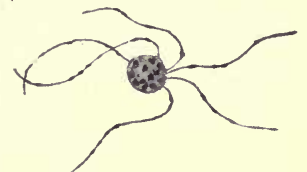

e.

FIG. 40.- Stages of development of the pernicious parasites in the intestine of Anopheles maculipennis (after Grassi). (a) Macrogamete (crescent) still clinging to the human blood corpuscle; (b) macrogamete (sphere) half an hour after the mosquito has sucked; (c) microgametocyte (crescent adhering to the blood corpuscle); (d) microgametocyte (sphere) half an hour after sucking (the nucleus is broken up); (e) microgamete attached to the residual body (polymitus stage).

When conveyed into the intestine of Anopheles they mature rapidly, and the filamentous microgametes, which are chiefly composed of nuclear substance, but have no flagella, penetrate into the macrogametes which, shortly before, have reduced their nucleus. The copula thus formed is not immediately transformed into an oocyst as is the case with the coccidia, but first becomes a motile fusiform body ("vermicule," Danilewsky, " ookinet," Schaudinn, fig. 4I), which bores actively into the intestinal wali of the mosquito's stomach, where it settles. A very delicate integument, which is probably a product of the host, then develops on the surface of the ookinet, which becomes round, and the oocyst is thus formed. The number of parasites in one mosquito may be very considerable. As they become gradually larger they project like protuberances beyond the outer surface of the posterior mid-gut, which is greatly dilated (fig. 42).

' For the classification, structure and life history of mosquitoes, see The Diptera. 
The development of the sporonts in mosquitoes (of the genus Anopheles) is dependent on the atmospheric temperature and the species of parasite. The plasmodium of the malignant tertian (tropical fever) completes its development within eight days at a temperature of $28-30^{\circ} \mathrm{C}$; ; below $18^{\circ} \mathrm{C}$. the development ceases. The same condition also holds good for Plasmodium vivax, whereas Plasmodium malaria requires a lower temperature, that is to say, it will still develop at $16.5^{\circ} \mathrm{C}$., but not if the temperature is over $30^{\circ} \mathrm{C}$.

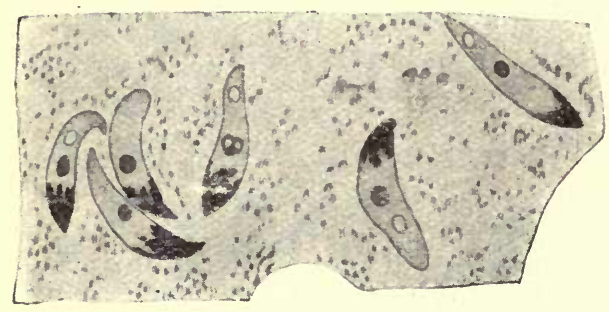

FIG. 4I.-Ookinets of pernicious parasites in the stomach of Anopheles maculipennis thirty-two hours after having been sucked in. (After Grassi.)

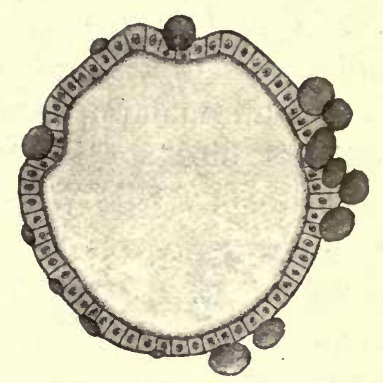

FIG. 42.- Transverse section of the stomach of an Anopheles, with cysts of the pernicious parasites. (After Grassi.)

The oocysts resting in the intestinal wall are at first oval, but with their further growth they become globular. First of all the nucleus within them divides up into a large number of daughter nuclei. A portion of protoplasm gathers round each one of these nuclei, and thus a number of mononuclear polyhedric cells are formed and connected one with the other by bridges of protoplasm which occupy the entire internal space of the cystic membrane (fig. 43, a). These cells may be termed sporoblasts, but contrary to the similarly termed forms in coccidia, they remain naked and immediately form the sporozoites. This process begins by a division of the nucleus in each sporoblast; the numerous daughter nuclei take up a peripheral position in the plasma of the sporoblasts and receive a thin coating of hyaline protoplasm. The entire substance of the sporoblast is not, however, consumed thereby; the larger part remains undivided, becomes elongated and granular; it represents a residual body which is surrounded by numerous roundish sporozoites (fig. $43, b$ and $c$ ). The sporozoites soon become small, elongated forms pointed at both ends, one of which still adheres to the residual body. The 
separation of the sporoblasts is never complete, and thus it may. happen that the residual bodies remain more or less connected together for a long time. It is only when the sporozoites are quite mature that a separation takes place; then the sporozoites, which are about o.oI $4 \mathrm{~mm}$. in length and are provided with an elongated nucleus, become detached from the residual body (fig. 43, d).

The size attained by the mature oocysts fluctuates between $0.03-0.09 \mathrm{~mm}$.; on an average, however, they seldom exceed $0.06 \mathrm{~mm}$. The number of sporozoites in each oocyst varies to a much greater exterit (between a few hundreds and over I0,000).

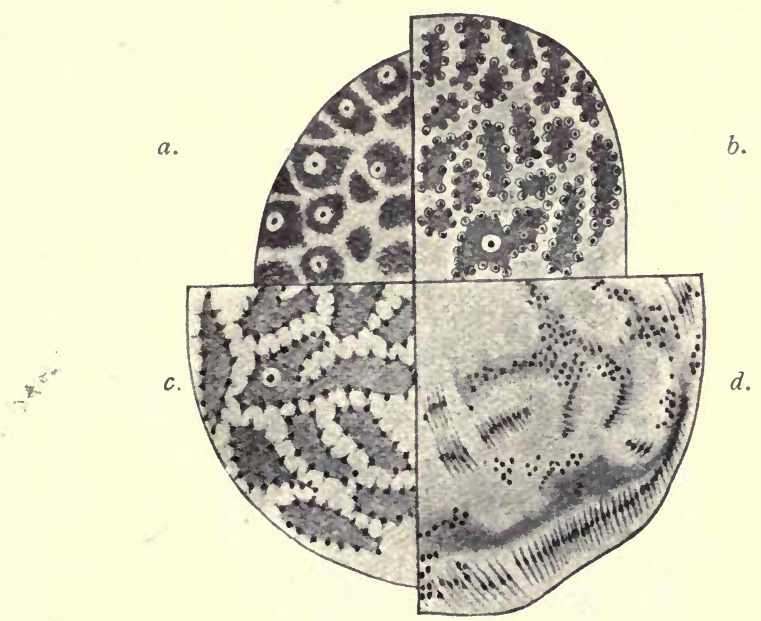

Fig. 43.-Four different stages of sporulation of malaria parasites from Anopheles maculipennis, strongly magnified. $(a-c)$ The pernicious parasite ; $(a)$ four to four and a half days after ingestion; $(b$ and $c$ ) five to six days after ingestion ; $(d)$ tertian parasites, eight days after ingestion. (After Grassi.)

According to all appearances the mature oocysts burst spontaneously and discharge their sporozoites into the body cavity of the host. Here they are distributed by the circulation of the blood, and after a few hours they already accumulate within the salivary glands. It has not been ascertained whether they penetrate actively or are drawn in by chemical action. In any case, according to Grassi and Ruge (Io) they possess specific movements which hardly differ from those of the sporozoites of coccidia, but are only observable when the atmospheric temperature is rather high.

During the process of puncture by the mosquitoes the sporozoites are introduced into the wound with the saliva, and by this means man becomes infected, as has been proved by experi- 
ment. It may be assumed that they are transformed directly into the amœboid form of the Hæmosporidia, and multiply by schizogony until their number is sufficiently great to produce the first paroxysm of fever. If a small number only happen to be present in the salivary glands of the mosquito they are all discharged with its first bite; in other-cases only a few are got rid of, so that under these circumstances one single Anopheles is capable of infecting several persons. The same mosquito also may repeatedly take up malarial plasmodia from sick persons, and thus may harbour simultaneously different stages of development, and thus repeatedly replenish its salivary glands with sporozoites.

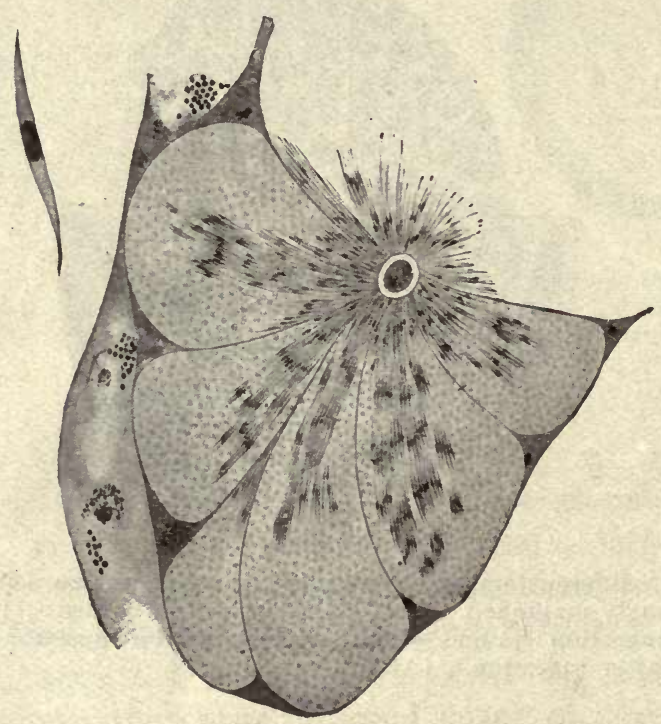

Fig. 44.- Section through a tubule of the salivary gland of an Anopheles, with sporozoits of the pernicious parasites; above an isolated sporozoit with higher magnification. (After Grassi.)

Research has demonstrated that: THE MALARIAL PARASITES OF MAN UNDERGO AN ALTERNATION OF GENERATIONS AND REQUIRE TWO DIFFERENT HOSTS FOR THEIR COMPLETE DEVELOPMENT; the asexual development (schizogony) takes place in the blood of man, the sexual development (SPOROGONY) in the body of species of the genus Anopheles. The transmission to man is effected exclusively by the bite of Anophelinæ, which harbour in their salivary glands the mature sporozoites of the various plasmodia: the infec- 
tion of Anopheles is effected exclusively by the mosquito sucking the blood of persons suffering from malaria. All hypotheses as to any other mode of infection do not hold good.

\section{LITERATURE.}

(I) Marshall, R. J. The Malaria Parasite (The Lancet, I896, ii., p. II87).

(2) Manson, P. A Method of Staining the Malaria Flagellated Organism (Brit. Med. Journ., I897, ii., p. 68).

(3) Mannaberg, J. Die Malariaparasiten. Wien, I893.

(4) Sacharoff, N. Rech. sur les hématoz. des oiseaux (Ann. Inst. Pasteur, I893, vii., p. 80 r).

Ueber die selbständ. Beweg. d. Chromos. bei Malariaparas. (C. f. B. u. P., I 895 [I], xviii., p. 374).

(5) MacCallum, W. G. On the Hæmatozoan Infect. of Birds (Journ. Exp. Med., Baltimore, I898, iii., p. II 7 ; and C.f. B., P. u. I., I 897 [I], xxii., p. 440).

(6) Opie, E. L. On the Hæmocytozoa of Birds (Bull. Johns Hopk. Hosp., I897, viii., No. 72, p. 52 ).

(7) Bignami and Bastianelir. Sulla strutt. d. paras. malar. e in spec. dei gameti die par. estivoautumnali (Atti soc. stud. d'ella malaria, I899, i.).

(8) Bignami and Bastianelli. Sulla sviluppo d. paras. d. terzana nell Anoph. claviger (ibid.).

(9) Косн, R. Ueb. d. Entwickelung d. Malariaparas. (Z. f. Hyg. u. Inf.-KrankhI 899, xxxii., p. I).

(io) Schaudinn, F. Ueb. d. Generationswechsel d. Coccid. u. d. neuere Malaria, forsch. (Sitzungsber. Ges. nat. Frde., Berlin, I899, p. 159).

(II) Ruge, R. Unters. üb. d. deutsche Proteosoma (C. f. B., P. u. I., Igor [I], xxix., p. I 87 ).

\section{ProphylaXis.}

Although our experience is but recent, the conclusions arrived at in regard to the prophylaxis of malaria have already led to brilliant results. Efforts are directed, first of all, to induce, if possible, all persons harbouring malaria parasites to undergo treatment, and thus bring about recovery, in order to simultaneously diminish the number of mosquitoes that contract infection from human beings and thus to minimise the danger of transmission to other people. Secondly, the measures are directed against the mosquitoes themselves, either by trying to destroy their breeding places and thus kill off the larvæ wholesale, or by protecting persons from the bite of mosquitoes. The protective measures must be modified in accordance with the local conditions and other circumstances, but the goal is most rapidly attained in malarial districts by preventing the bites of mosquitoes. Mosquito nets, which have been so long in use, are not sufficient for this purpose; more effective methods must be found to prevent mosquitoes 
from invading bed and sitting rooms, and to protect those occupied out of doors in the twilight. This object has been attained with the best results. ${ }^{12}$

\section{HEMATOZOA IN BERI-BERI.}

Under the term beri-beri, or kakke, is understood a disease occurring in various tropical and subtropical countries of Asia, Africa, America, and Australia. It occurs endemically and epidemically, and by predilection affects natives and immigrants of the coloured races. The principal symptoms are motor disturbances and disorders of sensation, dropsy, and cardiac disorders, which are attributable to a degenerative inflammation of numerous peripheral nerves. That beri-beri is an infectious disease we may consider proved (Scheube). Various authors have found the most varied bacilli and cocci in the blood of beri-beri patients who not rarely arrive at European ports. Nevertheless, none of these forms can, with any certainty, be recognised as the agents of the disease. Recently several authors report that they have found amoboid forms bearing a certain resemblance to the malaria plasmodia in the blood of beri-beri patients. The first statements on the subject were those of Glogner, ${ }^{3}$ then followed those of Fajardo. ${ }^{4}$ Although the latter describes several forms which point to a multiplication stage, and also develop black or red pigment, their protozoal nature does not seem to be as yet sufficiently proved. The opinion has also been expressed that in such cases it was perhaps a question of a combination of malaria with beri-beri.

1 On this subject compare: Grassi, B., "Erst. summar. Ber. «b. Vers. z. Verhutung d. Malaria" (C. t. B., P. u. I., I900 [I], xxviii., p. 535); Relaz. dell' esper. di preserv. d. mal. fatto sui ferrovievi n. piana di Capaccio, Milano, Igor ; Die Malaria, Jena, I90 ; Blanchard, R., "Instr. d̀ l'usage dés med., d. natur. et d. voyag." (Bull. Ac. méd., Paris, 1900 [3], xliv., p. 6 ; Celli, A., "Die neue Prophyl. d. Mal. in Latium" (C." $f$. B., P. u. I., I900 [I], xxviii., p. 696; Die Malaria nach d. neuest. Forsch., Wien, I900; Nuttall, G. H. F., "Neueve Forsch. üb. d. Rolle d. Mosq. bei d. Verbr. d. Malaria" (C. $f$. B., P. u. I., I900 [I], xxvii., pp. 193, 218, 260 and 328).

${ }^{2}$ Sambon and Low.--Reports on Two Experiments on the Mosquito-Malaria Theory.-(Transactions of the Medico-Chirurgical Society, vol. Ixxxiv., I902).

"Glogner, M., "Die Stellung d. Beri-beri unter d. Infectionskrankh." (Arch. f. path. An., cxxxii., p. 50) ; "Weitere Beitr. z. Aetiol. d. multipl. Neuritis in d. Tropen" (ibid., 1895, cxli., p. 40r); "Neue Unters. ub. d. klin. Verf. u. d. Aet., der Beri-berikrankh." (Arch. f. Schiffs-und Trop.- Hyg., I 897, i., pp. 46, I 25 ).

"Fajardo, F., "Von d. Hamotozoarie d. Beri-beri u. deren Pigm." (C. f. B., P. u. I., 1898, [1], xxiv., p. 558); "Die Hamotozoarie d. Beri-beri im Gehirn" (ibid., I900, xxvii., p. 249). 


\section{HæMAMœB⿸厂 IN LEUCÆMIA.}

According to Löwit ${ }^{1}$ two different species of hæmamœba occur in the leucocytes in leucæmia-Hamamoeba magna in myelæmia, and $H$. vivax, later termed $H$. parva, and still later $H$. intranuclearis, in lymphæmia; occasionally mixed infections have been observed. The disease is transmissible to rabbits, in which as a rule it takes a chronic course; and this infection can be transferred from animal to animal. Although the author describes stages of schizogony, and recently has also reported a sexual propagation of the parasites in the same host, the parasitical nature of the bodies observed is, to say the least, doubtful. Türk ${ }^{2}$ considers them to be artificial products.

\section{The Hamosporidia in Birds, Reptiles, Amphibia and Fishes.}

It is well known that amongst birds a large number of species belonging to the most different families, and inhabiting various parts of the earth, harbour hæmosporidia. Hitherto the life-history of Plasmodium precox, Gr. and Fel. (= Hamoproteus Danilewskyi, Kruse ; = Proteosoma Grassii, Labbé), has been the best investigated. The presence of this parasite in the blood of birds causes an elevation of temperature of $\mathrm{I}^{\circ}-\mathrm{I}^{\circ} 5^{\circ}$. It is worthy of note that schizogony, which occupies four or five days, is accomplished in two ways: in the one there are only six to seven merozoies arranged in a rosette shape, in the next the schizonts are considerably larger and divide into very numerous merozoies. Ross was the first to establish the fact that mosquitoes of the genus Culex are the hosts of this parasite -in Europe, Culex pipiens, L., and C. nemorosus, Meig., and in India C. fatigans, Wied. Within the body of the mosquito copulation and sporogony are accomplished in a manner similar to that of the malaria plasmodia of man within Anopheles. By means of the bite of the mosquito the sporozoies collected in the tubules of the salivary glands pass into the blood of the bird. The infection is particularly dangerous to nestlings, and also to older birds during moulting.

Halteridium Danilewskyi (Gr. et Fel.) is a second species likewise found in numerous kinds of birds, but which does not affect the host to the extent of the first-named species. The mature schizonts are of a dumbbell shape, and the merozoies, for the development of which about a week is necessary, are grouped like rosettes or morulæ at the two thickened extremities. The microgametocytes are also dumb-bell-shaped. The further development is still little known, but mosquitoes of the genus Culex are likewise the hosts of this parasite.

1 Löwit, M., "Die Aetiol. d. Leukaemie" (C. f. B., P. u. I., I899 [1], xxv., p. 503) ; “Weitere Unters. ub. d. Paras. d. Leuk." (ibid., 1900, xxvii., p. 503); Die Leukaemie als Protozoën-Infection, Wiesbaden, 1900.

"Türk, "Ueb. d. Hamamoeben Löwit's im Blute Leukaemischer" (Med. Woche., 1900, No. 18, p. 173). 
Still a third species known as Lankesterella avium (Labbé) has been observed, particularly in the blood of birds of prey. Only the stages of schizogony are known.

The number of hæmosporidia known in the blood of reptiles is far more numerous, and all, with one exception, are referred to the genus Hamogregarina ${ }^{1}$ they are, as a rule, comparatively elongated creatures
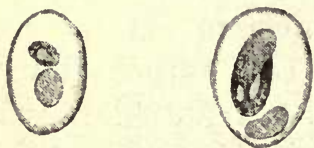

FIG. 45. - Hamogregarina Stepanowi, Danil., in the red blood corpuscles of Cistudo europaca. (After Danilewsky.)

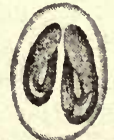

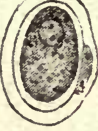

Fig. 46.-Hamogregarina Stepanowi, Danil., in schizogony. The blood corpuscle is still there, its nucleus at the edge; to the right two merozoites. (After Danilewsky.)

(fig. 45) that occasionally attain a length double that of the blood corpuscles, and also occur free in the blood plasma. As we do not know the entire development, and only schizogony (fig. 46) has been observed, I will confine myself to the enumeration of the species:-

I. Hamogregarina Stepanowi, Danil. .. Cistudo europaa, Trionyx sp.,

$\begin{array}{ll}2 . & \quad \\ 3 . & \quad \\ 4 . & \quad, \\ 5 . & \quad,\end{array}$

Testudo marginata.

$6 . \quad$,

$7 . \quad$,

Labbéi, Börn. $\quad$. . Platemys sp., Clemmys elegans,

Laverani, Simond .. Cryptopus granosus,

Mesnili, Simond .. Emys tectum,

Billeti, Simond .. Trionyx stellatus,

Hankini, Simond .. Gavialis gangeticus, crocodilinorum,Börn. Crocodilus frontatus, Alligator mississipiensis,

8.

lacertarum, Danil. . . Lacerta muralis, L. agilis, $L$. vividis, L. ocellata,

9. ,

Lacazei, Labbé .. Lacerta agilis, L. muralis,

IO. platydactyli, Billet.. Platy. mauritanicus,

II. ", bungari, Billet . B Bungarus fasciatus,

I2. $"$ pythonis, Billet .. Python reticulatus,

I3. $\quad$ " sp. Billet . . $\quad \ldots \quad$ Tropidonotus stolatus,

I4. "Joannoni, Hagenm. Macroprotodoa cucullatus,

I5. $\quad$, colubri, Börn. . Coluber asculapii.

This list is not, however, complete, because several authors have not given names to the hæmosporidia they have found in reptiles. The total number harbouring hæmosporidia with which we are so far acquainted comprises thirty

${ }^{1}$ It is doubtful if this species also occurs in invertebrate animals, though a $H$. nasuta Eisen, from an Oligochæte, has been mentioned in literature. 
species appertaining to the Ophidia, seven to the Saurians, three to the Crocodiles, and nine to the Chelonians. One of these species (from a tortoise; Trionyx indicus) is classified as belonging to the genus Hamamoeba (= plasmodium), and has been described by Simond as H. Metschnikowi.

The Hæmosporidia of the amphibians are usually ascribed to the genus Lankesterella (=Drepanidium, Lank., nec Ehrb.). The differentiation of the species has been disputed: the species we have known longest, as well as best (see above, p. 83) is Lank. minima (Chauss), (=Drepanidium ranarum, R. Lank.), from Rana esculenta. Drepanidium princeps, Labbé, is identical with this species, and very probably also Laverania ranarum, Gr. et Fel. (= Hamogregarina ranarum, Kruse), and Dactylosoma splendens, Labbé. Lank. monilis (Labbé) may be a particular species that certainly resembles Lank. minima in the early stages, but differs from it when fully developed. Perhaps Drepanidium magnum, Grassi and Fel., is also an independent species, as is certainly Hamogregarina Riedyi, Eisen. In this Californian variety Batrachoseps attenuatus is the host; all other forms are European and live in Rana esculenta. One other form, known formerly as Cytamceba bacterifera, Labbé, from the green frog, is to be entirely eliminated, because what was so termed is not a living organism at all but phases of degeneration in the blood corpuscles induced by long bacteria (Laveran). ${ }^{2}$

Gros (1845) and Wedl (I850) appear to have been the first to see Hæmosporidia in the blood of fishes. Danilewsky (I889) gives a short account of the latter in Perca fuviatilis, and two species have been recently described by Laveran and Mesnil ${ }^{3}$ (Hamogregarina Simondi, from Solea vulgaris, and $H$. bigemina from Blennius pholis and B. gassorugine).

\section{THE MOST IMPORTANT LITERATURE.}

Danilewsky, B. Die Hæmatoz. d. Kaltblüer (Arch. f. mirk. An., I885, xxiv., p. 588).

Matér. p. serv. à la paras. du sang (Arch. slav. de biol., r886, i., pt. 89).

III. Hémat. des lézards (ibid., p. 364). IV. Hém. d. tortues (ibid., I887, ii., pp. $33,157,370)$.

La parasitol. comp. du sang. Charkow, I889 (Russ.).

Dévelop. d. paras. malar. dans les leucocytes des oiseaux (Ann. Inst. Pasteur, I 890 , p. 427).

Sur les microb. d'infect. mal. (ibid., p. 753). Contrib. à l'étude de la microbiose malar. (ibid., I891, p. 758).

Grassi, B., and R. Felettr, Malariapar. i. d. Vög. (C. f. B. u. P., i89i, ix., pp. 403, $429,461)$.

Weiteres z. Malariafrage (ibid., I89I, x., pp. 449, 48 I, 5 I 7 ).

Contrib. allo stud. d. paras. mal. (Atti Acc. gioenea sc. nat., Catania v., Ser. 4, I892).

Celli, A., and F. Sanfelice. Sui paras. d. glob. rosso nel uomo e negli anim. (Ann. Ist. d'ig. esp. R. Univ. Roma. N.S., I89I, i.

Fortsch. d. Med., I891. Nos. I I-I 5.

Kruse, W. Ueb. Blutparas. (Virch. Arch. path. An., I890, cxx., p. 45I, and cxxi., p. 359).

"Laveran, A., "Sur le bacille parasite des hématies de rana esculenta" (C. R. soc. biol., Paris, I899, i., p. 355.

${ }^{2}$ Laveran, A., and Mesnil, F., "Deux hémogr. nouv. d. paras." (C. R. Ac. sc., Paris: I901, cxxxiii., p. 572.) 
LABBÉ, A. Rech. zool. et. biol. sur les par. endoglob, du sang d. vertébr. (Arch, zool. exp. et gén., I 894 [3], ii., p. 55).

Sporozoa in : Das Thierreich. Book 5. I 899.

OpIE, E. L. Hæmacytozoa of Birds (Bull. Johns Hopk. Hosp., 1897, viii., No. 72).

Ross, R. Cultiv. of Proteosoma in Grey Mosq. Calcutta, I898.

HAGENMÜlleR, P. . Hémosp. d'un ophid. du syst. europ. (Arch. zool. exp. et gén. 1898 [3], vi., Note No. 4, p. li).

Billet, A. Laverania bungari (C. R. soc. biol., 1895, xlvii., p. 30).

Hémat. endogl. d. Platydact. (ib., I900, No. $2 \mathrm{I}$, p. 547).

Hém. endogl. des Trionyx (ib., 1901, No. 10, p. 257).

Laveran, A. Hémat. endoglob. chez Padda oryzivora (C. R. soc. biol., I898, v., p. 47 I).

Hemogreg. stepanowi (ib., pp. 885, 919).

Drepanid. ranar. (ib., p. 977).

Laverania danilewskyi (ib., I899, [II] i., p. 603).

Langman,, G. On hæmosp. in Americ. Rept. and Batrach (New York Med. Journ., 1899).

Simond, P. L. Contrib. à l'étude d. hémat. endogl. d. reptiles (Ann. Inst. Pasteur, 1901, p. 319).

Lutz, A. Drepanidien d. Schlangen (C. f. B., P. u. I., I901, xxix., p. 390).

BörNer, C. Unters. üb. Hæmospor. I. (Z. f. wiss. Zool., 1901, Ixix., p. 398).

Ruge, R. Unters. üb. d. deutsche Proteosoma (C. f. B., P. u. I., I90I [I], xxix., p. I87).

Galli-Valerio, B. Unters. üb. d. Hæmosp. d. Alpenvögel (C. f. B., P. u. I., I902, [1], xxxi., Orig., p. I62).

Sambon, L. W., and Low, G. C.-Report on Two Experiments on the MosquitoMalaria Theory. Appendix A. Hæmocytozoa of Animals (Medico Chirurgical Transactions, London, 1902).

\section{Order 4. Myxosporidia, Bütschli.}

These parasites, which were discovered by Joh. Müller (I), live principally in fishes, and occasionally cause destructive epidemics amongst their hosts. Müller first observed them in the form of whitish-yellow pustules on the skin or on the gills of various fishes; these pustules contained masses of small shell-covered bodies with or without tails (Psorospermia, see fig. 47). Similar bodies were also found in the air bladder of the Torsk (2). Creplin (3) simultaneously demonstrated the resemblance of the cysts harbouring the Psorospermia (Psorosperm tubes) to the "pseudonavicellcysts" of a gregarine, as described by v. Siebold, and Dujardin (4) considers that there is possibly some connection between the sarcode-like psorosperm tubes and the spores they contain (psorosperms), with the developmental stages of monocystide gregarines from the vesicula seminalis of earth-worms. The relationship of the psorosperm tubes was placed on a firmer basis by Leydig (5) and Lieberkühn (6). The former found numerous forms in salt water fish and, in species which live free in the gall bladder of cartilaginous fishes, he discovered that the psorospermia originate in a manner similar to the gregarines; while Lieberkühn studied the myxosporidia in the bladder of the pike (fig. 49), and observed their amœboid movements, as well as the formation of the psorospermia, from each of which a small amœboid body escaped (fig. 53), a discovery that was confirmed by Balbiani (7). The same author also found that spiral filaments were enclosed in the so-called polar body of the psorosperms, and that these could be protruded (fig. 56, $d$, and fig. 59).

The term which at the present day is universally applied to the psorosperm tubes (myxosporidia) was introduced by Bütschli (8), who studied not only the structure and development of the spores, but also the protoplasmatic body of the parasites in question, and confirmed the 
occurrence of numerous nuclei. Recently the following authors have contributed important additions to our knowledge of th? myxosporidia: -Perugia (9), Thélohan (10), Mingazzini (I I), L. Pfeiffer (I 2), L. Cohn (I3), and Doflein (14); while the presence of this parasite outside the class of fishes has become known through Lutz, Laveran, and; others.

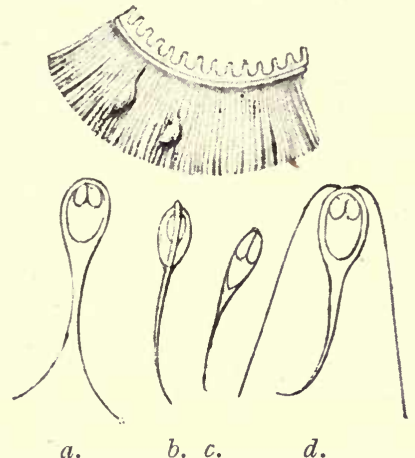

FIG. 47. - Part of a gill of Leuciscus rutilus. (natural size), with two myxosporidia $(a, b, d)$ Spores of myxosporidia from Esox lucius (c) Spores from Platystoma fasciatum (after J. Müller).

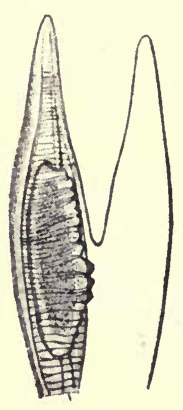

$a$

FiG. 48. - (a) Myxobolus Müllevi, Bütschli, on the lobe of the gill of a cyprinoid; (b) the tailless spore, with the polar bodies and their nuclei and the sporozoite (after Bütschli).

The species causing diseases in fishes have been described by Ludwig (I 5), Railliet (I6), Weltner (I7), L. Pfeiffer (I2), Zschokke (I8), Hofer (I9), Doflein (14), Gurley (20), and in regard to classification the works of Thélohan (2I) and Gurley (22) may be mentioned. The myxosporidia live either free on the epithelial surfaces of hollow organs (gall or urinary bladder,

FIG. 49.--(a) Myxidium Lieberkühnii B., from the urinary bladder of Esoxlucius ; $(b)$ a pansporoblast; (c) complete spore (after Bütschli).

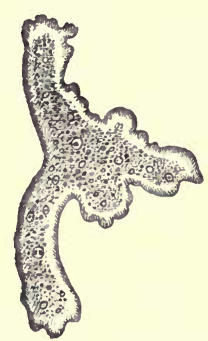

$a$.
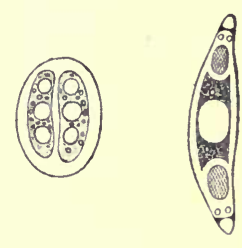

$b$. c.

renal tubules, but never in the intestine), or are enclosed in the tissues of their host. The gills and muscular system are their favourite habitat; but other tissues or organs, with the exception of the bones and cartilages, are apt to be attacked.

The free forms move with the assistance of variously shaped pseudopodes, have a constant form, or may exhibit contractions of the body; 
the tissue-parasites often attain a considerable size, so that the integument of the host forms protuberances over them; they are of a roundish or irregular shape, which does not change, except as regards the alterations induced by growth; they are usually enveloped in a connective tissue covering formed by the host.

The protoplasmatic body usually permits the finely granular ectosarc to be distinguished from the coarsely granular endosarc; occasionally the former is thickened into a kind of integument. In addition to various enclosures, there are as a rule numerous nuclei, which divide mitotically, and all originate from the primary nucleus of the early stage (amoboid germ), enclosed in the spore.

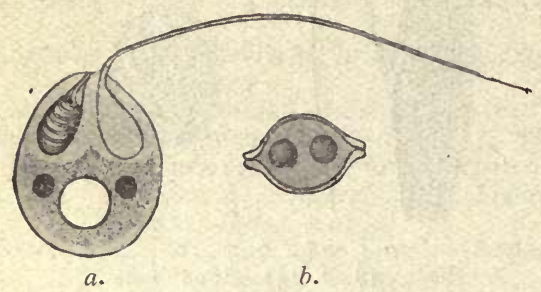

FIG. 50.- Schema of a spore of Myxo bolus : (a) One polar capsule has protruded the filament ; two nuclei and a "vacuole" in the sporozoite; $(b)$ spore seen in optical section - the two polar capsules in the interior (after Doflein).

The development of the spores commences long before the ultimate size is attained, and in some species their number is remarkably large, in others small, or limited to two only (Polysporea-Disporea). The spores (fig. 50) are surrounded by two concave shells, turned facing each other and united at the borders; the external surface may be smooth or sculptured, and may carry one. or two caudal appendages at the one pole; they enclose at the pointed anterior pole two formations resembling nettle-capsules, the polar capsules, the spirally rolled hollow filaments of which may be protruded spontaneously or through the action of certain agents. The posterior larger half of the internal space is occupied by a proto-

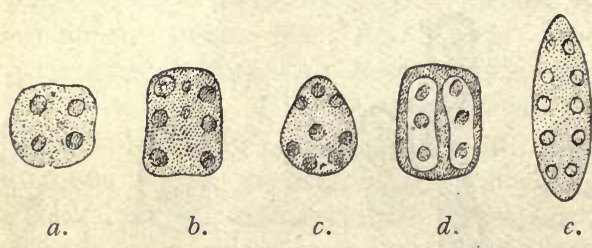

FIG. 51.-Myxidium lieberkühnii : (a) Pansporoblast, with four nuclei ; $(b, c)$ pansporoblast with eight nuclei ; (d) pansporoblast divided into two sporoblasts, after expulsion of two nuclei ; (e) pansporoblast with Io nuclei (after L. Cohn).

plasmatic body (amœboid germ, sporozoite), containing one or two nuclei and a so-called vacuole, which represents the young myxosporidia; it becomes free in consequence of the bursting open of the two halves of the shell, and then can execute amœboid movements (fig. 53).

The spores are formed by a portion of protoplasm (pansporoblast) gathering round each nucleus of the parent (sporont), the nucleus again repeatedly dividing until eight to ten daughter nuclei-rarely more-are formed (fig. 51); the protoplasm of the pansporoblast then divides into two halves (sporoblasts), in which the nuclei are equally distributed after two of them have been extruded. Accordingly, each sporoblast contains at least 
three nuclei. The protoplasm subsequently gathers round each nucleus. Of the three cells thus formed, which develop a shell on the exterior surface, two pass into the polar body and one into the amoboid germ, the nucleus of which, sooner or later, again divides (fig. 52).

In pansporoblasts with ten nuclei, four nuclei are left for each sporoblast after the extrusion of two; the protoplasm gathers round them in such a way that it forms two mononuclear cells, the future polar bodies, and one binucleated cell, the amœboid germ. In those few cases in which twelve to fourteen nuclei appear in the pansporoblasts four pole-capsules appear in each spore.

FIG. 52.- $(a, b)$ Myxoproteus ambiguus; $(a)$ sporoblast showing position of the two polar capsules and the sporozoit ; $(b)$ pansporoblast with two older sporoblasts, the rejected nuclei being between them; the nucleus in the sporozoits already divided ; $(c)$ mature spore of Myxobolus cyprini (after Doflein).

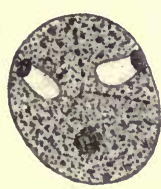

a.

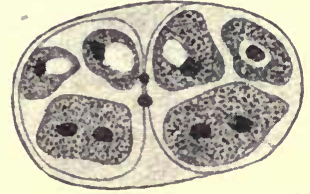

b.

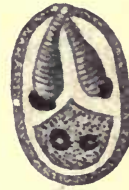

c.

The spores, no doubt, fulfil the mission of effecting transmission to other hosts; infection occurs by the ingestion of the parasites per os after their escape by some means from their host. Thélohan (IO) has demonstrated that the shells of the spores soon open under the influence of the intestinal juices, thus allowing the young myxosporidia to escape. Their further history is unknown; but it may be surmised that they either travel direct to the organs usually affected (gall bladder, urinary bladder), or are distributed in the body by means of the circulation.

In a few species increase has been observed to take place by means of division or budding, which leads to a more aggravated infection. of the already affected host; possibly this process (multiplicative propagation by plasmotomy) is very much more frequent than we are aware of.

Fig. 53.-Spores of a myxosporidium from the gills of Gobio fluviatilis, the contents of which are escaping. $600 / 1$. (after Bütschli).

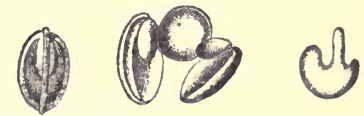

Whether there is copulation, and at which stage it takes place, is as yet unknown.

Myxosporidia are divided into two sections-Disporea and Polysporeaaccording to whether they form only two or several spores during their growth; the former, up to the present, appear to consist of two genera limited to fishes, which are easily distinguishable by the shape of the spores: Leptotheca, Thél., with a rounded spore-shell, and Ceratomyxa, Thél., with a very elongated spore-cell. The larger number of genera appertain to the Polysporea, which are divided into three families:

(I) Amœboid-germ with a vacuole ((a) With two pole-capsules-Myxidiida. the contents of which do not stain with iodine.

(b) With four pole-capsules.-Chloromyxida.

(2) Amœboid-germ with a vacuole stainable with iodine. Spores with two pole-capsules-Myxobolidee.

For further subdivisions the differences of the spores are principally utilised 


\section{LITERATURE.}

(I) MÜLleR, J. Ueb. eine eigenth. krankh. paras. Bildung mit specif, organis. Samen körp. (Arch. f. An. u. Phys., 184I, p. 477).

(2) Müller, J., and A. RetziUs. Ueb. paras. Bildungen (ib., I842, p. 193).

(3) Creplin, J. C. H. Beschr. d. Psorosp. des Kaulbarsches nebșt Bemerk. üb die der Plötze (Arch. f Naturg., 1842, viii., I, p. 61).

(4) Dujardin, F. Hist nat. d. helm. Paris, 1845, p. 643.

(5) Leydig, F. Ueb. Psorosp. u. Gregarinen (Arch. f. An. u. Phys., I85I, p. 221).

(6) Lieberkühn, N. Ueb. d. Psorosp. (ib., I 854, p. 349).

(7) Balbiani, G. Sur l'organis. et la nature d. psorospermies (C. R. Ac. sc., Paris, I 863 , lvii., p. I 57 ).

(8) Bürschli, O. Z. Kenntn. d. Fischpsorosp. (Z. f. w. Z., I88 I, xxxv., p. 629); Protozoa in: Bronn's Cl. u. Ordn. d. Thierr., I. Lpzg., I882, i., p. 590).

(9) Perugia, A. Sulle myxosporidie d. pesci marini (Bull. scientif. Ann., I889, xii., 1890 , xiii. p. 10).

(I0) Thílohan, P. In numerous reports published in C. R. soc. biol., Paris, and C. R. Ac. sc. Paris, I889-1894, as well as in Rech. sur les Myxosp. (Bull. scient. France et Belg., I895, xlvi., p. 100).

(II) Pfeiffer, L. Die Protoz. als Krankheitserr. 2 edit. Jena, I89I.

(I2) Mingazzini.

Unters, üb. d. Krebs. Jena, I 892.

(I ) Corn, L. Ueb. d. Myxospor. v. Esox lucius u. I'erca fluviat. In.-Diss. Kgsbg., I 895, and Zool. Jahrb. Abth f. Anat., ix., I 895.

(14) Doflein, F. Stud. z. Nat. d. Protoz. III. Ueb. Myxosp. (Zool. Jahrb. Anat., xi., 1898, p. $28 \mathrm{I}$ ).

(I 5) Ludwig, H. Ueb. d. Myxosp. d. Barben i. d. Mosel (Jahr.-Ber. d. Rhein. Fisch.-Vereins, 1888-89, p. 27).

(i6) Railliet, A. La mal. d. barbeaux de la Marne (Bull. soc. centr. d'aquicult. France pour I 890 , ii., p. II 7 ).

(i 7) Weltner, W. Ueb. Myxosp. i. d. Eiern v. Esox lucius (Stzgsb. Ges. nat. Frde. Berlin, I 892 , p. 28).

(18) Zschoкke, F. Myxosp. d. Gttg. Coregonus (C. f. B., P. u. I., I898 [I] xxiii., pp. 602, 646, 699; and Mitth. d. nat. Ges. Luzern, I898, 2, p. 205).

(19) Hofer, B. Die sogen. Pockenkrankh. d. Karpfen (Allg. Fisch.-Ztg., I 896, pp. 2, $28,186$; and $i b ., 1902$, p. 22$)$.

(20) Gurley, R. The Myxosp. or psorosp. of Fish, and the Epid. Produc. by them (Rep. U.S. Comm. of Fish and Fisher. f. 1892, Washington, 1894, p. 65).

(2I) Thélohan, P. Observ. sur les myx. et essai de classif. des ces org. (Bull. soc. phil., Paris, I 892 [8], iv., p. 165).

(22) Gurley, R. On the Classific. of the Myxosp. (Bull. U.S. Fish Com. f. I89I, Washington, 1893, p. 407).

\section{Order 5. Microsporidia, Balbiani.}

These are the forms discovered in the stickleback by Gluge in 1834, and in Coccus hesperidum by Leydig in 1853 , and which have later been found in numerous other arthropoda, insects and arachnoids. They acquired particular importance when it was discovered that they were the cause of the pebrine sickness (gattina of the Italians) which caused so much destruction amongst silkworms (Bombyx mori). Pasteur (1870) and especially Balbiani participated in the researches on Nosema bombycis, and it was the latter who classed the "pebrine bodies" or "psorospermia of the arthropoda" amongst the sporozoa as microsporidia (I884). But the occurrence of this group is not confined to insects and arachnoids, they are now known to occur also in crustaceans, worms, bryozoa, fishes, amphibians (Rana) and reptiles (Emys); they have even been known to form tumours in fishes. similar to those formed by many myxosporidia.

These small protoplasmatic creatures seem to parasitise in all cells and 
to spare no tissues; they form pansporoblasts, with or without envelopes, in the interior of their body, which then grows still further, or the latter is completely occupied by the pansporoblasts; generally each pansporoblast develops a great number of spores, rarely as few as four or eight. The spores are remarkably small, are usually oval or pear-shaped, and surrounded by a comparatively thick shell which probably always consists of two halves. At one pole, the anterior one, there is always one pole-capsule with a

$a$.

FIG. 54,- $-a$, Section through the abdominal wall of a silkworm, whose epithelial cells contain Microsporidia (Nosema bombycis) ; $b$, a spore the contents of which are escaping; $c-e$, sporulation stages. (After Balbiani.)

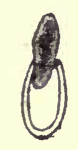

$b$.
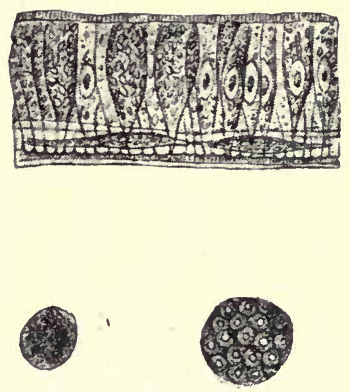

d.

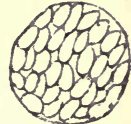

e.

projectile filament, only observable by means of reagents. For this reason some authors, since this fact has become known, have included the microsporidia as Glugeidae or as cryptocyst myxosporidia of the latter. The spores, moreover, contain the "amœboid-germ," the exit of which from the spore Balbiani had already seen.

The manner of infection as regards the silkworms is well known; it occurs through the ingestion of the spores which reach the food already contaminated by the excrements of infected silkworms; probably an

Fig. 55.-Nosema bombycis, Naeg. Spores treated with nitric acid, thus rendering the polar capsule perceptible, and the filament has protruded itself from the one spore. (After Thélohan.)

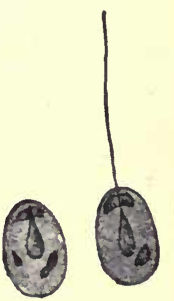

increase of the parasites within the infected host takes place in some way as yet unknown to us. This leads to the enormous infection of all the tissues and organs that is so frequently observed, and to which the silkworms succumb; or, on the other hand, the chrysalis stage and the formation of cocoons is omitted because the salivary glands are also attacked. When the infection is less extensive the silkworms not only become pupæ, but the moths emerge, and often deposit infected eggs, so that the disease may also be congenital. Fortunately, however, eggs may be recognised as infected under the microscope, as Pasteur has shown, and as the little caterpillars may transmit the disease to healthy ones they are therefore promptly destroyed. 
The species of Thélohania that occur in the muscular system of river craw-fish and Palæmonidæ are likewise capable of causing diseases, which, however, have nothing to do with typical craw-fish plague, as the latter is decidedly and solely caused by the Bacillus pestis astaci, Hofer.

Four genera are now distinguished in the Microsporidia: Thélohania, Henneg., Nosema nagali (= Glugea, Thél.), Plistophora, Gurley, and Gurleya Dofl. ${ }^{1}$

\section{Order 6. Sarcosporidia, Balbiani.}

This group, which is the one that has been least studied, was first discovered by Miescher ( $\mathrm{I}$ ) in $\mathrm{I} 843$. This author found milk-white filaments running parallel with the direction of the fibres in the voluntary muscles of domestic mice; they were visible to the naked eye, and proved to be cylindrical tubes rounded off and tapering at each end; they were as long as the muscular fibres, were enveloped in a membrane, and contained innumerable elongated or kidney-shaped bodies and a smaller number of little globular forms. J. Hessling (2) confirmed the occurrence of these "Miescher's tubes" within the muscular fibres, this author having discovered the same formation in the miocardium of deer, cattle and sheep. Both investigators considered them to be pathological transformations of the muscles. v. Siebold (3), from his own experiences, regarded them as fungus-like entophytes.

Rainey (4) discovered similar formations in the muscular system of domestic pigs, and proclaimed them to be early stages of the Cysticercus cellulosa, which error Leuckart (5) rectified, simultaneously emphasising their relationship with Myxosporidia. Both these authors found them in the muscular fibres and both observed that they possessed a thick striated membrane. Manz (6) published the results of more minute investigations on the structure and contents of the cylinders. This observer also recognised the disease in rabbits and attempted to cultivate the parasites; he also tried to induce experimental infection in guinea-pigs, rats and mice, but the result was negative.

However domestic and wild, mammals are not the only hosts of Sarcosporidia; these parasites are also harboured by birds. Thus, according to Kühn (7) they are found in the domestic fowl, according to Rivolta (8) in Turdus Corvus and other birds; according to Stiles (9) in North American birds. Neither do the reptiles escape. Bertram (10) found them in the gecko, Lühe (II) in the wall-lizard. It also became evident that the Sarcosporidia found conditions suitable to their development not only in the muscles but also in the connective tissue. This led to the foundation of a new classification [Blanchard (12)]. Finally, Sarcosporidia have also been observed in man.

The relation of these parasites to certain diseases of domestic animals has been especially studied by veterinary surgeons (I3).

But little that is fresh (i4) has been added to the results of the work of Bertram (10) mentioned above, and on which the following

'The recent literature of the myxosporidia also contains information respecting the microsporidia (Gurley, Thélohan, Doflein, \&c. ; see also Labbé, Sporozoa, I 899). 
description of the Sarcosporidia is based, so that there is still a wide field open for research in regard to the structure and development of these parasites and the manner in which the hosts are infected.

The Sarcosporidia usually appear as elongated, cylindrical, or fusiform bodies, rounded at both extremities and of various lengths and breadths (fig. 56); they lie inside the striated muscular fibres which they distend more or less. The forms found in the connective tissue are apparently parasites which originally inhabited the muscular fibres, and only on disintegration of the fibres reached the connective tissue, where they grow to large oval or globular bodies (fig. 57). In fresh flesh cut into exceedingly thin

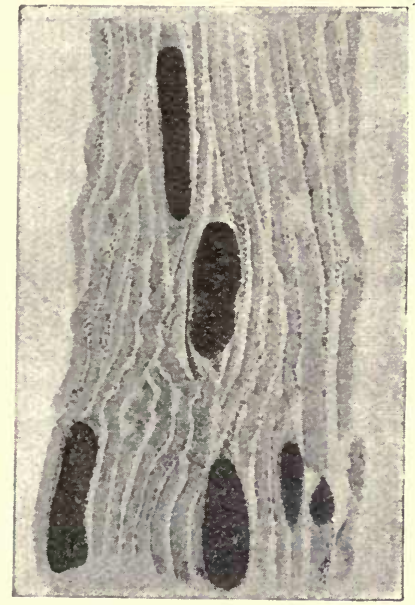

FIG. 56.-Longitudinal section of a muscle of the domestic pig, with Sarcocystis miescheriana (Kühn). $30 / 1$.

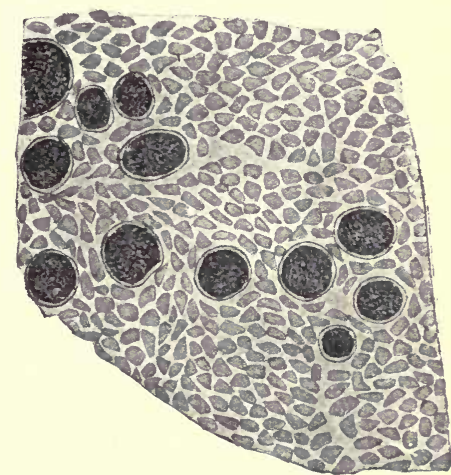

FIG. 57.-Transverse section of the muscle of a pig, with Sarcocystis miescheriana (Kühn). $38 / \mathrm{I}$.

slices they are frequently recognisable, even with the naked eye, on account of their yellowish-white colour; under the microscope, by a refracted light, they appear to be dark and coarsely granular; beginners will find some difficulty in distinguishing them from other foreign bodies, such as dead and calcified encapsulated Trichinæ, or from cysticerci that have died and become calcified in the early stages, more particularly as the Sarcosporidia also occasionally may become calcified.

The Sarcosporidia are always enveloped in a membrane, which is probably formed at an early stage; in a few cases it remains thin and simple, in other cases a so-called "rod-like armature" is exhibited, which has been variously described. From the inner integument, which may be homogeneous or fibrous, thick or thin, 
there arise membranes in the interior of the body that form anastomosing partitions, or rather a system of manifold chambers of various sizes that do not communicate with one another (fig. 58). These chambers are occupied by sickle or bean-shaped bodies (sporozoites), or rather their stages of development; frequently, however, they are empty, and this is particularly the case in the central chambers of the large species.

In the youngest Sarcosporidia $(0.04 \mathrm{~mm}$. in length) from the muscles of the sheep one finds, according to Bertram, small

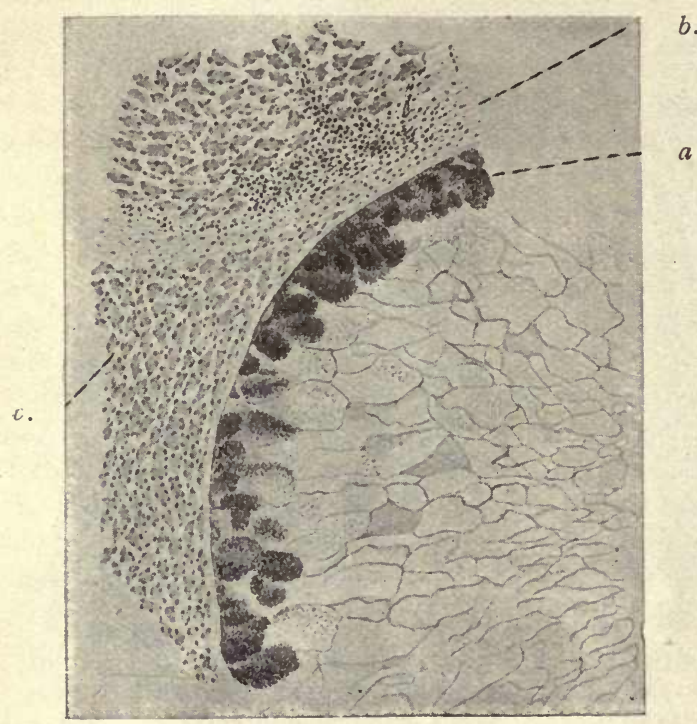

FIG. 58. - Transverse section of Sarcocystis tenella, Raill. (from the œsophagus of Ovis aries). 38/1. (a) Marginal chambers filled with spores; (b) connective tissue of the œsophagus: (c) muscles of the œsophagus. b.

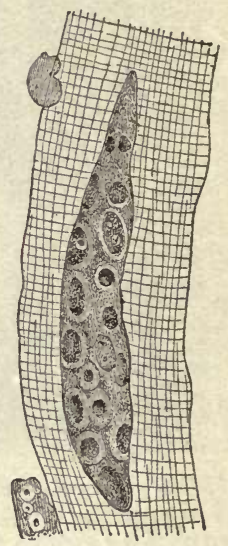

FIG. 59.-Young Sarcocystis tenella of the sheep $\left(0^{\circ} 047\right.$ $\mathrm{mm}$. in length) (after Bertram).

roundish or oval cells $\left(0^{\circ} 004-0.005 \mathrm{~mm}\right.$.), the nuclei of which are half their size, and are embedded in a granular and apparently protoplasmatic mass ; in somewhat larger, and therefore older, cylinders, the investing membrane of which already presents both layers, the cells have become larger (to $0.007 \mathrm{~mm}$.) and are more sharply outlined from each other (fig. 59). Taking their later condition into account they may be considered as sporoblasts, for their nuclei commence to divide; finally they become isolated within the chambers, the dividing partitions of which originate from the granular protoplasm which is present between the sporoblasts; 
the numerous bodies thus originated are nucleated and become spores direct.

The process commences in the centre of the cylinders, and then progresses towards the extremities, the parasites meanwhile increasing in size, and new sporoblasts being continually formed at the extremities (fig. 6o).

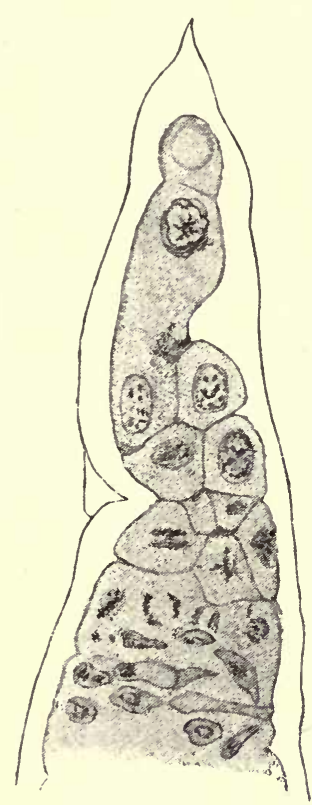

FIG. 6o.-Termination of a Sarcocystis miescheriana from the diaphragm of the pig. 800/I. (After Bertram.)

The spores vary in shape according to the species, but are also of different form individually; they are mostly kidney-, bean- or sickle- shaped, and of a very small size. They are apparently surrounded by a membrane, and at one extremity (according to the discovery of L. Pfeiffer, confirmed by van Eecke, Laveran and Mesnil) contain an obliquely striated body (fig. 6r) understood to be the pole capsule, while the greater part of the spore is taken up by the nucleated sporozoit.

Several authors state that they have also observed filamentous appendages at one pole of the spores, and have seen two sorts of spores in the same Sarcosporidium, but these observations require confirmation.

The duration of life of the Sarcosporidia is a comparatively long one; the affected muscular fibres may remain intact and capable of performing their functions for a long time, but at last they perish, if the host lives long enough, so that the sarcosporidia of the muscles are then enveloped only by sarcolemma, and finally, when this likewise disappears, they fall into the intra-muscular connective tissue. In many cases the sarcosporidia die off within their hosts, this, according to Bertram, being brought about by a disintegration of the spores in the central chambers; in other cases the leucocytes play a part in the destruction of the sarcosporidia, and finally, it is a common occurrence for lime salts to be deposited in and around the vacant cylinders.

The manner in which the hosts become infected is entirely unknown, although transmission must occur very frequently, as in some places pigs, sheep, mice and rats are infected to a remarkably high percentage, indeed, not far below Ioo per cent. Young animals also show that they are already infected, and perhaps infection only takes place during youth. As most of the hosts 
are herbivorous, the idea of a direct transmission through eating infected flesh may be summarily dismissed; experiments, such as the inoculations carried out by Kasparek, ${ }^{1}$ have also yielded negative results. Moreover, the spores have not much power of resistance; for instance, they perish in the gastric juices.

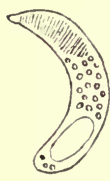

a.

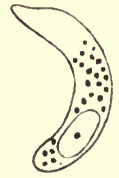

b.

FIG. 6I.-Spores of Sarcocystis tenella, Raill. I00o/r.) (a) Fresh with the polar capsule; (b) stained (after Laveran and Mesnil).

We are still unacquainted with the manner in which the enormous infection of the same host comes to pass. That which Pfeiffer says on the matter is altogether hypothetical. The cLAssIFICATION OF THE SARCOSPORIDIA as proposed by R. Blanchard, and which was based on their various habitats, can no longer hold good, because the same species may occur in the muscles as well as in the connective tissue; for the present the few species that are known may be placed in one genus (Sarcocystis, R. Leuck.).

\section{The Sarcosporidia observed in Man.}

(I) Lindemann (Ueb. d. hyg. Bdts. d. Gregarinen in Dtsche. Ztschr. $f$. Staatsarzneikde, I868) found on the valves and in the myocardium of a person that had died of dropsy certain brownish masses, $3 \mathrm{~mm}$. in length and $1.5 \mathrm{~mm}$. in breadth which he regarded as gregarines. If these were actually independent animal organisms it may be suggested that they were Sarcosporidia.

(2) Rosenberg '(Ein Befund von Psorosp. in Herzmusk. d. Menschen in Ztschr. f. Hygiene, I892, xi., p. 435) found a cyst $5 \mathrm{~mm}$. in length and $2 \mathrm{~mm}$. in breadth in a papillary muscle of the valvula mitralis of a woman, 40 years of age, who had died from pleuritis and endocarditis. The cyst contained no scolex nor hooklets of tænia; numerous small refracting bodies, round, oval or kidney-shaped, were found in a daughter cyst, as well as sickle-shaped bodies. The description hardly appears to indicate Sarcosporidia.

' It may incidentally be mentioned that the sarcosporidia contain a toxin (sarcocystine) that has a serious effect on warm-blooded animals. More on this subject can be learned from L. Pfeiffer and from Laveran and Mesnil (De la sarcocystine, toxine d. sarcospor. In. C. R. soc. biol., Paris, I 899 [Io], vi. p. 3II). 
(3) Kartulis observed Miescher's cylinders of various sizes in the liver (?) and in the muscular system, but not in the fibres of a Soudanese who had succumbed to multiple abscesses of the liver and abdominal muscles. This may be considered as the first actual case of the occurrence of sarcosporidia in man (Kartulis, Ueb. pathog. Protoz. b. Menschen, in Ztschr. f. Hyg. u. Inf., I893, xiii.. p. I. Compare also Braun, M., Die Thier. Par. d. Mensch., 2nd Edit., Wrzbg., I895, p. 92. Braun, M., Z. Vork. d. Sarcosp., b. Menschen, in C. f. B. P., I895, xviii., p. I3).

(4) The case reported by Baraban and St. Remy ("Sur un cas de tub. psorosp. ob. chez l'homme," in C. R. soc. biol., Paris, I894 (x.), I., p. 20I. "Le parasitisme d. Sarcosp. chez l'homme" in Bibliogr. anat., I894, p. 79), was at once demonstrated as certain. It related to a man who had been executed, and in the laryngeal muscles of whom Sarcosporidia were found; the length of the parasites fluctuated between $0^{\circ} 5_{50}$ and $\mathrm{I} \cdot 6 \mathrm{~mm}$., their breadth between 0.077 and 0.168 mm. 'The affected muscular fibres were distended to four times their normal thickness.

\section{LITERATURE.}

(I) Miescher, F. Ueb. eigenth. Schläuche i. d. Musk. einer Hausmaus (Bericht üb. d. Verhandl. d. naturf. Ges. Basel., I 843 , v., p. 198).

(2) V. Hessling. Histol. Mitth. (Z. f. w. Zool., I854, v., p. I89).

(3) Siebold, C. Th. v. Addition (ib., p. 199).

(4) Rainey, G. Struct. and devel. of Cyst. cell. as found in the Muscles of the Pig (Transact. R. Phil. Soc., I 858 , cxlvii., p. II I).

(5) Leuckart, R. Die menschl. Parasit. (I edit., I vol., I863, p. 237 ).

(6) Manz, W. Beitr. z. Kenntn. d. Miesch. Schl. (Arch. mikr. Anat., I867, iii., p. 345).

(7) KühN. Mitth. landw. Inst. Halle, I 865, p. 68.

(8) Rivolta. Dei parass. veget., Torino, 1873 , and Giorn. an., fis. e. pat. d. anim., I874, vi., p. 25).

(9) Stiles, CH. W. Notes on par. 18, Pres. of Sarcosp. in birds (U.S. Dep. of Agric. Bur. of anim. ind. Bull., No. 3, Washington, I893, p. 79).

(10) Bertram, A. Beitr. Z. Kenntn. d. Sarcosp. In. Diss. Rostock, I892 (Zool. Jahrb. Abth. f. Morphol., v.).

(II) LÜHE, M. Ergebn. d. neuer. Sporoz.-Forsch. Jena, 1900, p. 89.

(iz) Blanchard, R. Sur un nouv. typ. d. Sarcosp. (C. R. Ac. sc. Paris, c. I885, p. 1 599). Note sur les Sarcosp. et sur un ess. d. classif. de ces sporoz. (Bull. soc. zool. France, 1885, x., p. 244).

(13) Rieck, V. Sporozoën als Krankheitserr. (Dtsche. Ztsch. f. Thiermed. u. vergl. Path., I 889, xiv., p. 75).

(14) Leisering and Winkler. Psorosp.-Krkht. beim Schaf (Ber. üb. Vet. Wes. Kgr. Sachsen, I865 ; Virchow's Arch. f. patho. An., I865, xxxvii., p. 431).

(15) Dammann, C. Psorosp.-Krkht. beim Schaf (ibid., I867, xli., p. 283).

(i6) Siedamgrotzky, O. Psorosp. i. d. Musculatur d. Pferde (Wochschr. f. Thierhlk. u. Viehzucht, 1872, xvi., p. 97).

(I7) SchneIdemÜHL, G. Ueber Sarcosp. (Thiermed. Vortr. III., I I, Lpzg. I897).

(18) Pluymers, L. Des sarcosp. et de leur rôle dans la pathog. d. myositis (Arch. méd. exp. et d'an. pathol., I 896, p. 76I ; C. f. B., P. u. I. [I], xxii., p. 245).

(19) Pfeiffer, L. Die Prot. als Krankhtserr. II. edit. Jena, I891. Unters, uib. d. Krebs. Jena, 1893. 
(20) Eecke, J. VAN. Sarcosporidien (Geneesk. Tijdsch. v. Nederl.-Indië, 1892, xxxii. ; Jaarsverl. Labor. path. An. en Bact. te Weltevreden [1892], Batavia, I 893).

(2 i) Piana, G. P. Fasi evolut. d. Sarcosp. (La clinica veter. I 896, p. I45. C. f. B., P. u. I. [I], xx., p. 39).

(22) Laveran and Mesnil. Morph. d. Sarcosp. (C. R. soc. biol. i 899 [io], vi., p. 245),

\section{ApPENDIX TO THE SPOROZOA.}

After bacteriology had, through R. Koch, attained unforeseen importance, the living agents of a number of the so-called infectious diseases of man and domestic animals were discovered, but the participation of living organisms in the causation of other diseases as well as neoplasms was denied. The character of these disturbances, however, led investigators to conjecture that living organisms were also to blame for their causation, and to search for them. Although investigations were instituted by various persons, it cannot be denied that the entire question was first brought forward by the works of L. Pfeiffer in Weimar. Starting with the search for the specific agent of smallpox, this author with untiring zeal pursued the study of the parasitical protozoa, and his publications, independent of many discoveries for which science is indebted to him, aroused much interest, and inspired, directly and indirectly, that impetus which has led to so many important discoveries. Of course many hopes and expectations have remained unfulfilled, although they appeared to be justified, and the investigations, especially directed to the discovery of the agents of malignant neoplasms, have as yet had no favourable results and are still a matter of dispute. Now, as formerly, the opinions of parties are strongly opposed to each other, that which appears to one person to be Blastomycetes or Myxomycetes, others declare to be Sporozoa or other primitive animals, whereas still others declare that the same formations are the degeneration products of cells.

However necessary a knowledge of the works and opinions of his predecessors may be to the investigator of this difficult subject, the less it appears, under the present circumstances, to be necessary to entcr here on to debated ground. It is to be hoped, however, that the time is not far distant that will yield suitable methods for the attainment of more certair: results.

\section{Class IV. Infusoria.}

The bilaterally symmetrical body of the infusoria is enveloped in a cuticle which has numerous openings for the passage of the cilia. Most kinds have a fixed shape, whilst changes in the form of others are brought about by the contractions of the body substance. The latter exhibits the hyaline ECTOSARc, in which contains numerous vacuoles. The CILIA, the various arrangement MYOPHANES and occasionally also TRICHOCYSTS (minute spindleshaped bodies) appear, and the granular ENTOSARC which frequently of which supplies the principle on which this class is divided, are always processes of the ectosarc; their form varies; they may be 
hair-like, or more 'rarely thorn-like, spur-like, or hook-shaped; undulating menıbranes also occasionally occur.

With the exception of some of the parasitical species, an oral cavity, Peristome or Cytostome, is always present; it is frequently beset with longish cilia or provided with undulating membranes, which help to engulf the food; frequently also there is an anal aperture (cytopyge) generally placed at the opposite pole. A CYTOPHARYNX clothed with cilia or supported by ligaments is joined on to the peristome. Vacuoles form round the ingested food, and in many species a constant rotation goes on in the endosarc. Frequently one, sometimes two, contractile vacuoles are present, the frequency of the pulsations of which depends on the surrounding temperature. Sometimes there are in the plasma special conducting channels to the vacuoles or outlet channels leading to the exterior.

There is almost in every case a LARGE NUCLEUS (macronucleus), and lying close up to it a SMALL NUCLEUs (micronucleus); the form of the large nucleus varies exceedingly according to the species. Numerous nuclei are of rare occurrence (as in Opalina, which lives in the terminal gut of amphibians, and is also distinguished by the absence of an oral aperture).

Reproduction is effected by binary fission; less commonly, after encystment, by multiple division, or by budding. The divisions can be many times repeated, but finally cease, and then the conjugation of two specimens brings about a regeneration, particularly of the nuclei. Numerous examinations (Buitschli, Hertwig, Maupas) have demonstrated the fact that after two individuals have joined by homologous parts of the body, the micronucleus separates from the macronucleus, becomes larger and divides twice by the karyokinetic process, so that four micronuclei are present in each one of the two individuals forming the couple (gamete). Three of these nuclei perish and become absorbed, the fourth gradually shifts to the connecting bridge of the protoplasm, which has originated by absorption of the cuticle at the point of contact of the gametes; and changes half of its substance for half of the substance of the fourth micronucleus of the other gamete; a new nuclear body is thus formed and divides, usually twice, in each gamete. Of the segments thus originated one becomes a micronucleus, and one or several of the others, as the case may be, form or amalgamate into a new macronucleus, the old macronucleus usually perishes or becomes absorbed towards the termination of the conjugation. Usually, sooner or later, the two gametes separate and again increase 
independently by segmentations until a series of segmentations are again followed by conjugation. I cannot here go into the theoretical signification of conjugation; only this may be remarked, that the macronucleus plays no part in it, but governs entirely the metabolism of an infusorian, whereas the micronucleus is essentially a sexual nucleus from which macro- and micro- nuclei are produced again and again.

Encystment amongst the infusoria is very general, and is essentially a means of protection when the waters dry up; no doubt these cysts are frequently carried long distances by the wind, which explains the wide geographical distribution of most species. Frequently, also, reproduction takes place in the encysted condition.

Some infusoria live a free life, others are stationary, the latter form colonies in fresh as well as in salt water; numerous species are parasites of various kinds of the lower and higher animals, ${ }^{1}$ and a few also are parasitic in man.

The Prague zoologist, v. Stein, introduced a classification of the infusoria that has been almost universally adopted. It is founded on the different position of the cilia on the body; though, no doubt, very artificial, it is a convenient system. Bütschli has compiled a better one (Bronn's Cl. $u$. Ordn. d. Thierr., vol. i., Protozoa. Part 3, Infusoria). But for our purpose Stein's system is sufficient :--

Order I. Holotricha, infusoria with cilia that are evenly distributed over the entire body.

Order 2. Heterotricha ciliated all over like the Holotricha, but have stouter cilia about the peristome.

Order 3. Hypotricha, ciliated only on the ventral surface.

Order 4. Peritricha, with only a ring of spiral cilia, mostly stationary.

The infusoria observed in man belong to the order of the Heterotricha.

Genus I. Balantidium, Clap. et Lachm.

Heterotrichous infusoria of oval or sac-like form and almost circular on transverse section; the anterior extremity narrowed, the posterior end broad and rounded off, or also narrowed; the peristome starting at the

II may briefly state that numerous peculiarly-shaped species live in the stomach of ruminants, others in the colon of horses; several species are found in the rectum of frogs and toads; others, again, on the surface of the bodies of fishes; and various other species find the conditions for their existence in and on the bodies of invertebrate animals. 
anterior end is there broadest and becomes narrower as it obliquely approaches more or less towards the posterior extremity; there are coarse cilia along the entire left border and the front part of the right border; longitudinal striation distinct and regular; there are two contractile vacuoles to the right, and occasionally also two or more to the left. The anus has a terminal position. Macronucleus oval or horse-shoe shaped, micronucleus contiguous. The movement is always darting. The cysts are globular or oval. Parasitic in the terminal gut of human beings and pigs, in amphibians and in the body cavity of polychaetic annelida.

\section{Balantidium coli (Malmst.), I857.}

Syn. Paramacium coli, Malmsten, I857.

Body oval, o.06-0. I mm. in length (up to $0.2 \mathrm{~mm}$. according to Janowski), and $0.05-0.07 \mathrm{~mm}$. in breadth. The peristome is funnel-shaped or contracted, the anterior end being, accordingly, either broadened or pointed. The ecto- and endo- sarc are distinctly

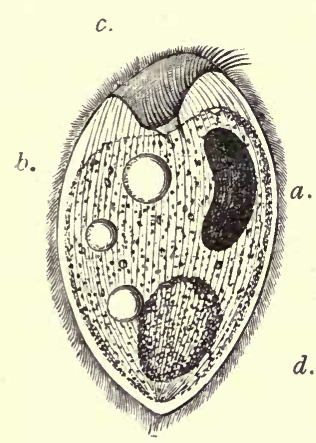

Fig. 62.-Balantrdium coli. (a) Nucleus ; (b) vacuole; (c) peristom (d) bolus of food (after Leuckart).

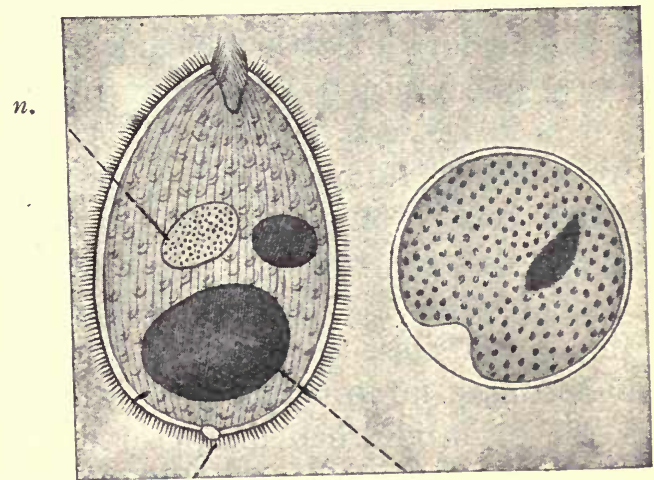

$a$. b.

Fig. 63.-Balantidium coli, free and encysted ; $(a)$ anus ; $(n)$ nucleus; $(b)$ bolus of food (after Casagrandi and Barbagallo).

separate, the latter granular, and containing drops of fat and mucus, granules of starch, bacteria, and occasionally also red and white blood corpuscles; there are usually two contractile vacuoles, sometimes even more. The anus opens at the posterior extremity. The macronucleus is bean- or kidney-shaped, rarely oval ; the micronucleus globular.

It lives in the large intestine of man and in the rectum of the domestic pig; it propagates by transverse division, but conjuga- 
tion and encystment are known to take place $;^{1}$ transmission to other hosts is effected during the encysted stage.

Balantidium coli was discovered by Malmsten in 1857 in a man aged 35 years, who had two yearș previously suffered from cholera, and since then had been subject to diarrhœa; the examination revealed an ulcer in the rectum above the mid sphincter ani, in the sanguineous purulent secretion of which numerous Balantidia were swimming about. Although the ulcer was made to heal, the diarrhœa did not cease and the stools contained numerous balantidia, the number of which could only be decreased by extensive enemas of hydrochloric acid.

The second case related to a woman who was suffering from severe colitis, and who died ten days after admission. The malodorous, watery evacuations contained innumerable balantidia in addition to pus, and at the autopsy the anterior portion of the large intestine was found to be their habitat.

Subsequently this parasite has often been observed in human beings, and according to Shegalow's compilation 63 cases have been recorded. These occurred as follows : 24 cases in Russia, 15 cases in Scandinavia, 7 cases in Finland, 6 cases in Cochin China, 5 cases in Italy, 3 cases in Germany, 2 cases in the United States, and I case in the Sunda Islands.

In addition 5 more cases came under observation in Königsberg, Prussia (Collmann), one was incidentally mentioned by Maggiora as occurring in the Province of Alexandria, and one case occurred in Tomsk (Solowjew).

In the greatest majority of the cases the patients suffered from obstinate intestinal catarrh, which did not always cease even after the balantidia had disappeared; whereas, on the other hand, balantidia have occasionally still been found to be present, though in small numbers, after the catarrh has been cured. Most authors, nevertheless, do not regard balantidia as the primary cause of the various diseases of the large intestine, which often commence with the development of ulcers, but they consider that they may aggravate these diseases and render them obstinate. According to

1 According to Gourvitch " Bal. coli. Darmk. d. Menschen," Russ. Arch. f. Path., klin. Med. u. Bact., St. Petersb., I 896), the conjugated balantidia are supposed to amalgamate with each other and form oval cysts two or three times the size of the free creatures, and to divide into numerous globules within the cystic membrane; the process, however, has hitherto not been observed. The supposed balantidium cysts appeared in two patients after the administration of anthelminthic, and who were simultaneously suffering from Bothriocephalus latus; it therefore appears to me, according to the description, that in reality these forms were actually abnormally large, possibly swollen, young eggs of the tapeworm mentioned. 
Solowjew, however, the parasites penetrate the intestinal wall, and give rise to ulcerations which may extend deeply into the subserosa ; this author states that he has also seen them in the blood and lymphatic vessels of the intestinal wall. Strong and Musgrave (Bull. Johns Hpk. Hosp., Igor, xii.) have made similar observations, as also has M. Askanazy (Vortrag. i. d. biol. Sect. d. Phys. Ges. Königsberg, Pr., I902). According to Stokvis, Balantidium coli occurs also in the lung; at all events this author states that he found one living and several dead paramaecia (?) in the sputum of a soldier returned from the Sunda Islands, and who was suffering from a pulmonary abscess.

Since Leuckart confirmed the frequent presence of Balantidium coli in the rectum of pigs, and corresponding observations were made in other countries, the pig is universally considered to be the means of the transmission of balantidium to man. The encysted stages alone can subserve transmission, because, according to all observations, the free parasites have a very small power of resistance; they even perish when the fæces have become cool, they cannot live in ordinary, or slimy, or salt water; and as they are killed by acids even when much diluted, it follows that they could not pass through the normal stomach alive except under the most exceptional circumstances. The pigs, in whose intestines the balantidium appears to cause no disturbances, evacuate numerous encysted balantidia with the fæces, and their occasional transference to man brings about their colonisation there, but apparently only when a disease of the colon already exists. No colonisation takes place in healthy persons, as has been demonstrated by Grassi and Calandruccio from experiments made on their own persons.

Experimental transmission of the free parasites to animals (per os or per anum) yielderl negative results, even in the case of pigs; only Casagrandi and Barbagallo had positive (as well as negative) results; they employed healthy young cats, or cats in which catarrhal entero-colitis had been artificially induced (and which in other experiments is apt to cause the death of the animals experimented upon in about six or seven days), or finally cats that had dilatation of the rectum with alkaline reaction of the fæces. The experiment to infect three healthy cats by injecting human fieces containing balantidium in the rectum proved negative, in so far as the freces of the experimental animals had an acid reaction and contained no balantidia, but at the autopsy performed after eight days a few ENCYSTED parasites were found in the mucus of the 
ileum. In the case of four cats suffering from entero-colitis, into which human fæces containing balantidia were introduced per os, balantidium cysts were found in the fæces three days after the last ingestion; great numbers, moreover, were found in the cæcum and the posterior part of the small intestine at the autopsy of the animals which died about eight days after the commencement of the experiment; actual colonisation, therefore, was not achieved in either series of experiments. Free or encysted balantidia of pigs were used for further experiments. The experiments proved negative when fæces containing cysts were injected into the rectum of healthy cats (three experiments), or cats (two) suffering from spontaneous intestinal catarrh, or when such material was introduced per os into three healthy cats. In the case of two cats with intestinal catarrh artificially produced, a small number of the non-encysted balantidia injected into the rectum remained alive; larger quantities of fæces containing encysted balantidia were introduced into two other cats affected with the same complaint; these, certainly, did not appear in the fæces, but small numbers, free and alive, were found in the cæcum. Similarly encysted balantidia were introduced into two cats with dilated rectum, and whose fæces had an alkaline reaction; in these cases also no parasites appeared in the fæces, but three and five days later, when the two animals were examined, a very small number were discovered free in the large intestine.

These experiments teach us that human fæces and the fæces of pigs have a different effect on cats, moreover, that they are neither pathogenetic to these animals nor capable of influencing intestinal diseases, artificial or spontaneous, and finally that even when not encysted they pass through the stomach of cats uninjured when introduced with large quantities of fæces of an alkaline reaction. It stands to reason that this mode of infection cannot be considered as a means of transmission to man.

\section{LITERATURE.}

Malmsten, P. H. Infusorien als Intestinalthiere b. Mensch. (Virch. Arch., I857, xii., p. 302.)

Shegalow, J. P. Ein Fall v. Bol. coli bei einem 5 jähr. Mädch. (Jahrb. f. Kdrhlkde., I 899, xlix., p. 425).

JANowski, W. Ein Fall v. Bol. coli im Stuhl (Ztschr. f. klin. Med., I 897, xxxii., p. 4I5). (A complete list of the literature is given by Janowski, Shegalow and Solowjew.)

Collmann, B. 5 Fälle v. Bol. coli i. Darm d. Mensch. In. Diss. Kgsbg., 1900.

Maggiora, A. Micr. u. bact. Beob. währ. ein. epid. dys. Dickdarmentzünd. (C. f. B. u. P., $1892, x i .$, p. 181 ).

Solowjew. Bol. coli als Erreg. chron. Durchf. (C. f. B., P. u. I., I90I [I], xxix., pp. $821,849)$. 
Srokvis, B. J. Paramecium in sputa (Nederl. Tijdsch. voor Geneeskde., I 884 [2], xx. Leuckart, R. Die menschl. Par., ist edit., ist vol., I863, p. I 47.

Grassi, B. Signif. patol. d. prot. par. dell'uomo (Atti Accad. d. Lincei Rendic., I 888 [4], iv., Sem. I, p. 86).

Casagrandi, O., and P. Barbagallo. Bol. coli s. Param. coli. Catania, i896. $8^{\circ}$.

\section{Balantidium minutum, Schaudinn, I899.}

Body of oval form, anterior extremity pointed, posterior extremity broad and rounded off. Length $0.02-0.032 \mathrm{~mm}$., and $0.014-0^{\circ} 02 \mathrm{~mm}$. in breadth; the peristome, fissure-like, extends to the centre of the body; the right lateral border of the peristome is beset with cilia the same length as those of the body, the left side terminates in a thin hyaline membrane that extends towards the back and flaps over the right border of the peristome. A row of longer and stronger cilia on the left border of the peristome. The cuticle is light, refracting, the ectosarc hyaline, the endosarc granular, with numerous food vacuoles.

A single contractile vacuole lies dorsally on the left in the posterior extremity. The macronucleus, which is always globular, lies in the centre of the body and is $0.006-0.007 \mathrm{~mm}$. in diameter; the micronucleus, close in front of it,

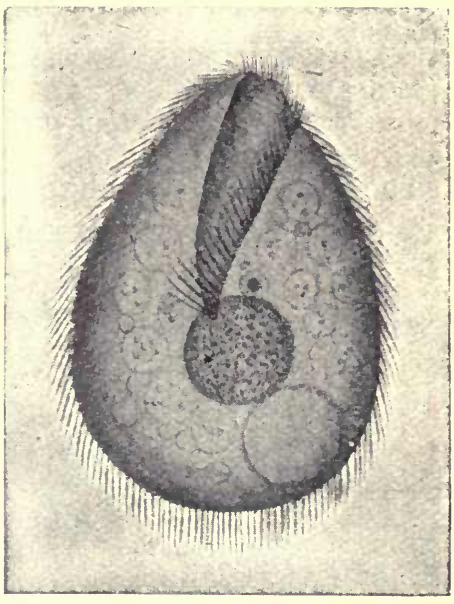

FIG. 64. - Balantidium minutum, Schaud. The contractile vacuole is almost as large as the granulated macronucleus in front of it; close to the latter is the micro-nucleus; the food vacuoles are in the endosarc (after Schaudinn). only measures o.0oI $\mathrm{mm}$. The cysts are oval.

These parasites were found in masses in the evacuations of a man aged 30, who was born in Germany and had repeatedly travelled between Hamburg and North America, where he made long stays. The patient came to the Charité in Berlin to seek advice for constipation alternating with diarrhœea accompanied by abdominal pain.

A second case (termed Colpoda cucullus by Schulz) was observed in a patient in the same institution.

As, in both cases, the parasites only appeared during the diarrhœa, and disappeared as soon as the fæces had assumed a normal consistency, or could only be demonstrated in a few 
encysted specimens, it may be assumed that the small intestine or the duodenum is their habitat. ${ }^{1}$

\section{Genus 2. Nyctotherus, Leidy, I849.}

Flat, heterotrichous infusoria, kidney- or bean- shaped. The peristome commences at the anterior pole of the body and extends along the concave side up to the middle, where the oral aperture is situated. The cytopharynx runs in an oblique direction and is more or less bent. The anus is at the posterior extremity, where a single contractile vacuole is also situated. The macronucleus is almost in the centre of the parasite. This species lives parasitically in the intestine of amphibians, insects and myriapods, and one species is also found in man.

\section{Nyctotherus faba, Schaudinn, I899.}

The body is bean-shaped, and a little flattened dorso-ventrally, $0.026-0.028 \mathrm{~mm}$. in length, 0.016-0.018 mm. in breadth, 0.010-

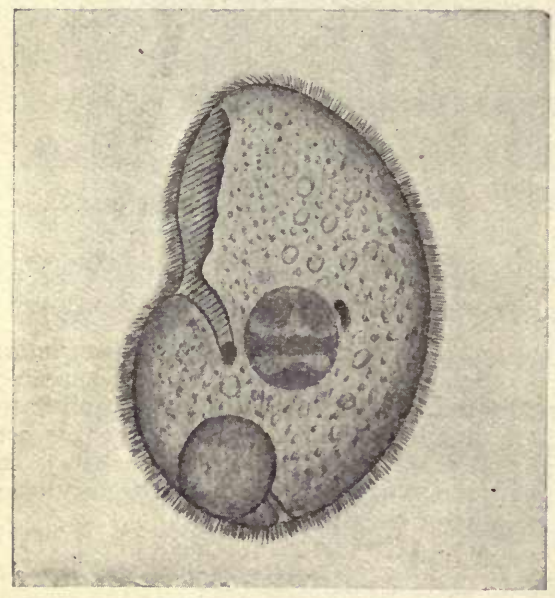

Fig. 65.-Nyctotherus $f a b a$, Schaud. From life (after Schaudinn). $0.012 \mathrm{~mm}$. in thickness. The peristome is on the right border and extends to the middle; at the left there are large adoral cilia; the cilia on the right border not being larger than those on the body; the cytopharynx is short, slightly bent and turned backwards. The contractile vacuole is large, globular, situated at the posterior extremity, and its contents are voided through the anus at its left. The macronucleus is in the centre of the body; it is globular (0.006$0.007 \mathrm{~mm}$. in size), and has four or five largish collections of chromatin; the micronucleus lies close to it, and is globular or somewhat elongated (0.00I-0.00I5 mm.). Cysts oval.

This species has hitherto only been seen once in the same patient in whom Balantidium minutum was discovered. ${ }^{2}$

'Jakoby, M., and F. Schaudinn, "Ueb. 2 neu Inf. i. Darm d. Mensch." (C. $f$. B., P. u. I., I 899, xxv., p. 487); Schulz, "Colpoda cucullus im Darm d. Mensch." (Berl. klin. Wchschr., I 899 , No. 16, p. 353).

${ }^{2}$ For literature see above, Balantidium minutum. 


\section{APPENDIX TO THE INFUSORIA.}

In order to guard against renewed ERRORs it must be mentioned that little objects moving by means of cilia have repeatedly been found in the sputum or nasal mucus in diseases of the respiratory passages, and being regarded as genuine parasites have been brought into connection with these diseases. The very irregular and varied form of these bodies, their rapid and peculiar disintegration, and the origin of the fluids in which they are found, should have guarded from error. These little bodies are nothing but loosened ciliated cells from the trachea, the bronchial tubes or the nose, which move with the assistance of the cilia for some time. though this does not prove their independent nature. To this category belong Asthmatos ciliaris, Salsb., ${ }^{1}$ Deichler's protozoa of whooping cough," as well as Kurloff's parasites of whooping cough. ${ }^{3}$

G. Lindner, of Cassel, has also become the victim of repeated errors and mistakes in spite of all protests; he never tires of hunting for certain peritrichous infusoria (non-pedunculated vorticella), and seeks to bring them into connection with the most various diseases of man and beast. and he even tries to connect them with the sarcosporidia of pigs. It is not necessary for the author of this book to go further into the relation of these mistakes. ${ }^{+}$

\section{B. PLATYhELMinthes, or Flat worms.}

Bilaterally symmetrical worms, the form of which is blade or tapelike, rarely cylindrical, and whose primary body cavity (segmentation cavity) is mostly filled up by a mesenchymatous tissue (parenchyma). The mouth is either situated at the anterior end of the body, or is shifted more or less backwards onto the flat abdominal surface. The alimentary canal consists of a short fore-gut, which is frequently provided with a muscular pharynx, and of a simple forked or branched mid-gut ; there is neither a hind-gut nor an anus; in one group the Cestodes the alimentary canal has entirely disappeared.

The INTEGUMENT OF THE BODY consists either of a ciliated epithelium of only one layer (Turbellaria), or of a cuticle and of glandular cells sunk into the parenchyma, which is termed a subcuticular layer (Cestodes, Trematodes). The musculo-dermal layer consists of annular, longitudinal, and even diagonal fibres, whereas the parenchyma is traversed by dorso-ventral fibres.

The central Nervous system, which is embedded in the parenchyma

${ }^{1}$ Salisbury, J. H., "Infus. Catarrh and Asthma; discovery of the Cause of one form of Hay Fever, \&c." (Ztschr. f. Parasitenkde. (Hallier), iv., [1873], I875, p. 6); Cutter, E., "Rhizop. a Cause of Disease" (Vivginia Med. Monthly, v., I878, p. 605, and vi., I879, p. 28); Leidy, J., "Asthm. ciliaris, is it a Parasite?" (Amer. Journ. Med. Sc., I879, lxxvii., p. 85).

"Deichler, C., "Ueb. paras. Prot. im Keuchhustenauswurf" (Z. f. w. Z., I 885, xliii., p. I44, and I889, xlviii., p. 303).

"Kurloff, M., "Keuchhusten-Parasiten" (C. f. B., P. u. I. [I]. xix., I 896, p. 5 I 3).

+ According to a written statement, Schaudinn has repeatedly found vorticella with lively movements in freshly-evacuated fæces, but always only after water enemas. 
of the body, consists of cerebral ganglia, united together in the shape of dumb-bells, and of two or several MEDULLARY FASCICULI forming often anastomoses. Organs of sense usually occur only in the free-living species, more rarely during the free-living stages of a few parasitic species and in a few ectoparasites.

[In Platyhelminthes simple eye-spots frequently occur, and in a few an auditory vesicle.

BLOOD-VESSELS and definite RESPIRATORY ORGANS are lacking [except in Nemertinea]; the EXCRETORY APPARATUS (formerly also termed water-vascular system) is typical of the entire class. It commences in the interstices of the parenchyma, with peculiar ciliated infundibuli which will be described further, the capillary processes of which go on uniting into larger branches, and finally form two large collecting vessels, which, sometimes separately and sometimes united, open to the exterior through one, two, or numerous pores.

Nearly all the Platyhelminthes are HERMAPHRODITIC [the exceptions are the Bilharzia, Microstomidae and Nemertinea-F. V. T.], and in nearly all there are in addition to the ovaries producing ova, other glands attached to the female genital apparatus, namely, the yolk glands, which provide a substance termed yolk, which serves as nourishment for the embryo. The fully-formed eggs have shells and are composed of the ovum, which is surrounded by numerous yolk cells or their product of disintegration. The two sexual openings usually lie close together, frequently in the base of a genital atrium; they are rarely separated from one another. Shell-glands also usually occur.

Reproduction is sexual, often, however, combined with asexual methods of propagation (segmentation, budding). The Platyhelminthes live partly free in fresh or salt water, exceptionally, also, on land. The greater part, however, live as parasites on or in animals.

\section{Classification of the Platyhelminthes.}

Class I.-Turbellaria, or Eddy worms. Flat worms for the most part, free-living and always covered with a ciliated epithelium. [They are usually leaf-shaped or oval.-F. V. T.] Their intestine is either simple (Rhabdocclida) or ramified (Dendrocalida), ${ }^{1}$ or they have an entodermal syncytium gradually dispersed throughout the parenchyma (Accla). ${ }^{2}$ Development direct or through metamorphosis. They live in fresh and salt water or on land; very seldom as parasites.

Class II.-Trematoda, Sucking worms. ${ }^{3}$ [Usually known as Flukes.F. V. T.] Flat worms, living as ecto- or endoparasites, that are only

${ }^{1}$ [These are also known as Polycladida and Tricladida.-F. V. T.]

${ }^{2}$ [These are a division of the Rhabdocalida.-F. V. T.]

${ }^{3}$ This grouping goes back to the year I800, and was made by J. G. H. Zeder, a doctor and helminthologist of Forchheim, who divided the helminths, which until I 85 I were generally regarded as particular classes of animals, into the groups of hook, round, sucker, tape and cyst worms, as which they are recognised up to the present time. In I809, however, K. A. Rudolphi gave them the names, Nematodes, Acanthocephali, Trematodes, Cestodes and Cystici. 
ciliated in the larval condition, ${ }^{1}$ and in their adult state are covered with a cuticle, the matrix cells of which are sunk into the parenchyma. They have either one, a few, or several sucking discs, and frequently also possess chitinous clasping [suckers with chitinous armour] and clinging organs [hooks]. The intestine is simple, but generally bifurcated, and not rarely there are transverse anastomoses between, or blind ducts at the branches of, the fork. Excretory organs double, with two orifices at the anterior extremity or a simple one at the posterior end. [The two trunks usually open into a common contractile vesicle, which opens at the posterior end of the body.-F. V. T.] Development takes place by a metamorphosis or alternation of generations. These worms are almost always hermaphroditic; with two [Polytomum and most Monogenea] or several female and one male sexual orifices." They live, almost without exception, as parasites on vertebrate animals, but the intermediatry generations are passed in molluscs.

Class III.-Cestoda (Tape worms). Endoparasitic flat worms without an alimentary canal. The larval stages are rarely ciliated, but are usually provided with six hooklets; the adult worm is covered with a cuticle, the matrix cells of which are sunk into the parenchyma. The body is either simple (Cestodaria), or composed of a chain of segments, in which case it consists of the scolex, and the segments containing the sexual organs '(Proglottides) (Cestodes s. str.). The scolex is provided with various sucking and clinging organs, and there are calcareous bodies in the parenchyma. Excretory organs symmetrical, opening at the posterior end. These worms are almost always hermaphroditic, and then possess one or two female and one male sexual orifice. During development a larval intermediary stage termed "cysticercus" appears which almost always lives as the sexual animal in another host. The adult stage is parasitic in vertebrate animals and the larval stage in invertebrates. [This is not always the rule, for this cyst stage occurs abundantly in vertebrates, such as Cysticercus cellulosa in the pig, Cysticercus pisciformis in rabbits, \&c.-F. V. T.]

\section{Class I. Trematoda, Rud.}

These worms are usually leaf- or tongue- shaped, rarely barrelshaped or conical; they vary from $o^{\circ} \mathrm{I} \mathrm{mm}$. to almost I m. in length; most of them, however, are small (5- $55 \mathrm{~mm}$.). The surface on which the orifice of the uterus and the male sexual opening are situated is termed the ventral surface; the oral aperture, which also acts as anus, is always at the anterior end, except in the genus Gasterostomum, which is parasitic in fishes.

Sucking discs are common and occur in varying numbers and positions at the anterior and posterior extremities as well as on the ventral surface, and occasionally on the lateral border and on the

' [An exception to this occurs in Temnocephala, in which the skin, especially on the surface of the tentacles, is provided here and there with cilia.-F. V. T.]

${ }^{2}$ [In Diplozoon and one or two other forms the vagina is unpaired.-F. V. T.] 
dorsum; usually also the beginning of the intestine is surrounded by a sucker.

In or near the suctorial apparatus there are chitinous hooks, claws or claspers, or the surface of the body is more or less covered with spines, scales or prickles; in one species (Rhopalias) there is a projectile rostrum beset with spines.

The body of all the Trematodes is covered by a homogenous CUTICLE of varying thickness, which either lies directly over the external layer of the parenchyma, which is thickened into a kind of basement membrane, or is situated immediately over the muscles embedded in the parenchyma: The pyriform or fusiform EPITHELIAL CELLS lie in groups with their thickest parts between or directed towards the internal of the diagonal muscles, but a process directed outwards also connects them with the basal surface of the cuticle. There are also unicellular cuticular glands, lying isolated or in groups, which are termed head, abdominal, or dorsal glands according to the position of their orifice.

THE PARENCHYMA is a connective substance, i.e., it consists of numerous multipolar cells, the offshoots from which branch strongly, then anastomose with each other as well as with the offshoots of other cells, so that a network, permeating the entire body and encompassing all the organs, is produced. There is in addition a homogenous matrix, in the form of lamellæ and trabeculæ, that border small cavities communicating with each other and filled with a liquid substance. ${ }^{1}$ In some species the parenchyma encloses pigment cells.

The MUSCULAR SYSTEM of the Trematodes is composed of a musculo-dermal tube, the dorso-ventral or parenchymal muscles, the suctorial discs, and the special muscles of certain organs.

The musculo-dermal tube, which lies fairly close to the cuticle, consists of annular, transverse, and longitudinal fibres which surround the entire body in one or several layers, and as a rule are more strongly developed on the ventral surface as well as in the anterior part of the body. The MUSCLES OF THE PARENCHYMA are found chiefly in the lateral parts of the body and pass through

1 According to other authors, the parenchyma of the Trematodes consists originally of similar cells, of which, however, in the adult stage, only the cellular membranes have remained, between which an intercellular mass has appeared, while the protoplasm has been transformed into a watery liquid in which only here and there a nucleus, surrounded by a little unaltered protoplasm, has remained. By partial absorption of the walls contiguous spaces become connected, and their originally flat partitions become trabeculæ. 
the parenchyma in a dorso-ventral direction; their diverging brushlike ends are inserted on the inner surface of the cuticle (fig. 67).

The suctorial discs seem to be specially differentiated parts of the musculo-dermal tube. Their concave inner surface is lined by the continuation of the cuticle and their vaulted external surface is covered by a more dense tissue that frequently takes the form of a shiny membrane.

The principal mass of the suctorial discs consists of muscular fibres which run in three directions - equatorial, meridional and radial. The equatorial fibres correspond to the annular muscles, the meridional fibres to the longitudinal muscles, and the radial fibres to the muscles of the parenchyma; the radial fibres are always most strongly developed. The function of these muscles is consistent with their position; the meridional fibres flatten the suctorial disc and diminish the depth of its cavity, so that the internal surface may touch the object to be held; if the equatorial fibres then contract, the suctorial pore rises by means of longitudinal stretching, and the inner surface of the organ is drawn in by the contraction of the radial muscles. Thus the sucking disc becomes adherent. Usually also there is a sphincter at the border of the suckers,

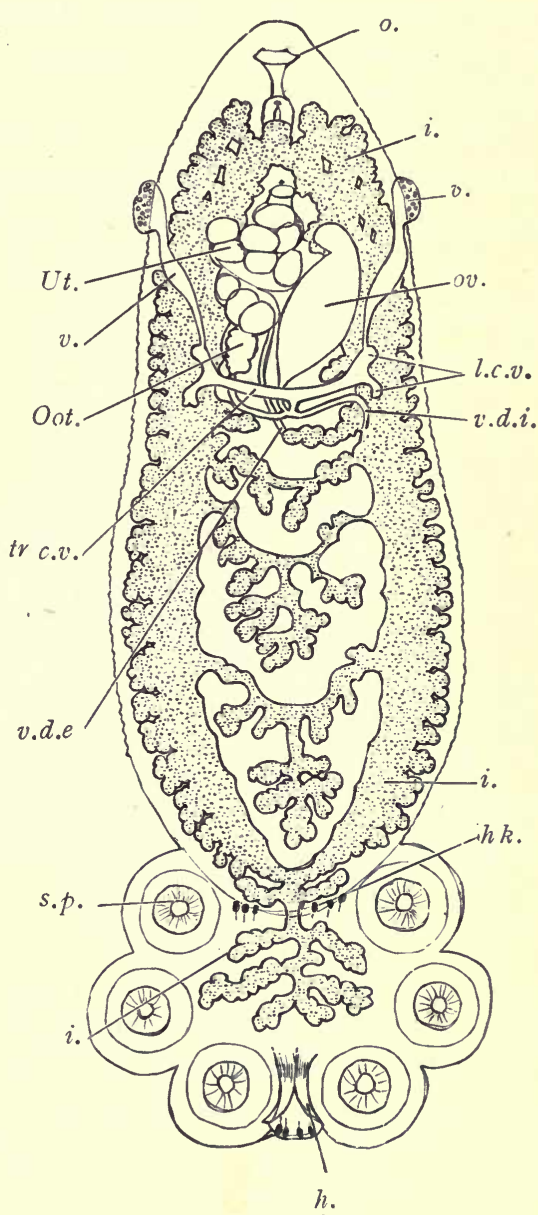

FIG. 66. - Polystomum integerrimum from the urinary bladder of the frog. (After Zeller.) $i .$, intestine; $h .$, large hook of the sucker; $h k$., smaller hooklets; l.c.v., longitudinal canals of the vitelline sac; o., oral orifice; oot., ootype ; ov., ovary; s.p., suctorial pores of the disc; tr.c.v., transverse canals of the vitelline sac; $u t$. , uterus with ova; $v$. , entrance to the vagina; v.d.e., vas deferens; v.d.i., ductus vitello intestinalis ; the vitelline sac and testicular vesicles are not seen. (Magnified.) which plays its part during the act of adhesion by constricting in a circular manner that part of the nucous membrane to which 
it is attached. The loosening of the fixed sucker is effected by relaxation chiefly of the radial fibres, by the contraction of the meridional fibres and certain bundles of muscles situated at the base and in the periphery of the suckers. The connective and elastic tissues between the muscles of the suckers probably also take part in this process.

Of the muscles of the organs which have developed from the parenchyma muscles we may briefly mention those bundles that are attached to certain parts of the genital apparatus, to the suckers, to the hooks and claws, and also, at all events in Distomum hepaticum, to the spines. The sheaths used for the projection of the rostrum of the Rhopaliadea are also muscular.

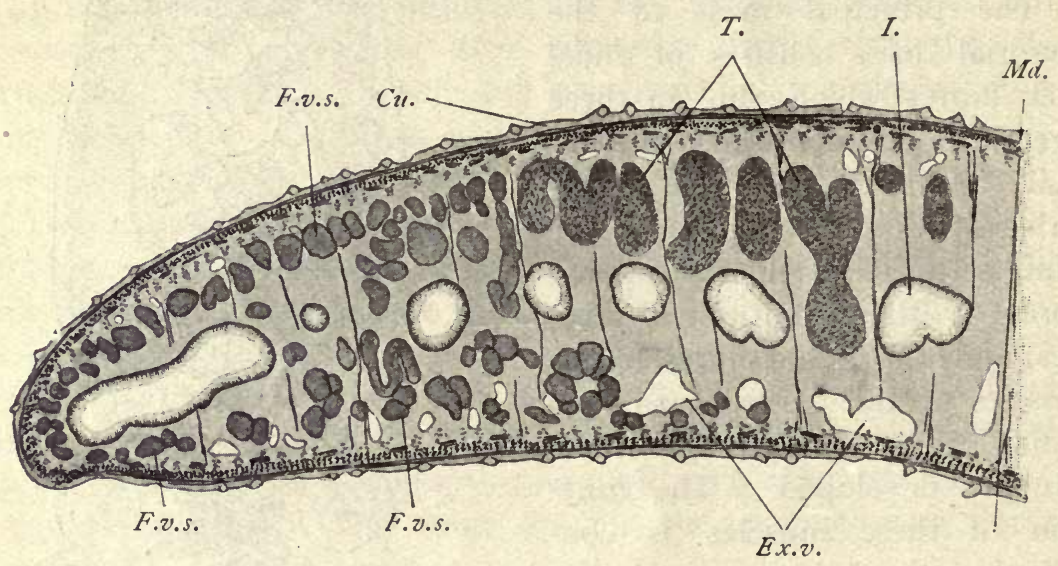

FIg. 67.- Half of a transverse section through Fasciola hepatica, L. 25/1. Cu., Cuticle with scales; under the cuticle are circular muscles which adjoin the longitudinal and diagonal muscles; within the latter are the matrix cells of the cuticle; $I$., intestinal tube; the remaining similarly contoured space cavities are intestinal culs-de-sac that have been transversely or obliquely sectioned; F.v.s., follicles of the vitelline sac; Ex.v., excretory vessels; $T$., testicular tubules; Md., median plane; the fibres passing from the ventral to the dorsal surface are the muscles of the parenchyma. The parenchyma itself is omitted.

The contractile elements consist of fibres of various lengths that are mostly parallel to one another, and frequently anastomose; a cortical substance of delicate fibres can usually be distinguished from an internal homogenous mass; large nucleated cells of equal size are always connected therewith, these have been variously named, but have finally proved to be myoblasts; one or more of their processes are the muscular fibres.

The movements of the Trematodes consist in alterations of form and position of the body, as well as in creeping movements. 
In the Nervous SYSTEM (fig. 68) can be distinguished a cerebral portion as well as fasciculi (usually termed nerves) running from them, and peripheral nerves. The cerebral portion always consists of two large ganglia situated in the anterior end of the body which pass dorsally over the œesophagus and are connected by means of a broad and thick commissure composed of fibres only. From each ganglion three nerves project towards the front-the inner and dorsal nerve for supplying the anterior dorsal part of the body; the median and ventral for the oral sucker: and the exterior and lateral likewise for the supply of the sucker.

In a similar manner three fasciculi proceed backwards from each ganglion, one dorsal, one lateral and one ventral. The dorsal and ventral fasciculi become united and curve backwards ; the symmetrical lateral fasciculi are connected by means of transverse commissures, the number of which vary according to the species. Such commissures also exist between the lateral and the

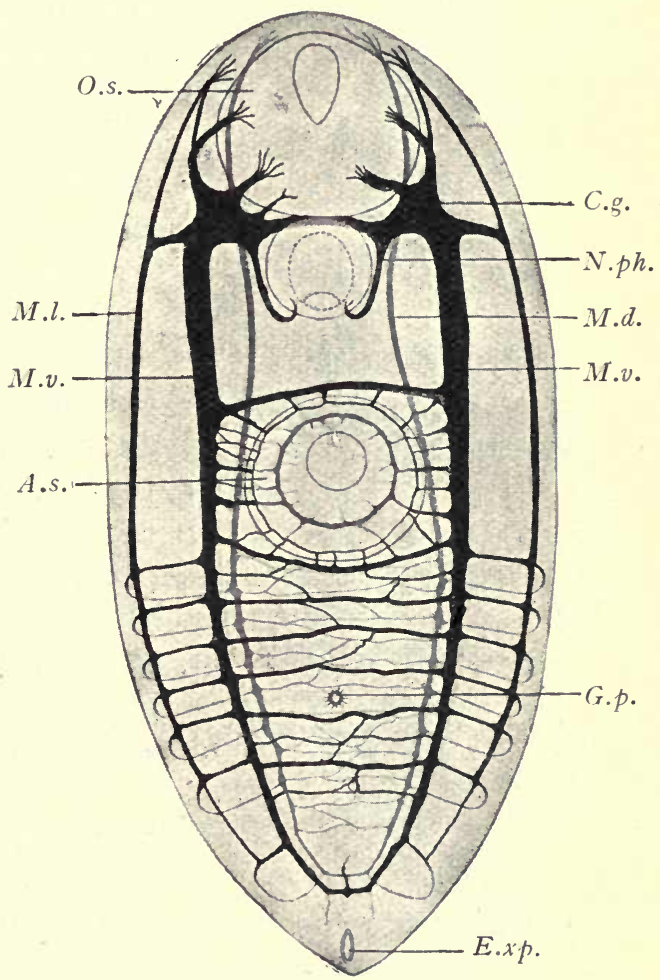

FIG. 68.-Harmostomum leptostomum (Olss.) in its immature condition (from Helix hortensis). Nervous system, according to Bettendorf, magnified: A.s., Abdominal sucker; C.g., cerebral ganglion; E.x.p., excretory pore; G.p., genital pore; O.s., oral sucker; $M . d .$, dorsal medullary fasciculus; M.l., lateral medullary fasciculus; N.ph., pharyngeal nerve; $M . \tau$. , ventral medullary fasciculus. two other fasciculi on each side. There are ganglion cells along the entire course of the posterior cords, more particularly at the points of departure of the commissures. There also appears to be in addition a fourth anterior and posterior pair of nerves, the front pair for the oral sucker and the hind pair for the pharynx.

The peripheral nerves, which spring from the, posterior cords 
as well as from the commissures, either pass directly to the muscular fibres or to the sensory cells that are situated at about the same level as the sub-cuticular cells, or they reach these after the formation of a plexus situated immediately beneath the fibres of the cuticular muscles; the processes directed outwards terminate in small vesicles in the cuticle.

As to other ORGANS OF SENSE, simple eyes, two or four in number, are known in several ectoparasitic species as well as in

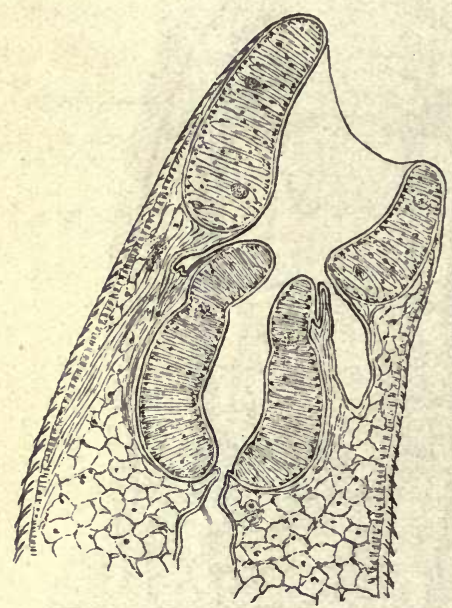

FIG. 69. Median section through the anterior part of Distomum hepaticum; the oral sucker, pharynx with bursa and the osophagus have been cut through.

a few free-living larval stages of endoparasitic forms (Cercaria). In the adult stage, however, they usually undergo complete retrogression.

The ALIMENTARY CANAL commences with an oral aperture situated on the ventral surface of the anterior extremity and usually connected with an oral cavity surrounded by a sucker; the œesophagus of varied length is directed backwards and is generally provided with an elastic muscular pharynx (fig. 69). Sooner or later the intestine divides into two lateral branches directed backwards, both of which end blindly at the same level. ${ }^{1}$

In many ectoparasites (Monogenea)

a connection is established between the genital glands and one of the intestinal branches [ductus vitello-intestinalis (fig. 66).] [This duct has

${ }^{1}$ The following conditions represent deviations from this type: (I) In Gasterostomum the oral aperture is situated in the middle of the ventral surface, and occasionally is even nearer to the posterior than to the anterior end. There is no proper oral sucker, but the pharynx is thus termed. (2) A few genera, such as Gasterostomum, Aspidogaster, Diplozoon, \&c., have only one intestinal pouch, which is undoubtedly to be understood as representing the primitive condition, as it is also often found in the young stages of the Trematodes. (3) The branches of the intestines are curved and united, behind (several Tristomidea and Monostomidea), while in Polystomum integerrimum (in the bladder of frogs) there are several commissures between the intestinal branches, and in Schistosominea the united intestinal branches proceed as one channel towards the posterior end. (4) The termination of the two intestinal branches is not always on a level, they are therefore of different lengths. (5) When the œesophagus is very long the intestinal branches extend both forward and backward, so that the gut exhibits the form of an $\mathrm{H}$. (6) In the broad and flat species the intestinal diverticules mostly develop laterally, or may also run along the median line, and may again branch off. (i) In a few cases (Nematobothrium, Didymozoon) the intestine completely disappears up to the pharynx. 
apparently the same relations as the "canal of Laurer" of the Digenea, except that the latter opens to the exterior direct.F. V. T.].

The oral cavity, the œsophagus, and the pharynx with its pharyngeal bursa, are lined with a continuation of the cuticle of the body; the intestinal branches are lined with high cylindrical epithelium (fig. 67). The œsophagus and intestinal branches also have often one layer of annular and longitudinal muscles ; the pharynx has essentially the structure of a sucker (fig. 69).

The accessory organs of the alimentary canal consist of groups of unicellular SALIVARY GLANDS that discharge into the œesophagus in front of or behind the pharynx, or even into the pharynx itself.

The food of the Trematodes consists of cutaneous mucous, epithelial cells, the intestinal contents of the hosts, and often also of blood, and this not only in those species living in the vascular system, or in the intestine or biliary passages of their hosts, but also in species living as ectoparasites.

The final products of assimilation which are soluble in the fluids of the body are distributed throughout the parenchyma and are thence expelled by a definite tubular system (excretory apparatus, protonephridia, formerly also termed the watervascular system). This system, which is distributed throughout the entire body (fig. 70) is symmetrically developed, and, in the monogenetic (ectoparasitic) Trematodes it opens, right and left, at the anterior end of the dorsal surface; in all other species, however, it opens singly into the excretory pore (foramen caudale) at

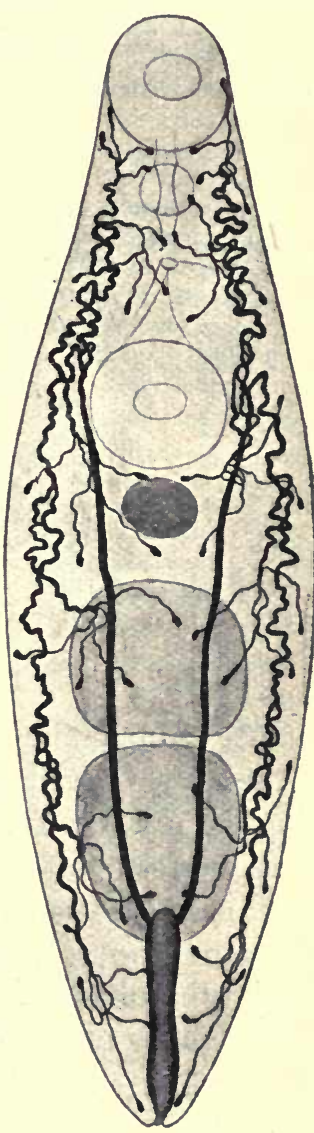

FIG. 7o. - Allocreadium isoporum (Looss). 38/1. Excretory apparatus. Of the other organs, the oral sucker, pharynx, genital pore, abdominal sucker, ovarium and testes are sketched in; the cylindrical excretory bladder is in the posterior end. (After Looss.) the centre of the posterior border; in those cases, however, where a sucker is present at the posterior end, as in the Paramphistomidea, the excretory pore is situated on the dorsal surface close in front of the sucker. 
The EXCRETORY SYSTEM ${ }^{1}$ consists of several parts: (I) of the more or less numerous terminal or infundibular cells (figs. $70,7 \mathrm{I}$ ); (2) of the capillaries joined to them ; (3) of larger vessels taking up the capillaries, and (4) of the excretory bladder. Terminal cells and capillaries may be compared to unicellular glands with long excretory ducts; the cellular body (fig. 7I) is comparatively large, stretched lengthways, more rarely transversely, and provided with numerous

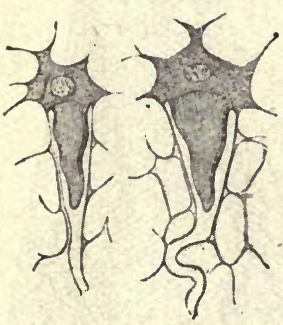

FIG. 7 I.-Terminal cells of Cotylogonimus heterophyes (v. Sieb.). 700/r. Left from the side, right from the surface. (After Looss.) processes that are lost in the parenchyma; it contains within a conical alveolus (analogous with the secretory space of unicellular glands) which continues direct into the structureless capillary; at its blind end is a bunch of cilia which reaches the open space, and which, during life, shows a waving motion (ciliary movement). In the protoplasm of the terminal cell at its blind end the nucleus is situated.

The entire apparatus begins as a cul-de. sac, i.e., enclosed within the terminal cells, to which may be ascribed the capacity of taking up from the fluid that permeates the parenchyma the part to be excreted, which is first collected into their own cavities and thence carried out by means of the capillaries and vessels.

The vessels possess definite walls, but some authors state that these canal-like spaces taking up the capillaries are only separated by a homogenous layer belonging to the parenchyma. They may repeatedly reunite on either side, and again give rise to other canals (GATHERING TUBES), which finally, travelling towards the posterior end, discharge into the excretory bladder (fig. 70).

The form and size of the bladder varies much according to the different species, but it always possesses its own epithelium, surrounded by circular and longitudinal muscles, the circular muscles forming a sphincter around the opening. Frequently also the structure of the bladder extends to the tubules discharging into it, which therefore are not to be regarded as separate "vessels," but rather as tubular diverticula of the bladder, directed anteriorly. In some few species the diverticula also branch off and the branches anastomose, so that a network of tubules ensues which

${ }^{1}$ The following description relates to the Fasciolidea. 
is connected with the vèssels. In such cases there are also ciliary lobes in the tubules.

The contents of the entire apparatus usually consist of a clear or sometimes reddish fluid; in some species there are larger or smaller granules, and occasionally concretions also occur.

Sexual Organs.-Nearly all the Trematodes are hermaphrodites, and only a few (Schistosominea, Koellikeria) are sexually differen-

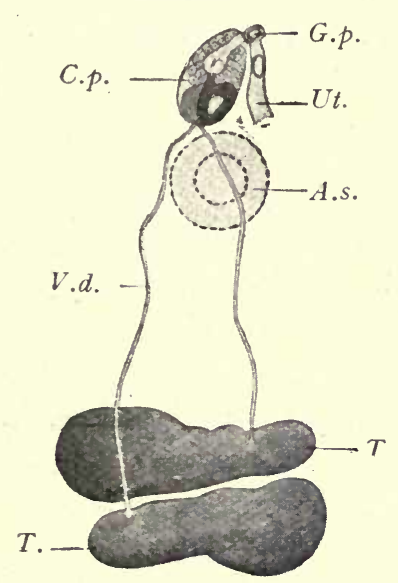

FIG. 72.-Opisthioglyphe endoloba (Duj.), from the frog. Male genitals. $7 \mathrm{I} / \mathrm{I}$. A.s., abdominal sucker; C.p., cirrus pouch, with cirrus, prostatatic cells and vesicula seminalis; G.p., genital pore; $T$., testes; $U t$., terminal portion of the uterus; $V . d$. , vas deferens. (After Looss.)

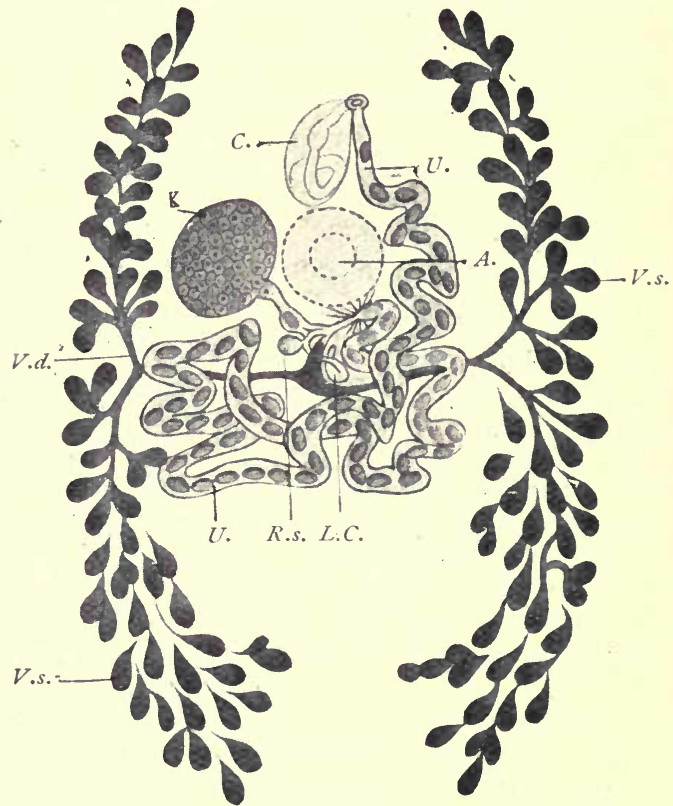

FIG. 73.-Opisthioglyphe endoloba (Duj.). Female genitals. $7 \mathrm{I} / \mathrm{I}$. A., Abdominal sucker; $C$., pouch of cirrus; V.d., vitelline duct; V.s., vitelline sac; L.C., Laurer's canal ; R.s., receptaculum seminis ; $U .$, uterus ; $K$., ovary. (After Looss.)

tiated. The sexual organs usually lie in the "central field" surrounded by the intestinal branches; the vitelline sacs, on the other hand, are, as a rule, placed laterally beyond the intestinal branches in the lateral areas.

The male apparatus ${ }^{1}$ is composed of two variously formed testes (fig. 72) (globular, oval, indented, lobulated, or ramified) which may lie side by side or one behind the other, from each testicle a tube (vas efferens) originates; sooner or later, both tubes become as a rule united to form the muscular vas deferens

\footnotetext{
1 The following description mostly relates to the Fasciolidea.
} 
which opens close to the genital orifice, or more rarely discharges direct into the genital pore and enters the muscular CIRRUS POUCH ; the cirrus itself, after being exerted, may be projected, and serves as an organ of copulation. In the atrium, and as a rule enclosed in the cirrus pouch, is found a mass of one-celled glands (prostata) as well as a vesicula seminalis (which is likewise within, or may also be outside the pouch).

The female genitals (fig. 73) consist of an ovary usually situated in front of the testes, the form of which varies according to the species, the usual pair of vitelline sacs, the conducting passages and a number of auxiliary organs; the short oviduct directed towards the centre starts from the ovarium, and is connected at the median line with the excretory ducts of the vitelline glands. These grape-like glands possess longitudinal excretory ducts, which assume an oblique direction behind the ovary, unite together at the median line and form one single tube, often carrying a vitelline reservoir that unites with the oviduct. At this spot, moreover, there frequently occurs a canal (Laurer's canal) which originates on the dorsal surface, and to the inner end of which a vesicle filled with sperm (receptaculum seminis) is usually suspended. Moreover, there are also numerous radial one-celled glands (shell glands) at the place where the oviducts, vitelloducts and Laurer's canal are united. In this region (ootype), which is usually distended, the germ cells are fertilised, surrounded with vitellus and shell material, and as ova with shells they pass direct to the uterus, which, with its many convolutions, occupies a larger or smaller portion of the central field, but the terminal part of which lies next the cirrus pouch and discharges beside the male orifice either to the surface of the body or into a genital atrium. The terminal portion of the uterus, which is often of a particular formation, serves as a vulva (METRATERM).

The orifice of the sexual organs is generally situated at or near to the median line on the ventral surface and in the anterior region of the body; in the Fasciolidea it is frequently in front of the ventral sucker, in other families at a suitable spot in the vicinity of the intestinal bifurcation. ${ }^{2}$

1 The typical position of the genitals is subject to many deviations, which are of importance in the differentiation of the species and families. The following lines give some few of these deviations: (I) The genital pore remains on the ventral surface, but is situated next to or behind the abdominal sucker, or it becomes marginal, and is then found in front of or next to the oral sucker or at a lateral edge, or, finally, in the centre of the posterior border; the conducting passages also 
The spermatozoa do not differ essentially in their structure from those of other animals; the germinal cells or ova are cells without integument and which contain a large nucleus and a little protoplasm; the vitelline sacs also yield nucleated cells, in the plasm of which there are numerous yellow yolk granules; the yolk cells, like the germinal cells, detach themselves from the ovarium and move into the excretory ducts to surround each germinal cell in the ootype. They disintegrate sooner or later, in the complete ovum, and there are utilised as food by the developing embryo.

\section{Development of the Trematodes.}

(I) Copulation.-Observation has demonstrated that the one or two vaginæ occurring in the ectoparasitic Trematodes are utilised as female organs of copulation, and that the copulation is alternative; it is also known that Laurer's canal, which was formerly generally indicated as the vagina, has never served the digenetic Trematodes as such -it appears to be homologous with the canalis vitello intestinalis of the Monogenea-but is the terminal portion of the uterus termed metraterm. Reciprocal copulation is observed as well as auto-copulation and auto-fecundation. The spermatozoa accordingly wander through the entire uterus till they reach the place of their final abode.

(2) Formation of the Ova.-The germinal cells are probably already fertilised in the germinal ducts and then pass singly into the space where they develop and where a large number of yolk cells collect around them (fig. 74). The shell is then formed from the secretion of the shell glands, which exudes in drops, the wall of the ootype meanwhile contracting considerably, and the ovum moving into the uterus. The completed ova are of various forms

correspondingly alter their direction. (2) The germinal trunk usually lies in front of the testes, not rarely, however, behind them or between them. (3) The three genital glands mostly lie together close in front of, or behind, the centre of the body; they may be moved far back, and may incidentally become separated one from the other. (4) The vitelline sac may be single, in which case it also then lies in the central field. (5) A few forms possess but one, others several or numerous testes. Amongst the ecto-parasitic Trematodes there are also varieties with but one testis; but they mostly have several. As a rule, their uterus is short, but the ootype well developed. The particular single or double canals (vagina) are used for copulation, not the uterus. The vitelline ducts also communicate with the intestine through the canalis vitellointestinalis. 
and sizes. They are mostly oval, at all events in the digenetic Trematodes, and the yellowish or brown shell is provided with an opening at one pole which is closed up by a watch-glass-shaped cover. Appendices (filaments) on the shell-at one or both poles -are uncommon, but are the rule in the ova of the Monogenea. The latter contain very few or only one ovum in their uterus, whereas in the Digenea the number of ova is large, often even very considerable; correspondingly the ova are also very much smaller.

(3) Deposition of the Ova. - Soon after the formation of the ova the Monogenea deposit them round the place of their attachment on

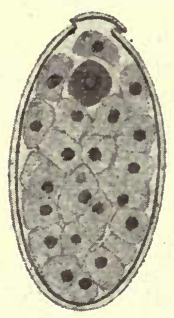

FIG. 74.-Ovum of Fasciola hepatica (L.), cut longitudinally. The cover has been removed in the process. Within the shell numerous yolk cells, and at the lid end there is the still unsegmented ovum (dark). 240/I.

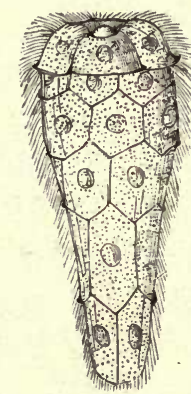

FIG. 75.- Miracidium of Distomum hepaticum that has just hatched from the egg, and has a distinct cuticular epithelium (magnified).

(From Leuckart.)

the skin or the gills of their hosts. The embryonic development thus takes place outside the parent; in other Trematodes the ova remain in the uterus for a longer or shorter period, and in it often go through the entire development or a part of it. Sooner or later the ova are deposited and leave the affected organs by the natural channels.

(4) The embryonic development, after irregular segmentation, leads to the formation of a morula stage which is surrounded by a cellular investing membrane, while the principal mass of the cell forms the embryo, which uses for its nourishment the yolk cells, which have in the meantime disintegrated. Usually, after the ova have reached the water, the embryos hatch out, leaving their investing membrane in the egg-shell; in other cases, however, the embryos only hatch out after having been subjected to the influence of the intestinal juices, that is to say, in the intestine 
of an intermediary host which has ingested with its food the ova escaped from the [primary] host.

(5) The post-embryonic development of the Trematodes is accomplished in various ways; the process is the most simple in the ecto-parasitic species, the young of which are certainly to be regarded as larvæ, because they possess characteristics that are lacking in the adult worms (cilia, simple gut, \&c.), but which, nevertheless, pass into the adult state direct, after a relatively simple metamorphosis (Monogenea). In the Holostomidea that are found chiefly in the intestine of aquatic birds, and which rarely occur in other vertebrates, the ova develop in the water. The young are ciliated all over, and, after having entered an intermediary host living in the water (hirudinea, molluscs, arthropoda, amphibia, fishes), they undergo a metamorphosis into a second larval stage;

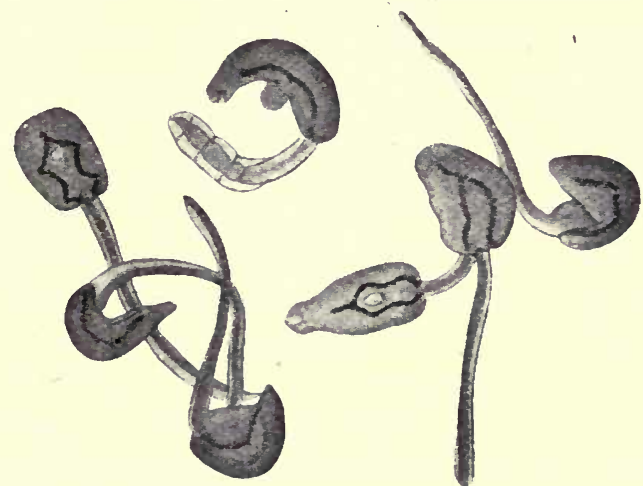

Fig. 76.-A group of Cercaria of Echinostomum sp. (from fresh water). 25/ .

they then encyst and await transmission into the final host, where they become adult (metastatic Trematodes).

In the remaining so-called digenetic trematodes one or two intermediate generations interpose between the larval and terminal stage, so that quite a number of adult animals may originate from one egg. Usually the young, which are termed Miracidia ${ }^{1}$ (fig. 75), hatch in the water, where they move with the aid of their cilia. Sooner or later they penetrate into an intermediary host, which is always a snail or a mussel, and while certain of their organs disappear, they grow into an intestineless germinal body (sporocyst, fig. 77). In these, according to the species, the 
larval stages of the forms that will ultimately become adult (cercaria) are produced, or the cercaria are only brought forth after having gone through another intermediate generation, that of the REDIAE (fig. 78), which are always provided with an intestine. The Cercaria, as a rule, leave their host and move about in the water with the assistance of a rudder-like tail (fig. 76). After a little time, however, they usually again invade an aquatic animal (worms, molluscs, arthropoda, fishes, amphibians), then they lose their tail and become encysted; here they wait until they attain the terminal host suitable for them, in company with their bearer, and in this new situation they settle down and reach maturity. Or, again, the cercaria may encyst themselves in the water or on foreign bodies (plants) and wait until they are taken up direct by the terminal host [liver 'fluke of sheep].

Accordingly the following conditions are necessary for the completion of the entire development: (I) The terminal host in which the adult stage lives; (2) an intermediary host into which the miracidia penetrate and in which they become germinal tubes; (3) a second intermediary host in which the cercaria become encapsuled. In certain species this last stage is omitted, when their cercaria encyst themselves, or, again (in other species), it may occur within the first intermediary host, especially when the cercaria (which in that case do not acquire the oar-like tail) do not swarm out, but encyst themselves at once within their sporocysts. The development, moreover, may be further complicated by rediae appearing in addition to the sporocysts, though this occurs in the first intermediary host and not in a fresh one.

Animals that harbour adult digenetic Trematodes have probably become infected by ingesting their encysted forms, which they have either swallowed with certain animals (secondary intermediary hosts) on which they feed, or ingested with water or with plants, or finally with the first intermediary host ; whereas animals fostering encysted (digenetic) Trematodes have been infected by the corresponding cercaria stages, and animals bearing germinal bodies (sporocysts and redia), have been straightway attacked by the miracidia.

Certain species of ducks and geese become infected with Echinostomum echinatum by devouring certain water snails (Limnaus, Paludina) in which the encysted stages occur. Oxen become infected with Paramphistomum cervi (i.e., Amphistomum conicum) by swallowing with the water, cysts of this species which occur at the bottom of puddles and pits. Sheep are infected with Fasciola hepatica by eating grass to which the cysts of the liver fluke are attached; 
our singing-birds infect themselves or their young with Urogonimus macrostomus by tearing off pieces of the corresponding sporocysts from the snails (Succinea amphibia), which act as the first intermediary hosts, and eating, or offering their fledgelings these pieces, which are full of encysted cercaria.

The miracidia of the digenetic trematodes are comparatively highly organised; they have a cuticular epithelium (fig. 75) entirely or partly covered with cilia, beneath this a dermo-muscular tube composed of circular and.longitudinal muscles; moreover, a simple intestinal sac with an œesophagus, occasionally also with pharynx,

a.

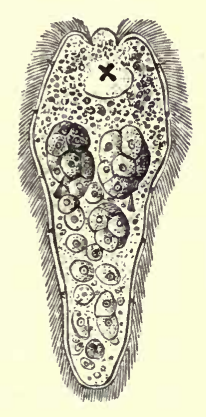

$b$.

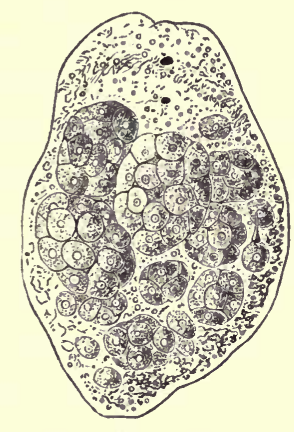

$c$.

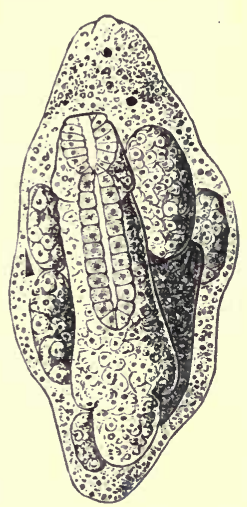

FIG. 77.-Development of Fasciola hepatica, L. a., The miracidium, optical section with germinal bodies and cilia. $b$., Young sporocyst with germinal bodies. c.. Sporocysts with redia (magnified). (From Leuckart.)

salivary glands and boring spine, also a cerebral ganglion on which, in some species, there are eyes (fig. $77, a$ ); as to the excretory organs, they are represented by two symmetrically-placed terminal cells joined to vessels that discharge separately; there is a more or less ample (primary) body cavity between the parietes of the body and the intestine; from the cellular parietal lining of this cavity single cells become loosened (fig. $77, a, b$ ), and later become cercaria or rediae.

The SPOROCYSTS, which are produced direct from the miracidia, are very simple, as all the organs of the latter disappear during or after penetration into the intermediary host, even to the muscles and excretory organs, whereas the loosened and still loosening cells of the body continue to develop rapidly. The sporocysts when fully developed have the appearance of tubes or fusiform bodies 
with rounded edge; they are frequently of a yellow colour. Their length rarely exceeds a few millimetres; in some species their size increases exceedingly through proliferation, and then occupy a large portion of the body of the intermediary host.

The REDIAE (figs. 78 and 79), on the other hand, are more cylindrical and always have a simple intestine of varying length, provided with a pharynx ; they likewise possess a genital orifice situated at the anterior end of the body which serves for the exit of the cercaria originating within them.

The CERCARIA are very different; typically they consist of the

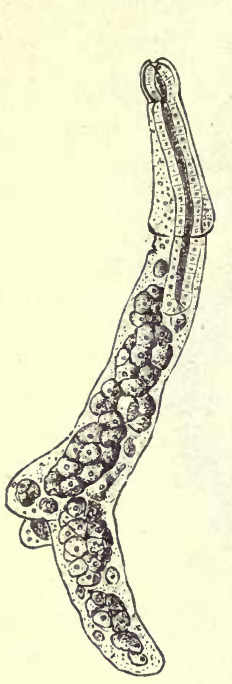

FIG. 78.-Young redia of the Liver Fluke, with intestine and germinal masses (magnifi ed). (F r o m Leuckart.)

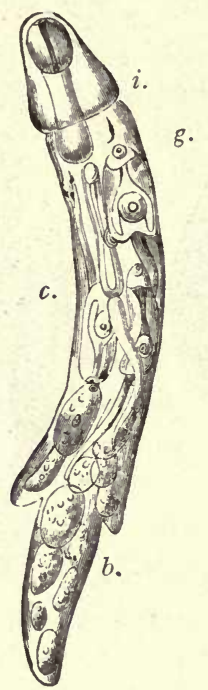

FIG. 79. - Germinal cylinder (redia) of Cercaria echinata, with rudimentary intestine $(i$.$) , cercaria$ (c.), germinative bodies (b.), and -generative orifice (g.) (magnified). anterior body and the oar-like tail joined to the posterior end (fig, 80). The former, even to the genitals, has the organisation of the adult digenetic trematodes, and these peculiarities allow the easy recognition of that large group to which the species in question belongs. On the other hand, however, there are also organs that are lacking in the adult form, such as the boring spine in the oral sucker in many, or the eyes situated on the cerebal ganglion ; moreover, also, cutaneous glands (fig. 80), the secretion from which forms the cystic membrane. The oar-like tail may be long or short (stump-tailed cercaria) or entirely absent; a fin-like membrane may occur at each side, or the creature may be whorl-like and beset with bristles; its free end may be partly split (furcate Cercaria), or split to its base (Bucephalus); in various forms also the anterior end of the tail is hollow, and has enclosed within it the anterior body, which is otherwise free. The size also of the cercaria belonging to the different species is very diverse; in addition to forms swimming in the water that have the appearance of minute milky-white bodies, there are forms which measure as much as $6 \mathrm{~mm}$. in length.

The encysted forms (fig. 8I) are globular or oval, and are surrounded by a homogenous membrane, which may be striated or 
contain granules. The tail is always cast off when encystment occurs, and organs peculiar to the cercaria stage (boring papilla, eyes) disappear almost entirely. On the other hand, the genitals appear or become more or less highly developed; in extreme cases to such an extent that they become functional, and that after autocopulation the creatures produce ova.

The cycle of development of the digenetic Trematodes has hitherto been generally explained as a typical alternation of GENERATIONS, one sexual generation regularly alternating with one or two asexually reproducing generations. Recently, however, a few authors regard the cells from which the sporocysts or rediae produce cercariæ as parthenogenetically developing ova, and the sporocysts as well as the rediae as generations propagating parthenogenetically; we therefore speak of HETEROGENY, or rather of ALLOIOGENESIS, because the former expression should be confined to the change of generation caused by sexual intermediate generations, such as occur in Rhabdonema nigrovenosa.

Other authors, again, only regard the development of the digenea as a complicated metamorphosts, which is distributed over several generations before it is concluded.

\section{Biology.}

Endoparasitic Trematodes, as fully-developed creatures, occur in vertebrate animals only, with very few exceptions; they inhabit almost all the organs (with the exception of the nervous and osseous systems and the male genitals), by preference the intestine in all its parts from the oral cavity to the anus, and in such a manner that certain species or groups inhabit each only certain parts of the intestine. Next to the intestine other species live 
in the liver, or in its bile ducts, and in the gall-bladder; other accessory organs of the intestine, such as the pancreas, bursa Fabricii (of birds), are only attacked by a few species. Others inhabit the lungs, or the air sacks in fowls, a few the trachea. Trematodes have also been known to occur in the urinary bladder, the urethra and the kidneys of all classes of vertebrates; they are also present in the vascular system of a few tortoises, birds and mammals; in birds they even penetrate into the oviducts, and are occasionally found enclosed in the deposited eggs; one species is known to occur in the cavum tympani and in the Eustachian tube of a mammal (Halicore), another in the frontal sinus of the polecat; several kindred species settle in the conjunctival sac under the membrana nictitans of birds, one species even lives in cysts of the skin of singing birds. In an analogous manner the monogenetic trematodes are not entirely confined to the surface of the body or the trachea of the lower vertebrate animals; a few species appear exclusively in the urinary bladder, in the œsophagus, and in sharks also in an accessory gland of the rectum.

Trematodes live free and active within the organs attacked, though they may attach themselves by suction for a longer or shorter period; in other cases, however, they bore more or less deeply into the intestinal wall, with their anterior end, or lie in cysts of the intestinal wall which only communicate with the lumen through a small opening; in those species living in the lungs of mammals the host likewise produces a cyst which usually encloses two specimens; these double-tenanted cysts are also observed in other situations, and, though they form the rule in species sexually distinct, they are not entirely confined to these. .

As regards the AGE attained by endoparasitic trematodes, there are but few reliable records, and these differ considerably; the overwhelming majority of species certainly live about a year, or perhaps a little longer, but there are some whose term of life extends to several or many years.

Trematodes are but rarely found encysted in the higher vertebrate animals ; the condition, however, is more frequent in amphibians, and especially in fishes, as well as in numerous invertebrate animals. 


\section{Classification of the Trematodes.}

Order I.-Heterocotylea, Montic. Exclusively ectoparasitic species, with strongly developed clinging or clasping organs, characterised by excretory organs discharging on the dorsal surface at the anterior end, development direct; live mostly on the body or on the gills of fresh or saltwater fish, but may also live in the urinary bladder of amphibians and in the œesophagus of tortoises.

Order II.-Aspidocotylea, Montic. Trematodes with a low organisation living endoparasitically; they are distinguished by a large ventral sucker, the excretory organs discharge through a posterior pore, development direct; parasitic in the intestine or gall-bladder of tortoises and marine fishes, as well as in a few shell-fish, especially in their excretory organs.

Order III.-Malacocotylea, Montic. Trematodes, the clinging apparatus of which as a rule only consists of one or two sucking discs (oral and ventral suckers); accessory suckers are rare, and in only one familythe Holostomidea - a strongly developed clinging, apparatus is present at the anterior end; chitinous clasping organs are always lacking. The intestine is usually forked; the oral orifice (with the exception of Gasterotomum) is situated at the front. Both sexual organs are almost always combined in the same individual; the genital pore is usually on the ventral surface. The excretory organs discharge through a pore at the posterior end. Always endoparasitic, and living almost without exception in vertebrate animals, particularly in the intestine.

This order is divided into two groups, ACCORDING TO THE DEVELOPMENT: A. Metastatica, Lkt. Development without alternation of generations, yet with the formation of two larval forms and a change of hosts.

Fam. Holostomidea, with several sub-families and the genera Hemistomum, Holostomum, Diplostomum and Polycotyle.

B. Digenea s. str., Lkt. Development complicated by the interpolation of generations that reproduce asexually (sporocysts, redia) and by one or two changes of host.

Fam. Paramphistomida, ventral sucker at the posterior end, the excretory bladder discharges on the dorsal surface, above the acetabulum. The genital pore, situated on the median line of the ventral surface is at about a third of the body from the anterior end; the intestinal fork always without appendages; the pharynx is very near the front, and is usually termed the oral sucker; hermaphrodites.

Divided again into several sub-families and genera (Paramphistomum, Gastrothylax, Gastrodiscus, \&c.).

Fam. Fasciolide, with oral and ventral suckers, excretory pores discharging at the posterior border; genital pore on the ventral surface, or situated on the lateral or posterior border. The intestinal fork is generally without appendages; hermaphrodites.

Divided into numerous sub-families and genera, of which only Fasciola, Fasciolopsis, Paragonimus, Opisthorchis, Cotylogonimus and Dicrocolium interest us here. 
Fam. Schistosomide resemble the Fasciolide in structure, but differ sexually.

Genera: Schistosomum, Bilharziella.

Fam. Didymozoonida, a group that is but little known, and the members of which (Didymozoon, Nematobothrium) live in pairs in cysts on the exterior surface of the body of marine fishes or in the cavities of their mouth or gills; sexually distinct.

Fam. Rhopaliada; hermaphrodites. Resemble the Fasciolide in their organisation. They have an oral and a ventral sucker, with two retractile rostrella; the genital pore is rather forward and on the ventral surface; genital glands are situated in the posterior end.

Genus : Rhopalias.

Fam. Gasterostomida, with the oral orifice on the ventral surface and a simple intestinal sac. Gasterostomum in the intestine of fishes. The cercaria stage termed Bucephalus also belongs here.

Fam. Monostomatide, resemble the Fasciolide in their organisation, but have only the anterior sucker; the genital pore is situated on the anterior part of the ventral surface; the genital glands are usually in the posterior third of the body; the intestinal fork may be with or without appendages, often again meeting at the back in the shape of an arch.

Divided into several sub-families and numerous genera.

\section{LITERATURE.}

The literature on Trematodes is very extensive, but also very scattered; that which has been published up to $\mathrm{I} 892$ is mentioned and has been utilised in my work on Trematodes (Braun's Cl. u. Ordn.d. Thierr., Lpzg., vol. iv., part I). Of the works that have appeared later the following only need be mentioned here :-

Bettendorf, H. Musc. u. Sinneszell. d. Tremat. In.-Diss. Rostock, I897 (Zool. Jahrb. Anat., 1897, part x., p. 307).

Blochmann, F. Die Epithelfrage bei Cest. u. Trem., Hamburg, i 896.

Braun, M. Arten d. Gttg. Clinostomum (Zool. Jahrb. Syst., I900, part xiv., p. I).

Tremat. d. Chelonier (Mitth. zool. Mus., Berlin, 190 r, ii., p. I).

Tremat. d. Chiropt (Ann. k. k. nat. Hofmus., Wien., I900, xv., p. 217).

Z. Kenntn. d. Trem. d. Säugeth (Zool. Jahrb. Syst., I9OI, part xiv., p. 3 I I).

Fascioliden der Vögel (ibid., 1902, xvi., p. I).

Fischoeder, F. Paramphist. d. Säugeth. In. Diss., Kgsbg., 1902.

Kowalewski, M. Several works in Polish, but with résumés in French or German, in d. Sitzber. d. Ak. d. Wiss. Krakau.

LёHe, M. Ueb. Hemiuriden (Zool. Anzgr., I90I, xxiv., p. 394).

Looss, A. Die Distomen unsr. Fische u. Frösche., Stuttgart, I894 (Bibl., zool. xvi.).

Rech. faune paras. de l'Egypte, i. (Mém. Inst. égypt., I896, iii., p. I).

Weit. Beitr. z. Kenntn. Trem.-Fna. Aeg. (Zool. Jahrb. Syst., I9oo, part xii., p. 521 ).

Monticelli, F. S. Stud. Trem. endop., i. (Zool. Jahrb. Suppl., iii., I893). 


\section{The Trematodes OBserved in MAN.}

\section{Fam. I. Paramphistomider, Fischoed.}

Gen. Gastrodiscus, Lkt.

Paramphistomide with bodies slender anteriorly and the posterior part broadened into a disc-like form concave on the ventral surface, the small ventral sucker lying at its posterior border. The pharynx has two pouch-like diverticula. Gastrodiscus lives in the intestine of the Equidæ in Egypt and India as well as in man. [The species in the horse is G. sonsinoi, Cobbold (G. polymastos, Leuck.). It occurs in Senegal and Quadiloupe. It occurs from pharynx to anus and in the nasal fossæ.--F. V. T.]

\section{Gastrodiscus hominis (Lew. and McConn), I $876 .{ }^{1}$}

Syn., Amphistomum hominis, Lew. and McConn.

The body when fresh is of a reddish colour; it measures 5$8 \mathrm{~mm}$. in length, $3-4 \mathrm{~mm}$. in breadth, and presents a large circular disc at the posterior border of which the small sucker is situated (fig. 82); the genital pore is

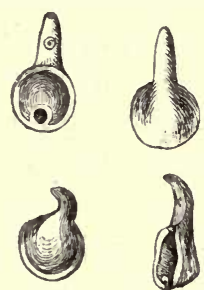

FIG. 82.-Gastrodiscus hominis, slightly magnified. (After Leuckart.) on a level with the bifurcation of the intestine; the generative organs consist of the two lobate testes, a sinuous vas deferens, the uterus, and the vitelline sacs placed laterally; parts of the nervous and excretory system have also been seen. The eggs are oval and measure $0.150 \mathrm{~mm}$. in length by $0.072 \mathrm{~mm}$. in breadth.

This parasite has hitherto only been observed twice in human beings, in an Assamese and in an Indian, and was present in the cæcum and colon in large numbers; it is doubtless only incidentally a parasite of man, its normal host being some Indian mammal.

\section{Fam. 2. Fasciolide, Raill. Gen. I. Fasciola, L., I758.}

Large Fasciolidæ with leaf-shaped bodies, the anterior end of which is shaped into a conical head. The ventral sucker is situated near the mouth, and is large and powerful. The cuticle is covered with spines; the œesophagus is short, the pharynx is well developed; the intestine bifurcates near the median line and extends far backwards; the intestinal cæca are provided with numerous long lateral and fewer and shorter median branches. The excretory system is much ramified, and the long terminal part is

'Lewis, T. R., and McConnel, " A New Para. aff. Man" (Proc. Asiat. Soc., Bengal f., เ876, p. 182$)$. 
cylindrical. The genital pore is situated in the median line anterior of the ventral sucker. The ovary is on one side of the body in front of the testes. It has many ramifications, as have also the testes, which lie obliquely one behind the other. The uterus, in the shape of a rosette, lies in front of the sexual glands; the vitelline sacs at the sides and in the posterior end are amply developed in both directions. Laurer's canal is present, but there is no receptaculum seminis; the vesicula seminalis is situated in the cirrus pouch; the ova are large, not very numerous, and only develop after they have been deposited. This parasite infests the biliary ducts of herbivorous animals.

\section{Fasciola hepatica, I., I758.}

Syn.: Distomum hepaticum, Retz., I786 ; Fasciola humana, Gmel., I789;

Distomum cavice, Sons., I 890 ; Cladocolium hepaticum, Stoss., I 892.

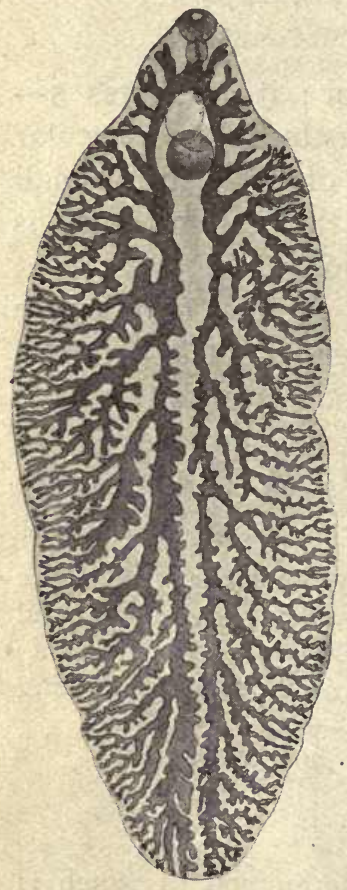

Fig. 83. - Intestine of Fasciola hepatica, L. 5/I. From a specimen that is not yet pubescent.

Length $20-30 \mathrm{~mm}$, breadth $8-\mathrm{I} 3 \mathrm{~mm}$., head-cone $4-5 \mathrm{~mm}$. in length and sharply differentiated from the posterior part of the body. Spines in alternating transverse rows and extending on the ventral surface to the posterior border of the testes, and on the dorsal surface not quite so far. The spines are smaller on the head cone than on the posterior part of the body, where they are discernible with the naked eye. The suckers are hemispherical, and near each other; the oral sucker is about I $\mathrm{mm}$. and the ventral sucker about $\mathrm{r} \cdot 6 \mathrm{~mm}$. in diameter. The pharynx, which includes almost the entire cesophagus, measures $0.7 \mathrm{~mm}$. in length, and $0+\mathrm{mm}$. in breadth. The intestine bifurcates in the head-cone and the branches are even here furnished with blind sacs directed outwardly. The ovary is ramified and situated in front of the transverse vitello duct; the shell-glands lie near the ovary in the median line; posterior to the transverse vitello duct are the greatly ramified testes, which occupy the greatest portion of the posterior part of the body, with the exception of the lateral and posterior border; the vasa efferentia only unite at the entry into the cirrus pouch. The vitellaria occupy the sides "of the posterior part of the body commencing at the level of the ventral sucker and uniting behind the testes. The ova are yellowish-brown, 
oval, with cap-like lid, $0^{\circ} \mathrm{I} 30-0^{\circ} \mathrm{I} 45 \mathrm{~mm}$. in length, $0^{\circ} 070-0^{\circ} 090 \mathrm{~mm}$. in breadth (average size $0^{\circ} 132-0^{\circ} 070$ ).

The Liver Fluke inhabits the bile ducts of numerous herbivorous mammals (sheep, ox, goat, horse, ass, rabbit, ${ }^{1}$ guinea-pig, squirrel, beaver, deer, roe, antelope, camel, kangaroo, and others, and is distributed over the whole of Europe, though not to an equal extent. It is further known in North Africa, in N. and S. America, as well as in Australia; it is also found in Asia, as it has been reported from Japan and China. In. some districts of Germany it is very frequent and the slaughterhouse reports of various places show that it is of daily occurrence.

[The liver fluke also occurs in Tasmania. In India it has been found in the buffalo. In Burmah it is found impossible to keep

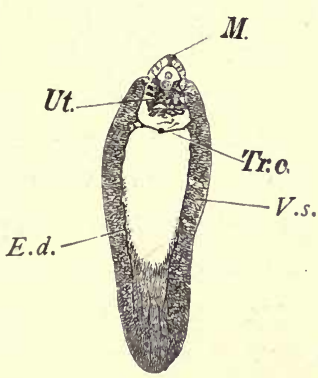

FIG. 84.-Fasciola hepatica, natural size (Mull. fluid, alcohol, creosote, Canada balsam). E.d., Excretory duct of the vitelline sacs; V.s., vitelline sacs; M., mouth; Tr.c., transverse canals; $U t$., uterus.

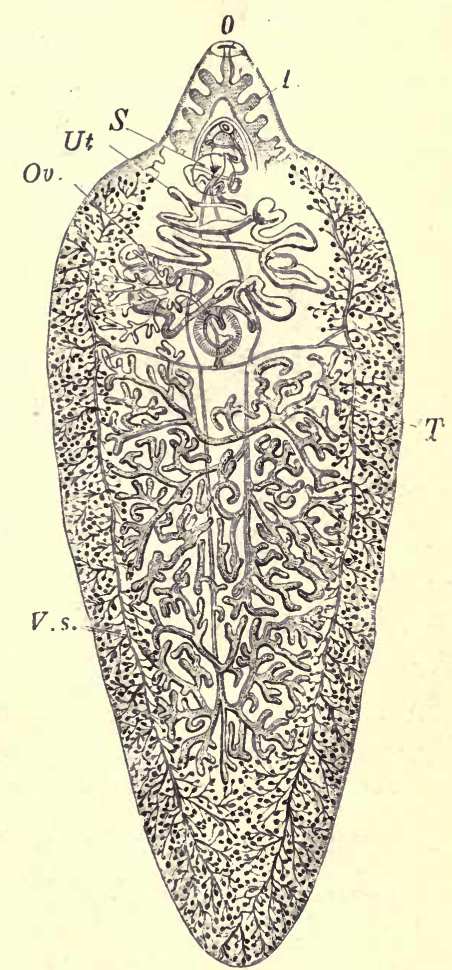

FIG. 85. - Fasciola hepatica, L., with sexual apparatus. $I$. , intestine ; $V . s$. vitelline sacs; Ov., ovary; $O$., oral aperture ; Ut., uterus ; $S_{\text {., ventral }}$ sucker; $T$., testes. (After Claus.)

sheep owing to its ravages ("A Treatise on the Diseases of Sheep," I890, p. I36, Steel). According to Hamont (the Veterinarian, vol. vii., pp. 557,587 ) the annual fall of the Nile causes the loss from "rot" of 160,000 sheep. This parasite is

1 [There does not seem to be any direct evidence of either rabbits or hares normally being invaded by this Fluke.-F. V. T.] 
said to have been introduced into Australia in 1855 by imported rams sent from Germany to Victoria.-F. V. T.]

The liver fluke, however, is by no means a harmless parasite, for it produces in domestic animals, more especially in sheep, a disease of the liver that appears epidemically in certain years and districts, and commits great ravages amongst the flocks.

[The following records show the enormous loss caused in sheep by this parasite. In 1812 , in the Midi, principally in the Departments of the Rhone, Herault, and Gard, the disease was rampant; 300,000 sheep perished in the Arles territory, and 90,000 in the arrondissements of Nimes and Montpellier. In 1829 and 1830 , in the Department of the Meuse and near localities, not only sheep but oxen died in enormous numbers: for instance, in the arrondissement of Verdun out of 50,000 sheep 20,000 died, and out of 20,000 cattle 2,200 died. In England, in $1830,2,000,000$ sheep were carried off; whilst in 1862 , 60 per cent. of the sheep died in Ireland; and in 1879 over 300,000 were lost in England; whilst as late as $189 \mathrm{I}$ one owner in the same country lost over ro,000 sheep (Live Stock Journal, October 30, I89r).--F. V. T.]

The disease usually commences towards the end of summer with an enlargenent of the liver, induced by the invasion of numerous young flukes; in the autumn and winter the animals suffer from the consequences of disordered biliary secretion; they become feverish, emaciated and anæmic, and lose their appetite. In consequence of the consecutive atrophy of the liver cedema and ascites set in and many animals succumb to this "liver rot." On examination the liver is found to be shrunken, the bile ducts are enormously dilated, and in parts contain sacculations full of hepatic flukes. Should the animals survive this stage, a spontaneous recovery ensues in consequence of the flukes commencing to leave the liver in the spring, but the liver renains altered and its sale is prohibited ${ }^{1}$ when the changes are extensive. ${ }^{2}$

[The following stages may be noticed in sheep suffering from distomatosis. Gerlach recognised four stages, based.on the varied relations that the flukes contract with the liver of their host.

${ }^{1}$ [This is not the case in Great Britain ; Fluky sheep are sent to market ; there being no danger to man eating the flesh.-F. V. T.]

${ }^{2}$ As an example, this occurred in Berlin in the case of 19,034 oxen, 15,542 sheep, 1,704 pigs, and 160 calves in the period of $1883-1893$; during which time 719,157 oxen, I,519,003 sheep, 2,258, IIO pigs, and 567,964 calves were slaughtered. As a matter of fact, however, the number of infected beasts was really larger. 
These periods are sometimes very marked, but at others, owing to subsequent ${ }^{\circ}$ infestations, the features become merged and so obliterated. But when a single infestation occurs they are very marked.

The first period is called the PERIOD of IMmigration. This occurs at the fall of the year and generally passes unperceived, as the young flukes do little harm to the liver. It varies from four to thirteen weeks. Gerlach has remarked upon cases of death from apoplexy at this period.

The second period is the PERIOD OF ANEMIA. This occurs in November and December. The sheep at first fatten rapidly, but later their mucous membranes become pale and of a yellowish hue. and they become sluggish and cease to feed. The fæces are normal, but may contain fluke ova.

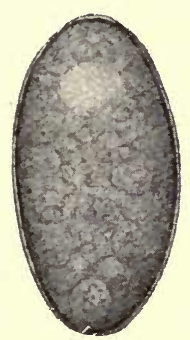

FIG. 86.-Egg of Fasciola hepatica, L. 240/I. At the lid-end the yolk cells may be observed through the shell.

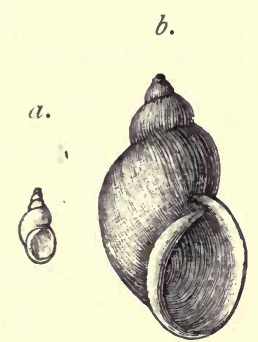

FIG. 87.-Limnaus minutus, the intermediary host of the Liver Fluke. $a$, natural size; $b$, magnified. (From Leuckart.)

The third period is the PERIOD OF WASTING. This corresponds with the beginning of January-about three months after the entry of the larvie. Emaciation now becomes very marked, the skin and mucous membranes blanched, temperature variable and marked by an-irregular curve; respiration laboured and quick; appetite regular; abortion frequently occurs in pregnant ewes; pressure on the back causes the animals to fall; local oedemas occur, the most perceptible in the submaxillary space, extending below the larynx and over the cheeks and parotids (called "bourse," "boule," in France; "watery poke" or "cockered" in England). Death usually occurs at this period, but a fourth stage may occur.

The fourth period is the PERIOD OF FMIGRATION OF THE FL.UKES, This is a period of convalescence and recovery, generally in May and June.-F. V. T.] 
Oxen suffer less in general, but even in these animals "stray" hepatic flukes are occasionally found in the lungs, enclosed in thickwalled cysts.

The HISTORY OF THE DEVELOPMENT of the liver fluke has been discovered by $\mathrm{R}$. Leuckart and P. Thomas. According to these investigators the elongated miracidium (fig. 75), ciliated all over, develops from the eggs of the liver fluke a few weeks after the latter (figs. 74, 86) have reached the water, and after it has become free, the embryo penetrates a water-snail (Limnreus truncatulus, Müll, $=L$. minutus, Drap.) that is common in fresh water, and can live in the smallest collection of water as well as in meadows that have been flooded, and becomes a sporocyst (fig. 77). The sporocyst first of all produces rediae, which remain in the same host, and under-certain circumstances it develops a second generation of rediae and finally forms cercaria (fig. 80). The latter become encysted on the meadows and are taken up by the respective hosts with their food; this takes place towards the end of summer, while the sheep feeding on the pasture land in the spring spread the eggs of the hepatic fluke, and sometimes the entire animal, by passing them with their fæces.

In districts where Limnaus minutus is absent, analogous species act as the intermediary hosts, of which one example, according to Lutz, is the Limnaus oahuensis ${ }^{1}$ in the Sandwich Islands.

[The host in Europe is Limnaus truncatulus. This snail extends from Siberia to Algeria and Sicily, and according to Captain Hutton is a native of Afghanistan. It also occurs in Thibet, Amoor, Morocco, Tunisia, Canary Islands and the Faroe Islands. It deposits its eggs or spawn upon the mud around ponds, ditches, and streams. The eggs are laid in batches of thirty to a hundred, each snail laying as many as I,500 eggs; they are united into strips of a gelatinous substance. In about two weeks young snails appear. It is amphibious, being more

1 The most important literature is as follows: Stieda, L., "Beitr. z. Anat. d. Plattw. I." (Arch. f. An. u. Phys., I867, p. 52); "Ueb. d. angebl. inn. Zusammenh. d. männl. u. weibl. Org. bei. Trem." (Ibid., I87 I, p. 31) ; Sommer, L., "Anat. d. Lebereg." (Z. $f . w$. Zool., I880, xxxiv., p. 539); Macé, E., Rech. anat. sur la grande douve du foie. Thèse de Nancy, Paris, I 882 ; Leuckart, R., "Z. Entw. d. Lebereg." (Arch. $f$. Naturg., 1882, i., p. 80); Thomas, P., "The Life Hist. of the Liver-Fluke" Quart. Journ. Micr. Sc., 1883, xxiii., p. 99); Schaper, "Die Leberegelkrankh. d. Schafe" (Dtsch. Ztsch. f. Thiermed., I889, xvi.); Lutz, A., "Z. Lebensgesch. d. Dist. hep." (C. f. B. u. P., xi., p. 783 ; xiii., p. 320); Coë, W. R., “Bau des Embr. v. Dist. hep." (Zool. Jahrb. Abth., ix,, p. 56I); Havet, J., "Contrib. à l'étud. d. syst. nerv. d. txém." ("Cellule," I 900 , xvii., p. 35 I). 
frequently met with out of the water than in it. It occurs in elevated spots as well as in low-lying districts. Moquin-Tandon found it at 4,000 feet in the Pyrenees. In the allied species, L. peregra, the fluke will develop up to a certain stage, but never completes all its varied phases.

In South America the host is probably Limnaus viator, Orb., and in North America, L. humilis, Say.-F. V. T.]

In human beings as well as in some of the mammals quoted above, the liver fluke is only a casual parasite, and hitherto only twenty-three cases have been observed in $\operatorname{man}^{1}$; the infection was mostly a mild one and there were no disturbances, or only very trifling ones; a few isolated cases were only discovered post mortem. Occasionally, however, even when the infection was inconsiderable, severe symptoms were set up, which in isolated cases led to fatal issue. The symptoms observed (enlargement and painfulness of the liver, icterus) certainly only indicated a disease of the liver.

As the liver fluke feeds on blood it is possible that it also reaches the circulatory system, particularly when young, and cases have been known in which it has been carried into organs far from its original situation by the blood. Such cases also have been repeatedly observed in man; probably the parasite described by Treutler, I793, as a Hexathyridium venarum, which protruded from the ruptured vena tibialis antica of a man, was a young liver fluke. A few adult specimens were found by Duval in the portal vein and other blood-vessels at an operation or post mortem at Rennes ( 1842 ) on a man, aged 49, and a similar statement is reported by Vital from Constantine (1874). Giesker, in I850, found two hepatic flukes in a swelling on the sole of the foot of a woman. Penn Harris states that he observed six specimens in Liverpool which were present in a spontaneously burst abscess of the occiput of a two-months-old infant. Another case which, like the previous one, is reported by Lankester, ${ }^{2}$ relates to a sailor who suffered from an abscess behind the ear, and from which a liver fluke was expelled. Finally, Dionis de Carrières ${ }^{3}$ reports the

\footnotetext{
'Casuistic of Davaine (Traité des entoz., 1877, 2nd edit., p. 253); R. Blanchard (Traits de Zool. med., I889, i., p. 589), and R. Leuckart (Die menschl. Paras., 2nd edit., vol. ii., p. 316), which works also mention the literature; also in Huber's Bibliogr. d. klin. Helm. (München, I895). Case 23 is quoted by Malherbe (Progr. med., 1898, vii., No. 4).

2In the English translation of Küchenmeister's work on Parasitology (London, 1857). The specimen is preserved in the Hunterian Museum, London, and is a pubescent liver-fluke, measuring $18 \mathrm{~mm}$. in length and $7 \mathrm{~mm}$. in breadth.

${ }^{3}$ Communicated by Davaine (l.c.).
} 
case of a man aged 35, in whose right hypochondriac region a tumour the size of a pigeon's egg had formed, and from which a young liver fluke was extracted.

After such experiences it is not improbable that Distomum oculi humani, Ammon, 1833, as well as Monostomum lentis, v. Nordm., I832, may have been very young hepatic flukes that had strayed. Ammon found four specimens (length $0.5-\mathrm{I} \mathrm{mm}$.) of his species (termed Distomum ophthalmobium by Diesing in I850) between the opaque lens and the capsule of a five-months'-old child.in Dresden, and von Nordmann discovered the Monostomum lentis to the number of eight specimens (only $0.3 \mathrm{~mm}$. in length) in the opaque lens of an old woman.' The fact that Ammon found that the intestinal cæca

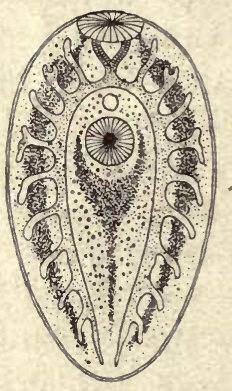

FIG. 88.-Young Fasciola hepatica, soon after travelling into the liver: the intestinal forks carry lateral blind ducts (magnified). (From Leuckart.)

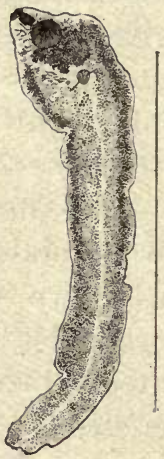

FIG. 89.-Fasciola hepatica var. angusia, Raill. (natural size). (After Stiles and Hassall.)

of the worm discovered by him had no lateral branches does not oppose the above opinion, as in the liver fluke the intestinal cæca are originally unbranched, and according to Lutz they only later develop lateral ramifications between the twelfth and twenty-second day of the infection (fig. 88).

2. Fasciola hepatica var. angusta, Raill., I895.

Under this name Raillet ${ }^{2}$ describes elongated and slender flukes which occur in the bile ducts of oxen slaughtered at Saint Louis

'Gescheidt and Ammon, "Die Entoz. d. Auges" (Ztsch. f. Ophth., I833, iii., p. 405); Ammon, Darst. d. Krankh. d. menschl. Aug. Dresd., 1838); Nordmann, A. v., Mikrogr. Beitr. z. Naturg. d. wirbellos. Thieve., Berlin, 1832, part ii., p. ix.

"Railliet, A., "Sur une form. part de douve hép. prov. du Sénegal" (C. R. soc. biol., Paris, 1895 [10], ii., p. 388 ). 
(Senegal), and which are distinguished from the European liver fluke by their more elongated shape, lesser breadth (in their contracted state $26-38 \mathrm{~mm}$. in length, $6-8 \mathrm{~mm}$. in breadth), short anterior cone, larger ventral sucker and larger eggs (O.I43-O.I5I $\mathrm{mm}$. in length, $0.082-0.088$ in breadth, average size $0.147: 0.082$ mm.).

An analogous form from the bile ducts of slaughtered animals of Egypt (buffaloes, oxen, sheep and goats) has been described by Looss ${ }^{1}$ as var. agyptiaca, and later, like Railliet's variety, was declared to be an independent species (Fasciola angusta, Fasc. egy'ptiaca). ${ }^{2}$

As now the ordinary hepatic fluke (Fasciola hepatica, L.) is known to invade man, this may likewise be the case in analogous forms, which would then probably develop in a similar manner.

As a matter of fact, an observation exists that confirms this supposition. A medical man, $\mathrm{H}$. de Gouvea, ${ }^{3}$ observed a French naval officer in Rio de Janeiro who was suffering from fever, cough and slight hæmoptysis; the lungs appeared to be intact except for a sharply circumscribed spot at the base of the left lung; twenty days later the patient, during an attack of coughing associated with hæmoptysis, expectorated a fluke $25 \mathrm{~mm}$. in length, which was distinguished by its slender form and the size of its ventral sucker, which was situated close to the oral sucker. The author himself called attention to the resemblance of the worm to the flukes which inhabit the liver of Egyptian buffaloes.

Taking into consideration the fact that de Gouvea's patient had made a stay of scveral weeks in Dakar (Senegambia) during July of the same year, where Fasciola hepatica var. angusta occurs amongst cattle, and considering also the peculiarities of the worm observed by de Gouvea, Railliet (l.c.) is inclined to regard the two forms as identical, and no objection to this opinion can be advanced.

But in I856 Cobbold described a species found in the liver of the giraffe which he named Fasciola gigantica, and which attained a length of $75 \mathrm{~mm}$. and a breadth of from $4-\mathrm{I} 2 \mathrm{~mm}$. It is nearly related to Looss' and Railliet's varieties, which are hardly distinguisháble one from the other; it is likewise very long and narrow, the lateral borders of the posterior part of the

${ }^{1}$ Looss, A., “Rech. faune par. de l'Eg." (Mem. Inst. égyt., i 896, iii., p. 33).

"Looss, A., "Obs. à prop. d'une note . . . ." (C. f. B., P. u. I., I 898 [I], xxiii., 'p. 459).

${ }^{3}$ Gouvea, H. de, La distomatose pulm. par la douve du foie Thèse (Paris, 1895). 
body run almost parallel, the head cone is short, the large ventral sucker very prominent and very close to the oral sucker, while the

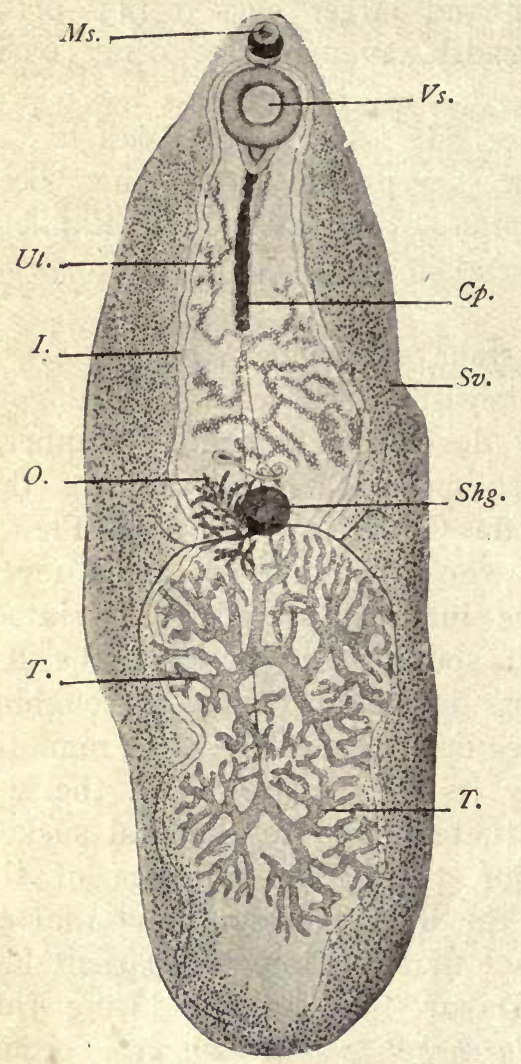

FIG. 90.-Fasciolnpsis buski (Lank). (magnified). Vs., Ventral sucker; $C_{p}$., cirrus pouch; $I$., intestinal fork ; $S_{n}$., vitelline sac; $T$., testes ; $O$., ovarium ; Ms. mouth sucker: Shg., shell sland; $U t$., uterus. (After Odhner.) eggs measure $0.145^{-}-0.150 \mathrm{~mm}$. in length by $0.082-0.088$ in breadth. On the strength of these characters R. Blanchard ${ }^{1}$ regards the flukes living in the Senegambia oxen and in the Egyptian buffalo as belonging to Fasciola gigantica, Cobb., and likewise includes the species from de Gouvea's case. This may be so, but, apart from the different size of the body there remain peculiarities which, if the descriptions are correct, indicate a difference of species. ${ }^{2}$

\section{Gen. 2. Fasciolopsis, Looss, I 898.}

No head cone; cuticle without spines, ventral sucker large and elongated posteriorly into the shape of a sack; the intestinal branches are not ramified. The testes lie in the posterior half of the body and are much branched. Cirrus pouch long and cylindrical, its greatest length being occupied by the sinuous tubular seminal vesicle, on which a blind duct is developed. The ovarium is ramified; Laurer's canal present. The oviducts occupy almost the whole of the sides of the body.

"Blanchard, R., "Mal. paras., par an." (Traité de path. gen. [Bouchard], I895, ii., p. 733. )

${ }^{2}$ Illustrations of Cobbold's species may be seen in "Cobbold's Entozoa".(London, I 864), plate I, reproduced in Braun's $\mathrm{Cl}$. u. Ord. $d$. Thierr., vol. iv; plate I in Journ. comp. med. and vet. arch., 1895, p. 141, and in U.S. Dep. of agr. Bur. of an Ind. Bull., No. 19, Wash., 1898, p. 50, fig. 27. An illustration of the Egyptian form may be seen in Looss (l.c., plate 3, fig. I6), and has been reproduced in the Bull. quoted. No. I9, fig. 26, represents Railliet's form (ibid., figs. 23 and 24 , original). 
Fasciolopsis buski (Lank.), I857.

Syn.: Distomum buski, Lank., I857; Dist. crassum, Busk, 1859, nec v. Sieb, 1836 .

The length of the body varies; it may measure $24-37$ or even attain $70 \mathrm{~mm}$.; the breadth is from 5.5 to $\mathrm{I} 2-\mathrm{I} 4 \mathrm{~mm}$. The oral sucker measures $0.5 \mathrm{~mm}$. in diameter, the ventral sucker is three to four times as large ; the pharynx is globular, $0.7 \mathrm{~mm}$. in diameter ; the prepharynx is provided with a sphincter; the intestinal branches extend to the posterior border. The genital pore is at the anterior border of the ventral sucker; the tubular cirrus pouch is about one-fourth of the length of the body. The ovary and shell glands are situated in about the middle of the body with the testes behind them, and the uterus in front. The vitelline sacs extend from the ventral sucker to the posterior border. The eggs measure $0.12-0.130 \mathrm{~mm}$. in length and $0.077-0.08 \mathrm{~mm}$. in breadth.

This species has hitherto only been observed in the intestine of man, and then only in East and South Asia (Budd, Lankester, Leidy, Cobbold, Odhner), seven cases representing the total.

\section{Distomum rathouisi, Poirier, 1887 ,}

is related to the above but not identical with it. It measures $25 \mathrm{~mm}$. in length, by I6 $\mathrm{mm}$. in breadth, and the contour is oval with a slightly prominent head cone; the cuticle has no spines, the suckers are near

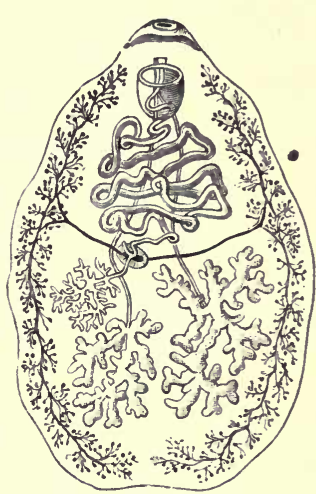

FIG. 91. - Distomum rathouisi (Poir.). The mouth at the top, and under it the genital pore and ventral sucker, behind which again is the uterus. The vitelline sacs are at the sides, and posteriorly in the central field the ramified testes, the ovary is in front of the right one. (After Claus.) to each other, the oral sucker measuring I.5 and the ventral sucker $2 \mathrm{~mm}$. in diameter. The intestines have no lateral branches; the testes and ovary are situated in the posterior half of the body, the branched testes are side by side, the ramified ovary is in front of one testis and behind the transverse vitello duct. The vitelline sacs occupy almost the entire sides, of the body and do not meet at the back. The uterus is in the central field of the anterior half of the body. The genital pore is close in front of the ventral sucker. Eggs $0.15-0.80 \mathrm{~mm}$. Hitherto this parasite has only been observed once-in a Chinese 
woman who evacuated the specimen described, after violent pains in the hepatic region.

According to a written communication by $\mathrm{P}$. Manson to $\mathrm{R}$. Blanchard, two further cases (which species?) have been observed in North Borneo, the host of one being a Chinaman and the other a Malayan. Nothing is known about the development of either species.

\section{Literature of D. Buski.}

BuDD, G. On Diseases of the Liver. Lond., I 852.

Lankester, E. In Manual of An. and Veg. Paras. (Küchenmeister). Lond., I857, i., App. B., p. 437.

Leidy, J. On Dist. Hepatic. (Proc. Ac. Nat. Sc., Philad., I873, p. 364.)

Coвbold, T. Sp. On the supposed rarity of . . . . of Dist. crassum. (Journ. Linn. Soc., I875, xii., p. 285.) Obs. on the large human fluke . . . (The Veterin., I 876.$)$

ODhner, Th. Fasciolopsis buski. . . (C. f. B., P. u. I. [I], I9O2, xxxi., Orig., p. 573.)

Polrier, P. Dist. rathouisi Not. s. une nouv. esp. de dist. par. de 1'homme. (Arch. zool. exp. et gén., I 887 [2], v., p. 203:)

[According to Scheube ("Diseases of Warm Climates," Second Revised Edition), Distomum buski, Lank. (i.e., Fasciolopsis buski, Lank.), is the same as D. rathouisi, Poirier, and D. crassum, Busk, and occurs in Selangor and Assam.-F. V. T.]

\section{Gen. 3. Paragonimus, Braun, I899.}

Fasciolidæ, with thick oval or broad fusiform bodies, the transverse section of which is almost circular. The cuticle has scale-like spines. The suckers are at a distance of half the length of the body from each other; the œesophagus is short, the pharynx almost globular; the intestinal cæca have no lateral branches, and run in a zig-zag manner to the posterior extremity; the excretory bladder is elongated and reaches to the pharynx; the genital pore lies laterally near posterior margin of ventral sucker; no cirrus pouch. The testes are round or ramified, and lie side by side in the posterior half of the body, the ovary, corresponding in form, lies in front of one testis. The vitellaria occupy the whole of the sides and almost reach the median line on the back. Laurer's canal is present; there is no receptaculum seminis; the uterus, behind the ventral sucker, forms a prominence. The eggs are fairly large. The parasites live mostly in pairs within cysts in the lungs of mammals.

\section{Parágonimus westermani (Kerb.), I878.}

Syn.: Distoma westermani, Kerb., I878; Distoma ringeri, Cobb., I880; Distoma pulmonale, Baelz., I883 ; Distoma pulmonis, Suga, I883; Mesogonimus westermani, Raill., I 890.

The body is of a faint reddish-brown colour and plump oval shape. The ventral surface is a little flattened; the parasite 
measures 8--ro $\mathrm{mm}$. in length, 4--6 $\mathrm{mm}$. in breadth and diameter. The suckers are of equal size $\left(0^{\circ} 75 \mathrm{~mm}\right.$.), the oral sucker is subterminal; the ventral sucker is placed somewhat in front of the middle of the body. The pharynx is small and close behind the oral sucker; the œesophagus is very short, and the intestinal cæca present slight sinuosities. The cuticle is provided with scale-like spines; the excretory pore opens at the posterior end rather on the ventral surface, the elongated excretory bladder gathers in branches from all sides. The genital pore is placed near the posterior margin of the ventral sucker and a little laterally; next to it on one side is the prominence of the uterus, and on the other side the ramified ovary; the two ramified testes lie side by side in the posterior end. The vitellaria are at the sides, almost reaching the median line on the dorsal surface, but only reaching the intestinal branches on the ventral surface. The eggs are oval, brownish-yellow, fairly thin-shelled, and measure 0.0875-0.1025, $\mathrm{mm}$. in length by $0.0525-0.075 \mathrm{~mm}$. in breadth (average 0.0935:0.0570 mm.)

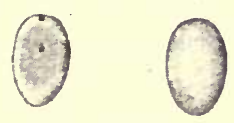

FiG. 92.-Paragonimus westermani (Kerb.) (natural size). To the left, dorsal aspect; to the right, ventral aspect. (After Katsurada.)

Paragonimus westermani was discovered by Kerbert in a royal tiger that died in Amsterdam; the parasites were found-mostly in pairs-enclosed in superficial cysts of the lungs. Soon after, Bälz observed the eggs of this species in the sputum of some Japanese who were suffering from hæmoptysis, that was of endemic occurrence in a certain district of Japan. The observer, nevertheless, mistook them for the spores of gregarines (Gregarina pulmonalis $s$. fusca). The worm arising from these ova was

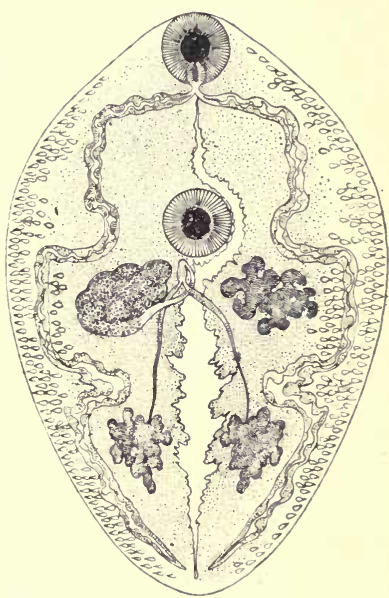

FIG. 93.-Paragonimus wes. termani (Kerb.). Seen from the ventral surface. Io/r. (After Leuckart.) Mouth, pharynx, intestinal branches; at the sides of which the vitelline sacs are observed. The genital pore is behind the ventral sucker, and next to it, at the left, the ovary ; at the right, the uterus ; the two testes at the back; the excretory vessel in the middle. first observed in man by Ringer (in the bronchi of a native of Formosa, who was likewise suffering from parasitic hæmoptysis). The specimens sent to Manson and Cobbold have been described as Distoma ringeri; whereas Bälz, after finding the species himself, gave it the name of Dist. pulmonale. Subsequently the parasite has often been observed in China, Korea, and especially in Japan, where, according to Katsurada, there are no districts that are entirely free from hepatic flukes. The mountainous provinces of 
Okayama, Kumamoto, Nagano and Tokushima are the principal centres. [Stiles has also observed this species in North America, and Naunyn saw a case in Strasburg in a colonist who had lived in Mexico and California for fifteen years (Deutsch. Med. Woch., I897, Vereins Beil., No. 20, p. I 46). -F. V. T.]

In addition to its occurrence in the royal tiger and in man, Paragonimus westermani, according to Janson, has been found in pigs; according to Railliet and Katsurada in the dogs of Japan, and according to Ward and Stiles it also occurs in dogs, cats and pigs in N. America.

The presence of flukes in the lung is naturally not innocuous to man, but the symptoms are, as a rule, so trifling that the

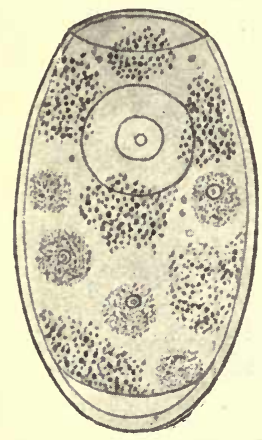

Frg. 94. - Egg "' of Paragonimus westermani (Kerb.), from the sputum. Iono/r. (After Katsurada.) patients are able to follow their occupations and hardly ever consult a doctor concerning the hæmoptysis. The worms are found, in the case of human beings, often singly, in cysts with hard walls the size of hazel nuts, that do not belong to the actual tissue of the lung, but to the bronchial tubes with which they communicate.

[This disease occurs principally in the male sex, but seldom in old men; children and women are seldom affected. The manner of infection is unknown.-F. V. T.]

One danger threatens the patients, in so far as it is possible for large blood-vessels to be opened by the disintegration of the lung tissue in the vicinity of the cysts, and thus copious hæmorrhage may be set up. Moreover, the flukes also appear to enter the blood-vessels and then are carried about in the body; at all events softened centres or tubercle-like neoplasms have sometimes been found in the brain or other organs, and have been found to contain the eggs of the lung fluke in large numbers. In this position the worms appear to have perished at some period before the examination, but it is certainly not improbable also that the eggs invade the circulation direct from the lung, and are then conveyed to different parts of the body.

[Kanamori doubts that the ova found by Yamagiva and others in the brain, liver, \&c., have anything to do with this parasite, especially as they exhibited no lid, and believes they belong to another parasite. He found them in a cirrhotic liver and in an adenoma of the rectum.-F. V. T.]

As to the development, only the following details are known: 
That the eggs which reach the open with the sputum before segmentation develop in the water into a miracidium ciliated all over, which hatches and swims about freely. Recently Stiles has identified with the lung fluke a Distomum first found by Duncker encysted in the muscular system of pigs.

\section{LITERATURE.}

Kerisert, C. Z. Trem.-Kenntn. (Zool. Anzgr., I878, i., p. 27i.)

Beitr. z. Kenntn. d. Trem. (Arch. mikr. Anat., I88I, xix., p. 5 I9.)

Baeiz, E. Ueb. paras. Hæmopt. (Ctrbl. f. med., Wiss., I880, p. 721. )

Manson, P. Dist. ringeri. (Med. Tim. and Gaz., I88I, ii., p. 8 ; and I 882, ii., p. 42.)

BaElz, E. Ueb. einig. n. Par. d. Mensch. (Berl. klin. Wchschr., I883, p. 234.)

Yamagiva, K. Lungendistomenkrkht. i. Japan. (Arch. f. path. An., I 892, cxxvii.)

Z. Aet. d. Jackson'schen Epilepsie. (Ibid., I890, cxix.)

Miura, M. Fibr. Tuberkel verurs. d. Paras.-Eier. (Ibid., I889, cxvi.)

WARD, H. B. Dist. west. i. d. verein. Staaten. (C. f. B. u. P. I894, xiv., p. 362, and I 895 , xvii., p. 304.)

Railliet, A. Par d. anim. dom. du Japon. (Le natural, i89i, xii., p. I43.)

Janson. Mitth. d. Ges. f. Natur- u. Vlkrkde. Ostas., I 897, Nos. 59, 60.

Katsuruda, F. Beitr. z. Kenntn. d. Dist. west. (Ziegler's Beitr. z. path. Anat. u. z. allg. Path., I900, xxviii., p. 506.)

\section{Gen. 4. Opisthorchis, R. Blanch.,' 1845 .}

Fasciolidæ of medium size, with long flattened bodics, usually attenuated anteriorly. The cuticle usually has no spines. The suckers are small and fairly close together. Intestine with pharynx, short œsophagus and long unramified intestinal cæca. The genital pore is close in front of the ventral sucker; there is no cirrus pouch. The testes in the posterior end, situated obliquely one behind the other, are lobulated or ramified; the ovary in front of them lobulated or unlobulated; and behind it there is a large receptaculum seminis. Laurer's canal present; vitellaria at the sides not extending beyond the ventral sucker towards the front. The uterus, with oblique coils, occupies the central field in front of the ovary. The excretory bladder is $\mathbf{Y}$-shaped, the long united part running in the shape of an $\mathbf{S}$ between the testes. The parasite lives in the bile ducts of mammals and birds.

\section{Opisthorchis felineus, Riv., I885.}

Syn.; Distoma conus, Gurlt, I83I (nec Creplin, I825); Dist. lanceolatum, v. Sicb., I836, v. Tright, I889 (nec Mehlis, $1825=$ Fasciola lanceolata, Rud., I803); Dist. sibiricum, Winogr., I892; Dist. tenuicolle, Mühl., I896.

This parasite is yellowish-red in the fresh condition, and almost transparent. The body is flat, with a conical neck at the level of the ventral sucker marked by a shallow constriction: this, however, is only noticeable in fresh and somewhat contracted specimens. Posteriorly to the ventral sucker the lateral borders run fairly parallel; the posterior end is either pointed or rounded off. The length and breadth vary according to the contraction, being 
usually 8 - II mm. by $\mathrm{I}_{5}--2 \mathrm{~mm}$. The suckers are about $\frac{1}{5}$ to $\frac{1}{6}$ of the length of the body distant from each other, and of about equal size $(0.23-0.25 \mathrm{~mm}$.). The oosophagus is hardly any longer than the pharynx, which lies close behind the oral sucker; the

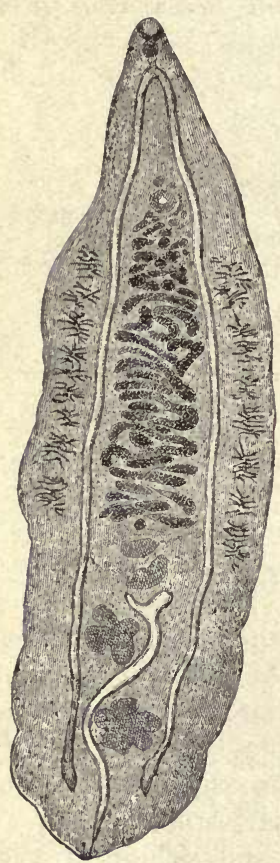

5: FIG. 95.-Opisthorchis felineus, Riv., from the liver of the domestic cat. IO/ $\mathrm{r}$. intestinal branches reach almost to the posterior border and are often filled with blood. The excretory pore is at the posterior extremity, and the excretory bladder forks in front of the anterior testis. The testes in the posterior fourth of the body lie obliquely one behind the other; the anterior one has four lobes, the posterior one five lobes; the ovary is in the median line, stretched obliquely, with simple or slightly lobate border; behind it lies the large pear- or retort-shaped receptaculum seminis and the Laurer's canal. The uterus is in the median field. The vitellaria occupy the fairly broad

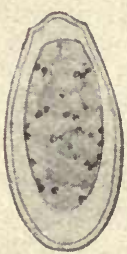

Fig. 96.Egg of Opis thorchis felineus, Riv. $830 / 1$. lateral areas, in about the central third of the body beginning behind the ventral sucker, and terminating at about the level of the ovary; the acini are small and arranged in groups of seven to eight, separated by interstices. The genital pore is close in front of the ventral sucker. The eggs are oval with sharply-defined operculum at the pointed pole, 0.030: 0.0II mm.

This species, which is frequently confused with others, ${ }^{1}$ inhabits the gall bladder and bile ducts of the domestic cat in particular; but is also found in the dog, in the fox, and in Gulo borealis. It has been observed in France, Holland, North Germany (being particularly frequent in East Prussia), in Russia, Scandinavia, Siberia, Japan, Hungary, and Italy. The North American form (from cats and Canis latrans) is a distinct species (Opisthorchis pseudo-felineus).

In man this species was first found by Winogradoff in Tomsk (nine cases), then by Kholodkowsky in a peasant from the neigh-

'Braun, M., "Die Leberdistomen der Hauskatze u. verw. Avten" (C. f. B. u. P., I893, xiv., p. 38 r). 
bourhood of St. Petersburgh who had travelled a great deal in Siberia, and finally by Askanazy in five persons who were natives of the East Prussian district of Heydekrug. In Tomsk Opisthorchis felineus is the most frequent parasite of man that comes under observation at post mortem (6.45 per cent.), whereas Tania saginata has only been found in $3^{*} 2$ per cent., Echinococcus in 2.4 per cent., Ascaris lumbricoides in $\mathrm{I} \cdot 6$ per cent., and Oxyuris vermicularis in 0.8 per cent. of the autopsies. In the district of Heydekrug, however, the species in question is also frequent, as in a few years five cases came to our knowledge (of which three were diagnosed by the discovery of the eggs in the fæces).

In none of Winogradoff's nine cases had the death of the patient been caused direct by the parasites, yet more or less extensive alterations in the liver were found in all of them; such as dilatation of the bile ducts with inflammation and thickening of their walls, and centres of inflammation or atrophy in the liver substance; icterus was present five times and atrophy of the liver an equal number of times; ascites was observed three times, and in two cases, probably of recent date, the organ was enlarged. The number of parasites found fluctuated between a few and several hundreds.

In two of Askanazy's cases, which he exanined more closely, a carcinoma was revealed at the post mortem, which had developed

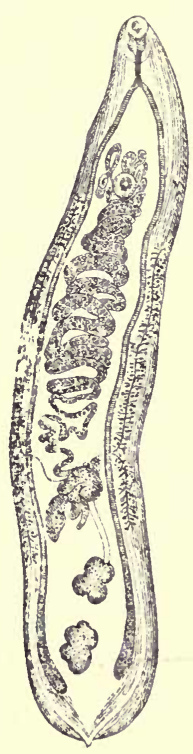

FIG. 97.-Distomum sibiricum, from the liver of man. (AfterWinogradoff.) at the places most invaded by flukes, so that perhaps there may

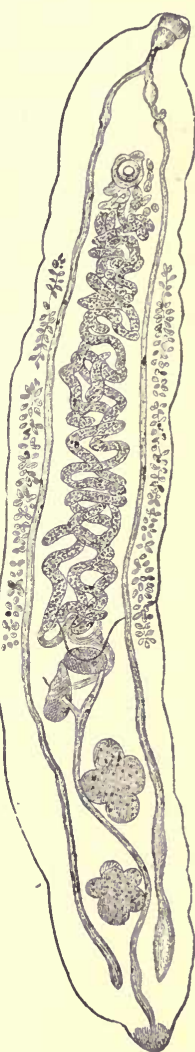

FIG. 98.-Opisthorchis felineus, Riv., from the liver of the donestic cat. Extended specimen for comparison with $D$. sibiricum. be grounds for the connection which the author seeks to establish between cancer of the liver and the changes induced by the parasites; these changes consist of numerous and even ramified proliferations of the epithelium of the biliary duct into the connective tissue, which is likewise proliferated. The number of worms 
found in one case amounted to over one hundred; in a second case, in which the parasites had also invaded the excretory duct of the pancreas, their number was even larger.

Winogradoff as well as Askanazy found isolated flukes in the intestine also.

Unfortunately, nothing much is known of the history of the development of Opisthorchis felineus; we are only aware that when deposited the eggs already contain a ciliated miracidium, which, however, according to my experience, does not hatch out in water, but only after the introduction of the eggs into the intestine of young Limnaus stagnalis; no further development, however, occurred. Winogradoff states that he has seen the miracidia hatch after the eggs had been kept in water for a month at $37^{\circ} \mathrm{C}$.; the author has even observed free miracidia in the bile of a human corpse and that of a dog respectively.

In one of his nine cases Winogradoff also saw a small fluke beset all over with spines, which he conjectured to be the young stage of Opisthorchis felineus; as, however, according to my experience, this species, even in smaller specimens, is always without spines, the above hypothesis cannot be accepted. It is much more probable that one of the other species that also invade the liver of cats may incidentally be introduced into man; we know; in fact, that Metorchis albidus (Braun) and Met. truncatus (Rud.) are both covered with spines. As, however, the spines of the first-named species are fairly variable and the creatures also possess a differently formed body (spatula-shaped), it may be assumed that probably Winogradoff had found Mctorchis truncatus (Rud.), I8I9, in his patient.

\section{Metorchis truncatus (Rud.), I8I9.}

The specimens of this species, which attain a length of $2 \mathrm{~mm}$., are slender and skittle-shaped; the anterior end is pointed and the posterior truncated, and provided with a tuberosity that resembles a terminal sucker; for this reason the discoverer of the species (Rudolphi) classed it with the amphistomes. The cuticle in the young, as well as in the adult specimens, is entirely and closely covered with spines. The suckers are on an average of equal size $(0.134-0.172 \mathrm{~mm}$.), the ventral sucker lies somewhat in front of the middle of the body. The pharynx is small $(0.09$ $\mathrm{mm}$.), the nesophagus minute, the intestinal branches reach to the 
posterior extremity. Between them, and in front of their blind ends, lie the two elliptical testes, one generally a little in front of the other. In front of them, either in the median line or somewhat laterally, the spheroid ovary is situated; in front, again, is the uterus, the coils of which usually extend beyond the median field. The vitellaria are at the sides of the central third of the body, thus commencing in front of the ventral sucker; the cirrus pouch is lacking; the genital pore is close in front of the acetabulum. The excretory pore is situated at the posterior extremity. Eggs, -0.029: 0.0II mm.

This species is known to occur in the seal, in the domestic cat and dog, in the fox and in Gulo borealis, but it easily escapes observation in consequence of its small size. Some circumstances point to the likelihood that both this species and Opisthorchis felineus may invade their hosts by means of infected fish, but hitherto the experimental feedings conducted in this direction by Askanazy have not yielded

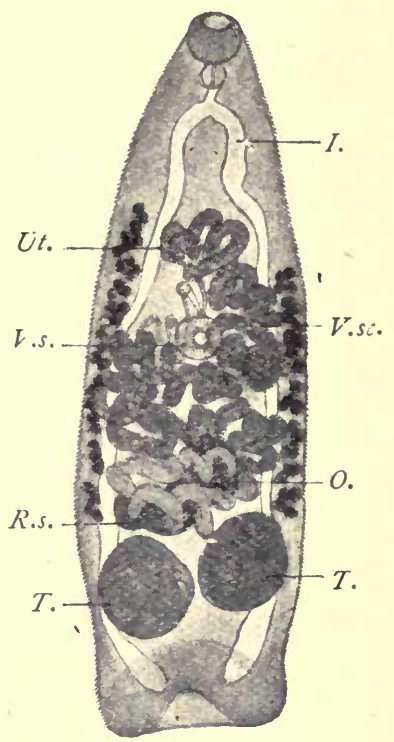

FIG. 99.-Metorchis truncatus, Rud., from the biliary ducts of the domestic cat. 25/1. V.s., Ventral sucker; $I .$, intestinal fork; V.sc., vitelline sacs; $T$., testes ; O., ovary ; R.s., receptaculum seminis; Ut., uterus. positive results; in any case it is a remarkable circumstance that, in the five cases from East Prussia, specimens of Dibothriocephalus latus were also present, and these undoubtedly originate from fish. ${ }^{1}$

'Rivolta, "Sopra una spec. di Distoma nel gatto e nel cane" (Giorn. anat., fisiol. $e$ pat. d. anim., I 884, xvi., p. 20) ; Zwaardemaker, H., "Cirrhos. paras." (Arch. $f$. path. An., I 890, cxx., p. I97); Winogradoff, K., "Ein neues Dist. a. d. menschl. Leber (Nachr." d. K. Tomsk'schen Univ. [1891] I892, iv., p. I16); "Ein zweit. Fall v. D. sib." (ibid., p. I3I); "Ueb. Würmer, welche i. menschl. Körp. paras." (ibid., [I892] 1 893, v.) ; Braun, M.,. "Ueb. ein f. d. Mensch neues Dist." (C. f. B. u. P., 1894, xv., p. 602); Ward, H. B., "On Dist. fel. in the Un. St." (Veterin. Magazine, I 895); Kholodkovsky, N., "Sur quely. var. par. de l'homme en Russie" (Arch. paras., I 898, i., p. 354); Cholodkovsky, N., Icones heim. hom. II., St. Petersb., I898, plate xi., fig. II 5; Askanazy, M., "Ueb. Inf. d. Mensch. mit Dist. felin. in Ostpreussen u. ihren Zusammenhang mit Leberkrebs" (C. t. B., P. u. l., I900 [1], xxviii., p. 49I); "Dist. fel. beim Mensch. i. Ostpr." (Verh. d. D. pathol. Ges., I900, iii., p. 72); Kamensky, G., "Net. helm., i., Charkow, Igoo; Braun, M., "Z. Kenntn. d. Trem. d. Säugeth." (Zooi. Jahrb. Sy'st., I901, part xiv., p. 314). 


\section{Opisthorchis sinensis (Cobb.), I875.}

Syn.: Distoma sinense, Cobbold, 1875 ; Dist. spathulatum, R. Leuck., I876 (nec Rudolphi, I8I9); Dist. hepatis endemicum, s. perniciosum," Baelz, I883; Dist. hepatis innocuum, Bael7, I883; Dist. japonicum, R. Blanch., I 886.

This parasite resembles Opisthorchis felineus in shape and colour, though the form may differ according to the condition of contraction and state of preservation; the length is IO- I4 $\mathrm{mm}$., the breadth $2 \cdot 4-3.9 \mathrm{~mm}$. No spines. The oral sucker is larger than the ventral sucker, and one is about one-fourth of the length of the body distant from the other. The testes are in the posterior third of the body, one behind the other, greatly ramified and extending beyond the intestinal bifurcation; the cucumber-shaped receptaculum seminis lies in front of them, and in front of the receptaculum seminis is the slightly lobate ovary. The uterus spreads in obliquely directed convolutions into the central field between the ovary and ventral sucker; the genital pore lies close in front of the ventral sucker. The vitellaria situated in the lateral areas, commence more or less near the ventral sucker, and extend to the level of the ovary. The eggs are oval with a sharply-defined operculum at the pointed pole; they measure 0.027-0.030:0.015-0.0175 mm.

This parasite inhabits the bile ducts and gall-bladder of domestic dogs and cats, as well as of human subjects. It was discovered in man by McConnell, in Calcutta (I874), in a Chinaman who died soon after his admission to hospital. McGregor confirmed eight more cases in Chinese in St. Louis (Mauritius), and subsequently some Japanese doctors and Baelz found the worm in Japan. At the present date the worm is known to occur in Tonquin, China [and Japan]; it has also been found in Hindoos in Bengal; one case also has been observed in New York in a Chinaman. Opisthorchis sinensis occurs sporadically all over Japan, and is endemic in certain districts of several provinces of Hondo (Central Japan), and in Kiushu (South-west Island). The province of Okayama, in Central Japan, has a specially evil reputation in this respect, for, according to Katsurada, there are isolated regions in which it was discovered (by examination of the fæces) that 56 to 67 per cent. of the population were infected. The number of worms that may collect in a person is said to amount to over 4,000 (counted!), and in about 12 per cent. of the cadavers examined by Katsurada they were also present 
in the pancreas; occasionally also the parasites were found in the intestine, particularly in the duodenum.

The parasites in the liver produce alterations in the bile ducts and in the substance of the liver itself; in the former case the changes consist in local dilatations; occasionally also in sacculations, with proliferation of the connective tissue of the wall and epithelium; in the liver itself interstitial hepatitis of varying intensity develops, a ccompanied by atrophy or fatty degeneration of the hepatic cells; the peritoneal covering and the capsule of the liver are also affected, and in addition the mechanical functions are interfered with by the engorgement of the bile ducts. After enlargement of the liver has subsisted for some time the organ commences to shrink. In extensive infection the death of

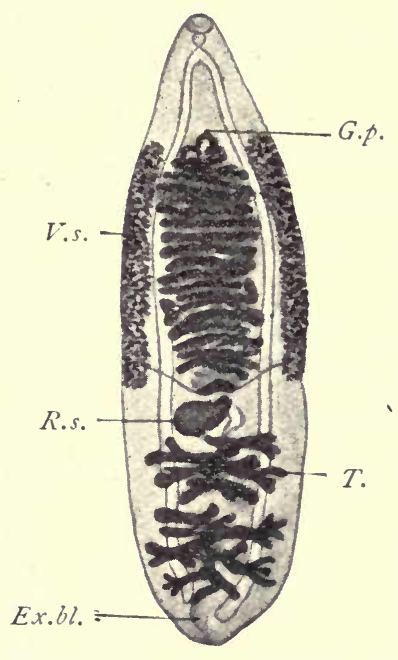

FIG. IOI.-Opisthorchis sinensis, Cobb. ; contracted. About 6/1. (After Katsurada.) V.s., vitelline sacs; Ex.bl., excretory bladder; G.p., genital pore ; $T$., testes; R.s., receptaculum seminis, in front of which is the ovary.

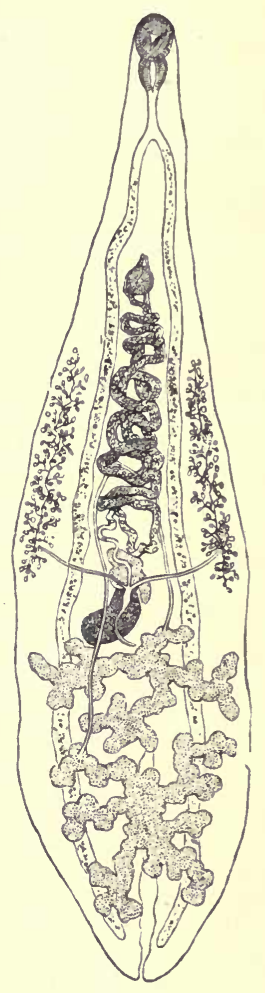

Fig. 100. - Opisthorchis sinensis, Cobb., seen from the ventral surface; ex tended.

(After Leuckart.) the patient is unavoidable (about I4 per cent. of the sufferers).

Hitherto, notwithstanding all investigations, the mode of infection has not been discovered; of the development we only know the miracidium stage. The eggs, when deposited, already contain a miracidium; it is ciliated on all sides, but does not leave the shell spontaneously. ${ }^{1}$

1 McConnell, J. F. P., "Rem. on the Anat. and Path. Rel. of a New Species of Liver-Fluke" (The Lancet, 1875, ii., p. 271 ; and 1878, i., p. 406); Cobbold, 'T. Sp., "The New Human Fluke" (ibid., t875, ii., p. 423); McGregor, "A New Form of Paralytic Disease associated with the Presence, of a Xew Species of Liver Parasite" (ibid., 1877, i., p. 775); Baelz, E., "Ueher einige nene Paras. d. Mensch." (Berl. klin. Wochschr., I883, p. 235); Ijima, J., "Dist. endemicum" (Journ. Coll. Sc. Imp. Univ., Japan, 1886, i., p. 47); Moty, "Lesions anat. prod. par le D. sinense" (C. R. soc. biol., Paris, 1893, p. 224); Katsurada, F. "Beitr. z. Kenntn. d. Dist. spathul." (Beitr. z. path. Anat. u. z. allg. Pathol." [E. Ziegler], I900, xxviii., p. 479). 
[In its living state this parasite is almost transparent. The eggs are brownish or black with a thin
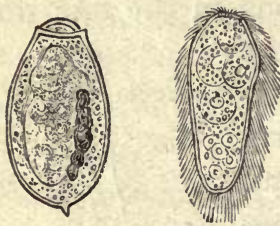

FIG. IO2.-Uterine egg and miracidium of Opisthorchis sinensis. (After Leuckart.) shell. The development of the embryo proceeds within the worm, cilia appearing while the embryo is within the parent.F. V. T.]

\section{Opisthorchis noverca, nov. nom.}

Syn. : Distoma conjunctum, Lew. and Cunn., 1872: McConnell, 1876 (nec Cobbold, 1859).

At the autopsy of two Mahommedans who died in Calcutta, McConnell found a large number of Fasciolidæ in the thickened and dilated bile ducts. The worms were lancet-shaped, covered with spines, and

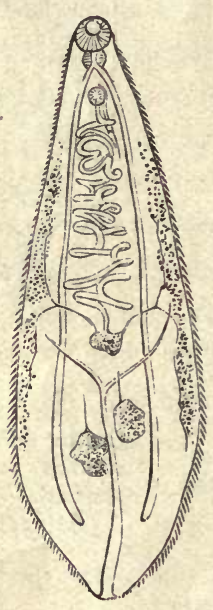

FIG. I03.-Opisthorchis noverca, Mihi. 6/1. (After Leuckart.)

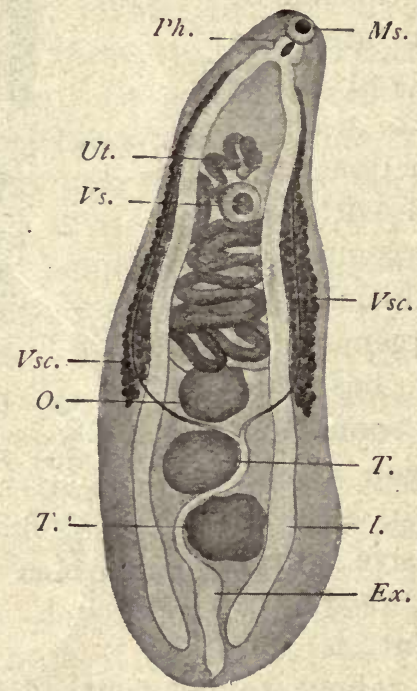

FIG. I04.-Distomum conjunctum, Cobb (nec Lewis and Cunn., nec McConnell), from Canis fulvus. (After Cobbold.) Vs., Ventral sucker; $I$., intestine; Vsc., vitelline sacs ; Ex., excretory bladder ; $T$., testes ; $O .$, ovary ; Ms., oral sucker ; $P h$., pharynx ; Ut., uterus.

measured $9.5-12.7 \mathrm{~mm}$. in length and $2.5 \mathrm{~mm}$. in breadth. The two suckers were very close to one another, the anterior one being larger than the ventral; the genital pore opened immediately in front of the acetabulum; the pharynx was spheroidal and the intestinal cæca extended far back. At the commencement of the posterior 
third of the body were the two testes, somewhat apart, the anterior one roundish, the posterior one distinctly lobate. The oblique and slightly lobate ovary was situated in front of the bifurcation of the $\mathrm{Y}$-shaped excretory bladder, whence the uterus, in convolutions barely spreading beyond the central field, extended to the pore; the vitellaria in the lateral areas commenced behind the ventral sucker and extended to the testes. The cirrus pouch was lacking; the eggs were oval, $0.034-0.02 \mathrm{Imm}$.

A few years previously Lewis and Cunningham found a very similar parasite in the liver of pariah dogs, likewise in Calcutta. It may therefore be assumed that in both cases the same species is dealt with, namely, an Opisthorchis, nearly related to $O p$. felineus and $O p$. sinensis. The authors, however, connect their discovery with a species that Cobbold found in the liver of an American fox (Canis fulvus) that died in London, and which Cobbold described as Distoma conjunctum.

This name is equally applied in literature to McConnell's and to the Lewis-Cunningham worm, although there can be no doubt that Dist. conjunctum, Cobb., is a distinct although related species. As, however, two different species cannot bear the same name, I have given the Indian species the name " noverca."

\section{LITERATURE.}

McConneli, J. F. P. On the Dist. conj. as a Hum. Entoz. (The Lancet, I 876 , i., p. 343 ; and 1878 , i., p. 476 .)

Lewis, T. R., and D. Cunningham. Micr. and Physiol. Res., XI. Ann. Rep. San. Com. Gov. India. Calcutta, I872, Append. C., p. 168.

Cobisold, T. Sp. Syn. of the Distomidæ. (Journ. Linn. Soc., London, Zool., 1859, v., p. 8.)

Furth. Obs. on Entozoa with Exper. (Trans. Linn. Soc., London, 1862, xxiii., p. $34 \%$, plate 33 , figs. I and 2.)

\section{Gen. 6. Cotylogonimus, Lühe.}

Small Fasciolidæ, the body of which is divided into a narrow, movable, anțerior part (neck), and a broader, less movable, posterior portion, which contains the genitaiia. The cuticle closely beset with scale-like spines. The suckers separated from one another by a space equal to half the length of the body or more; the pharynx is close behind the oral sucker; the œsophagus is long, the intestinal branches extend to the posterior border; the genital pore is placed laterally, and behind the ventral sucker. It is surrounded by a muscular annular elevation (genital prominence), which is provided with a wreath of chitinous rodlets, shaped like stags' horns. There is no cirrus pouch. The testes are at the posterior end, 
the ovary in a median position between them. Laurer's canal with receptaculum seminis present; the small vitellaria are at the sides of the posterior part of the body. It lives in the intestine of mammals and birds.

\section{Cotylogonimus heterophyes (v. Sieb.), 1852.}

Syn.: Distomum heterophyes, v. Siebold, I852; Mesogonimus heterophyes, Raill., I890 ; Conogonimus heterophyes, Looss, I900.

This parasite reaches up to $2 \mathrm{~mm}$. in length and I $\mathrm{mm}$. in breadth; the neck is not sharply constricted off; in life it

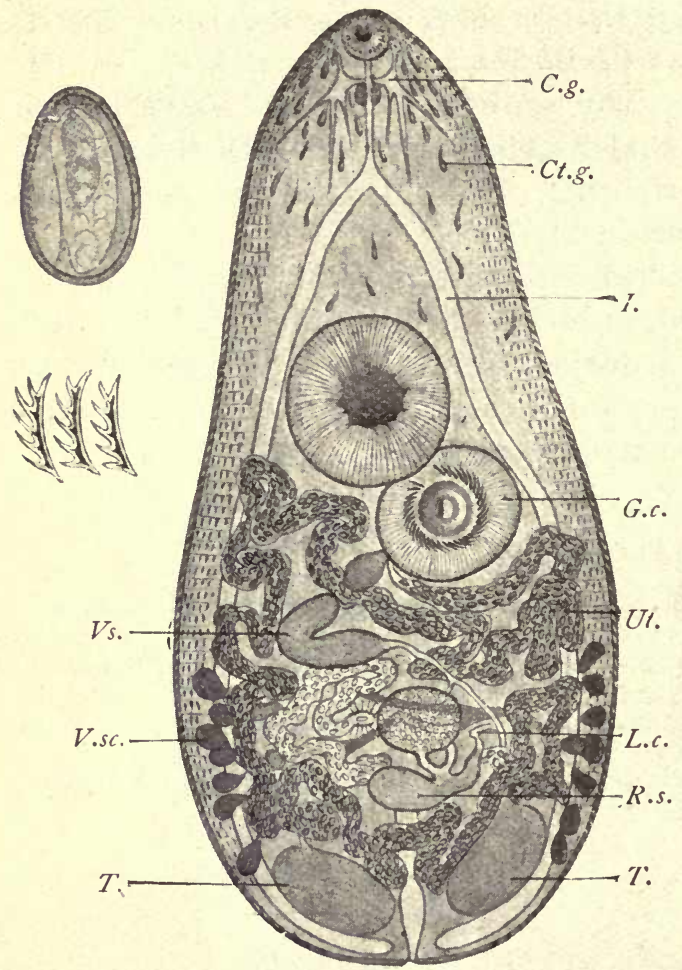

FIG. I05.-Cotylogonimus heterophyes (v. Sieb.) 53/I. C.g., Cerebral ganglion; I., intestinal branches; Ct.g., cuticular glands; V.sc., vitelline sacs ; G.c., genital cup ; $T$., testes-the excretory bladder between them ; L.c., Laurer's canal ; R.s., receptaculum seminis, with the ovarium in front of it ; Ut., uterus; V.s., vesicula seminalis. On the left side above, an egg, 700/I, is depicted, and below it three chitinous rodlets from the genital cup, 700/I. (After Looss.) stretches to double the length of the body. The scales are rectangular, $0.005-0.006$ : 0.004 , their posterior margin serrate with 7 to 9 points. The cuticular glands are numerous on the ventral surface, especially in the forepart of the body, and partly discharge at the anterior border of the oral sucker. The oral sucker is $O \cdot I$, the ventra! sucker $0.35 \mathrm{~mm}$. in diameter; the pharynx measures $0.05-0.07 \mathrm{~mm}$. in length ; the œsophagus is about three times as long: posteriorly the intestinal branches are directed one towards the other and terminate next to the excretory bladder. Close in front of the posterior ends of the intestinal branches are the two elliptical testes, which are not exactly on the same level. In the middle in front of them is the receptaculum seminis, and in front of the latter lies the spheroidal or elliptical ovarium. The two vasa efferentia 
are united to the vas deferens, which after a short course passes over into the angularly bent seminal vesicle; after taking up the prostatic glands it becomes united with the metraterm, and the common passage discharges into the genital cavity. The latter is somewhat smaller than the ventral sucker, lies to the side close behind it, and carries a not entirely closed ring of from 75 to 80 chitinous rods $\left(0^{\circ} 02 \mathrm{~mm}\right.$. in length). The vitellaria on either side consist of about fourteen acini. The uterus is spread almost throughout the entire posterior part of the body. The eggs have thick shells and measure $0.03: 0.017 \mathrm{~mm}$.; they contain a miracidium ciliated on all sides and with a rudimentary intestinal sac.

This species was discovered in $185 \mathrm{I}$ by Bilharz in the intestine of a boy who died in Cairo; a second discovery was only made in I89I and communicated by $R$. Blanchard, so that it appeared as if the species were very scarce. According to the reports of Looss, this is, however, not the case, but the species easily escapes notice on account of its small size. Looss found it in Alexandria twice in nine autopsies, and once in Cairo, and has recently stated that in man "it is not at all uncommon to meet with the parasite in cadavers, and the eggs of the worm in the stools of the patients." The parasites occupy the central third of the small intestine.

The same species, according to Looss, frequently occurs in Egypt in dogs, next in cats, and has also been found in the fox, as well as once in Milvus parasiticus; Janson also reports this species from the intestine of the dog in Japan.

\section{LITERATURE.}

Siebold, C. Th. v. Beitr. z. Helm. hum. (Z. f. w. Zool., i 852 , iv., p. 52.)

Blanchard, R. Note prél. sur le Dist. heteroph. (C. R. soc. biol., Paris, i891 [9], iii., p. 792.)

Looss, A. Ueb. d. Bau v. Dist. fraternum, n. sp. Cassel, I 89.4.

Not. z. Helm. Aeg. I. (C. f. B., P. u. I., I $896[1]$, xx., p. 836.)

Weit. Beitr. z. Kenntn. d. Trem.-Fna. Aeg. (Zool. Jahrb. Syst., i 899, part xıi., p. 699.)

Sandwith, F. M. Dist. heteroph. in a living patient. (The Lancet, 1899, ii., No. 14, p. 888.)

\section{Gen. 7. Dicrocalium, Dag.}

Medium-sized Fasciolidæ, with leaf-shaped bodies, pointed posteriorly and anteriorly. Cuticle without spines; the suckers near each other; powerful ventral sucker. Alimentary canal with pharynx, short œsophagus and long intestinal branches, which do not usually extend to the postericr end. The genital pore is usually close behind the pharynx; 
the cirrus pouch, situated in front of the ventral sucker, contains the vesicula seminalis. The testes have either smooth or serrated borders, and lie symmetrically or obliquely next to or behind the ventral sucker.

The ovarium approaches the median line

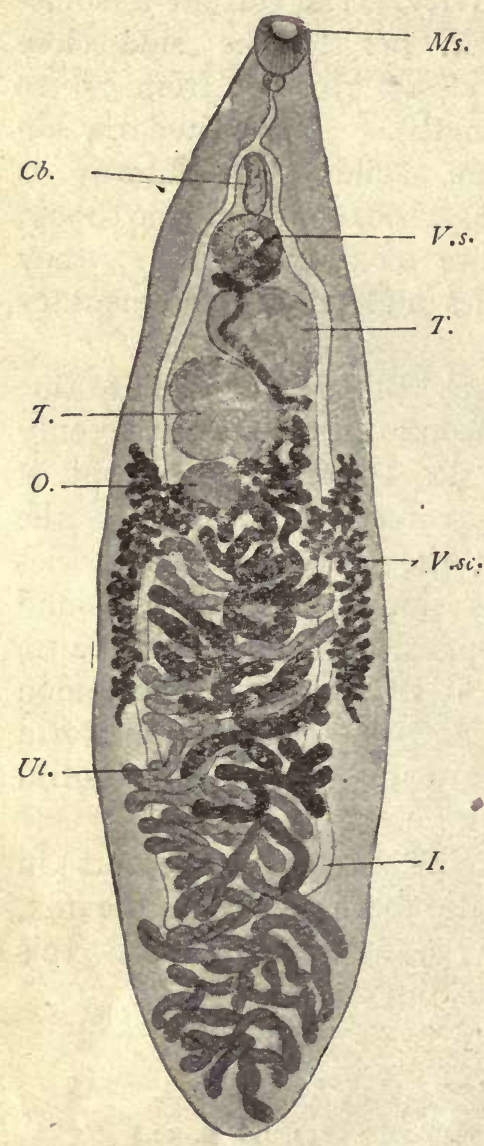

FIG. I06.-Dicrocolium lanceatum, Stil. and Hass. I 5/I. V.s., Ventral sucker; $\mathrm{Cb}$., pouch of cirrus ; $I$., intestinal furcations; $V . s c$., vitelline sacs ; $T$., testicles ; $O$., ovarium ; $M s_{.}$, oral sucker; $U t$., uterus. and is behind one testis. Laurer's canal and receptaculum seminis are present. The uterus lies behind the sexual glands and spreads to the posterior border. The vitellaria in the lateral areas are small. The ova are mostly dark brown and numerous. The excretory bladder is tubular in form. The worm lives parasitically in the liver and gall-bladder (rarely in the intestine) of members of all classes of vertebrate animals-by preference in birds and mammals.

Dicrocolium lanceatum, Stil. and Hass., I 896 .

Syn. : Fasciola lanceolata, Rud., I803 (nec Schrank, I790); Distomum lanceolatum, Mehlis, I 825 ; Dicrocolium lanceolatum Dujardin, 1845 .

The body is pointed at both ends, but is particularly narrow at the anterior extremity; the length of the body averages 8 - $10 \mathrm{~mm}$., the breadth is from $\mathrm{I} .5-2.5 \mathrm{~mm}$., the greatest breadth usually being behind the middle of the body. Suckers distant from each other by about one-fifth the length of the body; the oral sucker measures about 0.5 , the ventral sucker about $0.6 \mathrm{~mm}$. The pharynx is globular and adjoins the oral sucker; the œsophagus measures 0.6 $\mathrm{mm}$. in length; the intestinal branches occupy four-fifths of the body. The genital pore is at the level of the bifurcation of the intestine; the cirrus pouch is small and slender. The large, slightly lobate testicles lie obliquely one at the back of the other behind the ventral sucker, and the ovarium, which is considerably smaller, is placed behind the posterior one; the vitellaria, commencing at the level of the posterior testicle, 
terminate even before the intestines. The uterus, situated behind the ovarium, extends throughout the posterior end, not keeping in the central field, but spreading to the lateral areas with its transverse coils; at the posterior edge of the body it turns back again and winds forwards to the ovarium in transverse loops, then between the testes, and finally over the back of the ventral sucker to the genital pore, where it terminates. The thickshelled eggs when young are yellowish, when older dark brown. They measure $0.038-0.045$ by $0.022-0.030 \mathrm{~mm}$. They contain an oval or more roundish miracidium, the anterior part of which is ciliated, and which possesses a rudimentary intestinal sac with a boring papilla. The miracidia do not hatch out in the water spontaneously, but, according to Leuckart, they hatch within the

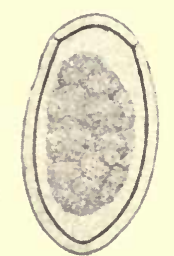

FIG. IO7. - Eggs of Dicrocolium lanceaium, Stil. and Hass. 600/I. To the left seen flat, to right lying on one side.

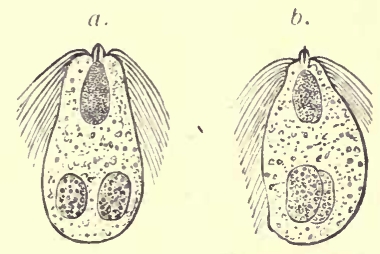

FIG. Io૪. - Miracidia of Dicrocclium lanceatum. a., from the side; $b$., from the dorsum (after Leuckart).

intestine of slugs (Limax, Arion), but they do not increase either in these (slugs) or in water-snails.

The lancet fluke inhabits the biliary duct of herbivorous and omnivorous mammals (sheep, ox, goat, ass, horse, deer, hare, rabbit, pig), and is often found associated with the liver fluke; it is not, however, so common nor so widely disseminated, nevertheless, it has been met with beyond the boundaries of Europe, namely, in Algeria, Egypt, Siberia, Turkestan, and N. and S. America.

In man it is still more uncommon than the liver fluke and has hitherto only been observed seven times (Germany, Bohemia, Italy, France, and Egypt); it may, however, have occurred more frequently, and have been overlooked, as in slight infection it produces no special symptoms.

The intermediary host is still unknown. Leuckart for some time held the opinion that small species of Planorbis from fresh water, 
which contain encysted fasciolidæe, were to blame, and he supported his views on a feeding experiment which seemingly yielded positive results; this, however, is not definitely proved. Piana's statement that small land snails are the intermediaries has also not been proved.

\section{LITERATURE.}

Jönens, T. H. Entonı. u. Helm. d. menschl. Körpers. Hof, I802, p. 64.

Brera, V. L. Mem. fis.-med. sopra i princip. vermi di corpo. Rom., $1 \$_{11}$

Merlis, C. F. L. Observ. Anat. de Dist. hep. et lanc. Gotting, 1825.

Dubini, A. Fntozoograf. umana. Milano, 1850.

Piana, G. P. Le cercarie d. moll. stud. in rapp. colla pres. del D. epat. e I). lanc. (La clinica veter., I882, v.)

Aschoff, L. Ein Fall v. Dist. lanc. i. d. menschl. Leber. (Arch.'f. path. All., 18:)2, cxxx., p. 493.)

Zschокке, F. Selt. Par, d. Mensch. (C. f. B. u. P., 1892, xii., p. 50..)

\section{Fam. 3. Schistosomida, Looss.}

Gen. Schistosomum, Weinl, 1858 .

Syn.: Gyncecophorus, Dies, I858; Bilharzia, Cobb., 1859; Thecosoma, Moq. Tandon, I 860 .

Digenetic Trematodes, that are sexually distinct, and with the oral and ventral suckers in close contiguity; the females are filiform; the males have bodies that widen out considerably behind the ventral sucker, and the lateral parts of which curl ventrally, forming the almost completely closed canalis gynæcophorus, within which the female is enclosed. [The female being longer than the male, part usually protrudes from the posterior end of the male.-F. V. T.] There is no pharynx; the intestinal branches reunite at the posterior end of the body. The genital orifices in both sexes are in the middle behind the ventral sucker. There is no cirrus pouch. The male has five or six testes; the female one ovary: the uterus is long. There is no Laurer's canal. The ova are equally attenuated at either extremity; they have a small terminal spine, and are not provided with a lid. They contain a miracidium, ciliated on all sides, which is characterised by the possession of two large glandular cells, which discharge anteriorly next to the gastric sac. They live in the vascular system of mammals. (An analogous species [Bilharziella] lives in birds.)

\section{Schistosomum hamatobium, Bilharz., I852.}

Syn.: Distoma hamatobium, Bilh.; Dist, capense, Harley, 1864.

The male is whitish, and measures $\mathrm{I} 2-\mathrm{I} 4 \mathrm{~mm}$. in length, but is already mature when $4 \mathrm{~mm}$. long. The anterior end is $0.6 \mathrm{~mm}$. or a little over in length. The suckers are near each other, the oral sucker is infundibular, and the dorsal lip is a little longer than the ventral one. The ventral sucker is a little larger, $0.28 \mathrm{~mm}$., and is pedunculated. A little behind the ventral sucker the body 
broadens to a width of I mm., decreasing, however, in thickness; the lateral edges curl in ventrally, so that the posterior part of the body appears almost cylindrical, $0.4-0.5 \mathrm{~mm}$. in diameter; the posterior extremity is somewhat more attenuated. The dorsal surface of the posterior part of the body is covered with spinous papillæ. [These are used by the males to hold on to the wall of the veins during their wanderings.] There are delicate spines on the suckers and larger ones invest the entire ventral surface of the gynæcophoric canal, as well as a longitudinal zone at the edge of that side of the dorsal surface that is covered by the other edge rolling over it. The osophagus is beset with numerous glandular cells (fig. III), and presents two dilatations; the intestinal bifurcation is close in front of the ventral sucker, the two branches uniting sooner or later behind the testes into a median trunk, in the course of which it may again divide at short intervals. The excretory pore is at the posterior end, but placed somewhat dorsally; the genital pore is at the beginning of the gynæcophoric canal, thus behind the ventral sucker; at this spot a duct discharges, which, towards the interior, broadens into the seminal vesicle, and then

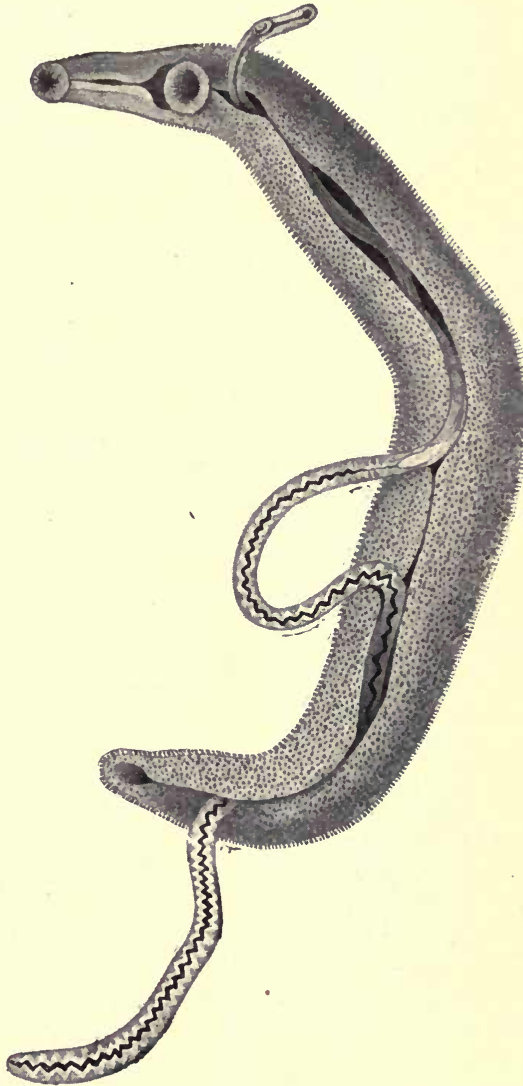

FIG. I09.-Schistosomum hamatobium Bilh. I2/I. Male conducting the female into the canalis gynæcophorus. (After Looss.) continues into the excretory duct of the four or five testes (fig. III).

The females are filiform, about $20 \mathrm{~mm}$. in length, pointed at each end, and measuring $0.25 \mathrm{~mm}$. in diameter in the middle. Their colour varies according to the condition of the contents of the intestine. [Posteriorly they are dark brown or blackish.] The cuticle is smooth except in the sucker, where there are very delicate spines, and at the tail end, where there are other 
larger spines. The oral sucker is a little larger than the pedunculated ventral sucker $(0.07$ and $0.059 \mathrm{~mm}$. respectively). The anterior part of the body measures from 0.2 $-0.3 \mathrm{~mm}$. in length; the œsophagus

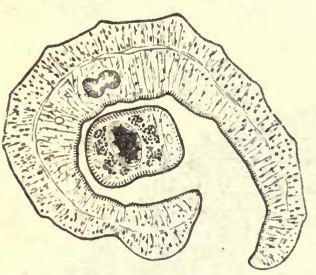

FIG. IIO.-Transverse section through a pair of Schistosomum. In the male the point of reunion of the intestinal forks has been cut across. (After Leuckart.)

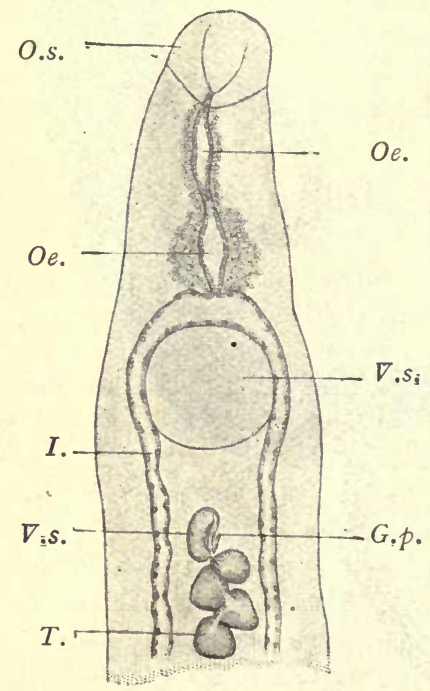

FIG. III.-Anterior end of the male Schistosomum hamatobium (Bilh.). 40/I. V.s., ventral sucker ; I., intestinal branches ; G.p., genital pore; $T_{\text {., testes ; }}$ $O$. s., oral sucker; $O e$., œesophagus with glandular cells ; V.s., vesicula seminalis. (After Looss.)

vicinity of the posterior border but laterally.

[The eggs are yellowish in colour, slightly transparent and provided with a thin shell. The spine may sometimes be absent. The eggs apparently vary a great deal in size.-F. V. T.] 
Schistosomum hamatobium lives in man in the portal vein and its branches, and thence is distributed to the remaining veins of the abdomen, particularly those of the pelvis or the bladder, and of the rectum. The worm is known in Lower Egypt and Cape Colony, and has likewise been found in Upper Egypt, Abyssinia, Sudan, Mozambique, Natal (possibly it is present on the entire East Coast); it also appears to be found in the interior of Africa; in any case it has been found on the Gold Coast, in Tunis, and in Algeria; beyond Africa it only occurs in imported cases, but there appears to be a centre of infection in Arabia (Mecca). It is particularly frequent in the natives of Lower Egypt, where boys and youths are especially attacked.

[It has also been observed in Angola in the Congo State, in the Sahara region, on the White Nile, near the Lake Albert Nyanza and in the basin of the Zambesi. It has. also occurred in Mauritius, Syria, Bombay, Penang, Shanghai, and N. America. -F. V. T.]

The consequences of the infection are manifested by catarrh of the bladder, with pains in the bladder and in the lumbar region. At first the urine is still clear, later on blood or purulent sanguineous flakes appear at the end of micturition, at the commencement intermittently, but later daily. The disease may thus continue for some time without essentially altering the general condition, and may finally terminate in recovery. If a renewed or more severe infection sets in, the catarrh becomes more intense, the urine contains larger quantities of blood and pus, and calculi are also formed. The causes that have induced these

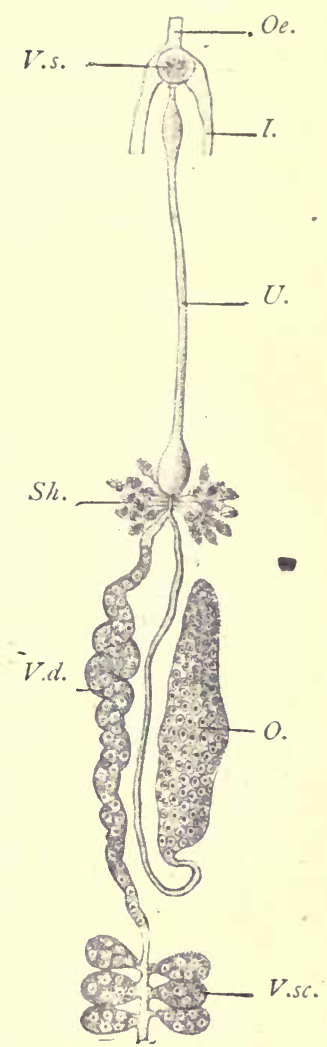

FIG. II 2. - Schistoso. mum hamatobium, Bilh. Genitalia of the female (magnified). V.s., ventral sucker; $I_{.}$, intestinal branches; V.d., vitelline ducts; V.sc., vitelline sacs; $O$., ovarium; $O e$. œesophagus ; Sh., shell glands ; $U$., uterus.

(After Leuckart.) symptoms also attack the ureters, the pelvis of the kidney, the kidneys, and the rectum ; the nutrition suffers considerably, and death may set in from uræmia, pyæmia, an intercurrent pneumonic process, or general marasmus. On section, the wall of the bladder is found to be much thickened, the internal surface more or less extensively covered with proliferations resembling cock's combs or villi ; very often the epithelium is missing, and ulcerations also have appeared. Corresponding changes are also found in the other organs, the kidneys are affected with intense interstitial nephritis. All these symptoms are caused by the eggs of the Schistosoma, deposited by the female, which has pene- 
trated into the venous plexus of the pelvis, and which eggs reach the walls of the bladder, \&c., from the blood-vessels. The eggs pass through the walls of the bladder, and are consequently easily found in the urine of the patients, mostly in the flakes. Many of the eggs, particularly those provided with a lateral spine, remain stationary in the bladder, irritating it still further; but they finally perish and become calcified, the eggs remaining in the lumen of the bladder are thus frequently the cause of the bladder stones that are so common in bilharziosis. The eggs are also swept into other parts of the body by the circulation, and may thus be found in all the organs, though usually only in small numbers.

The means by which infection is brought about are still uncertain; we only know that the mira-

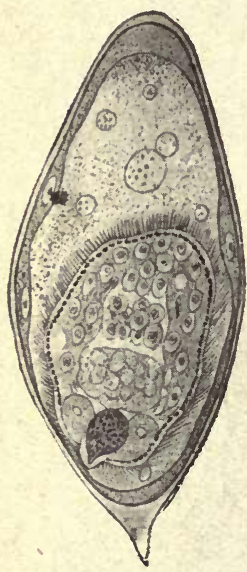

FIG. I I 3.-Ovum of Schistosomum hamatobium, Bilh., with miracidium, which has turned its anterior end towards the posterior of the egg. 275/I. (After Looss.) cidia (fig. II3) enclosed in the evacuated eggs do not hatch if the eggs remain in the urine; they perish with the calcified ova. As soon, however, as the urine is diluted with water the shell splits open, generally bursting lengthways, and releases the miracidium from its investing membrane, so that it can swim about with the aid of its cilia. In its structure it differs but little from the miracidium of the liver fluke, as, for instance, in the lack of eyes; the two large gland cells situated near the intestinal sac are also present in the miracidia of the liver fluke.

The circumstance that this stage of development already carries within it the germs of the future generation, indicates that sporocysts - and within these cercaria - must ensue ; hitherto, however, in spite of all experiments, it has been impossible to discover the suitable intermediary host, so that the conjecture may be mooted that the sporocyst stage is gone through in man himself. The experiments on monkeys, however, conducted by Looss to demonstrate this had negative results. The infection is said to be induced by drinking impure water from canals and pits, and recently it has been stated that the miracidia penetrate through the skin of human beings while they are bathing.

\section{LITERATURE}

Bilharz, Th. Beitr. z. Helm. hum. (Z. f. w. Zool., I 852 , ii., pp. 453 and 454.)

Chatin, J. Obs. sur le dév, et l'org. du proscol. de la Bilharzia. (Ann. Sc. Nat. Zool., I 88 I [6], xi.)

Sonsino, P. Ric. s. sviluppo d. Bilh. (Giorn. R. Acc. Med., Torino, I889, xxxii., p. 380.$)$ 
Kartulis. Vork. d. Eier v. Dist. hæm. (Arch. f. path. An., I885, xcix., p. I39.)

Weit. Beitr. z. path. Anat. d. Bilh. (Ibid., I 898 , clii., p. 474.)

Fritsch, G. Z. Anat. d. Bilh. hæm. (Arch. f. mikr. An., 1888, xxxi., p. 192.)

Chaker, M. Et. sur l'hématurie d'Eg. Thèse, Paris, I 890 .

Railliet, A. Obs. s. l'embr. du Gynæcoph. hæm. (Bull. soc. zool., France, r892, xvii., p. IOI.)

L.ooss, A., Bcob. üb. Eier u. Embr. v. Bilh. (In Leuckart: D. Paras. d. Mensch., I 894, and edit., i. 5 , p. 52 I.)

Bemerk. z. Lebensgesch. d. Bilh. hæm. (C. f. B. u. P., I894, xvi., pp. 286 and 340.)

Rech. faun. par. de l'Eg. (Mém. Inst. ég., I 895, iii., p. I 58.$)$

Z. An. u. Hist. d. Bilh. hæm. (Arch. f. Mikr. An., I 895 , xlvi., p. I).

RÜtIMEYER, L. Ueb. Bilharziakrkht. (Mitth. Klin. u. med. Inst. d. Schweiz., I 894 [I], xii., p. 871.) Also separately.

Lortet and Vialleton. Etud. sur la Bilh. hæm. Paris, I895. (Ann. de l'univ. de Lyon, I894, ix.)

Laveran and R. Blanchand. Les hématoz: II. Vers. du sang. (Bibl. Méd.—CharcotDebove.) Paris, I895.

\section{Schistosomum japonicum, Katsurada, I904.}

Syn. : Schistosoma cattoi, Blanchard, 1905.

Schistosomum japonicum was discovered in Ig,04 by Professor D. F. Katsurada, of the Pathological Institute of Okayama. For some years the Japanese physicians had observed in the provinces of Yamauashi, Hiroshima (Central Japan) and Saga (in Kinshu, northwest island) an endemic disease characterised by enlargement of the liver and spleen, cachexia and ascites. The patients suffered from diarrhœa (frequently with mucous and blood-stained motions), anæmia, occasionally fever, and a number died from extreme weakness. At the autopsy of such cases Yamagiva, Kurimoto, Fujinami and others found in several organs (more especially the liver) numerous eggs of a hitherto unknown helminth.

In April, I904, Professor Katsurada had the opportunity of examining several cases of the disease, and he noticed that the eggs eliminated with the fæces contained a ciliated embryo not unlike the miracidium of Schistosomum hamatobium. Having no opportunity of making an autopsy, he thought of examining the dogs and cats of the endemic areas, because he had already found that some trematodes of frequent occurrence in man are also not infrequently present in dogs and cats. And he had the good fortune of at once finding in the portal system of two cats from the province of Yamauashi numerous schistosomidæ containing eggs exactly similar to those previously found in man. He published this information on August I3th, and named the new trematode Schistosomum japonicum.

Three months later the same parasite was found by Dr. John Catto in sections of the mesocolon from a Chinaman of the province of Fukien, who died of cholera at St. John's Island, Quarantine Station, Singapore. During life the patient presented enlargement of the liver and 
spleen. At the autopsy the adipose tissue was found to be remarkably abundant throughout the body. The appearance of the peritoneum suggested repeated attacks of peritonitis. The appendices epiploicæ were thickened and in some places matted together. The recto-vesical pouch was almost obliterated. The mesenteric tissues were all thickened and loaded with fat. The mesenteric and prevertebral glands varied in size from a bean to a golf-ball, the largest forming a cluster near the duodenum. The liver was considerably hypertrophied, its surface nodular, its consistence greatly increased. The coats of the gall bladder were thickened, and a layer of fat almost completely incased this organ, which was distended with clear mucoid material containing several minute black gall-stones.

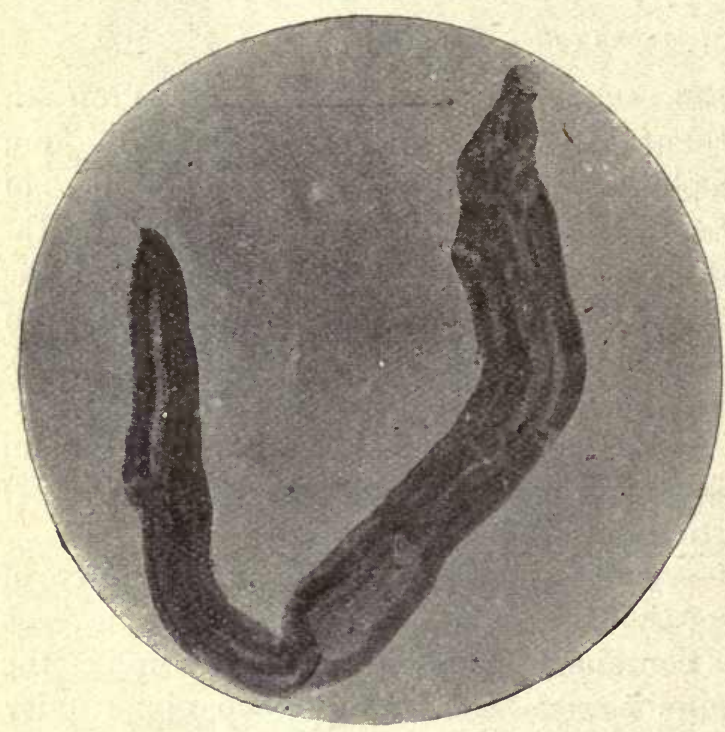

FIG. I14.-Schistosomum japonicum. 8 .

The spleen was enlarged and pigmented. The colon was much thickened throughout. Its mucous membrane was swollen, hyperæmic, and friable; it presented numerous small circular superficial erosions and patches of necrosis. The outer coats were very tough, almost cartilaginous. The rectum was three-quarters of an inch thick all round, and was adherent to the bladder. It nearly filled the true pelvis.

The sigmoid flexure was uniformly thickened. In tracing the bowel upwards the thickening became less marked and more patchy. The coats of the cæcum and appendix vermiformis were uniformly hypertrophied, the mucous membrane presenting small patches of ulceration and necrosis. The lower end of the ileum was thickened in patches, and the mucosa congested over corresponding areas. The liver and bowel cut gritty on section. The bladder was thickened where adhesions had formed with the rectum, but elsewhere it was healthy, and nowhere was the vesical mucosa diseased. The stomach, pancreas, suprarenals, kidneys, heart and lungs showed no signs of coarse disease.

As the lesions above mentioned were peculiar, some of the viscera 
were preserved. Sections of the liver, mesenteric glands and bowel were made in Singapore by Dr. Finlayson, and at the Kuala Lumpur Research Institute by Dr. Daniels. Numerous small oval bodies having a smooth stout capsule were found. These bodies were taken for Coccidia, and the case was published in the Journal of the Malaya Branch of the British Medical Association as a case of coccidiosis in man.

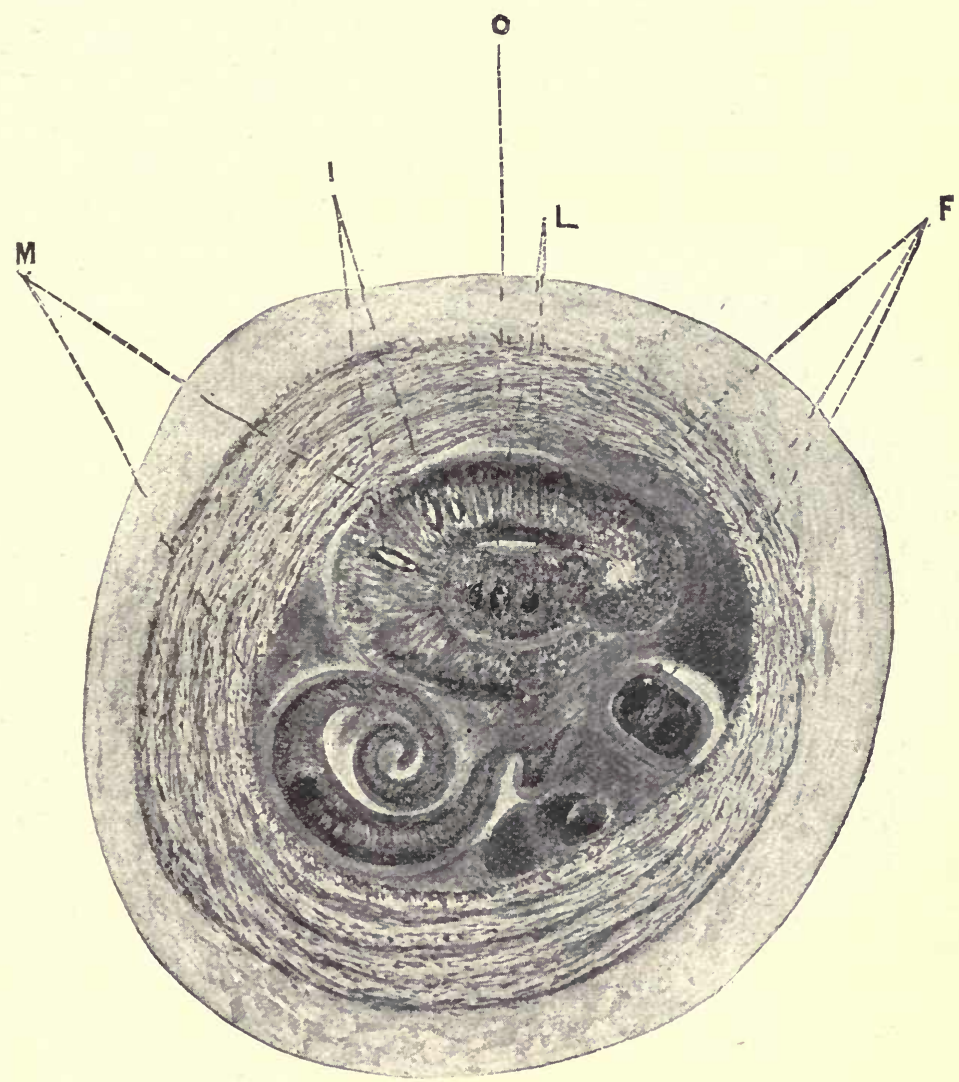

FIG. I I 5.-Transverse section of a mesenteric vessel, showing: (M) two male schistosomes; (F) females; (I) cæca in male; ( $\mathrm{L}$ ) cæca in female; (O) ovum. Magnification, $56 \times$.

On his return to England Dr. Catto had the opportunity of working out the case at the London School of Tropical Medicine, where systematic examinations and sections of all the preserved tissues were made. Sections of the intestine showed the same oval bodies and numerous small nematodes arranged in batches in the mucosa and villi of the small intestine. The latter were soon recognised to be the larvæ of Filaria bancrofti, and were probably within 
the lacteals. The former were supposed to be the ova of some hitherto undescribed species of worm. The fact of their having been taken for Coccidia is not very surprising. Many times before the ova of worms have been taken for Coccidia, and conversely Coccidia have been mistaken for the ova of worms. In the earliest recognised case of coccidiosis in man (Gubler's case), the Coccidia were at first regarded as the eggs of a trematode. At length, in the smaller mesenteric blood-vessels, Catto found male and female specimens of a new species of trematode belonging ${ }_{1}^{\text {to }}$, the genus Schistosoma, and noticed that the ova within the uterus of the female worm corresponded in every way with the oval bodies found in the various

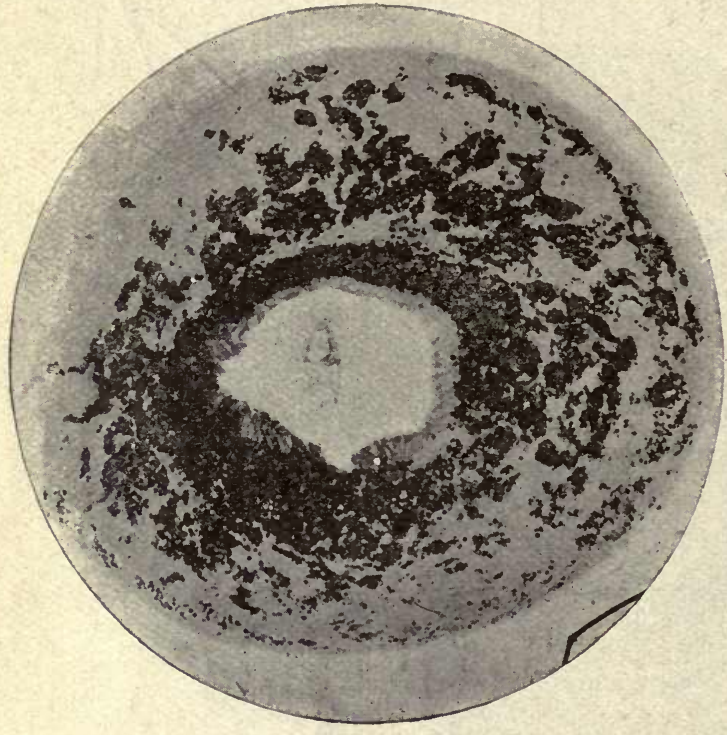

FIG. 116.-Section of appendix (stained), showing ova in masses, a dense submucous layer, and a less marked subperitoneal layer.

organs. In the bowel of this case were also found specimens of the more common parasitic worms - Tricocephalus trichurius, Uncinaria duodenalis and Ascaris lumbricoïdes - together with their respective eggs. It was clear, however, that the anatomical lesions aforementioned were due to the trematode parasite.

Specimens of the trematode were sent to Professor Blanchard, who recognised that they belonged to a new species which he named Schistosoma cattoi.

After the publication of his paper Dr. Catto received a section of intestine prepared in Japan in I90o, which showed ova having exactly the same characters and occupying the same position in the intestine as in his own case.

Morphologically, Schistosoma japonicum is not unlike the wellknown S. hamatobium discovered by Bilharz in I85I. The distinctive characteristics of the new trematode are its smaller dimensions; the larger size of its acetabulum or posterior sucker as compared with the anterior sucker; the smooth, non-tuberculated integument of the male; the smaller, non-spined ova contained in 
the female. A comparative study of the anatomy of the two Schistosomidæ will probably show other morphological differences. Dr. Catto mentions a larger vas deferens and lobular testicles in the male, and a different arrangement of the yolk cells in the female.

The dimensions given by Dr. Catto refer to a few spirit specimens, and are, therefore, only relative. The male measures $9 \mathrm{~mm}$. in length by less than $\frac{1}{2} \mathrm{~mm}$. in breadth. The slender, almost cylindrical, female . is longer than the male and measures $0.113 \mathrm{~mm}$. in diameter. The eggs are of a yellowish-brown colour, they are oval, have neither operculum nor spine, and measure from 60 to $90 \mu$ in length by 30 to $50 \mu$ in breadth.

Professor Katsurada's measurements refer to fresh specimens from the cat. $\mathrm{He}$ measured eight males, and found I0. $43 \mathrm{~mm}$. to be the average length. The longest male specimen measured I2 $\mathrm{mm}$. The greatest breadth of this specimen a little behind the centre of the body was $.53 \mathrm{~mm}$. Only a few females were found intact; they measured from 8 to $\mathrm{I} 2 \mathrm{~mm}$. The greatest breadth of

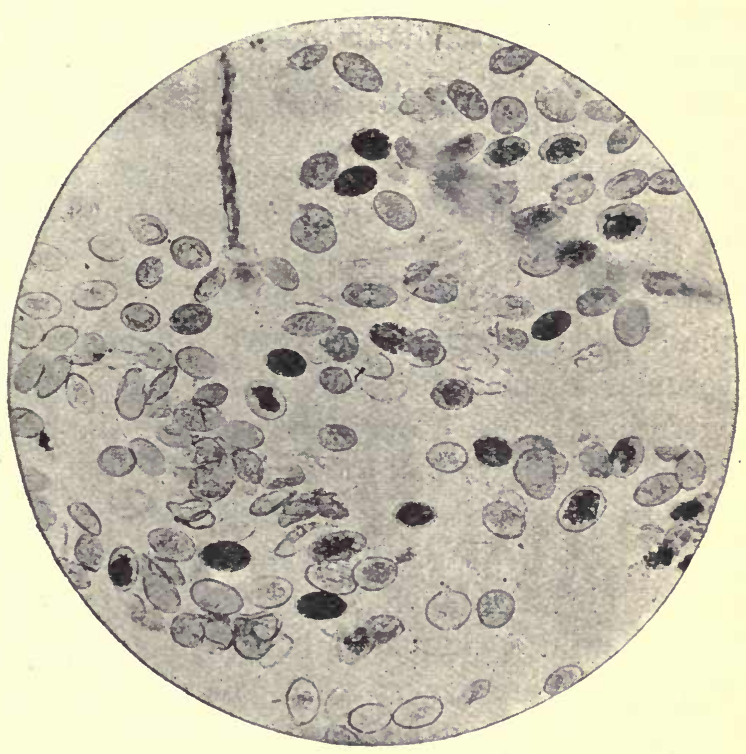

FIG. I 17.-Magnified view of fig. I 6 , showing ova. the female was $4 \mathrm{~mm}$.

The adult worms are found in the smaller mesenteric bloodvessels. Dr. Catto was unable to determine whether they occupy the arteries or the veins, but believes they occur in both. However, the smooth, non-tuberculated skin of Schistosomum japonicum would suggest a different anatomical habitat to that of Schistosomum hamatobium, the integument of which is beset with numerous spinebearing protuberances. Schistosomum hamatobium inhabits the venous system, and its rough integument obviously enables it to adhere to the inner coat of the venule during oviposition, and thus prevents its being carried away by the ascending blood-stream. If Schisto- 
somum japonicum inhabits the arteries, the absence of integumental protuberances might be easily explained by the fact that the arterial current would maintain it in its proper position.

In Catto's case the ova of the parasite were found chiefly in the intestinal tract and its appendages. In the intestine, from cæcum to anus, the ova occupied roughly two concentric layers, the one subperitoneal, where the ova were comparatively scarce, the other in the submucous coat, where they were innumerable. Between these zones in the muscular layers there were single or double rows of eggs lying with their long axes at right angles to the bowel. In the mucosa they were also plentiful, especially in the necrotic areas. Of the intestinal tract, the rectum and appendix were most affected. Everywhere throughout the small intestine ova were found, but only in patches and in relatively small numbers. In the liver the ova were plentiful, lying singly or in clusters embedded in the markedly hypertrophied fibrous connective tissue. They were also found in many of the enlarged mesenteric lymphatic glands, in the outer wall of the gall-bladder, in the pancreas, in the liver capsule, and in the fibrous coat of the larger mesenteric vessels. The eggs were not in the capillaries-which they are too large to enter-but in the perivascular tissue. Probably the female schistosoma has a means of extruding them through the walls of the blood-vessel. Their further distribution is probably due to the lymph stream. Where ova accumulate they provoke a small-celled infiltration, which gives place later to a great proliferation of fibrous tissue.

Nothing is known of the life history of this schistosoma. The ova contain a ciliated embryo, which may develop in the fæces even before they are evacuated. The geographical distribution of Schistosomum japonicum is probably a wide one, and Dr. Catto suggests that the parasite was not recognised before because its ova in the stools were mistaken for the ova of Uncinaria duodenalis, which they resemble in size, shape and general appearance.-[L. W. S.]

\section{Class II. Cestodes, Rud., I808.}

Tapeworms have been known from ancient times-at all events, the large species inhabiting the intestines of man-and there has never been a doubt as to their animal nature. The large cysticerci of the domestic animals (occasionally of man also) have been known for an equally long period, but they were generally regarded as excrescences, or hydatids, until almost simultaneously Redi in Italy, and Hartmann and Wepfer in Germany, concluded from their movements and organisation that they were of animal nature. From that time the cysticerci have 
been included amongst the other intestinal worms, and Zeder (I800) established a special group (cystici) for them. Things remained in this condition until the middle of the last century, when Küchenmeister, by means of his successful feeding experiments, demonstrated that the cysticerci were definite stages of development of certain tapeworms. Before Küchenmeister, E. Blanchard, van Beneden, and v. Siebold had held the same opinion in regard to other asexual cestodes.

Since the most remote period another question had occupied the naturalists again and again, the question of the morphological nature, that of the INDIVIDUALITY OF THE TAPEWORM. The ancients, who were well acquainted with the proglottides that are frequently evacuated (Vermes cucurbitani), were of opinion that the tape-worm originated through the union of these separate proglottides, and this view was maintained until the end of the seventeenth century. In I683 Tyson discovered the head with the double crown of hooks in a large tape-worm of the dog; Redi (I684) was also acquainted with the head and the suckers of several Tæniæ, and Andry (1700) found the head of Tania saginata, Bonnet (I777), and Gleichen Rusworm (1779) found the head of Dibothriocephalus latus. Consequently most authors, on the ground of this discovery, considered the tapeworm as a single animal, that maintains its hold in the intestine by means of the head, and likewise feeds itself through it. The fact was recognised that there were longitudinal canals running through the entire length'of the worm, and it was thought that these originated in the suckers; and naturalists regarded the entire apparatus as an intestine. As it was found, moreover, that the joints form at the neck, and are cast off from the opposite extremity, the tapeworm was also compared with the polyps, which were formerly regarded as independent beings.

Steenstrup, in his celebrated work on the alternation of generations (I84I), was the first to inaugurate another stage of advance. His studies were followed still further by van Beneden, v. Siebold and Leuckart, and until a few years ago all authorities adopted his views. Accordingly, the tapeworm is composed of numerous individuals, something like a polyp stem, and, in addition to the proglottides - the sexual individuals which are usually present in large numbers-there is ONE individual of different structure, the Scolex, which not only fastens the entire colony to the intestine, but actually produces this colony from itself, and therefore is present earlier than the proglottides. The scolex is a nurse which, though itself produced by sexual means, increases asexually like a Scyphistoma polyp; the tapeworm chain has, therefore, been termed a Strobila. Consequently the development of the tapeworms was explained by an alternation of generations. In support of this opinion it was demonstrated not only that the adult sexual creatures, the proglottides, can separate from the colony and live independently for a time, but that in certain Tæniæ, and especially in many cestodes of the shark, the proglottides detach themselves long before they have attained their ultimate size, and thus separated continue to develop, grow and finally multiply; the scolex also exhibits`a certain independence in so far as, though not, as a rule, capable of a free life, yet in some cases lives as a free being, partly on the surface of the body of marine fishes and partly in the sea. With the more intimate knowledge of the development of the cysticerci, the independent nature of the scolex was recognised. It is formed by an invagination of the 
cyst developing from the oncosphere, in some cases (Conurus) in large numbers, in other cases (Echinococcus) only after the parent cyst has developed several daughter cysts. Released from its cyst and placed in suitable conditions, it goes on living, and increases at its posterior end by proliferation. In these cases a double change of generations must be accepted (ONCOSPHÆRA-mother cyst; SCOLEX, one or several in numberPROGLOTTIDES).

The view that the tapeworm consists of a colony originating from dimorphous individuals, and that its development takes place through an alternation of generations, has been recently assailed by several authors. The cause for this disagreement was furnished partly by changes in the views concerning the alternation of generations itself, partly by those cestodes which exhibit no external segmentation, as Ligula, in which the genitalia only are repeated again and again, and partly by the so-called one-jointed cestodes (Amphilina, Caryophyllaus, Gyrocotyle, \&c.), the genitalia of which only appear once in each specimen. Without arguing the pros and cons of the opposing views, we must nevertheless remark that even though the single-jointed cestodes must be considered the most primitive tape-worms, it does not follow that the proglottides are merely segments of the body. The advancement of a "morphologically strictly limited subordinate stage of individuality" in itself essentially concedes the individuality of the proglottides. If, on the other hand, the appearance of numerous little heads in Conurus and Echinococcus is regarded as a multiplicate, there is no reason why the formation of only ONE head in Cysticercus should be anything else; the NUMBER of the offspring, is of no importance. A difficulty is certainly presented by such forms as Ligula, but one can in these either take it for granted that the formation of the proglottis has not yet set in or that it has already disappeared. In the former case a lower development of the single individual must be present, a view that can hardly be opposed, as in other creatures forming colonies we know that there may be a reduction of one or numerous individuals until only the stage of one organ is left.

If we except the tapeworms with only one proglottis, the Cestodaria, we can always distinguish in the cestodes in the narrowest sense, one scolex and a large or small number of segments (proglottides). The Scolex serves the entire tapeworm by fastening it to the internal surface of the intestinal wall, and therefore carries at its end various organs which assist in this function, and which are as follows: (I) SUCTORIAL ORGANS, i.e., the four round suckers (acetabula), which are placed cross-wise at the circumference of the thickened end of the scolex; further, the double or quadruple groove-like suckers (bothridia) which are diversely shaped according to the genera and families. ${ }^{1}$ (2) CLINGING ORGANS (hooklets) that

'They may remain simple, and are then not separated from the remaining muscles of the scolex; or they rise as roundish or elongated formations over the scolex, hollow on their free surface, and are often divided into numerous areas by muscular transverse ribs. They may also carry accessory suckers on their surface. 
likewise appear in varying numbers and different positions, they may be on the suctorial organs or above them on the apex of the scolex; for instance, in many of the Tæniadx they appear in a circle around a single protractile organ, the rostellum, or the latter may be rudimentary, and is then replaced by a terminal sucker. (3) Rostrum. One family of the cestodes, the Rhynchobothriidia carries four rostra, moved by their own muscular apparatus, on the scolex, and they are beset with the most diverse hooks. (4) TentaCle-LIKE formations are only known in one genus (Polypocephalus).

The thickened part of the scolex that carries the suckers is usually called the head; the following flat part connecting it with the proglottides is called the neck, and is sometimes quite small. In a few cases the entire scolex (or head) disappears, and its function is then undertaken by the contiguous portion of the chain of proglottides which is transformed into the so-called PSEUDO-SCOLEX.

The proglottides are joined to the scolex in a longitudinal row, and are arranged according to age in such a manner that the oldest proglottis is furthest from the scolex, and the youngest nearest the neck.

The number of segments varies according to the species, from only a few to several thousands; they are either quadrangular or rectangular; in the latter case their longitudinal axis falls either longitudinally or perpendicularly to that of the entire chain; when the number of segments is very large, the youngest ones are, as a rule, transversely oblong, the middle ones are squarish, and the mature ones longitudinally oblong. The posterior border of the segments, as a rule, carries a longitudinal groove for the reception of the shorter anterior border of the following proglottis. The two lateral borders of the segment are rectilinear, but converge more or less towards the front, or they are bent outwards. In most of the cestodes the segments, even starting at the neck, are very flat; in rare cases their transverse diameter is equal to their dorso-ventral diameter. As a rule the segments, singly, or several united together, detach themselves from the posterior end, in many cases only after complete maturity is attained, and in others much earlier; they then continue to live near their parent colony in the same intestine and continue their development. Even when evacuated from the intestine the proglottides under favourable circumstances can continue to live and creep about until they perish, sooner or later.

The first proglottis formed, and which in a complete tape- 
worm [i.e., sexually complete] lies at the posterior end, is as a rule of smaller size and different shape, it also frequently remains sterile, as likewise happens in the next younger segments in a few species; otherwise, however, sooner or later the generative organs develop in all the segments, mostly singly, sometimes in pairs; in the latter case they may be quite distinct from each other or possess some parts in common. Most of the species combine male and female genitalia in the same segment, only a few are sexually distinct (Dicecocestus). In the hermaphrodite species one male and one female sexual orifices are always present, and, in addition, there may be a second female orifice, the mouth of the uterus; as a rule, however, this is lacking, and in one genus the other sexual orifice, the opening of the vagina, is also absent. The position of these orifices varies; the cirrus and vagina usually open into a common space on one lateral border or on a surface of the segments; the orifice of the uterus may be on the same surface or on the opposite one.

The surface on which the uterus opens is termed the VENTRAL SURFACE; if this orifice is absent, one must depend on the female organs, particularly the ovary, which almost always approaches one of the two surfaces; the proximal surface is then called the ventral.

The length of the Cestodes-independently of their age-depends on the number and size of the segments, as well as on their contraction; the smallest species (Davainea proglottina) may measure $0.5-\mathrm{I} \cdot 0 \mathrm{~mm}$. in length; the largest may attain a length of Io mo., and even more.

\section{Anatomy of the Cestodes.}

The entire superficial surface of the tapeworms is covered with a fairly resistant and elastic cuticle, which also covers the suckers, and is reflected inwardly at the sexual orifices; in some species fine hairs appear, either on the entire body or only in the region of the neck, on the external surface of the cuticle, which exhibits several indistinct layers. Close under the cuticle lies the external layer of the parenchyma (basal membrane) and immediately after the elements of the dermo-muscular tube. The matrix cells of the cuticle are, as in the Trematodes, only on the other side of the peripheral muscles in the external zone of the parenchyma; they are fusiform cells forming one or two layers, but are not arranged in the manner of epithelial cells. They have fine branching processes which run between the cuticular muscles, pass through the 
basal membrane and penetrate the internal surface of the cuticle with small pistil-like enlargements; at the internal surface of the cuticle they spread out into a thin layer (fig. II8.)

In addition to the abovementioned, there are other cuticular formations occurring on the cuticle of some cestodes, such as immotile little hairs and variously formed hooks, such as are seen principally on the scolex. Their development is only roughly known in a few species; they are usually already present in the cysticercus stage, and in the same order and form as they are found in the fully-developed tape-worms ; systematically this is of importance, because by these structures cysticerci can be recognised as belonging to certain species of tape-worms.

The cuticular GLANDS in cestodes are scarce.

The parenchyma forms the chief tissue of the entire body, and in all essentials its structure is similar to that of the Trematodes.

In the parenchyma of almost all the Cestodes there is found in adult specimens, as well as in cysticerci, light refracting concentrically striated structures, of a spherical or broad elliptical shape, which, on account

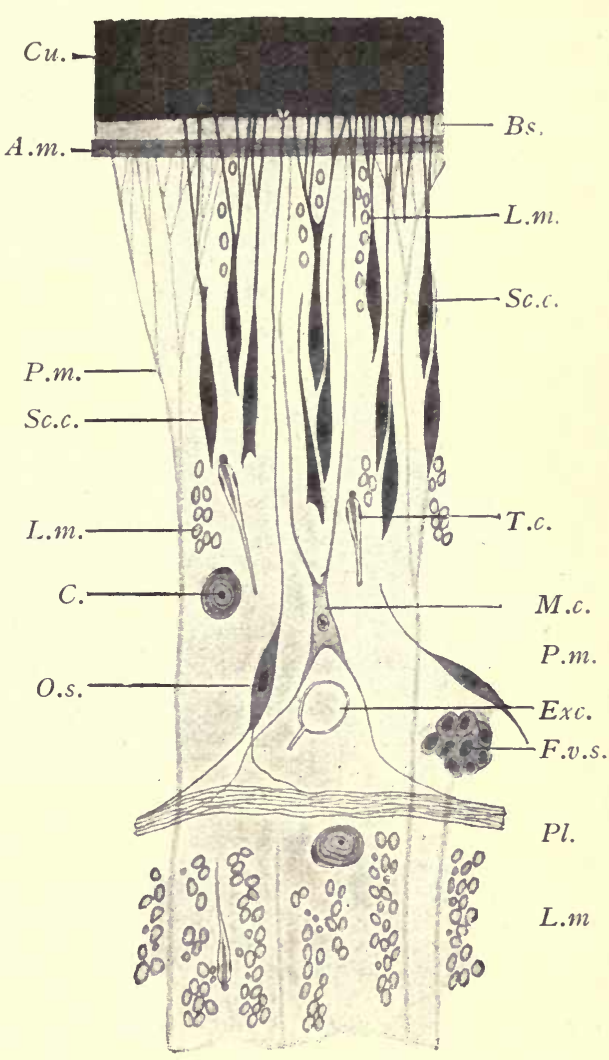

FIG. II8.- Schematic representation of a small part of a transverse section of Ligula. 500/I. (After Blochmann.) Bs., Basal membrane; $C u$., cuticle; at its base are the terminal laminx of the sub-cuticular (epithelial) cells; in the centre there is a cuticular organ of sense; F.v.s., follicle of vitelline "sac; Exc. excretory vesse! ; $C$., calcareous body; L.m. longitudinal muscles; M.c., cell of muscular formation: $P, m_{\text {., }}$ parenchymatous or dorsoventral muscles; Pl., plexus of nerve-fibres; A.m., annular muscles; Sc.c., sub-cuticular cell ; O.s., organ of sense ; T.c., terminal cell. of their containing carbonate of lime, are termed calcareous bodies (fig. II8, C.). Their size varies according to the species between 0.003 and $0.030 \mathrm{~mm}$.; 
their frequency and position in the parenchyma also varies, but they are chiefly found in the cortical layer. They are the product of certain parenchymatous cells, in the interior of which they lie like a fat globule in an adipose cell.

The MUSCULAR SYSTEM of the proglottides is composed of bundles of fibres which lie immediately below the basal membrane, of dorso-ventral fibres, and of muscle plates that are embedded more deeply in the parenchyma. The sub-cuticular muscles (figs. II8 and II9) as a rule consist of a layer of circular muscles and of longitudinal muscles, which are frequently also represented by only one layer of fibres; in other cases, however, the longitudinal fibres extend to between and even beyond the matrix cells. The dorso-

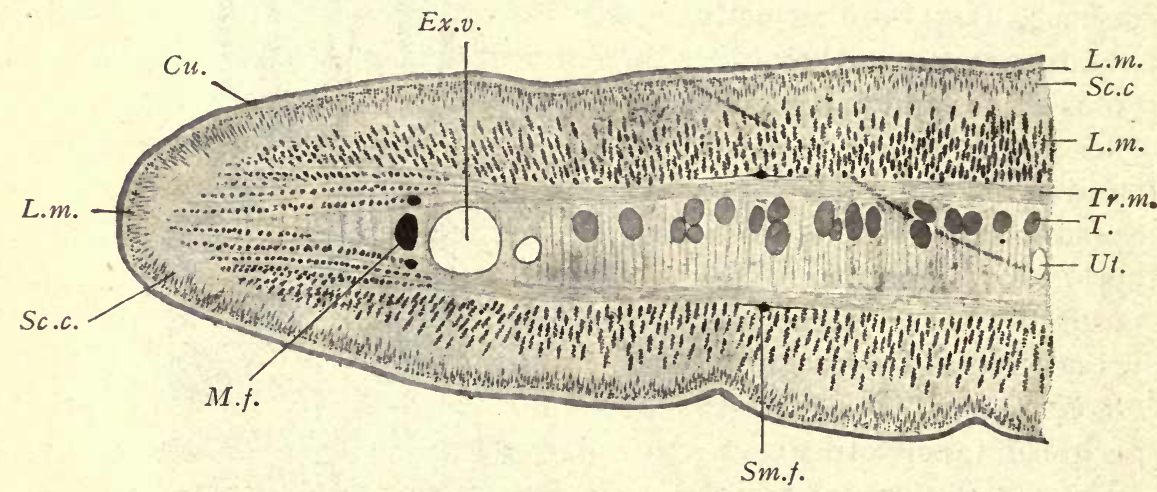

FIG. I I9.- Half of a transverse section through a proglottis of Tania crassi. collis. 44/r. Cu., cuticle; Ex.v., exterior excretory vessel, to the right of which there is the smaller internal one; $T$., testicular vesicles; L.m., longitudinal muscles (outside and inside); M.f., lateral medullary fascicula with the two accompanying fascicula; Sc.c., sub-cuticular cells; Sm.f., submedian fascicula; Tr.m., transverse muscles; Ut., the uterus, and represents the middle of the entire transverse section.

ventral fibres extend singly from one surface to the other, and at both ends open out in a brush-like manner, and insert themselves in the basal membrane. The deeper muscles consist of a peripheral layer of longitudinal fibres, which are either disposed in bundles or more evenly distributed, but in either case the number of fibres or bundles considerably exceed the number of sub-cuticular muscles. On each surface a bundle of transverse fibres follows them, the elements of which penetrate to the borders of the segments, thus passing through the longitudinal muscles and reaching the cuticle.

The mass of parenchyma included by the transverse muscles is termed the MEDULLARY layer, while the mass lying outside them is termed the CORTICAL LAYER. 
It was known long ago that the myoblasts adhere to the dorso-ventral fibres as protuberant formations ; but it is only recently that they have been found to be also muscle fibres in the form of large star-shaped cells, which are not close to the fibres (fig. II8), but are connected with them by offshoots (Blochmann, Zernecke).

Within the scolex the direction and course of the muscular layers change.

The suckers are parts of the musculature, locally transformed, with a powerful development of the dorso-ventral muscles into radial fibres. The ROSTELLUM of the armed tæniæ, like the rostrum of the Rhynchobothridiæ, also belongs to the same category of organs.

In the simplest form, the rostellum (as in Dipylidium caninum

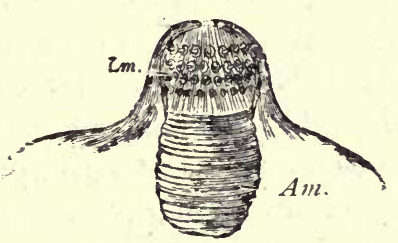

FIG. I 20.-Rostellum of Dipylidium caninum. Lm., longitudinal muscles; $A m$., annular muscles.

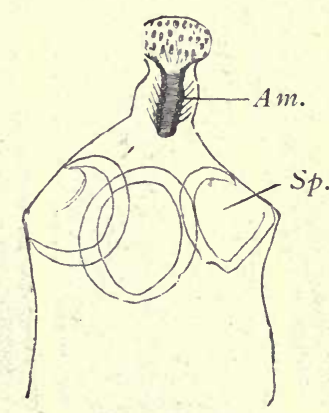

FIG. I 2I. - Head of Dipylidium caninum of the dog, with projected rostellum. ' $7 \mathrm{I} / \mathrm{I}$. Am., annular muscles; $S p$., suckers.

=Tania cucumerina) appears as a closed oval sac, the anterior part of which, projecting beyond the upper surface of the head, carries several rows of hooks (figs. I20 and I2I). The entire internal space of the sac is occupied by an elastic, slightly fibrous mass, while the anterior half of the surface of the rostellum is covered by longitudinal fibres and the posterior half by annular fibres. On contraction of the latter the entire mass is driven forwards, the surface of the rostellum becomes more arched, and the position of the hooks is, in consequence, altered. The rostellum of the large-hooked tænix, which inhabit the intestine of man and beasts of prey, is of a far more complicated structure, for, in addition to the somewhat LENTIFORM rostellum carrying the hooks on its outer surface, there are secondary muscles grouped in a cup- 
like manner (fig. I22). Every change in the bending of the surface of the rostellum induces an alteration in the position of the hooks. In the hookless treniadie the muscular system of the rostellum is altered in a very different manner; in a few forms a typical-sucker appears in its place.

The NERVOUS SYSTEM commences in the scolex and runs through

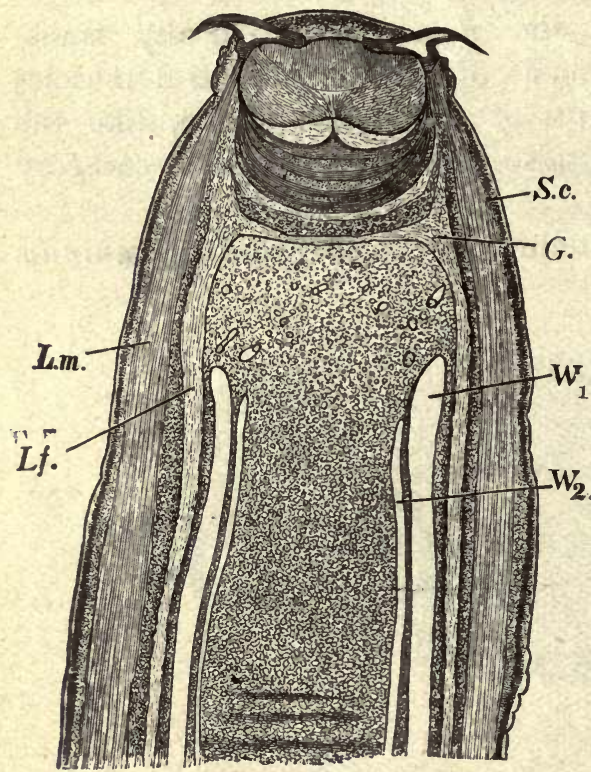

FIG. I 22.--Longitudinal section of the head and neck of Tania crassicollis. 30/1. Lm., longitudinal muscles of the neck; $L f$., lateral fasciculi ; $G$., ganglion; Sc., subcuticular layer; $W_{1}$., external; $W_{2}$., interior excretory vessel. the neck and the entire series of proglottides. Within the proglottides it consists of a number of medullary fasciculi running longitudinally, and of which those at each lateral border are usually the most powerful. In the tæniæ the lateral fasciculi are accompanied both dorsally and ventrally by a thinner fasciculus (concomitant fasciculus (fig. II9); on each surface, moreover, between the lateral fasciculi and the median plain, there are two somewhat stronger fasciculi (sub-median fasciculi), so that there is a total of ten longitudinal fasciculi. They lie exteriorly to the transverse muscle plates, and the lateral and concomitant fasciculi lie exteriorly to the principal excretory vessels, and are everywhere connected by numerous anastomoses which again anastomose; one typical annular commissure is usually found at the posterior border of the segments. In the Bothriocephalidæ the distribution of the fasciculi is different (for instance, two lie in the medullary layer), or they are split up into a larger number of branches. In the scolex the fasciculi are connected in a very remarkable manner by commissures with that which is generally termed the central part of the entire nervous system. There occurs normally a commissure between the two lateral fasciculi, at the same level, and the dorsal and ventral median fasciculi are also connected AT EACH SURFACE as well with each other as with the lateral fasciculi, so that a hexagonal or octagonal figure is formed. The so-called apical 
nerves pass from this commissural system anteriorly, embrace the secondary muscular system of the rostellum semi-circularly, and form an annular commissure (rostellar ring) at the inner part of the rostellum.

The peripheral nerves arise from the fasciculi, as well as from the commissures situated in the scolex; some go direct to the muscles, while others form a close plexus of nerves from the inner to the outer longitudinal muscles, which plexus likewise sends out fibres to the muscles, but principally to numerous fusiform organs of sense (fig. II8, Pl.); they pass between the subcuticular cells and reach the cuticle with their peripheral processes, there

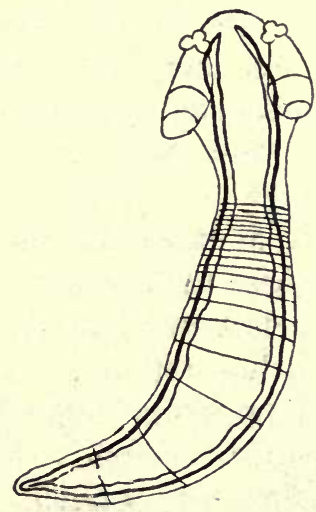

Fig. I23.-Young Acanthobnthrium coronatum, v. Ben., with the excretory vessels outlined; slightly enlarged. (After Pintner.)

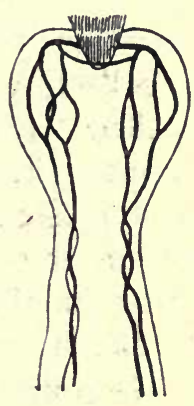

FIG. I 24.-Scolex of a cysticercoid from Arion, with the excretory vessels outlined. (After Pintner.)

finishing with a small terminal plate. Higher organs of sense are not known.

The EXCRETORY APPARATUS of the cestodes is similar to that of other flat worms. The terminal cells, which hardly differ in appearance from those of the trematodes, are distributed throughout the parenchyma, but are more common in the cortical than in the medullary layer (fig. II8, Ts.). Before reaching a collecting tube, the capillaries run straight, tortuously, or in convolutions, they greatly anastomose with one another or form rete mirabile. The collecting tubes, which have their own epithelial and cuticular wall, and which also appear to be provided with muscular fibres, occur typically as four canals passing through the entire length of the worm (fig. 123), they lie side by side, two on either lateral border; in the head the two vessels on each side unite by means of a loop, at the posterior extremity they open into a short pyriform or fusiform terminal bladder 
which discharges in the middle of the posterior edge of the original terminal proglottis.

This primitive type (fig. I23) of collective tubes is subject to variation in most cestodes, in the scolex as well as in the segments. Indeed, even the lumen of the four longitudinal tubes does not remain the same, because the dorsal or exterior tubes are more fully developed and become broader, whereas the ventral or inner ones remain small, and in some species quite disappear in the older segments (figs. II9 and I22). Moreover, very frequently connections are established between the right and left longitudinal branches, as in the head, where a "frontal anastomosis" develops, which in the tæniadæ usually takes the form of a wreath encircling the rostellum (fig. 124), and in the segments transverse anastomoses form at each posterior border, especially between the larger branches, and more rarely between the smaller collecting tubes älso (fig. 125).

The so-called "island" formation is another modification, and this may appear in the collecting tubes themselves as well as in their anastomoses; at any spot a vessel may divide and after a longer or shorter course the two branches reunite. The abovementioned ring in the frontal commissure of the taniadæ is such an island; similar rings also frequently encircle the suckers (fig. I24). In extreme cases (Tricenophorus, Ligula, Dibothriocephalus, \&c.) this island formation extends to all the collecting tubes and their anastomoses. Instead of two or four longitudinal canals only connected by transverse anastomoses at the posterior border of the segments, there is an irregular network of vessels, situated in the cortical layer, from which the longitudinal branches, having again subdivided, can only be distinguished at intervals, . and even then not in their usual number.

The opening of the longitudinal branches at the posterior end requires more accurate investigation; it is true that a single terminal bladder is mentioned as being present in many species, but this is also disputed; when the original end proglottis has been cast off, the longitudinal branches discharge separately. Some species possess the so-called foramina secundaria, which serve as outlets for the collecting tubes; they are generally at the neck, but may be situated on the segments.

The contents of the excretory vessels is a clear fluid, the regurgitation of which is prevented-by the valves present at the points of departure of the transverse anastomoses. The fluid contains a substance similar to a solution of guanine and xanthine. 
Generative Organs.-With the exception of one genus (Dicecocestus, Fuhrm.), which is stated to be sexually differentiated, all the cestodes are hermaphroditic; the genitals first develop gradually in the segments (never in the scolex), the male organs, as is usual in hermaphroditic animals, forming earlier than the female. The youngest proglottides generally do not exhibit even traces of gęnitals; these, as a rule, develop first in the older segments, and the development proceeds onwards from segment to segment. In a few exceptional cases (Ligula) the sexual organs are already

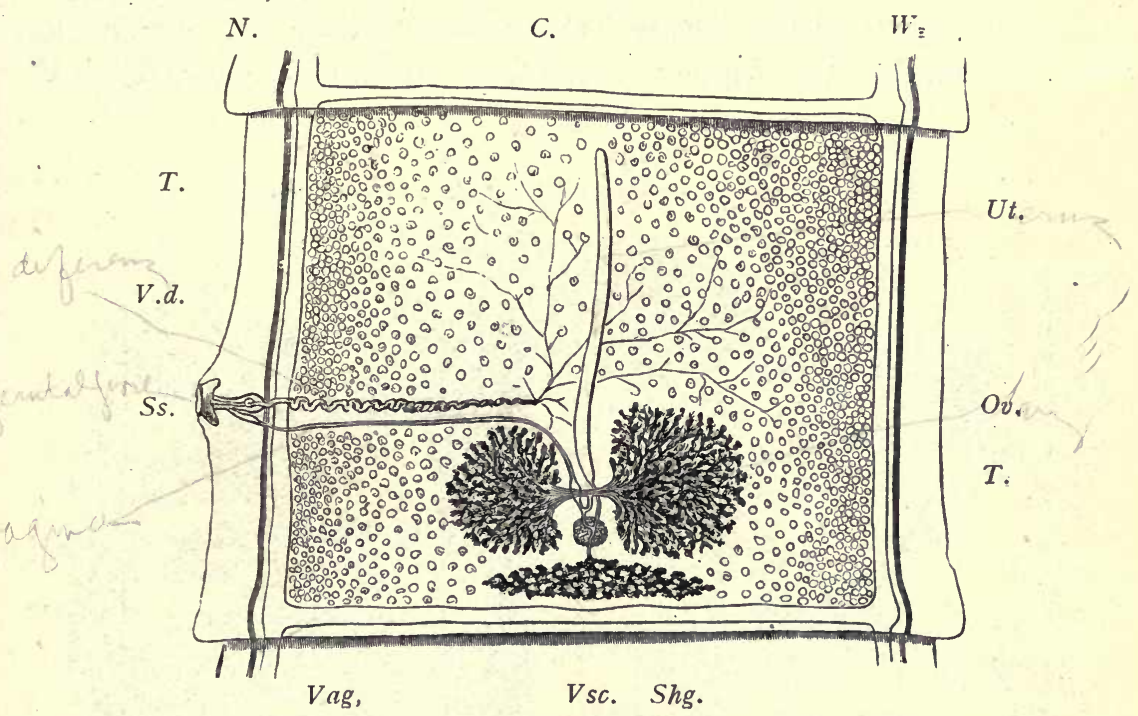

Fig. I25. - Proglottis of Tania saginata, G., with genital organs. I0/I. C., transverse canals of the excretory system; Ss., genital pore; Vsc., vitellogene gland; $T$., testicles; $N$., lateral longitudinal nerve; Ov., ovary; Shg., shell gland; Ut., uterus ; Vag., vagina; V.d., vas deferens; $W_{\text {., }}$ excretory vessel.

developed in the cysticercus stage, but are only functional after the introduction of the parasite into the terminal host.

With the exception of the end portions of the vagina, cirrus and uterus, all the parts of the genital apparatus lie in the medullary layer; only the vitellaria in many species are in the cortical layer. The male apparatus consists of the testes, of which, as a rule, there are a large number, ${ }^{1}$ and which are in a dorsal position from the transverse plane (fig. II9, T.), a vas efferens springs

1 There are, however, tape-worms with only one, others with only two or three testes in each segment. 
from each testis, unites with those that are contiguous, and finally discharges into the muscular vas deferens that is situated in about the middle of the segment. According to its position the genital pore opens on a lateral border or in the middle line towards the front; it is much convoluted or twisted and frequently possesses a protuberance termed the vesicula seminalis. It finally enters the cirrus pouch, which is usually extended; within the cirrus pouch lies the projectile end, the penis, which is sometimes provided with hooklets.

The male sexual orifice almost always lies by the opening of the vagina in a genital atrium, the raised border of which rises above the edge of the segment and forms the genital.pore (fig. I25).

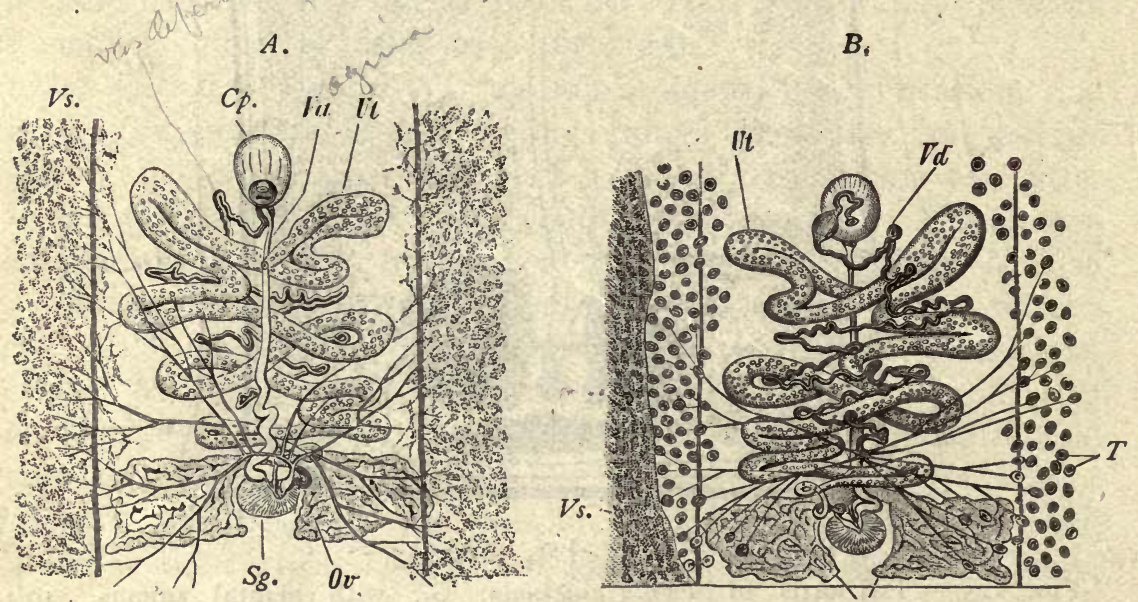

$B_{\text {, }}$

Fig. I 26.- Central field of the proglottis of Dibothriocephalus latus. $A$., from the ventral surface; $B$., from the side. $C_{p}$, cirrus pouch; $V s$. , vitellogene gland: $O v_{\text {., }}$ ovarium; $S g_{\text {. }}$, shell gland; $T$., testicles; $U t$. , uterus; $V a_{\text {., }}$ vagina ; $V d$. , vas deferens. (From Claus.)

The vagina, like the vas deferens, usually proceeds inwardly or posteriorly, where it assumes a spindle-shaped form (receptaculum seminis); its continuation, the spermatic duct, unites with the oviduct, the common excretory duct of the ovaries. The ovaries, usially two in number, are represented by combined tubular glands in the posterior half of the proglottis, and they spread out into the medullary layer, but are also distributed spread out ventrally on the transverse plane.

At the origin of the oviduct there is frequently a part which is dilated and provided with annular muscles, and which 
receives the germinal cells and advances them further. After the union of the oviduct with the spermatic duct the canal proceeds as a duct for fertilisation, and after only a very short course takes up the vitellogene gland or glands and then the numerous ducts of the shell gland (ootype). The vitellogene gland may be a single one, but often exhibits the primitive duplication more or less distinctlv. in which case it is situated at the posterior border of the segments in the medullary layer (fig. I25). The original position of the double organ is then the same as in the trematodes. i.e., at the sides of the proglottides, and thence eventually spreading more or less on both aspects (figs. I26 and I28); the gland is distinctly grape-like and the follicles lie mostly in the cortical layer.

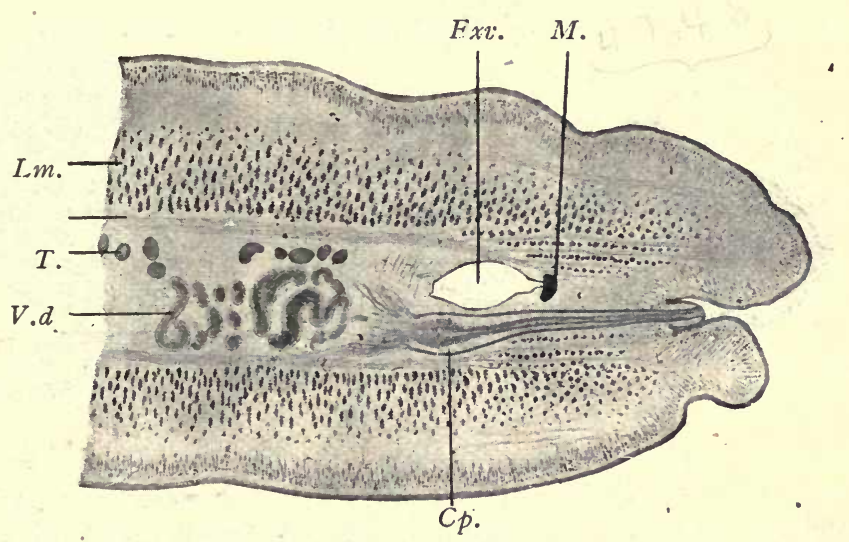

FIG. 127.-External aspect of a transverse section through a proglottis of Tania crassicollis. 44/1. $C p$., cirrus pouch, with cirrus and the retractors at its base; Exv., excretory vessel; T., testicles; L.m., longitudinal muscles ; $M$., medullary fasciculus; $V . d$. , vas deferens.

The fertilised ova, surrounded by masses of vitellus, receive the shell material at the place of junction of the shell gland, and, as completed eggs, then move onward to the uterus. In those cases in which the uterus in its further course presents a sinuous canal and forms a rosette, as in the liver fluke (Ligula, Trianophorus, Schistocephalus, Dibothriocephalus, and others), there is generally an external opening which is usually separate from the genital pore, and lies on the same or the opposite surface. In all other cases, however, the uterus terminates blindly and is represented by a longer or shorter tube lying in the longitudinal axis (fig. I25); (in some forms, however, it extends transversely) 
but with the accumulation of eggs it becomes modified in various ways; it sends out lateral branches, sometimes also forms numerous little diverticula which shelter single eggs or groups of eggs. This part of the female genital apparatus is not immediately confined to the spot where the eggs are formed, but a narrow passage, the uterine canal, intervenes between the two.

In species in which the uterus lacks an opening, simultaneously with the growth of this organ an atrophy of the male apparatus, at least of the testes and their excretory ducts, takes place; this atrophy also frequently occurs in the female germinal glands, so that the entire mature segments have only separate residues of the genitals left, with the exception of the uterus.

In the Acoleinæ the vagina is more or less further atrophied, and in any case has no external opening.

A number of genera are distinguished by the duplication of

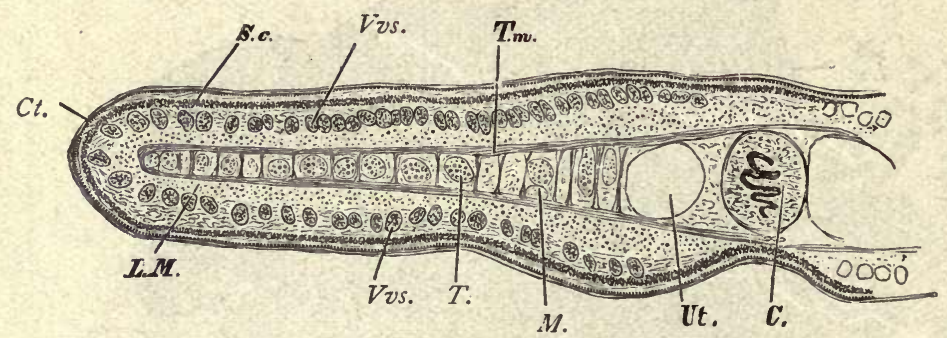

FIG. I28.-Part of a transverse section through a proglottis of Dibothriocephalus latus. . 20/1. Ct., cuticle ; $C$., cirrus; Vi's., vesicles of vitellogene gland ; $L m$., longitudinal muscles; $T$., testicles; $M$., medullary fasciculus; $S c$., subcuticle; Tm., transverse muscles: Ut., uterus.

the genitalia in every segment; the genital apparatus in its entirety, or with the exception of the uterus, is double, or the genital glands and the uterus are single, but the cirrus, vas deferens and vagina are duplicated.

On comparing the genitalia of the trematodes and cestodes the parts ' will be found to agree, but the vagina of the cestodes corresponds to the uterus of the trematodes, and the uterus of the tapeworms to Laurer's canal of the trematodes; which in most of the cestodes has lost its external orifice.

\section{DEVElOPMENT OF THE TAPEWORMS.}

Copulation.-As each proglottis possesses its own genital àpparatus and male as well as female organs are united, the following pro- 
cesses may occur: (I) Self-impregnation, auto-fecundation (without "immissio cirri"). (2) Self-copulation, auto-copulation (with immissio cirri). (3) Alternative or mutual copulation between proglottides of the same or different chains (of the same species), and (4) mutual or interchangeable copulation in the same proglottis in the species with double genital pores. These various modes have actually been observed.

In those species which lack the vagina (Acoleine) it appears that the cirri, which are always furnished with hooks, are driven into the tissues and thus come into contact with the receptaculum seminis.

The eggs of all cestodes are provided with shells, but the shells, like their contents, vary. In genera that possess an uterine orifice the mature eggs frequently do not differ from those of the

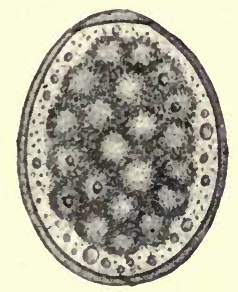

FIG. I 29.--Egg of Diplogonoporus grandis. $440 / \mathrm{I}$. (After Kurimoto.)

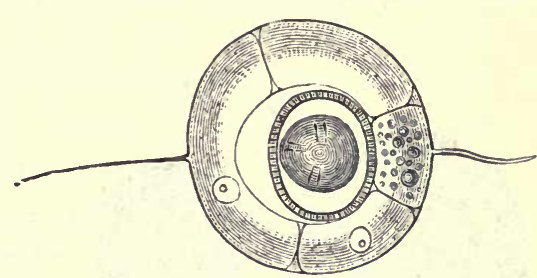

FIG. I 30.-Uterine egg of Tania saginata, G. Shell with filaments; the oncosphere with embryonal shell in the centre. 500/1. (After Leuckart.)

Fasciolidæ; they have a brown or yellow shell of oval form provided with an operculum, and contain a number of yolk cells in addition to the fecundated germinal cell (fig: I29). In other cases the lid is absent and the egg-shell is very thin. In regard to their eggs, these forms approach those cestodes in which the secretion of the vitellogene gland is a light albumin-like substance that contains only a few granules, and the egg-shell is very delicate and without operculum.

The embryonal development in most species takes place during the stay of the eggs in the uterus; in other species it takes place after the eggs have been deposited and are in the water. Always separate cells or a layer of cells separate from the segmentation cells, as well as from the embryonal cells, and form one or more envelopes round the embryo ; usually two such envelopes are formed, the inner one of which stands in intimate relationship with the embryo itself and is often erroneously termed the egg-shell. 
In some species it carries long cilia, by aid of which the young swim about when released from the egg-shell; as a genera rule, however, there are no cilia and the integument is homogeneous, or is composed of numerous rods and is calcified (fig. I30). The exterior envelope (investing integument) lies close to the eggshell and remains within it when the ciliated embryo hatches out, and in many species it perishes at the end of the embryonal development with the delicate egg-shells, so that one observes not the entire ovum, but only the embryo in its embryonal shell (fig. I $3 \mathrm{I}, a$ ).

The embryo enclosed within the embryonal shell, the ONCOSPHERE, is of spheroid or ovoid form (fig. I3I, b), and is distinguished by the possession of three pairs of hooklets, a few terminal cells, and is provided with muscles to move the hooklets.

NO FURTHER DEVELOPMENT of the oncosphere takes place either
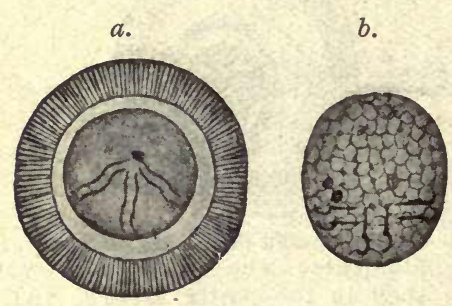

FIG. 131.-a., Oncosphere, with shell of Tania africana greatly magnified) after von Linstow); $b_{\text {., freed oncosphere of }}$ Dipylidium caninum (greatly magnified) (after Grassi and Rovelli).

in the parent organism or in the open; in fact, in all cases in which the oncospheres are already formed within the proglottides they do not become free, but remain in their enveloping sheath; it is only when the oncospheres are provided with a ciliated integument, that they leave the egg-shell, and even cast off the ciliated integument, after having swum about in water for some time. Sooner or later, however, all the oncospheres leave the host that harbours the parental tapeworm and reach the open, either still enclosed in the uterus of the evacuated proglottides, after the disintegration of which they become free, or (as eggs with shells) after being deposited in the intestine of the host, which they leave with the fæces; in the former case, the slightest injury to the mature proglottides while still in the intestine suffices to allow a part of the oncospheres with their integument to be released and mingled with the frces; they have then been erroneously termed "eggs of Tæniæ."

In any case, however, the oncospheres must be transmitted into 
suitable animals to enable their further development; in only very rare cases an active invasion might be possible, as, for instance, takes place with the miracidia of many trematodes. The entry into an animal is, as a rule, entirely passive, that is to say, the oncospheres are swallowed with the food or water. Many animals are coprophagous and ingest the oncospheres direct with the fæces, others swallow them with water, mud, or food contaminated by such fæces. Infection is easily produced artificially by feeding suitable animals with mature proglottides of certain cestodes or introducing the oncospheres with the food. As the mature tapeworm frequently finds the conditions suitable for, its development in only one species of host, or in species nearly related, and perishes when artificially introduced into other hosts, experience has taught us that to succeed in cultivating the oncospheres certain species of animals are necessary. Thus we are aware that the oncospheres of Trenia solium, which lives in the intestine of man, develop only in the pig, and only quite exceptionally develop into the stage characteristic of all cestodes-the cysticercus-in a few other mammals. The oncospheres of Tania saginata develop further only in the ox, those of Tania marginata (of the dog) in the pig and sheep; those of Tania serrata (of the dog) in hares and rabbits; those of Dipylidium caninum (of the $\operatorname{dog}$ and cat) in parasitic insects of the dog and cat, \&c., \&c. It is not unusual that young animals only appear to be capable of infection, while older animals of the same species are not so.

Once introduced into a suitable animal, which is only exceptionally the same individual or belongs to the. same species to the one which harbours the adult tapeworm, the oncosphere passes into the cysticercus stage common to all cestodes, but varying in structure according to the species; in the simplest case such a cysticercus resembles the scolex of the corresponding tapeworm, as in Dibothriocephalus, only that the head, provided with suckers, is retracted within the forepart of the neck. The conditions appear to be similar in Ligula, Schistocephalus, Tricenophorus, but here the cysticercus is very large, indeed, as large in the first-mentioned genera as the tapeworm originating from it, and the sexual organs are already outlined; doubtless, however, this stage is preceded by one that corresponds to the scolex of the genus in question, and which represents the actual cysticercus stage. In such cases the development of the body of the tapeworm from the scolex already sets in within the preceding or intermediary host; in other cases, except in the single-jointed cestodes, this only 
takes place in the definitive host. In the cysticercus stages of other tapeworms we can always distinguish the scolex and a caudallike vesicular or compact appendix. The scolex alone forms the future tapeworm, the variously-formed appendix perishing.

It has now been proved that the appendix, the caudal vesicle, originates direct from the body of the oncosphere, and therefore is primary, and that the scolex only subsequently forms through proliferation within this appendix. On account of this origin the scolex is generally regarded as the daughter, and the part usually designated as the appendix as the mother, originating from the oncosphere.

Accordingly, two modes of development of the cysticercus stage may be distinguished; in the one case the oncosphere changes direct into the scolex, thus forming the body of the tapeworm within the primary host; in the other case the scolex only forms secondarily in the transformed body of the oncosphere, which

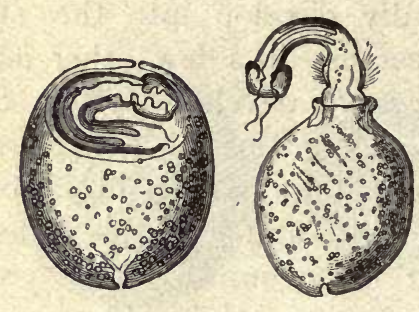

FIG. 132.-Plerocercus of Tetrarhynchus. 20/1.
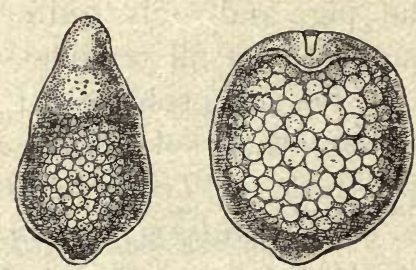

FIG. I 33.-Young cysticerci of T ania saginata, G. (magnified). On the left seen from above, on the right optical section with rudiment of scolex. (From Leuckart.)

later on perishes, the scolex alone remaining as the originator of the tapeworm colony.

The direct metamorphosis of the oncosphere into the cysticercus form termed plerocercoid, has hitherto not been investigated, although Ligula, Schistocephalus and Bothriocephalus are very common parasites, but many circumstances point to the conclusions arrived at by us and by other observers.

In a broad sense, our knowledge of the development of the cysticerci is limited almost exclusively to that of a few "cystic worms"; in other cases we know either only the terminal stage, the complete cysticercus, or, exceptionally, one of the intermediary stages, but we are not acquainted with a complete series; the description must therefore be incomplete.

We know from feeding experiments that, after the intro- 
duction of mature proglottides or of the fully developed ova of Trenia crassicollis (of the cat) into the stomach of mice, the oncospheres escape from the shell in the middle portion of the small intestine, and a few hours later penetrate into the intestinal wall by means of a boring movement; they have been found in this position twenty-seven to thirty hours after the infection. By means of this migration, for which purpose they employ their hooks, they attain the blood-vessels of the intestine, indeed, already nine hours after the infection and later they are found in the blood of the portal vein, and in the course of the second day after infection they are found in the capillaries of the liver, which this species does not leave.

Leuckart, in experimental feeding of rabbits with oncospheres of Tania serrata (of the dog), found free oncospheres in the stomach of the experimental animal, but not in the intestine; however, he came across them again in the blood of the portal vein. The way through blood-vessels to the liver is the normal path for those species of Tænia, the offspring of which beçome cysticerci in mammals; and this, even in those cases in which the oncospheres develop further in the omentum or in the abdominal cavity (Cysticercus tenuicollis, $C$. pisiformis), for here also distinct alterations are observable in the liver, that lead one to the conclusion that there has been a secondary migration out of the liver into the abdominal cavity. Indeed, one must not imagine that the young stages of the cestodes are absolutely passive; once they have invaded an organ they travel actively, and leave distinct traces of their passage.

In other cases the oncospheres leave the liver with the circulation, and are thus distributed further in the body; they may settle and develop in various organs, or they may only do so in certain organs. Many oncospheres may, by travelling through the intestinal wall, penetrate through it and attain the abdominal cavity direct; some also reach it by means of the lymph stream. Where there are no blood and lymphatic vessels in the intestinal wall, as in insects, the oncospheres attain the body cavity or its organs direct; in short, they never remain in the intestinal lumen itself, and only rarely-as in Hymenolepis murina of the rat-do they remain in the intestinal wall.

When the infection has been great, and the body is crowded with numerous oncospheres, acute feverish symptoms are induced to which the infected animals usually succumb (" acute cestode tuberculosis"); while in other cases the alterations in the organs attacked-as the liver in mice, and the brain in sheep-may cause death. 
Sooner or later the oncospheres of tapeworms come to rest, and are first transformed into small cysts, which may be round or oval according to the species. The embryonal hooks disappear sooner or later, or remain close together or spread over some part of the cyst (fig. I34, $b$ ). Their discovery by v. Stein in the bladder-worm of the larva of Tenebrio molitor first led to the conclusion that the cysticerci actually originate from the oncospheres of Tæniæ.

The cyst may remain as a cyst, and then by proliferation the scolex forms within it (fig. 136 ), or it may divide into an anterior cystic portion and a solid tail-like appendix of various length, on which the embryonal hooks are to be found, and this is particularly

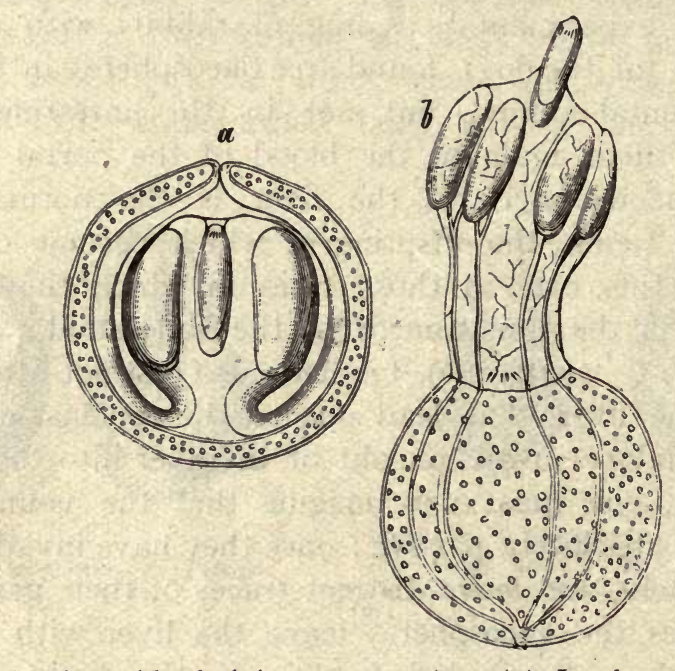

FIG. 134.-Cysticercoid of Arion ater. 50/1. (a) In the contracted condition. (b) In the extended state with the embryonal hooks maintained, and with water vessels, \&c.

the case in regard to those species of Tænia (cysticercoids) that develop in invertebrate animals, such as arthropoda.

As mentioned above, the scolex is understood to be an individual that originates through proliferation of the wall of the parent cyst, mostly singly, but in those cystercerci that are termed Conurus (fig. I35) many occur, whereas in the cysticercus stage of Echinococcus the parent cyst originating from the oncosphere of Tcenia echinococcus (of the dog) first produces a number of daughter cysts, which in their turn form numerous scolices. Echinococcuslike conditions also occur in cysticercoids, as, for instance, in those peculiar to earthworms; and similar conditions prevail in a 
form of cysticercus known as Staphylocystis, and found in the woodlouse (Glomeris). Thus it happens that finally one tapeworm egg produces not one, but numerous tapeworms, for, under favourable conditions, each scolex can form a tapeworm.

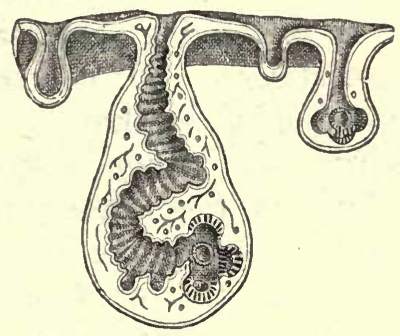

Fic. I35.-Section through a piece of a Conuris cerebralis, with four cephalic cones in different stages of development. (From a wax model.)

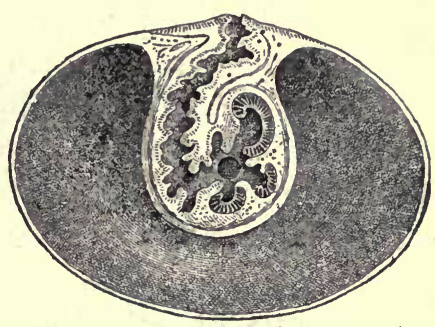

FIG. I36. - Median section through a Cysticercus. with complete scolex. (After Leuckart.)

As the foundation of the scolex there appears a hollow bud, the cephalic cone, usually directed towards the interior of the bladder cavity; on its internal surface arise the four suckers, and the rostellum with the hook appa. ratus is formed in its blind end; it will thus be observed that the head of a Tænia is formed with the parts inside out (fig. I 36 ;). In many cysticerci the head forms at the base of the cephalic cone, and is subsequently invaginated. A more or less elongated piece of neck also develops, and even proglot tides may appear, as in Cysticercus fasciolaris of the Muridæ (appertaining to Tania crassicollis of the cat), a process somewhat analogous to that of Ligula, \&c.

The period that elapses from the time of infection till the Cysticercus is fully developed varies according to the species; the cysticercus of Tania saginata requires twenty-eight weeks, that of Tania marginata seven to eight weeks, that of Tania solium three to four months, and that of Tenia echinococcus longer still.

With one single exception (Archigetes) the cysticerci do not become mature in the place where they developed; they must be enabled

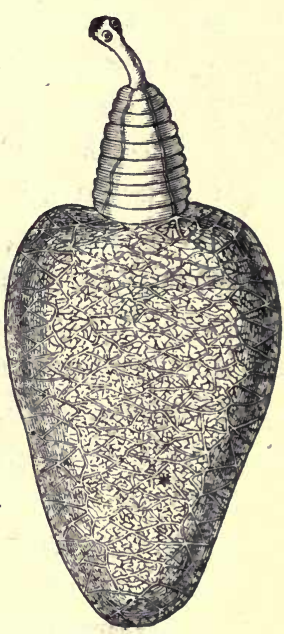

FIG. 137.-Cy'sticercus pisitormis in an evaginated position $18 / 1$. to enter the terminal host, a matter that is usually purely passive, the carriers of the cysticerci or infected parts of animals being usually devoured by other animals. In this manner, for instance, the cysticerci of mice and rats (Cysticercus fasciolaris) 
reach the intestine of cats, those of the hare and rabbit (Cysticercus pisiformis) reach the intestine of hounds; those of the pig (Cysticercus cellulose) are introduced into man, those of insects are swallowed by insectivorous birds, those of crustaceans are ingested by ducks and other water fowl; perhaps, also, the infection of herbivorous mammals is caused by their having accidentally swallowed smaller creatures invaded by cysticerci. Of course, the researches of Grassi and Rovelli have taught us that such an intermediary host is not always necessary; the Tania murina of rats and mice in its cysticercus stage lives in the intestinal wall of these rodents, and as a cysticercus it breaks into the intestinal lumen and develops into a tapeworm in exactly the same way as the cysticerci of other species that reach the intestine of the terminal host by means of an intermediary carrier. Probably the curtailed manner of transmission also occurs in many other species. In some cases the cysticerci quit the body of the intermediary host actively as Ligula and Schistocephalus, which travel out of the body cavity of infected fishes and reach the water, where they may be observed in hundreds in summer, at all events in some localities. The cysticercus stage of Calliobothrium-wrongly termed scolex-has been observed swimming free in the sea, and the scolices of Rhynchobothrium, without their parent cysts, have been observed free within the tissues of some marine animals. In any case there is almost always a change of hosts even in the singlejointed cestodes, for the cysticercus of Caryophyllceus, which lives in fishes of the carp family, is found in Oligochrta, that of Gyrocotyle (chimæra) in shell-fish (Mactra) and different conditions can hardly be possible for Amphilina. Archigetes alone becomes sexually mature in the cysticercus stage, but the life-history of this creature is not well known, so that it is not impossible that the attainment of sexual maturity as a cysticercus in an invertebrate animal (Oligochæta) is perhaps abnormal, and somewhat analogous to the maturity of some encysted trematodes.

The METAMORPHOSIS OF THE CYSTICERCUS into the tapeworm is rarely accomplished in a simple manner; the transformation, however, is not complex in the single-jointed cestodes, nor in Ligula and Schistocephalus; the latter is swallowed by birds (Mergus, Anas, $\mathcal{F}_{c}$.), produces eggs after only a few days, and very soon quits the intestine of its terminal host. In all other cases it is the scolex only which, by proliferating at its posterior extremity, forms - the proglottides, after having invaded as a cysticercus the intestine of a suitable host. All parts belonging to such 
cysticerci, as, for instance, the mother or daughter cyst, and a piece, sometimes segmented, that is present between the latter and the scolex (fig. 76), with the exception of the scolex or scolices, die off, are digested, absorbed, or perhaps even evacuated. It is not certain whether the cysticerci of the Bothriocephalina lose any part, probably they do not.

The time required by the scolex to complete the entire chain of proglottides does not depend only on the number it has to produce, for Tania echinococcus, which, as a rule, only possesses three or four segments, takes quite as long a time for their growth (eleven to twelve weeks) as Tania solium with its numerous segments; Tania conurus is fully developed in three to four weeks, and the same holds good for Dibothriocephalus latus, which possesses many more segments than the above-mentioned tænia of the dog. In a number of species it has been possible to follow the average daily growth and register it almost accurately; for instance, in Dibothriocephalus latus the daily growth is $8 \mathrm{~cm}$., in Tania saginata, $7 \mathrm{~cm}$., \&c.

The history of the development of the cestodes demonstrates that human beings and animals that harbour tapeworms in their intestines acquire them by ingesting the respective cysticercus stages living in other animals (mostly with food) ; it also shows that persons and beasts harbouring these cysticerci may have become infected by having swallowed the oncospheres of the species of tapeworm to which they belong. In regard to Tania murina alone, it is known that the introduction of the oncospheres into those species of animals which may harbour the adult tapeworm leads to the formation of the latter after the development of a cysticercus stage in the intestinal wall; nevertheless only young animals (rats) are capable of infection, for a previous infection, or the presence of mature tapeworms in the intestine, appears to produce a kind of immunity.

\section{Biology.}

In their adult stage, the tapeworms inhabit almost exclusively the alimentary canal of vertebrate animals, the small intestine being the chief abode with but few exceptions; a few species select definite parts of the intestine. A small number of Rhynthobothriidæ of marine fishes live apparently always in the stomach, while in rays and sharks the spiral intestine is their special seat. Bothriocephali generally attach themselves with 
their head on to the appendices of the pylorus of fishes; other species (Hymenolepis diminuta) occasionally fix their heads in the ductus choledochus, and this is more frequent still in the tapeworms of the Hyrax, which occasionally penetrate entirely into the biliary ducts. [Dr. Theiler of Pretoria has sent me a new tapeworm which invades the liver of sheep in the Transvaal.-F.V.T.]

In the diseases of sheep induced by cestodes, the worms have been observed also in the pancreas. Specimens found in the large intestines were probably being evacuated.

The cestodes are looked upon as fairly inert creatures; this opinion having been formed by observing their condition in the cold cadavers of warm-blooded animals. Actually, however, they are exceedingly active and accomplish local movements within the intestine, for they have been found in the ducts communicating with the bowel, or in the stomach, and may even make their way forward into the œsophagus.

They also invade other abdominal organs through abnormal communications, or through any that may be temporarily open between the intestine and such organs; they thus reach the abdominal cavity or the urinary bladder, or they work their way through the peritoneum.

They produce changes in the intestinal mucous membrane at the place of their attachment, the alterations varying in intensity according to the structure of the clinging organs. The mucous membrane is elevated in knob-like areas by the suckers; the epithelial cells become atrophied or may be entirely obliterated. Dipylidium caninum bores into the openings of Lieberkühn's glands with its rostellum, dilating the lumen to two or three times its normal size, while the suckers remain fixed between the basal parts of the cells. Species with powerful armatures penetrate deeper into the submucosa, and some that are not provided with exceptionally strong armatures or are even unarmed, may be actually found with the scolex embedded in the muscles of the intestinal walls or even protruding beyond (Tania tetragona, Mol., in fowls, \&c.). Other species, again, even cause perforation of the walls of the intestine of their hosts.

THE LENGTH OF LIFE OF THE ADULT TAPEWORMS certainly varies; as a rule it appears to last only about a year; in other cases (Ligula) it averages only a few days, but we are likewise aware that certain species of cestodes of man attain an age of several or many years (thirty-five). The natural death of ces- 
todes often appears to be brought about by alterations in the scolex, such as loss of the hooks, atrophy of the suckers and rostellum, finally the dropping off of the scolex; it is unknown whether the chain of segments deprived of its scolex likewise then perishes or first attains maturity. It has already been mentioned that in a few species the foremost proglottides are transformed into organs of attachment on the normal loss of the scolex.

Abnormalities and malformations are encountered relatively frequently in the Cestodes-such as abnormally short or long segments; the so-called triangular tapeworms, which-if belonging to the tænia-always possess six suckers; often also club-shaped segments occur between normal ones, or there may be a defect (fenestrated segments) in one segment or in the centre of a number following one another; bifurcated chains of segments have likewise been observed, as well as incomplete or complete union of the proglottides, abnormal increase of the genital pores, reversion of the genitalia. Besides the above-mentioned increase of the number of suckers on the scolex (in tænia), there may be a decrease in the number; in other cases the crown of hooks may be absent, or abnormally-shaped hooks may be formed.

\section{LITERATURE.}

The literature of the Cestodes up to 1895 is comprised in my work on Cestodes, in Bronn's Cl. u. Ordn. d. Thierr (iv., 2). Of the more recent works the following deserve mention:-

Blanchard, R. Sur quelq. Cest. monst. (Progr. méd., I894 [2], xx.)

Brandes, G. Teratolog. Cestod. (Ztsch. f. Nat., I899, lxxii., p. I05.)

Blochman, F. Die Epithelfr. b. Cest. u. Trem. Hbrg., I896.

Cattaert, P. A. Contr. à l'ét. d. Tén. trièdr. (Arch. parasit., I899, ii., p. I 53. )

Corn, L. Z. An. d. Vogelcest. (Z. f. w. Zool., I900, lxvii., p. 255.)

Unters. üb. d. centr. Nervens. der Cest. (Zool. Jahrb. An., 1898, part xii.,

Z. P. A9.) u. Syst. d. Vogelcest. (Nov. Act. Ac. Caes. Leop.-Carol. Nat. Cur., lxxix., No. 3, Halle, I901.)

Funrmann, O. Arbeiten über Vogeltænien in : Rev. suiss. de Zool. et Ann. Mus. d'hist. nat. Genève, iii., iv., v., vii. ; C. f. B., P. u. I. [I], xxvi.

Ueb. Prosthecocotyle. (Ibid., xxv.)

Neuere Vogelcest. (Ibid., xxix.)

JACOBI, A. Diploposthe laevis. (Zool. Jahrb., I897, x.)

LÜrie, M. Beitr. z. Kenntn. d. Bothriocephaliden. (C. f. B., P. u. I., I899 [I], xxvi., p. 720 ; I900, xxvii., p. 200.)

Z. Anat. u. Syst. d. Bothr. (Verh. d. D. zool. Ges., I899, p. 30.)

Unters. üb. Bothr. mit. marg. Genit. (Z. f. w. Zool., I900, lxviii.)

Revis. m. Bothr.-Syst. (C. f. B., P. u. I. [I], Orig., I902, xxxi., p. 3I8.)

Pintner, Th. Rhynchodäaldrïs. b. Tetrarh. (Arb. zool. Inst. Wien., 1899, xii.) RIgGeNBACH, E. Genus Ichthyotænia. (Rev. Zool. Suisse, I 896, iv.)

Stiles, Сн. W., and A. Hassal. Tapeworms of Poultry. U. S. Dep. of Agric. Bur. of an Ind. Bull., I2, Wash., 1896.)

Stiles, CH. W. Rev. of ad. Tapew. of Hares and Rabb. (Proc. U. S. Nat. Mus., I 896 , xix.)

Vaullegerad, A. Rech. s. 1. Tétrarhynq., Thèse, Paris, 1899.

Wolffhügel, K. Beitr. z. Kenntn. d. Vogelhelm. In.-Diss., Basel, I90n.

Zernecke, E. Unters. üb. d. fein. Bau d. Cest. In.-Diss., Rostock, I895.

Zschoкke, F. Cest. d. Mars. u. Monotr. (Semon: Zool. Forsch. in Austr. u. d. Mal. Arch. [Jen. Denkschr., I 898 , viii.], v.)

Neue Stud. an Cest. aplac. Säugeth. (Z. f. w. Zool., I899, lxv., p. 404.; 


\section{The Classification of the Cestodes.}

The classification of the Cestodes, like that of the Trematodes, has so far been undertaken by a number of investigators, but has not yet been definitely concluded. The genera, numbering about eighty, are classified in the following manner :-

I. Bothriocephaloidea. Scolex armed or unarmed, with two usually slightly developed groove-like suckers on the flat surface; the external segmentation may be absent or distinct; three genital orifices; the genitalia rarely duplicated; numerous follicles of vitellaria, situated in the lateral field and mostly in the cortical layer. The eggs are similar to those of the Fasciolidea, but do not always possess a lid.

Fam. I. Dibothriocephalida. The suckers are variously developed: by coalescence of the free borders they may be transformed into suctorial tubes, or may be replaced by a cephalic suctorial organ. The uterus forms a rosette; eggs are provided with lids.

(I) Subf. Ligulina (Ligula, Schistocephalus).

(2) "Dibothriocephalina (Dibothriocephalus, Diplogonoporus, \&c.).

(3) " Cyathocephalina (Diplocotyle, Cyathocephalus, Bothrimonus).

(4) " Tricnophorince (Fistulicola, Ancistrocephalus, Trianophorus, \&c.).

Fam. 2. Ptychobothriide. Scolex unarmed; the uterus does not form a rosette, but presents a spacious uterine cavity. The eggs have a thin shell and no lid.

(I) Subf. Amphicotylince (Amphicotyle, Abothrium, \&c.).

(2) "Ptychobothriina (Ptychobothrium, \&c.).

Fam. 3. Amphitretida. Vitellogene gland in the medullary layer; uterus with cavity; eggs with thin shells without lids (Amphitretus, \&c.).

1I. Tetraphyllidea. Scolex armed or unarmed, with four very motile pedunculated or sessile bothridia, or with four round suckers ; segmentation always distinct; no uterine orifice; the cirrus and vagina open at the border; the follicles of the vitellaria in the side fields or at the borders, in the cortical layer. Eggs thin-shelled; no lid.

Fam. I. Onchobothriida. There are always hooks in the sessile or pedunculated bothridia, in addition to accessory suckers or areoles (Onchobothrius, Calliobothrium, \&c.).

Fam. 2. Phyllobothriida. Bothridia mostly pedunculated, simple, or with accessory suckers or areoles, always without hooks (Anthobothrium, Phyllobothrium).

Fam. 3. Ichthyotaniida. With four suckers, mostly unarmed (Ichthyotania).

III. Cyclophyllidea. Scolex with four suckers, between which an apical rostellum may be present; hooks on the rostellum, rarely on the suckers; segmentation almost always distinct; no uterine orifice ; cirrus and vagina usually open at the border; genitalia rarely duplicated; vitellogene gland single, usually placed behind the ovary; eggs thin-shelled, without lids ;oncospheres with one or several integuments. 
Fam. I. Taniide, with the characteristics of the order.

(I) Subf. Mesocestoidina, with genital pores on the flat surface (Mesocestoides).

(2) ",Acoleince, without vagina, Acolëıs. Dioecocestus sexually differentiated.

(3) " Amabiliina. Vagina on the surface; cirrus situated at the border (Amabilia).

(4) " Tetrabothriina. Vitellarium in front of the ovary; suckers with a muscular process, extending outward from the anterior border; genital pores at one side (Tetrabothrius).

(5) " Anoplocephalina. Scolex unarmed; large; without neck; uterus in an oblique direction, tubular or reticular; eggs with "pyriform apparatus" (Anoplocephala, Bertia, Stilesia, \&c.).

(6) " Dipylidiince. Rostellum armed; suckers unarmed; genital pores marginal; genitalia simple or duplicated. Uterus merging in to the ovarian follicle or becoming atrophied; eggs then free in the parenchyma (Dipylidium, Cotugnia, Hymenolepis, Dilepis, \&c.)

(7) „ Davaineince. Rostellum and suckers armed; eggs mostly encapsuled (Davainea, \&c.).

(8) " Taniina. With rostellum and usually double crown of hooks; uterus with median trunk and lateral branches (Tænia).

IV. Echinobothriida. Scolex consisting of the head and its neck; the head has a rostellum and two bothridia; the neck has longitudinal row of $\mathrm{T}$-shaped hooks; genitalia as in the Tetraphyllidea. but with the genital pores on the flat surface (Echinobothrium).

V. Rhynchobothriida. Scolex with head and neck; the head having two or four suckers and four retractile and armed rostella; the neck unarmed (Rhynchobothrius, \&c.).

\section{The Cestodes of Man.}

Most of the species to be mentioned live in man in their adult stage and occupy the small intestine: man is the definitive host of these parasites, but is not the specific host for all the species; some of these species, as well as others (of mammals) may occur in man also in the cysticercus stage.

\section{A. Bothriocephaloidea.}

Gen. I. Dibothriocephalus, Lhe., I899.

Syn.: Bothriocephalus, p. p. Rud., I8I9; Dibothrius, p. n. Rud., I8I9;

Dibothrium, p. p. Dies, I850.

Dibothriocephalidea with a more or less elongated, unarmed scolex, and flat suckers, cutting rather deeply into the head; neck present or 
absent; single genitals in each proglottis; genital orifices in the median line of the ventral surface, the cirrus and vagina open into a genital atrium; the uterus is behind them; there are papillæ in the vicinity of the genital atrium; the testes and follicles of the vitellaria are in the lateral areas, the former in the medullary layer, the latter in the cortical layer on both surfaces and occasionally extending to the median line; the ovary is situated ventrally, the shell gland dorsally. The uterus is in the central field and forms a rosette. The eggs are operculated.

\section{Dibothriocephalus latus (L.), I748.}

Şyn.: Tania lata, L., I748; T. vulgaris, L., I748; T. grisea, Pallas, I796; T. membranacea, Pall., 178I ; T. tenella, Pall., I78I ; T. dentata, Batsch, I786; Bothriocephalus latus, Brenter, I819; Dibothrium latum, Dies., I850; Bothriocephalus cristatus, Davaine, $1874 ;^{1}$ Both. balticus, Kchnmstr., I 855 ; Both. latissimus, Bugn., 1886.

Length $2-9 \mathrm{~m}$. or more; colour yellowish-grey; after lying in water the lateral areas become brownish, and the rosette of the uterus brown. The head is almond-shaped, $2-3 \mathrm{~mm}$. in length, the dorso-ventral axis is longer than the transverse diameter; the head therefore generally flat, concealing the suctorial grooves at the borders; these suckers are deep and have sharp edges (fig. I39). The neck varies in length according to the degree of contraction and is very thin; there are 3,000 to 4,200 proglottides and there may be more ; their breadth is usually greater than their length, but in the posterior third of the body they are almost square, and the very
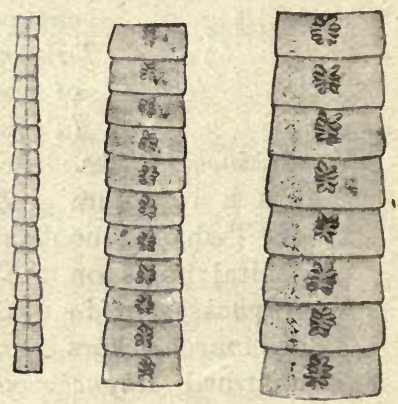

HIG. I38. - Various chains of segments of a Dibothriocephalus latus (natural size). oldest are sometimes longer than they are broad. There are numerous testes situated dorsally and laterally in the medullary layer; the vas deferens (fig. I40) passes dorsally in obliquely directed loops in the central field towards the front and forms a seminal vesicle before its entry into the large cirrus pouch.

The orifice of the vagina is close behind the orifice of the cirrus pouch; the former passes almost straight along the median line towards the back, and widens into a receptaculum seminis

${ }^{1}$ Until recently this worm, which was understood to belong to a separate species, was proved on examination by R. Blanchard ("Mal. Par.", I 896), to be Dibothr. latus. Compare also Galli-Valerio, in C. f. B., P. u. I. (I), I900, xxvii., p. 308 . 
shortly before its junction with the oviduct; the vitellaria are in pairs; in shape they resemble the wings of a butterfly and they lie ventrally in the medullary layer; the shell glands lie in the posterior division of the vitellaria; the uterus, forming numerous transversely-directed convolutions, passes ventrally from the vas deferens towards the front. Eggs (fig. I4I) large, with brownish shells and small lids; $0.068-0.07 \mathrm{I}$ : $0^{\circ} 045 \mathrm{~mm}$., the germinal cells,

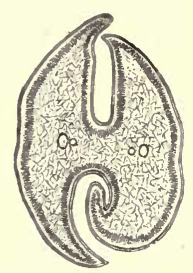

FIG. I 39. - Transverse section of the head of $D i$ bothriocephalus latus. 30/I.

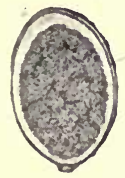

Fig. I41.-Egy of Dibothriocephalus latus. $240 / \mathrm{I}$.

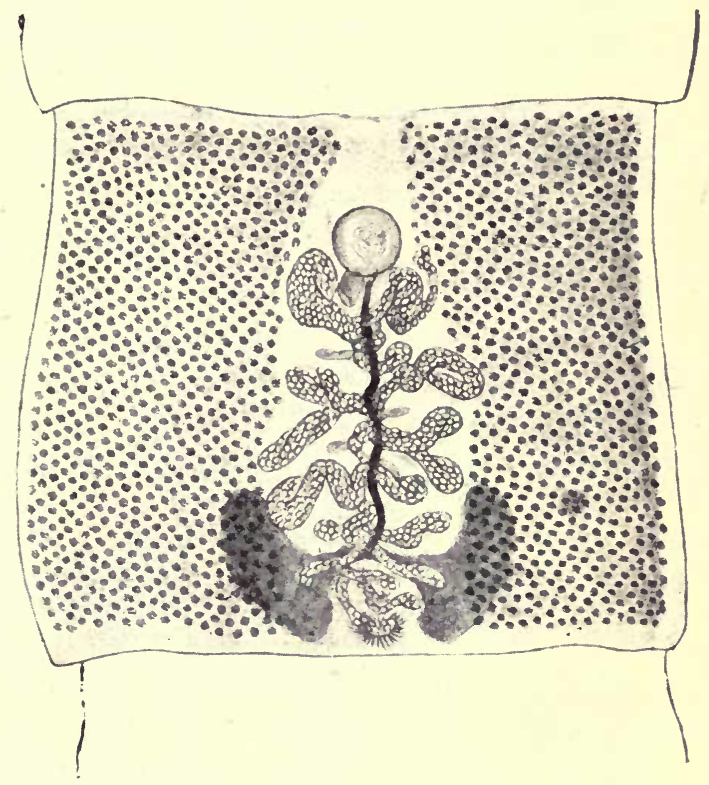

FIG. I40.-Fairly mature proglottis of Dibothriocephalus latus. I5/r. From a stained preparation. The follicles of the vitellaria are at the sides; the uterus, filled with eggs, is in the middle, also the vagina (the dark stripe passing almost straight from the front to the back), and the vas deferens (almost hidden by the uterus) above. In the centre is the cirrus pouch, and below the shell gland and ovary are seen.

which are already, as a rule, in process of segmentation, are surrounded by numerous large yolk cells; the proglottides nearest the posterior extremity are frequently eggless.

The eggs, which are deposited in the intestine and evacuated with the fæces, hatch in water (Schubart, Bertolus, Knoch) after several weeks; the embryonal integument of the oncosphere is provided with cilia : after bursting open the lid of the egg the oncosphere reaches the water with its integument and swims slowly about (figs. I42 and I43); often it slips out of its ciliated mem- 
brane, sinks to the bottom and is capable of a creeping motion; sooner or later it dies in the water. The manner and means of its invasion of an intermediary host is still unknown; yet we are aware that the cysticercus stage (plerocercoid, fig. I44), which resembles the scolex and may reach a length of $30 \mathrm{~mm}$., lives in the intestine, in the intestinal wall, in the liver, spleen, generative glands and muscular system of various fresh water fishes (fig. I45), the pike (Esox lucius), the miller's thumb (Lota vulgaris), the perch (Perca fuviatilis), Salmo umbla, Trutta vulgaris, Tr. lacustris, Thymallis vulgaris, Coregonus lavaretus, C. albula and Onchorhynchus perryi. The transmission of the plerocercoids from these fish to the dog, cat and man (Braun, Parona, Grassi and Ferrara, Grassi and Rovelli,

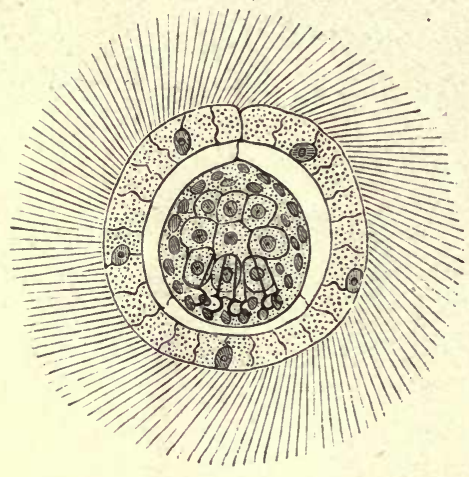

Fig. I42,-Free-swimming oncosphere of Dibothrincephalus latus. (After Schauinsland.)

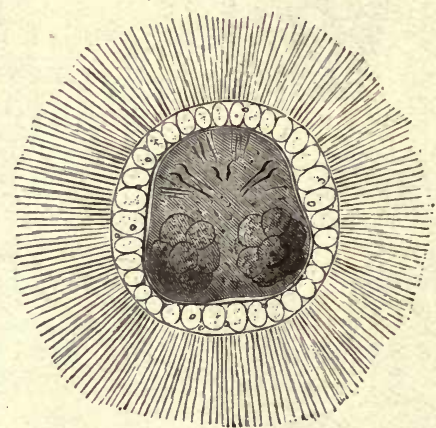

FIG. 143.-Free-swimming oncosphere of Dibothriocephalus latus. 500/ז. Distinct muscular fibres are seen in addition to the three pairs of hooklets. (After Leuckart.)

Ijima, Zschokke, Schroeder) leads to the development of the broad tapeworm, the growth of which is rapid. In my experiments on human beings the average number of proglottides formed per diem averaged $3 \mathrm{I}$ to 32 for five weeks, with a length of $8-9 \mathrm{~cm}$. According to Parona the eggs appear soon after the man has been infected-(twenty-four days). Zschokke found the average growth in the experimental infection of man between $5^{\circ} 2$ and $8.2 \mathrm{~cm}$. per diem, and the person experimented upon by Ijima evacuated a piece of a Dibothriocephalus latus, $22.5 \mathrm{~cm}$. in length, only twenty-one days after the infection.

The "broad tapeworm" is a frequent parasite of man in some districts, but it also occurs in the domestic dog, and on rare 
occasions is found in the domestic cat and fox. French Switzerland and the Baltic provinces of Russia are the centres of distribution; from the former district the distribution radiates to France and Italy (Lombardy, Piedmont), from the Baltic Provinces over Ingermanland to St. Petersburg, over Finland to Sweden (on the shore of the Gulf of Bothnia), in a southerly direction to Poland, and into the Russian Empire and across it to Roumania, and towards the west along the coast of the Baltic Sea to the North Sea, where, however, its frequency considerably diminishes (Holland, Belgium, and the North of France).

In Turkestan and Japan the "broad tapeworm" is the most frequent parasite of man; it has been reported in Africa from the vicinity of Lake N'gami as well as from Madagascar; a case has also come under observation in North America (Philadelphia).

In Germany Dibothriocephalus latus-apart from the fact that

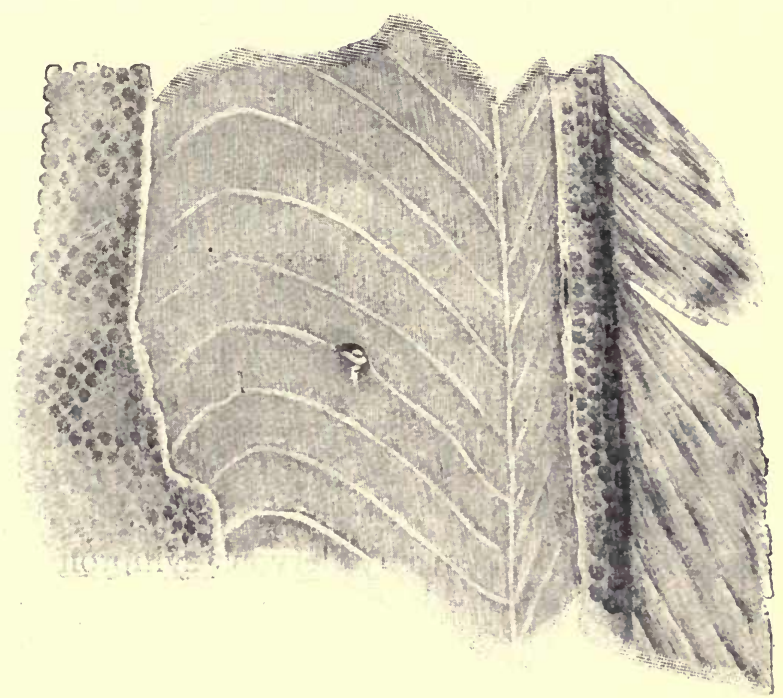

Fig. I45.-A piece of the wall of the body of a Lota vulgaris. The tangential section has laid open the muscles of the trunk with a plerocercoid of Dibothriocephalus latus. (Natural size).

it is undoubtedly imported from Switzerland, Russia or Italy-is particularly frequent in East Prussia amongst the inhabitants of the low coast on the Baltic at Courland, and the district of the 
bay of Courland; it is, however, also found in the province and even in Königsberg. In West Prussia and Pomerania it is very much scarcer.

It is also found in Munich and in the vicinity of the Lake of Starnberg (Bollinger).

Krabbe found it in Io per cent. of the sufferers from tapeworms in Denmark; Szydlowski found the ova of this worm in Dorpat in Io per cent. of the freces examined; Kruse found the worm in 6 per cent. of post mortems ; Kessler, in St. Petersburg, found the eggs in the fæces in 7.8 per cent.; at post mortems he found the worm in $I \cdot I 7$ per cent., though Winogradoff only found it in 0.8 per cent. In Moscow, acco-ding to Baranovsky, 8.9 per cent. of the fæces examined contained the ova of Dibothriocephalus. In the interior and southern provinces of Sweden the worm, according to Lönnberg, is only found sporadically, but, on the other hand, in Angermanland about ro per cent. of the population are affected, while again in Norbotten the majority of persons are affected, and in Haparanda the entire population (with the exception of infants) harbour this parasite. In Switzerland Dibothriocephalus latus is very frequent in close proximity to the lakes of Bieler, Neuchatel, Morat and Geneva (according to Zaeslin Io-I5-20 per cent. of the population are affected); the parasite is less frequent in districts one to four hours removed from these lakes.

The frequency and distribution have, nevertheless, decreased perceptibly in places; at the commencement of the eighteenth century the broad tapeworm was very common in Paris; at the present date it only occurs when imported (Blanchard); in Geneva, also, according to Zschokke, it has become rarer (formerly ro per cent., now only I per cent.).

The disturbances produced in man by the presence of broad tapeworms are, as a rule, very trifling; in other cases they produce partly gastric disorders and partly nervous symptoms; in a number of cases, again, they set up severe anæmia, ${ }^{1}$ apparently caused by

\footnotetext{
'Reyher, D., Arch. f. klin. Med., xxix., p. 31 ; Runeberg, ibid., I886, xli., p. 304; Schapiro, Zeitschr. f. klin. Med., 1889, xiii., p. 416; Podwissotzky, Jahrb. f. Kdrhlkde., I889, xxix., p. 223; Schaumann, Z. Kenntn. d. sog. Bothr.Anamie, Berlin, A. Hirschwald, I894; Askanazy, "Bothr.-Anamie u. d. prog. Bedtg. d. Megalobl. im anam. Blute" (Zeitschr. f. klin. Med., xxiii., p. 492); Babes, V., "Bothr. lat. u. d. Bothr.-An. in Rumänien" (Arch. f. path. An., cxli., p. 204; Schaumann and Tallquist, "Ueb. d. Blutk. auflös. Eigensch. d. b. Bdws.' (D. med. Wchschr., I898, No. 20 ; Neubecker, O., Bothr.-Anamie ohne Bothrioc., Inaug.-Diss., Königsbg., I 898.
} 
toxins produced by the worms and absorbed by the host. There is no danger of auto-infection, as the cysticercus stage lives only in fishes, not in warm-blooded animals. The case reported by Meschede $^{1}$ (ova of Dibothriocephalus latus in the brain of a man who had suffered from epilepsy for six years) is differently interpreted.

Human beings, like other hosts, can only acquire the broad tapeworm by ingesting its plerocercoids with the previously mentioned fresh-water fishes; the opportunity is afforded the more readily for such infection by the fact that not only do the lower classes not pay sufficient attention to the cooking of fish, so that all the larvæ that are present may be killed, but that in certain localities the custom exists of eating some parts of these fishes in a raw condition; even the mere handling of the usually severely infected intermediary hosts may occasionally cause infection. This plerocercoid is as well known as the cysticercus of the pig (Cysticercus cellulosa) from which it differs materially in appearance. In Germany the occurrence of the plerocercoids of Dibothriocephalus latus has been confirmed in the pike, miller's thumb and perch of East Prussia, and more particularly in those taken from the inland sea of Courland.

\section{LITERATURE.}

A.-Anatomy :-

Eschrichx, D. F. Anat.-phys. Unters. über die Bothrioceph. (Nov. Act. Ac. Cæs. Leop. ; Carol. nat. curios., i84I, xix., Suppl. ii.)

Stieda, L. Zur Anat. d. Bothr. latus. (Arch. f. Anat. u. Phys., I864, p. 174.) Bötrcher, A. Stud. üb. d. Bau d. Bothr. latus. (Arch. f. path. Anat., I864, xxx., p. 97 ; 1869, xlvii., p. 370.)

Sommer, F., and L. Landois. Beitr. z. An. d. Plattw. I. B. latus. (Z. f. w. Zool., I 872 , xxii., p. 4O.)

Niemiec, J. Untersuch. üb. d. Nervensyst. d. Cestoden. (Arb. a. d. zool.-zoot. Inst., Wien., 1886, vii., p. I.)

B.-Embryonal development :-

Kмосн, J. Die Naturgesch. d. br. Bdws. mit bes. Berücks. sein. Entw. (Mém Ac. d. sc. de St. Pétersbourg, I862 [7], v., No. 5.)

Journ. de l'anat., I 879 , vi., p. I 40.

Berrolus. Sur le dével. du Bothrioc. de l'homme. (C. R. Ac. sc., I863, lvii., p. 569.$)$

Schauinsland, H. Die embr. Entw. d. Bothr. (Jen. Zeitschr. f. Naturw., I885, xix., p. 520.)

C.-Infection :-

Braun, M. Zur Frage der Zwischenwirth. v. Bothr. latus. (Zool. Anz., I88I, iv., p. 593 ; 1882, v., pp. 39, 42, 194; 1883, vi. p. 97.)

Bothr. lat. u. seine Herk. (Arch. f. path. Anat., I883, xcii., p. 364.)

Zur Entw. d. br. Bandw. Würzb. Stuber., I 883.

Küchenmeister, F. Wie steckt sich d. Mensch mit B lat. an ? (Berl. klin. Wchschr., I 885 , xxii., pp. 505, 527.)

Braun, M. Salm oder Hecht? (Ibid., p. 807.)

'Meschede, Tagebl. der 45 Versammlung der Naturf. u. Aerzte in Leipzig, 1872, p. I86; Arch. f. Psych., ii., p. 501 : Allgem. Zeitschr. f. Psych., xxx=, p. 109. 
Küchenmeister, F. Die Finne des Bothr. u. seine Uebertr. auf d. Mensch., Lpzg., I 886.

Weit. Bestät. m. Behauptg., die Finne des Hechts hat nichts mit Bothr. lat. $\mathrm{zu}$ thun. (D. med. Wochenschir., I 886 , p. 55 I.)

Parona, E. Il B. lat. in Lomb. (Rend. R. Ist. Lomb., I886 [2], xix., No. I4.)

Braun, M. Ueb. d. Zwischenw. d. br. Bdws., eine Entgegnung an Küchenmeister. Würzb., Stuber., I 886.

Grassi, B., and Ferrara. Zur Bothriocephalusfrage. (D. med. Wochenschr., I 886, p. 699.)

LEUCKart, R. Z. Bothriocephalusfrage (C. f. B. u. P. I., I887, pp. I, 33).

Parona, E. Sulla quest. d. B. lat. (Gazz. med. ital.-lomb., I887.)

Grassi, B., and G. Rovel.li. Contr. all. stud. d. svil. d. Bothr. I. (Giorn R. Acc. med., I887, No. II.)

Grassi, B., and G. Rovelli. Bandwürmerentw. (C. f. B. u. P., I888, iii.,

IJImA, J. The Source of $B$. latus in Japan. (Journ. Coll. Sc. Imp. Univ., Tokyo, I888, ii., [I] p. 49.)

ZschоккE, F. Weit. Zwischenw. d. B. lat. (C. f. B. u. P., I888, iv., p. 4I7.) LöNnBerg, E. C. f. B. u. P., I892, xi., p. I 89.

Schroeder, A. v. Wie bek. d. Einw. St. Petersb. d. br. Bdw. ? (St. Petersb. Med. Wochenschr., I 892 , xvii., No. 22.)

Braun, M. Bothr.-Finnen im Hecht d. St. Petersb. Fischmarktes. (Ibid., No. 28.) Schroener, A. v. Wratsch., I894 No. I 2 ; I895, No. I5; Jesched. Journ. Prakt. Med., I896, Nos. 19 and 27 (Russ.-Ref. in C. f. B. u. P., xvi., p. 314 ; xviii., p. 24 , and xx., p. 62I.)

\section{Dibothriocephalus cordatus (R. Leuck.), I863.}

Syn. : Bothriocephalus cordatus, R. Leuck.

Length, 80-II5 cm.; the head is heart-shaped and measures $2 \mathrm{~mm}$. by $2 \mathrm{~mm}$. The suctorial grooves are on the flat surface; the segments commence close behind the head and increase rapidly in breadth. At only $3 \mathrm{~cm}$. behind the head

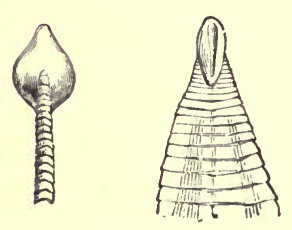

Fig. I46.-Cephalic end of Dibothriocephalus cordatus; on the left viewed sideways, on the right from the dorsal surface. (After Leuckart.) they are already adult; the greatest breadth attained by them averages $7-8 \mathrm{~mm}$., the length 3-4 $\mathrm{mm}$.; the number of proglottides averages 600 ; the most posterior ones are usually square. The rosette of the uterus is generally formed of six to eight lateral loops. The eggs are provided with lids and measure $0.075 \mathrm{~mm}$. in length by $0.05 \mathrm{~mm}$. in breadth.

Dibothriocephalus cordatus is a common parasite of the seal, the walrus and the dog in Greenland and Iceland, occasionally of man also. No doubt its larva lives in fishes. ${ }^{1}$

The statement that Dib.cordatus also occurs in Dorpat in human beings has been proved erroneous (Zool. Anzg., 1882, v., p. 46), as also has the report that this worm lives in hares in the neighbourhood of Berlin, 
whither it was supposed to have been carried by Esquimaux dogs (Rosenkranz in Deutsch. med. Wchnschr., I877, iii., p. 620). The parasite stated by the author to be Dib. cordatus, is Trenia pectinata, Goeze, which has been known since I 766 .

\section{Gen. 2. Diplogonoporus, Lönnbrg., I892.}

Syn.: Krabbea, R. Blanch, 1894.-The scolex is short and has powerful suctorial grooves; no neck; the proglottides are short and broad; there are two sets of genital organs side by side in each segment, which in all essentials resemble the single one of Dibothriocephalus.

[The genera Diplogonoporus and Krabbea are distinct; the uterus opens dorsally in the former, ventrally in the latter.F. V. T.]

\section{Diplogonoporus grandis, R. Blanch., I894.}

Syn.: Bothriocephalus, sp., Ijima et Kurimoto, I 894 ; Krabbea grandis, R. Bl.

Scolex unknown; chain of proglottides over Io $\mathrm{m}$. in length. I.5 mm. broad in front, $2.5 \mathrm{~mm}$. broad at the back. The proglottides are very short $\left(0^{\circ} 45 \mathrm{~mm}\right.$.), but broad. On either side to the right and left of the worm, along the entire ventral sur-

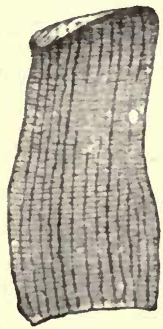

FIG. I47.-A segment of Diplogonoporus grandis (natural size). (After Kurimoto.)

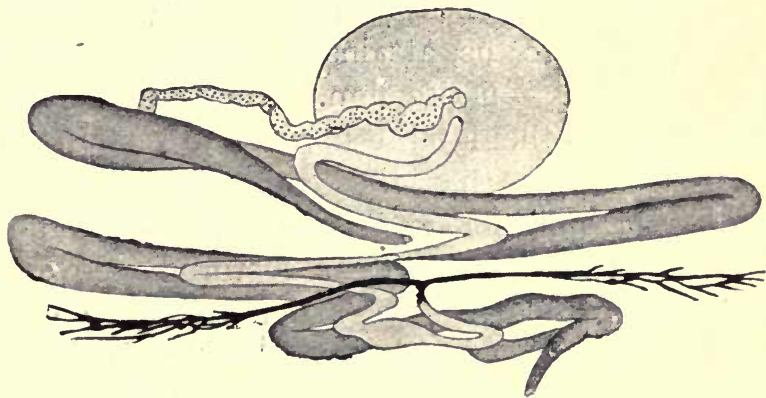

FIG. I48.-Genitalia of Diplogonoporus grandis. Above the cirrus pouch, to the left, vas deferens (dotted); below, the vagina (light); the uterus (dark); ovary (black). (After Kurimoto.) 150/1.

face, there is a longitudinal groove; these grooves are nearer to each other than to the lateral margin; in them lie the genital pores, and they are in the same sequence as in Dibothriocephalus; the ovary is only developed transversely; the uterus only makes a few loops. Eggs (fig. I29) thick-shelled, brown, $0.063: 0.048$ $-0.05 \mathrm{~mm}$. This parasite has hitherto been observed twice in Japanese. Similar species are known in cetacea and seals. 


\section{LITERATURE.}

Ijima, J., and T. Kurimoto. On a New Hum. Tape-Worm. (Journ. Coll. Sc. Imp. Univ., Tokyo, I894, vi., p. 37 I.)

Blanchard, R. Not. sur les par. de l'homme, iv. (C. R. soc. biol., Paris [10], i., 1894, p. 699).

KuRimoto, T. Diplog. grandis. (Ztsch. f. klin. Med., 1900, xl., p. I.)

Bothriocephalus mansoni, Cobb., I883.

Syn.: Ligula mansoni, Ċobbold, 1883; Bothriocephalus liguloides, R. Leuck., I 886.

Plerocercoids of Bothriocephalidæ living between the tissues and organs of various vertebrate animals; the adult stage to which they give rise is unknown, and they cannot therefore be assigned to a definite genus. These plerocercoids were discovered in $\mathrm{I} 882$ by $\mathrm{P}$. Manson during the post mortem on

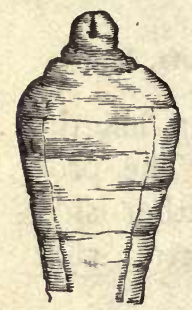

FIG. I49. Cephalic end of Bothr. mansoni, $\mathrm{Cobb}$. (After Leuckart.)

a Chinaman who had died in Amoy, twelve specimens being found beneath the peritoneum and one free in the abdominal cavity. Cobbold described them as Ligula mansoni, and Leuckart, who contemporaneously reported a case in Japan, termed them Bothriocephalus liguloides. Ijima and Murata reported eight further cases.

The plerocercoid, which hitherto alone is known to us, attains a length of $30 \mathrm{~cm}$. and a breadth of 3-6-I2 $\mathrm{mm}$. The ribbon-shaped body is wrinkled, the lateral borders are often somewhat thickened, so that the transverse section has the form of a biscuit; the anterior end is usually wider and carries a retractile head, provided with two weak suctorial grooves.

The parasite makes migrations within the body, and thus may reach the urinary passages; then it is either evacuated with the urine or has to be removed from the urethra; not rarely it causes excrescences on various parts of the skin, when this takes place it has to be removed by an operation.

Nothing is known of its development and origin:

\section{LITERATURE.}

Manson, P. Case of Lymph Scrotum Assoc. with Filar. and other Par. (The Lancet, 1882, ii., p. 616.)

Cовводd, T. Sp. Descr. of Ligula mans. (Linn. soc. Journ. Zool., I883, xvii., p. 78.) Lond.

Leuckart, R. Demonst. ein. selt. menschl. Entoz. (Tagebl. 57. Vers. D. Nat. u. Aerzte zu Magdeburg, 1884, p. 32I.)

Die Paras. d. Mensch. 2nd edit., i., p. 941.

IjIma and Murata. Some New Cas. of the Occ. of Bothr. ligul. (Journ. sc. Coll. Imp. Univ., ii., I 888 , Tokio, p. I49.) 


\section{B. Taniida.}

Gen. 3. Dipylidium, R. Leuck., I863.

Rostellum retractile with several rings of alternating hooks, the latter usually have a disc-like basis. Suckers unarmed. Genital pores prominent; genitalia duplicated. Testes very numerous in the central field; ovary with two lobes; the vitellaria, which are smaller, lie behind; the uterus forms a reticulum in the network of which the testicular vesicles lie; later on it forms into one or several sacs enclosing eggs. The eggs have a double shell.

\section{Dipylidium caninum (L.), I758.}

Syn.: Tania canina, L., I758, p. p; T. moniliformis, Pallas, I78I ; T, cucumerina, Bloch, I782; T. elliptica, Batsch, I786; Dipylidium cucumerinum, Leuck., I 863.

This worm measures $\mathrm{I} 5-35 \mathrm{~cm}$. in length and $\mathrm{I} 5-3 \mathrm{~mm}$. in breadth. The scolex is small, rhomboidal, and has a club-shaped rostellum on which there are three to four rings which carry from forty-eight to sixty hooks resembling rose-thorns, the size of the foremost of which varies from 0.011 -Oor 5 , and the posterior ones average $0.006 \mathrm{~mm}$. The neck is very short, the most anterior segments broad and short, the middle as long as they are broad, the mature segments are longer than wide $(6-7: 2-3 \mathrm{~mm}$.) fairly thick, are frequently of a reddish colour, and when cast off resemble cucumber seeds. The genital pores lie symmetrically at the lateral borders; the roundish ovarian follicles arising from the reticulum of the uterus contain eight to fifteen eggs packed in a reddish mass. The eggs are globular $\left(0^{\circ} 043\right.$ - $0.050 \mathrm{~mm}$. ); the embryonal shell is thin, the oncosphere measures $0.032-0.036 \mathrm{~mm}$.
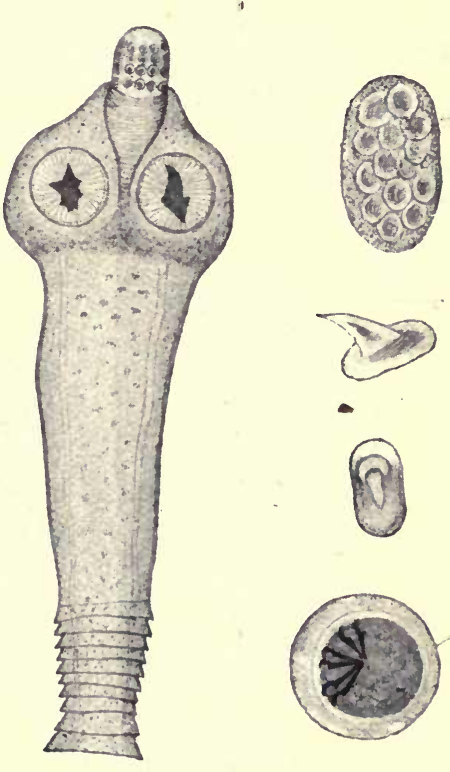

FIG. I50. - Dipylidium caninum. (After Diamare.) On the left, the scolex and the first proglottides; on the right, at the top, a packet of ova; below, hooks of the rostellum, side and front views; below, an ovum. (Various enlargements.)

Dipylidium caninum is a common intestinal parasite of dogs, 
in which it grows larger (Tania cucumerina, Bloch) than in cats

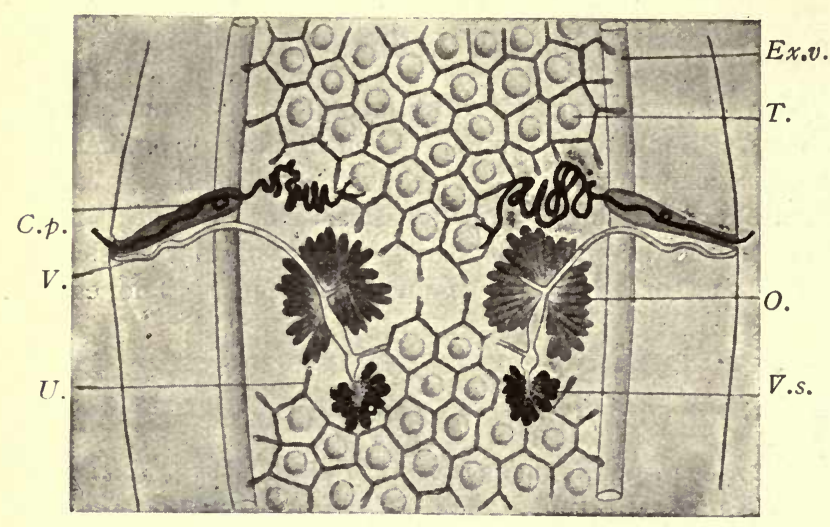

FIG. I5I.-Dipylidium caninum. Central portion of a proglottis (magnified). (After Neumann and Railliet.) C.p., cirrus pouch; V.s., vitellaria; Ex.v., excretory vessels; $T$., testicular vesicles ; $O$., ovary; $U_{\text {. }}$, reticulum of uterus ; $V_{\text {., }}$ vagina.

(T. elliptica, Batsch) ; it has, however, also been found in jackals, as well as in human beings, though in the latter it is of comparatively rare occurrence (twentyfour cases), and almost always affects children, generally of tender age. Only one case affect-

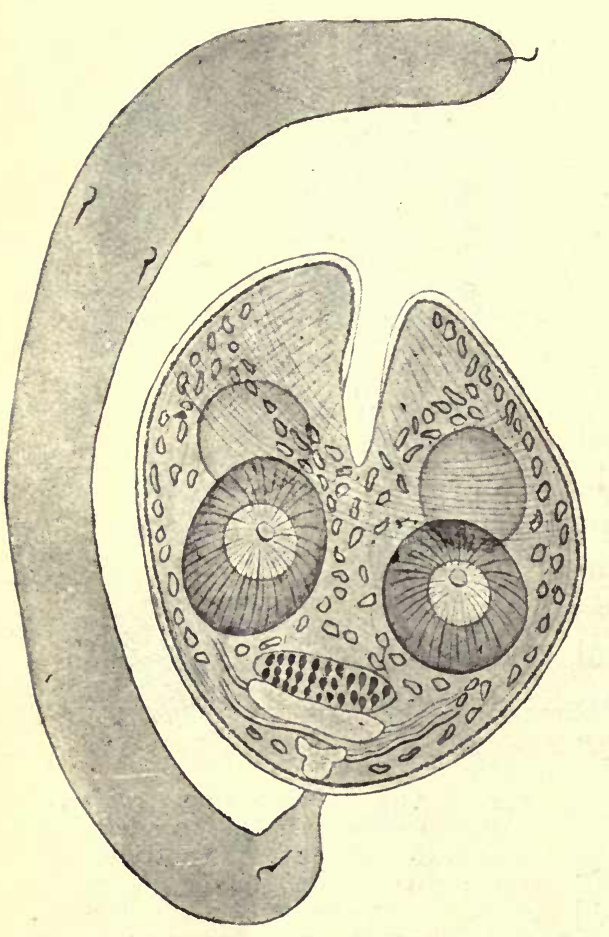

FIG. 152.-Cysticercoid of Dipylidium caninum (enlarged). (After Grassi and Rovelli.) ing an adult is known. The proglottides, which leave the intestine spontaneously, are recognisable by the naked eye on account of their form and colour, as well as their two genital pores. As a rule, the presence of this parasite sets up no marked symptom in the patient.

The corresponding cysticercoid lives in the louse of the dog (Trichodectes canis), a fact that was first established by Melnikow and Leuckart ; according to Grassi and Rovelli, as well as Sonsino, it also lives in the flea of the dog (Pulex serraticeps) and in the flea of man (Pulex irritans), but not in its larva. The adult segments, which leave the rec-
ously, creep about around the 
anus and get into the fur, and are thus transmitted by their hosts. Part of the segments, or the oncospheres released by disintegration, are then taken up by the lice and fleas, within which they develop into cysticercoids. Dogs and cats are thus infected by their own skin-parasites, which they bite and swallow whilst gnawing at their fur. The infection of human beings must occur in an analogous manner, by transmission of the cysticercoids present on the lips or tongue of dogs when licking them, or it may be that the vermin of cats and dogs harbouring cysticercoids infect human beings direct.

\section{LITERATURE.}

Leuckart, R. D. menschl. Paras., I863, i., p. 400.

Steudener, F. Unters. üb. d. fein. Bau d. Cest. (Abh. nat. Ges. Halle, i 877 , xiii., p. 295.)

Diamare, V. Il genere Dipylidium. (Atti R. Acc. sc. fis. e mat. Napoli., I893, ii., Ser. 2, No. 7.)

Melnikow, W. Ueb. d. Jugendzust. d. T. cucum. (Arch. f. Naturg., I869, xxxv., i., p. 62.)

Grassi, B., and G. Rovelli. Embr. Forsch. a. Cest. (C. f. B. u. P., I889, v., p. 370.)

Ric. embryol. sui Cest. (Atti Accad. Gioen. sc. nat. Catania., I892, Ser. 4, vol. iv.)

Sonsino, P. Ric. s. ematoz. del cane e sul ciclo evol. d. T. cucum. (Att. soc. tosc. sc. nat., I 888 , x., p. I.)

Salzmann. Ueb. d. Vork. d. T. cuc. i. Mensch. (Jhrshfte. d. Ver. f. vaterl. Naturkde. Württ., I86I, xvii., p. I02.)

Hoffman,, A. Tæn. cuc. b. ein. 4 Monate alten Kinde. (Jahrb. f. Kinderhlkde, N. F., I 887 , xxvi.)

KRÜGER, F. St. Pet. med. Wchschr., I 887 , No. 4 I.

Brandt, Ed. 2 Fälle v. T. cuc. b. Mensch. (Zool. Anzgr., I888, xi., p. 48I.) TrIIs. Nord. med. Arkiv., I 884, xvi., No. 6.

Blanchard, R. Trait. Zool. med., I889, i., p. $48 \mathrm{I}$; and Mal. Paras., I895, p. 7 I 8 .

\section{Gen. 4. Hymenolepis, Weinland, 1858 .}

The scolex is small: rostellum armed; suckers unarmed; the neck is long; the breadth of the segments is greater than their length. The genital pores lie all on the left. Three testes in each proglottis. The mature uterus fills the entire segment; the eggs are round or oval with three distinct envelopes. Found in mammals and birds.

The genus has recently been divided into two sub-genera-Hymenolepis, s. str., and Drepanidotania, Raill.

[The following are the characters of the two genera, Hymenolepis, Weinland, I858, and Drepanidotania, Railliet, I892.]

Genus Hymenolepis, Weinland, I858 (Diplacanthus, Weinland, I858 [nec L. Agassiz]).

Head small, provided with retractile rostellum, well developed and armed with a single crown of 24 to 30 hooks, or rudimentary or unarmed. Neck long. Segments serrated, longer than broad, seldom less than 150 in 
number. Genital pores marginal, on left side; the female surface ventral. Testes few, generally three in each segment-one left and two right of the median line. Eggs with three separate shells; inner shell with a small knot at each pole. The larva a Crytocystis or Staphylocystis. Intermediate host insect or myriapod. Weinland proposed this with Tania flavopunctata as type, which is the same as diminuta.

\section{Genus Drepanidotania, Railliet, I892.}

Head provided with a single row of uniform hooks, few ( 8 to 20) in number, with dorsal root much longer than ventral root, the latter always small, with prong directed posteriorly when the rostellum contracts. Larval stage found in small crustaceans.

The two genera thus differ in having the dorsal root of the hooks much longer than the ventral or prong in Drepanidotania, and the hooks few in number; the hooks are similarly formed in Hymenolepis, but when present vary from 24 to 30 .

A third genus is closely related, Dicranotania, Railliet, I892, which has the dorsal root of hooks shorter than the ventral root or prong. The two latter only are known in birds.-F. V. T.]

\section{Hymenolepis nana (v. Sieb.), I852.}

Syn.: Tania nana, v. Sieb., 1852 (nec van Beneden, 1867); T. agyptiaca, Bilh., I852; Diplacanthus nanus, Weinld., I858; T. (Hymenolepis) nana, Lckt., r863.

The worm is ro- $15 \mathrm{~mm}$. in length and $0.5-0.7 \mathrm{~mm}$. in breadth; the head is globular, $0.25-0.30 \mathrm{~mm}$. in diameter. The rostellum has a simple crown consisting of twenty-four or twenty-eight to thirty hooks, which are only o.or $4-0.018 \mathrm{~mm}$. in length. The neck is moderately long; the proglottides are very narrow, about 150 in number, $0.4-0.9 \mathrm{~mm}$. in breadth, and $0.0{ }_{4}-0.030 \mathrm{~mm}$. in length. The eggs are globular or oval, $0^{\circ} 030-0^{\circ} 037-0^{\circ} 048 \mathrm{~mm}$.; the oncospheres measure 0.016 - o.oI9 $\mathrm{mm}$. in diameter.

This species was discovered by Bilharz in Cairo, in I85I; it was found by him in great numbers in the intestine of a boy who had died of meningitis. For several years this was the only case, until I885, since when numerous cases have come to light. Spooner, 1873, even reported a case from North America, which may, however, have related to Hymenolepis diminuta. In Europe the worm is particularly frequent in Sicily, but it has also been repeatedly observed in North Italy; it has, moreover, been 
reported from Russia, Servia, England, France, Germany, South America, Siam and Japan. Notwithstanding its small size this worm causes considerable disorders in its hosts-mostly childrenas it sets up loss of appetite, diarrhœa, various nervous disturbances, and even epilepsy; all these symptoms, however, disappear

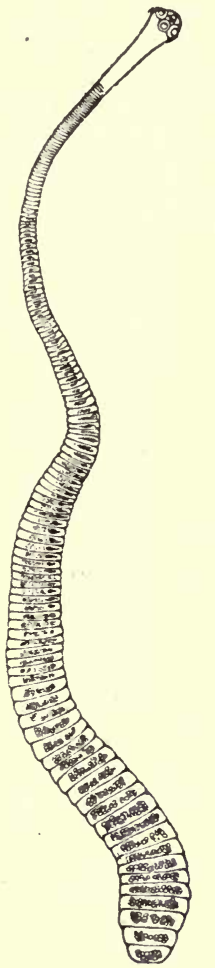

FIG. I 53. - $H y$. menolepis nana (v. Sieb.), about 12/1. (After Leuckart.)

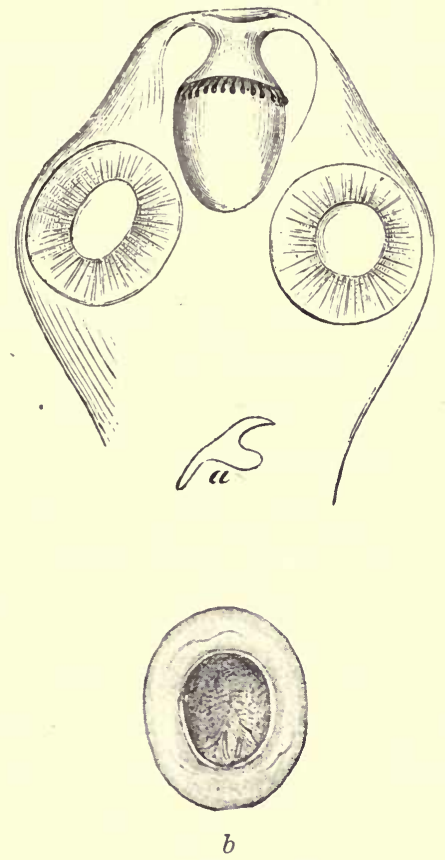

Fig. I54. - Head of Hymenolepis nana, with rostellum retracted. IOO/1. (a) A single hook. 600/r. (After Leuckart.) (b) An egg, highly magnified. (After Grassi.)

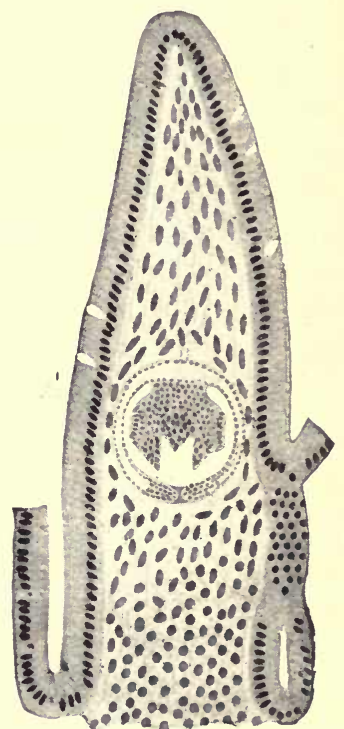

FIG. I 55.-Longitudinal section through the intestinal villus of a rat, with the cysticercoid of Hymenolepis murina (magnified). (After Grassi and Rovelli.)

after the expulsion of the parasites, which are generally present in large numbers.

The development as well as the manner of infection is still unknown; Grassi certainly is of opinion that Hymenolepis nana is merely a variety of Hym. murina (Duj.) which lives in rats. According to Grassi direct development takes place by means of the omission of the intermediary host, but with the retention of the cysticercus stage, that is to say, rats infect themselves with Hymenolepis murina direct, by ingesting the mature segments or 
oncospheres of this species, from which subsequently the small cysticerci originate in the intestinal wall (fig. I55); when fully developed they fall into the intestinal lumen and become tapeworms. The identity of the two forms has nevertheless been disputed (Moniez, R. Blanchard, v. Linstow), though their near relationship cannot be denied. Grassi gave mature segments of Hymenolepis murina to six persons, but only one person evacuated a tapeworm. This, however, proves nothing in a district where Hymenolepis nana frequently occurs in man; it was, moreover, not possible to infect rats with segments of Hymenolepis nana (of man). Accordingly this form may represent an independent species, which, however, like Hymenolepis murina, also omits an intermediary host.

[Stiles and others state that the intermediate hosts of the Hymenolepis are insects and Myriapoda.-F. V. T.]

\section{LITERATURE.}

Siebold, C. Th. v. Ein Beitr. z. Helm. hum. (Z. f. w. Zool., I852, iv., p. 64.) Spooner, E. A. Spec. of T. nana. (Am. Journ. med. sc., I873, lxv., p. I36.) Grassi, B. Die T. nana u. ihre med. Bedtg. (C. f. B. u. P. I., I887, p. 97.) Einig. weit. Nachr. üb. T. nana. (Ibid., I 887 , ii., p. 282.)

Entw. d. T. nana. (Ibid., p. 305.)

Cenno prev. int. ad una nuov. mal. par. nell' uomo. (Gazz. d. osp., I886, pp. 450, 619.)

Cominı, E. Epilessia rifl. da T. nana. (Gazz. d. osp., I887, viii., p. I74.)

Due casi d. T. nana. (Gazz. med. ital.-lomb., I888, p. 8I.)

Perroncito, E. Caso di T. nana. (Giorn. R. Acc. med., Torino, I887, xxxv., p. 7.

Perroncito, E. and P. Airoldi. Caso di T. medioc. e di molte T. nan. (Ibid., I 888, xxxvi., p. 3I2; Gazz. d. Osp., I 888, p. 554.)

Senna. Stor. clin. di sei casi d. T. nana. (Gazz. med. ital. Lomb., I889, xlviii., Ser. 9, vol. ii, pp. $245,255,265$.

Orsi, F. Sei casi d. T. nana. (Ibid., p. 235.)

Sonsıno, P. Tre casi di T. nana nei dint. di Pisa. (Riv. ital. clin. med., I89I, iii.)

Ransom, !W. H. Prob. exist. of T. nana . . . in Engl. (The Lancet, I888, ii.)

Nuov. oss. di T. nana. (Boll. soc. med. Pisa., I 895, i., p. 4.)

Zograf, N. Note sur la myol. d. Cest. Congr. intern. d. Zool., IIe sess., Moscou, 2nd part, p. 23.

Wernicke, O. Tænia nana. (Anal. circ. med. argent., I89o, xiii., p. 349.)

C. R. soc. biol., Paris, I89I, [9], iii., p. 44 I [Blanchard].

Lutz, A. Beob. üb. d. als T. nana u. T. flavop. bek. Bandw. d. Mensch. (C. f. B. u. P., I 894 , xvi., p. 6I.)

Mertens. Berl. klin. Wchschr., I 892, Nos. 44, 45.

Roeder, H. Ueb. ein. weit. Fall v. T. nana i. Deutschl. (Münch. med. Wchschr., I 899, p. 344.)

RASCH, CHR. T. nana in Siam. (D. med. Ztg., I895, p. I43.)

MiURA, K., and Yamazaki. Ueb. T. nana. (Mitth. med. Fac. Kais. Univ. Tokio, I 897, iii., p. 239.)

Moniez, R. Sur la T. nana. (C. R. Ac. sc. Paris., I888, cvi., p. 368.)

Blanchard, R. Hist. zool. et méd. d. Téniad. du genre Hymenol., Paris, I89r.

Linstow, v. Ueb. T. nana u. T. murina. (Zeitschr. f. d. ges. Naturw., I896, p. 57 I.)

Grassi, B., and G. Rovelli. Ric. embr. sui Cestodi. (Atti Acc. Giern. sc. nat., Catania, 1892, Ser. 4, vol. iv.) 
2. Hymenolepis diminuta, Rud., I8I9.

Syn.: Tania diminuta, Rud., I819; T. leptocephala, Crepl., I825; T. flavopunctata, Weinld., I858; T. varesina, E. Parona, I884; T. minima, Grassi, I 886.

This species measures $20-60 \mathrm{~cm}$. in length, and up to $3.5 \mathrm{~mm}$. in breadth; there are from 600 to $\mathrm{I}, 000$ segments. The head is very

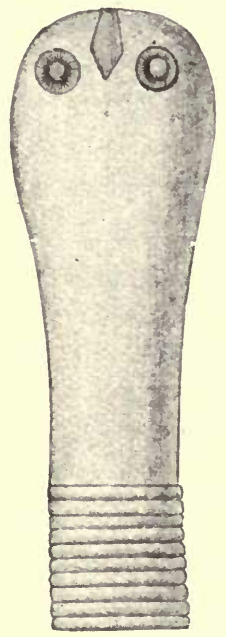

Fig. I 56. - Hy. menolepis diminuta, scolex magnified. (After Zschokke.) small $(0.2-0.5 \mathrm{~mm}$.$) ; it is club-shaped and has$ a rudimentary unarmed rostellum; the neck is short; the mature segments are $3.5 \mathrm{~mm}$. in breadth, $0.66 \mathrm{~mm}$. in length; the eggs are round or oval $\left(0^{\circ} 060-0.070: 0.070-0.086 \mathrm{~mm}.\right)$. The egg-shell is yellowish and thickened, with indistinct radial stripes; embryonal shell double, thin; the outer one is somewhat pointed at the poles; oncosphere $0^{\circ} 028-0^{\circ} 036 \mathrm{~mm}$.

Hymenolepis diminuta lives in the intestine of rats and mice: Mus decumanus, the sewer rat; $M$. rattus, the house rat, $M$. musculus, the mouse, and $M$. alexandrinus; it is occasionally also found in human beings.

Weinland described it from specimens collected by Dr. E. Palmer in I842, in Boston, from a child aged I9 months, as T. flavopunctata. A second case was only reported in 1889 by Leidy relating to a three-year-old child from Philadelphia ; a third case was simultaneously reported of a two-yearold girl in Varese ( $T$. varesina), and Grassi described another case

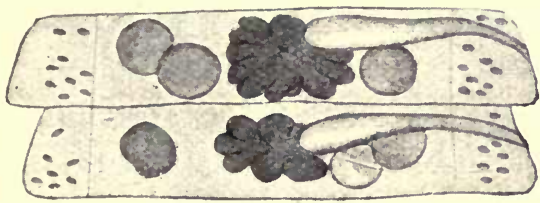

FIG. I 57.-Hymenolepis diminuta ; two proglottides slightly enlarged. (After Grassi.)

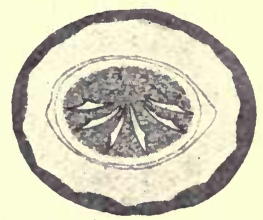

Fig. I 58.-Ovum of Hymenolepis diminuta; greatly magnified. (After Grassi:)

relating to a twelve-year-old girl from Catania (Sicily). Sonsino and Previtera reported the same species in Italy, Zschokke in France, Lutz and Magalhães in South America, and Pachard in North America.

According to Grassi and Rovelli the cysticercus stage lives in 
a small? moth :Asopia farinalis), as well as in its larva, in an orthopteron (Anisolabis annulipes), and in coleoptera (Acis spinosa and Scaurus striatus). Experimental infections have been successful on rats as well as on human beings. In America other species of insects may be the intermediary hosts.

\section{LITERATURE.}

Rudolphi, C. A. Entoz. syn. Berol., I819, p. 689.

Creplin, F. C. H. Obs. de entoz., i., Gryph, I825, p. 7 I.

Weinland, D. F. An Essay on Tape-worms of Man. Cambridge, U. G., 1858.

Beschreibung zweier neuen Tænoiden an d. Menschen. (Nov. Act. Acad. Cæs. Leop.-Carol., I86I, xxviii.)

I,EIDY, J. Occur. of a rare hum. Tapew. (Amer. Journ. of Med. Sc. [2], I884, lxxxiii., p. I I0; Proc. Ac. nat. Sc., Philad., I884, p. I37.)

Parona, E. ' Du un caso di T. flavop. risc. in una bambina di Varese. (Gior. R. Acc. med., Torino, I882, xxxii., p. 99.)

Grassi, B. Bestimmg. d. 4 von Parona ?. gef. Tænien. (C. f. B. u. P., I 887 , i., p. 257.)

T. flavop., leptoc., diminuta. (Atti. R. Acc. sc., Torino, I888, xxiii., p. 492.)

Sonsino, P. Su par. dell' uomo con un nuovo caso di T. flavop. (C. f. B., P. u. I., I $896[\mathrm{I}]$, xix., p. 937.)

Previtera, G. Due casi prob. di T. leptoc. nei minat. d. zolfare. (Boll. Acc. Gioen. sc. nat., N. S., 1900, No. 63, Catania, p. 9.)

Zschокке, F. Seltene Par. d. Menschen. (C. f. B. u. P., I892, xii., p. 497.)

Lutz, A. Beobacht. üb. d. als T. nana 11. flavop. bek. Bdw. d. Mensch. (Ibid., I 894, xiv., p. 61.)

Magalhâes, P. G. de. Ein zweit. Fall v. Hym. dimin. als menschl. Paras. in Brasil. beob. (Ibid., I 896 [I], xx., p. 673.)

PACHARD, F. A. T. flavop., with descr. of a new Specim. (Journ. Am. med.

Ass., 1900, $\mathrm{xxxv}_{\text {., }}$ p. I55I.)

Grassi, B., and G. Rovelli. Ric. embr. s. Cestodi., Catania, I892.

\section{Hymenolepis lanceolata, Bloch, I782.}

Syn.: Tania lanceolata, Bloch ; Drepanidotania lanceolata, Railliet, 1892.

[This comes in the genus Drepanidotania.-F. V. T.]

The parasite measures $30-\mathrm{I} 30 \mathrm{~mm}$. in length and $5-\mathrm{I} 8 \mathrm{~mm}$. in breadth; the head is globular and very small; the rostellum is cylindrical, with crown composed of eight hooks $(0.03 \mathrm{I}-0.035 \mathrm{~mm}$. in length). The neck is very short. The short segments increase gradually and equally in breadth, but only a little in length; the female glands lie on the side opposite to that on which the genital pore is situated; the three elliptical testes are on the same side as the pores; the cirrus is armed and slender. The eggs have three envelopes and are oval $\left(0^{\circ} 050-0.035 \mathrm{~mm}.\right)$, the external envelope is membranous and much wrinkled, the middle one is thick and the internal one very thin.

It inhabits the intestine of ducks, geese, and diving birds. 
Zschokke reports the receipt of two specimens which a twelveyear-old boy in Breslau evacuated spontaneously at two different times.

The corresponding cysticercoid, according to Mrázek, lives in freshwater cyclops; according to Daday it is likewise found in Diaptomus spinosus.

[The synonymy of this species is as follows: I727, Tania anserum, Frisch; T. acutissima, Pallas (vide Krabbe, I867); T. anseris, Bloch (vide Rud., I8Io); I782, T. lanceolata, Bloch; ז786, T. lanceola, Batsch (vide Rud., I8Io); I803, Halysis lanceolata (Bloch, I782), Zeder (vide Rud,, I8Io) ; I858, Hymenolepis (Dilepis) lanceolata (Bloch, I782), Weinland. It occurs in the following birds, Domesticated ducks and geese, the Muscovy duck (Cairina moschata), white-headed duck (Erismatura leucocephala), the pochard (Aythya rufina), and the flamingo (Phanicopterus antiquorum). It has been recorded from Great Britain, France, Denmark, Austria and Germany.-F. V. T.]

\section{LITERATURE.}

Bцосн, M. E. Abhdlg. v. d. Erzg. d. EingeweideWürmer, Berlin, I 782 .

Feuereisen, J. Beitr. z. Kenntn. d. Taen. (Z. f. w. Z., I 868 , xviii., p. I61.)

WolfFhǗGel, K. Drep. lanc. Bl. (C. f. B., P. u. I., I900 [I], xxviii., p. 49.)

ZschoкKe, F. Hym. lanc. Bl. als Schmar. d. Menschen.

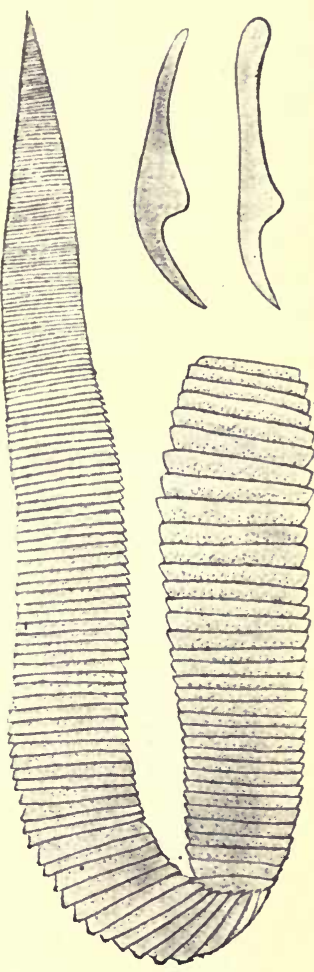

FIG. I 59.-Hymenolepis lanceolata, natural size. (After Goeze.) To the right above, two hooks are illustrated. I $20 / 1$. (After Krabbe.)

MrázeK, A. Zur Entw. einig. Taenien. (Sitzgsber. K. böhnı. Ges. d. Wiss. Math. nat. Cl. Prag., I896, Art. xxxviii.)

Daday, E. v. Helm. Stud. Einige in Süssw.-Entomostr. leb. Cercocystis-Formen. (Zool. Jahrb. Syst., 1900, Part xiv.)

\section{Gen. 5. Davainea, R. Blanch., I89I.}

The scolex is more or less globular with a rostellum furnished with two rings of hammer-shaped hooks; the suckers are surrounded by several rings of small hooklets; the genital pores are either on the same lateral border or are irregularly alternating; ova, generally in egg capsules, are usually present in large numbers, almost taking up the whole of the mature segments. This genus occurs chiefly in birds.

[The larval stage of the Davaineas takes place in slugs (Limax) and snails (Helix).-F. V. T.] 


\section{Davainea madagascariensis, Davaine, I869.}

Syn.: Tania madagascariensis, Dav.; Tania demerariensis, Daniels, I 895.

This worm measures $25-30 \mathrm{~cm}$. in length; the head has four large round suckers; the rostellum has 90 hooks $(0.018 \mathrm{~mm}$. in length); there are 500 to 700 segments, of which the last hundred are filled with eggs and form half of the entire worm. The segments, when mature, measure $2 \mathrm{~mm}$. in length by $\mathrm{I} .4 \mathrm{~mm}$. in breadth; genital pores on the same lateral border; about 50 testes; the uterus consists of a number of loops, which at each side are rolled up into an almost spherical ball; when filled with eggs the convolutions unwind, permeate the segment and then lose their wall; the eggs lying free in the parenchyma

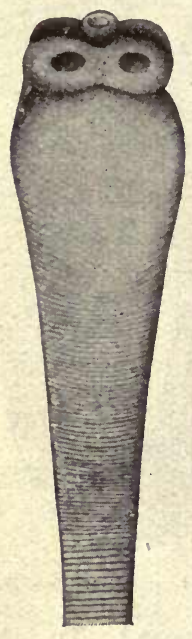

Fig. 160.-Scolex of Davainea madagascariensis. I4/I. (After Blanchard.) The hooks have fallen off. become finally surrounded, one, or several together, by proliferating parenchymatous cells; this is how the 300 to 400 ovarian vesicles, taking up the entire mature segment, are formed. The globular oncosphere $\left(0^{\circ} 008 \mathrm{~mm}\right.$.) is surrounded by two perfectly transparent shells; the external shell terminates in two pointed processes.

Davainea madagascariensis has hitherto been found in man only. Davaine described this species from fragments sent to him from Mayotte (Comores), and which were found in two Creole children. Chevreau observed four cases in PorteLouis (Island of Mauritius), likewise in children; Leuckart received the first perfect specimen; it was obtained from a three-year-old boy in Bangkok, the son of a Danish captain; Daniels, at the post mortem of an adult native of George Town, Guiana, found two specimens (Tania demerariensis), and finally Blanchard describes another perfect specimen which was in Davaine's collection of helminths in Paris, and which was obtained from a little girl three years old, of Nossi-Bé (Madagascar). The intermediary host is unknown.

\section{LITERATURE.}

Grenet and Davaine. Not. sur une nouv, esp. de Taenia rec. à Mayotte: (Mém. soc. biol., Paris, 1869 [5], i., p. 233; Arch. de méd. nav., I870, xiii., p. I 34.) Chevreau, P. Le T. madagasc. (Bull. soc. méd. de l'île Maurice, I891, ix., p. 523.)

Blanchard, P. Note sur quelq. vers par. de, l'homme. (C. R. soc. biol., Paris, I89I [9], iii., p. 604.) 
Leuckart, R. Ueber T. mad. (Verhandl. d. D. Zool. Ges. I. Leipzig, I89I, p. 68.)

Daniels, C. W. T. demerariensis. (Brit. Guiana med. Ann. Hosp. Rep., I895; The Lancet, I896, ii., p. I455.)

Blanchard, R. Le Dav. mad. à Guyane. (Bull. Ac. méd., I897 [3], xxxvii., p. 34.)

Blanchard, R. Un cas inéd. de Dav. mad. consid. sur le genre Davainea. (Arch. parasitol., I 899 , ii., p. 200.)

\section{Davainea (?) asiatica (v. Linst.) IgoI.}

Syn.: Tania asiatica, v. Linstow.

There exists only one headless specimen of this species, which is not quite adult and which is preserved in the Zoological Museum of the Imperial Academy of Science in St. Petersburg. It came from a human being and was found by Anger in Aschabad (Asiatic Russia, near the Northern frontier of Persia). The specimen measures $298 \mathrm{~mm}$. in length. The breadth anteriorly is only $0.16 \mathrm{~mm}$., the posterior part measures $I \cdot 78 \mathrm{~mm}$. across. The number of segments is about 750. The genital pores lie on the same lateral border; the testes are globular and lie in a dorsal and ventral layer in the medullary layer; the cirrus pouch is pyriform, $0.079 \mathrm{~mm}$. in length, and $0.049 \mathrm{~mm}$. in breadth; the female glands lie in the forepart of the segments, the ovary reaching to the excretory vessels; the vitellarium is small and round. The vagina has a large fusiform receptaculum seminis; the uterus breaks up into 60 to 70 large, uneven, ovarian follicles.

\section{LITERATURE.}

Linstow, v. Tænia asiatica, eine neue Tænie d. Mensch. (C. f. B., P. u. I., I90I [I], xxix., p. 982.)

\section{Gen. 6. Tania, L., I758. ${ }^{1}$}

Tæniidæ, usually of considerable length, the mature segments of which are much longer than they are broad. The scolex has a rostellum and

1 The Greeks termed the tapeworms $e^{\prime \prime} \lambda \mu \iota \nu \delta \epsilon s \quad \pi \lambda \alpha \tau \epsilon i a l$, more rarely $\chi \eta \rho^{\prime} a$ (=fascia); the Romans called them tania, tinea, taniola; later lumbrici, usually with the addition lati, to distinguish them from the Lumbrici teretes. The proglottides were called Vermes cucurbitini; the cysticerci $\chi \alpha$ á $\alpha \zeta \alpha$ (hailstones), later hydatids. Plater (1602) was the first to differentiate Trania intestinorum (= Bothriocephalus latus), amongst the Lumbrici lati of man, from: Tania longissima (= Tania solium). The term saginata was already used by Arnoldus Villanovanus, who lived about I 300 ; and, according to him, it signifies "cingulum" (belt, chain); while N. Andry, in I7OO, traces this word from "solus," because the worm occurs in man alone. Leuckart and Krehl derive the word "solium" from the Syrian "schuschl" (the chain), which in Arabian has become "susl" or "sosl," and in Latin has become "sol-ium." What Linné described uncler the term Tania saginata was really Tania solium; the latter was first distinguished by Goeze, but was forgotten until Küchenmeister, in 1852, again called attention to the differences. 
usually a double crown of hooks, exceptionally the rostellum is transformed into an apical sucker, the primitive armature of which then disappears. The neck may be long or short. The young segments are broader than they are long; the fairly mature ones almost square; the genital pores project at the lateral borders, and alternate irregularly. Genitals single in each segment.

The testes are usually very numerous, and are situated in the lateral parts of the central field; the ovary, shell gland and vitellarium are situated in the posterior half of the central field. The uterus has a median trunk with lateral branches which develop later; as these develop, the testes, and later on the ovary and vitellarium, become atrophied. The egg-shell is thin and frail, round, and with or without filaments; the embryonal shell is thick with radial stripes. There is a cysticercus, cœnurus or echinococcus stage which is usually passed in herbivvorous animals; the adult stage is passed in carnivorous animals and in man.

\section{Tenia solium, L., p. p., I767.}

Syn.: Tänia cucurbitina, Pall., I7EI ; T. pellucida, Goeze, I782; T. vulgavis, Werner, I782; T. dentata, Gmel., I790; Halysis solium, Zeder, I800; $T$. bumana armata, Brera, I802; T. (Cystotania) solium, Leuck., I862.

The average length of the entire tapeworm is about $2-3 \mathrm{~m}$., but may be even more; the head is globular, $0.6-0.8-\mathrm{I}^{\circ} \mathrm{m} \mathrm{mm}$. in. diameter. The rostellum is short with a double wreath of hooks, $22-32$ in number, usually $26-28$; large and small hooks alternate regularly; the length of the large hooks is $0.16-0.18 \mathrm{~mm}$., of the small ones $0 . \mathrm{II}-\mathrm{O}^{\circ} \mathrm{I} 4 \mathrm{~mm}$. The rostellum is sometimes pigmented. The suckers are hemispherical, $0_{4} 4-0.5 \mathrm{~mm}$. in diameter. The neck is fairly thin and long (5-Io mm.). The proglottides, the number of which averages from 800 to 900 , increase in size very gradually; at about I $\mathrm{m}$. behind the head they are square and have the generative organs fully developed. Segments sufficiently mature for detachment measure io- I2 mni. in length by $5-6$ $\mathrm{mm}$. in breadth. The genital pores alternate fairly evenly at the lateral border a little behind the middle of each segment. The fully-developed uterus consists of a median trunk, with 7 -Io lateral branches at either side, some of which are again ramified. The eggs are oval, the egg-shell very thin and delicate; the embryonal shell is thick, with radial stripes; it is of a pale yellowish colour, globular, and measures $0.03 \mathrm{I}-0.036$ in diameter; the oncospheres, with six hooks, are likewise globular, and measure $0.02 \mathrm{~mm}$. in diameter. 
Malformations are not so common as in Tania saginata; they consist of two or several proglottides being partly or entirely amalgamated, formation of single club-shaped segments, fenestration on long or short series of segments and so-called double formation, in which the head has six suckers and the segments exhibit a $\mathrm{Y}$-shaped transverse section. The oncospheres occasionally also possess more than six hooklets. Very slender specimens have led to the description of a particular species or variety ( $T$. tenella).

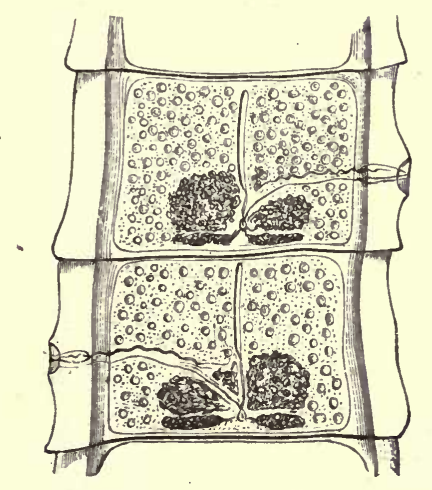

FIG. I6I.-Two fairly mature proglottides of Tania solium, with sexual organs and excretory vessels.

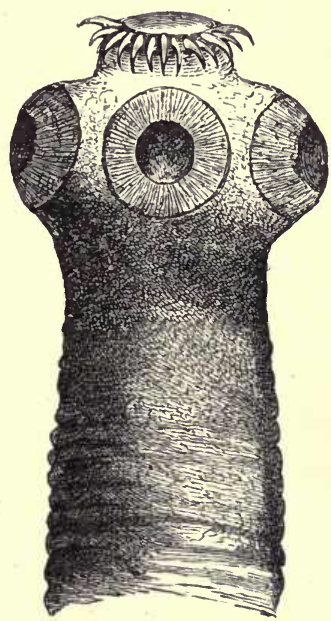

FIG. 162. - Head of Trnia solium. $.45 / 1$.

In its fully-developed condition Tania solium is found exclusively in the small intestine of man; the head is usually attached in the anterior third, and the chain, in numerous convolutions, extends backwards; a few mature detached proglottides usually lie at the most posterior part, and these are usually evacuated during defæcation. In exceptional cases single proglottides or whole worms may reach contiguous organs if abnormal communications with them exist, thus they may reach the abdominal cavity and the urinary bladder, or they may be found in a so-called worm abscess of the peritoneum; occasionally, in vomiting, single segments or several together may be brought up.

The cysticercus stage (Cysticercus cellulosa, fig. 136) that gives rise to Trenia solium lives normally in the intramuscular connective tissue and other organs of the domestic pig, but it is known to exist also in a few other mammals, such as the wild boar, the 
sheep, ${ }^{1}$ the stag, dog, cat, brown bear and monkey, as well as in man. The cysticercus of the pig is an elliptical vesicle with a longitudinal diameter of $6-20 \mathrm{~mm}$., and a transverse diameter of 5- $\mathrm{ro} \mathrm{mm}$.

Even with the naked eye a white spot may be observed in the centre of the long equator, this being the invaginated head; it is easy to make it project by pressing on the vesicle, and on examining it under the microscope one can convince oneself that it corresponds with the head of Tania solium.

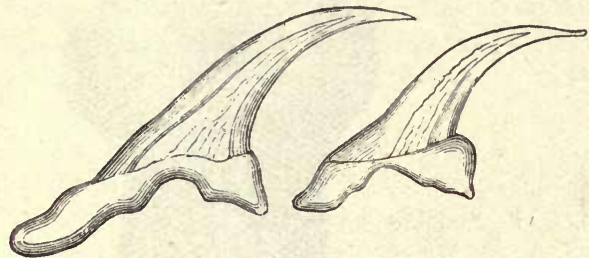

FIG. 163.-Large and small hooks of Tania solium, 280/1. (After Leuckart).

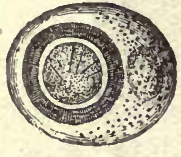

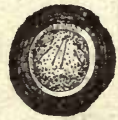

$b$

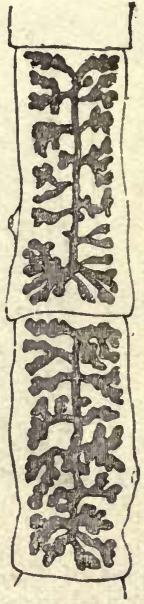

FIG. $165 .-$ Two mature proglottides of $T$, solium with fully developed uterus. $2 / \mathrm{I}$. embryo; the residue of the vitellus within the egg-shell (b) Isolated embryo of $T$. solium within the embryonal shell. $450 / 1$.

Numerous experiments have proved that the Cysticercus cellulosa of the pig, if introduced into the intestine of man, grows to a Trenia solium (Küchenmeister I855, Humbert I856, Leuckart I856, Hollenbach 1859 , Heller $I 876)$; the cysticercus has frequently also been cultivated purposely by feeding pigs with mature proglottides of Trnia solium. (P. J. van Beneden I853, Haubner and Küchenmeister I855, Leuckart I856, Mosler I865, Gerlach I870, \&c.); but success did not attend the efforts to make Cysticercus cellulose settle in the intestine of pigs, dogs, guinea-pigs, rabbits

The cysticerci, which on rare occasions are found in the muscular system of sheep, are either strayed specimens of Cysticercus tenuicollis, which normally develon in organs of the abdominal cavity, and appertain to Tania marginata of the dog, or Cysticercus cellulosa. (Compare Bongert, in Zeitschr.f. Fleisch u. Milchhyg., 1899, ix., p. 86.) 
and monkeys (Macacus cynomolgus), and thus transform them into tæniæ; the attempts, also, to infect dogs with cysticerci were likewise, as a rule, abortive. ${ }^{1}$

The development of Cysticercus cellulose takes two and a half to three or four months; it is not known how long the cysticerci remain alive in animals; not uncommonly they perish at earlier or later stages, and become calcified or caseated. Extracted cysticerci die in water at a temperature of $47-48^{\circ} \mathrm{C}$., in flesh at normal temperature they remain alive for twenty-nine days or more. On account of the present rapid means of pickling and smoking meat the cysticerci as a rule are not killed, but the effect of cold on them for some time is certain death (Ostertag).

There is not the least doubt that human beings are almost exclusively infected with Tania solium by eating pork containing, cysticerci, in a condition that does not endanger the life of the cysticerci. The infection may likewise be caused in man by eating the infected meat of other animals subject to this species of bladder worm, though practically this means of infection only occurs exceptionally in consequence of the rarity of Cysticercus cellulose in the stag, sheep and dog.

Pigs, on the other hand, are much more liable to be affected with cysticerci, but the conditions have considerably improved since the introduction of official inspection of cattle and meat ; in the Kingdom of Prussia there was on an average one infected pig to every 305 slaughtered between I876-1882; from I886-89, there was 1 to $55 \mathrm{I}$; from $1890-92$, there was I to 817 ; in 1896 , I to $\mathrm{I}, 470$, and in 1899 , I to 2,102 ; in the kingdom of Saxony in I894 there was I infected pig to every 636; in I895 there was I to every 2,049 , and in I 896 only I infected pig was found of 5,886 slaughtered. In South Germany pigs with cysticerci are very rare, but are more frequent in the eastern provinces of Prussia; in 1892 the number of infected pigs compared to the total slaughtered were as follows:-

$\begin{array}{llllllll}\text { In the district of Marienwerder } & . & \ldots & \ldots & \ldots & \ldots & \ldots & \text { I : }\end{array}$ $\begin{array}{llllllll}\text { Oppeln } & . . & . . & . & \ldots & \ldots & \text {.. } & \text { I : } 80,\end{array}$ $\begin{array}{llllllll}\text { Königsberg } & \ldots & \ldots & \ldots & \ldots & \ldots & \text { I : } & \text { 108, }\end{array}$ Stralsund and Posen .. $\quad . . \quad \ldots \quad \ldots \quad$ I : 187 , Danzig, Frankfort a. O. and Bromberg ‥ I : 250,

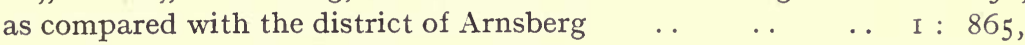

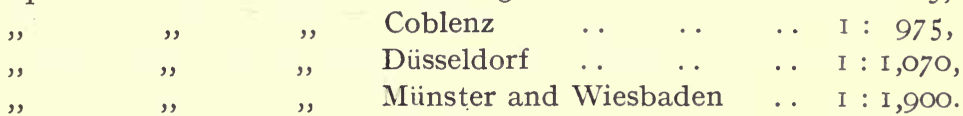

The average for the whole of Prussia in the same year was I:I,290, for the eastern provinces on the other hand, $\mathrm{I}: 604$. The cause for this is most likely attributable to the manner in which the pigs are kept. When

${ }^{1}$ According to Gerlach only young pigs (up to six months old) are capable of infection, and perhaps the failures may have been due to the animals chosen for experiment being of the wrong age. 
allowed to be in the farmyards of the small farmers for the whole day or allowed to wander in the village streets and pasture lands, they are more liable to take up the oncospheres of the Tania solium than when shut up in good pigstyes.

The geographical distribution of Tania solium generally corresponds with that of the domestic pig and the custom of eating pork in any form insufficiently cooked or raw. There are or were some isolated districts in Germany, France, Italy and England where the "Armed tapeworm" was frequent (for instance, Thuringia, Brunswick, Saxony, Hesse, Westphalia, whereas it is and was very scarce in South Germany); it is thus easily understood why it occurs very rarely in the East, in Asia and in Africa, in consequence of the Mahommedans, Jews, \&c., not eating pork. In North America, also, Trenia solium is very rare; the tapeworm which is known there by this name is generally Tania saginata (Stiles). During the last decades tapeworm infection has, however, considerably decreased in North and East Germany in consequence of the precautions exercised by the public in the choice of pork to avoid trichinosis, especially, however, because meat infected with cysticercus must be sold for what it is and must be thoroughly cooked before being placed on the market; indeed, if badly infected it may not be sold for food, but can be turned to account for industrial purposes.

The occurrence of Cysticercus cellulose in man has been known since I558 (Rumler, Obs. med., liii., p. 32); there is hardly an organ in man in which cysticerci have not been observed at some time; they are most frequently found in the brain, ${ }^{1}$ where they grow to a variety known as Cysticercus racemosus; next in frequency they are found in the eye, in the muscular system, in the heart, in the subcutaneous connective tissue, the liver, lungs, abdominal cavity, \&c. The number of cysticerci observed in one man varies between a few and several thousands. Of the sexes, men are most subject $(60$ to 66 per cent. of the number attacked). The disturbances caused in man by cysticerci vary according to the nature or position of the organs attacked; when situated in the cerebral meninges they have the same effect as tumours.

${ }^{1}$ Dressel, for instance, examined 87 persons suffering from cysticercus, and found it seventy-two times in the brain, thirteen times in the muscles; $K$. Müller, in 36 cases, found it twenty-one times in the brain, twelve times in the muscles, three times in the heart; Haugg in 25 cases, found it thirteen times in the brain, six times in the muscles, twice in the skin, \&c. According to Graefe, amongst 1,000 ophthalmic cases in Halle and Berlin, there was one with cysticercus in the eye; in Stuttgart there was only one in 4,000 ; in Paris one in 6,000 , and in Copenhagen one in 8,000 . 
During the last decades, however, these cases have also become less common; thus, according to Virchow, since the introduction of official inspection of meat, the number of cases of cysticercus of the brain has fallen from $I$ in every $3 \mathrm{I}$ post mortems to $I$ in every 280 ; Hirschberg between I869 and I885 discovered cysticerci in the eye seventy times in 60,000 ophthalmic cases, but during the following six years the parasite was only present twice amongst a total of 46,000 cases of ophthalmic diseases.

The infection of human beings with cysticerci can only take place by the introduction of the oncospheres of Trenia solium into the stomach with vegetable foods, salads that have been washed in impure water containing oncospheres, also by drinking contaminated water; the carriers of Trenia solium, moreover, infect themselves still more frequently through uncleanliness in defæcation, the privies in public localities and many private houses contributing to this cause. The minute oncospheres can thus easily reach the fingers and thence the mouth (as in twirling the moustache, biting the nails). More rarely a third manner of transmission or internal auto-infection may possibly take place, as, when in the act of vomiting, mature proglottides near the stomach are drawn into it; the oncospheres or segments there retained are then in the same position as if they had been introduced through the mouth.

On account of these dangers of internal or external auto-infection, it is therefore the duty of the medical attendant, after recognising the presence of tapeworms, to expel them, ${ }^{1}$ and in doing so to employ every possible means to prevent vomiting setting in; it is, however, equally important to take the necessary steps to destroy the parasites evacuated. It may be incidentally mentioned that in using certain remedies the scolex not rarely remains in the intestine; the cure in such cases has not been accomplished, as the scolex again produces new proglottides, and after about eleven weeks the , first formed ones are again mature and appear in the fæces.

Amongst the Cysticerci also many malformations appear; thus absence of the rostellum and the hooks; or double formation with six suckers, or abnormalities of growth on account of the surroundings, and which have had a particular name given to them: Cysticercus racemosus, Zenk. (=C. botryoides, Hell.; C. multilocularis, Küchenm.); these forms are more

${ }^{1}$ The diagnosis as a rule is not difficult; the patients themselves frequently observe the pumpkin-seed-like segments in the fæces. But in such cases the diagnosis must still be confirmed. In other cases the discovery of the oncospheres in their shells, which cannot be confounded with the other constituents of the fæces, gives complete certainty, although the differential diagnosis between $T$. solium and $T$. saginata is hardly possible from the oncospheres; but, if evacuated segments are placed between two slides and lightly pressed, the species is easily recognisable by the shape of the utuers. 
especially found at the base of the brain, are irregularly ramified and often without the head.

A certain interest is attached to those forms that have led to the establishment of a distinct species :

\section{Cysticercus acanthotrias, Weinl., I858.}

In making the autopsy of a white Virginian woman who had died of phthisis, a Cysticercus was found on the dura mater, and eleven or twelve specimens in the muscles and subcutaneous tissue. Weinland ${ }^{1}$ and Leuckart, ${ }^{2}$ who examined the specimens, found that they resembled Cysticercus cellulosa in form and size, but that they carried on the rostellum a triple crown, each consisting of 14 to 16 hooks, which differed from the hooks of Cysticercus cellulose or of Tania solium by the greater length of the posterior root process and the more slender form of the hooks; the large hooks measured O. I 53-0.196 mm., the medium-sized hooks, O.I14-O.14, and the small ones $0.063-0.07$.

On account of these differences a distinct species of cysticercus was established, and this naturally presupposed a corresponding species of Tænia ( $T$. acanthotrias, Lkt.); this could be done with justice as long as the case remained isolated, i.e., in America, as there was the possibility of the resulting tænia being found. In this respect, however, the position has changed; Delore ${ }^{3}$ first described a cysticercus the size of a nut from the biceps muscle of the arm of a silk-worker in Lyons; according to Bertolis this specimen possessed hooks of three different sizes, the dimensions of which corresponded with the figures given by Weinland and Leuckart; the correctness of the diagnosis could hardly be doubted, as Bertolis was known to be a very conscientious observer. A second case has become known through Cobbold ${ }^{4}$ who regards a specimen of a cysticercus in Dallinger's collection, as likewise belonging to Cysticercus acanthotrias; this specimen also came from a man's brain; finally a third case, also from France, has

'Weinland, D. F., “ An Essay of the Tape-worms of Man, illus. with orig. woodc.,' Cambridge, U. S., I 858 ; "System. Catalog. aller Helminthen, die im Menschen gefunden werden" (Arch. f. Naturgesch., 1 859, 25. Jhrg., i., p. 276"; "B.eschreibung zweier neuer Taenioiden aus dem Menschen," \&c. (Non!. Act. Acad. Leop.-Caes, I861, xxviii., with 5 plates.

${ }^{2}$ Leuckart, R., Die mensch. Paras. u. d. v. ihnen herrürh. Krankh., 1863, i., p. 3 IO.

"Delore, X., "Cysticercus acanthotrias observé chez une jeune fille" (Mem. et Compt. rend. soc. sc. méd., Lyon, I863, vol. ii., p. 202).

+Cobbold, T. Sp., "On a rare and remarkable Parasite from the collection of the Rev. W. Dallinger (Rep. Fortieth Meet. Brit. Assoc. Adv. Scienc, I870-7 I, not., p. 135 ). 
been published by Redon. ${ }^{1}$ This author, amongst numerous Cysticerci cellulose of a man, found one that had $4 \mathrm{r}$ hooks in three rows, and he was the first to express the opinion that Cysticercus acanthotrias does not represent a distinct species, but is only an abnormality of Cysticercus cellulose. This view was also taken by Blanchard and Railliet, and is probably correct, as the discovery of the large Tania belonging to it and furnished with three rows of hooks is not to be expected in European beasts of prey, and in Redon's case Cysticercus acanthotrias as well as Cysticercus cellulose occurred simultaneously.

The duration of life of Cysticercus cellulose in man is very long; cysticerci of the eye have been known to persist for twenty years, and in cysticercus of the brain ten to nineteen years may elapse from the first appearance of cerebral symptoms until death. Dead cysticerci may shrivel up or become calcified, perhaps also become fatty-degenerated and then absorbed. Finally, it may be mentioned that if particular proof is required that $C y s t i$ cercus cellulose of man is connected with the cycle of development of the Tania solium, such proof has been furnished by Redon (l.c.).

Note.-Tania tenella, mentioned on p. 214, was ascribed by Cobbold to Cysticerci of the muscular system of sheep. It has, however, been demonstrated that these cysticerci belong to the cycle of development of Tania marginata (dog) (Cyst. tenuicollis, from the omentum of sheep); but, as already stated, Cysticercus cellulosa also occurs in sheep. Chatin himself swallowed the cysticercus, which Cobbold termed Cysticercus ovis. without causing a tænia to develop in his intestine. Müller also vainly sought to induce the colonisation of Cysticercus tenuicollis in his own person. On the other hand, the feeding of a dog with Cysticercus ovi; resulted in the production of Tania marginata.

\section{LITERATURE.}

The most important literature on T cenia solium and Tania saginata :-

Küchenmetster, E. Ueb. Cest. i. Allg. u. die d. Mensch. insbes. Zittau, r853.-

Exper. Nachw., dass Cyst. cellul. sich in Taenia solium umwandelt. (Wien. med.

Wchschr. I 855 , I 856 , No. I, p. 319.-Dtsche. Klinik., I860, xii., p. I87),

Leuckart, R. Die Blasenbandw. u. ihre Entw., Giessen, i 856.

Finnenzust. d. T. medioc. (Gött. Nachr., I862, pp. I 3 and 195).

Thier., Paras. d. Mensch, Ist and 2nd edit.

Haubner. In Mag. f. d. ges., Thierhlkde, I854, xx., pp. 243 and 366; 1855, xxi., p. IOO.

Gerlach, A. C. Fütterungsvers. bei Schweinen mit T. solium. (Jhrsber. Kgl. Thierarzneisch., Hannover, 1869 [1870], ii., pp. 66 and 69.)

'Redon, "Exp. sur le dév. rubanaire de Cyst. de l'homme” (C. R. Ac. sc. Paris, I877, vol. lxxxv., p. 675; Gaz. méd. Paris, $48 \mathrm{e}$ ann., 1877, p. 5 in; Arch. vétér. publ. à l'école d'Alffort, i877, ii., p. 910; Ann. d. sc. nat. Znol., I877 [6]. vi., art. No. 4.) 
Mosler, F. Helm. Stud. u. Beob., Berlin, i 864.

Sommer, F. Bau u. Entw. d. Geschlechtsorg. v. T. medioc. u. T. solium. w. Zool., 1874, xxiv., p. 499.)

LEwin. Cyst. cell. u. sein Vork. i. d. Haut d. Mensch. (Charité-Annal., I877, ii., p. 609; Arch. f. Dermat., 1894, xxvi., pp. 71 and 217.)

Perroncito, E. Esp. s. prod. del Cyst. della T. medic. . . (Ann. R. Acc. agric., Torino, $1877, \mathrm{xx}$; Zeitschr. f. Vet.-Wiss., 1877, v.)

Steudener, F. Unters. üb. d. Bau d. Cest. Halle, I877.

Moniez, R. Ess. monogr. sur les Cyst. (Trav. inst. zool. Lille., I880 [1], iii.); Mém. sur les Cest. (Ibid., I 881 [2], iii.)

ZENKER, F. A. Cyst. racem. d. Gehirns. Bonn., 1882.

Beneden, E. v. Rech. s. le dév. embr. de quelqu. Tén. (Arch. de biol., I88I, ii., p. I83.)

Berenger-Férand, L. J. B. Leç. clin. sur les Ténias de l'homme. Paris, 1888.

Schwarz. Zur Unterscheidung der Cyst. cell. v. C. tenuicollis. (Zeitschr. für Fleisch- und Milchhyg., I 893 , iii., p. 89.)

\section{Tenia marginata, Batsch, I786.}

Syn.: T. e. Cysticerco tenuicolli, Küchenmeister, 1853.

This species, which in structure resembles Tania solium, lives in the intestine of the dog and the wolf. It attains $\mathrm{I}^{\circ} 5-4 \mathrm{~m}$. in length, possesses a double crown of thirty to forty hooks; on an average thirty-

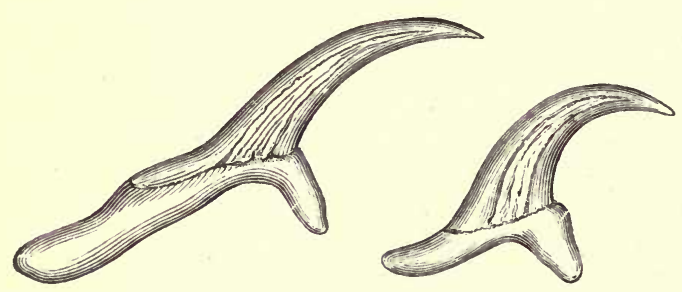

FIr. 166.-Large and small hooklets of Tania marginata. 280/1. (After Leuckart.) six to thirty - eight hooks, and in its cysticercus stage (Cysticercus tenuicollis) lives in monkeys, pigs, sheep and oxen.

It is included in this work because, according to one statement, Cysticercus tenuicollis is supposed to have been observed in $\operatorname{man}^{1}$ in North America. But the case is not quite certain, as the number of hooks was less than in Cystrcercus tenuicollis, and coincided with Cysticercus cellulosa; although the size of the cysticercus] appeared to point to Cysticercus tenuicollis. A yet earlier statement of Eschricht, that $C$. tenuicollis had been observed in Iceland in the liver of a man, is undoubtedly due to an error.

\section{T'ania serrata, Goeze, I782.}

This parasite attains a length of from $0.5-2 \mathrm{~m}$., possesses a double crown of thirty-four to forty-eight (mostly forty) hooks. It lives exclusively in the intestine of the dog, the corresponding cysticercus (Cysticercus pisiformis) living in the abdomen of the hare and rabbit. We mention this species with all reserve amongst the parasites of man, because Vital' ${ }^{2}$ states

'Braun, M., "Helm. Notizen III. Cyst. tenuicollis und C. acanthotrias beim Menschen" (C. f. B. u. P., 1894, xv., p. 409). 285).

2 Vital, A., "Les entozoaires à l'hôpital de Constantine" (Gaz. méd. Paris, 1874, p. 
that he has observed it twice in Constantine (Algeria) in human beings. The descriptions, however, are not sufficiently explanatory to characterise the species. It is highly probable that they relate to Tania solium. Galli Valerio even swallowed five specimens of Cysticercus pisiformis, but without result. ${ }^{1}$

\section{Tania crassicollis, Rud., I8Io.}

I only mention this species from the intestine of the domestic cat because Krabbe regards its occurrence in man as possible. It attains a length of $60 \mathrm{~cm}$. and is armed; its cysticercus (Cysticercus fasciolaris) lives in the liver of mice and rats. In Jutland, according to Krabbe, chopped-up mice (spread upon bread), are eaten raw, being a national remedy for retention of urine, and this custom affords the possibility of the introduction of Cysticercus fasciolaris into the intestine of man (Nord. med. Arkiv., I880, xii.).

\section{Trenia saginata, Goeze, I 782 .}

Syn.: T. solium, L., I767 (pro parte); T. cucurbitina, Pallas, I78I (p. p.); T. inermis, Brera, I802; Moquin-Tandon, I860; T. dentata, Nicolai, I830; T. lata, Pruner, I847; Bothriocephalus tropicus, Schmidtmüller, 1847 ; T. mediocanellata, Küchenmeister, I 855 ; T. zittavensis, Kchmst., I 855 ; T. tropica, Moquin-Tandon, I860; T. (Cystotcenia) mediocanellata, Leuckart, I 863 .

The length of the entire tapeworm averages 4-8-io m. and more, even up to $36 \mathrm{~m}$. According to Bérenger-Feraud it attains a length of $74 \mathrm{~m}$. (?) The head is cubical in shape, $\mathrm{I} \cdot 5-2 \mathrm{~mm}$. in diameter; the suckers are hemispherical $(0.8 \mathrm{~mm}$.$) , and are$ frequently pigmented; there is a sucker-like organ in place of the rostellum, and this also is frequently pigmented. The neck is moderately long and about half the breadth of the head; the proglottides, the number of which arerages more than I,ooo, gradually increase in size; the mature detached segments are shaped exactly like pumpkin-seeds, and are about $16-20 \mathrm{~mm}$. in length and $4-7 \mathrm{~mm}$. in breadth. The genital pores alternate irregularly and are situated somewhat behind the middle of the lateral borcier. There are twenty to thirty-five lateral branches at each side of the median trunk of the uterus, and these again ramify. The eggs are more or less globular, the egg-shell frequently remains intact and carries one or two filaments; the embryonal shell is thick, radially striated, is transparent and oval; it is $0.3-0.04 \mathrm{~mm}$. in length, and $0.02-0.03 \mathrm{~mm}$. in breadth. Several segments simultaneously are usually passed without defæcation. 
Malformations are not uncommon, and resemble those of Trenia solium ; a triangular form has been termed $T$. capensis by Küchenmeister, and $T$. lophosoma by Cobbold, names that naturally possess as little value as does the term $T$. fenestrata for fenestrated specimens. Moreover, $T$. solium, var abietina, Weinl., I858, which was evacuated by an Indian, was probably a $T$. saginata, with somewhat close uterine branches.

Tania saginata in its adult condition lives exclusively in the intestinal canal of man. ${ }^{1}$ The corresponding cysticercus is called Cysticercus bovis, and is found almost exclusively in the ox; it is small, $7.5-9 \mathrm{~mm}$. in length, and $5.5 \mathrm{~mm}$. in breadth, may easily escape notice and requires from three to six months for its

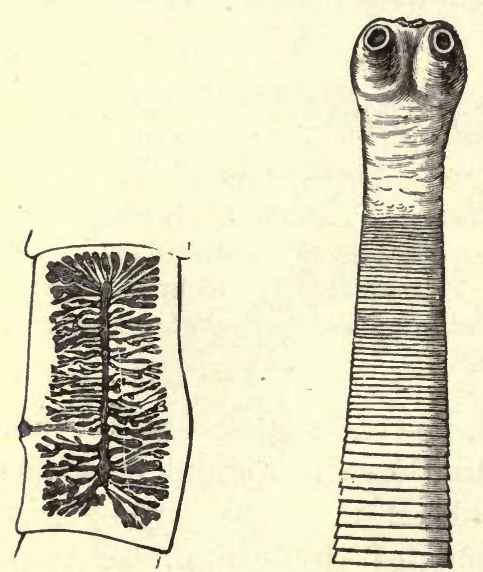

FIG. 167. - Mature segment of Tania saginata, G., with distended uterus. $2 / 1$.
FIG. 168.-Cephalic end of Tania saginata in the contracted condition. $8 / 1$. development. Numerous experiments have confirmed the connection of Cysticercus bovis with Tania saginata; indeed, the cysticercus was only discovered by feeding experiments after attention had been called to the ox as the probable intermediary host of this Trenia.

Medical men observed that weakly children, who were ordered to eat raw scraped beef to strengthen them, contracted Tania saginata. It was found, moreover, that Jews, who are prohibited from eating pork from religious motives, suffered especially from $T$. saginata; when $T$. solium was found to occur in a Jew he often confessed to having eaten pork; and finally it was found that certain nations-for instance, the Abyssiniansfrequently harbour $T$. saginata, and only eat beef-raw by preference.

These observations led Leuckart in I86I to feed young calves with the proglottides of $T$. saginata in order to discover the corresponding cysticercus, which was then not known. This experiment was successful. Similar experiments, with similar results, were then conducted by Mosler (1863), Cobbold and Simonds (1864 and I872), Röll (1865), Gerlach (1870), Zürn (1872), Saint Cyr, Jolicœur (1873), Masse and Pourquier (i876), and Perroncito, in 1876 . The attempts to infect goats, sheep, dogs, pigs, rabbits and monkeys were unsuccessful. Only Zenker and Heller were able to infect kids, and Heller infected one sheep, but these are exceptions.

I Abnormal migrations of this species have also been known. Compare, anongst others, Stieda, A., "Durchbohr. d. Duod. ". d. Pancreas durch eine Taenia" (C. f. B., P. U. I., I900, xxviii. [I], p. 430). 
Artificial infections of human beings with Cysticercus bovis

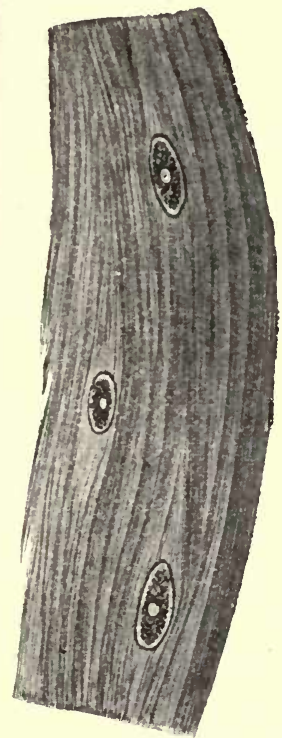

FIG. 169. - A piece of the muscle of the ox, with three specimens of Cysticercus bovis, natural size.

(After Ostertag.) to obtain the tapeworm were less numerous and indeed quite superfluous, yet this was also done by Oliver (1869) in India, and Perroncito (1877) in Italy. The experiments of the latter prove that the extracted cysticerci of the ox certainly perish in water at $47-48^{\circ} \mathrm{C}$.

It is a remarkable circumstance that, at least as regards Central Europe, Cysticercus bovis in the ox, after natural infection, was so seldom found, that almost every case was published as a rarity; whereas the tænia is very frequent in man. The reason for this is, that in Germany cattle are not severely infected, and that the small, easilydried-up cysticerci easily escape notice in the large body of the host. Hertwig, the late director of the town cattle market in Berlin, in 1888 , pointed out that the cysticercus of the bx is found chiefly in the musculi pteryogoidei externi and interni, and since that time a far greater number of infected oxen have been found in Berlin.

Since 1892 an increase has taken place in the number of oxen infected with cysticercus, but this is probably attributable to the more general

\begin{tabular}{|c|c|c|c|}
\hline Year & $\begin{array}{l}\text { Number of Oxen } \\
\text { Slaughtered }\end{array}$ & Infected & Proportion \\
\hline I $888-89$ & I 4 I, 8 I 4 & I I 3 & I : I, I 25 \\
\hline I $889-90$ & I 54,2 I 8 & 390 & I : 395 \\
\hline I $890-9 I$ & I 24,593 & 263 & 474 \\
\hline $1891-92$ & I 36,368 & 252 & I : $\quad 54 \mathrm{I}$ \\
\hline I $892-93$ & I 42,874 & $2 \mathrm{I} 4$ & I : 672 \\
\hline
\end{tabular}

and searching examinations. In the slaughter-houses of Prussia the number of infected beasts was as follows :-

$\begin{array}{rrr}1892 & . & 567 \\ 1893 & \ldots & 686 \\ 1894 & \ldots & 748 \\ 1895 & \ldots & \text { I } 143 \\ 1896 & \ldots & 1,918 \\ . \quad 1897 & . & 2,629\end{array}$

The condition was most frequent in Neisse (3.2-4 per cent.), Eisenach ( $1 \cdot 9 \mathrm{r}$ per cent.), Ohlau ( $1^{\circ} 57$ per cent.), Oels i. Schles ( 1 per cent.), Marienwerder $\left(0^{*} 34-I^{\prime} 2\right.$ per cent.). The flesh of oxen only slightly infected (containing not more than ten living cysticerci) is sold in pieces of not more than $5 \mathrm{lbs}$. to 
consumers after having been rendered innocuous by cooking, or by pickling for twenty-one days in 25 per cent. salt brine, or hanging for twenty-one days in suitable refrigerators; oxen in which only one cysticercus is found are allowed free commerce, and those strongly infected (i.e., containing more than ten living cysticerci) may only be used for industrial purposes.

The cysticercus of the ox has hitherto been found in man on very rare occasions. Arndt (Zeitschr. f. Psych., xxiv.) mentions a case in the brain, Heller in the eye, and Nabiers and Dubreith also in the brain. (Journ. méd. Bordeaux, I889-9o, p. 209); but the diagnoses are not quite certain, as absence of hooks also occasionally occurs in Cysticercus cellulosa.

Tania saginata is the most frequent tapeworm of man (with the exception of Dibothriocephalus latus in a few districts), and the parasite is widely distributed over the surface of the globe ; it has been known in the east for ages; according to accounts received, it is frequent in Africa, America and Europe. Its frequency has perceptibly increased during the last few years, but a decrease should soon take place in consequence of the extent and improvement of the official inspection of meat.

The following table shows the relative frequency of the cestodes of man :--

\begin{tabular}{|c|c|c|c|c|c|c|c|c|}
\hline Author & & Year & $\begin{array}{l}\text { Number of } \\
\text { Cases }\end{array}$ & T. saginata & $\begin{array}{l}\text { T. so. } \\
\text { lium }\end{array}$ & $\begin{array}{l}\text { Dibr. } \\
\text { latus }\end{array}$ & $\begin{array}{l}\text { Dipy-1 } \\
\text { canin. }\end{array}$ & $\begin{array}{c}U_{n-} \\
\text { decided }\end{array}$ \\
\hline Parona (Milan) .. & . & I 899 & I 50 & I 2 I & I I & 4 & - & I 4 \\
\hline Parona (Italy) .. & . & I $868-99$ & 5 I 3 & 397 & $7 \mathrm{I}$ & 26 & - & 19 \\
\hline Krabbe (Denmark) & . & I 869 & 100 & 37 & 53 & 9 & I & - \\
\hline , $\quad \quad, \quad \ldots$ & . & I $869-86$ & 200 & I 53 & 24 & I6 & 8 & - \\
\hline , $\quad, \quad \ldots$ & . & I $887-95$ & 100 & 89 & - & 5 & 6 & - \\
\hline Blanchard (Paris) & . & I 895 & ? & 1000 & $2 \mathrm{I}$ & - & - & - \\
\hline Stiles (United States) & . & I 895 & $\begin{array}{c}\text { more than } \\
300\end{array}$ & $\begin{array}{c}\text { more than } \\
300\end{array}$ & - & 3 & - & - \\
\hline Schoch (Switzerland) & . & I 869 & I9 & I6 & I & 2 & - & - \\
\hline Zaeslein (Switzerland) & .. & I 88 I & $?$ & I 80 & I9 & $?$ & - & - \\
\hline Kessler (St. Petersburg & & I 888 & ? & 22 & 16 & 47 & - & - \\
\hline Mosler (Greifswa]d) & . & I 894 & $\mathrm{I} \dot{8} \mathrm{I}$ & I I 2 & 64 & 5 & - & - \\
\hline Bollinger (Munich) & .. & I 885 & 25 & I6 & $I$ & 8 & - & - \\
\hline
\end{tabular}

\section{Tania africana, v. Lstw., I900.}

This worm measures over $\mathrm{I} \cdot 3 \mathrm{~m}$. in length. The segments are all broader than they are long. The'scolex is unarmed and is provided with an apical sucker (0.16 mm.). The parasite measures $\mathrm{I} \cdot 38 \mathrm{~mm}$. in breadth, $\mathrm{I} \cdot 03 \mathrm{~mm}$. in width; the suckers measure $0.63 \mathrm{~mm}$. in diameter. The neck is very short and somewhat 
broader than the scolex; number of segments about 600 ; the hindmost segments measure $7 \mathrm{~mm}$. in length and $\mathrm{I} 2-\mathrm{I} 5 \mathrm{~mm}$. in breadth. The genital pores alternate irregularly in the middle of the border

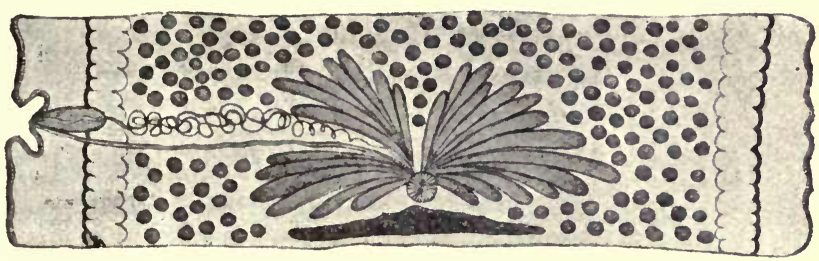

FIG. I70.-Nearly mature segment of Tania africana, magnified. (After v. Linstow.) The ovary is in the middle, and behind it are the shell-gland and vitellogene gland; at the sides are the testicular vesicles, and the excretory canals pass to the exterior: the cirrus pouch, the vas deferens and the vagina are on the left.

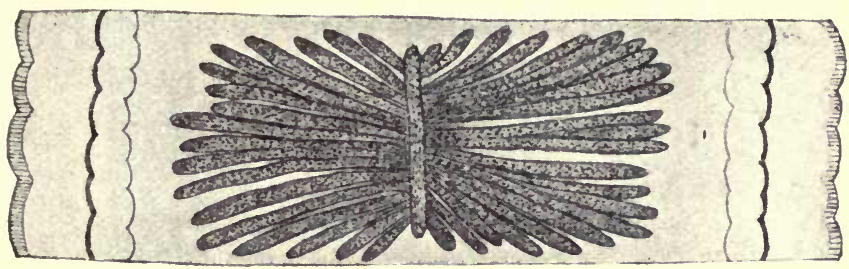

Fig. I7r.-Proglottis of Tania africana, with uterus, magnified. (After v. Linstow.)

of the segments; the testes are very numerous and occupy the entire medullary layer; the vas deferens is much convoluted; the

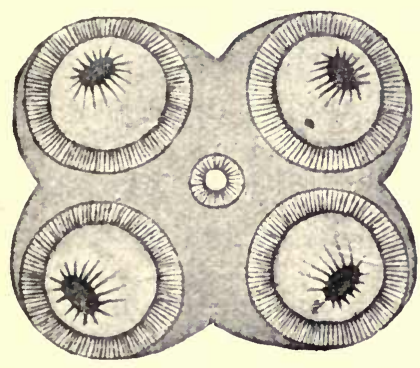

FIG. I72. - Head of Tania africana; apical surface; magnified. (After v. Linstow.) cirrus pouch is pyriform and thick walled; the cirrus and vagina are beset with bristles directed outwards; the receptaculum seminis is fusiform; the ovary is large and double, and consists of radially placed club-shaped tubes that do not anastomose and do not branch; the vitellogene gland is at the posterior border of the proglottides, the round shellgland in front of it; the uterus consists of a median trunk and fifteen to twentyfour non-ramified lateral branches on each side; the embryonal shell is thick and has radial stripes-it may be round $(0.03 \mathrm{I} 2-0.0338 \mathrm{~mm}$.) or oval (0.0390-0.0338 $\mathrm{mm}$.) ; the hooklets of the oncospheres measure $\cdot 0078 \mathrm{~mm}$. in length (fig. I3I, $a$ ). 
At present only two specimens are known; they came from a black soldier from the vicinity of Lake Nyassa. The cysticercus is unknown; perhaps it lives in the zebu, the flesh of which the Askáris are in the habit of devouring uncooked. ${ }^{1}$

\section{Tania confusa, Ward, I896.}

Length $8.5 \mathrm{~m}$., breadth about $5 \mathrm{~mm}$. The scolex is unknown; there is no neck; number of proglottides 700 to 800 , always longer than they are broad; the hindmost measure $35 \mathrm{~mm}$. in length, 4-5 $\mathrm{mm}$. in breadth; the genital pores alternate irregularly behind

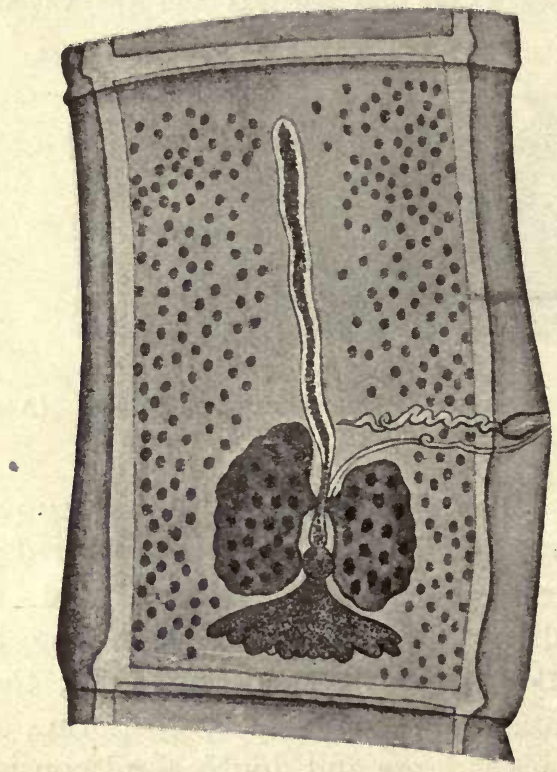

FIG. I73. - Tania confusa; fairly mature segment. I 5/1. (After Guyer.)

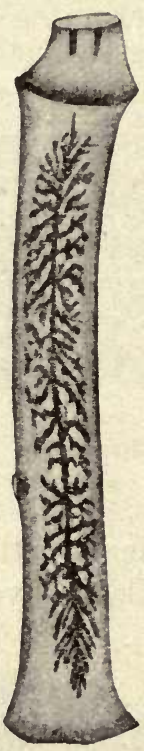

Fig. 174. - Tania confusa. Mature segment. 25/1. (After Ward.)

the middle of the lateral border; testicular vesicles numerous; vas deferens not much coiled; the cirrus pouch thick-walled, elongated and club-shaped, with globular vesicula seminalis; the cirrus is beset with little hairs; the receptaculum seminis is globular; ovary small, double; each half is bean-shaped;

'v. Linstow, "Tania africana, eine neue Tania d. Menschen aus Afrika (C. f. B., P. u. I., 1900 [1], xxviii., p. 485); "Helm. v. Ufer d. Nyassasees (Jen. Zeitschr. f. Naturw., I900, xxxv., p. 420). 
vitellogene gland narrow, triangular; shell-gland globular; uterus with median trunk and fourteen to eighteen short ramified lateral branches on either side. The oncospheres, which have shells, are oval $(0.039-0.30 \mathrm{~mm}$.) ; the shell is thick and radially striated.

Of this species only two specimens have been recorded; they occurred in human beings and were sent at different times to the first describer of them by a doctor in Lincoln (Nebr.). Perhaps Tania solium, var. abietina, Weinld., which was found in a Chipeway Indian, is of the same species in spite of the shorter segments.

\section{LITERATURE.}

Ward, H. B. Rep. of the Zoologist. (Ann. rep. Nebraska State Board Agric. f., I $895-6$, p. 257 ; ibid., f. I 896-7, p. I73.)

A New Hum. Tape-worm. (West. Med. Rev., I896, i., p. 35 ; Proc. Nebr. State Med. f., I896, p. 83.)

Note on T. confusa. (Zoolog. Anzeiger, I897, xx., p. 321.)

Guyer, M. F. On the Struct. of T. confusa. (Zoolog. Jahrb., Part f. Syst., I 898 , xi.)

\section{Tania echinococcus, v. Sieb., 1853 .}

Syn. : Tania nana, v. Ben., I86I (nec. v. Sieb., I853).-Echinococcifer echinococcus, Weinl., I861.

Tania echinococcus measures 2.5 to 5 or $6 \mathrm{~mm}$. in length; the head is $0.3 \mathrm{~mm}$. in breadth, and has a double row of twentyeight to fifty hooklets on the rostellum.

The size and form of these hooklets vary (the larger ones are $0.040-0.045 \mathrm{~mm}$. in length, the smaller ones are $0^{\circ} 030-0.038$ $\mathrm{mm}$. in length). The suckers measure $0^{\circ} \mathrm{I} 3 \mathrm{~mm}$. in diameter; the neck is short; there are only three or four segments, the posterior segment being about $2 \mathrm{~mm}$. in length and $0.6 \mathrm{~mm}$. in breadth. The genital pores alternate; there are forty to fifty testicular vesicles; the vas deferens is spirally coiled; the cirrus pouch is pyriform. The ovary is horseshoe-shaped with the concavity directed backwards; the vitellogene gland double, each half almost bean-shaped, at right angles to the level of the segment; the shell-gland is round. The median trunk of the uterus is dilated when filled with eggs and (instead of lateral branches) has lateral protuberances. It is not unusual for the eggs to form local heaps. The embryonal shell is moderately thin, with radiating fibres, almost globular, $0^{\circ} 030-0.036 \mathrm{~mm}$. in diameter.

When mature this parasite lives in the small intestine of the 
domestic dog, the jackal, and the wolf, and is usually present in great numbers. ${ }^{1} \quad$ The cysticercus stage (Echinococcus polymorphus)

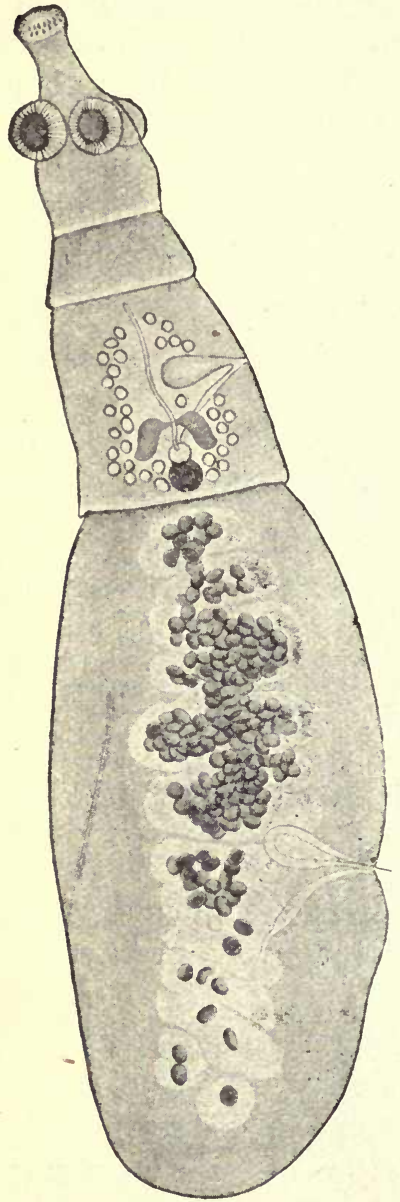

FIG. I75. - Tania echinococcus. 50/1. The cirrus pouch, the vagina, uterus, ovary, shell-gland and vitellogene gland, and the testicular vesicles at the sides are recognisable in the second proglottis ; the posterior proglottis shows the uterus partly filled with eggs, as well as the cirrus pouch and the vagina. lives in various organs - chiefly in the liver and lungs - of numerous species of mammals (twenty-seven), especially in the sheep, ox and pig, and it is even not uncommon in man, though the tænia itself has never been found in a human being; accordingly man can only acquire the Echinococcus by ingesting the oncospheres of the "dog worm." The dogs disseminate the oncospheres of $T$. echinococcus wherever they go, or carry them to their mouths and coats by biting up the evacuated segments, and are thus able to transmit them directly to human beings (by licking them or making use of the same crockery, \&c.). In other cases the oncospheres, which are enclosed in a shell, must withstand desiccation for a time and then (as when the dogs are "kissed" or otherwise caressed) are transmitted into or on to man. As echinococcus disease - in man is always very dangerous, it would be a matter of general interest to prevent dogs being infected by destroying the echinococci, ${ }^{2}$ and all measures would be justifiable which would diminish the superfluous number of house-dogs (for instance, high taxes); measures should also be adopted to limit the association of men with dogs, particularly in such frequented places as restaurants, railway carriages and tramcars.

In Iceland 28 per cent. of the dogs are infected with this tænia, in Lyons $7 \cdot 1$ per cent., in Zurich 3.9 per cent., in Berlin I per cent., and in Copenhagen 0.4 per cent. In Australia even 40-50 per cent. of the dogs are affected. It is, however, a question whether, in addition to $T$. echinococcus, a second analogous form is not involved; as the form from Canis dingo attains a length of $10-30 \mathrm{~mm}$.

${ }^{2}$ Mosler, F., "Ueb. Mittel z. Bekämpfg. endem. vork. Echinococcuskrankh." (Dtsche. Medic.-Ztg., I889, No. 72). 
Echinococcus is very common in slaughtered animals; in Germany, however, the figures in the reports of the abattoirs present an erroneous view in so far as, besides the total number of animals slaughtered, only the numbers of those organs (liver and lungs) are published that were so severely infected with echinococci that, even when the parasites were cut out, the flesh could not be placed upon the market and was therefore "condemned."

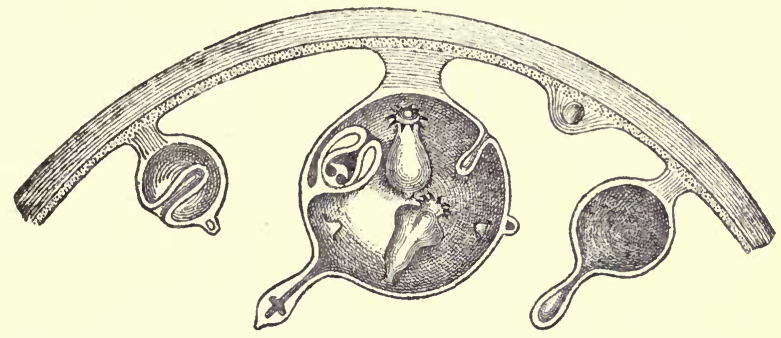

Fig. I76.-Section through an Echinococcus cyst with brood capsules. (From a wax model.)

In Berlin the following animals were slaughtered :-

\begin{tabular}{|c|c|c|c|c|c|c|c|}
\hline \multicolumn{2}{|c|}{ Year } & I 888.89 & I 889.90 & I $890 \cdot 91$ & $189 \mathrm{r}-92$ & I 892.93 & $1896-97$ \\
\hline Oxen & . & $\mathrm{I}_{4} \mathrm{I}, 8 \mathrm{I} 4$ & I 54,2 I 8 & I 24,593 & I 36,368 & I 42,874 & 146,6 I 2 \\
\hline Sheep & . & 338,798 & 430,362 & 371,943 & 367,933 & 355,949 & 395,769 \\
\hline Pigs & . & 479, I 24 & 442 , I I 5 & 472,859 & $530,55 \mathrm{I}$ & 518,073 & 694,170 \\
\hline
\end{tabular}

During the same years the following were condemned in consequence of being infected with Echinococci :-

\begin{tabular}{|c|c|c|c|c|c|c|c|c|c|c|c|c|c|}
\hline & & Lung & Liver & Lung & Lirer & Lung & Liver & Lung & Liver & Lung & Liver & Jung & Liver \\
\hline Oxen & & 6,578 & 2,668 & 7,266 & $2,4 \times 8$ & & I,938 & & & 2,563 & 739 & 3,284 & I , I 56 \\
\hline Sheep & & 5,041 & 3,363 & 5,479 & 2,742 & 4,595 & 2,059 & 4,435 & 1,669 & $3,33 \mathrm{I}$ & $\mathrm{I}, \mathrm{I} 6 \mathrm{I}$ & $4,56 \mathrm{I}$ & I,939 \\
\hline Pigs & & 5,910 & 5,285 & 6,523 & 5,078 & 5,083 & 3,735 & 6,037 & 4,374 & 6,785 & 4,3 I 2 & 7.888 & 5,398 \\
\hline
\end{tabular}

Nevertheless there are statistics that give the total number of animals infected with Echinococcus :-

\begin{tabular}{|c|c|c|c|c|c|}
\hline Author & & Place & Oxen & Sheep & Pigs \\
\hline $\begin{array}{l}\text { Längrich } \\
\text { Olt . . } \\
\text { Steuding } \\
\text { Prettner }\end{array}$ & $\begin{array}{l}\cdots \\
\cdots \\
\cdots \\
\cdots\end{array}$ & $\begin{array}{ll}\text { Rostock i. M. } \\
\text { Stettin } & \ldots \\
\text { Gotha } & \ldots \\
\text { Prague } & \ldots\end{array}$ & $\begin{array}{r}26 \cdot 2 \% \\
7 \cdot 10 \% \\
24 \cdot 6 \% \\
23 \cdot 2 \%\end{array}$ & $\begin{array}{l}37.0 \% \\
25.8 \% \\
35.4 \% \\
5.5 \%\end{array}$ & $\begin{array}{r}5 \cdot 4 \% \\
7 \cdot 3 \% \\
21 \cdot 4 \% \\
?\end{array}$ \\
\hline
\end{tabular}

In Güstrow, in Mecklenburg, half of the animals slaughtered are said to be infected with Echinococcus; in Wismar 25 per cent. of the oxen, I 5 per cent. of the sheep and 5 per cent. of the pigs are infected; according to Mayer, in Leipzig, 3.79 per cent. native pigs, $24^{\circ} 47$ per cent. Hun- 
garian pigs, and I 3.09 per cent. of sheep were infected with Echinococcus; at the same time it was stated that in regard to the native pigs the liver was more frequently affected than the lungs $(3.8 \mathrm{I}$ per cent. as compared with 0.26 per cent.); in sheep the lungs were more frequently infected (I 2.7 I per cent. to 3.73 per cent.), whereas in the Hungarian pigs both organs were almost equally infected ( 14.78 per cent. to $12^{\circ} \mathrm{O} 3$ per cent.).

\section{Structure and Development of Echinococcus (CASEWORM).}

Echinococcus is represented by a spherical or roundish bladder full of a watery liquid which originates from the oncosphere, and in man may attain the size of a child's head, but remains smaller

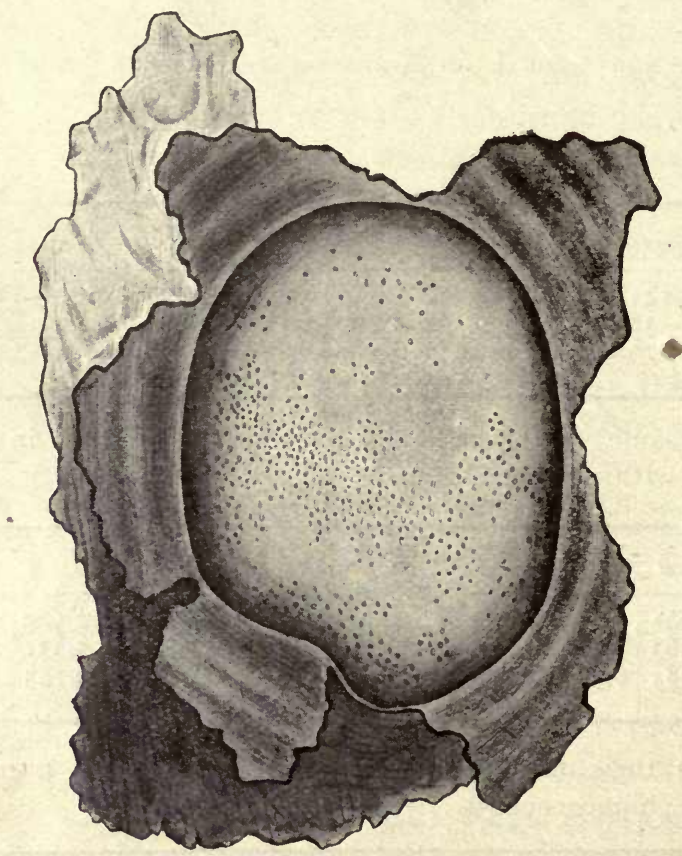

1. Fig. 177.-Echinococcus veterinorum, natural size. The fibrous sac enclosing the Echinococcus has been opened and laid back in five parts, so that the surface of the bladder-worm may be seen with the brood capsules showing through it. (After Leuckart.)

in cattle (the size of an orange or apple). The thin wall of the bladder is composed of an external stratified cuticle, and an internal germinal or parenchymatous layer (endocyst): The latter again exhibits two layers; an outer layer of small cells that are not very distinct, and an inner layer of larger cells. It con- 
tains, in addition, calcareous corpuscles, muscular fibres and excretory vessels.

The development in cattle often remains stationary at this stage, and they are then called "acephalocysts" or echinococcus cysticus sterilis. In other cases large numbers of small, hollow "brood capsules" are formed within the internal space, but are not arranged in any particular order. The order of the layers is just the reverse in them to what it is in the parent cyst, that is to say, they are clad inside by a thin cuticle and carry the parenchymatous layer on their external surface. Scolices (fig. I76) form, internally or

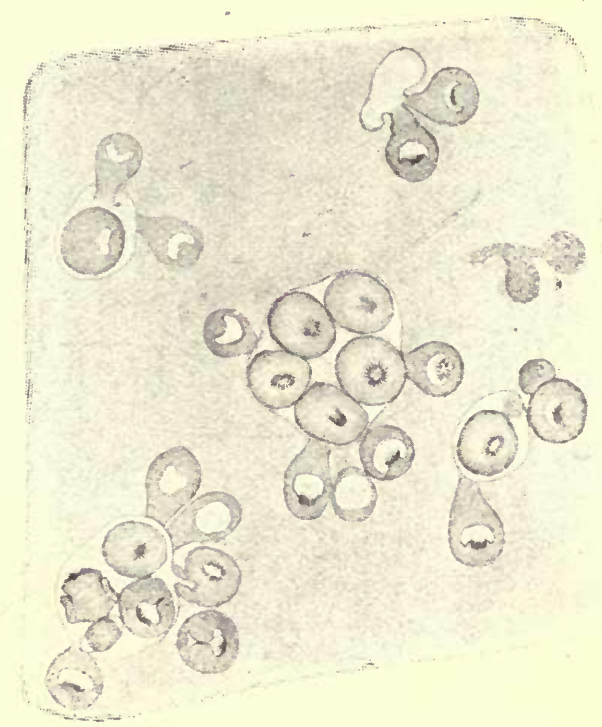

Fig. 178.-A piece of the wall of an Echinococcus veterinorum stretched out and seen from the internal surface. 50/I. A few brood capsules with scolices directed towards the interior and exterior.

externally, their number being variable (three to twenty or even more) ${ }^{1} \quad$ This form occurs chiefly in domesticated animals and is termed Echinococcus veterinorum, Rud., or Echinococcus cysticus fertilis.

In man, and only rarely in cattle, the mother cyst first forms "daughter cysts" (Echinococcus hominis, Rud., fig. I79), which, though smaller than the "mother cyst," resemble it in the structure of their walls; thus they are covered externally by a stratified

'Goldschmidt, R., “Z. Entw. d. Echinococcusköptchen" (Zool. Jahrb. Anat., I900, part xiii., p. 467 ). 
cuticle and internally by the parenchymatous layer. They originate between the strata of the cuticle of the mother cyst from small, detached portions of its parenchymatous layer; during their growth they bulge inwardly or outwardly and may separate themselves entirely from their parent cyst. 'In the latter case they lie between the mother cyst and the capsule of connective tissue formed by the host (Ech. granulosus or Ech. nydatidosus exogenus); when growing inwardly they reach the interior of the mother cyst (Ech. hydatidosus endogenus). Their number is very variable and does not depend on the size of the mother cyst.

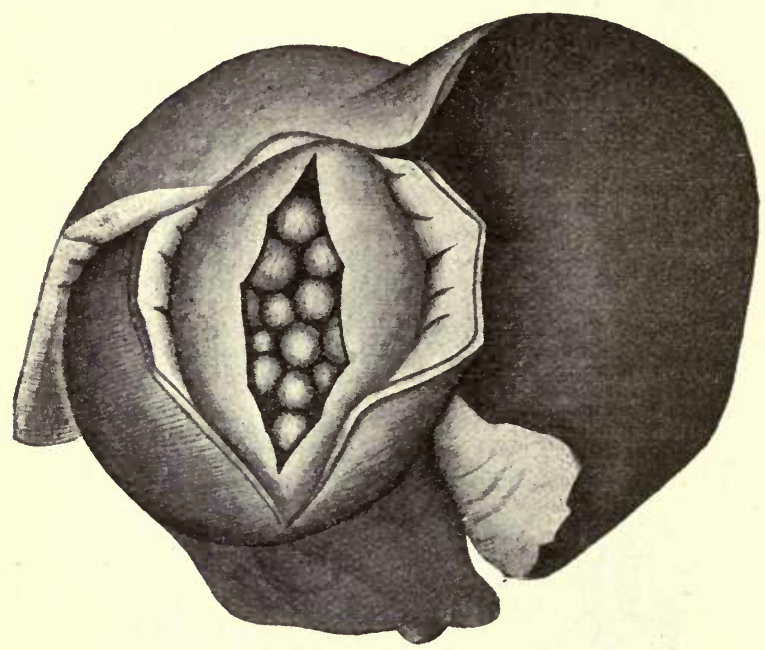

FIG. I79.-Echinococcus hominis in the liver, reduced. The fibrous capsule and the wall of the echinococcus have been incised, so that the daughter cysts may be seen. (After Ostertag, from Thoma.)

The endogenous "daughter cysts" are attributed by some authors to transformed brood capsules and to scolices that have fallen off the mother cyst. However feasible this theory sounds, there can be no doubt that the views of the less recent observers are correct. Sterile mother cysts, however, also occasionally contain daughter cysts, and these Naunyn considers to arise from parts of the wall of the mother cyst, constricted off.

The "daughter cysts" may be constituted like the "mother cysts," that is to say, they may remain sterile, or may produce brood capsules, or again other cysts, which are called "granddaughter cysts." The mother cyst may perish, so that the cysts then lie in the internal space of the connective tissue capsule. 
The echinococcus fluid, which originally is formed from the blood of the host, is light yellow, with a neutral or slightly acid reaction; its specific gravity averages 10,09 to 10,15 . It contains about ${ }^{\circ} 5$ per cent. of inorganic salts, half of which is common salt; in addition (besides water) it contains sugar, inosite, leucine, tyrosin, succinic acid (associated with lime or soda) and albumens which are not coagulated by warmth; occasionally also the fluid has been found to contain hæmatoidine and uric acid salts (in echinococcus of the kidneys), which doubtless demonstrates that the echinococcus liquid originates from the host; finally, there is present a substance with toxic properties (leucomaine) which, if introduced into the abdominal cavity, causes peritonitis, which, as a rule, has a fatal termination.'

According to the researches of Leuckart, the growth of the echinococcus is very slow; four weeks after infection the average size is only $0.25-0.35 \mathrm{~mm}$., at the age of eight weeks it is $\mathrm{I}-2.5 \mathrm{~mm}$., and at this period the formation of the central cavity commences; at the age of five months and with a size of $\mathrm{I}_{5}-20 \mathrm{~mm}$. the first brood capsules with scolices are formed. The consequence of this gradual increase of size is that the organ attacked can maintain its functions by vicarious hypertrophy, and that many echinococci induce no special symptoms and cannot even be diagnosed, the latter circumstance being due to their hidden position.

The Echinococcus cannot be said to be scarce in man, as is shown by the following table for Central Europe :-

\begin{tabular}{|c|c|c|c|c|c|c|c|c|}
\hline \multicolumn{5}{|c|}{ Place } & \multirow{2}{*}{$\frac{\text { Period }}{\text { I } 861-83}$} & \multirow{2}{*}{$\frac{\begin{array}{c}\text { No: of } \\
\text { Sections }\end{array}}{1,026}$} & \multirow{2}{*}{$\begin{array}{l}\begin{array}{l}\text { No. of cases } \\
\text { of Ech. }\end{array} \\
25\end{array}$} & \multirow{2}{*}{$\frac{\text { Percentage }}{2 \cdot 43}$} \\
\hline Rostock & . & $\ldots$ & $\ldots$ & .. & & & & \\
\hline Greifswald & . & . & . & . & I $862-93$ & 3,429 & $5^{I}$ & I. 48 \\
\hline Jena ... & $\ldots$ & $\ldots$ & .. & $\ldots$ & $1866-87$ & 4,998 & 42 & 0.84 \\
\hline Breslau & . & . & .. & .. & $1866-76$ & 5,128 & 39 & 0.761 \\
\hline Berlin & . & . & . & . & $1859-68$ & 4,770 & 33 & 0.69 \\
\hline Würzburg & $\ldots$ & .. & .. & .. & - & 2,280 & I I & 0.48 \\
\hline Göttingen & $\ldots$ & .. & .. & . & - & 639 & 3 & 0.469 \\
\hline Dresden & $\ldots$ & .. & .. & $\ldots$ & $1852-62$ & 1,939 & 7 & $0 \cdot 36$ \\
\hline Münich & . & . & .. & .. & $1854-87$ & 14,183 & 35 & 0.25 \\
\hline Vienna & .. & .. & .. & .. & 1860 & $\mathrm{I}, 229$ & 3 & 0.24 \\
\hline Prague & .. & .. & .. & . & - & 1,287 & 3 & 0.23 \\
\hline Kiel & $\ldots$ & $\ldots$ & $\ldots$ & $\ldots$ & $1872-87$ & $3,58 \mathrm{I}$ & 7 & 0.19 \\
\hline Zürich, Basle & e, Bern & & .. & .. & - & 7,982 & 31 & O.I 3 \\
\hline Erlangen & . & . & . & . & $1862-73$ & 1,755 & 2 & OP. I I \\
\hline
\end{tabular}

These, however, are only cases that have become known by post mortem; in addition there are cases that have been treated medically, of which there are a few statements, at all events

'Drago, U., Ric. sull' azione di alc. lig. idatid. e significato biol. dei medesmi Rassegna internaz. d. Med. mod., 1900, i., No. 16, and other authors. 
relating to the principal districts of Germany. According to Madelung, one case of echinococcus occurs to every $\mathrm{I}, 0.56$ inhabitants in the town of Rostock, in the district of Rostock one to every $\mathrm{I}, 283$, in Schwerin one to every 5,887, and in Ludwigsort one to every 23,685; according to Peiper (in Up er Pomerania), one case occurs to every 3,336, in the district of Greifswald one to every I,535 inhabitants. The northern districts of Pomerania are more affected than the southern ones.

Accordingly, Echinococcus is also considerably more frequent in cattle. On an average in Germany $10^{\circ} 39$ per cent. oxen, 9.83 per cent. sheep, and 6.47 per cent. pigs are infected, whereas in Upper Pomerania $37^{\circ} 73$ per cent. oxen, $27^{\circ} \mathrm{I}$ per cent. sheep and $\mathrm{I} 2.8$ per cent. pigs are infected; in Griefswald, indeed, $64^{.58}$ per cent. oxen, $55^{\circ} \mathrm{O} 2$ per cent. sheep, but only 4.93 per cent. pigs are infected; in accordance with these figures Tania echinococcus must be frequent in dogs in Pomerania, especially in Upper Pomerania; on the other hand, the conjecture that the frequency of Echinococcus in Mecklenburg is explained by the occurrence of Tania echinococcus in foxes has not been confirmed.

Beyond the European Continent, Echinococcus is frequent in the inhabitants of Iceland as well as in those of Australia. In Iceland, according to Finsen, one person is affected with Echinococcus to every forty-three inhabitants; according to Jonassen the proportion is $I: 63$; this is due either to the habits of the people of Iceland or to the frequency of Tania echinococcus in dogs, and the prevalence of the "bladder-worm" in cattle. In certain districts of Australia it is just as frequent. In Cape Colony, Egypt and Algeria Echinococcus is not rare, but it is scarce in America and in Asia, with the exception of the Nomadic tribes by Lake Baikal.

Echinococcus attacks persons of every age, though it is rare in children up to ten years of age and in old people. It occurs most frequently between the ages of $2 \mathrm{I}$ and 40 years. According to all statistics it preponderates in women (about two-thirds of the cases). The liver is its favourite seat (50 to 69 per cent. of the cases) ; next. in order come the kidneys, lungs, cranial cavity, genitalia, organs of circulation, spleen, \&c. As a rule one organ only is invaded; multiple occurrence may originate from one infection, or eventually from a later infection, or it may come to pass that from some cause (through the spontaneous rupture of an echinococcus, or the rupture of one caused by an injury or surgical operation) daughter cysts, brood capsules or scolices escape 
into the abdominal cavity, ${ }^{1}$ where they may colonise or become transformed and go on growing. This possibility, suggested by clinical observations, was first experimentally confirmed by Lebedeff and Andrejew by the transplantation of echinococcus cysts of man into the abdominal cavity of rabbits; though all the subsequent experimenters in this direction did not obtain positive results yet there are a sufficient number of successes (Stadnitzky, Alexinsky, Riemann).

The echinococci may die off at various stages of development, become caseous or calcified, or may be absorbed, the cause for this being either disease of the bladder-worm itself or inflammation of its connectivetissue capsule; the discovery of the stratified cuticle, which has great powers of resistance, or the finding of the hooklets of the scolices are sufficient to form a conclusion as to the nature of such formations.

Siebold (1853) was the first to rear Tania echinococcus in the dog by feeding it with the Echinococci of cattle and especially

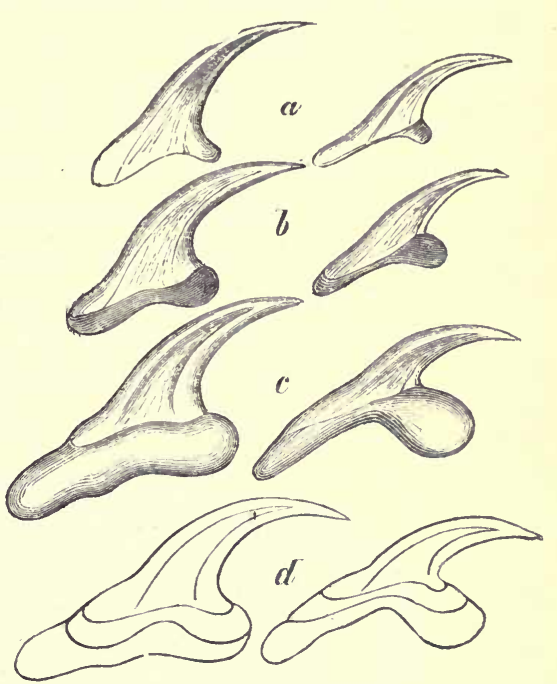

FIG. I80.-Hooklets of Echinococcus. 600/1. (a) Of Echinococcus veterinorum; (b) of Tania echinococcus, three weeks after infection; $(c)$ of the adult $T$. echinococcus; (d) the three forms of hooklets outlined one within the other. (After Leuckart.) of sheep. Küchenmeister, van Beneden, Leuckart, Railliet and others obtained similar results, and Thomas, Naunyn, Krabbe and Finsen succeeded in rearing $T$. echinococcus in dogs from the bladderworms of human beings; these grow comparatively slowly (one to three months) and only develop their hooklets in their definitive form (fig. I80). Finally, Leuckart infected young pigs by feeding them with mature segments.

\section{Echinococcus multilocularis (Alveolary colloids).}

In addition to the form of echinococcus already described and which is also frequently termed Echinococcus unilocularis, there is a second form which occurs in man as well as in animals and which

1 In such cases the toxic effects of the echinococcus fluid usually-if not always-manifest themselves. Such effects are manifested by severe symptoms of poisoning being set up, by urficaria, peritonitis, and ascitis, and not infrequently they cause a fatal termination. 
is termed Echinococcus multilocularis, s. alveolaris (alveolary colloid.)

It was originally regarded as a mere proliferation, and its animal nature was first established by Zeller and R. Virchow. The parasite, which varies in size from that of a fist to a child's head, presents a collection of numerous cysts, measuring between 0.1 and $3-4-5 \mathrm{~mm}$. in diameter, which are embedded in a connective tissue stroma; the cut surface has, therefore, a honeycomb appearance. The cysts are surrounded by a pellucid and stratified cuticle, and each according to its size encloses either solid cellular contents or a space cavity lined by a parenchymatous layer; the fluid contained in such a cavity may be transparent or is rendered opaque by globules of fat, gall pigment, hæmatoidine and fat crystals. According to a few authors all or most of these cysts intercommunicate ; others state that this is the case at least as regards the cuticle.

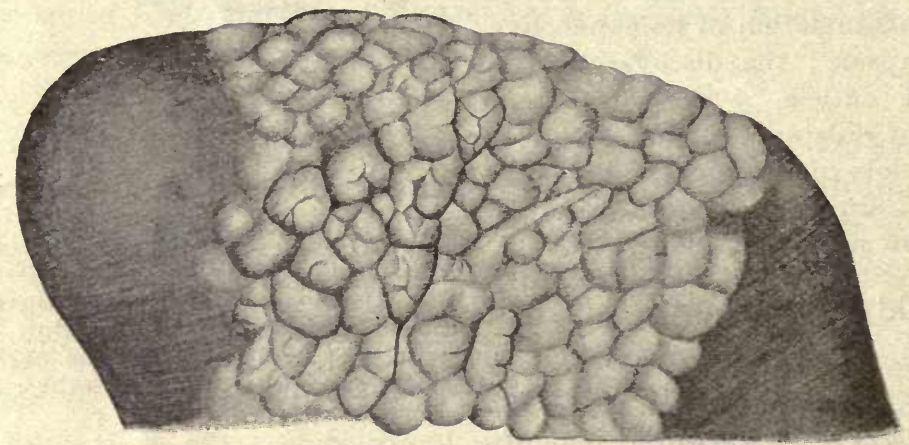

Fig. I8r.-Echinococcus multilocularis in the liver of the ox; natural size. (After Ostertag.)

The scolices are by no means found in all the cysts, and when present in only a few, rarely half of the cysts contain scolices (one or several); it is supposed that at least some of these little heads are formed in brood capsules.

One circumstance is peculiar to the multilocular echinococcus of man, namely, the disintegration that sets in at certain stages; in the centre of the parasite a cavity forms that frequently becomes very large and is filled with a purulent, or brownish or brownishgreen viscid fluid; within this fluid one finds shreds of the wall of the cavity, calcareous bodies, echinococcus cysts, also scolices and hooklets, as well as fat globules and crystals of hæmatoidine, margarine and cholesterine and.concretions of lime. Such ulcera- 
tive processes, according to Ostertag, are never present in the multilocular echinococcus of oxen, ${ }^{1}$ in which the separate cysts are larger and the connective tissue integument less powerfully developed.

Hardly anything positive is known with regard to the development of the alveolar echinococcus; its peculiar conformation is attributed by some to enormous agglomerations of oncospheres, by others to the abnormal situation of one oncosphere; a few authors ascribe it to agglomerations in lymphatic vessels, others to agglomerations in the biliary ducts or to peculiarities of the surrounding hepatic tissue; Leuckart ascribes it to a grape-like variety of form which continues budding; a few more recent authors consider multilocular echinococcus to be specifically different from unilocular echinococcus, and therefore also different the species of tænia arising from them. Melnikow-Raswedenkow is also of this opinion. According to this author the oncospheres settle in the lumen of a branch of the portal vein in Glisson's capsule of the liver and grow into an irregularly-shaped formation (chitinous convolution), which breaks through the vascular. walls and thus forms the alveola. So far the views coincide well with Leuckart's opinion of the original grape-like form of the Echinococcus multilocularis; according to Melnikow-Raswedenkow the "granular protoplasmatic substance" (parenchymatous layer) is not only present in the interior of the loculi but also outside, and, moreover, " ovoid embryos" are supposed to develop in the chitinous convolutions, which, "thanks to their amoboid movements, reach the lumen of a vessel, where, under favourable circumstances, they begin to develop further," that is to say, they become " chitinous cysts with fantastic outlines," or also "single-chambered chitinous cysts"; scolices may develop in both.

The multicular echinococcus, which in man produces a severe disease and almost always leads to premature death, settles most frequently in the liver, but may also be found primarily in the brain, the spleen and the supra-renal capsule; by means of metastasis it may reach the most various organs from the liver, especially those of the abdomen, but also the lungs, the heart, \&c. Hitherto 235 cases have been described, being 70 from Russia, 56 from Bavaria, 32 from Switzerland, 30 from the Austrian Alps, 25 from Würtemburg; the remaining cases are distributed over Central Germany, Baden, Alsace, France, Upper Italy, North America; in some the origin is doubtful; in any case after Russia, the mountainous South of Europe is the principal region of distribution. As to the domesticated

1 This may perhaps be explained by the fact that the hosts are slaughtered before the parasites have attained the size or other conditions necessary to disintegration. 
animals, the same parasite is found principally in the ox (according to Meyer, in Leipzig 7 per cent. of the oxen there are affected with echinococcus); it is rarer in the sheep and very scarce in the pig.

It has already been mentioned above that recently the multilocular echinococcus has been stated to be specifically different from hydatid or unilocular echinococcus; this view is supported by experimental feedings with the multilocular bladder-worm. These experiments were first undertaken by Klemm (I882) on dogs ; this author, however, obtained tæniæ which were not distinct from the typical $T$. echinococcus; Vogler, Mangold and Müller, on the other hand, report that the tænia reared in their experiments exhibited differences in the form of the hooklets as well as in the distribution of the ova within the terminal proglottides; no weight, however, can be laid on these two circumstances, because these conditions vary in $T$. echinococcus. More important is the fact that. Mangold, who fed a young pig with oncospheres of tænia reared from the multilocular echinococcus, found two growths in its liver four months later, and these were recognised as Echinococcus multilocularis; nevertheless chance may have favoured him, and thus this question has remained undecided until the present time.

\section{LITERATURE.}

Siebold, C. TH. v. Ueb. d. Verw. v. Echinococcusbrut in Taenien. (Z. f. w. Z., I 853 , iv., p. 409.)

Eschrichr, T. F. Om the hydatider. (Ov. Kgl. Dansk. Vidensk. Selsk. Forh., I853, p. 2 II ; I856, p. I 27 ; Zeitschr. f. d. ges. Naturw., I857, x., p. 23I.)

Leuckart, R. Ueb. Echinococcus. (Gött. Nachr., I862, p. I3, and in his book on Parasites.)

Naunyn, B. Entw. d. Echinococcus. (Arch. f. An. u. Phys., 1862, p. 612 ; I 863 , pp. 412 and 417 .)

Krabbe, H. Die isl. Echinococcen. (Virchow's Arch., I863, xxvii., p. 225 ; Dtsch. Zeitschr. f. Thiermed., xvii.)

NeIsSER, A. Die Echinococcen-Krankh. Berlin, 1877.

KLemm, H. Z. Kenntn. d. Ech. multiloc. der Leber. (Bayr. Aerzte-Intelligenzblatt, 1883 , xxx., p. $45 \mathrm{I}$; also in In.-Diss. München.)

Thomas, J. D. Hydatid disease . . . in Australia. Adelaide, I884.

Madelung, O. W. Beitr. meckl. Aerzte 7. Lehre v. d. Echinococcen-Krankh., Stuttg., 1885 .

VIERORDt, H. Abh. üb. d. multiloculären Echinococcus. Freiburg, I 886.

LeNDENFEid, R. Tænia echinococcus. (Zool. Jahrb., I886, i., p. 409.)

LEBEDEW, A. J., and N. J. ANDREJEW. Transp!. v. Echin. v. Menschen auf Kaninchen. (Arch. f. path. An., 1889, cxviii., p. 55.2.)

Guillebeau, A. Zur Hist. d. mult. Ech. (Arch. f. path. Anat., I890, cxix.. p. 108.)

ERLANGer, R. v. D. Geschlechtsapp. d. T. ech. (Ztschr. f. w. Zool. L., I89o, p. 555.$)$

Ostertag, R. Ueb. d. Ech. multil. bei Rind. u. Schwein. (Dtsch. Zeitschr. f. Thiermed., I 891, xvii., p. I72.)

MANGold, Ueb. d. multil. Ech. u. seine Taenia. (Berl. klin. Wochenschr., I892. No. 2; also In.-Diss. Tübingen, I 892.) 
Müller, A. Beitr. z. Kenntn., d. T. echin. (Münch. med. Wochenschr., 1893. No. I 3.)

Peiper. Verbr. d. Ech.-Krankh. in Vorpommern., Stuttg., I 894.

Wiedenann, C. Z. Statist. d. Ech.-Krankh. in Vorp. In.-Diss., Greifswald, i 895. Schmidt, W. Ueb. d. geogr. Verbr. d. F.ch. mult. u. hyd. i. Bayern. In.-Diss., München, 1899.

Riemann, H. Ueb. d. Keimzerstr. d. Ech. im. Periton. (Beitr. zur klin. Chir., xxiv ; also In.-Diss., Rostock, I 899.)

Tsснӧтsсhel, K. Zur Cas. d. Ech.-Krankh. in Vorp. (In.-Diss., Greifsw., I900.) Posselt, A. D. Geogr. d. Verbr. Blasenwurmleid., insb. d. Alveolarechin. -a. Leber seit, I 886. Stuttg., I 890 .

Melnikow-Raswedenkow, N. Studien üb. d. Echin. alveol. s. multil. (Beitr. z. path. An. u. allg. Path. [Zeigler], Suppl. iv., January, I90ı.)

\section{AdDexdum.}

Tania hominis, v. Lstw., I902.

Scolex measures $\mathrm{I} \cdot 34 \mathrm{~mm}$. in length, $2 \mathrm{~mm}$. in breadth. There is a rudimentary rostellum without hooks on the apex; the suckers are deep; behind them there is a ring-shaped swelling; no pigment. The neck is I.II $\mathrm{mm}$. in breadth. Calcareous bodies very numerous, o॰oI $3 \mathrm{~mm}$. in size. Genitalia? Only one immature specimen has come to our knowledge, which was found in Aschabad by Anger (C. f. Tania asiatica, p. 233), (r. Linstow in C. f. B., P. u. I., IgO2 [I.], xxxi., p. 770).

\section{NEMATODES, Thread-worms.}

Nematodes are as a rule elongated round worms of a filiform or fusiform shape; their length varies according to the species from about $1 \mathrm{~mm}$. to $40-80 \mathrm{~cm}$. The outer surface of the body is smooth or annulated, and at certain points provided with papillæ, occasionally also with bristles and alar appendices. The anterior end carrying the oral aperture is usually rather slender, occasionally quite thin; the posterior end is pointed or rounded; the anus, as a rule, lies somewhat in front of the posterior extremity. The sexes are almost always separate, and the male can as a rule be easily distinguished from the female because the former is smaller and more slender, its posterior extremity is often spiral or incurvated, or carries an alar appendix, whereas the female is larger and thicker, and its posterior extremity is straight. In the male the genitalia open into the anus; the sexual orifice of the female opens ventrally along the median ridge in the anterior half of the body, in the middle, or a little further back. Both sexes, moreover, have an orifice, the excretory pore, which is situated ventrally along the median ridge and fairly near the anterior extremity.

In large species, even with the naked eye, two lighter transparent stripes-the lateral ridges-may be distinguished; they run along the sides of the body from the anterior to the posterior end, while two other stripes, the median ridges, running along the ventral and dorsal median ridges are less evident; in exceptional cases there are also four sub-median ridges. 
Some nematodes live free in fresh or salt water, in soil, mud, or decaying vegetable matter, others parasitically in the most various organs of animals, as well as frequently also in plants.

\section{(a) Anatomy of the Nematodes.}

All the Nematodes are covered by a CUTICLE, which in the small species is thin and delicate, while in the larger species it is thickened, and may consist of several layers of complicated structure. ${ }^{1}$ Porocanals do not occur. According to general opinion, which is confirmed by the history of development, the cuticle is a product of the epithelium that had formerly existed or is still found beneath it; in young specimens and small species it is perceptible, but in older worms it frequently alters so considerably that not only do the borders of the cells disappear, but a fine fibrous differentiation appears in the plasm. The matrix or hypodermis then has the appearance of a connective tissue strewn with nuclei, so that it is hardly distinguishable from the texture of the cutis, which is always present, though it may be but feebly developed. ${ }^{2}$ It is the cutis alone which projects crest-like, and which forms the above-mentioned lateral and median ridges (fig. I82).

Unicellular cutaneous glands are known in parasitical as well as in free living species; they vary in number and arrangement, and are found discharging some at the anterior extremity, and others in the vicinity of the genital orifices. In other cases large numbers of them are present along the lateral ridges; they are strongly developed in most of the Trichotrachelidæ, where they discharge either along a part of the ventral surface or, along the lateral and median ridges; they are placed so closely together that the ridges of the cuticle perforated by the orifices have long been known, and have been described as "rodlet borders," or "fields of rods."

As the cutis is immediately adjacent to the dermo-muscular tube, the simple layer of the muscular cells is by the longitudinal ridges

'Bömmel, A. v., "Ueber die Cuticularbildung bei Nemat." (Arb. zool.-zoot. Instit. Würzburg, I 895, x., p. 189.) Toldt, C., "Ueber den feinen Bau der Cuticula bei Ascaris megalocephala" (Arb. aus d. zool. Inst. Wien., 1899, xi., p. 289).

2 The subcuticular stratum of the nematodes certainly requires further investigation. L. Jammes considers it nervous ("Contrib. à l'étude de la couche sous-cuticulaive des Némat." An. sc. nat. Zool., r892, Ser. vii., vol. xiii., p. 321), and M. Condorelli-Francaviglia does not find the hypodermis cells in epithelium-like order, but separated by a granular-fibrillary mass, which entirely resembles the substance of the deeper-lying layers of the cuticle ("Ric. zool. ed. anat.-ist. sulla Filaria labiata," Boll. soc. rom. stud. zool., I895, iv., pp. 93 and 248).

s Jägèrskiöld, L. A., "Weit. Beitr. z. Kenntn. d. Nemat." (Kgl. Sv. Vet.-Ak. Handl., igoI, xxxv., No. 2.) 
divided into four quadrants-two dorsal and two ventral. The elements of the dermo-muscular tube are in the simplest cases large, rhomboid cells, that lie two by two in each quadrant, so that on transverse section of the entire worm only eight cells are perceptible. The outer border of the cells is converted into fibrils, while the contiguous inner portion has remained protoplasmatic, and contains the nucleus. In large species the muscular cells do not only increase in length (up to $3 \mathrm{~mm}$.) and in number in every quadrant, but their contractile portion bends groove-like (fig. I82),

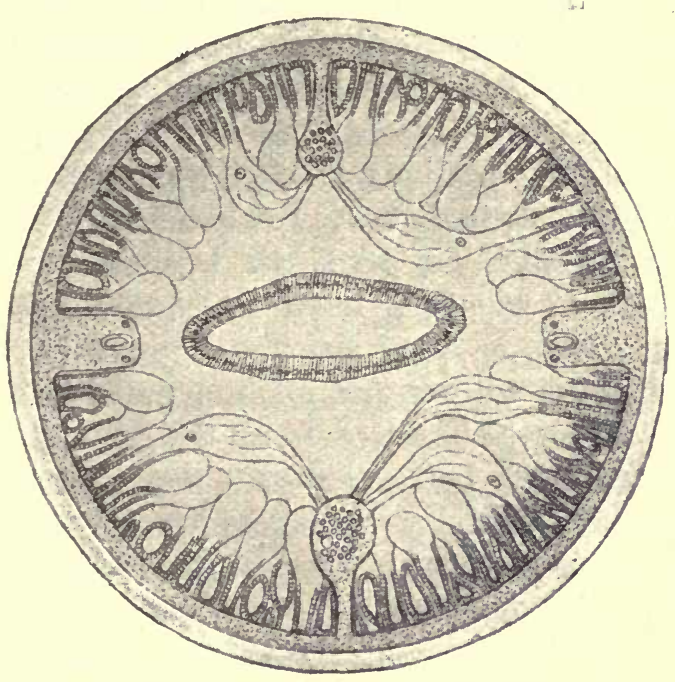

FIG. I 82.-Diagram of a transverse section of Ascaris lumbricoides, about $50 / \mathrm{I}$. The flat intestine is in the middle, and to the right and left near it within the wall of the body the lateral ridges with excretory vessel and lateral nerves, above and below in the centre the dorsal or ventral median ridges with the nerves radiating to the muscles (after Brandes).

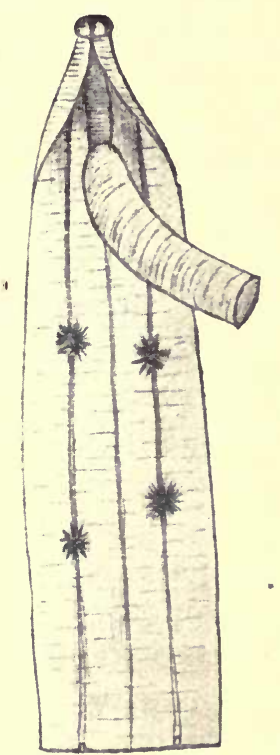

FIG. I 83.-Anterior end of an Ascaris megalocephala cut open and showing the four tuftlike organs lying on the lateral ridges, natural size (after Nassonow.)

thereby even becoming larger; simultaneously space is gained for more cells, the protoplasmatic parts of such cells (on transverse section) hang out of the grooves like vesicles. In all cases there is only one layer of longitudinal muscular cells, which by contracting can shorten the body, or by contracting one side can bend it. In the latter case the muscles of the opposite side have an antagonistic effect, in the former the elasticity of the cuticle acts in the same way. 
The BODY CAviTy, which lies between the body and intestinal walls, is according to its development not a cœlom but the cleavage cavity. It is considerably restricted by the protoplasmatic portions of the muscular fibres and by the genitalia; it contains a small quantity of hæmolymph, and sometimes also leucocytes.

We may now consider the "tuft-like" or "phagocytic organs," which attain I $\mathrm{cm}$. in size, and consist of four, six, or even more ramified cells, which lie close to the walls of the body (fig. I83). They are found either only in the anterior part of the body (Ascaris), or extend the whole length of the body (Sclerostomum, Strongylus), and their position usually corresponds to the lateral ridges. In some species there are small protoplasmatic cells at their processes. In consequence of their size they can be recognised with the naked eye, especially when loaded with granules of stain (carmine, Indian ink) injected into the body cavity. ${ }^{1}$

INTESTINAL CANAL. The oral aperture, which is situated at the tip of the anterior extremity, is frequently surrounded by thick lips, or small bristlès, or papillæ; it leads to a more or less strongly-developed oral cavity, which is lined by a continuation of the body cuticle, and which in some species is provided with "teeth," representing differentiated portions of the cuticle.

The cesophagus (fig. I84), which arises from the base of the oral cavity, is as a rule a short, bottle-shaped tube, its wall is chiefly composed of radiating muscular fibres, which give it the appearance of being transversely striped. The radiary fibres cause a dilatation of the lumen, and exercise an effect antagonistic to the elasticity of the cuticle lining the inner surface. The latter has its own particular layer, which is not in direct connection with that of the oral cavity. The posterior end of the œsophagus presents a bulb-like dilatation, and is frequently provided with small teeth. In a few forms, which belong to the family of the Trichotrachlidæ (Trichocephalus, Trichinella), the œsophagus is a very long cuticular tube, beset on its dorsal surface with a series of large nucleated cells. In others (Cucullanus, a few species of Ascaris, \&c.), a tube, the so-called glandular stomach, only lined by epithelial cells, follows behind the muscular œsophagus. This glandular stomach is, from its structure, easily distinguished from

'Nassonow, N., "Sur les org. phagocyt. d. Ascar." (Arch. parasit., I898, i., p. I70). "Z. Kennt. d. phagocyt. Org. b. d. parasit. Nemat." (Arch. f. mikr. An., igoo, lv., p. 488). Jägerskiöld, L. A., "Ueb. d. büschelf. Org. b. d. Ascaris-arten" (C. f. B.. P. u. I., I 898 [I], xxiv., pp. 737 and 785 ). 
the mid-gut, which is likewise cellular. The so-called mid-gut is a tube lined by flat, cubical, or cylindrical cells (fig. I82), which has no outer mesodermal layer (connective tissue, muscles); its transverse section is circular or flattened dorso-ventrally; the lumen may run in a straight line, or it may form sinuosities amongst the alternating prominences of the then flat epithelial cells.

The ectodermal hind-gut is, as a rule, very short; very frequently there is no cellular lining, so that it consists only of a cuticular tube, which in large species is surrounded by circular muscles. In some species there are special bundles of cutaneous muscles along the entire gut, or at least on the terminal gut. There is sometimes a retrogression of the alimentary tube in the adult stage of a few parasitical species.

Intestinal cæca and œsophageal glands sometimes appear as intestinal appendages; the former are cylindrical organ's of various size, running backwards or forwards, and arising from the posterior extremity of the œsophagus. They are lacking in many species. The œesophageal glands are unicellular; a dorsal and two subventral glands may be distinguished according to their position; as a rule they open into the œesophagus

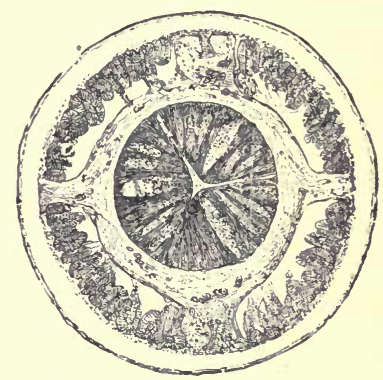

FIG. I 84.- Transverse section of anterior end of the body of Ascaris lumbricoides with the nerve ring surrounding the œsophagus. (Enlarged.) at a distance from one another. The glandular body lies in the bulb of the œesophagus, the dorsal ones in the $c u l-d e-s a c$ arising from it. ${ }^{1}$

The Nervous Systen of the larger species of Ascaris is the only one sufficiently known;" it consists of a pharyngeal ring containing 50-60 fibres closely surrounding the œesophagus (fig. I84), various groups of ganglion cells, and a certain number of nerves

${ }^{1}$ Jägerskiöld, L. A., "Beitr. z. Kenntn. d. Nemat." (Zool. Jahrb. Anat., I 894, Part vii., p. 449). "Ueb. d. Esophagus d. Nemat." (Bih. K. Svensk. Vet.-Akad. Handl., 1897, xxiii.-iv., No. 5). Looss, A., "Ueb. d. Bau d. Esoph. bei einig. Ascar." (C. $t$. B., P. u. I., I $896[\mathrm{I}]$, xix., p. 5).

2 Bütschli, O., "Beitr. z. Kenntn. d. Nervens. d. Nemat." (Arch. f. mikr. An., I874, x., p. 74). "Zur Herleitg. d. Nervens. d. Nemat." (Morph. Jahrb., 1885, x., p. 486). Rohde, E., "Beitr. z. Kenntn. d. Nemat." (Zool. Beitr. [A. Schneider], I885, i., p. I I). Hesse, R., "Ueh. d. Nervens. v. Asc. megaloceph." (Z. t. w. Z., I892, liv., p. 548). Apathy, St., "Das leit. Flem. in d. Muskelf. v. Ascaris" (Arch. t. mikr. An., 1894, xliii., p. 886). Brandes, G., "Das Nervens. d. als Nemathelm. zusammengef. Wurmtyp." (Ahh. d. naturf. Ges. Halle., I 899, xxi., p. 273). 
extending anteriorly as well as posteriorly. The remarkably small number of fibres, as well as ganglion cells, is characteristic of

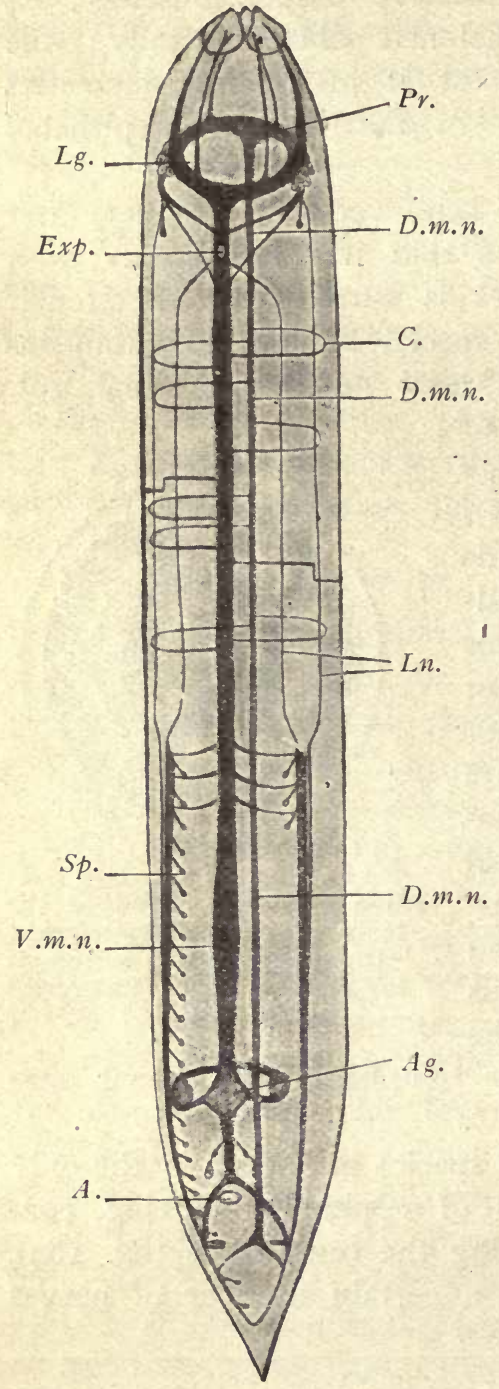

Fig. I 85.-Schematic representation of the nervous system of a male, Ascaris megalocephalus (after Brandes) A., Anus ; Ag., Anal ganglion; $C$., Commissures; D.m.n., dorsal median nerve; Exp., excretory pore ; $P r$. , pharyngeal ring; Lg., lateral ganglia ; Ln., lateral nerve; $S p$. , papilla of sense; $V . m . n$. , ventral median nerve. the nervous system of all Nematodes. Immediately behind the pharyngeal ring (fig. $185, L g$.) an agglomeration of ganglion cells lies at either side (lateral ganglia); part of their off-shoots form the pharyngeal ring, and part are directed posteriorly and ventrally, and unite partly in front of and partly at the back of the excretory pore, with fibres originating direct from the pharyngeal ring, and passing along the ventral median ridge to the back, these fibres then together form the ventral median nerve (fig. I 85 V.m.n.). This nerve, originally consisting of thirty to fifty fibres, becomes attenuated in the female quite evenly in its further course. There is also an agglomeration of ganglion cells close in front of the anus (anal ganglia), and then the median nerve divides in order to combine. with the lateral nerves on either side. In the male the median nerve enlarges to nearly the original number of fibres in front of the anal ganglion, which contains seven cells; there is also an anal ring embracing the terminal gut, and there are two ganglion cells in it on each side. In the dorsal median ridge the dorsal median nerve is alike in both sexes; arising in front with a single root from the pharyngeal ring it gathers its fibres from the lateral ganglia; in the anterior part of the body it consists of thirteen to twenty fibres; in the posterior part of the body the fibres are reduced to four 
or six; behind the anus it divides and combines with the lateral nerves. The latter consist of two fasciculi at either side extending to the hindermost part-one dorsal and one ventral-which in the greatest part of the body do not run in, but next to, the lateral ridges, and exhibit a different origin in the front. The ventral fasciculus at each side branches off from the ventral median nerve in front of the excretory pore, whereas the dorsal fasciculi originate from the pharyngeal ring close to the lateral ganglia. Each of the four fasciculi contains only two or three fibres, which run backwards parallel to the lateral ridges; a few centimetres in front of the caudal extremity they join the lateral ridges and remain separate from one another up to the level of the anal ganglion; here they amalgamate on either side, after each interpolating one ganglion cell, with the single short lateral nerve which first takes up the forked ends of the ventrai, and then of the dorsal median nerve; finally, both lateral nerves unite with each other at the back in arch-like manner.

In the male each ventral part of the lateral nerves becomes thickened by taking up fibres from the ventral nerves, which become thickened posteriorly to the nervus bursalis, which towards the middle gives off a mass of fibres to the "genital papillæ" situated in front of and behind the anus; the number of these fibres averages $80-100$; in its further course the bursal nerve resembles the corresponding ventral part of the lateral nerves of the female.

The ventral and dorsal nerves are connected by a number of semi-circular commissures, which originate from the ventral nerves and serve to supply the dorsal nerve, which is always being decreased by fibres departing from it. It is remarkable that these commissures are not placed symmetrically, and their position also is different in the two sexes; in the female there are thirty-one on the right side and only thirteen on the left side. In the male there are thirty-three commissures on the right side and fourteen on the left, which run into the sub-cuticular layer generally in pairs, and usually cross at the level of the lateral ridges.

The fibres of the two median nerves are chiefly motory; fascicular processes run from each protoplasmatic part of the muscular cells to the median nerves; from these they take up bundles of primitive fibrils, which separate, pass through the protoplasmatic part and enter the contractile part (fig. I82). One part of the fibrils, however, penetrates beyond the muscles into the subcuticular layer, where they form a network, probably of a sensory nature, with contiguous fibrils. Nerves directed anteriorly 
finally originate from the pharyngeal ring; they consist each of three fibres, carry three ganglion cells at their point of origin, and enter the sensory organs of the three papillæ surrounding the oral aperture. Two of these little trunks lie in the lateral ridges, the remaining four are situated in the middle of the four quadrants (Nn. submediani anteriores).

The parasitical species lack higher ORGANS OF SENSE; freeliving worms occasionally have two rust-red eyes, sometimes with lenses, at the front of the body. In addition to the abovementioned sensory papillæ surrounding the oral aperture and the genital papillæ of the male at the end of the body, the Ascarides possess still another pair, situated in the vicinity of the lateral ganglia of the "cervical papillæ"; they, moreover, possess two dorsal papillæ in the central region of the body and two lateral ones near the tip of the tail.

THE EXCRETORY ORGANS of the Nematodes are variable. In a great many cases the apparatus is symmetrical, and consists of a tube commencing in the posterior extremity along each lateral ridge (fig. I82), and passing towards the front. In the vicinity of the anterior extremity both tubes pass out of the lateral ridges, bend ventrally, and, in the median ventral ridge unite into a short duct, which opens into an excretory pore (fig. I85, Exp.), and is lined by a continuation of the cuticle of the body. Asymmetry is occasioned through the excretory duct proceeding from the ventral pore to the left at the lateral ridge, and then taking up the tube in the anterior part, which is broader, and passes along the left lateral ridge; shortly before its union with the excretory duct it throws out a branch to the right towards the lateral ridge, which, however, always remains weak, and passes posteriorly into the right lateral ridge; a few smaller branches in addition spring from the left principal part. In other species the right branch is completely suppressed; the entire organ thus lies along the left lateral ridge, and consists of the excretory duct, which occasionally opens quite in front near the lips, as well as the excretory canal, which throws out a number of lateral branches.

This excretory portion is one single elongated, or horse-shoeshaped cell, with a large nucleus and an intracellular tubular system, which is connected with the excretory duct originating from the outer surface. The so-called ventral gland is the only excretory organ of marine Nematodes, and probably represents a primitive form.

In a number of Nematodes (Cheiracanthus, Trichosomum, Tricho- 
cephalus, Trichinella, \& c.), however, special excretory organs are lacking; possibly the cutaneous glands, which are in these species generally powerfully developed, replace these organs. ${ }^{1}$

Sexual organs. With the exception of a few species, the Nematodes are sexually differentiated.'

(a) Female Sexual organs. The sexual orifice (vulva), surrounded by thick labia, is, as a rule, ventral and situated in the middle of the body, or a little more forward, rarely further back. It leads into a short vagina, continued by the two uteri, which may be long or short; the long filiform ovaries are contiguous to them (fig. I86). In smaller species one of the uteri, with its ovary, extends towards the front, the other towards the

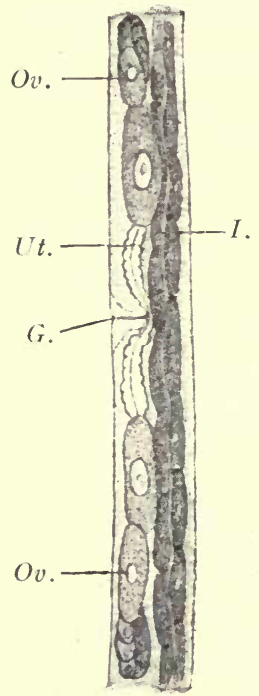

FIG. I86. - Central part of the body of the rhabditis form "of Rhabdonema nigrovenosum with female genitalia lying on its side. (Magnified.) I., intestine; $G$., genital orifice (vulva); Ov., ovarium ; $U t$., uterus. back. In larger species both the uteri and ovaries extend backwards (parallel), the latter attaining a considerable length, so that they form many convolutions in the body. The entire apparatus lies within the abdominal cavity, and in some species (for instance, Trichinella) is single.

At the blind end of the ovary there is a cumulus oöphorus, i.e., a mass of protoplasm with numerous nuclei that multiply continuously. Gradually the nuclei arrange themselves in longitudinal rows (fig. I87) and the protoplasm commences to leave the periphery and surround each nucleus. The nearer to the uterus the more progressive is this loosening process, until clubshaped cells each containing a nucleus are developed. The most slender end of each, however, is still attached to an axial fibre of protoplasm, the rhachis; probably this has some connection with the nutrition of the ova. Finally the ova fall off and reach the uterus, where they are fertilised and enclosed in shells.

(b) Male sexual organs. There is never more than one testis (fig. I88), which is a straight or sinuous tube of the same construction as an ovary, and in which the spermatic spore capsules originate in the same manner as the ova. In the same way as the ovary

'Jägerskiöld, L. A., "Beitr. z. Kenntn. d. Nemat." (l.c.) “ Büschelf. Org. b. Asc." (l.c.) "Weit. Beitr. z. Kenntn. d. Nemat." (l.c.). Hamann, O, “Die Nemathelm., II., Jena, 1895. Nassonow, N. (l.c.). Cobb, N. A., "Oxyuris-larva hatch. in the hum. stom." (Proc. Linn. Soc., N. S. Wales, I89 I [2], v., p. I68), and other authors.

"Nedkoff, P., "Ueb. d. Metamorph. d. Geschlechtsapp. b. Ascar. nigroven., In.-Diss. Leipzig, I 897 . 
passes into the uterus, so does the testis pass into the spermatic duct; the latter is often divided into the somewhat dilated
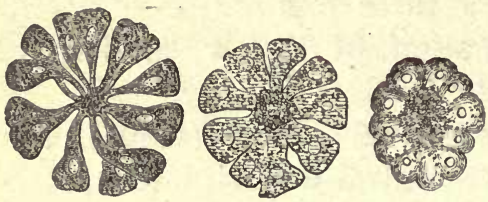

FIG. I87. - Transverse section through the ovarian tube of Ascaris mystax (of the cat) at various levels. To demonstrate the development of the ova and of the rhachis. (Magnified.)

corpuscles of the Nematodes present an unusual form. (They have no flagella but are capable of amøeboid movement.)

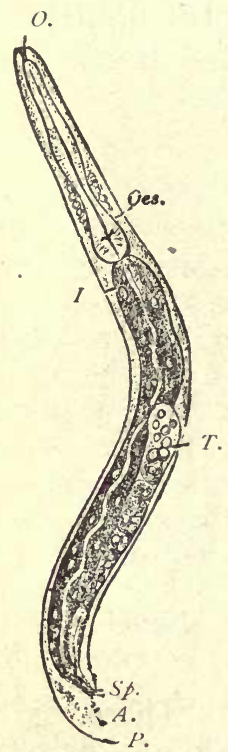

FIG. I 88. - Male of the rhabditis form of Rhabdonema nigrovenosum (nuagnified). $A$., anus ; $I$. , small intestine : $T$., testicular tube; $O$. , oral orifice; $P$. , papilla ; $S p$. spicula. seminal vesicle and into the muscular ductus ejaculatorius, which, running ventrally from the intestine backwards (fig. I89), finally opens into the hind gut. The spermatozoa of the Nematodes, it may be noted, only attain their full development after the spermmother cells have been conveyed by copulation into the uteri of the female genitalia. The spermatic am eboid movement.)

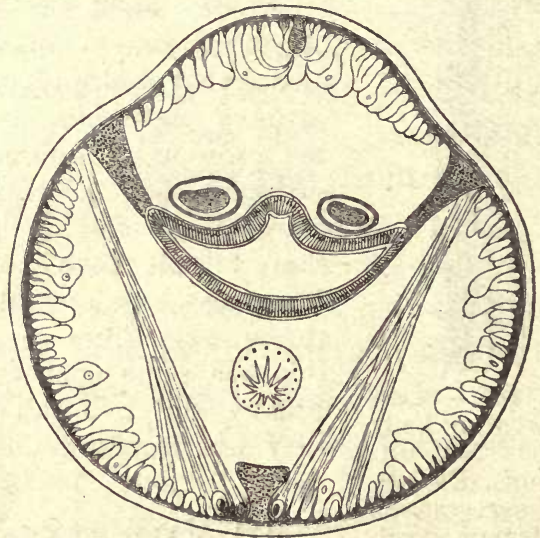

FIG. I89.-Transverse section through the posterior extremity of the body of Ascaris lumbricoides (Male). The intestine is in the middle, and the lateral ridges are subjoined thereto; above the intestine the two spicula sacs are seen; below is the ductus ejaculatoris. The muscular fibres are between the lateral and dorsal median ridges. (Magnified.)

The male genital apparatus is also provided with one or two glandular sacs, situated on the dorsal side of the intestine, and 
connected with the cloaca. In each glandular sac there is a chitinous rod-like formation, the spiculum. A special muscular apparatus, consisting of protractors and retractors, causes the movement of the spicula; they can be projected from the cloacal orifice (anus) during copulation, and when they are introduced into the vagina they serve as clinging organs, perhaps also as stimulatory organs.

The male Strongyloides possess two wing-like appendices at their posterior extremity; these are projections of the body wall supported by so-called ribs. This formation, most unsuitably termed bursa copulatrix, serves as an organ of prehension during copulation. Some forms, moreover, carry a suctorial disc at the posterior extremity; in others (Trichinella), the spicula and other clinging organs are absent; they are then replaced by an evertable cloaca.

\section{(b) Development of the Nematodes.}

This is not the place to describe minutely the well known processes of the fertilisation and development of the ova of the Nematodes. It may, however, be briefly mentioned that fertilisation always takes place within the uterus, and that then the eggs are surrounded by a thick or thin shell, to which may be added an albuminous mass, secreted by the epithelial layer of the uterus. The shape of the completed eggs is characteristic of the different species, and therefore a single egg often suffices to diagnose the species. According to the species, the eggs may be deposited sooner or later, either before or during segmentation, or with the embryo perfectly developed. Only a few species are viviparous; in the other Nematodes the further development of the extruded eggs takes place after various length of time in the open, in moist earth, or in water. Thick shelled eggs can maintain their developmental capacity for a long time, even after prolonged desiccation.

Finally, a Nematode-like embryo develops, which usually lies somewhat coiled up within the shell, and varies in its further development according to the species to which it belongs.

In the simplest forms, as in the free-living Nematodes, the embryos, apart from their size, resemble their parents, and are fully developed after leaving the egg shell. In many parasitical Nematodes, however, the young must be called larvie, as they present characters which are subsequently lost.

The manner of conveyance of the larval Nematodes from the open-which they have almost always attained from the body of the host-into the definitive host is very different in the various 
species. In many the conveyance into the definitive host is efferted direct after the larvæ have developed within the eggs; thus, for instance, the feeding of suitable animals with the embryo-containing eggs of species of Trichocephalus and Ascaris, leads to the settlement of the worms in the intestine; for the young Trichocephali or Ascarides only leave the egg shell when they have a,tained the intestine of the final host, in which they become adult.

In other cases (Dochmius, Sclerostomum, Strongylus, \&c.), the larvæ hatch in the open, and live for a time free in another shape; they grow, cast their skin, and finally gain the intestine of the

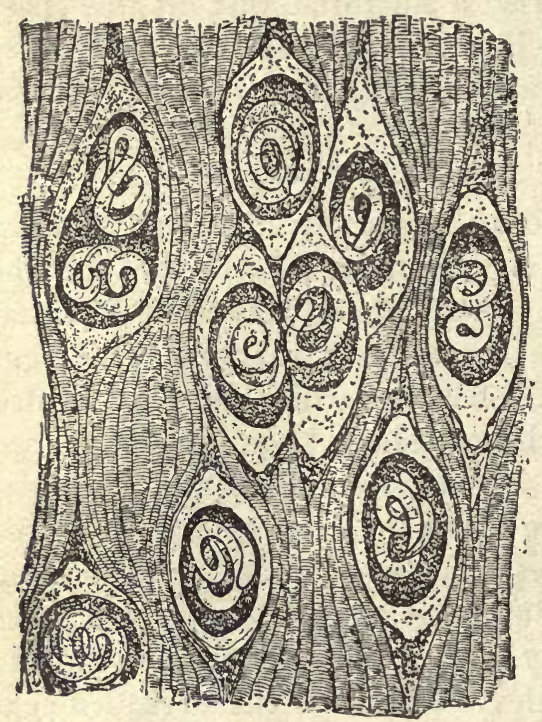

FIG. 19j. - A piece of the trunk muscular system of the pig with capsules containing trichinæ (magnified).

host by means of water or some other vehicle, when they lose their larval characters and assume the structure of the parents.

Frequently, however, the larvæ of Nematodes make use of one or even two intermediary hosts ; their condition then resembles that of Cestodes or Trematodes, excepting that there is never a multiplication within the intermediary hosts. The larve become encapsulated amongst the tissues of the intermediary host, and wait till they are introduced with the latter into the final host. For instance, Ollulanus tricuspis, the adult form of which is found in cats, lives previously encysted in the muscular system of mice. Cucullanus elegans, which attains the adult stage in fishes (Perch, \&c.), is found encysted in species of Cyclops.

${ }^{1}$ Peculiar conditions prevail in Trichinella spiralis. This species, which in its adult state lives in the intestine of man and of various mammals, is viviparous; the young Trichinæ, however, do not leave the intestine, but attain the intestinal wall (Cerfontaine, Askanazy). The female intestinal Trichinæ bore themselves into the intestinal wall, where they are found within the submucosa, or in the lumen of the dilated lacteal vessels. Here the young are born, within the intestinal wall, and leave this posi- 
tion with the lymph stream. Some of them, no doubt, actively bore through the intestinal wall, likewise attaining the lymph stream or blood circulation, or even pass into the body cavity. What occurs during their further migrations is difficult to say at present. It has hitherto been maintained that the wandering is entirely active; for instance, the ligaturing of an artery would be no protection against the part of the body supplied by such artery being invaded by Trichinella. This observation cannot be otherwise explained than by the active progress of the young Trichinella. The question, however, may be mooted as to where and when the worms quit the lymphatic system and the circulation of the blood to wander further independently, and ultimately reach the muscular system, in which they become encysted (fig. I90). Thus the progeny does not leave the body of the host inhabited by the parents, as is generally the case amongst helminths, but uses it as an intermediary carrier to reach another host, which is then the final host. The latter may belong to another species, or may be another individual of' the same species. This second migration is, of course, purely passive.

In a number of Nematodes, however, HETEROGONY occurs. This term signifies that manner of development in which two differently structured, sexual generations alternate with each other within the same species. To these appertains, for instance, Rhabdonema nigrovenosum, which lives in. the lungs of frogs and toads; this creature measures about I $\mathrm{cm}$. in length and is hermaphroditic (protandric). The eggs are deposited in the pulmonary cavity, and through the cilia of the same reach the oral cavity, where they are swallowed and thus conveyed into the intestine. They pass through the entire gut, and are finally evacuated with the fæces; often, indeed, the young themselves emerge from the egg-shell within the hind gut of the frogs. These young forms are sexually differentiated, remain much smaller than the parent, their oesophagus is differently constructed (rhabditis form), and they are not parasitical (fig. I88). After having grown in the open they copulate; the males die off soon after copulation, and the females in their own body develop a few young, which, given the opportunity to get into frogs, settle in them, and are transformed into hermaphroditic rhabdonema. The same manner of development occurs in other species of the same genus.

Finally, it must be mentioned that some forms classified with the Nematodes (Mermis, Gordius) are only parasitical during the 
larval stage (in insects), and when adult live free in moist soil, or in water.

\section{(c) Classification of the Nematodes.}

The Nematodes are usually divided into a number of families, amongst which a few aberrant groups are included. Although there are objections to such a classification it is here maintained for practical reasons :-

Fam. I. Enoplidee consists only of free species usually inhabiting the sea.

Fam. 2. Anguillulida, Nematodes, most of which live free in fresh water, in soil, or in macerating substances; amongst them there are some which live parasitically on plants, more rarely on animals. They are, as a rule, very small, and are particularly distinguished by the fact that their œsophagus possesses a double dilatation; many are provided with a chitinous spine or with teeth in the oral cavity. The males possess two spicules, sometimes also a bursa copulatrix; the females have pointed tails, the vulva is situated in the middle of the body (Anguillula, Rhabditis, Heterodera, Ecc.).

Fam. 3. Angiostomida, characterised by heterogony (Rhabdonema, Angiostoma, Allantonema, E.c.).

Fam. 4. Gnathostomida, a small family only comprising the genus Gnathostoma s. Cheiracanthus, the members of which live in the stomach of vertebrates, especially mammals; recognisable by numerous ramified spines - which cover either the whole body or only the anterior part.

Fam. 5. Filariida, very long filiform Nematodes, the oral aperture of which is often surrounded by papillæ or by two lips; the œesophagus is slender and without bulb; the male has one or two uneven spicules; the vulva is usually situated in the anterior half of the body; generally ovoviviparous (Filaria, Spiroptera, Dispharagus, E.c.).

Fam. 6. Trichotrachelida, recognisable by the œsophagus, which resembles a necklet of pearls; the anterior paft of the body is usually of threadlike slenderness, the posterior part of the body, which contains the genitalia, is more or less thickened; there may be no spicules or only one. There is a single ovary; vulva situated at the border line between the anterior and posterior parts of the body (Trichinella, Trichocephalus, Trichosoma, Evc.).

Fam. 7. Strongylide, a very large group divided into several sub-families; it is characterised by the possession of six oral papillæ; the male possesses a bursa copulatrix and one or two spicules at the posterior extremity; species usually small (Eustrongylus, Strongylus, Syngamus, Sclerostoma, Ankylostoma, Dochmius, Ecc.).

Fam. 8. Ascarida. Mouth with three papillæ, one dorsal and two ventral; œesophagus with bulb; one or two spicules; ovary double (Ascaris, Oxyuris, Heterakis.)

Addendum.-Gordiacea, greatly elongated Nematodes, which, in the larval stage, live parasitically in insects, but in their adult condition are free living; they have no lateral ridges and no spicules; the posterior extremity of the male is bifurcated; two testes; the male and female generative organs open through the anus. The intestine is partly obliterated. (Gordius, Mermis, Eoc.). 


\section{The Nematodes Observed in Man.}

(a) Fam. Anguillulida.

Gen. I. Rhabditis, Dujardin, I845.

Small anguillulidæ with double dilatation of the œesophagus; no teeth in the oral cavity; two short spicules provided with accessory pieces; no lateral ridges.

I. Rhabditis pellio (Schneider), I866.

Syn.: Pelodera pellio, Schn., I866; Rhabditis genitalis, Scheiber, I880.

Males, $0.8-\mathrm{I}^{\circ} 05 \mathrm{~mm}$. in length; females, $0.9-\mathrm{I} \cdot 3 \mathrm{~mm}$. in length. The posterior extremity of the body of the male has a heart-shaped bursa, and seven to ten ribs on each side; the bursa may, however, be lacking. The spicules measure 0.027$0.033 \mathrm{~mm}$. in length, but are never quite alike. The posterior extremity of the female is long and pointed; the vulva lies somewhat behind the middle of the body, the 'ovary is single, the eggs are oval, 0.06-0.035 $\mathrm{mm}$.

This species was found in Stuhlweissenburg by Scheiber in the acid urine '(containing albumen, pus and blood) of a woman suffering from pyelonephritis, pneumonia and acute intestinal catarrh; the observer was able to convince himself that the Nematodes which were found during the whole period of the illness lived in the vagina, and were evacuated with the urine.

Oerley proved that this species had long been known; during its lairval stage it lives in earth-worms (Anguillula mucronata, Grube, I849); in its adult stage it lives in decomposing matter in the soil. By introducing individuals of this species into the vagina of mice, Oerley succeeded in obtaining their settlement and multiplication (facultative parasitism). These Nematodes must likewise by some means have attained the vagina of Scheiber's patient.

Two other cases described by Baginsky and Peiper probably belonged to the same or a nearly-related species.

\section{LITERATURE.}

Scheiber, S. H. Ein Fall von mikr. kleinen Rundwürmern im Urin einer Kranken. (Virchow's Arch., I880, lxxxii., p. I61.)

Oerley, L. Die Rhabditiden u. ihre medicin. Bedeutung. Berlin, I886.

BAGINSKY. Hæmoglobinurie mit Auftreten von Rhabditiden im Urin. (Dtsch. med. Wochenschr., 1887, No. 27, p. 604.)

Peiper AND Westphal. Ueber das Vorkommen von Rhabditiden im Haine bei Haematurie. (Centralbl. f. klin. Med., I888, ix., p. 145.) 


\section{Rhabditis niellyi, Blanchard, $\mathbf{I} 885$.}

Syn.: Leptodera niellyi, Blanchard, I885.

In I882 Nielly had a cabin boy, aged I4 years, under observation in Brest. The lad had never left the neighbourhood of Brest, and had suffered from itching papules on the skin for five or six weeks; in the papules the observer found one or several rhabditis, measuring $0.33 \mathrm{~mm}$. in length by $0.030 \mathrm{~mm}$. in breadth. Their cuticle presented a delicate transverse striation; the intestine was the only internal organ recognisable, and it opened somewhat in front of the posterior extremity. Therefore, it must have belonged to the rhabditis-like larva of a Nematode, the adult stage of which is unknown.

'The manner of infection was established almost certainly by a further observation of Nielly's; at the commencement of the illness small Nematodes were found in the blood of the patient; later on, however, they disappeared, neither were Nematodes found in the fæces, urine or sputum. Therefore it must be concluded that the cabin boy, who was in the habit of drinking water from brooks, had thus ingested embryo-containing eggs of a Nematode; the young hatched out in the intestine, perforated it, reached the blood and then settled in the skin. ${ }^{1}$

It may be remarked that skin diseases caused by young Nematodes have also been observed in dogs (Siedamgrotzky, Möller, J. G. Schneider²), foxes (Leuckart) and horses (Semmer); Zürn also found young Nematodes (Anguillulide) in the flesh of pigs.

Gen. 2. Anguillulina, Gervais et Beneden, I859.

Syn.: Tylenchus, Bastian, I864.

Differentiated from Rhabditis by the possession of a spine in the oral cavity; bursa without papillæ in the male; uterus asymmetrical. Numerous species parasitical in plants.

\section{Anguillulina putrefaciens, Kühn, I879.}

Syn.: Tylenchus putrefaciens, Kühn; Trichina contorta, Botkin, I883.

In 1883 Botkin (Pet. kl. Wochenschr., I883) found a small Nematode, which was, however, entirely misunderstood, in the material vomited by a Russian; this was not; however, a species of Trichinella, but an Anguillulina living in onions which had already, in 1879, been described by Kühn

'Nielly, "Un cas de dermatose parasitaire observé pour la première fois en France" (Arch. méd. nav., I882, xxxvii., pp. 337 and 488). Bull. Acad. méd., I882 (2), xi., pp. $395,58 \mathrm{I})$.

"Schneider, J. G., "Nematodenembryon. in d. Haut d. Hundes.," In.-Diss. Basel (Ludwigshof., I895). 
as Tylenchus putrefaciens. These creatures attained the stomach with the onions, causing nausea and vomiting.

(b) Fam. Angiostomida.

Gen. 3. Strongyloides, Grassi, I879.

Syn., Pseudorhabditis, Perroncito, I88I ; Rhabdonema, Leuckart, r882, p.p.

The parasitical form possesses a simple mouth without teeth and without a spine; the cylindrical œsophagus is very long and almost reaches to the middle of the body. The free-living form possesses a small oral cavity ; the œsophagus is short, exhibits a double dilatation, in the hinder part of which there are small teeth; two spicules of equal size.

\section{Strongyloides intesti-} nalis, Bavay, 1877 .

Syn. : Anguillula intestinalis et stercoralis, Bavay, I 877 ; Leptodera intestinalis et stercoralis, Cobb; Pseudorhabditis stercoralis, Perroncito, $188 \mathrm{I}$; Rhabdonema strongyloides, Le uckar t, I 883 ; Strongyloides intestinalis, Grassi, I883 ; Rhabponema intestinale, Blanchard, I 886.

In 1876 , a number of French soldiers returned to Toulon from Cochin China suffering from severe diarrhœa. Dr. Normand, the doctor under whose treatment they were, discovered a large number of small Nematodes in the evacuated fæces, and Bavay described them as Anguillula stercoralis. Soon after Normand, at the post mortem of a man who had died of Cochin China diarrhœa, found numerous other Nematodes in the intestine, 
and these he likewise handed over to Bavay. The latter recognised another species, and described it as Anguillula intestinalis. Both forms were then regarded as the cause of Cochin China diarrhœa, until, in I882, Leuckart was able to demonstrate that the two forms are only two succeeding generations of the same species, of which the one (A. intestinalis) lives parasitically in the intestine, whereas its young (A. stercoralis) attain the open, where they come to maturity and propagate. The young of these live again parasitically. There thus exists the same heterogony as was discovered by Leuckart in Rhabdonema nigrovenosum of frogs, which heterogony indeed, according to $\mathrm{v}$. Linstow, appertains to the entire family of the Angiostomidæ.

(I) The parasitical generation (Anguillula intestinalis) measures $2.2 \mathrm{~mm}$. in length, and $0.034 \mathrm{~mm}$. in breadth; the cuticle is finely transversely striated; the mouth is surrounded by four lips; the œsophagus is almost cylindrical and a quarter the length of the entire body. The anus opens shortly in front of the pointed posterior extremity; the female genital orifice is situated in the posterior third of the body; the eggs measure $0.050-$ $0.058 \mathrm{~mm}$. in length, and $0.030-0.034 \mathrm{~mm}$. in breadth. As is the case in Rhabdonema nigrovenosum, Leuckart considers this generation to be hermaphroditic; other authors (Rovelli) regard it as consisting of females reproducing by parthenogenesis.

(2) The free-living generation (Anguillula stercoralis) is certainly sexually differentiated; its body is smooth, cylindrical, somewhat more slender at the anterior extremity and pointed at the tail end. The mouth has four indistinct lips; the osophagus is short, with a double (rhabditis-like) dilatation; there are three little teeth in the posterior dilatation; the anus opens in front of the tail end. The males measure $0.7 \mathrm{~mm}$. in length, $0.035 \mathrm{~mm}$. in breadth. They carry their posterior end rolled up; the two spicules are small and much curved. The females measure I mm. in length or a little over; $0.05 \mathrm{~mm}$. in breadth. The tail-end is straight and pointed; the vulva lies somewhat behind the middle of the body. The yellowish, thin-shelled ova measure $0.07 \mathrm{~mm}$. in length, and $0.045 \mathrm{~mm}$. in breadth.

As Askanazy has shown the form that lives parasitically bores deeply into the mucous membrane of the intestine, and frequently into the epithelium of Lieberkühn's glands, both for nourishment and oviposition. The eggs then develop in the intestinal wall. The young, which are hatched out, and measure $0.2 \mathrm{~mm}$. in length, again reach the lumen of the intestine, ${ }^{1}$ and grow to double or three times

' As a case published by Teissier testifies, they may also abnormally appear in the circulatory system (Arch. méd. expér. et d'an. path., 1895, vii., p. 675). 
that size, until they are passed out with the fæces. They already differ from the parent in the shape in the œesophagus. When the external temperature is sufficiently high $\left(26\right.$ to $35^{\circ} \mathrm{C}$.), they become mature after moulting. In about thirty hours they are completely developed and copulate. At a low temperature they certainly cast their skin, but do not escape from the old cuticle and do not develop further. At a temperature of about $25^{\circ} \mathrm{C}$. only some of the larvæ attain maturity.

Every female of the freeliving generation deposits from thirty to forty eggs, which develop rapidly, sometimes even within the uterus. After the young have emerged from the egg-shell, they measure $0.22 \mathrm{~mm}$. in length, and possess the characteristics of the parents (rhabditis form). When they have grown to $0.55 \mathrm{~mm}$. they moult, and while losing their own characteristics they acquire the characteristics of their grandparents (Strongyloid or Filariform larva). After about eight days the free-living adult generation in the cultures has disappeared, and all the young have been transformed into the Strongyloid form: they then die off unless they reach the intestine.

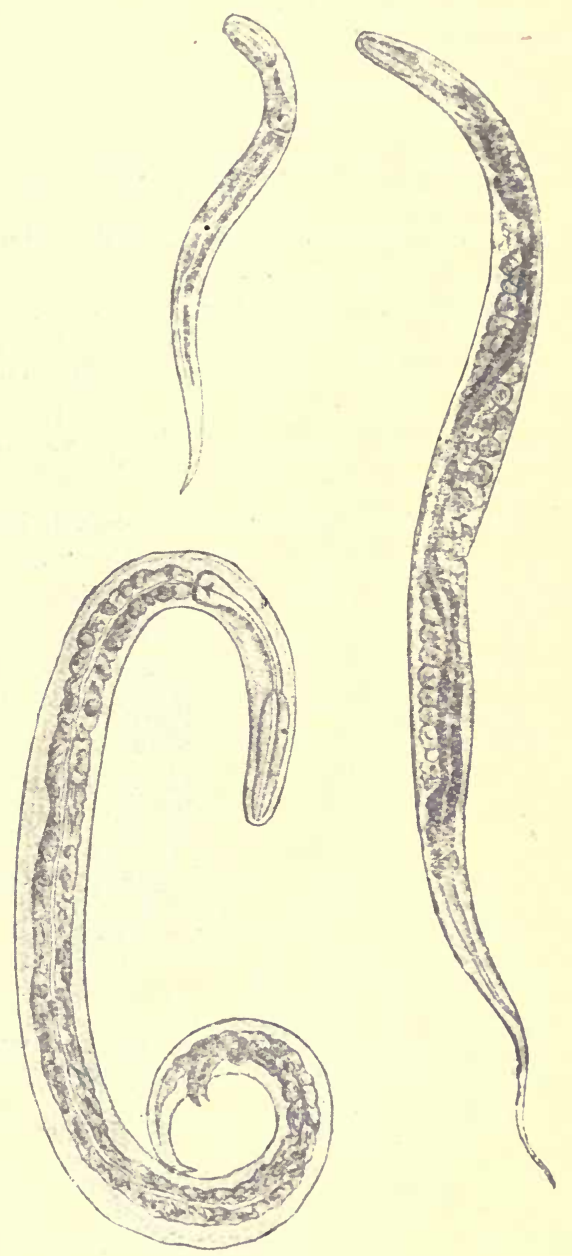

FIG. I92. - Strongyloides intestinalis. On the left above a larva from the faces; under it a male of the free-living generation, on the right a female. Magnified. (After Zinn.)

This cycle of development holds good for Strongyloides intesinalis of tropical origin (Bavay, Leuckart, Leichtenstern, Zinn). In the European Strongyloides the free-living generation, as a rule, is absent (Grassi, Sonsino, Leichtenstern, Braun); the rhabditislike larvæ evacuated with the fæces are transformed into the 
Strongyloid or Filariform type of larva in the cultures, which are easily prepared, and in any case will become adult if introduced into man.

Occurvence in Man.-Ass already mentioned, Strongyloides intestinalis was first observed in persons suffering from so-called Cochin China diarrhœa. By the enormous numbers of parasites evacuated with the fæces, the cause of the disease could be diagnosed at a glance. It appeared, however, that only some of the soldiers returning from Cochin China and Martinique, and suffering from diarrhœe, harboured Strongyloides (Chauvin). Breton made the same observations in Cochin China and found that only 104 per cent. of cases of chronic dysentery, and 8.8 per cent. of chronic diarrhoea, show Strongyloides. Normand, moreover, learned that only a few of the Europeans residing in Cochin China are exempt from Strongyloides intestinalis, yet the people exhibit no intestinal symptoms; if, however, from any cause a catarrhal condition of the intestine supervenes the condition is changed, the parasites appear in larger numbers, and the disorder is considerably intensified.

Strongyloides intestinalis, besides being present in the Indo-China region, also occurs in the Antilles, in Brazil, Africa and Europe; in 1878 it was discovered in Italy by Grassi and C. and E. Parona ; in I880 it was also found in the labourers working at the St. Gothard tunnel. It was imported into Germany, Belgium and the Netherlands by Italian labourers. One sporadic case has been observed in East Prussia, and the worm has also been reported ${ }^{\circ}$ from Siberia.

\section{LITERATURE.}

Normand, A. Sur la maladie dite diarrhée de Cochinchine. (C. R. Ac. sc. Paris, I 876, lxxxiii., p. 3I6.)

Mém. sur la diarrhée de Cochinchine. (Arch. méd. nav., 1877, xxvii., p. 35.)

Du rôle étiologique de l'anguillule dans la diarrhée de Cochinchine. '(Ibid., I 878 , $\mathrm{xxx}$., p. 214.)

Bavay. Sur l'anguillule stercorale. (C. R. Asc. sc. Paris, I876, 1xxxiii., p. 694.)

Sur l'anguillule intestinale, \&c. (Ibid., I 877 , lxxxiv., p. 266.)

Dounon. Etudes sur l'anatomie pathol. de la dys. chron. (Arch. de phys., 1877, ix., p. 774.)

Chauvin. L'anguillule stercorale dans la dysenterie des Antilles. (Arch. méd. nav., I 878 , xxix., p. I 54 .)

Grassi, B. Sovra l'anguillula intestinale. (Rend. Ist lomb. sc. e lett., 1879 [2], xii., p. 228.)

Grassi, B., and C. Parona. Sovra l'anguillula intestinale, \&c. (Arch. sc. med., I 879 , iii., p. IO.)

Perroncito, E. Obs. sur le dével. de l'anguillula intestinalis Bav. (Journ. de l'anat. et de la phys., I887, xvii., p. 499.)

Leuckart; R. Ueber die Lebensgesch. d. sog. Anguill. stercor., \&c. (Ber. d. math.phys. Cl. d. k. sächs. Ges. d. Wiss., I 883, p. 85).

Seifert. Ueber Anguill. stercoralis. (Stzgsb. d. phys.-med. Ges. Würzburg, I883, p. 22.)

Grassi, B., and R. SEgRE. Nuove osservaz. sull' eterogenia del Rhabd. intest. (Atti R. Accad. Lincei. Rendic., I 887 [4], iii., p. IOO.)

Rovelli, G. Rich. s. org. genit. d. Strongyloides. Como, I888.

Sonsino, P. Tre casi d. mal. da Rhabd. intest. o Rhabdonemiasi. (Suppl. d. Riv. gen. ital. di clin. med., i 89 I, 20, vii.)

Leichtenstern, O. Ueb. Anguillula intest. (Dtsch. med. Wchschr., I898, No. 8, p. II 8.)

Z. Lebensgesch. d. Ang. intest. (C. f. B., P. u. I., I 899 [I], xxv., p. 226.) 
Pappenheim. Ein sporad. Fall v. Ang. int. in. Ostpreuss. (Ib., I899, xxvi., p. 608.) Braun, M. Bemerk. z. d. spor. Fall v. Ang. int. in Ostpr. (Ib., p. 6I2.) ZiNN, W. Ueb. Ang. intest. (Ib., p. 626.)

Askanazy, M. Ueb. Art. u. Zweck d. Invas. d. Ang. int. i. d. Darmwand. (Ib., 1900, xxvii., p. 569.)

Kurlow, M. von. Ang. int. als Urs. blut. Durchf. b. Mensch. (C. f. B., P. u. I., $1902[\mathrm{I}]$, xxxi., Orig., p. 6I4.)

\section{(c) Fam. Gnathostomida.}

Gen. 4. Gnathostoma, Owen, I836.

Syn. : Cheiracanthus, Diesing, I839.

Easily recognisable by the numerous spines which cover the entire body or only the anterior extremity, and terminate in several points; head globular and beset with bristles; mouth with two lips; two spicules; vulva situated behind the middle of the body.

Gnathostoma siamense, Levins., I889.

Syn.: Cheiracanthus siamensis, Lev., I889.

Only one specimen, a female, has hitherto been known; it measures $9 \mathrm{~mm}$. in length, I $\mathrm{mm}$. in breadth.' There are eight rows of bristles around the head; the armature of spines extends over the anterior third of the body only; each spine on the anterior region of the body spreads into three points, of which the middle one is the longest; the posterior spines are simple; they gradually become smaller, and then disappear entirely. The vulva is situated behind the middle of the body.

The single specimen described by Levinsen was found by Dr. Deuntzer in Bangkok (Siam) and was obtained from a young Siamese woman who suffered from a small tumour of the breast, which had developed in the course of a few days. After the disappearance of the tumour, nodules, the size of beans, were

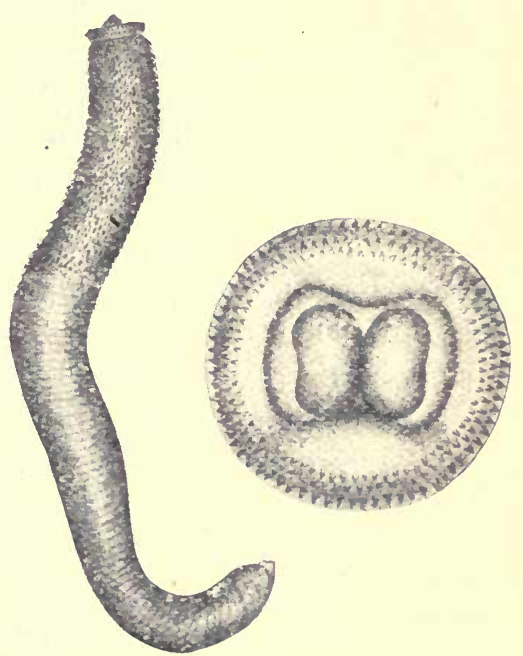

FIG. I93. - Gnathostoma siamense. To the left, the entire worm, $8 / 1 ;$ to the right the head seen from above, about 40/1. (After Levinsen.) found in the skin; out of one of these the worm was obtained. The same doctor observed this affection in two other persons. ${ }^{1}$

"Levinsen, G. M. R., "Om en ny rundworm hos mennesket" (Vidensk. meddel. fra naturh. Foren. i. Kjobenhavn f., 1889, p. 323, with one plate). Ref. in Centralbl. $f$. Bact. u. Paras., I 890 , viii., p. I 82 . 
A closely related species, Gn. spinigerum, Ow., lives in the stomach of some species of wild cats (Felis catus, F. concolor, F. tigris); another species (Gn. hispidum, Fedsch.) lives in the stomach of pigs in Turkestan, but has also been found by Csoker in pigs in Hungary, and by Collin in the stomach of an ox (Berlin). The pariah dogs of Calcutta are also subject to a species of Gnathostoma.

(d) Fam. Filariida.

Gen. 5. Filaria, O. Fr. Müller, I787.

These are mostly very long, slender Nematodes, the males of which are usually considerably smaller than the females. The tails of the males are bent or spirally rolled, and sometimes bear little wing-like appendices. The two spicules are very unlike in size and structure; almost always there are "four pre-anal papillæ, but the number of post-anal papillæ varies. The vulva is always situated at the anterior extremity. The filariæ live parasitically chiefly in the serous cavities and in the subcutaneous connective tissue.

\section{Filaria medinensis, Velsch, 1674.}

Syn.: Vena medinensis, Velsch, 1674; Dracunculus Persarum, Kämpfer, 1694 ; Gordius medinensis, Linné, 1758 ; Filaria dracunculus, Bremser, I819; Filaria cethiopica, Valenciennes, 1856; Dracunculus medinensis, Cobbold, I864; Guinea worm, Medina worm.

The females attain a length of $50-80 \mathrm{~cm}$., or even more, and average $0.5-I^{\circ} 7 \mathrm{~mm}$. in diameter. They are whitish or yellowish in colour. The anterior extremity is roundish. The mouth opening is surrounded by two lips, behind which there are two lateral and four sub-median papillæ; the posterior end terminates in a spine, ventrally directed, and about I $\mathrm{mm}$. in length ; the alimentary canal below the œesophagus is atrophied, but not entirely obliterated; the lateral ridges are very flat. The greater part of the body is occupied by the long uterus, in which a great number of young larvæ are always found. The ovaries probably lie at the ends of the uterus; the vulva and vagina are not known.

According to a recent observation of $\mathrm{R}$. H. Charles, the male - of Filaria medinensis has at last been discovered. On two female filariæ, which were found in a post mortem at Lahore, a smaller worm, measuring about $4 \mathrm{~cm}$., was found clinging to each, attached by its posterior extremity to a part of the female about I4 $\mathrm{cm}$. from the head extremity. It may be assumed that the males were attached to the vulva of the females, as is the case 
in Syngamus trachealis, ${ }^{1}$ and that the males die after copulation.

Occurrence.-Filaria medinensis has been known since the most remote period. The "fiery serpents " that molested the Israelites by the Red Sea, and which Moses mentioned, were probably filariæ. The term $\Delta$ paќvтเov already occurs in Aga-

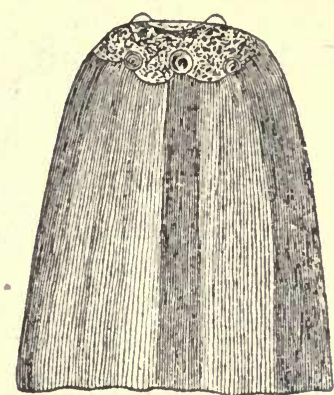

FIG. $194($ a).-Anterior extremity of Guinea worm. After Leuckart.
Galen called the disorder dracontiasis; the Arabian authors were well acquainted with the worm. It is found not only in Medina or Arabia, but also in Persia, Turkestan, Hindostan. The Medina worm is also widely distributed in Africa, on the coasts as well as in the interior. (The English term is Guinea worm:) It was carried to South America by negro slaves, but is said to have again disappeared thence; it is also frequently observed in mammals (ox, horse, dog, leopard, jackal, Canis lupaster, \&c).

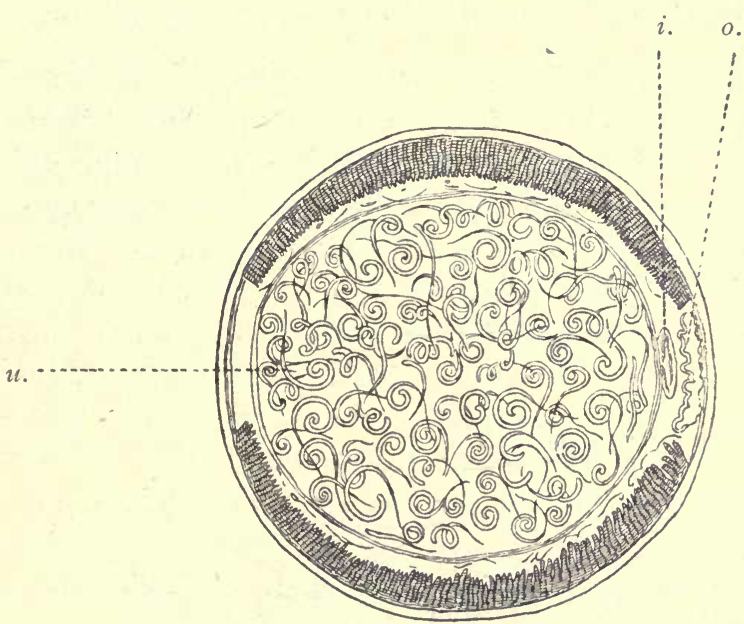

FIG. I94 (b).-Transverse section of female Guinea worm; $u$., uterus containing embryos; $i$., intestinal canal; o., ovary. After Leuckart.

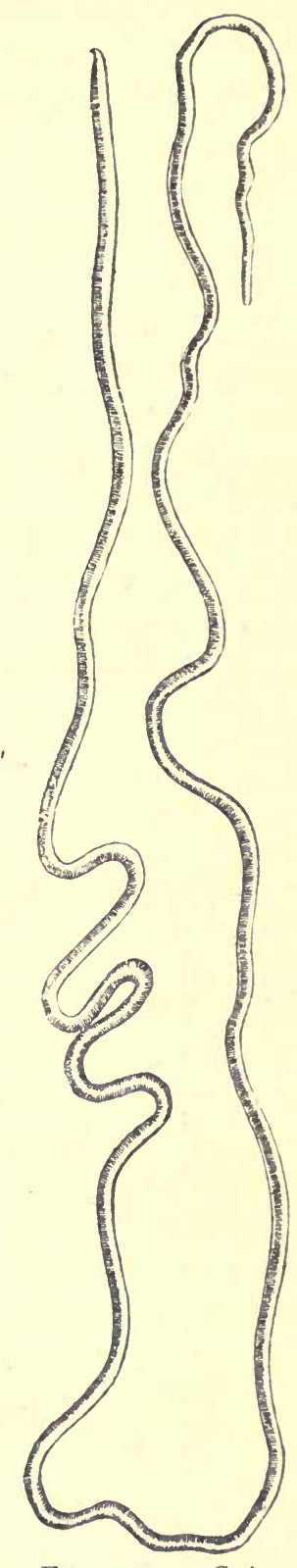

FIG. I94. - Guinea worm (Filaria medinensis). After Leuckart.

${ }^{1}$ The confirmation of this opinion can be seen in an observation of Neumann, who, in the connective tissue of Python natalensis, found the males as well as the considerably larger females of Filaria dahomensis; the males, apparently after copulation, finally die off and become calcified (Bull. soc. zool., France, 1895, xx., p. 123). 
Filaria medinensis in its adult stage lives beneath the surface of the body: it is seen most frequently on the lower extremities, more especially in the region of the ankle; but it also occurs in other parts of the body-on the trunk, scrotum, perinæum, on the upper extremities, and in the eyelids and tongue. As a rule, there is only one ulcer and one worm, rarely several. It attacks man without distinction of race, age or sex. It is observed most frequently during the months of June to August.

The following is known of the development of this filaria: The larvæ, which in form resemble those of Cucullanus belonging to the order of the Nematoda, can only reach the open after the bursting of the mother's body. For a few days they live in water or moist soil, and can withstand desiccation for a few hours. In consequence of their similarity to those of Cucullanus elegans (parasite of Perca fuviatilis), which live in cyclops, Fedschenko, by the advice of Leuckart, introduced the larvæ of the filaria into water containing cvclops, the larvæ of insects, \&c., and was able to confirm their invasion of the cyclops (not per os, but through the integuments of the body). On about the twelfth day they cast their skin and assumed another form. They could be observed within the cyclops until the fourth week, yet no changes occurred though the larvæ grew to a length of $\mathrm{I} \mathrm{mm}$. The experiment to infect young cats and dogs with filariæ by giving them infected cyclops in milk or water failed. There is, however, always the possibility that the infection of man is accomplished in this manner. A series of observations appear to demonstrate that the period of incubation averages from eight to ten months.

P. Manson and R. Blanchard have recently repeated the infection experiments with fresh-water cyclops, and have convinced themselves of the correctness of Fedschenko's observations. Daphnidæ were not used, only Copepodæ (Cyclops strenuus, C. bicuspidatus, and $C$. viridis). As the species mentioned are indigenous forms, Blanchard thinks the probability is not excluded that the Medina worm if imported-and such importation does occur-may also settle in Europe.

\section{LITERATURE.}

Bastian, A. On the Structure and Nature of the Dracunculus. (Transact. Linn. Soc., I 863 , xxiv., p. IOI.)

Leuckart, R. Die menschlichen Parasiten, \&c. (1876, i., Edit. ii., p. 644.)

Fedschenko. Bau und Entwickelung der Filaria. (Ber. d. K. Ges. der Frde. d. Natur. Anthrop. u. Ethnogr., I879, viii. [I], p. 71, I plate, Russ.)

Moster, F. Ueber die medic. Bedeutung des Medinawurmes. Wien, Lpzg., I 885.

Charles, R. H. History of the Male Fil. med. (Scientif. Mem. Med. Offic. Army of India, vii., I892, Calcutta.)

Railliet, A. De l'occurence de la Filaire de Médine chez les animaux. (Bull. soc. zool. de France, 1889, xiv., p. 73.)

Blanchard, R. Mal, par., par. anim., Paris, I895, p. 768.

Manson, P. On the Guinea-worm. (Brit. Med. Journ., London, I895, ii., p. I350; The Lancet, 1895 , xxxvii., ii., p. 309.) 


\section{Filaria immitis, Leidy, 1856 .}

The body is very thin and filiform; the posterior extremity is pointed, and the anterior one rounded off; the mouth is terminal, and behind it there are six small papilla; the anus opens near the posterior extremity; the male measures $12-\mathrm{I} 8 \mathrm{~cm}$. in length, $0.7-0.9 \mathrm{~mm}$. in breadth; the tail is slender and twisted like a cork-screw; it has a fold of skin at either side and four pairs of large pre-anal, and some smaller post-anal papillæ, the surface of which exhibit a smooth appearance. The female measures $25-30 \mathrm{~cm}$. in length and $\mathrm{I}^{\circ} \mathrm{O}-\mathrm{I} \cdot 3 \mathrm{~mm}$. in breadth; the vulva is about $7 \mathrm{~mm}$. distant from the anterior extremity; viviparous; the larvæ measure $0.285-0.295 \mathrm{~mm}$. in length, and $0.005 \mathrm{~mm}$. in breadth; the posterior extremity terminates in a very thin point.

Filaria immitis lives chiefly in the right cavities of the heart, also in the venous system of dogs, but appears also to occur in the wolf (Japan) and in the fox; in Europe it is most frequent in Italy; it is very frequent in China and Japan, where, according to Janson, about 50 per cent. of the dogs are infected. It has also been observed in N. and S. America.

According to Bowlby, this species occurs also in man. At the post mortem of an Arab, who had suffered from hæmaturia, this author found numerous filariæ in the portal vein, and the eggs of Nematodes in the thickened wall of the bladder, in the kidneys, ureters, and in the lung. Similar eggs are also said to have been found in a rectal tumour in a youth, aged 17 . The filariæ found were identified as Filaria immitis.

[The eggs of Nematodes found by Bowlby in the thickened wall of the bladder, in the kidneys, ureters and in the lung of an Arab suffering from hematuria, were undoubtedly those of Schistosoma hamatobium. Probably the worms he found in the portal vein of the same patient were female specimens of Schistosoma and not specimens of Filaria immitis.-L. W. S.]

Large numbers of Nematodes of a considerable length were found in the veins of a Russian whose body was dissected in Dorpat in 1885. Having myself seen and prepared the well-preserved worms I could not fail to observe their filarial nature, but $I$ am not in a position to give more details as I was unable to examine them more minutely.

The life history of Filaria immitis has been elucidated by Grassi and Noé. It was, however, already known that the larvæ appear in the blood of infected dogs, especially during night time.

The larvæ of Filaria immitis, like the malaria parasites, are taken 
up with the blood by mosquitoes in the process of sucking; however, whilst for the malaria parasites of man only the genus

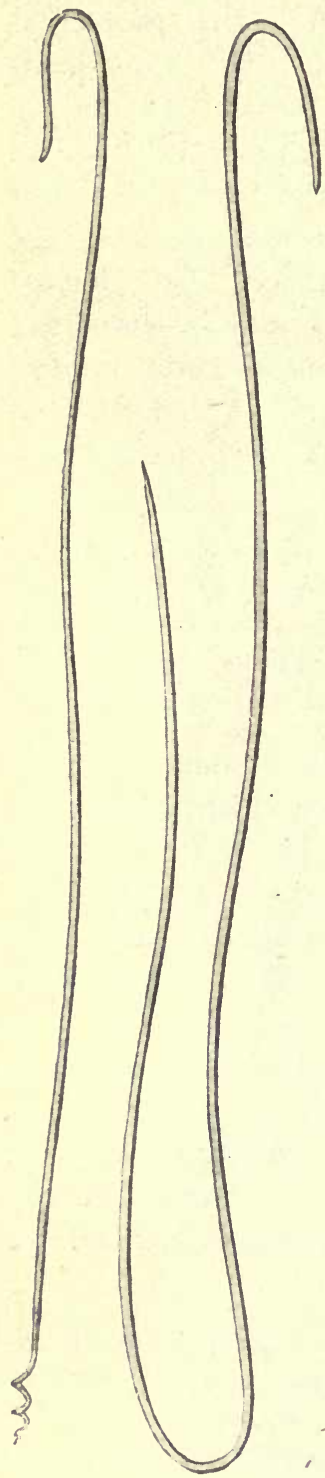

Fig. I95. - Filaria immitis, natural size; the male is on the left and the female on the right side. (After Railliet.) Anopheles comes into consideration, the larva of Filaria immitis thrive equally well in Anopheles and Culex. The conditions, however, are not quite alike, because Culex pipiens is not so easily infected. The filarial larvæ, however, leave the stomach of the mosquito, and penetrate into the malpighian tubes or their epithelial cells. They here undergo a series of changes, moult, and on the twelfth day after the infection of the mosquitoes perforate the organ they have been inhabiting, and thus reach the body cavity, which communicates with the labium; by penetrating into the thorax, the larvæ, which have attained a length of $0.9 \mathrm{~mm}$., reach the head and finally the labium, where they await until the mosquito bites a dog. Though the labium is not introduced into the wound made in biting, but bends backwards, forming an angle, yet during the process it tears its very delicate cuticle, and the larva avail themselves of this rent to escape. They penetrate between the labium and the stylets, thus finding the wound, which enables them to enter into the vascular system. In order to meet the objection that the dogs infect themselves per os--that is to say, by biting and swallowing infected mosquitoes swarming around them, the experimental animals were prevented (by muzzles) from devouring the mosquitoes. These experiments also succeeded.

[Grassi and Noè's theory as to the mode of escape of Filaria immitis is untenable. The filariæ escaping through a rent of the labium at the part which bends during suction would be unable to reach and penetrate the wound made by the lancets. In a paper published in the Journal of Tropical Medicine, ${ }^{1}$ Dr. Dutton suggested 
that the filaria might possibly escape at the tip of the labium between the labellæ. In a second and more recent paper $^{1}$ on the Transmission of $F$. immitis, Dr. Noè admits that it is impossible for the filariæ to escape, as he had at first suggested. Having made numerous and suitable experiments he found that the filarix invariably died when extruded at the seat of the bend. He. therefore believes that the filariæ must leave their insect host, as suggested by Dutton, through the delicate structures between the labellæ at the tip of the labium.

Having noticed that the filariæ (both $F$. immitis and F. bancrofti) collect in the lacunoma round the pharynx or pumping organ of the mosquito, and having found them also actually within the pharynx, I suggested ${ }^{2}$ that they might pierce the delicate membrane which connects the chitinous plates of the pharynx, and thus reach the buccal cavity of the insect, to pass between the piercing organs into the definitive host. I believe too much importance has been given to the fact that the filariæ are frequently found within the labium. Their presence in the labium does not necessarily mean that they must escape through that organ. It is obvious that

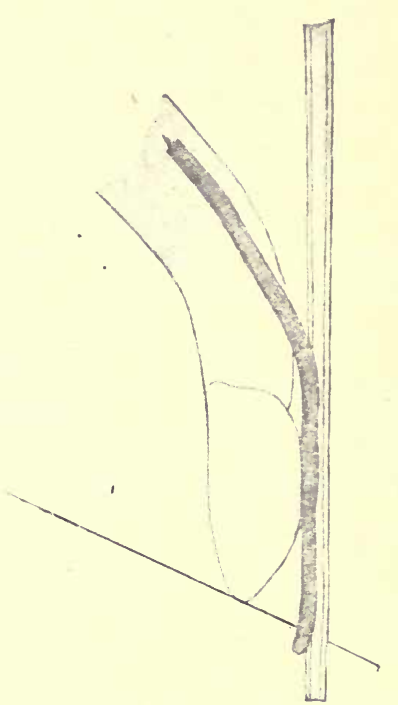

FIG. 196.- The inferior end of the mouth organs of a mosquito being introduced into the skin of a dog, by which means a filaria, lying between the labium and the stylets, is transmitted to the animal. Magnified. (After Noè.) when a number of filariæ have gathered round the pharynx, a few must be pushed forwards by new-comers into those parts which continue the body cavity anteriorly. Consequently the presence of filariæ in the labium has no other significance than their not uncommon presence within the palpi, from which they can certainly find no means of escape.-L. W. S.]

Filaria recondita is another parasite of dogs, the larve of which appear in the blood; fleas are their intermediary hosts.

\section{LITERATURE.}

Bowlby. Two cases of Filaria immitis in Man. (The Lancet, I889, i., p. 786.) Magelhães, P. S. de. Die Filaria Bancrofti, Cobb., u. Filaria immitis, Leid. (C. f. B. u. P., I 892 , xii., p. 5 I I.)

Grassi, B. Beitr. z. Kenntn. d. Entwickelungscyclus von 5 Paras. d. Hundes (Ibid., I 888 , iv., p. 609.)

'Noè, G., "Ulteriori studi sulla Filaria immitis" (Rend. Acc. d. Lincei, vo'. xii., I903).

"Sambon, L. W., "Filaria Bancrofti and Filaria immitis" (Lancet, I902.) 
Grassi, B., and CALANDruccio. Ueber Hæmatozoon, Lewis. (Ibid., I89o, vii., p. I8. LEwIs, T. R. On Nematode Hæmatozoa in the Dog. (Quart. Journ. Micr. Sc., I 875 , xv., p. 268.)

Sonsino, P. Ricerche sugli hemtozoi del cane. (Atti soc. tosc. di sc. nat., I 888 , x.)

Grassi, B., and G. Nó́. Uebertrag. d. Blutfil. ganz ausschliessl. durch d. Stich von Stechmücken. (C. f. B., P. u. I., I900, [i.] xxviii., p. 652.)

Sul ciclo evolut. d. Fil. Bancrofti e. d. Fil. immitis. (Ric. Lab. di An. norm. R. Univ. Roma ed in altri Labor. biol., I901, viii., p. 275.)

\section{Filaria bancrofti, Cobbold, 1877 .}

Syn.: Trichina cystica, Salisbury, I 868 (nec Filaria cystica, Rud. I819); Filaria sanguinis hominis, Lewis, 1872; Filaria sanguinis hominis agyptiaca, Sonsino, I875; Filaria wuchereri, da Silva Lima; Filaria sanguinis hominum, Hall, I885; Filaria sangunis hominis nocturna, Manson I891 ; Filaria nocturna, Manson, 1891 .

The male is colourless, and measures about $40 \mathrm{~mm}$. in length and $O . I \mathrm{~mm}$. in diameter. The cephalic extremity is a little thickened, the posterior extremity is bent and rounded, but is not twisted corkscrew-like. The anal orifice opens $0.138 \mathrm{~mm}$. in front of the posterior border. There are three pairs of small pre-anal and an equal number of post-anal papillæ; the spicules are unequal $\left(0^{\circ} 2\right.$ and $0.6 \mathrm{~mm}$. in length). The female is brownish, $76-80 \mathrm{~mm}$. in length, $0.2 \mathrm{I}-0.28 \mathrm{~mm}$. in breadth; the cephalic and caudal extremities rounded; the vulva is $\mathrm{I} \cdot 27 \mathrm{~mm}$. distant from the head, and the anus $0.28 \mathrm{~mm}$. away from the posterior extremity. Almost the entire body is occupied by the two uteri, from which the larve emerge early. The length of the latter averages $0.13-0.3 \mathrm{~mm}$., their breadth $0.007-0.01 \mathrm{~mm}$. They are surrounded by a delicate protective investing membrane, which is not quite close to them.

These parasites of man were for a long time only known in their larval stage. They were discovered in 1863 in Paris by Demarquay, in the hydrocele fluid of a Havannese emptied by puncture; they were next observed by Wücherer, in Bahia, in the urine of twenty-eight cases of tropical chyluria; they were likewise observed in North America by Salisbury, who gave them the name of Trichina cystica. The next discoveries in Calcutta, Guadeloupe, and Port Natal related to chyluria patients, until Lewis discovered the larvæ in the BLOOD of man (India); and found they were almost always present in persons suffering from chyluria, ELEPHANTIASIS, and lymphatic enlargements; he also, in exceptional cases, found them in apparently healthy persons (Filaria sanguinis hominis). Lewis and Manson studied the disease and the filariæ of the blood very minutely, and became aware that the filariæ were sucked up by mosquitoes with the blood. Manson described the metamorphoses that take place within the body of the mosquito. The adult female was discovered 
in Queenșland by Bancroft, and soon after Lewis found it in Calcutta; it was described by Cobbold as Filaria bancrofti. The male was first seen by Bourne in 1888 .

The lymphatic vessels of various parts of the body of man are doubtless the normal habitat of the ADULT wORMS, but these have also been found in the left ventricle of the heart. The females are viviparous, but exceptionally they also deposit eggs; the young larvæ, by means of the lymph stream, reach the blood, and are distributed with it throughout the body; they also pass through the blood vessels, and may be found in the secretions of glands, such as the lachrymal and Meibom's glands, kidneys, \&c. The manner of appearance in the peripheral circulation, which has been particularly studied by Manson, is peculiar: the larvæ are first seen in patients, the blood specimens of which have been taken after sunset. Their number then increases considerably until about midnight, and after begins to diminish ; from midday until the evening no filariæ are found in the peripheral blood. The cause of this peculiarity cannot be explained, as was conjectured, by a periodical production of larvæ, because the cycle can be reversed. If the patients are made to sleep in the day-time and remain awake at night, the filariæ appear in the day-time and disappear at night. The manner of appearance, therefore, is connected with sleep, and depends on the fact (v. Linstow) that during sleep the peripheral cutaneous vessels are somewhat dilated, but during the waking hours are contracted; the filariæ cannot pass through the contracted capillary system, but remain in the larger trunks in the depth of the cutis. ${ }^{1}$

[The night swarming of the larvæ of $F$. bancrofti in the peripheral circulation is correlated with the life-habits of its liberating agent. We can find a large number of similar remarkable correlations in Nature. Many flowers which open early in the morning are only visited by particular butterflies which leave their nocturnal haunts at the same hour; other flowers do not open till sunset, and they are visited by hawk-moths, silk-moths, owlet-moths and other Noctuæ, which commence their ramblings when dusk sets in.

Then again, the development of flower scent is simultaneous with

'Manson was able to examine the body of a man who died from poisoning at 8.30 a.m. During life the filariæe had appeared regularly in the blood from 6 p.m. to $8 \mathrm{a} . \mathrm{m}$. They were entirely absent from the peripheral circulation, but were found in the large vessels, particularly in the arteries; further, in the capillaries of the brain and of the voluntary muscles, in the vessels of the kidneys and the heart. The largest numbers were present in the pulmonary vessels. Manson does not accept v. Linstow's explanation, but is of opinion that the products of metabolisin of a waking person drives the filariæ from the periphery or attracts them to the interior (Manson, P.. "On Filarial Periodicity," Brit. Med. Journ., London, 1899, ii., p. 644). 
the time of flying of certain insects. The flowers of Hesperis tristis, and other flowers which are visited by small nocturnal moths, give off no scent during the day, but exhale a strong hyacinth odour at twilight; on the other hand, many flowers visited during the day become scentless at night.-L. W. S.]

It is an interesting fact that the appearance of the filarix in the peripheral circulation tallies with the swarming period of the mosquitoes, and this affords the mosquitoes the opportunity of extracting some of the filarix from the body of human beings whilst sucking their blood; others, again, through the blood vessels

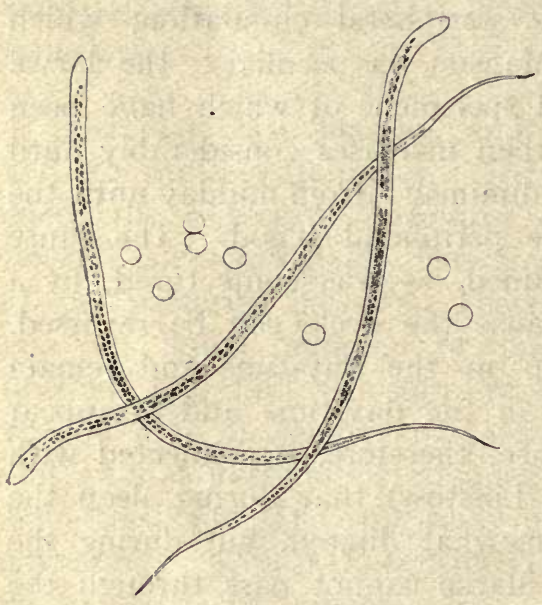

FIG. 197.-Larvæ of the Filaria bancrofti in the blood of Man. Magnified. (After Railliet.)

of the glomeruli, attain the urinary tubules and escape with the urine. This, however, only appears to be an unusual way.

The filariæ appear in the blood in great numbers - 140,000 according to Lewis's calculations, as many as $30,000,000-40,000,000$ according to Carter and Mackenzie, provided, however, always that their number in the total quantity of blood is evenly distributed and equal to the average contained in the blood tests.

By observing in the moist chamber a drop of blood containing filarial larvæ, it will be seen that after a little time, namely, when the hæmoglobin from the blood corpuscles appears in the plasma, the filarix escape from their sheaths; a six-lipped collar is then distinguishable at their anterior extremity, surrounding a conical and fairly thick rostellum, at the point of which there is a retractile filament. This complicated structure appears to be especially adapted for boring through and dilating the tissues. It comes into action when the filariæ have reached the intestine of mosquitoes, ${ }^{1}$ where the above-mentioned alterations of the blood take place. The filariæ, which have escaped from their sheaths, bore through the intestinal wall and settle amongst the thoracic muscles of the

${ }^{1}$ The species in question are stated to be Culex ciliaris, L. ; Culex skusi, Giles ; Culex treniatus, Meig. ; and Culex fatigans, Wied.

[C. ciliaris. L. $=$ C. pipiens, L. ; C. skusi, Giles $=$ C. fatigans, Wied. ; C. taeniatus, Meig, = Stegomyia fasciata, Fabr.-F.V.T.]. 
mosquitoes, where, in a few days, as already described by Manson in I884, they undergo considerable changes; they grow to a length of $\mathrm{I}^{\circ} 5 \mathrm{~mm}$. and a breadth of $0.25 \mathrm{~mm}$. Of course many specimens perish within the intestine of the mosquito. The general opinion was that the filarial larvæ, after such changes, attained the water at the death of the female mosquito and were introduced into man with the infected water. This opinion was supported by the observation that, whereas the unaltered filarixe are exceedingly susceptible to water, those that have come to maturity within the mosquitoes can bear immersion very well. Nevertheless, this view is not correct, although recently Maitland has sought to revive it. It is more probable that the larvæ of Filaria bancrofti are transmitted by the bite of infected mosquitoes just like those of Filaria immitis. It is quite certain that in the last stage of their metamorphosis the larvæ leave the thoracic muscles of the mosquitoes and enter the body cavity; from here they do not reach the open by way of the œesophagus, but proceed to the mouth parts, or rather the labium. We may therefore conclude quite positively that when the infected mosquitoes bite, the same mechanism that directs Filaria immitis into the punctured wound of the dogs is likewise adopted in the transmission of Filaria bancrofti to man. [The transmission of Filaria bancrofti through the mouth parts of mosquitoes was suggested by $\mathrm{me}^{1}$ and demonstrated by Dr. G. C. Low ${ }^{2}$ before Noə̀ and Grassi published their paper on the transmissions of Filaria immit's. -L. W. S.]

Filaria bancrofti, or Fil. sanguinis hominis, is known in nearly all tropical countries. It occurs in India, China, Japan, Australia, Queensland, the Islands of Polynesia (with the exception of the Sandwich Islands), Egypt, Algeria, Tunis, Madagascar, Zanzibar, Sudan, \&c., the south of the United States of America, Brazil, the Antilles, \&c. ${ }^{3}$

The disease (filariasis) presents a series of very diverse symp-

IJourn. of Tropical Medicine, April I4th, 1900, p. 219.

${ }^{2}$ Brit. Med. Journ., June I6th, I900.

${ }^{3}$ According to Font, indigenous filariasis also occurs in Europe; he reports the case of a man who, since his eighteenth year, had suffered from hamato-chyluria and enlargement of the szrotum, and whose blood exhibited filariæ. With the exception of a short time spent in San Sebastian, the patient had never left his birthplace (Canet de Mar, 4I km. north of Barcelona). Two further cases of hæmato-chyluria were reported from the same district, but no microscopical examination of the blood and urine was undertaken in these (Font, M. "De la Filariosis: expos. del primer caso esporad. observ. en Europa," Riv. cienc. méd. de Barcelona, 1894, pp. 73 and 97 ; ref. in $C$. f. B. u. P., xvi., p. 85). In a case of indigenous elephantiasis originating in Brest, the blood examination had a negative result (Guyot, "Un cas d'elephant. indig. obs. à Brest," Arch. med. nav., 1892, lviii., p. 192 ; "A Autre cas d'eleph. des arabes dével. en Bretagne," Ibid., I 893 , lix., p. I I 5 ). 
toms. During the initial stages, which may extend over a long period, there are no subjective disorders; the infection is only demonstrated by the filariæ in the blood; sooner or later anæmia, enlargement of the spleen and fever set in; lymphatic tumours also appear in various situations, the testicles or spermatic cord being mostly attacked in men. In consequence of engorgement of the lymph vessels it is not uncommon for a sort of elephantiasis to develop, generally in the scrotum and lower extremities; enlargements of the lymphatic glands are also set up; later on chyluria or hæmaturia, inflammation of the kidneys and other parts of the urinary apparatus, as well as of the peritoneum, occur.

\section{LITERATURE.}

Demarquay. Note sur une tumeur de bourse. . . renferm. . . des helmintes nématoïdes. (Gaz. méd., Paris, 1863, [3], xviii., p. 665).

LEwIS, T. R. On a Hæmatozoon Inhabiting Human Blood. Calcutta, I872. II. ed., ibid., 1874 .

The Patholog. significance of Nematode Hæmatozoa. Calcutta, 1874 .

СоввоLd, T. S. The life-history of Filaria Bancrofti. (Journ. Linn. Soc. Zool., I 879 , xiv., p. 356.$)$

Manson, P. The Metamorph. of Fil. Sang. Hom. in the Mosquito. (Transact. Linn. Soc., London, I884 [2], ii., pp. Io \& 367.)

The Filaria Sang. Hom., \&c., London, I $883,186 \mathrm{pp}, 8^{\circ}$, io pl.

Scheube. Die Filariakrankheit. (Volkmann's Samml. kl. Vortr., No. 232, 1883 ).

Hebra, v. Die Elephantiasis Arabum. (Wien Klinik, 1885 , Nos. 8 and 9.)

Bourne, A. G. Not. on Fil. Sang. Hom., with descr. of a Male Spec. (Brit. Med. Journ., I888, No. 1429.)

SibthoRPE. On the ad. male of Fil. Sang. Hom. (Ib., I889, No. 1485.)

Thiesing, H. Beitr. z. An. d. Fil. Sang. Hom. In-Diss. Basel (Leipzig, 1892.)

Linstow, v. Ueb. d. Art. d. Blutfil. d. Mensch. (Zool. Anzgr., Işco, xxiii., p. 76.$)$

Bancroft, Th. On the Metamorph. of the Young Form of Fil. bancrofti, Cobb., in the body of Culex ciliaris. (Proc. R. soc., N. S. Wales, 1900, xxiii., p. 48.)

Low, G. C. A Rec. Obs. on Fil. noct. in Culex. (Brit. Med. Journ., I900, i., p. I 456.$)$

Maitland, J. Note on the Etiol. of Filariosis. (Ibid., 1902, p. 537.)

Blanchard, R. Transmiss. de la filariose par les moustiques. (Arch. de parasit., I900, iii., p. 280.)

Grassi, B., and G. Nok. L.c. (Cf. Fil. immitis.)

Sambon, L. W: Filaria Bancrofti and Filaria immitis (Lancet, 1902, p. 422.)

\section{Filaria diurna, P. Manson, I89I.}

\section{Syn. : Filaria sanguinis hominis, var. major, Mans., r89r.}

Is only known in its larval stage, which resembles that of Filaria bancrofti; nevertheless, it is distinguished from the latter by the fact that in it the granulation of the intestine is lacking, and that it appears in the blood DURING the day only. This appears to indicate that the larvæ are liberated by a blood-sucking insect flying in the day time; the so-called mangrove flies are suspected to be the intermediary hosts.

This filaria was found by P. Manson in the blood of several negroes 
from the West Coast of Africa (Congo). The author seeks to connect these filariæ with Filaria loa (c.f. below), but the proofs thereof are still lacking.

\section{LITERATURE.}

Manson, P. The Filaria Sang. Hom., Major and Minor, two New Species of Hæmatozoa. (The Lancet, I891, i., p. 4. Ref. im. Centralbl. f. Allg. Path., ii., p. 298.)

Manson, P. Geograph. Distribution. . . . of Fil. Sang. Hom. Diurna and of Fil. Sang. Hom. Perstans. (Transact. Seventh Intern. Congr. of Hygiene and Demogr., London, I891, i., p. 79, I 893.)

Manson, P. Trop. Diseases. Lond., I 898.

\section{Filaria perstans, P. Manson, I89I.}

Syn.: Filaria sanguinis hominis, var. minor, Manson, I891.

This parasite is likewise only known in its larval stage from the blood of negroes of West Africa. It is distinguished from other blood filariæ of man by its small size $(0.2 \mathrm{~mm}$. in length), great motility and contractility, absence of sheath, as well as by the fact that it may be observed in the blood of patients at all times of the night and day. A few patients suffered from "negro lethargy." The author is of opinion that these Nematodes cause also the skin disease known by the negroes as craw-craw, the larvæ of the Nematodes appearing in the papules. According to Firket, blood filariæ are very frequent (55 per cent.) in the negroes of various districts of the Congo region, even in children; the persons affected had no skin eruption, and were for the most part in good health. One of the persons had already been in Europe six years and another eighteen months.

[Filaria perstans, in its larval form, was discovered by Sir Patrick Manson in I89I in the blood of a West African negro suffering from sleeping sickness, who was under the care of Sir Stephen Mackenzie in the London Hospital. Later, Manson found it in blood films from natives of the Congo and Old Calabar. In I897, he examined the blood of Carib Indians sent by Dr. Ozzard from British Guiana, and found larval filariæ closely resembling those of $F$. perstans, together with other sharp-tailed larvæ slightly larger in size but equally deprived of sheath. The co-existence of blunt and sharp-tailed filarial larvæ in the same host was somewhat puzzling, and Manson provisionally gave to these filariæ the name of Filaria ozzardi.

In I 898 , at the post-mortem examination of two Demerara Indians, Dr. Daniels found the adult form, both male and female, of the blunt-tailed larvæ, and soon after the adult forms of the sharp-tailed larvæ. This showed that the differently shaped larvæ belonged to two different species, one of which was undoubtedly 
a new species and retained the name of $F$. ozzardi suggested by Manson. Adult forms of the African blunt-tailed larvæ were next found by Mr. O'Neil at the necroscopy of a Congolese patient who died from sleeping sickness in Charing Cross Hospital, and Manson, after a comparison between these and the British Guiana specimens, came to the conclusion that they were identical.

The larval Filaria perstans measures on an average $0.2 \mathrm{~mm}$. in length by $0.0045 \mathrm{~mm}$. in breadth; it has a blunt, truncated tail, and possesses no sheath. The head is provided with a retractile fang. The anterior gap in the central column of cells (Manson's $\mathrm{V}$ spot) is at about $0.03 \mathrm{~mm}$. from the cephalic extremity. There is no marked tail gap. Having no sheath, these larvæ are able to move rapidly and freely all over the slide. The larvæ of $F$. perstans observe no periodicity. Their numbers in the peripheral circulation may vary considerably, but there is no marked difference between day and night. Their special seat of selection is not the peripheral blood, but that of the heart, lungs, aorta and other large vessels. They are never found in the spleen, and only rarely in the liver and pancreas.

The adult female $F$. perstans measures 70 to $80 \mathrm{~mm}$. in length by $0.12 \mathrm{~mm}$. in breadth. The head is club-shaped and measures $0.07 \mathrm{~mm}$. in diameter. The genital pore opens at 0.6 $\mathrm{mm}$. from the head. The tail is curved and presents a cuticular thickening, which forms two triangular appendages. The anus opens at the apex of a papilla situated in the concavity of the curve formed by the tail. The diameter of the tail just before termination is $0.02 \mathrm{~mm}$.

The adult male measures $45 \mathrm{~mm}$. in length by $0.06 \mathrm{~mm}$. in breadth. The diameter of the head is $0.04 \mathrm{~mm}$. Close to the opening of the cloaca there are four pairs of pre-anal papillæ and one pair of post-anal papillæ. Two unequal spicules may sometimes be seen protruding from the orifice.

The adult worms inhabit the connective tissue at the base of the mesentery. To find them the mesentery should be removed, placed in a 2 per cent. solution of formalin, and then carefully examined at leisure.

Filaria perstans has a wide geographical distribution. In Africa it is very common in certain districts along the west coast. Drs. Annett, Dutton and Elliott report its presence at Sierra Leone, on the Kroo Coast, on the Ivory Coast, on the Gold Coast, at Lagos, in Northern and Southern Nigeria; Manson found it in slides of blood from Old Calabar and from the Congo. 
Professor Firket has shown that in certain districts on the Congo it occurs in half the population. Moffat, Cook, Hodges and Low have found the parasite to be extremely common in many areas in Uganda. Low found it in 86 per cent. of the population in the Sese Islands to the south of Entebbe. Moffat and Low found it in 76 per cent. of the people of Unyoro; Daniels found one case in a native of British Central Africa on Lake Nyassa. On the east coast of Africa it is not found in the towns of Zanzibar and Mombasa, neither is it found in the country of the Masai; nor amongst the Kavirondo, who dwell along the north-east shores of Lake Victoria.

In South America, Filaria perstans is very common amongst the aboriginal Indians in the interior of British Guiana. However, it is not found in Georgetown and in New Amsterdam, neither is it found in the cultivated strip of coast lying between these two towns, but it is common on the coast further north near the Venezuelan boundary, where the forests stretch to the sea. The Waran Indians, who live at the mouth of the Waini river, harbour this parasite. Dr. Low, while studying filarial diseases in the West Indies in Igor, never met with Filaria perstans in these islands, although he examined the blood of large numbers of individuals in St. Kitts, Dominica, St. Lucia, Barbadoes, St. Vincent, Grenada, and Trinidad.

Topographically, Filaria perstans is found only in areas covered by dense forest growth and abounding in swamps. In Kavirondo, where the forest disappears and the land is covered with scrub and short grass, it is not found: likewise it is not found on the grassy plains of the highlands of British East Africa. Towns and cultivated areas are free from it.

In order to find the intermediary host of Filaria perstans, Dr. Low made numerous and careful experiments with many different species of mosquitoes (Culex fatigans, $M$. atratus, $C$. viridus, $C$. luteolateralis, C. quasigelidus; Anopheles argyrotarsis, A. costalis, A. funestus; Stethomyia nimbus; Janthinosoma musica; Mansonia africanus; Uranotenia caruleocephala; Taniorhynchus fuscopennatus) and other blood-sucking insects (Pulex irritans, P. penetrans, Pediculus capitis and $P$. vestimentorum). These insects were either caught in the huts of infected persons, or they were reared from the larva and then fed on infected persons. After a certain time they were dissected, but, with one exception, the results were negative. In one isolated instance two developmental forms were seen between the thoracic muscles of a Treniorhynchus fusco- 
pennatus reared from the larva and fed on infected persons. This seems to prove that Filaria perstans in its proper intermediary host, like Filaria bancrofti, develops between the thoracic muscles. Dr. Christy suggests that the true intermediary host of Filaria perstans is Ornithodoros monbata, ${ }^{1}$ a tick of the sub-family Argasina. However, he gives no evidence in support of this view, which is contradicted by facts of geographical distribution. I am inclined to think that the intermediary host of $F$. perstans is to be found amongst the blood-sucking flies.

At one time $F$. perstans was incriminated as a possible factor in the etiology of sleeping sickness. Recent researches have proved that it has no causal connection with the disease. $F$. perstans seems to have no pathological importance. The presence of the adult parasites in the mesentery appears to cause no harm to the host.-L. W. S.]

\section{LITERATURE.}

O'NeIL. On the Pres. of a Filaria in "Craw-craw." (The Lancet, I 875, i., p. 265.)

Manson, P. L. c.

Firket, C. M. Filariose du sang chez les nègres du Congo. (Bull. Ac. roy, Méd. de Belg., I 895, 4 Ser., ix., Ref. in C. f. B., P. u. Inf. [I], xix., p. 79I.)

Henry. Rem. on Filaria. (Proc. Ac. Nat. Sc., Philadelphia, I 896, p. 27 I.)

Brualt, J. Note sur le Craw-craw. (Ann. Dermatol., Paris, I899, p. 226.)

\section{Filaria demarquayi, Manson, I895.}

Of this form also we know only the larvæ circulating in the peripheral blood. They are found in the blood night and day, are provided with a sheath, but are only half the length of the larvæ of Filaria bancrofti. They have been observed in blood preparations from natives of the Island of St. Vincent (Lesser Antilles, West Indies). The same species is also supposed to occur in Brazil and Africa (Niger).

[Filaria demarquayi was discovered by Sir Patrick Manson in I895 in blood films from natives of St. Vincent, West Indies. Manson found the larval form of this filaria in ten out of $\mathrm{I}_{52}$ slides received from Dr. Newsan.

The larva of Filaria demarquayi measures, according to Dr. G. C. Low, $0.2 \mathrm{~mm}$. in length by $0.005 \mathrm{~mm}$. in breadth; it is sharp-tailed, and has no sheath. Its movements are very active, and the absence of a sheath enables it to glide along freely all

${ }^{1}$ [Professor Neumann informs me the correct name for this tick is Ornithodoros savignyi (Audouin). The specimens received from Uganda all belong to Neumann's variety caeca. (Vide Second Report Eco. Zool. p, I I3, I904. Theobald),-F.V.T.] 
over the slide. It observes no periodicity, being present in the peripheral circulation both by day and by night. As a rule, some eight or ten parasites are found in an ordinary preparation. Sometimes hundreds of these larval filariæ may be counted on every slide.

Identical larvæ have been seen by Manson, Galgey, Low, and St. George Gray in the blood of natives of St. Lucia, and Low found them also in the blood of natives of Dominica and Trinidad. Manson has seen this parasite or one exceedingly like it in the blood of the natives of New Guinea. The larvæ of $F$. demarquayi are indistinguishable from those of $F$. ozzardi.

The adult female form of $F$. demarquayi was found by Dr. Galgey in the body of a native of St. Lucia in whose blood the larvæ had been found during life. Five adult females were found in the connective tissue of the mesentery. Two of these specimens were presented to the London School of Tropical Medicine, and described by Dr. Daniels.

The adult female Filaria demarquayi measures from $65-80$ $\mathrm{mm}$. in length by $0.2 \mathrm{I}-0.25 \mathrm{~mm}$. in breadth. The head has a diameter of from $0^{\circ} 09-\mathrm{O}^{\circ} \mathrm{Im}$. The mouth is terminal. The genital pore opens at $0^{\circ} 76 \mathrm{~mm}$. from the head. The alimentary canal is nearly straight and terminates in an anus, which is subterminal. The opening of the anus is marked by a slight papilla. The tail is curved. It rapidly diminishes in size just below the anal papilla. A marked cuticular thickening covers the tip of the tail. The diameter near the tip of the tail before its termination is $0.03 \mathrm{~mm}$. $F$. demarquayi is a thicker worm than $F$. perstans. It differs from $F$. bancrofti and $F$. ozzardi in the greater size of the head, in the smaller tail and particularly in the marked cuticular thickening at the tip of the tail. This thickening is knobby, but the divisions are not so well marked as in $F$. perstans.

The male of Filaria demarquayi has still to be found. The intermediary host has not been discovered. The distribution of this filaria is singularly limited both geographically and topographically.-L. W. S.]

\section{Filaria ozzardi, Manson, I897.}

The larvæ are found in the blood of natives of British Guiana; they measure $0.173-0^{\circ} 240 \mathrm{~mm}$. in length by $0^{\circ} 0043-0.0050 \mathrm{~mm}$. in breadth, and have no sheath. The caudal extremity is obtuse, rarely pointed. They appear in the peripheral blood ${ }_{d}^{T}$ at all times of 
the day. The differentiation of Manson's four species remains uncertain as long as the adult stage is unknown.

[Filaria ozzardi was discovered by Sir Patrick Manson in 1897 in blood films prepared by Dr. Ozzard from aboriginal Carib Indians inhabiting the back country of British Guiana. At least half of the slides examined contained larval filariæ; some slides only one or two, other slides as many as forty or fifty. These larval filariæ were not all alike, they differed slightly in size and in the shape of their posterior extremity. Five out of six presented a blunt tail, the others had a sharp tail. Dr. Daniels proved that the blunt-tailed larvæ were the young of Filaria perstans, because he found the adult $F$. perstans, both male and female, at the post-mortem examination of two Demerara Indians, whose blood, during life, contained both blunt and sharp-tailed larvæ. Later, Dr. Daniels found, at the post mortem of another native in whose blood both the blunt and sharp-tailed larvæ had been found, a few adult specimens of Filaria perstans, and, in addition, a female and portion of a male worm of a new species closely resembling Filaria bancrofti in shape and size, but differing from it on account of the bulbous termination of its tail. This parasite was presumably the parental form of the sharp-tailed larvæ previously found in the peripheral circulation of the host.

The larval form of Filaria ozzardi measures $0.21 \mathrm{~mm}$. in length by $0.005 \mathrm{~mm}$. in breadth, it has a sharply-pointed tail and no sheath; it observes no periodicity.

The adult forms have been found only once by Dr. Daniels in the subserous connective tissue of the anterior abdominal wall. The female measures $8 \mathrm{I} \mathrm{mm}$. in length by $0.2 \mathrm{I} \mathrm{mm}$. in breadth. The head has a diameter of $0.05 \mathrm{~mm}$., the genital pore opens at $0.7 \mathrm{I}$ $\mathrm{mm}$. from the head. At this point the diameter of the body is $0.12 \mathrm{~mm}$. The anus is at $0.23 \mathrm{~mm}$. from the tail. The tail is bluntly truncated and slightly bulbous, it presents no cuticular thickening. The diameter near the tip of the tail before termination is $0.045 \mathrm{~mm}$.

The male worm measures $38 \mathrm{~mm}$. in length by $0.9 \mathrm{~mm}$. in breadth.-L. W.S.]

\section{LITERATURE.}

Manson, P. On Certain New Spec. of Nemat. Hæmat. occ. in America. (Brit. Med. Journ., London, 1897 , ii., p. I 837. .)

Daniels, C. W. Fil. and Fil. Disease in Brit. Guin. (Ib., I898, i., p. Ior I. ii., p. 878.$)$

Galgey, O. Fil. Dem. in St. Lucia. (Ib., I899, i., p. I45.) 
8. Filaria magalhicesi, R. Blanchard, 1895.

Syn. : Filaria bancrofti, v. Linstow, 1892 ; Fil. bancrofti, P. S. de Magalhães, I 892 , nec. Cobbold, i 877 .

The male measures $83 \mathrm{~mm}$. in length by $0.28-0.40 \mathrm{~mm}$. in breadth; the cuticle is firm and delicately striated. The anterior extremity is rounded off, and has no papillæ; the posterior extremity exhibits a double curve, with four pre-anal and four post-anal papillæe on each side. These are large and have a villous appearance. The mouth is round and unarmed, the pharynx measures I $\mathrm{mm}$. in length, is cylindrical, very muscular, and its hinder part is dilated. The anus is situated O.II mm. in front of the posterior border. There are probably two uneven spicules; one only, however, is known-apparently the shorter one - the length of which is given as 0.17 $0.23 \mathrm{~mm}$.

The female measures $15.5 \mathrm{~mm}$. in length and $0.6-0.8 \mathrm{~mm}$. in breadth; the rings of the cuticle are $0.005 \mathrm{~mm}$. apart (in the male $0.003 \mathrm{~mm}$. apart); the anterior extremity is slightly thickened and club-like, the posterior extremity is slender, and terminates obtusely; the lateral ridge is $0.127 \mathrm{~mm}$. in breadth (that of the male $0.007-0.008$ $\mathrm{mm}$.$) ; the anus opens 0.13 \mathrm{~mm}$. in front of the posterior border, the vulva is $2.5 \mathrm{~mm}$. distant from the mouth, the ovaria are two

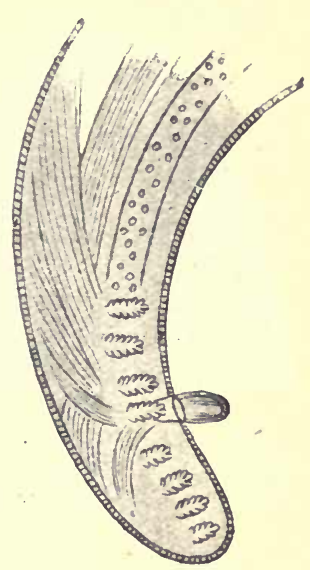

FIG. IS 8 . - Filaria magalhũesi; posterior extremity. (After v. Linstow.) convoluted tubes. The eggs measure 0.038: 0.0I4 $\mathrm{mm}$; the larvæ $0.30-0.35 \mathrm{~mm}$. in length, $0.006 \mathrm{~mm}$. in breadth, with a transversely striated cuticle.

This species was first discovered at a post mortem, in the left ventricle, by J. P. Figueira de Saboia in Rio de Janeiro, and has been described by P. S. de Magalhães.

\section{LITERATURE.}

Magalhĩes, P. S. de. Descrip. da uma. esp. de. filar. encontr. no coração humino. (Rev. d. curs. prat. e theoric, faculd de med. Rio de Janeiro, I 887 , iii., p. I 26.)

Linstow, v. Ueber Fil. bancrofti, Cobb. (C. f. B. u. P., I 892, xii., p. 88.)

Magalhìes, P. S. de. Die Fil. bancrofti u. Fil. immitis. (Ib., p. 5II.).

Linstow, v. Art. d. Blutfil. d. Mensch. (Zool. Anzg., I900, xxiii., p. 76.) 


\section{Filaria loa, Guyot, 1778 .}

Syn. : Filaria oculi, Gerv. et. v. Ben., I 859 ; Dracunculus oculi, Diesing, I 860 ; Dracunculus loa, Cobbold, I864; Filaria subconjunctivalis, Guyon, I864.

The male measures $22-30 \mathrm{~mm}$. in length, and $0.3-0.4 \mathrm{~mm}$. in breadth; the cuticle is not striated, but, with the exception of the anterior and posterior extremities $\left(\mathrm{I}_{5} \mathrm{~mm}\right.$.) is beset with numerous irregularly distributed protuberances. The anterior extremity is somewhat narrowed, and in front is conical and transversely obtuse. On each side of the posterior border of the conical part is a small papilla corresponding to the dorsal and ventral median ridges. The posterior extremity is attenuated and

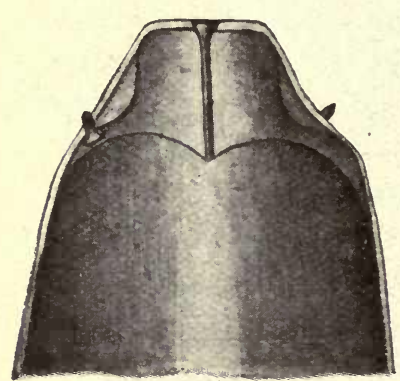

FIG. I99.-Filaria loa. The anterior end of the male, magnified. (After R. Blanchard.) somewhat curved ventrally; the anus is $0.082 \mathrm{~mm}$. distant from the rounded posterior border. In front of the anus on each side are three globular and pedunculated papillæ of different sizes, set close one behind the other; behind the anus on either side are two smaller papillæ of a different shape; the anterior one resembles the pre-anal papillæ in form, but is smaller; the posterior one is conical, and rests on the cuticle, with a broad base. The spicules differ but little in their length.

The female measures $32-4 \mathrm{I} \mathrm{mm}$. in length, by $0.5 \mathrm{~mm}$. in breadth. It is also beset with irregularly distributed chitinous bosses, which in places stand close to each other, and extend to the anterior extremity; posteriorly they become less frequent, but are not entirely absent. The anterior extremity is conical, the posterior one straight, attenuated, rounded off. The vulva apparently lies at the border of the first and second quarter of the body; the vagina, $3 \mathrm{~mm}$. in length, forks off into two long (Io cm.) tubes, extending almost throughout the entire length of the body, the narrow end of which are the ovaria; they contain eggs in the most various stages of development, as well as hatchedout larvæ, $0.253-0.262 \mathrm{~mm}$. in length, and $0.0047-0.005 \mathrm{~mm}$. in breadth. Their anterior extremity is rounded, the posterior extremity is slender and awl-shaped; the cuticle is smooth. In addition to the rudiment of the intestine the rudiment of the generative glands also can be recognised $0.08 \mathrm{~mm}$. behind the anterior extremity. 
Filaria loa lives in the connective tissue of the conjunctivæ between it and the bulbus oculi; sometimes, however, it retires into the depth of the orbit, to emerge nearer to the surface after a longer or shorter time; the wandering of the worm also from one eye to the other beneath the skin of the bridge of the nose has been observed, and occasionally the parasite has also been known to appear in other parts of the body within the subcutaneous connective tissue, notably in the fingers. It is doubtful whether it also occurs in the eye-ball. Several observations have been reported, some relating to a comparatively long worm, which may have been either Filaria loa or Filaria medinensis.
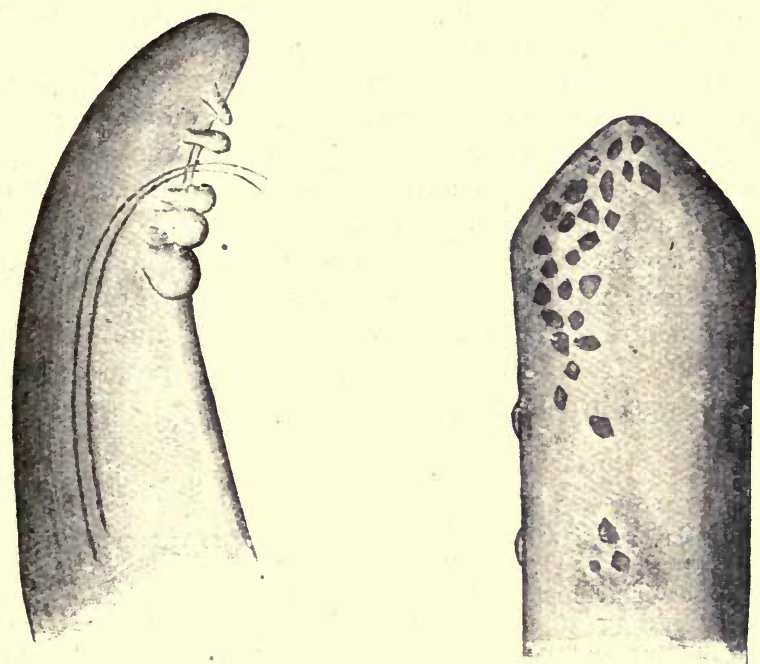

Fig. 200.-Filaria loa; to the left is the posterior extremity of a male; to the right the anterior extremity of a female. Magnified. (After R. Blanchard.)

The first accounts of Filaria loa-long since forgotten-were reported by Pigafetta, and are contained in a book of travels on the Congo printed in I598. In an accompanying illustration is depicted, not only the ancient method of extraction of the Medina worm, but also the operative removal of the filaria from the conjunctiva. Subsequently the presence of the worm in negroes was confirmed by Bajon in Guiana (1768) and by Mongin in Mariborou (San Domingo); likewise in a negro (1770). At about this time a French ship's doctor, Guyot, was cruising on the West Coast of Africa; he observed the parasite termed "loa" by the natives and learned that it was frequent in the negroes of the Congo district. Since that time numerous observations have been reported. It was formerly common in South America, where the parasite was imported by slaves, but it disappeared when the traffic ceased; it is particularly prevalent in the Congo, where it occurs not only in natives, but also in Europeans. During 
recent times it has repeatedly been observed in Europe in negroes as well as in white men who have lived on the West Coast of Africa.

Nothing is known regarding the development of Filaria loa. Manson advances the hypothesis that its larva is Filaria diurna, but this requires confirmation; however, in the few cases in which the blood of the host of Filaria loa has been examined blood filariæ have not been found; in the case adduced by Manson the patient certainly had filariæ in the blood, but at the time of observation had no Filaria loa.

The presence of this worm sometimes causes no inconvenience, but, as a rule, like any foreign body introduced into the conjunctival sac, induces symptoms of inflammation which may become periodically aggravated.

Nematodes of the most various sizes have been repeatedly observed in the anterior chamber of the eye as well as in the substance of the lens and vitreous humour. Thus Mercier ( 1771 and 1774) removed a filaria from the anterior chamber of the eye of two negroes in St. Domingo, of which one specimen measured $35 \mathrm{~mm}$. in length. There is a further statement of Barkan (1876), who extracted a filaria from the chamber of the eye of an Australian in San Francisco. For a few weeks Coppez and Lacompte (I894) had a little negro girl, $2 \frac{1}{2}$ years of age, under observation, in whose eye there was an immature nematode measuring $15^{\circ} 2 \mathrm{~mm}$. in length, and which was removed. It is difficult to say which species (Filaria loa or Filaria medinensis) was in question in these cases.

\section{LITERATURE.}

Pigafetra. Vera descr. regni afric., quod tam ab incolis quam a Lusitanis Congus appellatur. Francofurti, 1598.

Bajon. Mém. pour servir à l'hist. de Cayenne et de la Guyane franc., 1768, i., p. 325.

Abhdlg. v. d. Krankh. a. d. Insel Cayenne u. d. franz. Guyana. Erfurt, i78I.

Mongin. Obs. sur un ver trouvé dans la conjunct. à Mariborou. (Journ. de méd., 1770, xxxii., p. 338.)

Guyor in Arrachart. Mem., diss. et observ, de chirurgie, Paris, I805, p. 228.

Ludwig, H., and Th. Saemisch. Ueb. Fil. loa i. Auge d. Mensch. (Z. f. w. Z., I895, lx., p. 726.)

Blanchard, R. Nouv, cas de Fil. loa (Arch. de paras., I899, ii., p. 504).

I0. Filaria oculi humani, v. Nordmann, I832; Filaria lentis, Diesing, I85I.

The sexless nematodes observed in the lens of the human eye are termed Filaria oculi humani. Only three cases are known. v. Nordmann observed very small round worms in the lens of a man and woman with cataract, and Gescheidt once found three specimens in the lens of a woman similarly affected.

The demonstration of nematode-like formations in the vitreous remains uncertain even when movements are observed, and when they cannot be extracted and examined microscopically, the doubt 
may occur that one may have mistaken the remains of the hyaloid artery for a worm, which it resembles in form, size and colour; the slightest movement of the eye also causes it to move so that it simulates a living organism.

Accordingly it would be more correct to exclude all the cases known only ophthalmoscopically (Quadri, I857 ; Fano, I868 ; Schoeler, 1875; Eversbusch, I89I). There then remains only one positive case described by Kühnt in I89I. In this case it was possible to follow the gradual growth of the parasite for some time, and the worm, which measured only 0.38 $\mathrm{mm}$. in length, was finally extracted.

\section{LITERATURE.}

Nordmann, A. v. Mikrogr. Beitr. z. Naturgesch. d. wirbellos. Thiere, Berlin, I832, No. 1 , i., p. 7 ; No. 2 , p. 9 .

Gesche1Dt. Die Entozoön d. Aug. (Ztschr. f. Ophthalm., I833, iii., p. 405.)

KüHNT, H. Extr. in. neuen Entozoon a. d. Glaskörp. (Arch. f. Augenheilk, I89i, xxiv., p. 205.)

Kraemer, A. Die thier. Schmarotz. d. Aug. (Graefe-Saemisch's Handb. d. ges Aguenh., I 899, Part II., vol. x., chap. 18, Leipzig.)

II. Filaria conjunctiva, Addario, I885.

Syn.: Filaria peritonei hominis, Babes, 1880; Filaria inermis, Grassi, I887; Filaria apapillocephala, Condorelli-Francaviglia, I 892 .

The female only of this species is known. It measures $16-20$ $\mathrm{cm}$. in length and $0^{\circ} 5 \mathrm{~mm}$. in breadth, and is of a whitish or brownish tint. The cuticle is striated with the exception of a small field surrounding the mouth, which is terminal and has neither papillæ nor lips. The œesophagus measures 0.6 $\mathrm{mm}$. in length and is toothless. The anus is close in front of the rounded posterior extremity, and behind it there are two (glandular ?) sacs. The vulva is close behind the oral

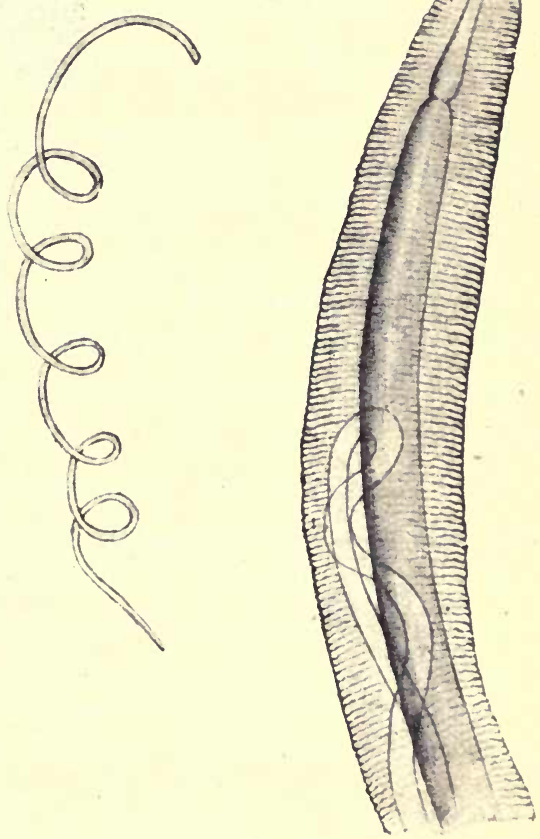

FIG. 201.-Filaria conjunctiva. To the left, life size; to the right, the anterior extremity magnified. (After Addario.)

aperture; the vagina soon divides into two convoluted uteri, which are filled with eggs and embryos. 
This species was first observed in Milan by Dubini in the eye of a man; subsequently it was observed, encysted and calcified, by Babes in the ligamentum gastrolienale of a woman in Buda Pest, and finally one was extracted by Vadela from a tumour the size of a pea in the conjunctiva bulbi of a woman in Catania (Sicily), which case has been described by Addario. Possibly Filaria palpebralis, Pace, I 867 (nec Wilson, 1844), which was removed from a tumour of the upper eyelid of a boy, belongs to this species; probably Filaria lentis, Dies. (Fil. oculi humani, v. Nordm.), may also be of the same species.

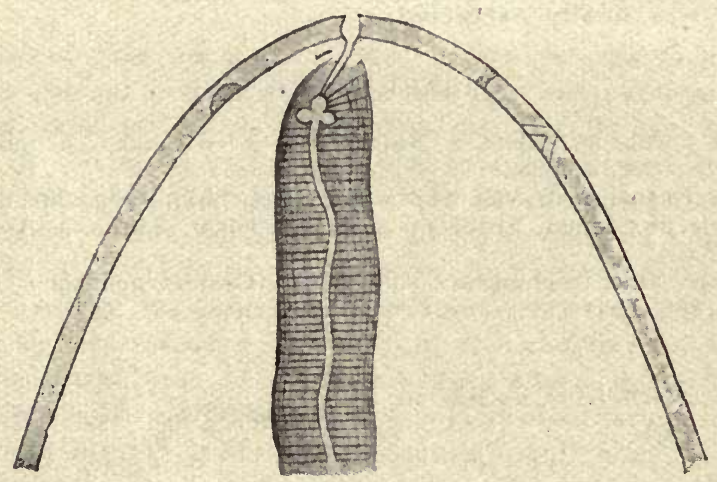

Fig. 202.-Filaria conjunctiva. Anterior end greatly magnified; the mouth with the pharynx in the middle; in the cuticle on the right side the opening of the vagina and behind it the excretory pore. (After Grassi.)

Filaria conjunctive is certainly only an incidental parasite of man; the horse and ass are its normal hosts, but it is not common in these animals, or is frequently confused with Filaria papillosa, Rud.

\section{LITERATURE.}

PACE, A. Sopra un nuovo nemat. (Giorn. sc. nat. ad econom., I867, ii.)

BAbEs, V. Ueb. ein. neuen Paras. d. Mensch. (Med.-chir. Centralbl., Wien, I879, xiv., p. 554:)

Ueb. ein. im menschl. Periton. gef. Nemat. (Arch. f. path. An., I880, lxxxi., p. I 58.)

AdDARIo, C. Su di un nemat. dell' occhio umano. (Ann. d. ottalm., I 885 , xiv.)

Grassi, B. Filaria inermis, ein Par. d. Mensch., d. Pferd. u. d. Esels. (C. f. B. u. P., I 887 , i., p. 617.)

I2. Filaria restiformis, Leidy, I880.

This worm measures $66 \mathrm{~mm}$. in length, pointed anteriorly, the posterior extremity broadened and rounded off ( $.5 \mathrm{~mm}$. in breadth); the mouth is terminal, without lips, \&c., the œesophagus measures I. $25 \mathrm{~mm}$. in length; the intestine appears to terminate blindly. 
This parasite was obtained in West Virginia from the urethra of a young man, aged 20 , who for a few days previous to expelling the worm passed cloudy and sanguineous urine. ${ }^{1}$

\section{I3. Filaria hominis oris, Leidy, I850.}

Fourteen $\mathrm{cm}$. in length, $0.16 \mathrm{~mm}$. in breadth; mouth terminal; posterior extremity obtuse and provided with a recurved hook.

The parasite was "obtained from the mouth of a child." "

\section{I4. Filaria labialis, Pane, I864.}

The parasite measures $30 \mathrm{~mm}$. in length; the anterior extremity is pointed; the terminal oral aperture is surrounded by four papillæ; the anus opens $0.5 \mathrm{~mm}$. in front of the posterior extremity ; the vulva is $2.5 \mathrm{~mm}$. in front of the anus; the uterus is double; the anterior one passes with convolutions forward to the cephalic end; the posterior one is directed backwards and remains rudimentary.

Extracted from a small pustule on the inner surface of the upper lip. ${ }^{3}$

\section{I5. Filaria equina (Abildg.), I789.}

Syn.: Gordius equinus, Abbild., I789; Filaria equi, Gmelin, I789 ; Hamularia lymphatica, Treutler, I793; Tentacularia subcompressa, Zedder, I 800 ; Fil. papillosa, Rud., 1802 ; Fil. hominis bronchialis, Rud., I819; Filaria hominis, Dies., I85 I ; Strongylus bronchialis, Cobb., I879.

The body is whitish, filiform, pointed posteriorly. The cuticle presents a delicate transverse striation. The mouth is small, round, and surrounded by a chitinous ring, the border of which carries, at the sides, two semi-lunar lips, and there is on the dorsal as well as on the ventral surface a papilliform process; behind, corresponding with each submedian ridge, is a papilla. The male measures $6-8 \mathrm{~cm}$. in length, the posterior extremity spiral; there are on each side four pre-anal and four post-anal papillæ; the spicules are of unequal lengths. The female measures

'Leidy, J., " On a Filaria reported to have come from a Man" (Proc. Acad. Nat. Sc., Philadelphia, I880, p. I 30$)$.

"Leidy, J., "Description of Three Filariæ" (Proc. Acad. Nat. Sc., Philadelphia, I 85 o, v., p. I I 7 ).

"Pane, "Nota su di un elminte nematöde" (Annali dell' Accad. degli aspiranti naturalisti, Napoli, I 864 [3], iv.). 
9-I2 $\mathrm{cm}$. in length and is viviparous; the embryos measure $0.28 \mathrm{~mm}$. in length and $0.007 \mathrm{~mm}$. in breadth.

Filaria equina is a frequent parasite of horses and asses; it inhabits the abdominal cavity and from there occasionally invades the female genitalia or even the liver; it is found more rarely in the pleural cavity or in the cranium. The statement that it also occurs in the subcutaneous connective tissue is probably due to confusion with Filaria hamorrhagica, Raill., I 885 (Fil. multipapillosa, Cond. et Drouilly, I878). Finally, small filariæ occur frequently in the eye of the horse; it is, however, doubtful whether they belong to Filaria equina.

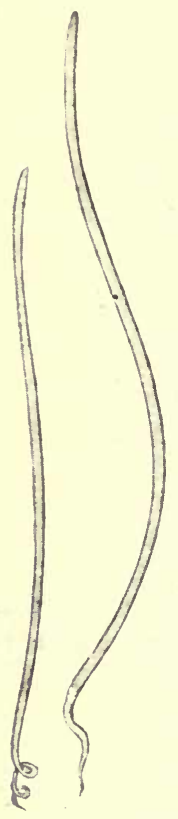

Frg. 203.-Filaria equina. Left, male ; right, female. $\mathrm{Na}$ tural size. (After Railliet.)

Treutler found a filaria in the enlarged bronchial lymphatic gland of a patient suffering from phthisis. It measured $26 \mathrm{~mm}$. in length and carried two small hooklets (spicules) at one end. Blanchard mentions another case from Geneva,

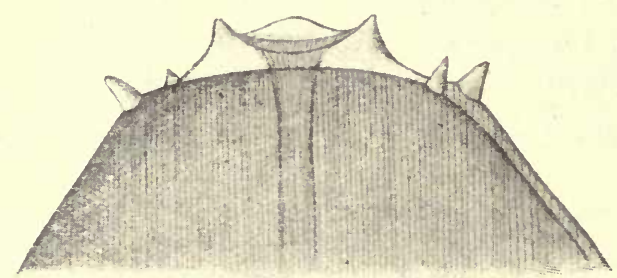

FIG. 204.-Filaria equina. Anterior end, magnified 'After Railliet.)

Brera a third and $v$. Linstow a fourth. As shown by the synonyms a few authors consider this form to be a distinct species, which is hardly probable; others again consider it to be Strongylus apri, which is still less likely, as the posterior extremity of male strongylidæ-and Treutler exhibited a male specimen-carries a bursa which can hardly be overlooked, and which is neither mentioned nor illustrated by the author.

\section{LITERATURE.}

Treutler, F. A. Observ. patholog.-anat. auct. ad helminthol. humani corporis continentes. Lipsiæ, I793.

BlanchaRD, R. Traité de Zool. méd., I890, ii., p. I6.

Brera. Mem. phys.-med. sopra i princ. vermi del corp. umano. Crema, I8II, p. 3 r. v. Linstow. Beob. an neuen u. bek. Nemathelm. (Arch. f. mikr. Anat. u. Entw., 1902, lx., p. 222.)

Deupser. Z. Entw. d Fil. papillosa. Zool. Anzg., I892, xv., p. I 29.

Exp. Unters. üb. d. Lebensgesch. d. Fil. pap. In.-Diss., Breslau, I 894. 
I6. Filaria romanorum-orientalis, Sarcani, I888.

Observed in the blood of a Roumanian woman; I $\mathrm{mm}$. in length, $0.03 \mathrm{~mm}$. in breadth; intestine and generative apparatus fully developed.

\section{LITERATURE.}

SARCAN, A. Fil. rom.-orient. (Wien med. Presse, 1888 , xxix., p. 222.)

\section{I7. Filaria volvulus, R. Leuckart, 1893.}

The male measures $30-35$, the female $60-70 \mathrm{~mm}$. in length. The parasite was first observed by a German medical man in tumours the size of a pigeon's egg, one situated under the scalp, the other on the thorax, of two negroes from the Gold Coast; Leuckart gave the first description. Another case (Labadie-Lagrave and Deguy) relates to a French soldier who had been in Tonquin for a long time, and had subsequently accompanied the Dahomey expedition. In this case a young female filaria, measuring $25 \mathrm{~mm}$. in length and $15 \mathrm{~mm}$. in breadth, was found in' a lymph ressel within a tumour removed from the shoulder; blood examinations yielded negative results. A fourth case is mentioned by Prout.

[The adult male measures $30-35 \mathrm{~mm}$. in length by $0 . \mathrm{I} 4 \mathrm{~mm}$. in breadth. The body is white, filiform, attenuated at both ends. The head is rounded and has a diameter of $0.04 \mathrm{~mm}$. The cuticle is distinctly transversely striated. The mouth is unarmed. The alimentary canal is straight and ends in a subterminal anus. The tail is curved and somewhat flattened on the concave surface. According to Brumpt there are three papillæ on each side of the cloaca and three pairs of post-anal papillæ. Two unequal spicules may be seen protruding from the cloaca.

The adult female measures $60-70 \mathrm{~mm}$. in length by $0.36 \mathrm{~mm}$. in breadth. The head is rounded and truncated; it measures $0.04 \mathrm{~mm}$. in diameter. The tail is curved. The striations of the cuticle are not so distinct as in the male.

The larva measures about $300 \mu$ in length ; it has no "sheath." The body tapers from about the last fifth of its length and terminates in a sharply pointed tail. At about the anterior fifth of the body there is a gap in the central column of cells (Manson's $\mathrm{V}$ spot).

Filaria volvulus is found in peculiar subcutaneous tumours, the size of a pea to that of a pigeon's egg. The same patient may present one or several of these tumours. The regions of the 
body most frequently affected are those in which the peripheric lymphatics converge. Thus they are usually found in the axilla, in the popliteal space, about the elbow, in the sub-occipital region and in the intercostal spaces. The tumours are never adherent to the surrounding structures, and can be easily enucleated. They are formed of a dense mass of connective tissue which enwraps the parasites and encloses small cyst-like spaces filled with a greyish viscous substance consisting almost entirely of filaria larvæ. The position of the adult worms within these tumours is very remarkable. The greater length of their coiled-up bodies is embedded in the connective stroma, but the posterior extremity of the male with its copulating organs, and the anterior extremity of the female with its vaginal opening, are free in one of the spaces for the purpose of copulation and parturition.

The formation of the tumours is elucidated by Labadie-Lagrave and Deguy's case. The authors found an immature female filaria volvulus in a lymphatic vessel partly obstructed by an infiltration of fibrin and leucocytes. It appears therefore that the presence of the parasites within the lymphatics gives rise to an inflammatory process, and that the consequent fibrinous deposit envelops the parasites, obliterates the lumen of the vessel, and ultimately isolates the affected tract. According to the natives, the tumours may last indefinitely and never ulcerate. Some old patients told Brumpt that their tumours had been present since childhood. Probably Filaria volvulus, like some other filariæ, may live for many years.

Filaria volvulus has been met with in various parts of West Africa. Leuckart's cases occurred on the Gold Coast. Prout saw two cases in Sierra Leone, Labadie-Lagrave's case became infected in Dahomey. During his travels through Central Africa, Brumpt had the opportunity of examining fifteen cases on the banks of the Welle between Dongon and M'Binia. He believes that in that region Filaria volvulus affects about 5 per cent. of the riverine population. Two other cases he saw along the Itimbri between Bouta and Ibembo. This filaria is also found on the Kibali and along several tributaries of the Welle, but appears to be unknown on the Congo.-L. W. S.]

\section{LITERATURE.}

Leuckart. In Manson, P., Diseases of the Skin in Trop. Clim. (Andrew Davidson's Hyg. and Diseases of Warm Countr., Edinb., Lond., 1893, p. 963.)

Labadie-Lagrave and M. Deguy. Un cas de Fil. volv. (Arch. de paras., I899, ii., p. 45 I.)

Prout, W. T. A Fil. found in Sierra Leone. ? Fil. volv., Lkt. (Brit. Med. Journ., I9OI, No. 2091, p. 209.) 


\section{Filaria kilimara, Kolb, I898.}

Several female specimens were once found free in the abdomen of a fallen Kitú warrior; according to Spengel, who examined them, the oral papillæ of these worms were similar to those of Filaria medinensis. Moreover, Kolb classifies together nematodes that probably have no connection whatever with each other.

\section{LITERATURE.}

KolB, G. Die Filaria kilimarae in Britisch-Ostafrika. (Arch. f. Schiffs.- u. Tropenhyg., 1898, ii., p. 28.)

\section{I9. Filaria sp.?}

Cholodkowsky calls attention to filariæ that are still unknown which cause tumours resembling whitlows on the fingers of the peasants of the Twer Government.

\section{LITERATURE.}

Cholodkowsky, N. A. In Wratsch, 1896, No. 3.

Ueb. einige selten b. Mensch. vork. Paras. (Stzgsb. d. St. Petersb. naturf. Ges., I897, p. I 85.$)$

(e) Fam. Trichotrachelida.

Gen. 6. Trichocephalus, Goeze, I782.

Syn.: Trichiuris, Röderer, I76I ; nec Trichiurus, L., I758; Mastigodes, Zeder, I 803 .

The anterior part of the body is very long and thread-like; the posterior part sharply truncated, is thickened, rounded posteriorly, and the anus is terminal. The males carry the posterior extremity spirally rolled up; there is one spicule; the females have only one ovary; the vulva is situated at the commencement of the posterior part of the body; the eggs are barrel-shaped. The trichocephali live in the large intestine of mammals, the cæcum by predilection; their development is direct, infection occurs through the ingestion of embryo-containing eggs.

\section{Trichocephalus trichiurus (L.) I77I.}

Syn.: Ascaris trichiuva, L., I77I ; Trichocephalus hominis, Schrank, I788; Trichocephalus dispar, Rud., I80I.

The male measures $40-45 \mathrm{~mm}$. in length, the spiculum is $2.5 \mathrm{~mm}$. long, and lies within a retractile pouch beset with spines. The female measures $45-50 \mathrm{~mm}$. in length, of which two-fifths appertain to the posterior part of the body. The ova are barrel-shaped and have a thick brownish shell which is perforated at the poles. 
Each opening is closed by a light-coloured plug. a The eggs measure $0.05-0.054 \mathrm{~mm}$. in length and $0.023 \mathrm{~mm}$. in breadth; they are deposited before segmentation. Trichocephalus trichiurus usually lives in the cæcum of human beings and is also occasionally found in the vermiform appendix and in the colon, exceptionally also in the small intestine; usually only a few specimens are present, and these do not cause any particular disturbances, although, as Askanazy found, they feed on blood; in other cases cerebral symptoms of more or less severity are observed when trichocephali are present in large numbers. At post mortems performed soon after death the filiform anterior extremity of the worm is frequently found embedded in the mucous membrane (Askanazy).

The whip-worm is one of the most common parasites of man and
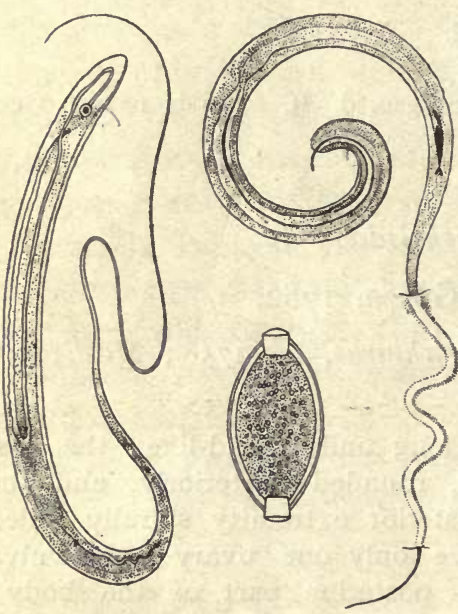

FIG. 205.-Trichocephalus trichiurus. On the left male; on the right female with the anterior extremity embedded in the mucous membrane of the intestine. Below egg. appears to be distributed over the entire surface of the globe ; it is, however, more frequent in the warmer regions. It is found in persons of both sexes and all ages with the exception of infants. In autopsies it is found in the following numbers In Dresden in 2.5 per cent., in Erlangen in II. I per cent., in Kiel in 31.8 per cent., in Munich in 9.3 per cent., in St. Petersburg in 0.18 per cent., in Göttingen in 46.1 per cent., in Basle in 23.7 per cent., in Greenwich in 68 per cent., in Dublin in 89 per cent., in Paris in about 50 per cent., and in Southern Italy in almost 100 per cent. On examining the fæces the eggs of the whip-worm were found as follows: In Munich in 8.26 per cent., in Kiel in $45^{\circ} 2$ per cent., in Greifswald in 45 per cent., in North Holland in 7 per cent., in Novgorod in 26.4 per cent., in St. Petersburg in $5^{\circ} \mathrm{O}$ per cent., in Moscow in 5.3 per cent.

The development of the eggs is completed in water or in moist soil, and occupies a longer or shorter time according to the season; the eggs possess great powers of resistance, as do the larvæ, which, according to Davaine, may remain as long as five years in the egg-shell without losing their vitality. Leuckart proved by experiment that direct infection with Trichocephalus affinis (ovis aries) and $T r$. crenatus (Sus scrofa dom.) was produced 
by embryo-containing eggs; Railliet obtained the same results with $T r$. depressiusculus of dogs, and Grassi subsequently, by means of two experiments, demonstrated the direct development of Trichocephalus trichiurus. In one case embryo-containing eggs were swallowed on June 27 , I884, and on July 24 the ova of trichocephali were found in the fæces for the first time.

Trichocephalus trichiurus is found not only in man, but also in various monkeys ( $T r$. palaformis, Rud.), as well as in lemurs (Tr. lemuris, Rud.).

\section{LITERATURE.}

Morgagni, J. B. Epist. anat., xviii., ad scripta pertinentium cel. viri A. M. Valsalvæ. Venetiis, I740, ii., Ep. xiv., p. 45.

Roederer, J. G. Nachr. v. d. Trichuriden. (Gött. gel. Anz., I76I, St. 25.)

Goeze. Vers. ein. Naturg. d. Eing.-Würmer, 1782, p. I 82.

Mayer, F. J. C. Beitr. z. An. d. Entoz., Bonn, I84I.

Davaine - Rech. sur le dév. et la propag. de l'Asc. tombr. et du Trich. de l'homme. (C. R. Ac. sc., Paris, I858, xlvi., p. I217.)

Eberth, J.G. Beitr. z. Anat. u. Phys. d. Tr. dispar. (Z. f. w. Z. I860, X., pp. 233 and 383 , and $I 862$, xi., p. 96.)

Leuckart, R Die menschl. Paras., I876, ii., p. 492.

Railliet, A. . Notices Helminthol. ' (Bull. Soc. centr. méd.' vétér., I 884, p. 449.)

Grassi, B. Trichocephalus u. Ascarisentwickelung. (C. f. B. u. P., I887, i., p. I 3I.)

Wichmann. Ueb. d. Verh. d. Trich. zur Darmschleimhaut. In.-Diss. Kiel, I889. Moosbrugger. Ueb. Trichocephaliasis. (Münch. med. Wochenschr., I895, p. I097.)

Askanazy, M. D. Peitschenwurm ein blutsaug., Paras. (Dtsch. Arch. f. klin. Med., I 896, Ivii., p. I04.)

Gen. 7. Trichinella, Railliet, I895.

Syn.: Trichina, Owen, I835, nec Meigen, 1830.

Very small trichotrachelidæ, the males of which have no spicules, but possess two conical appendages at the caudal extremity; the females are viviparous and possess one ovary; the vulva is situated at the border of the anterior fifth of the body. There is only one species.

Trichinella spiralis, Owen, I835.

Syn.: Trichina spiralis, Owen, I 835.

The male measures $\mathrm{I}^{\cdot} 4-\mathrm{r} \cdot 6 \mathrm{~mm}$. in length and $0.04 \mathrm{~mm}$. in diameter. The anterior part of the body is narrowed, the orifice of the cloaca is terminal and lies between the two caudal appendages, behind there are four papillæ. The females measure 3-4 $\mathrm{mm}$. in length and $0.06 \mathrm{~mm}$. in diameter; anus terminal.

Trichinella spiralis in its adult stage inhabits the small intestine of man and of various mammals. It is known to occur in the black rat (Mus. rattus), the sewer rat ( $M$. decumanus), the 
domestic pig (Sus scrofa dom.), the wild boar (Sus scrofa ferox), the domestic dog (Canis familiaris), the fox (Canis vulpes), the badger
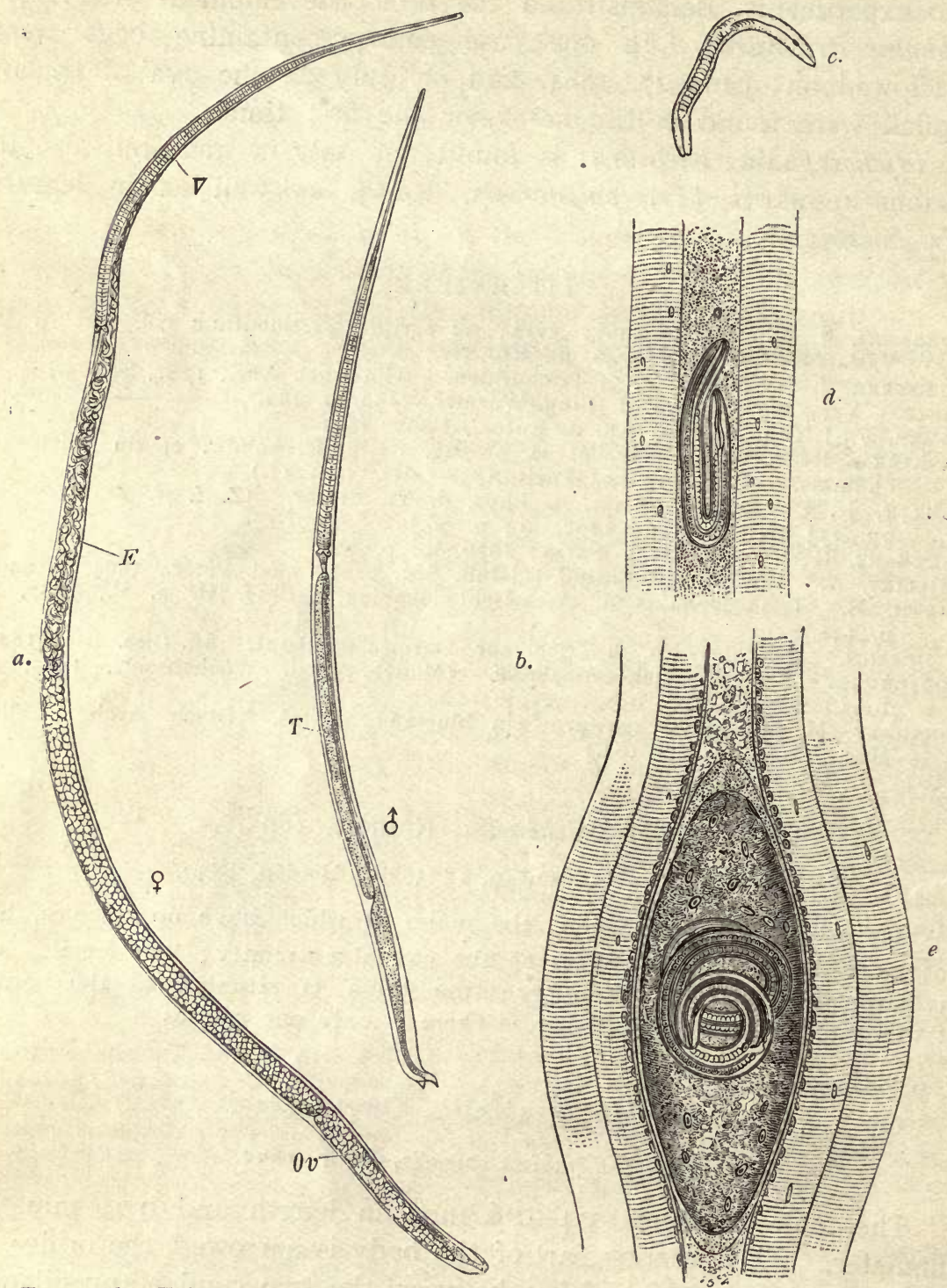

FIG. 206.-Trichinella spiralis. a, Mature female, "intestinal trichina"; E., embryos; V., vulva; Ov., ovary; $b$, muture male, "intestinal trichina "; $T$., testes; $c$, Newly-born larva; $d$, larva of trichinella in the muscles; $e$, encapsulated trichinella of the muscles. (After Claus.)

(Meles taxus), the polecat (Putorius fotidus), the marten (Mustela foina), the racoon (Procyon lotor), the Hippopotamus, and the cat; 
trichinellæ have been artificially introduced into the dog, the mole (Talpa europaa), the mouse (Mus musculus), the hare (Lepus timidus), the rabbit (Lepus caniculus), the hedge-hog (Erinaceus europaeus), the marmot (Cricetus vulgaris), the sheep, the calf, the horse, \&c. Human beings and the pig, rat, mouse, guinea-pig and rabbit are very easily infected; less easily the sheep, calf and horse; with more difficulty the cat, dog and badger. Trichinella can also be reared in birds (fowl, pigeon and duck). However, the young cannot be induced to settle in the muscular system, but are expelled with the fæces. By cold-blooded animals as well as by insects (Calliphora vomitaria) encysted trichinellæ are evacuated without undergoing any change, but they will still develop if subsequently ingested, say, by rabbits. According to Gujon, however, trichinella can develop in salamanders, because the same has found trichinella of the muscles in these animals, after they had been fed on encysted specimens. A high temperature $\left(30^{\circ} \mathrm{C}\right.$. $)$ must be provided in which to keep the experimental animals to ensure the success of the infection.

History. - Encapsulated trichinellæ had already been observed in London by Peacock (1828), and by J. Hilton (I833), in the muscular system of man; soon after (1835) Paget found them in London in an Italian who had died of tuberculosis, and recognised them to be encysted entozoa, which R. Owen described as Trichina spiralis. Soon after some further observations were reported on the occurrence of encysted trichinellæ in man in England, Berlin, Heidelberg, Denmark, N. America: they were also found in the pig (Leidy, Philadelphia) and the cat (Herbst, Göttingen, and Gurlt, Berlin). Herbst even succeeded in infecting a badger with encysted trichinellæ and subsequently infected two dogs with the flesh of this badger (I850). In I 855 R. Leuckart (Giessen) also commenced feeding experiments, and, like Küchenmeister and Virchow (1859), first went on the wrong track because it was believed at that time that trichinellæ were the larvæ either of Trichocephalus or Strongylus. Nevertheless, these experiments yielded some important results; they showed that trichinellæ become adult in the intestine within a few days, and that the females are viviparous (Leuckart). Until that time trichinellæ had been regarded as fairly harmless guests of man, but opinions soon changed when Zenker in Dresden (Janulary, I860), in performing the autopsy of a In-year-old girl who had entered the hospital with typhoid symptoms and there died, found trichinellæ (not yet encysted) in the muscles; the intestinal lesions characteristic of typhoid were lacking, but numerous adult trichinellæ were found in the intestine. Enquiries elicited the fact that at about Christmas-time the girl had been taken ill after eating pork, and at the same time the butcher from whom the meat was bought as well as several of his customers fell sick; the pickled pieces of the same meat were fuil of trichinellæ. In the face of this information it was not difficult to ascertain the cause of the disease and the manner of infection in Zenker's case, and it was not long before Leuckart, Virchow and Zenker 
were able by renewed experiments to demonstrate the cycle of development of Trichinella spiralis. Similar investigations followed by Claus in Würzburg, Davaine in Paris, Fuchs and Pagenstecher in Heidelberg, \&c., \&c.

Hardly had Zenker's case been published than numerous observations on trichinosis in man appeared, some referring to isolated cases, others to small or great epidemics, and nearly all from North Germany. The worst epidemic was that of Hadersleben (I865) in which place, numbering hardly 2,000 inhabitants, 337 persons were taken ill within a short time, and of these IOI died. The source of infection proved to be a single pig, the flesh of which had been mixed with that of three other pigs; 200 of the badlyinfected persons had exclusively eaten raw pork.

Moreover, it soon became clear that epidemics of trichinosis had been observed in Germany prior to I 860 , but that their nature had not been recognised, although in a few cases trichinellæ had been found in the muscles of those who had succumbed.

\section{History of the Development of Trichinella spiralis.}

Shortly after their introduction into the intestine of experimental animals the encysted trichinellæ escape from their capsules, which are destroyed by the gastric juices, and they then enter the duodenum and jejunum, where they become adult. During this period they do not grow considerably, the males grow from 0.8 I.o $\mathrm{mm}$. to $\mathrm{I} \cdot 2-\mathrm{I} \cdot 5 \mathrm{~mm}$. ; the females to ${ }^{\cdot} \cdot 5-\mathrm{I} \cdot 8 \mathrm{~mm}$. Soon after copulation, which already takes place in the course of two days, the males die off; the females, which during the following days attain a length of $3-3.5 \mathrm{~mm}$., either bore more or less deeply into the villi, or by means of the Lieberkühn's glands actually penetrate into the mucous membrane (Askanazy, Cerfontaine, Geisse), and thus usually attain the lymphatic spaces. A few also pierce through the intestinal wall and are found in the mesentery and its lymphatic glands. They deposit their young, the number of which, according to Leuckart, averages at least $\mathrm{I}, 500$, in the lymph spaces; the newly-born larvæ measure $0^{\circ} 09-0^{\circ} \mathrm{I} \mathrm{mm}$. in length, $0.006 \mathrm{~mm}$. in diameter; and they do not appear to increase in size during their migrations. The migrations are mostly passive, that is to say, the larvæ are carried along by the lymph stream or by the circulating blood, but sometimes they are active, as may be inferred from the fact that young trichinellæ are found in various parts of the intestinal wall beyond the chyle and lymph spaces, as well as free in the abdominal cavity.

The young brood is distributed throughout the entire body, but the conditions necessary to its further development are found 
only in the transversely striated muscular system; the young nematodes penetrate the capillaries, attain the intra-muscular connective tissue and then invade the transversely striated muscular fibres (Virchow, Leuckart, Graham ${ }^{1}$ ). On the ninth or tenth day after infection the first trichinellæ have reached their destination; but further invasions are constantly taking place because the intestinal trichinellæe live from five to seven weeks and continue. to produce their young.

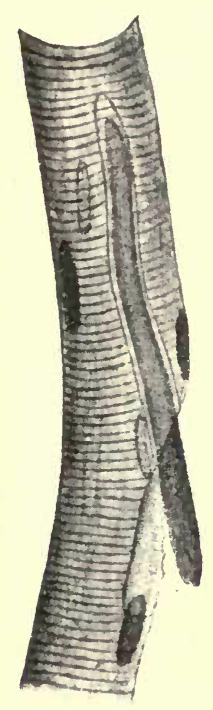

A.

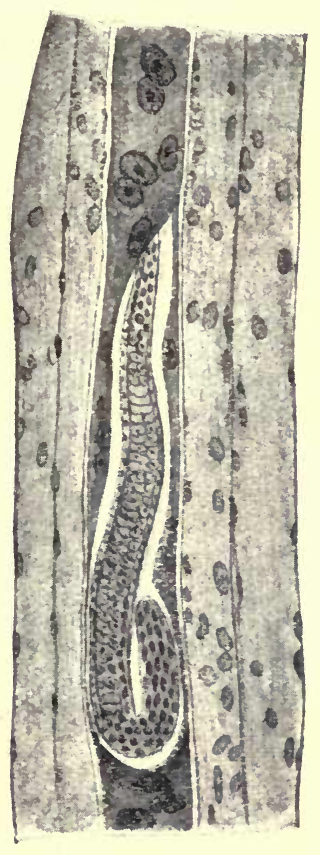

$B$.

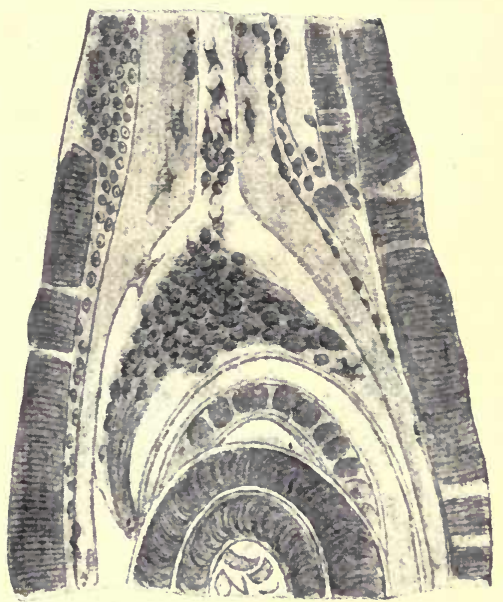

$C$.

FIG. 207.-A. Isolated muscular fibre of a rat, invaded by trichinella, $5 \mathrm{IO} / \mathrm{I}$. B. Section through the muscle of a rat: the infected fibre has lost its transverse striation; its nuclei are enlarged and multiplied, 3Io/I. C. Portion of a trichinella-capsule, at the pole of which connective-tissue cells are penetrating the thickened sarcolemma. (After Hertwig-Graham.)

The invasion of the muscles by numerous active worms causes more or less severe inflammation in man, which is manifested by fever, by pain in the muscles, and more particularly by muscular contracture; masticatory, respiratory, and swallowing movements are rendered difficult, and in con-

1 Trichinellæ that are unable to penetrate into muscular fibres invariably die off, no matter where else they settle; their occurrence in the adipose tissue is disputed, but is still possibly correct, as bundles of muscles are present in the fat of bacon. The trichinellæ do not settle in the myocardium, although they may reach it in cases of heavy infection; they then die off or wander into the pericardium, and eventually into the cavities of the heart. 
sequence of the pain they give rise to, the patients avoid using the voluntary muscles as much as possible. At the commencement of the disease there are more or less severe attacks of diarrhœa, which, together with the fever and abdominal pain arising at this period, can be ascribed to the boring female trichinellæ and the wounds they make in the intestinal wall. When the brood commences to migrate small œdemas appear, especially under the eyes.

The muscular fibres attacked degenerate, the transverse striation at first disappearing; the fibres then assume a granular appearance, the nuclei multiply and become enlarged, and are surrounded by an area of granular material, which stains more deeply than the remaining contents of the sarcolemma. Two or three weeks after infection, the spirally rolled-up trichinellæ have

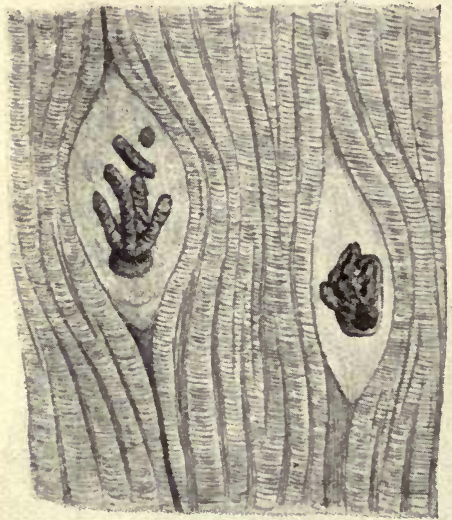

FIG. 208. - Calcified trichinella in the muscular system of a pig; the capsules are not calcified. (After Ostertag.)
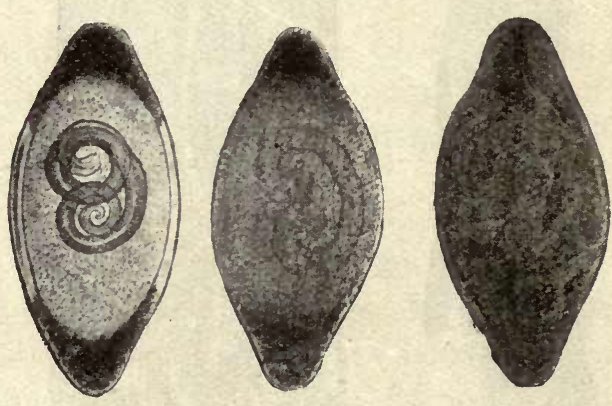

FIG. 209.-Various phases of the calcification of trichinella of the muscles, which starts at the poles of the capsule.

grown to $0.8-\mathrm{I}^{\circ} \mathrm{O} \mathrm{mm}$., and in their vicinity the muscular fibre is swollen, spindle-shaped, and the sarcolemma is glassy and thickened. The inflammation also extends to contiguous fibres, especially to the intra-muscular tissue, which proliferates greatly, especially in the vicinity of the degenerated firases. While the latter become more and more absorbed, the capsule is formed by the inflamed connective tissue, which, penetrating into the glassy and thickened sarcolemma by way of the poles of the spindle, takes its place and forms the cystic membrane. The cysts are lemon-shaped and usually lie with their longitudinal axis in the direction of the muscular fibres; on an average they measure $0.4 \mathrm{~mm}$. in length by $0.25 \mathrm{~mm}$. in breadth. 
Later on adipose cells appear at their poles, and after about six or nine months they commence to calcify, the process starting at the poles (fig. 209). Finally, sometimes after the lapse of years, the captive trichinellæe themselves become calcified.

According to experience, trichinellæ are not found to be evenly distributed in the muscular system of pigs; the muscular parts of the diaphragm, the muscles of the larynx, tongue, abdomen and intercostal spaces are their favourite positions; this predilection for the respiratory muscles is explained by their regular contractions; in addition, regular contractions of the capillaries take place and favour the fixing of the circulating trichinellæ. The same circumstance probably explains the frequency of the parasites in the tongue.

- Possibly also the trichinellæ that bore direct through the intestine may penetrate the muscles in the vicinity from the abdominal cavity. Frequently also encysted trichinellæ are found in remarkable numbers in the vicinity of the points of insertion of the tendons, this proclivity being probably connected with the fact that the trichinellæ first of all wander into the muscular fibres and find a natural barrier at the points of insertion of the tendons.

The trichinellæ, in their encysted condition, remain alive and capable of development for many years. (In the pig eleven years and in man twenty-five to thirty-one years.) Encystment, however, is not a necessary condition for the development of the brood.

In consequence of the new batches of young produced during several weeks, the above-mentioned symptoms of disease are often considerably aggravated; the fever increases, delirium may arise, and infiltration of the lungs, fatty degeneration of the liver and inflammation of the kidneys may ensue; the initial slight œdema may extend, the strength dwindles, and in many cases the patients succumb to the trichinosis. In severe cases improvement of the condition is only apt to occur in the fourth or fifth week; the convalescence is always protracted.

The black rat and more particularly the sewer rat (Mus rattus, Mus decumanus ${ }^{1}$ ) are the normal hosts of Trichinella spiralis. These animals, especially the last-named species, ${ }^{2}$ infect

' It is still a matter of dispute and can hardly be definitely settled whether trichinella were brought to Europe by the sewer rats which invaded Europe at the end of the eighteenth century, or whether they were imported with the Chinese pig in 1820 or 1830 , when it was introduced into England and Germany to cross with the native breeds, or whether finally trichinellæ are also indigenous to Europe.

${ }^{2}$ [The Sewer Rat is M. decumanus; Mus rattus is the Black Rat.-F.V.T.] 
themselves very easily, as they do not spare the members of their own family, and they also transmit trichinosis to other species by which they are devoured, such as pigs, dogs, cats, foxes, bears and martens. Man becomes infected with trichinella by eating the flesh, insufficiently cooked, of infected pigs, also, but more rarely, by eating the infected flesh of wild boars, dogs, cats, bears and foxes.

The infection of pigs may likewise take place by their having access to the offal of trichinous pigs or being actually fed on it. These are, however, exceptions which, as a matter of course, are of great importance in certain places. As a matter of fact the rats examined for trichinella were always found to be severely infected. Thus Billings, in the knacker's yard at Boston, found that 76 per cent. of the rats were infected, and in an export slaughter-house 100 per cent. were found to harbour the parasite; in the City of Boston 10 per cent. of the rats had trichinosis. Heller found that of 704 rats, from 29 different places in Saxony, Bavaria, Würtemberg and Austria, 8.3 per cent. were infected with trichinellæ; of the rats caught in the knacker's yards $2 \dot{2} \cdot I$ were diseased; of those taken in slaughter-houses $2 \cdot 3$ were infected, and of rats from other localities only 0.3 per cent. harboured the parasite. Leisering found almost the same figures, but in rats from slaughter-houses 5.3 per cent. were infected.

The geographical distribution of Trichinella spiralis does not correspond with the occurrence of trichinosis in man; local customs are an important factor, for instance, the custom of eating pork in a condition that does not affect the life of the enclosed trichinella. In places where such customs do not prevail epidemics do not occur, at the most there are isolated cases of the disease, although there be a great number of infected pigs. The following conditions prevail in North America: In Boston, Billings found that 4-5:7 per cent. of the pigs examined were trichinous; Belfield and Atwood found that 8 per cent. were infected in Chicago. Salmon found on an average that 2.7 per cent. were infected (but at various places the percentage fluctuated between $0.28-16.3$ per cent.), yet epidemics of trichinosis hardly ever occur in North America, and only isolated cases of the disease are met with in German immigrants, who keep to their native customs.

This report, according to the researches of $H$. U. Williams, must be considerably modified. This author has examined the muscular system of human cadavers according to the method employed by inspectors of meat for pigs. The investigations were conducted in the Pathological Institute of the University of Buffalo, and the observer has examined 505 bodies since I894, of which $27(=5.34$ per cent.) were invaded by trichinella. The cases, according to the nationality, are divided as follows:- 


\begin{tabular}{|c|c|c|c|c|c|c|c|c|}
\hline & & & & & & Tri & & Per cent. \\
\hline & & & & & E.xamined & Absent & Present & $\begin{array}{l}\text { Of Positive } \\
\text { Results }\end{array}$ \\
\hline Americans:- & & & & & & & & \\
\hline (a) Whites & . & . & .. & . & 207 & 201 & 6 & $2 \cdot 89$ \\
\hline (b) Negroes & $\therefore$ & . & . & . & 70 & 65 & 5 & $7 \cdot 14$ \\
\hline British and Irish & . & . & . & . & 62 & 57 & 5 & $8 \cdot 06$ \\
\hline Canadians $\quad \ldots$ & . & .. & . & . & 12 & Io & 2 & $16 \cdot 66$ \\
\hline Germans & . & . & . & . & 49 & 43 & 6 & I $2 \cdot 24$ \\
\hline Italians $\quad \therefore$ & . & .. & .. & . & I 2 & Io & 2 & 16.66 \\
\hline Other Nationalities & . & . & . & $\cdots$ & 27 & 27 & o & o \\
\hline Nationality unknown & . & . & . & . & 66 & 65 & I & $I \cdot 5 \mathrm{I}$ \\
\hline Total & . & .. & .. & . & 505 & 478 & 27 & $5 \cdot 34$ \\
\hline
\end{tabular}

It is worthy of remark that half of all the positive cases were mental patients which were found to be affected with trichinella to well nigh I 2 per cent. Trichinosis was not, however, the cause of death in any case. Very frequently the trichinellæ were found calcified and dead.

Conditions are similar in most countries of Europe, where, of course, the number of infected pigs is considerably smaller, but the disease depends less on this than on the way in which the pork is prepared.

Cases of trichinosis have been known to occur in nearly all the countries of Europe; further, in Egypt, Algeria, East Africa, Syria, India, Australia, and America. North Germany, more especially the Saxe-Thüring States, is the classical land for epidemics of trichinosis, the mortality varies, but it may be very high. ${ }^{1}$

Prophylaxis.-The grave nature of the disease and the comparatively high mortality relating to trichinosis led the authorities to adopt certain preventive measures, which are the more necessary as national

${ }^{1}$ For instance, extensive epidemics occurred in Hettstädt in 1863 ( 160 patients, 28 deaths); Hanover, I864-I 865 (more than 300 patients); Hadersleben, I865 (337 patients, IOI deaths); Potsclam, I 866 (I64 patients); Greifswald, I866 (I 40 cases, I death); Magdeburg, I 866 (240 cases, I6 deaths); Halberstadt, I 867 (IOO cases, 20 deaths); Stassfurt, I 869 (over Ioo cases); Wernigerode, I873 (IOO cases, I death); Chemnitz ( 194 cases, 3 deaths): Linden, I 874 (400 cases, I40 deaths) ; Niederzwohren, near Cassel, I 877 (half the population); Diedenhofen, I877 (99 cases, Io deaths); Leipzig, I877 (I 34 cases, 2 deaths); Ernsleben, I883 (403 cases, 66 deaths); Strenz Neuendorf, I884 (86 cases, I2 deaths), \&c., \&c. According to Johne, Iog epidemics with 3,402 cases and 79 deaths occurred in Saxony between 1860 and I 889 . Stiles, in a work recently published, states that there were 8,49I cases of trichinosis with 5 I 3 cases of death $\left(6^{\circ} 04\right.$ per cent.) in Germany from I 860 to 1880 ; that there were 6,329 cases and 318 deaths $\left(5^{\circ} \mathrm{O} 2\right.$ per cent.) between $188 \mathrm{I}-\mathrm{I} 898$ we are well aware. Of these latter, I88I-1898, 3,822 (225 deaths) occurred in Prussia, I,634 (76 deaths) in Saxony, and 873 ( 17 deaths) in the remaining states. There is, however, no doubt that many deaths from trichinosis were not recognised, as proved by experience at post mortems. 
customs cannot be altered in a short time. As the usual process of pickling and smoking, even when long continued, does not certainly ensure the death of the trichinellæ contained in the meat, and also because in roasting and boiling large pieces of pork a considerable time is necessary to permit the temperature required to kill off the parasites $\left(62-70^{2}\right.$ C. $)$ to penetrate to the middle of the joint, it appeared to be most practical to have all pigs microscopically examined for trichinellæ before they, or parts of them, were placed on the market, and all infected meat condemned, no matter whether the trichinellæ were present in large or small numbers, still undeveloped or calcified. Since 1877 obligatory examination of pork has been introduced in Prussia, though as yet it is not thoroughly carried out; other states of North Germany as well as the larger towns of South Germany soon followed; a complete army of trichina inspectors, officially examined and periodically controlled by experts, and whose number in Prussia amounted to 27,602 in 1896 , and was even increased to 28,224 in 1899 , have.the charge of examining pork on certain lines laid down. The orders, however, are by no means narrow. The proceeding is usually that the trichina inspector himself goes to the slaughter-houses, or special samplers take pieces of the muscles that are known to be the favourite seats of the parasite (strips of the diaphragm, the rib part of the diaphragm, muscles of the tongue and larynx, intercostal and abdominal muscles); six small portions are separated from each piece, pressed between slides or special compressors, and carefully gone through by examining them with a microscope at low power. The pigs, free from trichinellæ are passed for commerce; trichinous pigs, on the other hand, in Prussia, are only allowed to be used for industrial purposes, i.e., the hide and bristles are used, the fat is allowed to be melted down, or certain parts are used for the manufacture of soap or glue. In Saxony, however, it is still permitted to place trichinous flesh on the market, fully declaring its nature, and after having been heated to its deepest strata at a temperature of $100^{\circ} \mathrm{C}$. in a suitable apparatus, and under the supervision of a veterinary surgeon.

As to THE PROPORTION OF TRICHINOUS PIGS to healthy ones, the following tables give the figures for Prussia.

The proportion, however, is not only subject to variation in separate years, but differs according to the district; thus, in 1884, in the State district of Minden there was one trichinous pig to 30,146 healthy animals, in Erfurt I : 14,563, in the district of Gnesen I : IOI, in Schrimm I : 86, and in Schroda $\mathrm{I}: 68$.

In Germany trichinella is becoming LEss common in pigs (Ostertag).

(a) Prussia.

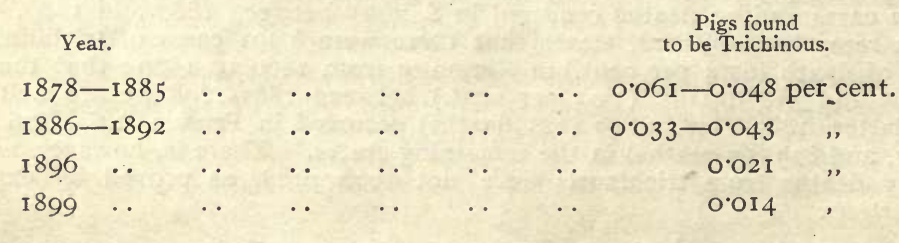




\begin{tabular}{|c|c|c|c|}
\hline Year & $\begin{array}{c}\text { Number of } \\
\text { Pigs Examined }\end{array}$ & $\begin{array}{c}\text { Number of } \\
\text { Trichinous Pigs }\end{array}$ & Proportion \\
\hline $\begin{array}{l}\text { I } 878 \\
\text { I } 879 \\
\text { I } 881 \\
\text { I } 882 \\
\text { I } 883 \\
\text { I } 884 \\
\text { I } 885 \\
\text { I } 886 \\
\text { I } 887 \\
\text { I } 888 \\
\text { I } 889 \\
\text { I } 890 \\
\text { I } 891 \\
\text { I } 892 \\
\text { I } 896 \\
\text { I } 899\end{array}$ & $\begin{array}{l}2,524, \text { IO } 5 \\
3,164,656 \\
3,118,780 \\
3,808,142 \\
4,248,767 \\
4,611,689 \\
4,421,208 \\
4,834,898 \\
5,486,416 \\
6,051,249 \\
5,500,678 \\
5,590,510 \\
6,550,182 \\
6,234,559 \\
8,759,490 \\
9,230,353\end{array}$ & $\begin{array}{l}1,222 \\
1,938 \\
1,695 \\
1,852 \\
2,199 \\
2,624 \\
2,387 \\
2,114 \\
2,776 \\
3,111 \\
3,026 \\
1,756 \\
2,187 \\
2,085 \\
1,877 \\
1,021\end{array}$ & $\begin{array}{l}\text { I }: 2065 \\
\text { I }: 1632 \\
\text { I }: 1839 \\
\text { I }: 2056 \\
\text { I }: 1932 \\
\text { I }: 1741 \\
\text { I }: 1852 \\
\text { I }: 2287 \\
\text { I }: 1988 \\
\text { I }: 1945 \\
\text { I }: 1818 \\
\text { I }: 3183 \\
\text { I }: 2996 \\
\text { I }: 2992 \\
\text { I }: 4666 \\
\text { I }: 9040\end{array}$ \\
\hline
\end{tabular}

(b) Saxony.

\begin{tabular}{|c|c|c|c|c|c|c|c|c|c|}
\hline & & & & & & \multicolumn{3}{|c|}{$\begin{array}{l}\text { Number of Pigs } \\
\text { found to be Trichinous }\end{array}$} \\
\hline I 891 & $\cdots$ & . & $\cdots$ & $\ldots$ & $\cdots$ & $\ldots$ & . & O०OI $4 \mathrm{p}$ & cent. \\
\hline ז 892 & . & . & $\ldots$ & . & . & . & . & O०OI I & , \\
\hline I 893 & . & . & . & .. & . & . & . & 0.008 & ", \\
\hline I 894 & . & . & . & . & . & . & . & 0.007 & ," \\
\hline 1895 & . & . & . & . & . & . & . & O'OI 2 & ," \\
\hline I 896 & . & .. & . & .. & . & . & . & O.OIO2 & , \\
\hline I 899 & .. & .. & . & . & . & . & . & 0.004 & ", \\
\hline
\end{tabular}

(c) City of Berlin.

Year.

I $883-$ I $893 \quad \ldots \quad \ldots \quad \ldots \quad \ldots \quad \ldots \quad \ldots 035-0^{\circ} 064$ per cent.

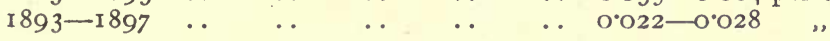

There is no doubt that the excellent preventive measure of official inspection for trichinella has led to the avoidance of grave disasters; 'its introduction has not yet caused an entire cessation of trichinosis in man, because inspection of pork is not obligatory everywhere, so that human beings may become infected by unexamined trichinous pigs from their own country or from abroad, and also because an infection may occasionally escape notice. For these reasons the meat imported into Berlin from abroad as free from trichinæ is examined again and not always in vain; finally, also, gross negligence may at times occur, or fateful errors may be made.

In addition private prophylaxis must not be neglected, and its chief aim should be directed to the suitable preparation of pork. 


\section{LITERATURE.}

OWEN, R. Description of a Microscopic Entozoon infesting the Muscles of the Human Body. (Transact. Zool. Soc., London, I835, i., p. 315, I plate.)

Herbst, G. Beobachtungen üb. Tr. spir. (Götting. Nachr., 1851, p. 260. Ibid., I 852, p. I83.)

LEUCKART, R. Unters üb. Tr. spir., I Edit., I860; 2 Edit., I 866.

VIrchow, R. Zur Trichinenlehre. (Arch. f. path. Anat., 1865, xxxii., p. 332.)

1 $\$$ Darstellung d. Lehre v. d. Trichinen. Berlin, I 864 and I 866.

Zenker, F. A. Ueber die Trichinenkrankh. d. Menschen. (Virch. Arch. f. path.

i $=1$ An., I 860, xviii., p. 56r.)

Beitr. z. Lehre v. d. Trichinenkrankh. (D. Arch. f. klin. Med., I 866, i., p. 90 ;

(i) I871, viii., p. 387.)

Pagenstecher, H. A. Die Trichinen. Wiesb., 1865.

Goujon, L. Expériences sur la Trich. spir. (Thèse, Paris, I866.)

Chatin, J. La trichine et la trichinose. Paris, 1883.

Blanchard, R. Article: Trichine, trichinose. (Dict. encycl. d. sc. méd., I887,

3 Ser., xviii., Paris.)

Cerfontaine, P. Contrib. à l'étude de la trichinose. (Arch. de biol., I893, xiii., p. I25. Bull. Ac. roy. de Belg., I 893 [3], xxv.; p. 454.)

Askanazy, M. Z. Lehre v. d. Trichinosis. (C. f. B. u. P., I894, xv., p. 225.) Arch. f. path. An., I 895 , cxli., p. 42.)

Johne, A. Der Trichinenschauer, 4 Edit. Berlin, 1893. Fo $\mathrm{F}$

GeIsse, A. Z. Frage d. Trichinenwand. In.-Diss., Kiel, 1894.

Hertwig, R. Entw. d. Trich. (Münch. med. Wchschr,, I895, No. 21.)

EhrhaRDT, O. Z. Kenntn. d. Muskelveränd, b. d. Trich. d. Kaninch. (Beitr. z. path. An. u. z. allg. Path., i 896 , xx., p. r.)

Z. Kenntn. d. Muskelver. b. d. Trich. d. Menschen. (Ibid., p. 44.)

Graham, J. Y. Beitr. z. Naturg. d. Trich. spir. (Arch. f. mikr. An. L., I897, p. 219.)

BRown, T. R. Stud. on Trichinosis. (Bull. Johns Hopk. Hosp., I 897, viii., No. 73.)

MARK, E. L. Trichinæ in Swine. (Twentieth Ann. Report Mass. State Board of Health for 1888 , p. Ir 3 .)

Williams, H. U. The Freq. of Trich. in the Un. Stat. (Journ. of Med. Res., I90I, vi., p. 64.)

Strles, Ch. W. Trichinosis in Germany. (U.S. Dep. of Agric. Bur. of An. Ind. Bull., I901, No. 30., Washingt.)

PIRL, D. Vork. v. Trich. i. Hundefl. u. deren Bedeut. f. d. Fleischbeschau. (Ztschr. f. Fleisch, u. Milchhyg, I 899 , x., p. 5.)

\section{(f) Fam. Strongylidae.}

\section{Gen. 8. Eustrongylus, Dies., I85I.}

Very large strongylidæ with cylindrical bodies; the mouth is surrounded by six papillæ; the male has one spicule and a collar-like bursa. One ovary. The vulva is in the anterior region of the body.

\section{Eustrongylus gigas, Rudolphi, 1802.}

Syn.: Ascaris canis et martis, Schrank, I788; Asc. visceralis et renalis, Gmelin, I789; Strongylus gigas, Rud., I802 ; Eustrongylus gigas, Dies., I85 I ; Strongylus renalis, Moq.-Tand., I860 ; Eustr. visceralis, Raill., I 885.

Colour, blood-red; the anterior extremity somewhat slender; there is a series of about $5^{\circ}$ papillæ along the lateral ridges; the submedian ridges are strongly developed, and from them spring the radiary muscles for the intestine. 
The males attain a length of $40 \mathrm{~cm}$., and a diameter of $4-6$ mm., the posterior extremity is transversely truncated; the anal orifice is within the base of the collar-like bursa, the thickened edges of which are beset with papillæ; the spicule measures 5-6 $\mathrm{mm}$. in length.

The females attain a length of IOO $\mathrm{cm}$., and a breadth of I2 $\mathrm{mm}$. The anus is crescentshaped and terminal. The vulva is $50-70 \mathrm{~mm}$. distant from the anterior extremity. The eggs are oval and have a thick shell presenting numerous depressions; the shell itself is brownish, but it is colourless at the somewhat thickened poles; it measures 0.064 $\mathrm{mm}$. in length by $0^{\circ} 04 \mathrm{~mm}$. in breadth.

Eustrongylus gigas lives in the pelvis of the kidney, more rarely in the abdominal cavity of the seal, otter, dog, wolf, fox, horse, marten and polecat, exceptionally also in human beings. Most of the cases in which this parasite has been reported as occurring in man may be traced back to unrecognised Ascaris lumbricoides, or to clots of fibrin; twelve certain cases, however, remain. The case recently described by Trumbull was probably not a case of eustrongylus.

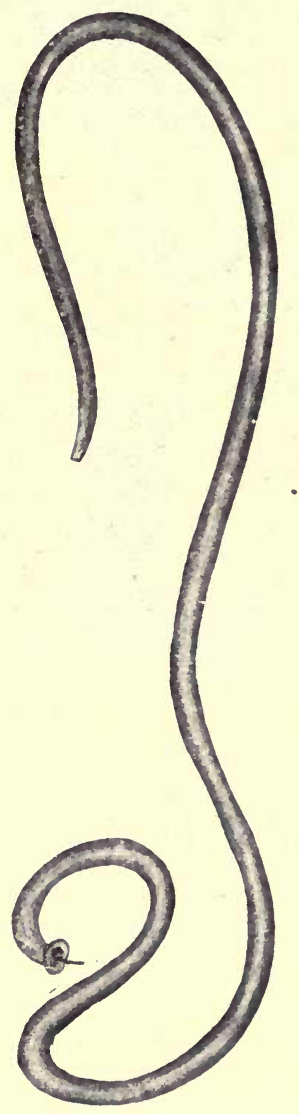

FIG. 2I0.- Eustrongylus gigas, o. Natural size. (After Railliet.)

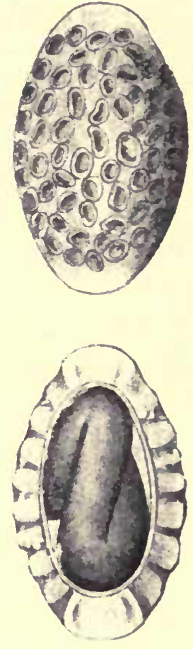

FIG. 2 II. - Eggs of Eustrongylus gigas, above seen from the flat, below the optical section, 400 1 . (After Railliet.)

We are not aware of the source 'of infection, but we have learned from Balbiani that the eggs develop an embryo in water or moist soil, and that this embryo may remain alive several years without hatching; the infection of dogs with embryo-containing eggs did not succeed; an intermediate stage in fishes is conjectured. 


\section{LITERATURE.}

Balbiani, G. Rech. sur le dév. et le mode de propagat. du Strongle géant. (Journ. de l'anat., I870, vii., p. I80. Compt. rend. soc. biol., Paris, 1874 [6], i., p. I25.) Blanchard, R. Nouv, observ. de Strongle géant chez l'homme. (Ibid., I 886 [8], iii., p. 379.)

Maguevr. Strongle géant du rein expulsé en partie par le canale de l'urètre chez un enfant de deux ans et demi. (Journ. méd., Bordeaux, 1887-88, p. 337.)

Trumbull, J. A Case of Eustrong. gigas. (Med. Record, 1897, lii., No. 8, p. 256. Ref. C. f. B. u. P., xxii., p. 619.)

Stiles, Ch. W. Notes on Paras. 49. (Ibid., I898, liii., No. 14, p. 469. Ref. C. f. B., P. u. I., xxiv., P. 505.)

Rothstadt, J. Ueb. d. Vork. v. Eustr. gig. i. Hund. d. Stadt Warschau. (Arb. zool. Labor. d. Kais. Univ. Warschau, 1897, Russ.)

Gen. 9. Strongylus, O. F. Müller, 1780.

The mouth has six small papillæ; the male has a bursa copulatrix and two spicules; the female has two ovaries, the posterior extremity is pointed. The vulva is situated in the posterior half of the body.

Strongylus apri, Gmelin, I789.

Syn.: Gordius pulmonalis apri, Ebel, 1777; Ascaris apri, Gmelin, 1789; Strongylus suis, Rud., I809: Strongylus paradoxus, Mehlis, I831; Strongylus elongatus, Duj., 1845; Strongylus longevaginatus, Dies., I851.

The male measures $\mathrm{I} 2-25 \mathrm{~mm}$. in length; the bursa copulatrix is two-lobed; there are five ribs in each lobe; the spicules are thin and about $4 \mathrm{~mm}$. in length. The females measure $50 \mathrm{~mm}$. in length, the anus is close in front of the posterior extremity, which is recarved like a hook; the vulva is close in front of the anus. The eggs are elliptical, $0.05-0.1 \mathrm{~mm}$. in length, 0.039$0.072 \mathrm{~mm}$. in breadth; when the eggs are deposited the embryo is already formed.

Strongylus apri frequently lives in the bronchial tubes-usually the smaller ones-of the pig $^{1}$ and wild boar; it is also found occasionally in sheep and in man; in young pigs it is apt to set up a bronchitis, which frequently causes death:

The reports of the city inspection of meat in Berlin state that Strongylide in the lungs of pigs are by no means rare; therefore, the lungs of I,94I pigs were condemned between $1885-86$, of I,64I between I886-7, of 3,237 between I $887-8$, of 4,855 between 1888-9, of 7,I97 between I889-90, and of 5.574 pigs between I890-I, \&c., \&c. Ostertag found Strongylus apri in 60 per cent. of the pigs examined in the Berlin abattoir; Meyer in Leipzig found the parasite in 15 per cent. of the native pigs and in 52 per cent. of the Hungarian pigs. 
The first communication as to the occurrence of strongylidæ in man was that of Diesing, who, in I845, in Klausenburg, had the opportunity of examining strongylidæ found in the lung of a little boy six years old (Strongylus longevaginatus, Dies.); probably also the nematodes found in the trachea and larynx of man, and described by Rainey and Bristowe as specimens of Filaria trachealis, belong to this group; according to Chatin strongylus apri may also occur in the intestine of man; this occurrence, however, may in all probability have been due to an accidental introduction of adult Strongyli into the intestine, and should not be attributed to a settlement from the larval stage.

The embryonic development and the larval stage have been made known by Wandolleck. No experiments to induce infection have been made; it is probable, however, that infection is direct and without the aid of an intermediary host.

\section{LITERATURE.}

Diesing, C. M. Systema Helmin. thum. Vindob., 1851 , ii., p. 317. Revision der Nematoden. (Stzber. d. K. Akad. Wiss Wien. math.-nat., I860, $\mathrm{Cl}$. xlii., p. 722. )

Rainey. Entozoon found in the Larynx. (Transact. Path. Soc., London, 1855, vi., p. 370.)

Chatin, J. Le strongle paradoxal chez l'homme. (Bull. Acad. méd., Paris, I888, No. I 5, p. 483.)

JelkmanN, F. Ueb. d. fein. Bau v. Strong. pulm. apri Eb. In.-Diss., Basel. (Lpzg., r 895.)

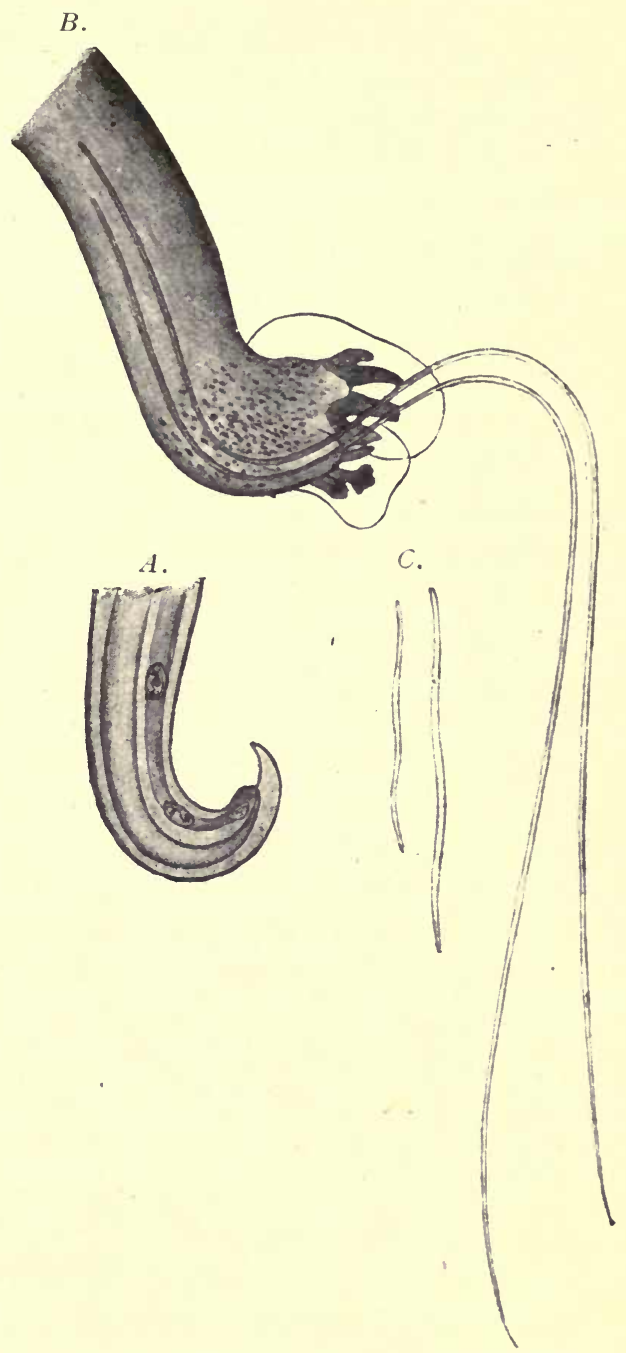

Frg. 2I2.- Strongylus apri. A. Posterior extremity of the female, magnified, $B$. Posterior extremity of the male, magnified. $C$. male and female, natural size. (After Railliet.) 
Wandolleck, B. Z. Embryonalentw. d. Strong. paradoxus. In.-Diss., Berlin, I89I, and Arch. f. Naturg., I892, lviii, p. I 23.

Spemann, H. Z. Entw. d. Str. parad. (Zool. Jahrb. An., 1895, Part viii., p. 30I.)

Strongylus subtilis, Looss, I895.

The male measures $4-5 \mathrm{~mm}$. in length and anteriorly measures only $0.009 \mathrm{~mm}$. in breadth, whilst at the back, just in front of the bursa, it measures $0.07 \mathrm{~mm}$. The muscular œesophagus occupies a little less than one-sixth of the body, and behind it there are two large gland cells; at the back of these starts the genital tube which extends through the entire body cavity as far as the anus. The bursa consists of two lateral semicircular wings, which ventrally are connected by a low cross-bridge; the ribs of the bursa appear to be asymmetrically arranged, the spicules are equal and measure $0^{\circ} \mathrm{I} 5 \mathrm{~mm}$. in length, and have irregularly running supports springing from the anterior: between them there is a chitinous fragment of a boat-like shape with two fine points directed ventrally. The females measure $5.6-7 \mathrm{~mm}$. in length and about $0.09 \mathrm{~mm}$. in breadth, though the cephalic extremity only measures $0.01 \mathrm{~mm}$. across; the anus is $0.097 \mathrm{~mm}$. in front of the posterior extremity which tapers suddenly into a slender pointed tail; the œsophagus, intestine and glands are the same as in the male; the vulva is situated at the commencement of the last fifth of the body; of the two genital tubes one passes forwards to the hindmost cervical gland, then bends backwards, and after a short run turns again with its blind end towards the front; the posterior tube runs as far as the anus, then turns to the front, and shortly in front of the middle of the body, turns back again and almost immediately terminates blindly. The mature eggs are oval, $(0.063-0.04 \mathrm{I} \mathrm{mm}$.$) and have thin shells; they are apparently$ deposited before segmentation.

This species was found by Looss in the anterior part of the small intestine in post mortems of fellahs of Alexandria and Cairo; it, however, also inhabits the intestine of the camel.

According to Ijima the same species was found in the stomach of a Japanese woman.

\section{LITERATURE.}

Looss, A. Strongylus subtilis n. sp., ein bisher unbekannter Parasit des Mensch i. Aeg. (C. f. B. u. P., I895 [I], xviii., p. I6I.)

Notiz z. Helm. Aegypts. i. (Ibid., xx., I 896, p. 864.)

IJima, J. Strong. subt. in Japan. (Zool. magaz., I896, vii., p. I55.) 
Gen. Io. Ankylostoma, Dubini, I843.

Syn. : Dochmius, Duj., 1845.

Characterised by the dorsally directed abrupt truncation of the anterior extremity within which is the large oral capsule; the oral aperture is round and contains two recurved chitinous teeth at each side of the median line on the ventral border, but only one dorsal tooth. In the base of the oral capsule there are two chitinous supports on the ventral side and one tooth on the dorsal side. The bursa is three-lobed, and is broader than it is long; there are two spicules; the vulva is behind the middle of the body. ${ }^{1}$

\section{Ankylostoma duodenale, Dubini, I843.}

Syn.: Strongylus quadridentatus, v. Sieb., I85I ; Dochmius anchylostomum, Molin, I860 ; Sclerostoma duodenale, Cobb., I864; Str. duodenalis, Schneid., I866; Dochmius duodenalis, Lckt., I876.

The body is cylindrical; attenuated anteriorly, and of a light reddish colour. In the oral cavity on the ventral surface close behind the orifice (fig. 2I4) there are four hook-like teeth directed backwards; on the dorsal surface there are two teeth directed forwards; in the base of the oral cavity there is one tooth directed forward on the dorsal surface and two chitinous lamellæ spreading out leaf like on the ventral surface. The males measure 8 - Io $\mathrm{mm}$. in length, $0_{4}-\mathrm{O}_{5} \mathrm{~mm}$. in breadth; the bursa has two large lateral and one small dorsal alar processes; the rib of the latter terminates into two tridentate points; a curved rib directed backwards arises from each side of the trunk of the central rib; each lateral wing is supported by four ribs; the two spicules are long and slender. The females measure $\mathrm{I} 2-\mathrm{I} 8 \mathrm{~mm}$. in length, the caudal extremity has a small spine; the vulva is somewhat in front of the posterior quarter of the body. The eggs are elliptical and have thin shells, they measure $0^{\circ} 055-0^{\circ} 065 \mathrm{~mm}$. in length and $0.032-0.045$ in breadth, and are laid in a state of segmentation.

Ankylostoma duodenale lives in the duodenum, more rarely in the first part of the jejunum; it is parasitical in human beings and in a few anthropomorphous apes; it appears to be distributed over all the peopled parts of the earth; it is very common in the warmer regions, and occurs also in the colder temperate zones; it is certainly not absent from Germany.

${ }^{1}$ Looss, A., "Ueb. d. Giltigk. d. Gattungsnamens Ancylostomum Dub." (C. f. B., P. u. I. (I), Orig., I902, xxxi., p. 422). 
This parasite was discovered by Dubini in Italy in I843, and soon gained notoriety from the fact that Griesinger was able to prove that

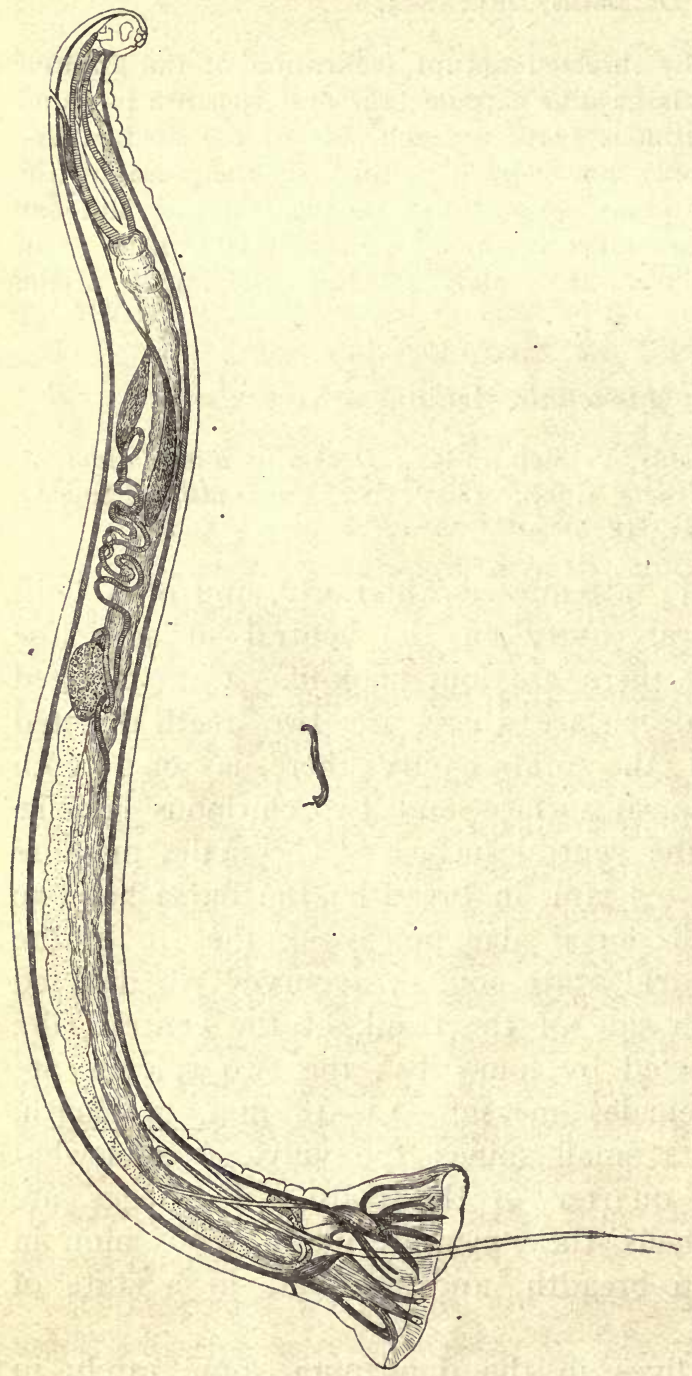

Fig. 213. - Ankylostoma duodenale. The male, to the left, magnified ; to the right in its natural size. (After Schulthess.)
Ankylostoma was the sole cause of "Egyptian chlorosis." According to Bilharz it is almost always present at post mortems in Egypt.' The disease caused by this worm is termed "mal-cœur" in the Antilles, "tun-tun" in Columbia, "opilação," or intertropical hypohæmia, in Brazil. The disease is due to the manner of nutrition of the parasites because these worms suck blood with their head always sunk more or less deeply into the mucous membrane of the intestine; they constantly leave the spots they have attacked, so that secondary hæmorrhages occur; in addition, the condition of the diseased intestine has some effect on the nutrition of the patients; perhaps also there are some toxins produced by the parasite itself, so that in cases of long standing the condition of the patient becomes serious.

Ankylostoma gained further notoriety when, during the construction of the tunnel of St. Gotthard, it was proved to be the cause of the "tunnel disease" prevalent amongst the labourers, and when later on it was found to be the cause of the disease of miners and pitmen. Brickmakers are also sometimes attacked by a

1 According to Looss (Dist. heterophyes $u$ Dist. frat., I894, p. 3), during 1892 it was found necessary to refuse applicants for official positions in consequence of excessive anæmia, caused by Ankylostoma, in the following proportions: In Upper Egypt, 3.3 per cent. ; in Lower Egypt, 6.2 per cent., and in Menonfieh the large proportion of I $3^{\circ} 9$ per cent. The disease, indeed, was already known to the ancient Egyptians. They called it $\bar{a} a \bar{a}$, or $u h a$, and the worm that caused it was termed Heltu. (R. Blanchard.) 
similar disease (anæmia), and ankylostoma has likewise been demonstrated to be the cause of this disorder. For the last twenty years the parasite has been frequently observed in Germany in brickmakers as well as in miners; it has principally been imported by Italians labouring in brick works or mines; but it also occurs amongst German labourers. It has appeared most frequently in brick-fields in Bonn, and Cologne; cases, moreover, are known from the neighbourhoods of Würzburg, Cöhsen, Söllingen (near Rastatt), and Berlin. Amongst mining districts the Ruhr region is most particularly liable; as an example, during a period of one year and nine months 2 I 5 cases came under observation in the Elisabeth Hospital in Bochum. Similar conditions prevail in Austria and Hungary (Kremnitz, Schemnitz, Funfkirchen, \&c.). Belgium and France have likewise yielded cases, and in Italy the worm appears to be distributed to a fairly equal (and frequent) degree.

Development.-The thin-shelled eggs are deposited in a state of segmentation and reach the open with the fæces; if the atmos-

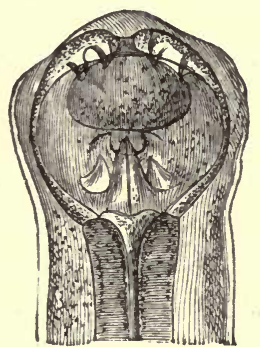

FIG. 214. - Cephalic extremity of Ankylostoma duodenale, with the oral capsule. (Magnified.)

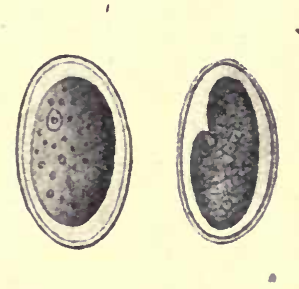

FIg. 215. - Ovum of Ankylostoma duodenale. (After Parona and Grassi.)

pheric temperature is sufficiently high $\left(20-25^{\circ} \mathrm{C}\right.$.), they develop, preferably within the excrement (but never in pure water), into a rhabditiform larva measuring $0.2 \mathrm{I} \mathrm{mm}$. in length, which under certain conditions may hatch out at the end of the first day, and at any rate always in the course of the second or third day. ${ }^{1}$ - The larvæ in a few days grow to $0.56-0.6 \mathrm{~mm}$. and moult; soon a second moult takes place, during which the œsophagus changes. Nevertheless the creatures do not slip out of their old larval integument. They remain actively motile, and now are no longer sensitive to water, in which they may be kept alive for three months; they can also withstand a certain degree of desiccation.

1 The development also depends on the concentration and condition of the fæces ; many eggs soon die off in fluid and malodorous fæces; the addition of a little water retards the development, as does the lack of oxygen and lowering of the temperature. The ova die without exception after twenty-four to forty-eight hours at $\mathrm{I}^{\circ} \mathrm{C}$. 
Leichtenstern conducted unimpeachable experiments on human beings, which proved that infection takes place through the direct

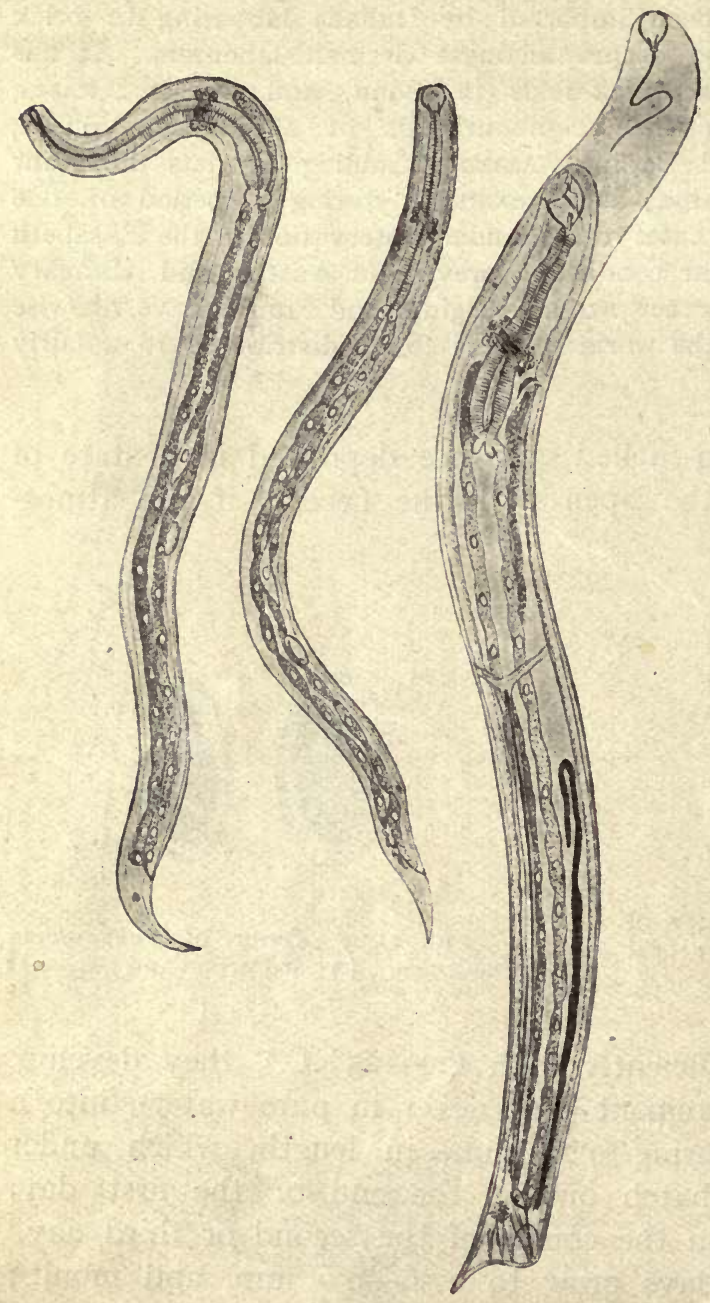

FIG. 2I6.-Ankylostoma duodenale. On the left, four days after transmission into the dog $190 / 1$; in the middle at the commencement of the second stage of development (five to six days), I05/I; on the right fourteen to fifteen days after infection, 42/1. (After Looss.) introduction of these larvæ. When the circumstances under which miners and brickmakers work are taken into consideration the frequency of the infection is easily understood, and as in above - ground occupations the ova, and, of course, also the larvæ, perish during winter from the effects of the cold, conditions are far more favourable to the worm in the deeper, and therefore warmer, mines.'

Looss, who succeeded in infecting young cats and dogs, studied the metamorphosis which the larvæ go through within their host (fig. $2 \mathrm{I} 6)$; it is completed in three stages. The larvæ pass through the stomach of the experimental animals comparatively quickly, yet hardly grow any longer during the first days; on about the fifth day the signs of a future moult become appa-

1 There is no relation at all between the Ankylostoma duodenale and horses, such as Rathonyi strives to prove (Dtsch. Med. Wchschr., I896, No. 4I), the author is the victim of an error; the supposed ova and larvæ of Ankylostomum, which he found or cultivated in the excrement of horses, originated from Sclerostomum tetracanthum and Scl. equinum (Railliet, A., in C. R. soc. biol., Paris, I897 [10], iii., p. I I32 ; Ratz, St., v. in C. f. B. P. u I., I 898 [I], xxiv., p. 298.) 
rent ; this"occurs on the seventh day, when the animals are provided with a provisional oral capsule which was not present previously. At the end of this second period the definitive oral capsule with the chitinous teeth is formed, and alterations in the position of the genital glands, in the intestine, \&c., set in, and on the completion of the second ecdysis, which takes place on the fourteenth or fifteenth day, the worms have attained their definitive organisation. Their length then averages $\mathrm{I} \cdot 9 \mathrm{~mm}$. (male) and $2 \cdot 0 \mathrm{~mm}$. (female); three weeks after infection, however, the males in the dog have already attained a length of $8 \mathrm{~mm}$., and therefore we may conclude that maturity is attained in about four or five weeks.

Recently Looss has discovered a second means of entrance of larvæ of Ankylostoma in the human body, which is THROUGH THE SKIN; the larvæ placed on the skin with a drop of water penetrate the hair follicles in a short time, and leaving these in the vicinity of the hair papillæ thus attain the corium. The author concludes that the larvæ then find their way into the lumen of the intestine, and is of opinion that this mode of infection-at all events as regards the fellahs-has a far greater importance than the infection per os. We must, however, await the proofs of this statement.

\section{Uncinaria (=Anchylostoma) Americana, Stiles, Igo2.}

[In May, I902, Dr. Stiles discovered that uncinariosis in America was not, as a rule, due to the old world hook-worm, Uncinaria duodenalis, but to a new species which he named Uncinaria Americana.

Uncinaria Americana can be readily distinguished from Uncinaria duodenalis. It is shorter and more slender. The male worm measures from 7 to $9 \mathrm{~mm}$. in length by 0.3 to $0.35 \mathrm{~mm}$. in diameter; the female 9 -II $\mathrm{mm}$. in length by $0^{\circ} 4-0^{\circ} 45 \mathrm{~mm}$. in diameter. The buccal capsule is much smaller; and presents an irregular border; instead of four ventral hook-like teeth, it is provided with a ventral pair of prominent semilunar plates similar to those of the dog hook-worm, Uncinaria stenocephala, the pair of dorsal teeth is likewise represented by a pair of slightly developed chitinous plates of the same nature. The outlet of the dorsal head-gland, usually called dorsal rib or dorsal tooth, projects prominently into the oral cavity. Deep in the buccal capsule are one pair of dorsal and one pair of ventral submedian lancets.

The caudal bursa of the male presents a short dorso-median lobe, which often appears as if it were divided into two lobes. 
The dorsal ray is divided to its base, its two branches are prominently divergent and their tips are bipartite instead of tridigitate as in $U$. duodenalis. The common base of the dorsal and dorso-lateral rays is very short.

In the female the vulva is in the anterior part of the body, but near the equator.

The eggs are larger than in $U$. duodenalis, they measure $64-75 \mu$ in length by $36-40 \mu$ in breadth.

So far, Uncinaria Americana has been found only in man, its anatomical habitat is the small intestine. Its distribution, so far as determined, includes Virginia, North and South Carolina, Georgia, Florida, Alabama, Texas, Porto Rico, Cuba and Brazil.

The life history of $U$. A mericana has not yet been investigated, but there is no reason for assuming that it will differ radically from that of $U$. duodenalis. - L. W. S.]

\section{LITERATURE.}

Dubini, A. Nuov. verm. int. umano. (Ann. univ. med. d'Omodei., I 843, cvi., p. 5.)

Siebold, C. Th. v. Ein Beitr. z. Helminthogr. hum. (Z. f. w. Z., r852, iv., p. 55.) Griesinger. Klin. u. an. Beob. üb. d. Krankh. v. Aeg. (Arch. f. phys., Hlkde., I 854 , xiii., p. 55.)

Parona, C., and Grassi, B. Sull. svil. dell' Anchil. duod. (Atti soc. ital. sc. nat., 1878 , xxi., p. 53.)

Perroncito, E. Helm. Beob. (Molleschotts Unters. z. Naturl. d. Mensch., xii., p. 532.)

Bugnion, E. L'ankylost. duod. et l'anémie du St. Gotthard. (Rev. méd. Suisse romande, Genève, I $88 \mathrm{I}$, Nos. 5 and 7.)

Schulthess, W. Beitr. z. An. v. Anc. duod. (Z. f. w. Z., I882, xxxvii., p. I63. Menche. Anchyl. duod. b. d. Ziegelbrenner-Anæmie i. Dtschld. (Ctrlbl. f. klin. Med., I882, p. I6I, and Ztschr. f. klin. Med., I883, vi., p. I6I.)

Perroncito, E. L'aném. d. mineurs au point de vue parasitol. (Arch. ital. de biol., I 882 , ii., p. 3 I 5 ; I 883 , iii., p. 7.)

Grassi, B. Anchilostomi ed Anguillule. (Gaz. d. ospit., I 882, No. 4 I ; Giorn. R. Acc. med. Torino, I 883 , xxxi., p. I I9.)

Lutz, A. Ueb. Anc. duod. (Volkmann's Sammlg. kl. Vortr., 1888, Nos. 255, 256 and 265.)

Leichtenstern, O. Ueb. Ancyl. duod. b. d. Ziegelarb. i. d. Umgeb. Cölns (Dtsch. med. Wchsch., I 885, xii., Nos. 28-30. Weit. Beitr. z. Ancylostomen. frage. (Ibid., I886, xii., Nos. I I-I4.)

Fütterungsvers. mit Ancyl.-Larven. (Ctrlbl. f. klin. Med., I 886, No. 39.)

Einig. über Anc. duod. (Ibid., I887, xiii., Nos. 26-32.)

ChIARI, H. Ueb. einen in Prag secirt. Fall v. Ancylostomiasis bei einem Kruneger (Prag. med. Wchschr., I 893 , No. 44.)

Looss, A. Not. z. Helm. Aeg. i. (C. f. B., P. u. I. I896 [I], xx., p. 865. ii. Ibid., I897, xxi., p. 913.)

Z. Lebensgesch. d. Ancyl. duod. (Ibid., I 898, xxiv., p. 484.)

ZinN, W., and M. JАсову. Ancyl. duod., Lpzg., I 898.

Looss, A. Ueb. d. Eindr. d. Ancyl.-Larv. in d. menschl., Haut. (C. f. B., P. u. I. I90I [I], xxix., p. 733.)

Stiles, Ch. WARdell. Report upon the prevalence and geographical distribution of Hook-worm disease in the United States. Washington, I903:

Gen. II. Physaloptera, Rud., I8I9.

Mouth surrounded by two even lips usually situated at the sides, and each provided with three papillæ and teeth. The posterior extremity of 
the male is lancet-shaped, in consequence of an expansion of the cuticle, with four pairs of pedunculated external papillæ and a number of unpedunculated inner papillæ: the spicules are unequal; the female has two ovaries; vulva in the anterior region of the body. It lives in the intestine, and more especially in the stomach, of carnivorous mammals, birds and reptiles.

\section{Physaloptera caucasica, v. Linstow, I902.}

The male measures $14.2 \mathrm{~mm}$. in length and $0.7 \mathrm{I} \mathrm{mm}$. in breadth; the bursa is broad, rounded off in front and narrower at the back, the right spicule measures $0.62 \mathrm{~mm}$. in length, the left spicule $\mathrm{I} \cdot 76 \mathrm{~mm}$.; there are two unpedunculated papillæ in front of the orifice of the cloaca, four behind it and six at the tail. The female measures $27 \mathrm{~mm}$. in length, I. $14 \mathrm{~mm}$. in breadth ; the caudal extremity is rounded off; the vulva is on the border of the first and second sixth of the length of the body; the eggs have thick shells, and measure $0^{\circ} 057-0^{\circ} 039 \mathrm{~mm}$. It has hitherto only been observed once by Ménétriés in the intestine of man (Caucasus).

(g) Fam. Ascarida.

Gen. I2. Ascaris, L., I758.

The oral cavity is surrounded by three largish papillæ, of which one is in a dorsal position and the other two ventral. The male has two spicules of equal length and numerous pre-anal and post-anal papillæ. The vulva lies in front of the middle of the body. All the species probably develop direct without an intermediary host.

\section{Ascaris lumbricoides, L., I758.}

The colouring, in the fresh condition, is reddish-yellow or greyish-yellow; the body is of an elongated spindle shape. The dorsal oral papilla carries two papillæ of sense, the two ventral oral papillæ each one papilla of sense. The male measures from I5- I7-2.5 cm. in length, and about $3 \mathrm{~mm}$. in diameter; the posterior extremity is conical and bent hook-like ventrally; the spicules measure $2 \mathrm{~mm}$. in length, are curved, and somewhat broadened at their free end; on each side around the orifice of the cloaca there are $70-75$ papillæ, of which seven pairs are postanal. The testicular tube is much folded on itself, shows through the body integument and is about eight times the length of the

' Linstow, v., "Zwei neue Paras. d. Mensch." (C. f. B., P. u. I. [1], 1902, xxxi., Orig., p. 769 ). 
body. The females measure $20-25-40 \mathrm{~cm}$. in length and about $5 \mathrm{~mm}$. in diameter, the posterior extremity is conical and straight. The vulva is at the border between the anterior and middle third of the body; the two uterine tubes pass straight to the posterior end of the body; the convoluted ovaries measure ten times the length of the body.

The ova are elliptical with a thick transparent shell (fig. 2I8), and an external coating of albumen which forms protuberances; the ova measure $0.05-0.07 \mathrm{~mm}$. in length, $0.04-0.05 \mathrm{~mm}$. in breadth; they are deposited before segmentation; the albuminous coating is stained yellow by the colouring matter of the fæces.

Ascaris lumbricoides is one of the most frequent parasites of
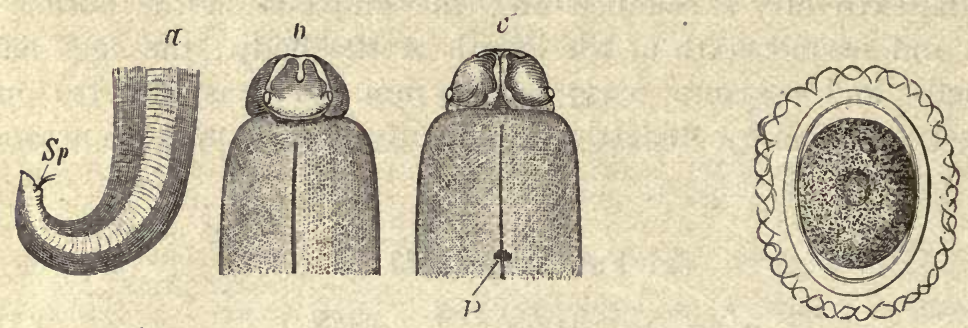

FIG. 217.-Ascaris lumbricoides. a, posterior extremity of the male with the spicules protruding from the orifice of the cloaca $(S p) \quad$.$b , anterior$ extremity from the dorsal surface. $c$, anterior extremity from the ventral surface. $P$., porus

Fig. 218.-Ovum of Ascaris lumbricoides, with shell and albuminous envelope. $400 / 1$. excretorius. (From Claus.)

man; it is distributed all over the inhabited parts of the world, and though it is particularly frequent in the warmer regions, yet it also occurs in Finland, Greenland, \&c. In temperate climates Ascaris lumbricoides occurs most frequently in young children; it is, moreover, more common amongst country dwellers than amongst the inhabitants of towns, but is not lacking in infants, adults and aged persons. As a rule only a few specimens of the ascaris are present in the irtestine, but many cases are known in our zone in which several hundreds of worms have been found in the same patient. The ascaris is particularly numerous in the negroes of Africa and America.

The parasite was already known in ancient times; the Greeks called it $\epsilon^{\prime} \lambda \mu \nu$ s $\sigma \tau \rho \circ \gamma \gamma u ́ \lambda \eta$, Plinius termed it Tinea rotunda, later on it was named Lumbricus teres; the ä $\sigma \kappa a \rho \iota s$ of the Greeks is our oxyuris. 
The small intestine is the normal habitat of Ascaris lumbricoides; the worms, however, often leave this part of the intestine and wander into the stomach, whence they are frequently evacuated by vomiting, or they may creep through the oesophagus into the pharynx and crawl out through the nose or mouth; very rarely they may find their way into the Eustachian tube or into the naso-lachrymal duct, or in to the excretory ducts of the liver and pancreas; exceptionally they may gain the trachea, and they have also been found in the abdominal cavity. They may bore through adhesions between the intestinal wall and the epigastrium (worm abscess); they occasionally penetrate the urinary apparatus and are passed with the urine; in feverish diseases Ascaris lumbricoides usually leaves the intestine spontaneously. It is obvious that these wanderings may be accompanied by the most serious symptoms; but in sensitive persons the invasion of even only a few intestinal ascarides gives rise to a series of almost inexplicable symptoms (hysterical, epileptiform attacks, cerebral congestion, aphonia, \&c.), which cease with the expulsion of the worms, so that many authors are driven to the conclusion that the ascarides secrete a toxin. Fortunately, the presence of Ascaris lumbricoides in the intestine is easily demonstrated by the microscopical examination of the fæces.

Development.-Sever al authors (Gros, Schubart, Richter, Leuckart and Davaine) have demonstrated that the ova of ascaris develop in water or moist earth after a long period of incubation. Freezing and desiccation (if for not too long) do not injure their powers of development; the duration of the development depends on the degree of the surrounding temperature. At a medium temperature, after the varying period of incubation, it takes from thirty to forty days for the embryo to become formed. The spirally rolled up embryo, with its so-called "tooth," formed by three papillæ close together, never leaves the egg-shell in the open, even if the eggs are kept for years under favourable conditions. Davaine proved that the larvæ hatch out in the intestine of the rat but are again expelled with the fæces; he therefore concluded that the hatching, likewise takes place within the intestine of man, but is followed by the settlement of the larvæ. In the meantime Leuckart had sought to infect himself by swallowing embryo-containing eggs, but without results, he therefore conjectured that there must be an intermediary host, and v. Linstow thought he had found it in myriapods (Julus guttulatus). Subsequently, Davaine's opinion proved correct; first of all Grassi succeeded in infecting himself by swallowing Ioo embryo-containing eggs of Ascaris lumbricoides; five weeks after ingestion the worms had attained maturity and their ova appeared in the fæces. Calandruccio also sought to infect himself, but failed, yet he succeeded in inferting a little boy seven 
years old. Lutz also reports a successful experiment which must have been positive, as the worms were expelled young. Finally, Epstein conducted unimpeachable experiments on three children, which places direct infection with embryo-containing eggs beyond doubt; he, moreover, proved that the development of the eggs takes place more rapidly in the fæces when there is free admission of air, sun, and a sufficiency of moisture.

Accordingly, infection occurs partly through water, but principally direct from the soil.

\section{LITERATURE.}

Cloquet, J. Anatomie des vers intestinaux. Paris, I824.

Czermak, J. Bau. . der Haut von Asc. lumbr. (Stzb. K. Acad. Wiss. math.-nat. Cl. Wien., I852, ix., p. 755.)

Rhode, E. Beitr. z. Kenntn. d. Anat. d. Nematoden. (Zool. Beitr. [A. Schneider], I 883 , i., p. II.)

Beneden, E. van. L'appar. sex. fem. de l'Asc. mégalocéph. (Arch. de biol., I 883 , iv., p. 95.)

Davaine, E. Rech. sur le dével. . . de l'Ascar. lombr. (Compt. rend. Ac. sc., Paris, I858, xlvi., p. I 217.) (Mém. soc. biol., Paris, I862 [3], iv., p. 26I.)

HALlez, P. Rech. sur l'embryol. et sur les condit. du develop. de quelques némat. Paris, 1885 .

Linstow, v. Ueber den Zwischenwirth von Asc. lumbr. (Zool. Anzg., 1886, ix., p. 525.)

Grassi, B. Trichocephalus- und Ascarisentwickelung. (C. f. B. u. P., I887, i., p. I 31, I888, Vol. iii., p. 748.)

Lutz, A. Zur Frage der Invasion von. . . Asc. lumbr. (Ibid., I887, ii., p. 7 I 3 .)

LeUCKART, R. Die Uebergangsweise der Asc. lumbr. (Ibid., p. 7I8.)

LUtz, A. Weiteres zur Uebertragung der Spulw. (Ibid., I 888, iii., p. 265.)

Epstein, A. Ueb. d. Uebertrag. d. menschl. Spulw. (Jahrb. f. Kdrhlkde. N. F., I892, xxxiii., No. 3.)

Nassonow, N. W. Z. Anat. u. Biol. d. Nemat., 2. (Arb. a. d Labor. d. zool. Inst. d. Warsch. Univ. f., I897, p. I33. Warschau, I898.) (C. f. B., P. u. i. [I], xxv., p. 837.)

Guiart, J. Rôle path. de l'Asc. lumbr. (Arch. de parasit., I900, iii., p. 70.)

Sick, C. Ueber Spulwürmer in den Gallenwegen. Tübingen I901.

\section{Ascaris canis, Werner, 1782 .}

Syn.: Lumbricus canis, Werner, I782;Asc. teres, Goeze, I782; Asc. cati et canicula, Schrank, I788: Asc. canis et felis, Gmelin, I789; Asc. tricuspidata et felis, Bruguière, I791; Asc. werneri, Rud., I793; Fusaria mystax, Zeder, 1800 ; Asc. marginata et mystax, Rud., I802; Asc. alata, Bellingham, I839.

The anterior end is somewhat recurvate, and provided with lateral alar appendages, which give it the shape of an arrow-head; three almost equal lips around the mouth. The male measures $40-60 \mathrm{~mm}$. in length, I $\mathrm{mm}$. in diameter; the posterior end is spirally bent and presents twenty-six pairs of papillæ, of which five 
are post-anal. The female measures $\mathrm{I} 20-\mathrm{I} 80 \mathrm{~mm}$. in length; the posterior end is straight and somewhat conical ; the vulva is in the middle of the anterior end of the body. The eggs are almost spherical with a thin shell and an albuminous layer that is but slightly protuberant. They measure $0.068-0.072 \mathrm{~mm}$.

Ascaris canis is a very common parasite in the intestine of cats and dogs, but it also occurs in the lynx, lion, puma, \&c. ; it has also been observed in man in about eight cases, four in Eng-

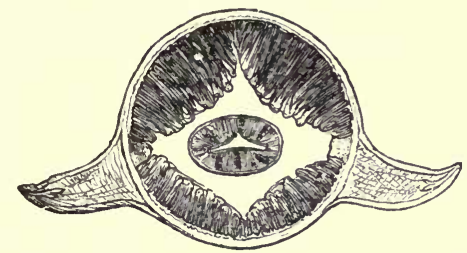

FIG. 219.- Transverse section through the head part of Ascaris canis from the cat, with the pterygoid prolongations of the cuticle. In addition, one may note the four fields of muscles, the longitudinal ridges with the œsophagus in the transverse section (magnified). (After Leuckart.)

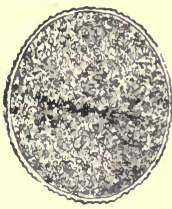

FIG. 220.-Ovum of Ascaris canis, with thin albuminous envelope (magnified).

land, two in Germany, one in Denmark and one in North America. In two of these cases the parasites were coughed up.

Grassi is of opinion that this species does not occur in man, as he vainly sought for it in over I,00o persons, and experimental infections on man yielded negative results.

The development of Ascaris canis is similar to that of Ascaris lumbricoides; but the eggs, in spite of the delicacy of their shells, have great powers of resistance and develop equally well in water and damp earth, in a solution of chromic acid, alcohol, turpentine, solution of soda, \&c. It is, however, but seldom that the embryos $\left(0^{\circ} 36 \mathrm{~mm}\right.$. in length) hatch out. The transmission is direct.

\section{LITERATURE.}

Bellingham, O. B.-Undescrib. Spec. of Human Intestinal Worm. (The Dublin Med. Press, I839, i., p. I04; Gaz. des hôpitaux, I 839 [2], i., p. 97.)

Соввоld, T. Sp. On the occurr. of Asc. m. in the Human Body. (The Lancet, I863, i., p. 3 I.)

Morton, F. Asc. myst. (Ibid., I 865 , i., p. 278.)

LEUCKART, R. Menschl. Parasiten. (Ist edit., ii., p. 26r.)

Kelly, H. A. (American Journ. of Med. Sc., I 884, [2] lxxxviii., p. 483.)

Davaine, C. Sur la const. de l'œuf des cert. entozoaires. (Mém. soc. biol., Paris, I 862 [3], iv., p. 273).

Heller, C. Ueb. Asc. lumbr. (Szgsber. d. Erlang. phys.-med. Societ., I872, iv., p. 7 I). Hering. Beitr. z. Entw. einig. Eing.-Würm. (Württemb. nat. Jahreshfte, I 873 , p. 305.)

Grassi, B. Beitr. z. Kenntn. des Entwickelungscyclus von 5 Paras. d. Hundes (C. f. B. u. P., 1888, iv., p. 609).

Grasst, B. Intorno all' Asc. myst. (Gazz. med. it. lomb., I879, xxxix., p. 276.) 


\section{Ascaris maritima, Leuckart, 1876 .}

Only one immature specimen, a female $(43 \mathrm{~mm}$. in length and I $\mathrm{mm}$. in breadth), has hitherto been described, and it was vomited by a child in North Greenland in 1865. (R. Leuckart, Die menschlichen Parasiten, I876, i., edition ii., p. 877.)

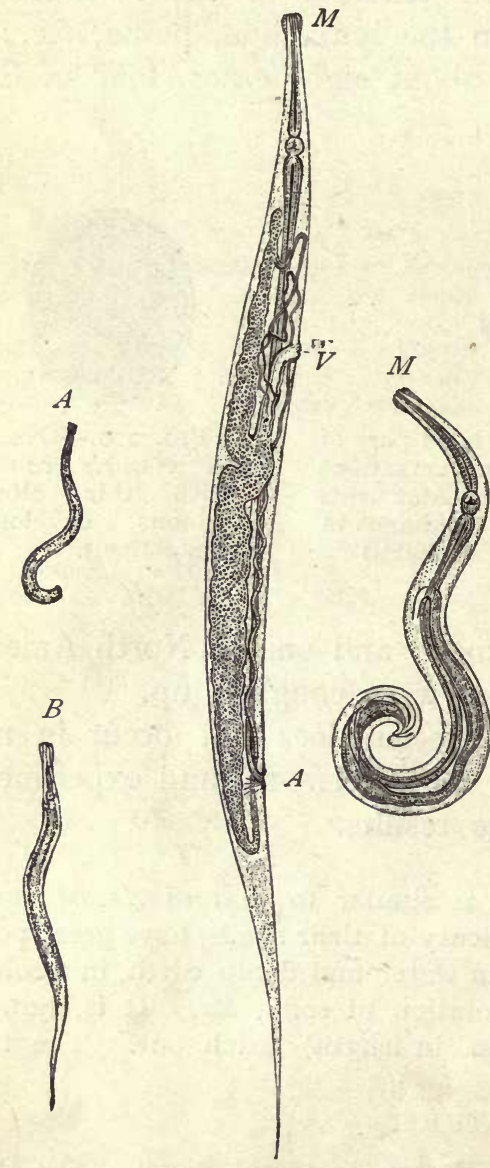

FIG. 221.- $A$., FIG. 222.-On the male ; and $B$. , left, female; on the female, of $O x y$ - right, male; greatly uris vermicula- enlarged. $A$., anus ; ris. (5/I.)
$M$., mouth ; $V$., vulva. (After Claus.)

\section{I3. Gen. Oxyuris, Rudolphi, I803.}

The three labial papillæ are only slightly protuberant, the œsophagus is long and presents a distinct dilatation. The male has one spicule and two pairs of pre-anal papillæ; the posterior end of the female is drawn out to a point. The vulva is in the anterior part of the body.

\section{Oxyuris vermicularis (Linné), I767.}

Syn.: Ascaris vermicularis, L. ; Fusaria vermicularis, Zeder, I803.

Colour white, the annulated cuticle forms swellings at the anterior end which extend some distance back along the middle of the ventral and dorsal surfaces; the longitudinal supports of the skin corresponding to the lateral ridges are much more feebly developed; there are three small retractile labial papillæ around the mouth. The male measures 3-5 $\mathrm{mm}$. in length, and shortens on death ; the posterior extremity of the body is rolled ventrally and presents six papillæ. The female is ro $\mathrm{mm}$. in length and $0.6 \mathrm{~mm}$.

-in diameter; the anus is about $2 \mathrm{~mm}$. in front of the tip of the tail; the vulva is in the anterior third of the body; the eggs are oval, thin-shelled and measure $0.05: 0.016-0.02 \mathrm{~mm}$.; they are deposited with embryos already developed and are very seldom found in the fæces. 
Oxyuris vermicularis has been known since a remote period, and is one of the most frequent and widely-spread parasites of man. It occurs principally in children, and lives in the large intestine.' The females are apt, in the evening, when the patients retire to bed, to leave per anum, causing troublesome itching, and to wander between the nates and perinæum, from whence, in girls, they occasionally reach the vagina." Large numbers may occasionally be harboured without inconvenience; in other cases various reflex symptoms are set up even in adults, which may rise to epileptiform attacks. Occasionally the oxyuris are evacuated by the mouth; it is only very rarely that they reach the urinary bladder.

Development.-The eggs, which often adhere together, contain a tadpole-like embryo, the thin tail of which is bent upwards ventrally; the embryo in a short time, given a sufficiently high temperature, passes into a second embryonal stage, a folded nematode shape, lying in the egg-shell, either in the fæces, with which also numerous females pass out, or in the moisture of the groove between the buttocks, and they there await the opportunity of being reintroduced into man per os. It is very improbable that the settlement may also take place direct in the large intestine, as is occasionally stated, because although the harbourers of oxyuris are frequently liable to auto-infection, this takes place through the mouth, and is conveyed by the fingers, on which the ova of oxyuris, and occasionally the female worms have clung.

The opportunity for this is afforded every evening, as naturally the troublesome itching caused by the travels of Oxyuris vermicularis is met by scratching and rubbing with the fingers. It is, therefore, possible that the eggs may even thus be introduced in to the nose, where the young oxyuris are perhaps hatched out, if they get high enough up on the moist pituitary mucous membrane. As a matter of fact the larvæ of oxyuris have been found in the nose. Moreover, it may be understood that the eggs of Oxyuris are transferred from person to person by the hand, directly or indirectly. This again explains the wholesale infections which occur in collective dwellings, after a person harbouring oxyuris has been admitted into boarding houses, \&c. The primary infection may be also caused in other ways-by foods; fruits, vegetables and other articles that are eaten raw, and are polluted with the ova of oxyuris. Perhaps also flies or their excrement

1 It has recently been stated that the lower part of the intestine is the original seat of the Oxyuris; in this situation it grows and copulation takes place, after which the males die off, this explaining why they are so rarely met with in the excrement. It is only after the eggs have developed that the females wander into the large intestine and reach the outer world. According to another statement, the vermiform appendix is said to be the normal abode of Oxyuris in children.

' Simons removed a specimen from the cervical canal of the uterus (Ctrlbl. f. Gyncekol. 1899, p. $26 ; C . f . B ., P . u . I .[\mathrm{I}]$, xxvi., p. 235). 
play a part in the distribution of the parasite similar to that demonstrated by Grassi as taking place in the spread of the ova of Trichocephalus and Tania.

The assumption of a direct development without an intermediary host was first substantiated by Leuckart by experiments on himself and three of his students; about fourteen days after swallowing the eggs the oxyuris has attained $6-7 \mathrm{~mm}$. in length; Grassi, and later on Calandruccio, infected themselves by swallowing adult female oxyuris, with the same results.

\section{LITERATURE.}

VIx, E. Ueber Entozoën bei Geisteskranken, insbes. über . . . Oxyuris vermicularis. (Allg. Zeitschr. f. Psych., I 860, xvii., p. I49.)

Stricker, W. Physpath. Bemerk. üb. Ox. verm. (Virchow's Arch., I861, xxi., p. 360.$)$

Flögel, J. H. L. Ueb. d. Lippen einiger Oxyuris-Arten. (Z. f. w. Z., I869, xix., p. 234.)

Michelson. Die Oberhaut der Genitocruralfalte u. ihre Umgebung als Brutstätte von Ox. verm. (Berl. klin. Wchnschrft., 1877, xiv., No. 33.)

Grassi, B. I malefizi delle mosche. (Gaz. degli ospitali, I 883 , No. 59.)

Windelschmidt, Ein Fall von langjähr. Reflex-Epilepsie in Folge von Ox. verm. (Allg. med. Centralztg., I883, p. 606.)

Proskauer, Th. Embryonen von Oxyuris in der Nase. (Zeitsch. f. Ohrenhlkde, I891, xxi., p. 3 10.)

\section{GORDIACEA.}

Very long thin worms similar to filariæ, which, in their adult condition, live free in brooks, pools and springs; the mouth and the commencement of the intestine are obliterated; there are no lateral ridges, and the muscular system presents a structure different to that of the nematoda. The posterior end of the male is split, and spicules are lacking; there are two testicles. In both sexes the genitalia discharge through the terminal gut.

The larvæ, which carry a rostrum beset with hooks, force themselves into the larvæ of water-insects; more rarely they invade molluscs, and they then become encysted within the body of the host. According to Villot, at least a part of them attain the intestine of fishes, where they again become encysted, and after a period of rest they travel into the tissues of their hosts, and finally again reach the exterior by way of the intestine, where they then become adult. In most cases, however, the gordius larvæ are taken up by predacious water insects; they live for a while in the body-cavity of these insects undergo a metamorphosis, and finally wander into the water.

A few species invade man accidentally with water, in which case they are usually vomited up :

Gordius aquaticus, Dujardin, $30-90 \mathrm{~cm}$. in length (Aldrovandi, Degland, Siebold, Patruban).

Gordius tolosanus, Duj., II-I3 cm. in length (Fiori).

Gordius varius, Leidy, IO-I6, Weibch., up to $30 \mathrm{~cm}$. in length (Diesing),

Gordius chilensis, Blanch. (Guy). Gordius villoti, Rosa (Bercutti, Camerano); Gordius tricuspidatus, L. Def. (R. Blanchard), Gordius violaceus, Baird (Topsent) and G. pustulosus, Baird (Parona). 


\section{LITERATURE.}

At.drovandi, U. De animalibus insectis, i638, Book VII., Chap. x., p. 720.

DEgLand, C. D. Descr. d'un ver filiforme rendu par vomiss. (Rec. trav. soc. d'amat d. sc., dé l'agricult. et des arts de Lille, I819-22, p. 166.)

Siebold, C. Th. v. Ueber d. Fadenwürm. d. Insect. (Stett. entom. Ztg., I854, xv., p. IO7.)

Diesing, C. M. Rev. d. Nemat. (Stzgsb. k. k. Ac. d. Wiss. Wien. math.-nat. Cl., I 880 , xlii., p. 604.)

Patruban, v. Vork v. Gord. aq. b. Mensch. (Wien. Med. Jhrb., 1875, p. 69.)

Camerano, L. Ric. int. al parassit. ed al polimorf. dei Gord. (Mem R. Acc. sc., Torino, 1887 [2], xxxviii., p. 395.)

Monografia d. Gordii. (Ibid., 1897, xlvii.)

Blanchard, R. Pseudoparas. d'un Gord. chez l'homme. (Bull. Ac. de méd. de Paris, 1897, xxxvii., p. 614.)

Topsent, E. Sur un cas de pseudopar. chez l'homme du Gord. viol. (Bull. soc. scient. et méd. de l'Ouest., igoo, ix., No. I.)

Parona, C. Altro caso di pseudopar. d. Gordio nell' uomo. (Clinica Med. Ann., 1901, No. IO.)

\section{ACANTHOCEPHALA (Rud.)}

Gutless, nematode-like worms that carry at their anterior end a retractile rostrum beset with hooks. In their adult condition they only live in vertebrate animals. During their larval stage they are often parasitic in invertebrate animals.

The Acanthocephala are elongated cylindrical worms, with a rounded posterior end. In some species an annulation is distinctly recognisable; they are, however, not segmented. The size varies according to the species, between about $5-\mathrm{IO} \mathrm{mm}$. and $40-50 \mathrm{~cm}$; in general, however, there is a preponderance of the small species. The sexes are separate, and the males can easily be distinguished from the females without examination of the genitalia, as the females are both larger and thicker.

The body wall of Echinorhynchus is limited by a thin cuticle, which is attached inwardly to the hypodermis. In only exceptional cases a syncytium with large nuclei, even in the adult condition, is represented by the hypodermis; and in it fibre systems, the elements of which run in layers in various directions, appear, and it is only towards the interior from these strata of fibres that the nuclei of the hypodermis are found. As a rule, these fibres, at all events the radiary fibres, are regarded as muscles. Hamann describes them as elastic fibres, which lie in a viscid gelatinous connective substance (transformed protoplasm?); a lacune system filled with a granular fluid, the central part of which are two longitudinal lacunes lying at the sides, also belongs to the cutaneous strata, as do the so-called lemnisci, two short, flat organs suspended in the body cavity, and the pedicles of which are attached anteriorly at the border between the rostrum and body: their structure as well as their origin permit them to be traced to the skin (fig. 223).

Finally, inwardly below the skin there follows a layer of annular, and after these a layer of longitudinal muscles, the structure cells of which remain present in the residues, carrying nuclei. The motor apparatus of the rostrum, the sheath of the rostrum, and the lemnisci also belong to the muscular 
system. The rostrum represents a finger-shaped hollow process of the cutaneous layer; but, according to Hamann, it originates from the entoderm and passes through the skin secondarily. It is covered by a thin cuticle and, as a rule, contains a large number of regularly-placed chitinous hooks that adjoin a granular formation tissue. From the base of the rostrum springs a tubular hollow muscle extending into the body cavity-this is the Receptaculum proboscidis - from the base of which again bundles of longitudinal muscles originate, which pass along its axis and that of the rostrum itself, and are inserted at the inner surface of its anterior end (retractor proboscidis). These muscles when they contract invaginate the proboscis and draw it into the receptaculum; when reversed they act again as protrusor proboscidis. The whole of the anterior body, however, can be invaginated, and for this purpose there is a muscle that originates from the body wall at a variable distance back, and which is joined to the receptaculum (vetractor receptaculi); there is also a bell-shaped muscle which springs from the body wall behind the lemnisci in rings, and passes forward to the spot of attachment of the lemnisci.

The nervous system consists of a cluster of ganglia situated at the base of 'the rostrum, from which three nerves pass towards the front and two towards the back. No sensory organs are known.

The excretory organs, according to Kaiser, lie at the upper border of the ductus ejaculatorius in the male, and at the so-called bell in the female. Here they represent the long-known villous tufts, placed on disclike cushions. In each of the cylindrical villi-which terminate blindly towards the body cavity-there lies a cilium, which springs from the membrane lining the villus, and which lies in a space cavity of the villus, which ultimately proceeds as a little canal. There are three canals discharging into the uterus that serve to conduct the excretory materials from the body cavity; special glandular cells corresponding to the terminal cells of the platyhelminths, at the commencement of the system, are not present in the acanthocephala.

\section{Sexual' Organs.}

A.-Male organs. The greatest part of the male genital apparatus is contained in a muscular sheath-the ligament-which originates at the posterior end of the receptaculum proboscidis, passes along longitudinally through the body cavity, and is inserted at the posterior end of the worm. The two oval testicles usually lie one behind the other; their vasa efferentia unite sooner or later into a vas deferens which passes backwards, and finally terminates in the penis; the terminal portion of the conducting apparatus is surrounded by six large glandular cells (prostatic glands), the excretory ducts of which open into the vas deferens. The penis itself is placed at the base of a bell-shaped invagination of the posterior end, the bursa, which is everted during copulation.

B.-Female organs. There are only two ovaries present in the ligament during the larval stage. During the course of growth they divide into accumulations of cells (placentulæ, loose or floating ovaries), which finally cause the ligament to burst, and they thus attain the body cavity. 
Thence a peculiarly constructed apparatus finally conveys the eggs out. This apparatus consists of the uterine bell and vagina; the latter discharging at the posterior extremity of the body. The bell is a muscular

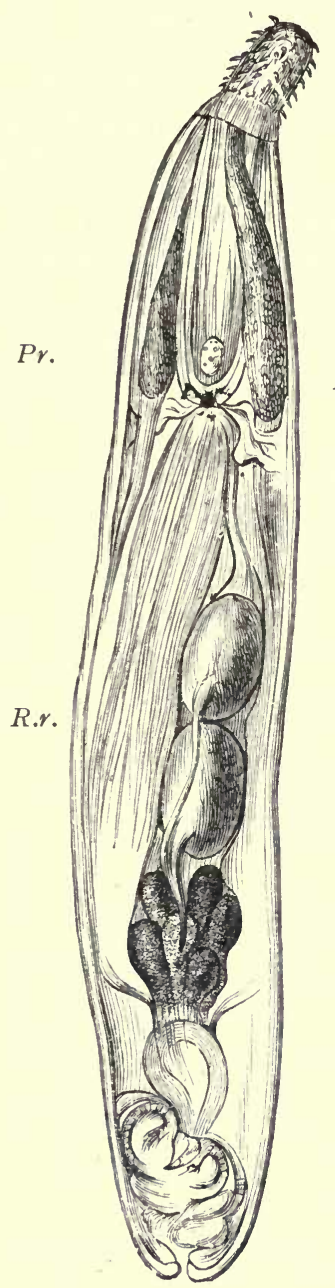

F1G. 223. - The male of Echinorhynchus angustatus. 25/I. L., lemnisci ; T., testicles ; P., prostatic glands ; $P r .$, sheath of proboscis, with ganglion; R.r., retractor of sheath of proboscis. canal provided with apertures at both the anterior and posterior extremities. Its interior space is in direct communication with the body cavity, and the anterior orifice takes up all material floatıng in the cavity-egg-balls, mature and immature eggs-and pushes these further backwards. The continuation of the bell-lumen is now narrowed by a number of large cells in such a manner that only bodies of a certain form can pass through this tract and attain the L. uterus; everything else is conveyed back into the body cavity through the posterior opening of the bell.

The eggs are already fertilised in the body cavity, and in this locality go through their development to the formation of the embryo. Completely developed eggs are surrounded by three shells, and are generally fusiform. The $T$. eggs agglomerate in masses in the uterus until they are finally deposited through the vagina and vulva. For the further development, the

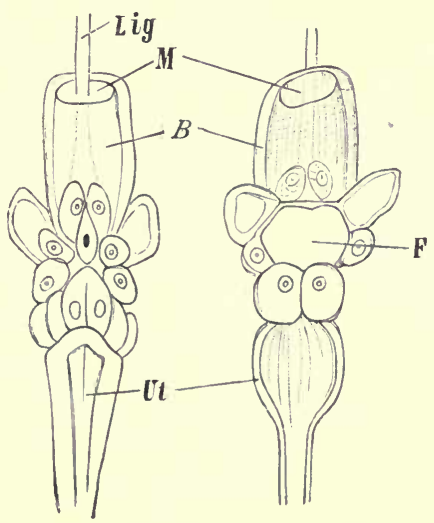

FIG. 224.-Anterior portion of the female apparatus of Echinorhynchus acus (magnified). (After Wagener.) On the left seen from behind, on the right seen from the front. $F$., Inferior orifice of the bell; $B$., bell ; Lig., ligament; $M$., mouth of bell ; Ut., uterus.

transmission of the eggs into an intermediary host, usually a crustacean or an insect, is necessary; the metamorphosis is very complicated; but this transmission may be very easily effected artificially by feeding suitable crustaceans (asellus, gammarus, \&c.) with the eggs of acanthocephala; this being the only method of inducing the larva to hatch out so that its 
structure may be studied. The larva appears in the form of an elongated, somewhat bent body at the stumpy anterior end of which there is a crown of hooks or spines; whereas the posterior end is pointed. Especial retractors draw in the hook-beset anterior surface, and an elastic cushion beneath them roundish heap of small cells are seen, from which the entire body of jerks them forward again when required. In the middle of the body a the echinorhynchus originates, even to the cutaneous layer; the latter is also the larval skin in which the small echinorhynchus gradually grows. The development of all the organs takes place within the intermediary host, and the parasite only needs to be imported into the terminal host to attain the adult stage after a certain growth. In some cases, however, a second intermediary host is utilised.

Species of acanthocephala only occur exceptionally in human beings.

I. Echinorhynchus gigas, Goeze, I782.

Syn.: Tania hirudinacea, Pallas, I78I.

The body is elongated, gradually decreasing in thickness towards the back. The rostrum is almost spherical, and is beset with five or six rows of recurved hooks. The males measure $10-15 \mathrm{~cm}$. in length, the females $30-50 \mathrm{~cm}$.; the eggs are provided with three shells, of which the middle one is the thickest. The eggs measure $0.08-0 \mathrm{~mm}$. in length. The GIANT ECHINORHYNCHUS occurs especially

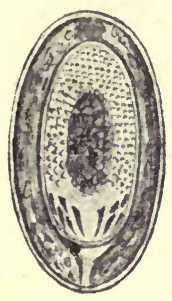

FIG. 225. - Egg of Echinorhynchus gigas. $300 /$ r. (After Leuckart.) in the intestinal canal of the domestic pig; it is less common in other mammals. It bores deep into the mucous membrane with its rostrum, and causes an annular proliferation around the perforated spot; occasionally also it causes perforation of the intestine.

It is doubtful whether the giant echinorhynchus occurs in man. Leuckart admitted that there were a few positive cases. According to Lindemann, Ech. gigas occurs in human beings in South Russia, and its presence is not rare. This statement, however, has not been confirmed. Its presence in man is by, no means impossible, as its intermediary host, the cankerworm, or cockchafer (Melolontha), is, according to Schneider, occasionally eaten raw by human beings. According to Kaiser, the golden beetle (Cetonia aurata), and, according to Stiles, another beetle in America (Lachnosterna arcuata) are also intermediary hosts.

2. Echinorhynchus hominis, Lambl, I859.

This term is applied to an ECHINORHYNCHus found by Lambl in the intestine of a boy who had died of leucamia; the worm was $5.6 \mathrm{~mm}$. in length, and the almost spherical head was beset with twelve transverse rows of hooks. 


\section{Echinorhynchus moniliformis, Bremser, I8I9.}

The male is $4 \mathrm{~cm}$. in length, the female $8 \mathrm{~cm}$. long. This species lives in the intestine of field-mice, rats, marmots and Myoxus quercinus. A beetle, Blaps mucronata, is the intermediary host.

This species has also once been artificially cultivated in man (Grassi and Calandruccio).

\section{LITERATURE.}

Lambl, W. Micr. Unters. d. Darm-Excrete. (Prag. Vierteljahrsschft. f. pract. Hlkde., I 859 , lxi., p. 45.)

Schneider, A. Entw. d. Ech. gigas. (Stzgsb. d. oberh. Ges. f. Natur- u. Hikde., 187 I, p. I.)

Leuckart, R. Commentatio de statu embryonali et larv. Echinorh. . . . Lipsiae, 1873. Kaiser, J. Ueber die Entw. d. Ech. gigas. (Zool. Anz., i887, x., p. 4I4.)

Grassi, B., and Calandruccio. Ueb. einen Ech., der auch im Menschen parasitirt. (C. f. B. u. P., r 888 , iii., p. 52 I.)

Hamann, O. Die Nemathelminthen. I. Monogr. d. Acanthoceph. Jena, I89i.

Stiles, C. W. Sur l'hôte intermédiaire de l'Ech. gig. en Amérique. (C. R. soc. biol., Paris, I 891 [9], iii., p. 764.)

Kaiser, J. E. Die Acanthocepha lenund ihre Entwickelung. Cassel, i893. (Bibl. zoologica, vii.)

\section{E. HIRUDINEA s. DISCOPHORA, Leech.}

The Hirudinea, which have been appropriately included amongst the annelida, differ in many respects from the typical members of the group; their body is long and flat, it lacks the parapodia that are characteristic to all forms of annelida; but, on the other hand, possesses a terminal posterior sucker, and in many species there is also an anterior sucker. The mouth is terminal at the anterior end, the anus lies dorsally above the posterior sucker (fig. 226). The body is segmented, but this is less manifest in the body covering than it is in the arrangement of the internal organs; the segmentation, nevertheless, is also indicated exteriorly by the appearance of the cutaneous sensory organs which correspond to the segments. This shows what the condition of the ganglia in the abdominal ganglion chain has taught us, that the anterior and the most posterior segments are considerably abbreviated-a part of the latter taking part in the formation of the suctorial organs. In a great many species the skin is distinctly annulated, four or five of such rings, at least in the central region of the body, appearing on one segment of the body. The condition of their body cavity is another peculiarity of the Hinudinea; it is narrowed by the powerful development of the connective tissue and the muscular system into four tubular sinuses, which have the appearance of blood-vessels. There are usually one dorsal and one ventral median trunks, as well as two lateral trunks; in addition, a particular blood-vessel system exists.

The skin consists of a very thin cuticle that is cast off from time to. time, it is secreted by the underlying cylindrical epithelium, which contains numerous goblet cells. The muscular system is strongly developed; it consists of long tubular fibres, which run circularly, longitudinally and in the 
dorso-ventral direction; the muscular system is subject to a particular expansion in the clinging organs and at the commencement of the intestine. On the whole, the alimentary canal represents a tube running straight from

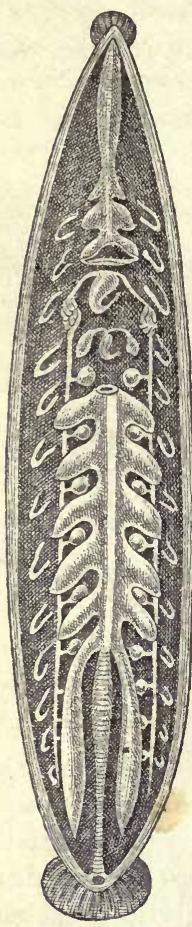

FIG. 226. - The internal organs of the leech. The creature has been opened from the dorsal surface, and part of the intestine has been removed. The testicles, with vas deferens, may be seen between the blind ducts of the intestine; beyond these on either side the segmental organs. The female genital organs are in front of the most anterior pair of testicles. (After Kennel.)

the mouth to the anus, which possesses a number of blind sac-like protuberances at the sides varying according to the species. The most anterior section, the pharynx, in the leeches with maxillæ, carries three chitinous, semicircular plates furnished with teeth-the jaws - which serve to tear up the epidermis in order to open the blood-vessels; in the leeches with rostra a long protractile proboscis rises from the base of the elongated pharynx. Numerous salivary glands, the secretion from which possesses toxic properties, discharge into the pharynx. The œsophagus, which follows the pharynx, and to the exterior of which numerous radiary muscles are fixed, is a suctorial organ in its entire structure. The nutriment in the larger species consists of the blood of vertebrate animals, in smaller species and in the young stages the food consists of small invertebrate animals.

The NERVOUS SYSTEM exhibits the typical structure of other segmented worms; the sensory organs consist of the above-mentioned goblet-shaped cutaneous sensory organs, of the organs of taste, and of eyes; the latter frequently being present in large numbers.

The EXCRETORY or segmental organs exhibit many peculiarities, which cannot, however, be detailed here. They commence with funnels in the lacunes of the body cavity, and usually discharge on the ventral surface.

Almost all the hirudinea are hermaphrodite and copulate reciprocally. The two ovaries are very small, and the oviducts that proceed from them soon unite into a common duct, which then goes over into the uterus and discharges through the short vagina in the median line of the ventral surface behind the male organs into the so-called clitellar region. The male sexual apparatus consists of symmetrically-arranged testicles, varying in number according to the species, the short vasa efferentia of which, one by one, run into the vas deferens, passing towards the front on each side. In front, at about the level, or a little in front of, the female genitalia, the two vessels pass into a convoluted mass of tubes to the so-called epididymis, and then discharge into the single protractile penis (fig. 226).

All leeches deposit so-called cocoons. These are small barrel-shaped, or pouch-like bodies, which are surrounded by a thicker shell, and contain a number of eggs in a large mass of albumen; the albumen originates from glands of the generative organs, the shell-substance from cutaneous glands of the clitellar region. 
I. Gnathobdellida, leeches with jaws.

These are distinguished by the possession of usually three jaws in the pharynx; the body consists of twenty-six segments. The posterior sucker is large and flat; the anterior sucker is smaller. The Hirudinea have five pairs of eyes, the Nepheline have four pairs.

\section{Gen. Hirudo, L., I758.}

The entire body consists of 102 annulations; five appearing on one segment in the central region of the body. The pharynx has three semi-circular jaws, the arched border of which is beset with numerous teeth (50-100). The male sexual orifice lies between the thirtieth and thirty-first rings, the female orifice between the thirty-fifth and thirtysixth. There are numerous species, some of which are utilised for medicinal purposes.

\section{Hirudo medicinalis, L., I758.}

It occurs in numerous colour varieties, one of which has been designated Hirudo officinalis, Moq. Tandon. Usually the dorsal surface is greyish-green, and is marked with six rustyred longitudinal stripes. The ventral surface is olive-green, more or less spotted with black, and marked at the sides with a black longitudinal line. The length averages 8 to I $2-$ $20 \mathrm{~cm}$. This leech lives in swamps, ponds and brooks, overgrown with plants and having a muddy bed. The cocoons are deposited in the soil at the sides. Europe, as well as N. Africa, is its home. At the present day it has been exterminated from most parts of Central Europe, but it is still very common in Hungary. Its use for medicinal purposes is well known. A large leech can suck about I5 grs. of blood and about the same amount is lost through

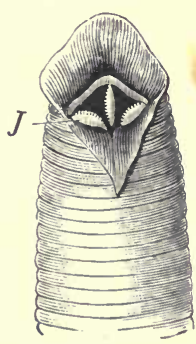

a

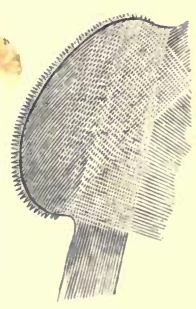

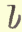

FIG. 227.-Hirudo medicinalis. (a) Anterior end, with open buccal cavity, with the jaws $(J$.$) at the base ; (b)$ one jaw isolated. (After Claus.) secondary hæmorrhage.

2. Hirudo troctina, Johnston, $18 \times 6 ́$.

Syn. : Hirudo interrupta, Moq.-Tandon, 1826.

This species measures $8-10 \mathrm{~cm}$. in length. The back is greenish, with six rows of black spots surrounded by red; the lateral borders are orangecoloured; the abdomen spotted or unspotted. Its habitat is in N. Africa and Sardinia. It is applied medicinally in England, Spain, France, Algeria, \&c. 
Gen. Limnatis, Mq.-Tandon, I826.

Nearly related to hrudo, but is differentiated by a longitudinal groove on the inner surface of the upper lip of the anterior sucker. The jaws are furnished with over IoO very sharp toothlets.

\section{Limnatis nilotica, Savigny, I820.}

Syn.: Bdella nilotica, Sav.; L. nilotica, Moq.-Tandon; Hamopis (vcrax) Moq.-Tandon, I826, p. p.; Hamopis sanguisuga, Moq.-Tandon, I 846 (nec Hir. sanguis Bergm., I 757 ).

This species measures 8-Io $\mathrm{cm}$. in length, and becomes gradually more pointed towards the front; the body is always soft. The back is brown or greenish, and has usually six longitudinal rows (rarely only two or four) of black dots. The abdomen is dark; but numerous colour variations occur.

The native place is $\mathrm{N}$. Africa, especially the coastal regions; it is also found in the Canaries, the Azores, Syria, Armenia, Turkestan, perhaps also Southern Europe. It is taken into the mouth with drinking water, and may settle in the pharynx, larynx, œsophagus, and nasal cavities of human beings. This species has also been observed in the vagina and on the conjunctiva. It is equally fond of attacking domestic animals.

Hirudo mysomelas (Senegambia) and $H$. granulosa (India) are placed with this genus, and, like our leech, are also used for medicinal purposes.

\section{Gen. Hamadipsa, Tennent, r86r.}

These leeches live on land, and measure $2-3 \mathrm{~cm}$. in length. About a dozen species are known. They are a veritable scourge to persons in the Tropics (Asia, South America), as they attack them to suck their blood. They are able to force their way even under close-fitting garments, so that it is difficult to protect oneself from their assaults ( $H$. ceylonica, B1., and other species).

\section{Rhynchobdellida, leeches with rostrum.}

These are furnished with a proboscis in lieu of the jaws; the segment consists of three annulations.

\section{Gen. Hamentaria, de Filippi, 1849.}

H. officinalis, de Fil. Inhabit Mexico, where they are used for medicinal purposes.

\section{Gen. Placobdella, R. Blanch.}

Pl. catenigera, Moq.-Tandon. Indigenous of South Russia, Hungary, Italy and South France. It is a parasite of the swamp turtle, but frequently attacks human beings. 


\section{LITERATURE.}

Moguin-Tandon. Monogr. de la fam. des Hirudinées, 2nd edit., Paris, 1846.

EBRARd. Nouv. monog. des sangs. médic. Paris, 1857.

Whitman, C. O. The external morph. of the Leech. (Proc. Amer. Acad. of Aits and Sc., 1884, xx., p. 76.)

The Segm. Sense Organs of the Leech. (Amer. Naturalist, I 884, xviii., p. I I04.)

The Leeches of Japan. (Quart. Journ. of Micr. Sc., I886 [2], xxvi., p. 317.)

Apatry. Analyse d. äuss. Körperf. d. Hirudineen. (Mitth. d. zool. Stat. Neapel., I 888, viii., p. I 53.)

Süsswasser-Hirudineen. (Zool. Jahrb. Abth.f. Syst. . . . . I888, p. 725.)

Blanchard, R. Art. Hirudinées. (Dist. encycl. d. sc. Méd., I 888, xiv., p. I29, and C. R. soc. biol., Paris, I7 Oct., I891; as well as in Bull. soc. zool., France, 1890-99.)

Leuckart, R. D. Paras d. Menschen. (2nd edit., I vol., ii., Hirudineen continued by G. Brandes. Lpz.. I886-Igor.)

\section{F. ARTHROPODA. (Jointed-limbed Animals )}

Bilaterally symmetrical segmented animals which 'are covered with a thick cuticle that is frequently calcareous (crustacea), but always thinner between the segments; they carry (primitively) a pair of jointed appendages on every segment. ${ }^{1}$ The segments of the body are uniform in certain regions, but differ from those of contiguous regions, so that it is easy to distinguish three parts (head, thorax, and abdomen), each composed of segments. The cephalic segments are always formed into an uniform head, the segmentation being scarcely recognisable at either end; the thoracic segments may also fuse, or part or all of them may coalesce with the head; the abdomen, as a rule, retains its segmentation; but this may possibly also be lost, in which case it is [sometimes, F. V. T.] united to the cephalothorax. The structure of the three regions depends mostly on the varying form and function of the appendages-those on the head are primitively locomotive organs (and frequently are still so in the early stages), but they become transformed into feelers and mouth-parts (mandibles, maxillæ); the limbs of the thorax, however, usually retain their ambulatory functions, as frequently do those of the abdomen; sometimes, however, the abdominal limbs disappear, entirely or partly; in the latter case they are then utilised for other purposes.

In their organisation the Arthropoda approach to the segmented worms. The Arthropoda are generally divided into five groups (Crustacea," Pro-

'[In most Arthropoda the skin is hardened by a deposit of chitin (Hexapoda, \&c.). -F. V. 'T.]

"Parasitic or free-living crustaceans may now and then invade man abnormally. Thus, according to Betten, Caligus curtus invade the cornea (Betten, R. A., "Par. Crust as a Foreign Body on the Cornea," Lancet, 1900, i., p. 1002; and Centralbl. fur Bakt., Paras. u. Inteht., xxix., p. 506). According to Laboulbène, Gammarus pulex (Labonl. bène, A., "Obs. d'accid. caus. par le G. pul. apport. avece l'eau de boison dans l'estomac d'un homme," Bull. Ac. méd., 1898, p. 2 I). 
tracheata, Arachnoidea, Myriapoda, ${ }^{\mathrm{I}}$ and Insecta or Hexapoda), of which only the Arachnoidea and the Hexapoda interest us here.

\section{A.-Arachnoidea (Spiders, Mites, \&c.).}

The head and thorax are always united together; the abdomen is either segmented or without exterior segmentation, in which case it is united with the cephalothorax. ${ }^{2}$ The number of pairs of appendages amount to six, of which the two front pairs, the cheliceræ and the pedipalpi, are attached to the head region and the four remaining pairs to the thoracic region. ${ }^{3}$ The abdomen in the adult condition has no appendages. The arachnoids are airbreathers, and for this purpose are either provided with tracheæ, or with so-called lung sacs, or they breathe through the surface of the body.

There are eight or ten orders of arachnoids, of which, however, only two, the Acarina and the Linguatulida, have to be considered here. $^{4}$

\section{Order Acarina (Mites).}

Small arachnoids, the three parts of the body of which are, as a rule, coalesced; it is only rarely that a faint line indicates the division. The two appendages on the head are designed for biting or puncturing and sucking, and vary according to their use. The cheliceræ ${ }^{5}$ are fang-like jaws or puncturing bristles, the pedipalpi are claw-like or sheer-shaped, or form a suctorial proboscis. ${ }^{6}$ The four pairs of legs are usually well developed, more rarely they are rudimentary or have partly vanished;

'R. Blanchard has compiled thirty-five cases in which Myriapoda have been observed in the intestine as well as in the nose of human beings ("Sur le pseudo-par d. myriap. chez l'homme," Arch. d. parasit., 1898, i., p. 452). E. Munoz Ramos reports an additional case (ibid., p. 49I): A few years ago a doctor in East Prussia sent me a rain-worm out of a lady's nose (compare Hanan, A., "Wahrsch. Pseudoparas. v. Schweiss fliegenlaro. u. angebl. Paras. v. Regenwurmern b. ein Hysterisch.," Arch. d. paras., 1899 , ii., p. 23).

" [This is only so in the Acarina or Mites, not in the Araneida or spiders. -F. V. T.]

${ }^{3}$ [The true character of the Arachnoidea is the presence of four pairs of ambulatory appendages. This number is reduced to two pairs in the gall-making Phytoptidæ.F. V. T.]

${ }^{4}$ Chelifer cancroides has also been observed as a pseudoparasite in man (Arnault de Verey, S. "Pseudopar. du chel. cancr. chez l'homme" (C. R. soc. biol., I901, liii., p. 105).

${ }^{5}$ [The Cheliceræ are sometimes regarded as modified antennæ, but it is more natural to regard them as the morphological equivalent of the mandibles of Hexapoda. - F. V. T.]

${ }^{6}$ [The pedipalpi or second pair of jaws consist of a stout basal joint and a palp, which may have the appearance of a leg in Arachnida; this may end with or without a claw or with a chela (scorpions); they may also form a tube enclosing the styliform cheliceræ (mites).-F. V. T.] 
many parasitic forms are provided with pedunculated suckers [ambulacra, F. V. T.]. Respiratory organs (tracheal tufts) may be present or absent. The nervous system is reduced to a minimum, eyes are usually lacking. The intestine, situated in the central part, generally has three blind appendages; the anus is situated on the venter above the posterior end. Sexes separated; nearly all the species deposit eggs, from which six-legged larvæ hatch. The acarina live either free in the water or in moist soil, or they are parasitic on plants and animals. ${ }^{1}$

\section{Fam. Trombidiida (Running Mites).}

Soft-skinned acarina with tracheæ and with two eyes, usually pedunculated; they are often brightly coloured; cheliceræ lancet- or claw- shaped; pedipalpi claw-like; legs composed of six segments, with suctorial discs between the terminal ungues.? Larvæ six-legged.

\section{Leptus autumnalis, Shaw, I79o.}

This name is used for the larvæ of mites' which are found towards the end of summer on grass plots, bushes and cereals, ${ }^{3}$ and which have a predilection for attacking mammals and human beings (Harvest-mites, Autumn-mites, Grass-mites, Rouget, Bêterouge, Aoûtat, Red bug). To all appearances these are the larvæ of at least two species, the corresponding adult forms of which have certainly long been known, but have hitherto not been definitely traced from these larvæ. P. Mégnin, in 1876 , asserted that Leptus autumnalis was the larval form of Trombidium holosericeum, a red-coloured species of mite which is frequently found on trees, on the earth, \&c., in the spring; and which in June and July deposits eggs from which reddish larvæ, $0.23 \mathrm{~mm}$. in length, and $0^{\circ}$ Ig $\mathrm{mm}$. in breadth, hatch out. ${ }^{4} \mathrm{As}$, however, Moniez

${ }^{1}$ [Acarina are also found living upon trees feeding upon other Arthropods and also upon spores of lichen and fungi (Oribatida or Beetle Mites); they also swarm indoors amongst stores and provisions (Tyroglyphida and Glyciphagi, Household, Sugar and Cheese mites).-F. V. T.]

${ }^{2}$ [Some have seven segments to the legs.-F. V. T.]

${ }^{3}$ [This minute parasite is especially obnoxious in barley fields. In walking across barley stubble one is sure to be attacked by this parasite in the autumn in many districts. This Leptus attacks poultry also when turned out on to the stubble fields in autumn, but does not do much harm.-F. V. T.]

1 [This mite occurs chiefly in gardens, and is often very prevalent amongst rows of peas. In the spring it may frequently be found on fruit trees. In barley fields, where Leptus autumnalis is most abundant, I have often found traces of Holosericeum early in the year. Nut pickers are frequently attacked by this Leptus, and also pickers in fruit plantations.-F. V. T.] 
points out, the characteristics of these larvæ do not entirely correspond with those of Leptus autumnalis. Mégnin has recently found the larvæ of various Trombidia on mammals and human beings (I897), whilst Brucker regards the larvie of Trombidium gymnopterum as Leptus (Rouget). The old opinion which has recently been revived that Leptus is the larva of Tetranychus telarius is entirely without foundation (von Hanstein). ${ }^{1}$

On the skin of man Leptus, as a rule, produces 1 tching and redness (autumnal erythema); sometimes also circumscribed flat wheals, the eruption of which is'accompanied by slight fever. These symptoms, however, disappear after a few days. It has been proved that the animals injure the skin and plunge their long hypopharynx into the wound, which occasionally is situated at the orifices of the sebaceous and sweat

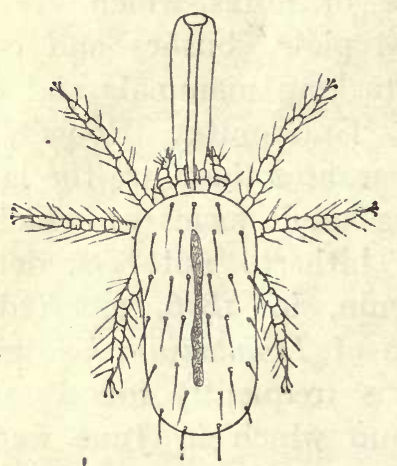

FIG. 228.-Leptus autumnalis, with the so-called suctorial proboscis (after Gudden). (Magnified).

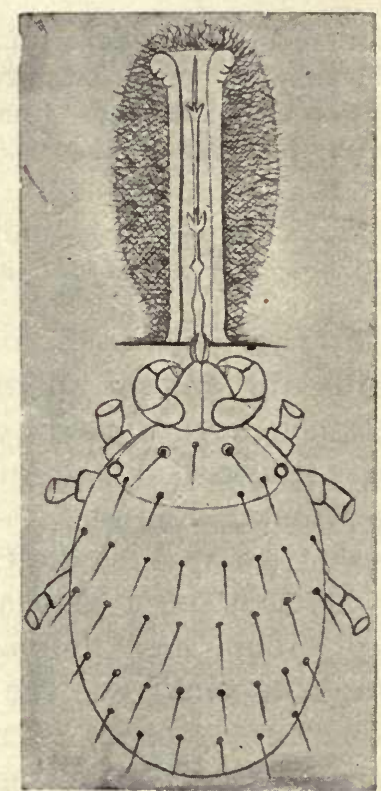

Fig. 229.-Leptus autumnalis, 100/0. The so-called proboscis is formed around the hypopharynx sunk into the skin. (After Trouessart.)

glands, in order to suck up blood with it. Around the stiletto-shaped hypopharynx a cylindrical tube, annularly thickened at the free end (fig. 229), is then formed by the host; this has hitherto been regarded as the proboscis of the Leptus; but as a matter of fact it belongs not to the parasite, but to the host, in the same way as the ramified chitinous tubules that arise in arthropoda as consequences of the bite of mites (Flögel, Trouessart). ${ }^{2}$

'[Tetranychus telarius is well known in all its stages as a vegetal pest. There is no connection in any way between it and the harvest bug.-F. V. T.]

"Küchenmeister, F., "Ueb. d. sog. Stachelbeer-oder Erntemilbe" (Varga's Zeitschr. f. Med. Chir. u. Geburtsh. N.F.I.," I 862, i., p. 289); Gruby, "Herbsterytheme" (Allg. Wien. med. Ztg., 1861, p. 19); Gudden, "Ueb. eine Jno. v. Lept. aut." (Arch. f. path. 
[Leptus autumnalis attacks small mammals by preference, such as moles and hares, which are often literally covered with them. Dogs are also subject to their attack and cats suffer similarly. This mite also frequently appears in colonies in cows ; cavalry horses after autumn manœuvres often suffer from an erythematous affection about the hocks and knees due to this pest.

A number of Leptus, so far undescribed, occur abroad which attack man in the same way to L. autumnalis here. Dr. Durham has brought me specimens from British Guiana called Bête rouge; these work under the skin much as does our European species, but it is very distinct, being considerably larger.-F. V. T.]

\section{Trombidium tlalsahuate (Lemaire), 1867.}

Trombidium tlalsahuate occurs in Mexico under conditions similar to those of Leptus here. It also frequently attacks men, and by predilection fastens itself on to the eyelids, in the axillæ or navel, or on the prepuce; it induces itching and swelling of the parts affected, and sometimes even causes suppuration; the symptoms, however, generally disappear after a week and remain localised. ${ }^{1}$

Other species of mites which attack man are reported, mostly by travellers, from various other places; zoologically, however, there is little known about them. The Pou d'Agouti in Guiana, Niaibi in New Grenada, Colorada in Cuba, Mouqui in Para, represent a few of these. ${ }^{2}$

An., I87 I, lii., p. 255); Krämer, “Beitr. z. Kenntn. d. Lept aut." (ibid., I872, lv., p. 354); Mégnin, P., "Mem. s. l. metamorph. d. Acariens" (Ann. d. sc. nat. Zool., I 876 [6], iv., Act., No. 5) ; Flögel, J. H. L., "Ueh. ein merkw. durch Paras. hervorger. Gewebsneubld." (Arch. f. Naturg., I 876, xlii., I876, p. I06); Henking, H., "Beitr. z. An., Entw. u. Biol. v. Tromb. fulig." (Z. t. w. Z., I 882, xxxvii., p. 553); Mégnin, P., "Les Acar. pur." (Encycl. scientif. des aide-mém., Paris); Moniez, R., "Sur les diff. Acariens, qui s'attach. d l'homme et qui ont reçu le nom de rouget" (Rev. biol. du Nord de la France, I 894-95, vii., p. 301), Traite de parasit., Paris, I896; Brandis, F., "Ueh. Lept. aut." (Fests:hr. z. 50 jahr. Besteh. d. Prov. Irrenanst. Neitleben bei Halle ja. S., 1897, p. 417) ; Brucker, "Sur le rouget de l'homme" (C. R. Ac., Paris, I 897, Exxv., [2], p. 879); Mégnin, P., "Observ. sur les rougets" (ibid., p. 967) ; Thiele, J., "Die Gras-oder Erntemilhe, eine Plage d. Feldarh." (Dtsche. landw. Presse, i 898, No. 98, p. 10 16). Trouessart, E. L., "Sur la piqure du rouget" (Arch. de paras., I 899, ii., p. 286); Hanstein, R. v., "Beitr. z. Kenntn. d. Gttg. Tetranychus Duf. nebst Bem. ub. Lept. aut." (Z.1.w. Z., I90I, lxx., p. 58).

'Lemaire, "Import. en France du tlalsahuate" (C. R. A c., Paris, I 867, 1xv., p. 21 5); Altamirano, F., and Dugès, A., "El tlalsahuate" (Fl estudio, I892, iv., p. 196) ; Riley, "The Mexican Jigger, or tlalsahuate" (Insect I ife, I893, iv., p. 2 I I).

2 Bonnet, G., "Contr. à l'étude du paras." (These de Aontpellier, I870, No. I I, p. 53). 


\section{Akamushi or Kedani.}

In a few districts of Japan there occurs a serious illness (with a mortality of 40 to 70 per cent.). It is called river or flood fever, and the Japanese doctors have connected it with a small mite (Akamushi, Kedani). Baelz has opposed this opinion on the grounds that he has repeatedly observed the same species of mite in his dwelling without any subsequent illness occurring. According to Keïsuke Tanaka, however, a connection certainly does exist,

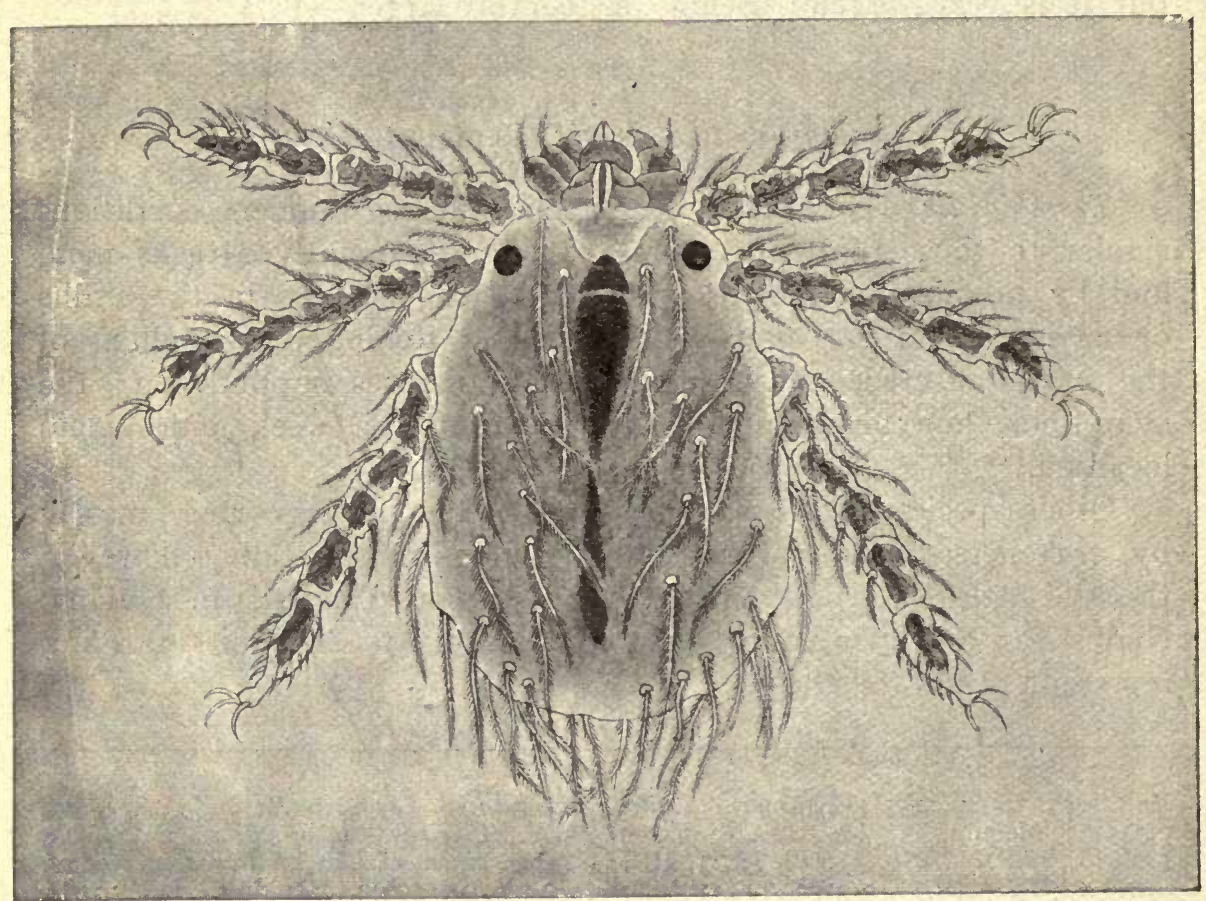

FIG. 230.-The Kedani Mite (enlarged). (After Tanaka.)

inasmuch as the akamushi, like Leptus, attacks persons to suck blood. If the mite is not removed, or if the spot attacked is injured by scratching, \&c., a papule, surrounded by a red area forms, and a pustule ensues; and finally a black scab covers the seat of injury. The lesion becomes the point of entrance of bacteria, especially a species of PROTEUS which produces river-fever. If the mites are carefully removed no general illness takes place. The orange-red mites, which we only know in their larval 
condition, measure $0^{\circ} \mathrm{I} 6-0^{\circ} 38 \mathrm{~mm}$. in length by $0^{\cdot} \mathrm{IO}-0^{\circ} 24 \mathrm{~mm}$. in breadth. They have leg-like palpi with three joints, hirsute bodies, and very hairy legs composed of five segments terminating with three ungues. ${ }^{1}$

\section{Fam. Tetranychida (Spinning Mites).}

These have tracheæ and eyes; the palpi are composed of four segments, of which the last but one has a powerful claw; the antennæ are two-jointed, the first joint solid and transformed into a blunt cone from which the long, bent stinging bristle (the second joint) protrudes. The legs have six segments with sucker discs between the claws.

\section{Tetranychus molestissimus, Weyenbergh, I886. ${ }^{2}$}

Found in Argentine and Uruguay on the under surface of the leaves of Xanthium macrocarpum; it attacks mammals and men, producing. severe itching, accompanied by fever in the latter.

It has been asserted by Haller that the Cape Ailment (Port Natal Sickness) is caused by mites, but this statement has been contested. ${ }^{3}$

\section{Tetranychus telarius (L.), $\mathrm{I} 75^{4}$ (var. russeolus, Koch).}

This common spinning mite likewise attacks human beings, but the papules produced by it very soon disappear. ${ }^{5}$

'Tanaka, Keis, "Ueb. A.t. u. Pathog. d. Kedani-Krankh." (Centr. t. Bak., Par. und Int., r 899 [1] ], xxvi., p. 432).

${ }^{2}$ [This species is also known as Bicho colorado. It spins a web under the lower surface of the leaves, and it is only from December to February that it attacks warmblooded animals and man.-F. V. T.]

"Haller, G., "Vorl. Nachr. uber einige noch wenige bekannten Milben" (Zool. Anzgr., I 886, ix., p. 52 ; Fritsch, G., "Bem. z. Herrn Haller's Aufs." (ibid., p. 229).

${ }^{4}$ [There is something wrong here, probably in the identification. T. telarius is purely a plant feeder, and it is extremely unlikely a variety would attack man. Anyhow it will not do so in Great Britain.-F. V. T.]

"Artault, L., "Le platane et ses mefauts; un nouv. Acar. paras. accid de l'homme" (Arch. de paras., 1900, iii., p. I I5). 


\section{Fam. Tarsonemida.}

A family distinguished by complete sexual dimorphism, the species of which are provided with tracheæ; the legs have five segments; the terminal segments of the front pair of legs of both sexes possess a claw ; the terminal segment of the posterior pair of legs of the male likewise has a claw. In the female this pair of legs, like the second and third pairs of both sexes, is provided with two hooklets and a sucking disc. The cuticle of the body on the back is " annulated."

\section{Pediculoides ventricosus (Newport), 1850.}

Syn.: Heteropus ventricosus, Newport, I850; Acarus tritici, LagrèzeFossot, 1851; Physogaster lavvarum, Lichtenstein, I868; Spharogyna ventricosa, Laboulbène and Mégnin, 1885.

Males are oval in shape, $0.12 \mathrm{~mm}$. in length and $0.08 \mathrm{~mm}$. in breadth, flattened. There are six pairs of chitinous hairs on the

$c$

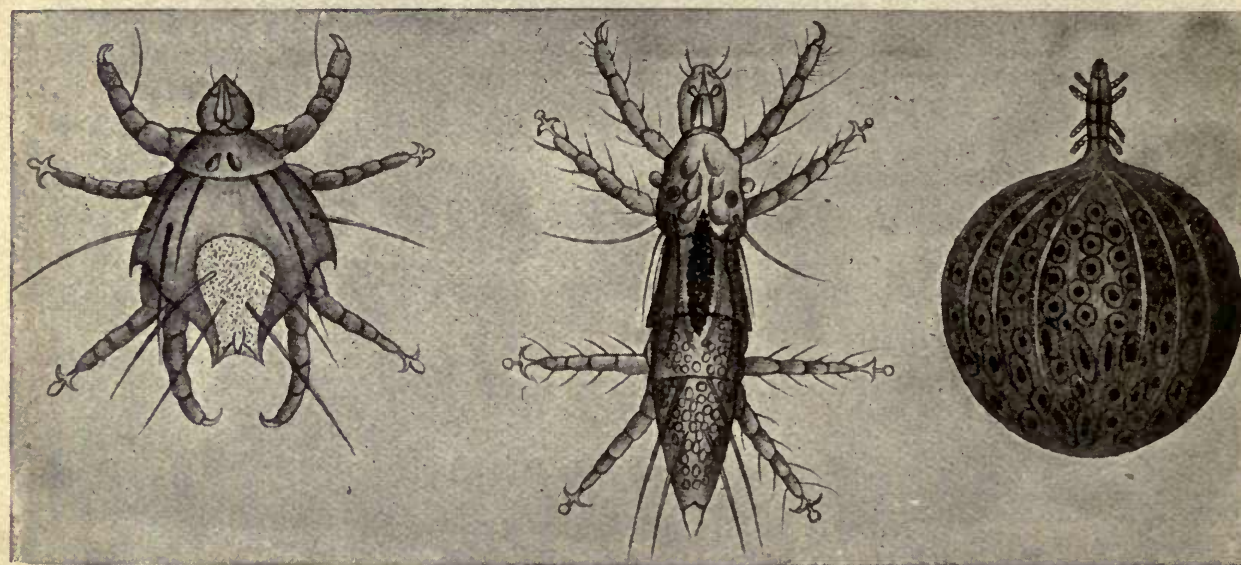

Fig. 232.-Pediculoides ventricosus. After Laboulbène and Mégnin (enlarged)$a$, male; $b$, young female; $c$, gravid female.

dorsal surface and a lyre-shaped lamella on the posterior part. The female in the non-gravid state is cylindrical in form, $0 \cdot 2 \mathrm{~mm}$. in length, and $0.07 \mathrm{~mm}$. in breadth; when gravid the posterior part of the body becomes enlarged into a ball, which may attain I.5 mm. in size, as in the case of Pulex penetrans, and of the female Termites. On emerging the young are already provided with four pairs of legs and copulate soon after birth. 
These animals live on the stalks of cereals, and feed on vegetable and animal juices; they are therefore also found on corn-infesting insects. They invade the barns and seek out the insects living in the dry grains of corn, or wait for an opportunity of obtaining food. They have been repeatedly observed on human beings, particularly labourers occupied in handling grain; their bite causes severe irritation, local elevation and reddening of the epidermis, as well as fever. It cannot be positively asserted that all cases of the occurrence of cereal mites on man relate to Pediculoides ventricosus, as the descriptions are often insufficient. Geber states that one form is Chrithoptes monunguiculosus, cr Acarus hordei; Flemming mentions Tarsonemus uncinatus; Koller Oribates sp., and Karpelles Tarsonemus intectus. ${ }^{1}$

\section{Fam. Eupodida.}

Small tracheate mites, with moderately long or short pedipalpi, composed of four segments, of which the last segments bend; cheliceræ forcepsshaped, with serrated edge; legs with two claws, more rarely with one, and terminating in a tuft ornamented with fine hairs; genital orifices on the abdomen, surrounded by a circle of little hairs. Most species live free, one lives parasitically on the bodies of slugs.

\section{Tydeus molestus, Moniez, I889.}

Male, $0.2 \mathrm{~mm}$. in length, 0.125 in breadth. Females, $0.225 \mathrm{~mm}$. in length, $0^{\circ} 135$ in breadth; gravid female $0.315-0.360 \mathrm{~mm}$. in length and $0.180 \mathrm{~mm}$. in breadth. They were observed by Moniez on an estate in Belgium, whither the creature had apparently

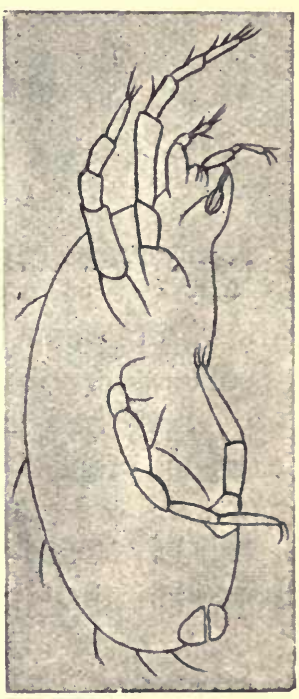

FIG. 233.-Tydeus moles tus seen in profile, enlarged. (After Moniez.) been imported twenty-five years previously with Peruvian guano; they appeared regularly in the summer and remained until the first frost set in ; they were found on

${ }^{1}$ Lagréze-Fossot, A., and Montané, R. J. (Rec. agronom. soc. d. sc., agric. et belles lettres du dep. de Tarn et Garonne, I851, xxxii., No. 2) ; Robin, Ch., and Rouyer, "Erupt. cutanee due a l'Acaris du ble" (C. R. soc. biol., 1867, iv., p. I78); Laboulbène, A., and Mégnin, P., "Mem. sur le Spharogyna ventricosa" (Journ. de l'anat.. I885, xxi., p. I); Geber, E., "Entzundl. Processe der Haut durch ein bis jotzt nicht bestimmte Milbe veranlasst" (Wien. med. Presse, I 879, xx.); Koller, J- (Pest. med. chir Presse. 1882 , No. 36, and Biol. Centralbl.; 1885, iii., p. 127); Karpelles, L., "Ein auf den Mensch $u$. auf Getreide lebende Milbe" (Anz. d. K. K. Acad. d. Wiss., Wien., 1885, xxii., p. 160, and Centralb. f. Bakt. u. Paras., 1887, i., p. 428); Flemming, J., "Ueber eine geschlechtsreife Form der als Tarsonemus beschriebenen Thiere" (Zeitschr. $f . d$. ges. Naturwiss., Halle, 1884, iii., p. 472) ; Kramer, "Zu Tarsonemus uncinatus Flem." (ibid., p. 67I); Moniez, R. "Sur l'habit. normal, dans les tiges d. cereales, d'un paras. accid. de l'homme" (Rev. biol. du Nord de la France, I895, vii., p. 148 ; Traite de Paras.. Paris, I 896). 
grass plots, on trees and bushes in masses; they regularly attacked persons, mammals and birds, tormenting their hosts in a terrible manner. ${ }^{1}$

5. Fam. Gamasida (Coleopterous mites).

Cheliceræ sheer-like or piercing; pedipalpi filiform; the legs are composed of six segments with two terminal ungues and a bladder-like sucking disc [caruncle, F. V. T.]. Stigmata situated between the third and fourth pairs of legs; the cuticle thickened, leather-like, no eyes; the larvæ have six legs.

Dermanyssus gallina (de Geer), I778.

Syn. : Pulex gallina, Redi, I674; Acarus gallina, de Geer, I778; Dermanyssus avium, Dugés, 1834 .

The male measures $0.6 \mathrm{~mm}$. in length by $0.32 \mathrm{~mm}$. in breadth; the female $0.7-0.75 \mathrm{~mm}$. in length by $0.4 \mathrm{~mm}$. in breadth. The body is somewhat pear-shaped; the colour whitish, reddish, or reddish-black, according to the contents of the intestine. The legs are fairly short and strong. During the day they live concealed in the nests, cracks, \&c., of the hen-house, and at night attack the inmates in order to suck their blood; they rarely remain long on the birds. They have been repeatedly found on persons, on whose skin they produce an itching eruption. ${ }^{2}$

\section{Dermanyssus hirundinis (Hermann), I804.}

Syn. : Acarus hirundinis, Herm., I804.

Of a brownish-violet colour, $\mathrm{I} \cdot 2$ or $\mathrm{I} \cdot 4 \mathrm{~mm}$. in length; lives in the nest of swallows and is occasionally found on man. ${ }^{3}$

[The Red Hen Mite (Dermanyssus gallina) not only attacks poultry and man, as stated above, but is found on all birds and

${ }^{1}$ Moniéz, R., Les Paras. de l'homme, Paris, 1889, p. 129; "Hist. nat. du Tydeus molestus." (Rev. biol. Nord de la France, I893-94, vi., p. 419).

${ }^{2}$ Alt, Ch. H., De phthiriasi. Diss. in. Bonne, 1824; Simon, G., Die Hautkrkh. durch anat. Unters. evl., 2nd edit., Berlin, 1851, p. 320 ; Itzigsohn, H., " Pathol. Bagatellen. I. Psora dermanyssica" (Virchow's Arch., I858, xv., p. 166); Judée, "Sur un nouveau paras. de la peau chez l'homme" (C. R. soc. biol., Paris, I867, iv., p. 73); Wagner, A., Ueb. d. Vork. v. Derman, avium b. Mensch. In. Disc. Greifswald, I873 : Geber, E., In Ziemssen's Handb. d. spec. Path. u. Ther., I884, xiv. [2], p. 394); Blanchard, R., "Not sur les par. de l'homme. 2 Ser. II. Nouv. cas de Derm. gallina dans l'esp. hum." (C. R. soc. hiol., Paris [10], 1894, i., p. 460).

${ }^{3}$ Die Gartenlaube, 1863, p. 23. 
many mammals. The Dermanyssus galline, is the same as $D$ avium. The species found in swallows' nests is also said to be the same. This mite can remain for weeks without any food from its normal host. They only attack man when entering or cleaning dirty and neglected fowl houses; upon him they do not produce a true dermatosis. They chiefly attack the back of the hands and forearms of those who constantly attend poultry and give rise to symptoms similar to the papular eczema of scabies. That they may remain some time upon the human body we know

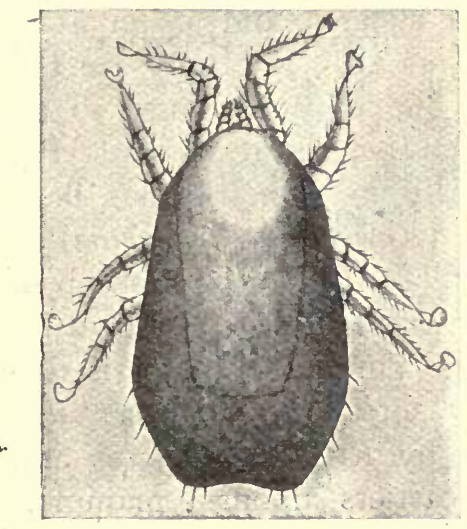

FIG. 234.-Dermanyssus gallince (enlarged). (After Berlese.)

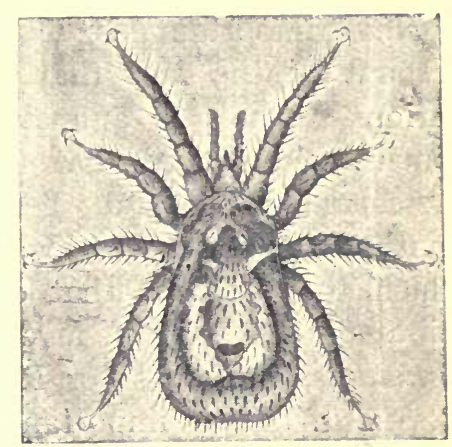

FIG. 235.-Dermanyssus hirundinis. 40/1. (After Delaford.)

from the following cases out of many recorded:-Geber observed that the Dermanyssus had caused a diffused eczema on a woman, which lasted four weeks and then disappeared. The Tique of F. V. Raspail is the bird Dermanyssus; he records children and adults beirg attacked not only when handling pigeons, but even when walking in a garden manured with pigeons' dung. The affection soon disappeared when the pigeons were destroyed and the excreta buried. I have frequently heard of poultrymen being seriously attacked by this pest.-F. V.T.]

\section{Holothyrus coccinella, Gervais, I642.}

Measures $5 \mathrm{~mm}$. in size; lives on birds in the island of Mauritius ; ducks and geese frequently fall victims to its bite; it also attacks human beings, on whose skin it causes severe burning and swelling, but no reddening; it may be dangerous to children, especially by settling in the oral cavity. ${ }^{1}$

${ }^{1}$ Gervais, P., "I5 esp. d. Insect. apt." (Ann. soc. ent., France, 1842, xi., p. I4) ; Mégnin, P., "Ün acarien dangereux de l'île Maurice" (C. R. soc. biol., Paris, 1897, v., p. 25 I). 


\section{Fam. Ixodida (Ticks). ${ }^{1}$}

Comparatively large acarines with a leathery skin; they are flattened in form, but after sucking blood the abdomen becomes spherical; the cheliceræ are rod-like and possess a serrated terminal joint, bent hooklike; the median parts of the pedipalpi (maxillæ) form a rostrum furnished with barbed hooks (fig. 236); the maxillary palpi themselves are club-like or rounded; the legs are composed of six segments with two terminal ungues; often also with "sucking-discs"; the stigmata are at the sides of the body, posterior to the fourth pair of legs. The larvæ are six-legged.

[The true ticks (Ixodida) are all blood-suckers, and as far as is known they do not take vegetable food at all. Not only are the Ixodide important as actual parasites, but they are most so on account of the fact that they are the active agents in carrying various diseases in animals and apparently in man. It has been conclusively proved that the Bont tick (Amblyomma hebrceum) is the carrier of the fatal "heart-water fever" so rife amongst sheep in South Africa, that the dog tick (Hamapsyllis leachi) is the agent by which the protozoa that cause malignant jaundice in dogs is distributed, that Texas fever in cattle is spread by Rhipicephalus annulatus, and Coast or Rhodesian fever by $R$. appendiculatus and $R$. Simus. Their importance as disease carriers amongst mammals is therefore considerable, and it may prove to be so for man. ${ }^{2}$ They frequently attack man (vide p. 368); but chiefly, according to my observations, in their early stages in Europe ; this is not so, however, abroad (vide.p. 373). The life-history of a number of ticks has been clearly demonstrated. Mr. Wheler has shown that in Ixodes reduvius it is as follows. The female deposits her eggs in masses upon the ground, and then gradually reducing in size as the eggs pass out until she finally remains a mere shrivelled empty bag and then dies. The eggs are oval, golden-brown in colour and smooth; in length they are $0.59 \mathrm{~mm}$.; as in all Ixodidæ they are covered with a glutinous secretion, by means of which they adhere together in masses. These egg masses may be deposited anywhere on the ground, but amongst rough coarse herbage seems to be the favourite place. The egg stage may last as long as twenty-two weeks, or it

\footnotetext{
1 Pagenstecher, H. A., Beitr. z. Anat. d. Milben., 1861, ii., L.pz.; Bertkau, Ph. "Bruchstucke a. d. Lebensgeschichte unserer Zecke" (Verh. d. nat. Ver. d. pr. Rheinl. u. Westf., Stzgsber., 1881, p. 145); Johannessen, A., "Acute Polyurie bei einem Kinde nach dem Stiche eines Ix. ric." (Arch. $f$. Kinderhlkde., I 885, vi., p. 337) ; Blanchard, R., "Penetr. de l'Ix. vic. sous la peau de l'homme" (C. R. soc. biol.. 189I [9], p. 689); Neumann, G., "Revis. de la frm. des Ixodides III." (Mem. soc. zool., France, I899, xii., p. 107$)$.
}

${ }^{2}$ This has been recently proved in Uganda-so called tick fever in man, 
may only take eight weeks. In the case of the Bont tick a single female will deposit 15,000 or more eggs. The process of egg-laying is described as follows by Mr. Wheler : "When egg-laying is about tơ take place, the head is further depressed till it rests close against the under side of the body. In this attitude the end of the rostrum actually touches the genital orifice, the palpi being at the same time widely opened out. Behind the head and from beneath the shield at what for the purposes of explanation may be described as the back of the neck, a white, perfectly transparent, delicate gelatinous membrane is brought down through inflation, either with air or with a transparent fluid, above the head, which it temporarily conceals. The end of this membrane terminates in two conical points which appear to be covered with a glutinous secretion, and at the same time an ovipositor of a somewhat similar character, but only semi-transparent, is pushed forward from the genital - orifice. This latter is a tube, within which is the egg. As the ovipositor projects it turns itself inside out, like the finger of a glove, leaving the egg protruded at the end and lying between the two finger-like points of the membrane. The membrane and the ovipositor are then withdrawn each from the other. The egg adheres to the former, which collapses through the withdrawal of its contents, dragging the egg forward and depositing it on the top of the head. Neither legs, palpi, nor the organs of the mouth take any part in oviposition, but after the collapse of the membrane the palpi are closed and the head is raised, by which action the egg is pushed forward to the front edge of the shield, forming in time an adherent mass of eggs, which are deposited in front of the tick."

The egg gives rise to the larval form, the so-called "seed-tick" stage. At first these minute specks are pallid and soft, but they soon harden and darken in colour. These larvæ are six-legged and soon crawl up grasses and various plants, and there await a passing host, waving their two front legs in the air and becoming attached by this means. The larval ticks feed upon the blood of the host, and when repleted fall to the ground, the body becoming inflated in the meanwhile. These larvæ may remain on the host only two days, or they may remain much longer. Eventually they moult on the ground, and change to the nymph or pupal stage, which has four pairs of legs. This pupa acts just as the larva, crawls up plants and waits to regain the host. After a time the nymphs, having gorged themselves with blood, fall off and remain on the ground for nearly three months; they then moult and become adult males and females. In about ten days they assume their normal 
colour and regain the host afresh; the female gradually swells until she attains that large inflated form so characteristic of ticks. The male does not swell, but nevertheless feeds upon the host and fertilises the female.

The act of coitus is strange, the male tick inserts its rostrum and other mouth organs into the sexual orifice of the female, between the base of the posterior pair of legs. The males then die and the females fall to the ground and deposit the ova. There are variations in the different species, of course, from those given above, which apply solely to Ixodes reduvius. The larvæ and nymphs seem to attack most animals, but the adults mainly keep to the same host. The periods in the life cycle of ticks not only vary in the different species but in each species according to climatic conditions. For instance, in the Bont tick (Amblyomma hebraum, Koch), Lounsbury has shown that the development is rapid in summer, slow in winter. The period from the time that the female drops to the time she commences to lay eggs varied in specimens observed by him from twelve days in summer to twelve weeks in winter, and the complete period from the dropping of the female to the hatching of the eggs, from eleven weeks in summer to thirty-six weeks through the winter. Other stages vary in a similar manner.

Ticks may live a long time away from the host provided they are supplied with a certain amount of moisture. Mr. Wheler kept dog ticks (Ixodes plumbeus) in the larval stage for ten months. The pupæ, male and female, of Ixodes ręduvius for six months.

In many species moulting takes place off the host, but in Ixodes bovis, now known as Rhipicephalus annulatus, Say (the carrier of Texas fever), moulting takes place on the host, and in many other species also. ${ }^{1}$ Some species of ticks leave their host on its death (as the dog tick, Hamaphysalis Leachi), but others die with the host (Bont Tick, Amblyomma hebraum).

\section{Classification OF IXODIDE.}

The Ticks, or Ixodida, are divided into two groups, known as (I) Argasinæ, (2) Ixodinæ. The Argasince are told from the Ixodinæ by the absence of dorsal or ventral shields in both sexes, and also by the rostrum being placed beneath the cephalo-thorax, which covers it over, except in the larval stage, in which it is terminal, and in the pupal, when it partly projects. Legs nearly equal in length. The sexual orifice is situated between the two first pairs of legs. The males usually smaller than the females.

' Some Ticks require only one ( $R$. decoloratus) others two ( $R$. evertsi) and some three hos.ts ( $R$. appendiculatus) in order to reach maturity. 
The Ixodince have the legs unequal, of six segments with two false segments, making them look as if composed of eight segments. The rostrum is terminal and never hidden beneath the body. The sexual orifice is situated between the haunches of the first three pairs of legs. In the males the orifice is obsolete or very rudimentary; sexual intercourse being effected by the rostrum. The males are smaller than the females. The shield in the females never covers so much as one half of the body even when fasting, also in the larvæ and nymphs; but in the males, which do not distend, the shield covers the body entirely, or all but a narrow margin. The Ixodina are divided into two groups: (I) the Ixoda and (2) the Rhipicephalce. The former have a long proboscis reaching nearly to the end of the palpi or even a little longer than the palpi. The palpi are longer than broad. The Rhipicephala have short palpi, nearly or quite as broad as long, more or less conical or subtriangular. They were called Conipalpi by Canestrini.

\section{Synopsis of Genera.}

A. Rostrum concealed in adult, partly exposed in larvæ and nymphs. No dorsal and ventral shields.

Body flat with thin edges, finely shagreened and punctate . Body with numerous small round granules and with thick sides

B. Rostrum terminal. Body with dorsal shield over some part of it.

I. Rostrum and palpi longer than broad (Ixodince).

a. A groove around anus in front. Palpi caniculated in both sexes.

Palpi claviform, not caniculated in the male; legs very long . . . . . . . . . . . . . .

Palpi claviform, not caniculated in the male; anal groove absent in the female

Argas.

Ornithodorus.

A groove around the anus behind.

No eyes; ad-anal shields

Eýes present.

Males with no ad-anal shields . . . . . . . .

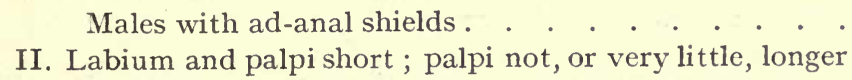

Ixodes.

Escatocephalus.

Ceratixodes.

Aponomma.

Amblyomma.

Hyalomma than broad (Rhipicephala).

a. No eyes.

Rostrum rectangular; no ventral shields in the male .

Hamaphysalis.

B. Eyes present.

Rostrum with salient angles; either two or four shields at the side of the anus in the male . . .

Rostrum rectangular. No ad-anal shields in the male, but usually with greatly-developed coxæ on fourth pair of legs .

Rhipicephalus.

Dermacentor. 
The genus Ceratixodes of Neumann (1902) occurs on birds.

The genus Eschatocephalus of Frauenfeld (1853), of which seven species are known, are mostly parasitic on bats, and are found in holes, caves and church towers.

The genus Aponomma of Neumann (1899) is exotic, and almost entirely confined to snakes and saurians.

The following are synonyms of the different genera :Argas, Latreille, 1796 (Rhynchoprion, Hermann, 1804).

Ixodes, Latreille, 1795 (Acarus, Linnæus, I758; Cynorhastes, Hermann, I804 ;

Crotonus, Dumeril, I822).

Ceratixodes, Neumann, 1902 (Ixodes, Cambridge, 1879 ; Hyalomma, Cambridge, I 879 ).

Eschatocephalus, Frauenfeld, I 853 (Sarconyssus, Kolenati, I 857 ).

Amblyomma, Koch, I 844 (Ixodes, Latreille, I 795).

Hamaphysalis, Koch, I 844 (Rhipistoma, Koch, I 844 ; Gonixodes, Duges, 1888 ;

Opitodon, Canestrini, 1897).

Rhipicephalus, Koch, I844 (Acarus, Linnæus, 1758 ; Ixodes, Latreille, I795 ;

Phanloixodes, Berlese, I889; Boophilus, Curtice, I890).

Dermacentor, Koch, I 844 (Ixodes, Latreille, I795; Pseudixodes, Haller, I882).

-F. V. T.]

\section{Ixodes reduvius (L.), $175^{8 .}{ }^{1}$}

Syn.: Acarus reduvius and vicivus, L.; Ixodes vicinus, Latreille, 1806.

The .males are oval ; their length $\mathrm{I} \cdot 2-2 \mathrm{~mm}$.; they are brownishred or black in colour; the females are yellowish-red, $4 \mathrm{~mm}$. long; when gorged they are lead-coloured and may attain I2 $\mathrm{mm}$. in length by $6-7 \mathrm{~mm}$. in breadth.

The dog tick (fig. 237) lives in thickets on leaves, \&c., and attacks sheep and oxen, and more rarely dogs, horses and human beings, into the skin of which the female bores with the rostrum in order to suck blood; the bite is not dangerous and sometimes is not even felt. Inflammation, however, is set up if the creatures are forcibly removed from the wound, as the rostrum as a rule is torn off in the process. If left alone or smeared over with some grease-vaseline, oil, butter, \&c. - the creatures drop off spontaneously. Sometimes the entire tick bores itself into the skin; they also appear to be permanent inmates of kennels.

[The species (Ixodes reduvius) is the same as Ixodes ricinus, Latreille. The male is $2.35-2.80 \mathrm{~mm}$. long; the body is dark brown, almost black, with a pale almost white margin; there are also traces of reddish mottling. Coxæ of the first pair of legs with a short spine. Rostrum much shorter than that of the female; shield

${ }^{1}$ Ixodes reduvius and $I$. ricinus are synonymous. [The above should read $I$ xodes vicinus, Latreille, $1804 .-F$. V. T.] 
oval; anal shield small, about one-third the length of ventral shield. The adult female varies from $2.80-3.5 \mathrm{~mm}$. when not distended, but when gorged may reach Io $\mathrm{mm}$. long. The shield and legs are dark blackish-brown, body deep orange-red with four dark longitudinal lines, paler beneath and light grey in front. When distending it is pale red to grey or white; when fully gorged olive-green, or dark red to black with irregular yellow streaks on the back and sides just before egg laying. Sexual orifice opposite fourth pair of legs. The pupa varies from ' $\mathrm{r} \cdot 60-\mathrm{r}^{\prime} 70 \mathrm{~mm}$. long when fasting; the body is olive-white, opaque, with four distinct brown posterior markings and similar anterior ones, leaving a pale centre to the shield. When fully gorged it is $3 \mathrm{~mm}$. long. As the pupa distends it changes from opaque white to blue-black and finally black. The

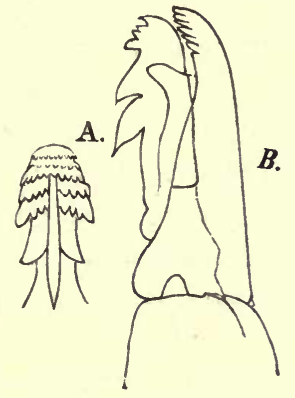

Fig. 236.-A, the rostrum of Ixodes vicinus (male); $\mathrm{B}$, the terminal joint of the maxillary palpi of the female (enlarged). (After Pagenstecher.)

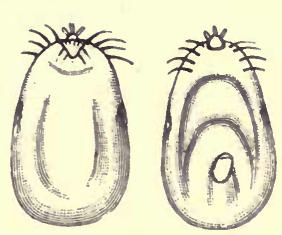

FIG. 237.-Female of Ixodes ricinus, gorged full, ventral and dorsal surfaces. 2/I. (After Pagenstecher.)

little larva is $0.80-I^{\circ} 5^{\circ} \mathrm{mm}$. long, transparent with olive-green intestinal markings ; as it becomes inflated it changes to blueblack and then black. They have no eyes. It is widely distributed and chiefly attacks sheep: sometimes it occurs on dogs and also attacks man. Mégnin records it from horses in the nymph stage. Amongst its other numerous hosts are goats, cattle, deer, hedgehogs, moles, bats, birds and lizards. It is usually known as the Grass Tick and Bottle-nosed Tick.

Synonyms.-Considerable confusion exists over the name of this and other common Ticks, owing to the same species having been described under a great many names. Observers have taken the same species on different animals and in various stages to be distinct and have described them accordingly.

The name Ixodes reduvius, Leach, does not stand, as Leach was 
describing quite a different parasite. The name Ixodes ricinus, Latreille, $\mathrm{I} 804$, is now substituted by Neumann and Wheler.

The synonyms given by Wheler are as follows: Reduvius, Charleton, I668; Ricinus caninus, Ray, I7Io; Acarus ricinoides, De Geer, I778 ; Acarus ricinus, Linnæus, I788; Cynorhastes reduvius, Hermann, I804; C. ricinus, Hermann, I804; Ixodes megathyreus, Leach, I8I5; Ixodes bipunctatus, Risso, I826; Cynorhastes hermanni, Risso, I826; Crotonus ricinus, Dumeril, I829; Ixodes trabeatus, Audouin, I832; T. plumbeus, Dugés, I834; I. reduvius, Hahn, I834; I. fuscus, Koch, I 835 (?); T. lacerte, Koch, I 835 (?); T. pustularum, Lucas, I866; I. fodiens, Murray, I877; I. rufus, I. sulcatus, and I. sciuri, Koch.-F. V. T.]

\section{Ixodes hexagonus, Leach (1815).}

Syn: : Ixodes sexpunctatus, Koch, I897; Ix. vulpis, Pagenstecher, I86I.

Lives in the same manner as the foregoing; has a predilection for attacking hunting dogs, but does not spare other mammals or even birds. The difference consists in the shape of the legs, the shorter rostrum, and the larger size of the male. It also occasionally attacks man, but is usually confused with the previously mentioned species. ${ }^{1}$

[The synonyms of this species are as follows:-Ixodes autumnalis, Leach, I8I5; Ixodes erinacei, Audouin, I832; Ixodes reduvius, Audouin, I832; Ixodes crenulatus, Koch; Ixodes erinaceus, Murray, I877; Ixodes ricinus, Mégnin, I880. Two other synonyms are given above by Braun.

The female when fully replete is II $\mathrm{mm}$. long, when fasting $3.86 \mathrm{~mm}$; the shield is heart-shaped and punctate, body finely hairy; palpi short and broad; labium shorter, and tarsi of all the legs more truncate than in Ixodes ricinus. The colour of the distended body - is drab and somewhat waxy; rostrum, shield and legs light testaceous. The male varies from $3.5-4^{\circ} \mathrm{o} \mathrm{mm}$. long, and is reddishbrown in colour with lighter legs; the shield is punctate and leaves a narrow margin around the body; the body is elliptical, almost as large in front as behind. There is a spine on the coxæ of the first pair of legs, which is shorter than in the male I. ricinus and longer than in the female. The genital orifice is opposite the interval between the second and third pair of legs. The fasting nymph is 
I.76 mm. long, light bluish-grey, margined and transparent, with four large posterior intestinal marks joined together behind the shield and smaller ones extending to the front and sides. When fully distended it is uniformly brownish-white; shield, legs and rostrum pale testaceous. The larva varies from $0.88 \mathrm{~mm}$, when fasting to $\mathrm{r}^{\prime} 76 \mathrm{~mm}$. when gorged. Its body is light, but gradually becomes darker, with similar intestinal marks to ricinus.

This tick is very common, especially on ferrets, stoats and hedgehogs. It is also found on sheep, cattle, \&c. The males do not generally occur in company with the females on the host. Pairing probably takes place on the ground. $-\mathrm{F}$. V. T.]

\section{Amblyomma cayennense, Koch, I844.}

Syn. : Amblyomma mixtum, Koch, I844 ; Ixodes herreva, Dugès, 1887 ; Amblyomma sculptum, Berlese, I 888 .

Characterised by the possession of eyes. The male measures $3.8 \mathrm{~mm}$ in length by $3 \mathrm{~mm}$. in breadth; the female $4 \mathrm{~mm}$. in length by $3 \mathrm{~mm}$. in breadth, but when full of blood may become $13 \mathrm{~mm}$. in length and II $\mathrm{mm}$. in breadth. They are common in the whole of Central America (Garrapatas), and attack mammals, amphibious animals and man. ${ }^{1}$

\section{Hyalomma agyptium (L.), I758.}

Syn.: Acarus agyptius, L., I758; Ixodes camelinus, Fischer, I823.

A species frequently found in Africa, particularly in Egypt and Algeria, and which also occurs in France and Italy, as well as in Asia. Male $8 \mathrm{~mm}$. in length, $4.5 \mathrm{~mm}$. in breadth. Female up to $24 \mathrm{~mm}$. in length and $\mathrm{I} 5 \mathrm{~mm}$. in breadth. It infests large and small animals as well as human beings. ${ }^{2}$

[This is one of the largest ticks, nearly reaching the size of the Bont tick. It is known in Africa as the Bont leg-tick; all farm stock is attacked, but sheep and goats suffer most. Only one generation appears to occur each year. The male is almost black with a pale marginal stripe; the replete female brown with irregular light blue stripes. It is abundant in parts of South Africa.-F. V. T.]

1 Neumann, G. L., cf. p. 205.

2 Neumann, G. L., cf. p. 285 ; Ronsisvalle, "Sui fenomeni morb. prodotti nel uomo da un Ixodide denominato Hyol. 'ag." (Boll. Acc. Gionia sc. nat., I891, xvii.). 


\section{Hamaphysalis punctata, Canestrini and Fanzago, $1877-8$.}

[Syn.: Hamaphysalis sulcata, Canastrini and Fanzago, I877-78; Rhicocephalus expositicius, Koch, I877; Hamaphysalis peregrinus, Cambridge, I 889 ; Herpetobia sulcata, Canestrini, I 890.

This species does not appear to be common. It occurs on sheep, goats, horses and cattle. I have seen a female taken from man in Britain. The female when fasting is $3.44 \mathrm{~mm}$. long, when gorged I $2 \mathrm{~mm}$. long. Colour, reddish-brown, leaden-grey when gorged; dorsal shield deeply indented in front; rostrum, shield and legs brownish: body finely punctate, both above and below; sexual opening opposite the coxæ of the second pair of legs in both sexes. Palpi a little longer than the labium; first segment short and narrow, second and third widened on the dorsal face. Coxæ with a short, broad blunt spine; tarsi short, terminated with a spur on the first pair. The male is $3^{\circ} 10 \mathrm{~mm}$. long. Body rather narrow, yellowish to reddish-brown; dorsal shield nearly covers the whole body; numerous punctures over the whole surface. Eleven indentations on the posterior margin of the body; peritremes lighter in colour, large and comma-shaped. The three anterior pairs of legs with a short spine on the haunches, the fourth with a very long one directed backwards. The nymph varies from $2.5-3.0 \mathrm{~mm}$., is oval, and light yellow to dark red in colour. Dorsal shield rounded with few punctations. No spur on tarsi, and sexual orifice nearly obsolete, Larva short and oval. Length $I \cdot 20 \mathrm{~mm}$.-F. V. T.]

\section{Dermacentor reticulatus (Fabricius), I794.}

Syn.: Acarus reticulatus, Fabr., I794; Ixodes reticulatus, Latreille, I806; Ix. marmoratus, Risso, I826.

This tick is provided with eyes, but it is distinguished from Ixodes and analogous genera by the lack of the abdominal plastron in the male, which measures $5-6 \mathrm{~mm}$ in length by $3.5 \mathrm{~mm}$. in breadth. The female may attain $16 \mathrm{~mm}$. in length and ro $\mathrm{mm}$. in breadth. It is found in the South of Europe, in Asia, and in America; it attacks chiefly oxen, sheep and goats, and occasionally man. ${ }^{1}$ EThis tick sometimes causes much annoyance to human beings. It has been most troublesome at Revelstoke. Specimens have recently been found on fowls in Kent.-F. V. T.]

'Neumann, G., "Rev. de la fam. des Ixodides" (Mém, soc. zool., France, I897, x., p. 360). 
Other synonyms are as follows:-Cynorhastes pictus, Hermann, I804; Çrotonus variegatus, Dumeril, I829; Ixodes pictus, Gervais, I844; Dermacentor albicollis, Koch, 1844-47 ; Dermacentor pardalinus, Koch, 1844-47 ; D. ferrugineus, Koch, I844-47 ; Ixodes holsatus, Kolenati, I857; Pseudixodesholsatus, Haller, I882 ; Hcemaphsalis marmorata, Berlese, I 887.

The female when fasting is $3.86 \mathrm{~mm}$. long by $2 \mathrm{~mm}$. wide. The body is depressed, larger behind and reddish-brown in colour. The shield is very large and extends to the level of the third pair of legs, with a few large and many small punctuations, milky white, variegated with reddish-brown. Sexual orifice opposite the coxæ of the second pair of legs. Coxæ of the front legs are deeply bifid, the others with a moderate spine. When gorged light brown, and may reach $\mathrm{r} 6 \mathrm{~mm}$. When depositing eggs the female is mottled with dark brown above and below. The male is like the female. The shield is reddish-brown, variegated with a milkywhite pattern. Coxæ of the fourth pair of legs three times the size of the third. There is a sharp backwardly-pointing spine on the second palpal segment, also seen (but smaller) in the female. Length $4.20 \mathrm{~mm}$.

[According to Mr. Wheler this is a very variable species both in size and colour. It occurs in England on sheep, but not commonly. It has probably been introduced into Britain. Besides the animals mentioned above it is also found on deer.-F.V.T.].

Rhipicephalus sanguineus (Latreille), I804.

Syn.: Ixodes sanguineus, Latr., I804; Ixodes vufus, Koch, I844; Rhipicephalus limbatus, Koch, I844; Rh. siculus, Koch, I844; Rh. stigmaticus, Gerstäcker, I873.

Spread over almost the entire tropical and sub-tropical regions, occurring in Europe in the South of France and in Italy; it infests dogs and more rarely sheep; oxen, cats, foxes and human beings are also attacked.'

\section{Argas reflexus (Fabricius), I794.}

Syn.: Acarus reflexus, Fabricius, I794; Acarus marginatus, Fabricius, 1794; Rhynchoprion columba, Hermann, I804.

The Argasinæ are distinguished from the Ixodinæ by the head, which in the former is situated on the inferior aspect of the cephalothorax, while in the Ixodinæ it projects freely; also by the very short proboscis, the 
small club-like palpi, the lack of suckers on the legs, as well as by the scutellum, which covers the entire back and is bent up round the borders. Two genera are distinguished: Argas, Latreille, I796 (Rhynchoprion, Hermann, I 804), and Ornithodoros, Koch, I844. The species live on mammals. but more especially on birds.

The European Marginated Tick, Argus reflexus (length of male $4 \mathrm{~mm}$., breadth $3 \mathrm{~mm}$., length of female $6-8 \mathrm{~mm}$., breadth $4 \mathrm{~mm}$.) is of a yellowish colour and has yellowish-white legs. The

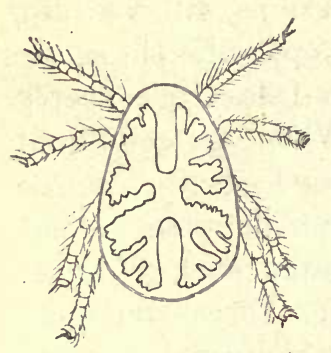

FIG. 238. - Argas reflexus from the dorsal surface, the intestine showing through the integuments. (After Pagenstecher.) ingested blood shows red or brown through the intestine, which is provided with blind sacs. It lives in dove-cots. It remains hidden during the day and at night crawls on to the sleeping pigeons to suck their blood. It has been observed in France, England, Italy, Germany, and Russia. Persons sleeping near infected dove-cots, or in apartments formed from pigeon lofts, are also attacked, even when the room in question has not been used for sheltering pigeons for years, as "marginated ticks" can live in a fasting condition for a very long time. The bite sometimes gives rise to serious symptoms, such as general erythema and sudden œdema. ${ }^{1}$

[This pest more often feeds on the blood of man than is imagined. Blanchard states that he has received them from men's clothes in Strasbourg. Boschulte, of Westphalia, records these parasites in a bedroom inhabited by children and connected with a pigeon house. The children were bitten during sleep on the hands and feet. The result of the bite was intense itching along the nerves, the bite only being marked by a red spot. In a girl of I4 or I5, vesicles were formed similar to those produced by burns, and in an old man an ulcer formed. Others record painful punctures and persistent œedema produced by this pigeon pest. It was once abundant in Canterbury Cathedral, and often

"Raspail, V., "Rech. d'hist. nat sur les insectes morbipares" (Gaz. des hôpitaux, 1839, i., p. 9); Boschulte, "Argas reflexus als Parasit des Menschen" (Virchow's Arch., 1860, xviii., p. 554; 1879, lxxv., p. 562); Gerstäcker, A., "Argas reflexus, ein neuer Parasit des Mensch." (ibid., 1860, xix., p. 457); Alt. K., " Die Taubenzecke als Parasit des Menschen" (Münch. med. Wochenschr., 1892, No. 30; and Centralbl. fur Bact., 1893, xiv., p. 468); Neumann, G., "Rév. de la fam. d. Ixodidés. I." (Mém. soc. zool., France, I 896, ix., p. 4) ; Gibert, J. M. " L'argas refl. et son paras. chez l'homme. Thèse de Bordeaux," I 896 (Centr. $f$. Bakt., Par. und Inf., xxiii., p. 5 I 5) ; Brandes, G., "Arg. refl. als gelegentl. Paras. d. Mensch" (Centr. f. Bakt., Par. und Inf., 1897, xxii., p. 747). 
caused much annoyance, I am told, to the worshippers; the ticks falling down from the roof, where they were living, derived from the numerous pigeons that breed in the towers. This acarus has enormous powers of vitality, living without food for months at a time.-F. V.T.]

Argas persicus, Fischer de Waldheim, I824.

Of oval form and brownish-red colour. The male measures $4-5$ $\mathrm{mm}$. in length by $3 \mathrm{~mm}$. in breadth; the female 7 - $10 \mathrm{~mm}$. in length by $5-6 \mathrm{~mm}$. in breadth. It frequents the entire north-west and northeast of Persia (the Gerib-gez or Malleh of the Persians, the Miana-bug of travellers). It lives concealed in houses and attacks man at night to suck his blood. Its bite is much dreaded, but the serious results may probably be attributed to unsuitable treatment of the wound or its invasion by bacteria. ${ }^{1}$

[This tick, sometimes called the Tampan a, Wandlius in South Africa, is mainly a fowl parasite. Fowls and ducks frequently die under its attack, particularly young ones; death being due to loss of blood. This tick remains attached to its host during its larval stage for about five days, it then leaves and moults in concealment. In its subsequent stages it visits its host by night and remains for about an hour only, during which time it distends itself fully with blood. As a nymph it moults twice, not once as do the cattle ticks. This tick

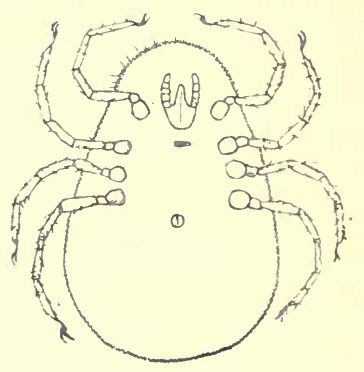

FIG. 239.-Argas persicus, ventral aspect. 7/I (After Mégnin.) and other Argas become larger with each moult, but retain their same general appearance. The female visits the host every now and then, and between deposits eggs in sheltered crevices. About 50 to 120 are deposited at once. Four weeks seem a necessary period to intervene between visits

'Oken, L., “Ueb. gift. Milben in Persien" (Isis, I8 18, p. 1567); Fischer de Waldheim, G., "Not. sur l'Acarus de Perse" (Mém. soc. natur. Moscou., I823, vi., No. 30), Ann. sc. nat., 1824, ii., p. 77 ; Heller, C., "Z. Anat. d. Arg. pers." (Stzgsb. d. K. k. Acad. d. Wiss. Wien; math-nat. Cl., I858, xxx., p. 297) ; Fritsch, G., "Ueb. d. gift, Wirkg. d. Arg. pers"'(Stzgsb. d. Ges. nat. Frde., Berlin, 1875, p. 6I) ; Laboulbène, A., et P. Mégnin, "Mém. sur les Argas de Perse" (Journ. de l'anat., 1882, xviii., p. 317) ; Mégnin, P., "Exp. sur l'action nocive des Argas de Perse" (C. R. soc. biol., Paris, I882. p. 305); Tholozan, J. D., "Des phénom. morb. prod. par la piqive . . . . Argas de Perse" (ibid., p. I 5); Neumann, G. L., I 896, p. 7. 
to the host and the interval may be extended to upwards of a year according to Lounsbury. ${ }^{1}$

This so-called Persian tick, the Miana, which is such a scourge to travellers in Persia, appears to infest the huts of natives in Persia. It has recently been sent me from Quetta, where it has invaded houses to such an extent, the natives cannot live in them. The virulence of its bite is probably due to the tick transmitting fever germs from natives, probably inured, to strangers, who would be susceptible.-F. V. T.]

Argas chinche, Gervais, I844.

This acarus, a native of the temperate parts of Columbia, is very troublesome to man. It is probably identical with Argas americanus, Packard, which infests domestic fowls and turkeys, and occasionally also cattle, ${ }^{2}$ and is differentiated from Argas reflexus by the sculpturing of the cuticle.

Ornithodorus sayignyi (Audouin), I827.

Syn.: Argas savignyi, Aud., I827; Ornithodorus morbillosus, Gerstäcker, 1873 , Argas monbata, Murray, I877; Argas schinzi, Berlese, I889.

Differentiated from Argas by its more rectangular body, the peculiar sculpturing of the cuticle, and by other characteristics into which we need not enter. Ornithodorus savignyi has eyes; it occasionally attains a length of I2 $\mathrm{mm}$., is very widely spread in Africa, and also occurs in Asia; its bite not only produces local symptoms, but affects the general health more or less, a fact that was already reported by Livingstone. ${ }^{3}$

[This tick is also known as the Tampan, and infests stock as well as man. It has a leathery skin, broadly oval in form and dull mud-coloured, and seldom reaches more than five-eighths of an inch in length. It occurs abundantly in the Transvaal, in Rhodesia, Bechuanaland, Cape Colony, German South-west Africa,

' Report of Government Entomologist for 1899, Cape of Good Hope, p. 33 (1900.)

${ }^{2}$ Gervais, P., Hist. nat. d. Insect aptères, I844, iii., p. 462 ; Packard, A. G., "Arachnida" (U. States geol. surv. of the territ.), I872, p. 740 ; Neumann, G., I896, p. 9.

${ }^{3}$ Audouin, Descr. de l'Egypte, 2nd edit., xxii., Zool., 1827, Explic. d. planch., n. 426; Gerstaecker, A., "Gliederth. Ostafrika's von C. v. d. Deckens Reise," r873, p. 464; Murray, "Econom. Entomol.," I877, i., p. 182; Neumann, G., 1896, p. 26. 
and Portuguese East Africa. It occasioned considerable annoyance to the troops during the South African war. It frequents for preference the shade of vegetation, but is found in exposed places, and also invades the native huts. All animals seem to be attacked, but it has a decided preference for man. This species also occurs abundantly in Uganda and bites natives severely, causing a fever from which they may die in a short time. I have recently received numbers alive from the Uganda Protectorate. This is the species connected with the recently discovered disease in manTick Fever.-F. V.T.]

\section{Ornithodorus turicata (Duges), 1876.}

Without eyes. Indigenous in Central America; attacks human beings and pigs. The bite is painful and is often followed by serious consequences. ${ }^{1}$

[So virulent is this species that pigs put in an infested sty often die in a night. This "turicatas" of Mexico often reaches $6 \mathrm{~mm}$. in length.-F. V. T.j

Ormithodorus talaje (Guérin-Méneville), I849.

Syn.: Avgas Talage, Guér.-Mén.

Likewise without eyes and a native of Central America. ${ }^{2}$

Ornithodorus tholozani (Laboulbène and Mégnin), I882.

Syn. : Argas tholozani, Lab. and Még., I882.

Without eyes. Males 4-6 $\mathrm{mm}$. in length and $2-4 \mathrm{~mm}$. in breadth; females 8 - ro $\mathrm{mm}$. in length and $4-5 \mathrm{~mm}$. in breadth. It especially attacks sheep. Native of Persia. ${ }^{3}$

[This species is reputed as being very dangerous to man. It is locally known as the kéné, or sheep-bug. In its fully gorged state it is deep violet.-F. V. T.]

1 Mégnin, P., "Les Argas du Mexique" (Journ. de l'anat. et de la phys., 1885, xxi., p. 463; Neumann, G., I896, p. 3I ; Dugès, A., "Piquire de Turicata", (C. R. soc, biol., Paris, 1885, ii., p. 2 I6).

" Guérin-Méneville, "Descr. de l'Arg. tal." (Rev. et mag. de zool., I849, p. 342; Mégnin, P., "Les arg. de Mex." (l.c., p. 460) ; Neumann, G., l.c., I 896, p. 34.

${ }^{3}$ Laboulbène, A., and P. Mégnin, "Mem. sur les Argas de Perse" (Journ. de l'an. et de la phys., 1882, xviii., p. 333); Neumann, G., l.c., 1896, p. 38. 


\section{Ornithodorus mégnini (Dugès), I883.}

Syn.: Argas mégnini, Dugès, 1883.

Length $8.5 \mathrm{~mm}$., breadth $5.5 \mathrm{~mm}$. Native of Mexico. ${ }^{1}$

[Another synonym for this species is Rhynchoprion spinosum, Marx. Wheler describes the nymph as follows: Length $3 \mathrm{~mm}$. to $4 \mathrm{~mm}$. fasting, to $9 \mathrm{~mm}$. when replete. Body brown, diamond shaped, with the rostrum exposed before repletion. Rostrum beneath the body and the latter squarer after distension. Palpi filiform. Legs far apart and coxæ almost entirely concealed beneath the skin. Surface of the anterior half of body covered with small brown spines, replaced by whitish hairs posteriorly, which are specially numerous in the hinder margin. The stigmata are placed above instead of behind the fourth pair of legs. These differ entirely from the stigmal plates and peritremes usually present, and consist of cone-like projections pointing backwards. The top is truncated and perforated by an orifice ; through this is a jointed organ, somewhat resembling the terminal joints of the palpi, which partially fills the orifice and is furnished with three hairs at the end. It can be projected and withdrawn with rapidity. This feature, according to Neumann, is absent in the male. The female is stated by Neumann to differ greatly from the nymph, which latter attains dimensions at least as large as the mature adult.

Two specimens in the nymphal state were taken from the ear of an American visitor to Cambridge by Dr. J. Christian Simpson. They were supposed to have entered the ear when the American was camping out in Arizona.

This species attacks the horse, ass and ox, generally around the ears, but it chiefly attacks man. It is well known in the United States as infesting the ears of children (New York Ent. Soc. Journ., pp. 49-52, I893).-F. V. T.]

\section{Fam. Tyroglyphida.}

Very small mites without eyes and without tracher," with smooth skin.

The males usually have a suctorial pore on either side of the anus, which is used during copulation, or suckers may be found in both sexes near the

1 Dugês, A., La Naturaleza, Mexico, 1883, v., p. 195; Mégnin, P., “ Les Argas de Mexique" (Journ. de l'an et de la phys., 1885, xxi., p. 460) ; Neumann, G., l.c., I896, p. 42 ; Guérin, in Bull. soc. chir., 1867, viii., p. 444 ; Simpson, J. Ch., "Case of Parasite (Arg. Megn.) in each ear" (Lancet, I901, No. I7, p. I 197).

${ }^{2}$ [Cheyletus has a distinct and peculiar tracheal system.-F. V. T.] 
sexual orifice: The mouth-parts form a cone with chelate cheliceræ, and three-jointed pedipalpi; the legs are usually short, have five segments with a terminal claw and suckers, or either one or other of these organs. The numerous species and genera live free and from choice in slowly decomposing vegetable and animal matter (cheese, cereals, flour, sugar, preserves, dried anatomical preparations, bacon, dried fruits and fungi), also in the corners of dwellings, \&c. ; they incidentally get into or on to man, or are found in chamber utensils and in spittoons; actual parasites are rarely found amongst them. ${ }^{1}$

[The chief genera are Tyroglyphus, Glyciphagus, Rhizoglyphus and Cheyletus. The first three have typical characters referred to, but are distinguished from each other by the two former having the hairs on the dorsum smooth, whilst in Glyciphagus they are hairy, plumose, or feathered. Rhizoglyphus can be told from Tyroglyphus by having claws on the tarsi without any suckers; Tyroglyphus has both claws and suckers. Cheyletus has enormous mandibles and a peculiar tracheal system; two ungues and appendages to the tarsi.-F. V. T.]

\section{Tyroglyphus farince (De Geer).}

The male measures $0.33 \mathrm{~mm}$. in length by o. $16 \mathrm{~mm}$. in breadth; the female $0.6 \mathrm{~mm}$. in length by 0.3 in breadth. These mites possess five pairs of suctorial organs of a light colour; the legs are reddish. Moniez observed them in Lille on the skin of labourers .who had been unloading Russian corn. ${ }^{2}$ A few of the species generally mentioned under the designation of Tyroglyphus siro are probably the common Flour-mite, which also occurs on dry cheese.

\section{Tyroglyphus siro (L.).}

Male $0.5 \mathrm{~mm}$. in length by $0.25 \mathrm{~mm}$. in breadth; female 0.53 $\mathrm{mm}$. in length by $0.28 \mathrm{~mm}$. in breadth; the males have two suckers on the tarsi of the fourth pair of legs. Penis straight. Colour whitish or reddish.

\section{Tyroglyphus longior, Gervais, I844.}

White or yellowish, with two black spots on the abdomen. Male $0.55 \mathrm{~mm}$. in length, $0^{\circ} 28 \mathrm{~mm}$. in breadth; penis bent. Female o $6 \mathrm{I} \mathrm{mm}$. in length and $0.28 \mathrm{~mm}$. in breadth.

Tyroglyphus siro and T. longior live on dry cheese, in flour, on

' Moniez, R., "Sur les Tyrogl. qui rivent aux depens d. mat. alim. ou d. prod. pharm." (Rev. biol. du Nord de la France, 1899, vi.).

${ }^{2}$ Moniez, R., "Parasit. accid. sur l'homme du Tyr. far." (C. R. Ac. sc., I889, Paris/ cviii., p. 1026). 
dried fruits, \&c., and have been occasionally observed in the stools, urine, or pus of human beings, and also on their skin. The so-called vanillismus is to be attributed to these species. ${ }^{1}$

[Tyroglyphus siro and $T$. farince are the same. They are described under other names, such as Acarus lactis, Linn.; Acarus favorum, Herm., \&c.; Acarus lactis in milk; farince in flour, and siro in cheese.

It is to this species that a case of dysentery was referred. Rolander, who studied under Linnæus, was attacked by what was called dysentery. The complaint soon gave way to treatment,

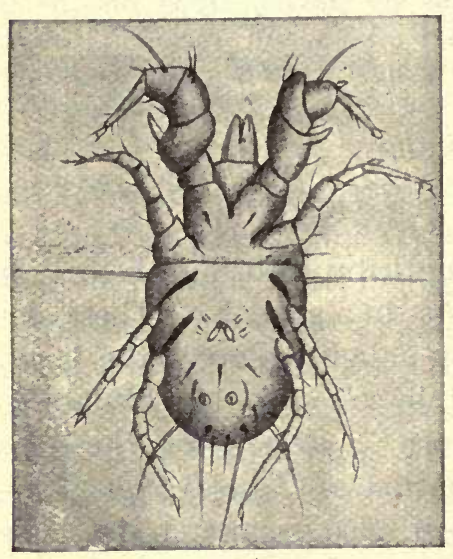

FIG. 240.-Tyroglyphus farine, male (enlarged). (After Berlese.)

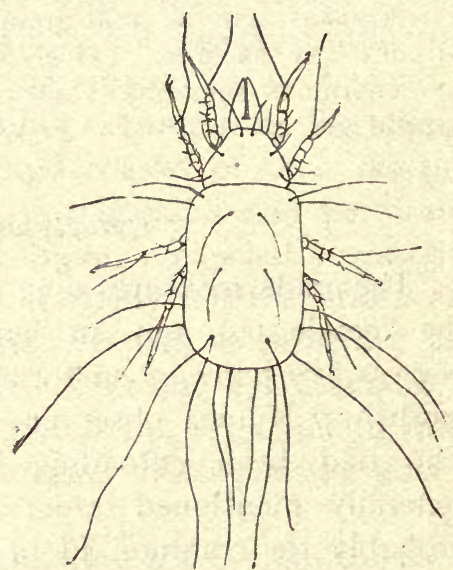

FIG, 24I. - Tyroglyphus longior, Gerv. (After Fum. and Robin.)

but eight days after it returned, soon disappeared, but again came a third time. All the time Rolander had been living like the other inmates of the house, who all escaped. Linnæus, aware that Bartholemy had attributed dysentery to insects which he said he had seen, advised his student to examine his stool. The result was that innumerable mites were found to be present. Their presence was easily accounted for by the fact that they were found in numbers in a cup made of juniper wood from which the student alone drank of a night, and they were found to be the same species. What this species is we do not know. Linnæus called it Acarus dysenteria. No records have occurred since. It cannot be, as Latreille supposed, the cheese-mite, for they have been eaten by millions since, and it is strange no such case has occurred. $-\mathrm{F}$. V. T.]

'Layet, A., "Etude sur le vanillisme" (Rev. d'hyg. et de policesanit., I883, v., p. 7 I I). 
Glyciphagus prunorum, Her., and Gl. domesticus (De Geer).

The Glyciphagi are differentiated from the Tyroglyphi in that the chitinous hairs on the body are toothed or feathered, and that they lack a furrow dividing the cephalothorax from the abdomen. They live under similar conditions to the Tyroglyphi and are occasionally found on man or in freces. ${ }^{1}$

[Sugar merchants and grocers are frequently troubled by swarms of these acari, which leave their stores when being handled, especially shopmen, who handle sugar kept in small stores for some time. These are the acari that cause that irritating temporary affection known as "grocer's itch."

\section{Glyciphagus cursor, Gervais.}

Under this name Signor Moriggia ${ }^{2}$ figures a horny excrescence of great length growing from a woman's hand, and containing in its cavities quantities of Acarus domesticus. It seems that this species is really $G$. cursor.

\section{Glyciphagus buski, Murray. ${ }^{3}$}

This is a mite found by Busk and named after him by Murray. It was taken from beneath the cuticle of the sole of the foot of a negro in the Seamen's Hospital Ship on the Thames in I84I, in large sores of a peculiar character confined to the soles of the feet. It appeared that the disease was caused by its burrowing beneath the thick cuticle. The disease was attributed to the wearing of a pair of shoes which had been lent to another negro whose feet had been similarly affected for nearly a year. The negro to whom the shoes were lent came from Sierra Leone. Mr. Busk stated that some water brought by Dr. Stranger from the river Sinoe, on the coast of Africa, contained one nearly perfect specimen, and fragments of others very similar if not identical with this Acarus. Mr. Busk adds that he had been informed by StaffAssistant Surgeon P. D. Murray that at Sierra Leone there is a native pustular disease called craw-craw-a species of itch breaking into open sores.

From Busk's original figure I see no reason to doubt that this is a Glyciphagus.-F. V. T.]

\footnotetext{
${ }^{1}$ Perrier, E., "Cas de paras. passager du Glyciph. dom." (C. R. Ac. sc., Paris, 1896, cxxii., p. 859).

${ }^{2}$ Atti. Acad. Sci., Torino I., p. 449, 1867.

"Cooper and Burk's Microscopic Journal, 1842, and "Economic Entomology," Murray, p. 280.
} 


\section{Rhizoglyphus parasiticus, Dalgetty, I9or.}

The Rhizoglyphii are to be recognised by their short legs, which are beset with spines, and by the tarsi, which terminate in a claw. They live on plants, roots and bulbs, especially the bulbs of lilies.

This species has been observed on the feet of Indian coolies working in the tea plantations; they produce a skin disease

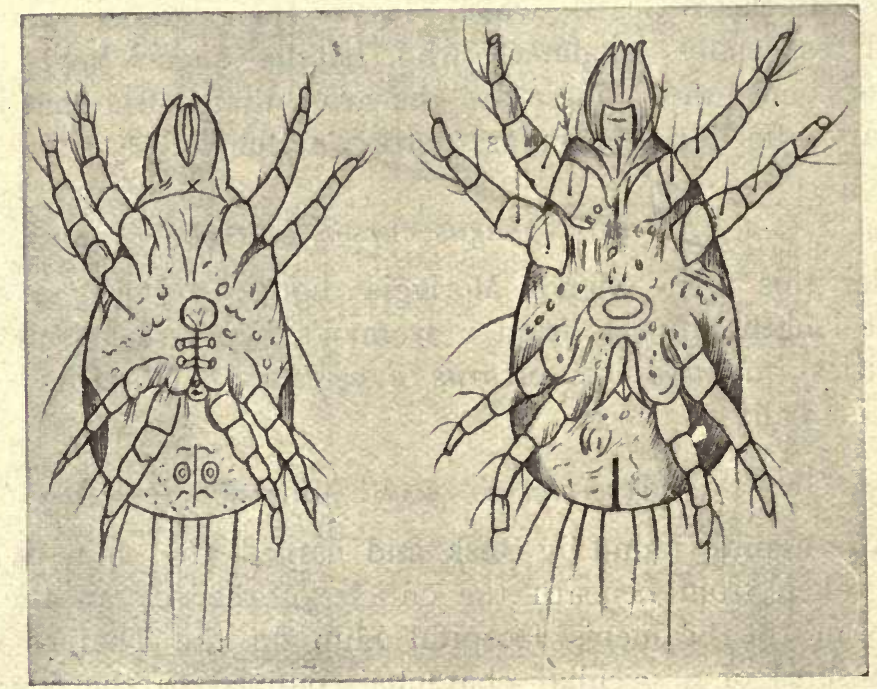

$a$,

z.

FIG. 242.-Rhizoglyphus parasiticus, enlarged ; $a$, male; $b$, female. After Dalgetty.

which always commences with blebs between the toes, and which almost always extends to the malleoli, but not beyond. The acari have an elliptical body, which is grey, but varies from greenish-yellow to greenish-brown when the stomach is full. Eves are absent. The legs are composed of five segnients and terminate with a claw. The males measure $0.18 \mathrm{~mm}$. in length by $0.08 \mathrm{~mm}$. in breadth, and possess genital and anal pores: the females measure $0.2 \mathrm{~mm}$. in length by $0.09 \mathrm{~mm}$. in breadth. ${ }^{1}$

\section{Histiogaster spermaticus, Trouessart, I900.}

The genus Histiogaster, which also approaches the Tyroglyphina, is characterised by the circumstance that the males possess suctorial pores used in copulation, as well as leaf-shaped appendages at the posterior end of the body. They feed on vegetables, especially on small fungi.

'Dalgetty, A. B., "Water-Itch; or, Sore Feet of Coolies" (Journ. Trop. Med., I90I, iv., p. 73). 
This species has been described by Trouessart, who found numerous specimens, some adult, others in the developmental stage (larvæ, nymphs), and ova, in the fluid removed by puncture from a cyst of the right testis. The males measure $0.25 \mathrm{~mm}$., the females $0.32 \mathrm{~mm}$., and the larvæ $0 . \mathrm{I} \mathrm{mm}$. in length. The author is of opinion that the animal-perhaps a fertilised female-was introduced by a catheter, and, as a matter of fact, it was afterwards found that the patient had had once the catheter passed in India while suffering from pernicious fever. ${ }^{1}$

\section{[Cheyletus mericourti, Lab. (Acaropsis mericourti, Moq. Tand.).}

This mite has been described from three specimens found in pus which flowed from an abscess in the ear of a naval officer, produced by inflammation of the auditory passage. Where the mites came from we do not know, as they were found near the Bank of Newfoundland.-F. V. T.]

\section{Fam. Sarcoptidce (Itch Mites).}

Small mites without eyes and tracheæ, and with delicate, transverselystriated cuticle. The mouth-parts form a cone, over which the shield-shaped upper lip protrudes; the cheliceræ are scissor-shaped; the pedipalpi (or maxillary palpi) have three joints; the legs are short and compact, and composed of five segments; the terminal joints have pedunculated suckers (ambulacra) or a long bristle. The larvæ are six-legged. They live on or under the skin of birds and mammals, on which they produce the skin disease known as scabies, or itch.

[The Sarcoptide attack the epidermis of animals and man, living as permanent parasites. The punctures they produce are followed by the formation of more or less thick crusts or scabs, beneath which the mites live and breed. Most are oviparous, some ovoviviparous. The eggs are minute, ovoid, with a thin semi-transparent shell. They incubate in a few days, varying from two to ten or eleven, as a rule. Generally sarcoptic diseases lie dormant in winter and revive in spring and summer in man; but in animals with long wool, such as sheep, they are most active during winter, although revival of active reproduction takes place in spring.

Speaking generally for the Sarcoptidæ, there are three distinct stages in the development of the male, four in the female, as follows:-

(I) The larva. In this stage only three pairs of legs occur.

(2) The nymph, in which a fourth pair of legs appear, and which thus

${ }^{1}$ Trouessart, E., "Faux parasit. d'une esp. de Sarcopt. détriticole dans un kyste du testicule chez l"homme" (C. R. soc. biol., Paris, 1900, lii., p. 742); "Deuxième note sur l'Hist. spermat. et sa prés. dans un kyste du testic. chez l'homme" (ibid., p. 893). 
approach the adult; but so far no sexual organs occur. Nymphs are of two sizes-the smaller being future males, the larger females.

(3) The next stage in the female is the age of puberty; the female now being provided with a vulvo-anal slit; this so-called pubescent female is fertilised by the male. The male then dies. But the female again casts her skin and enters another stage, the

(4) Ovigerous female - the egg-laying female-which has differently modified legs.

The rate at which these acari breed is very great. Gerlach has found that, roughly, in each Sarcopt gallery a female produces fifteen individualsten females and five males-and that the progeny reproduce again in fifteen days. The table given below thus shows that one pair may produce the enormous number of $1,500,000$ descendants in three months:-

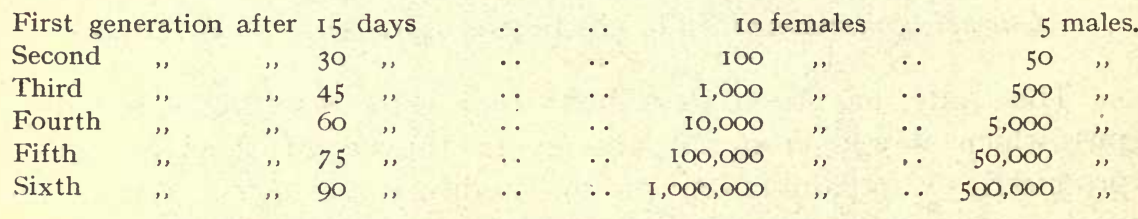

$=1,500,000$ individuals.

These Acarinæ are divided into three distinct genera :-

(I) Sarcoptes, Latreille.

(2) Psoroptes, Gerv. ; Dermatodectes, Gerlach; Dermatocoptes, Fürstenberg.

(3) Symbiotes, Gerlach ; Chorioptes, Gerv. ; Dermatophagus, Fürst. ; Sarcodermatodectes, Del.

The following are the main characters of these three genera:-

Sarcoptes-round or slightly oval; the two posterior pairs of legs being nearly or quite concealed beneath the body; the tarsi end in simple long pedicles, with ambulatory suckers.

Psoroptes-oval; the legs are all visible outside the margin of the body; the ambulatory suckers are carried on long triangulated stalks; the male has copulatory suckers and abdominal prolongations.

Symbiotes-oval ; legs long, thick, all visible; ambulatory suckers very wide, carried at the end of simple, short pedicles.

Sarcoptes make channels or furrows beneath the epidermis, and in these the female lays her eggs. This form of acariasis is thus difficult to cure. It is the cause of human itch (vide Sarcoptes scabiei):

Psoroptes do not make sub-epidermic galleries; they live and breed in colonies beneath crusts or scabs formed by the changes they produce in their host's skin. Sheep scab is a common type of disease produced by Psoroptes. This genus is of little importance as a parasite to man.

Symbiotes live as Psoroptes; they also do not affect man.-F. V. T.]

\section{Sarcoptes scabiei (L.), I748.}

Syn. : Acarus scabiei, I., I748; A. psoricus, Pallas, 1760; A. siro, L., 1761; Sarc. exulcerans, Nitsch, I818; S. hominis, Raspail, 1834; S. galei, Owen, I853; S. communis, Delaf. et Bourg., 1862.

The body is oval or nearly circular and whitish in colour, 
covered by transverse rows of folds partly interrupted on the back. There are transverse rows of small bristles on the dorsal surface, and groups of trichomæ on the front, sides and back. There are chitinous hairs at the base of the legs; the two first pairs (of legs) are provided with pedunculated ambulacra in both sexes, the two posterior pairs terminate each with a long bristle in the female; in the male the third pair of legs terminate in a bristle, the fourth pair with a pedunculated ambulacrum. The anus is situated at the posterior border of the dorsal surface.

Formerly numerous kinds were differentiated, according to the form of the acarus, the number, position and size of the prickles and spines, even according to the hosts, \&c. All these characteristics, however, fluctuate so considerably that absolute differentiation is impossible; the conjectural species might almost be regarded in the same light as Mégnin did, as varieties. It is also hardly possible to distinguish the mite of human scabies (Sarcoptes hominis) from that of a number of domestic animals (S. squamiferus). The simplest plan, therefore, is to accept one single species - Sarcoptes scabiei-which may give rise to different races or varieties by living in the skin of man and a few mammals, but can pass from one host to the other.

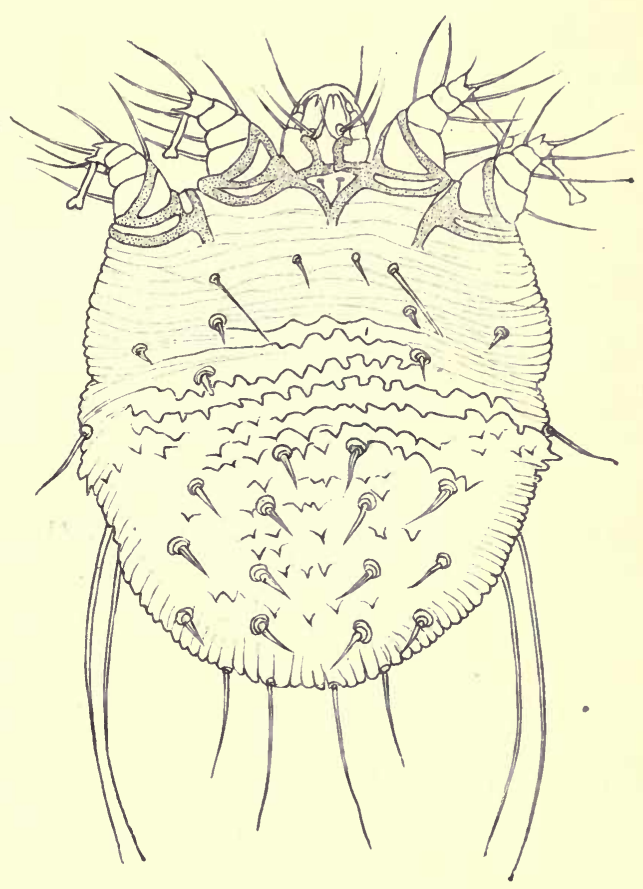

FIG. 243. - Sarcoptes scabiei, female, dorsal aspect. 200 I. (After Fürstenberg.)

The Sarcoptes scabiei of man (Sarc. scabiei, var. hominis) (length of male $0^{\circ} 2-0^{\circ} 3 \mathrm{~mm}$. and breadth $0^{\circ} .45-0^{\circ} .190 \mathrm{~mm}$.; length of female $0.33-\left(0^{\circ} 45 \mathrm{~mm}\right.$. and breadth $0^{\circ} 25-0.35 \mathrm{~mm}$.) lives in the tunnels that it excavates in the epidernis, and attacks by preference places with thin skin, such as between the fingers, in the bend of the elbows and knees, in the inguinal region, on the penis, on the manımæ, but may also affect other parts. The tunnels, from a few millimetres to a centimetre and more long, do not run straight, but are somewhat tortuous; the female is found at the terminal end. The tunnels contain the excrements and oval eggs (O. I4 mm. 
in length) of the parasite ; the males are rarely met with as they die off after copulation, the females die after depositing their eggs. The six-legged larvæ hatch out after four to eight days, and after about a fortnight, during which time they change their skins three times and undergo metamorphosis, they begin to burrow themselves. Transmission from person to person rarely is effected through linen, but by direct contact (as in coitus); transmission can be artificially effected on horses, dogs, and monkeys, but not on cats.

The smaller Sarcoptes scabiei crustosa, Fürstenberg, is the cause

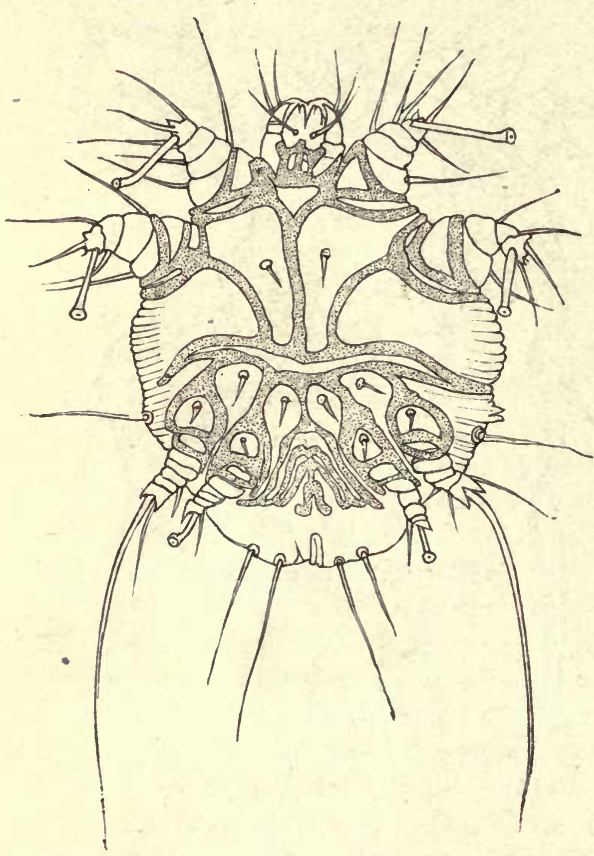

Fig. 244.-Sarcoptes scabiei, male, ventral aspect. 200 1: (After Fürstenberg.) of the scabby itch that occurs chiefly in Norway; it is not yet certain whether this is a distinct species of itch-mite. The following forms may be transmitted from DOMESTIC ANIMALS to MAN :-

(I) Sarcoptes scabiei, var. equi. Male, $0.2-0.23 \mathrm{~mm}$. long; 0.16 O. I7 mm. broad. Female, $0.40-$ $0.42 \mathrm{~mm}$. long, $0.28-0.32 \mathrm{~mm}$. broad. The horse is the normal host.

(2) Sarcoptes scabiei, var. ovis. Male, $0.22 \mathrm{~mm}$. long; 0.16 mm. broad. Females, $0.32-0.44 \mathrm{~mm}$. long; $0.24-0.36 \mathrm{~mm}$. broad. This mite lives on sheep, and passes over to goats and human beings: it may also be artificially transferred to horses, oxen, and dogs.

(3) Sarcoptes scabiei, var. capre. Male, $0.24 \mathrm{~mm}$. long, O.188 $\mathrm{mm}$. broad. Female, $0.345 \mathrm{~mm}$. long, $0.342 \mathrm{~mm}$. broad. On goats, passing from them to horse, ox, sheep, pig and man. In the latter, in contradistinction to the varieties I and 2, it produces a severe affection.

(4) Sarcoptes scabiei, var. cameli. Frequently observed in man, chiefly in Africa. A few cases have been observed in Europe; the affection induced by it is severe.

(5) Sarcoptes scabiei, var. auchenice. Male, $0.245 \mathrm{~mm}$. long, O.I82 mm. broad. Female, $0.34 \mathrm{~mm}$. long, $0.264 \mathrm{~mm}$. broad. It lives on the Llama, and may be transmitted to man.

(6) Sarcoptes scabiei, var. suis. Male, $0.25-0.35 \mathrm{~mm}$. long, 0.19-0.3 
mm. broad. Female, $0_{4} 4-\mathrm{O}_{5} \mathrm{~mm}$. long, $\mathrm{O}_{3}-\mathrm{O}_{39} \mathrm{~mm}$. broad. In the domestic pig and wild boar; occasionally also in man. The settlement, however, is usually of short duration.

(7) Sarcoptes scabiei, var. canis. Male, O I9-O.23 mm. long, O.I4O.17 mm. broad. Female, O.29-O.38 mm. long, $0.23-0.28 \mathrm{~mm}$. broad. In the house-dog, and also, not unusually, in human beings.

(8 and 9) Sarcoptes scabiei, var. vulpis, and Sarcoptes scabiei, var. leonis, of the fox and lion; have likewise been observed on man.

Sarcoptes minor, Fürstenberg, I86r.

Anus situated on the back, legs short, pedunculated ambulacra broad; living on cats (S. minor, var. cati) and rabbits (S. minor, var. cuniculi). In cats this mite usually lives in the cervical

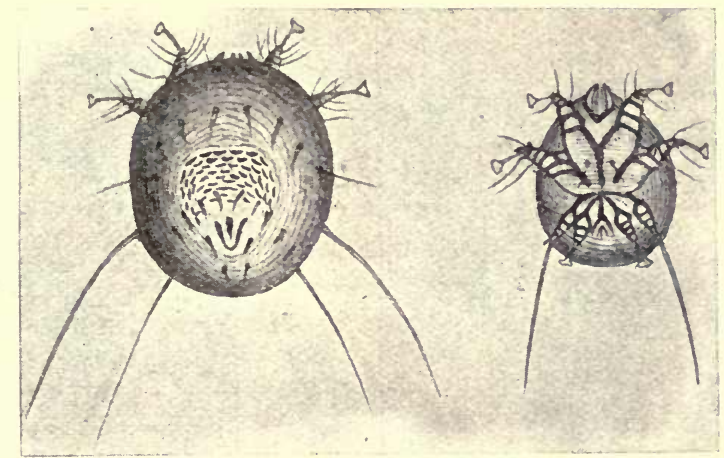

Fig. 245.-Sarcoptes minor, var. cati.-On the left, female (lying on its abdomen); on the right, male (lying on its back). (After Railliet.)

region, and thence spreads to the ears and head; it usually causes the death of the infected animals; it is easily transferable from cat to cat, is difficult to transmit to rabbits, but once settled on them can easily infect other rabbits. On the other hand, the transmission of the itch-mite of the rabbit to the cat does not succeed. In man Sarcoptes minor induces an eruption that disappears after about a fortnight.

The itch mites of domestic animals, which belong to the genera Psoroptes $(=$ Dermatodectes $=$ Dermatocoptes $)$ and Chorioptes $($ Symbiotes $=$ Dermatophagus), as a rule do not infest and live on man, even when artificially transmitted. It is, however, possible for this to occur. Thus Moniez (Traite de paras., 1896, p. 559) mentions that a species of Chorioptesprobably $\mathrm{Ch}$. bovis-had been found on man, as had also Demodex folliculorum. This author also includes Dermatophagoides scheremetereskyi, Bogdanoff (Bull. soc. imp. d. natural., Moscow, 1864, xxxvii., p. 34I), which has 
repeatedly been found on man in Moscow and Leipzig (Zürn. Ber. d. med. Ges., Leipzig, I877, p. 38), as Chorioptes bovis. ${ }^{1}$

Nephrophages sanguinarius, Miyake and Scriba, 1893.

Males measure $0.1 \mathrm{I} 7 \mathrm{~mm}$. in length and 0.079 in breadth; females up to $0.360 \mathrm{~mm}$. in length by $0.120 \mathrm{~mm}$. in breadth. The head is provided with two very large scissor-like jaws and two large round eyes. The legs are composed of five segments and are all of equal length; the three anterior pairs of legs have pedunculated ambulacra, the posterior ones terminate in a claw. The

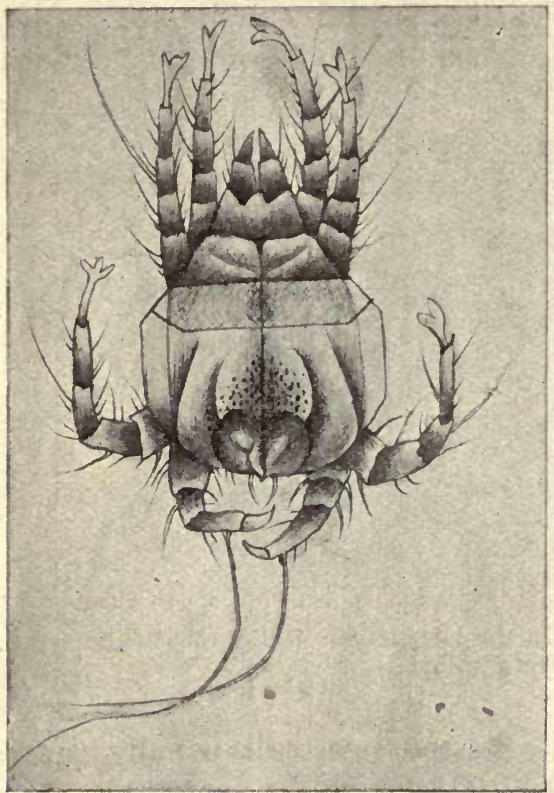

FIG. 246.-Nephrophages sanguinarius, enlarged. Male, ventral surface. (After Miyake and Scriba.)

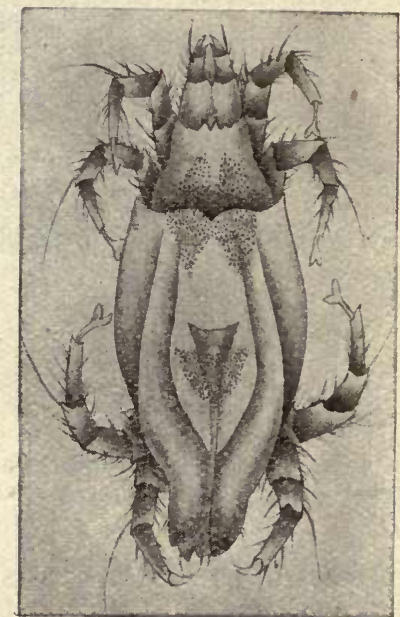

FIG. 247.- Nephrophages sanguinarius, female, dorsal aspect, enlarged. (After Miyake and Scriba.)

The most important literature respecting the Sarcoptida: Hertwig, C., "Ueber Krätz und Räudemilben" (Arch. f. Naturgesch., I835, i., p. 398); Gurlt and Hertwig., Vergl. Unters. üb. d. Haut d. Menschen u. üb. d. Kratz milben., Berlin, I 844 ; Fürstenberg, M. H. F., Die Krätzmilben des Menschen u. d. Thieve., Lpzg., I86I ; Bourguignon, H., "Rech. s. la contag. de la gale des animaux à l'homme" (Mém. soc. biol., Paris, I85I, iii., p. I09, Ann. d. sc. nat., I 855, iii., p. I I4); Mégnin, P., "Mém. sur l'acclim. des acariens psoriques des animaux sur d'autres esp. anim. et sur l'homme" (La France médicale, I876, xxiii., p. I66); Mégnin, P., "Sur certains détails anat. que présentent l'espèce Sarc. scab. et ses nombreuses var." (C. R. Ac. sc., Paris, I 875, lxxxi., p. IO58); Bergh, R., "Ueber Borkenkrätze" (Virchow's Arch., I860, xix., p. I, and Vierteljahrssch. f. Dermat. u. Syphilis, 1874, vi., p. 491); Mégnin, P., "Les acariens parasites, Paris" (Encycl. scientif. d. aide-mémoires) ; Weydemann, "Sarc. vulpis b. Mensch." (C. f. B. u. P., I 897, xxii., p. 442); Canestrini, G., and P. Kramer, "Demodicida u. Sarcoptide" (Das Thierreich., vol. vii., Berlin, I899); Alexander, A., "Uebertrag. d. Thierkrätze auf Mensch." (Arch. f. Dermatol. u. Syph., I900, lii., p. I 85). 
cuticle on the back is thickened in three places, shield-like; the abdominal surface without scutellum is longitudinally striped, and is beset with chitinous hairs. Colour greenish to brownish-yellow. Eggs 0.046-0.040 $\mathrm{mm}$.

The authors discovered these mites, but always dead, in the urine of a Japanese suffering from fibrinuria (complicated with chyluria and hæmaturia). They surmised that they were endoparasites, probably situated in the kidney; but this view is not convincing, though they also report that for a week, day after day, the mites were found in the patient's urine, as well as in urine drawn off by means of a catheter, and in the water used to wash out the bladder (one or two specimens and an egg). The statement that these mites have large eyes makes the discovery suspicious, to say the least. The significance of the discovery is not supported by the further statement that Disse is supposed to have found an encapsuled mite closely related to the Tyroglyphides on the wall of the vena cava.'

In the case of Marpmann, who found a dead Acarid in the urine of a man suffering from chronic nephritis, and in whom later examinations proved negative, the author himself was of opinion that the mite had reached the urine from outside. ${ }^{2}$

We are certainly acquainted with mites living endoparasitically, namely, the Cysticolæ Analgesinæ, of which Laminosioptes gallindrum live in the intra-muscular and subcutaneous connective tissue of fowls, and Cytoleichus sarcoptoides in their air-sacs. Another kind of mite (Halarachne halichoeri) is occasionally found in the nasal mucous membrane of the seal (Halichrerus grypus), and, quite recently, Pneumonyssus simicola, which is more nearly related to Halarachne, has been found in the lung of Cynocephalus sp. It is, therefore, not beyond the bounds of probability that endoparasitic mites are found in man; but no discovery has hitherto been made that is sufficiently convincing to banish all doubts. ${ }^{3}$

\section{Fam. Demodicida (Mites of the hair follicles).}

Small acarina, elongated in worm-like fashion, with annulated abdomen, and without eyes or tracheæ. The mouth parts consist of a suctorial proboscis and three jointed palpi; the legs are short, and have three segments with

'Miyake, H., and J. Scriba, "Vorl. Mitth. üb. ein. neuen Paras. d. Mensch." (Berl. klin. Wchsch., I893, No. 16, p. 374), "Nephroph. sang., ein neuer menschl. Par $i$. Urogenitalapp" (Mitth. a. d. med. Facult. d. K. jap. Univ., iii., p. 1).

"Marpmann, "Ueb. d. Vork. v. Milben i. Harn." (Centr. f. Bakt., Paras., u. Intekt., I 898 , xxv., p. 304).

${ }^{3}$ Mégnin, P., "Mém. sur les Ac. par. du tissu cellul. et des bours. aérienn. chez les oiseaux" (Journ. de l'an. et de la phys., 1879); Allman, G., "Descr. of a New Gen. of Trach., Arach." (Ann. and Mag. of Nat. Hist., I 847 , xx., p. 47.); Kramer, I'.. "Ueb. Halarach. halich." (Zeitsch. f. d. ges. Naturw., Halle, 1885 , lviii., p. 46) ; Grijns, G., and J. De Haan, "Acar. als endop." (Geneesk. Tijdsch. v. Nederl. Indic., 19or, part 41, i., p. I76); Banks, N., "A New Genus of Endop., Acar." (ibid., p. 334); Haan, J. de, and G. Grijns, "Eine neuc endop. Acaride" (C. t. B., P. u.iI. [1], 1901, xxx., p. 7); 
small terminal ungues. The anus is situated on the anterior border of the abdomen; oviparous; the larvæ have six stumpy legs. These mites live in the hair follicles of mammals.

\section{Demodex folliculorum (Simon), 1842.}

Syn: Acarus folliculorum, Sim, 1843; Dem. folliculorum, Owen, 1843 ; Macrogaster platypus, Miescher, 1843; Simonea folliculorum, P. Gervais, I 844 ; Steatozoon foll., Wilson, 1847.

As in Sarcoptes scabiei, numerous varieties of this species are

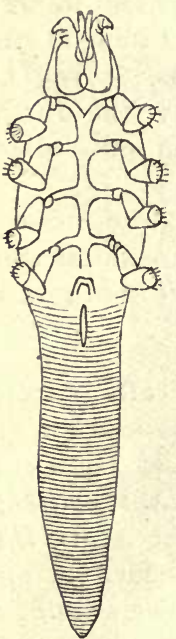

Fig. 248.-Demodex folliculorum of the dog. (After Mégnin.) known; the form parasitic on man lives in the hair follicles, the meibomian and sebaceous glands, and hardly ever causes inconvenience; the male measures $0.3 \mathrm{~mm}$. in length, and the female about $0.4 \mathrm{~mm}$. in length. The eggs $0.06-0.08$ in length, $0.04-0.05$ in breadth, and are thin-shelled. The creatures are always attached with the head-end downwards in the parts mentioned; they are most frequent in the sebaceous glands of the face, by the nose, lips and forehead, but they may be present on the abdomen and on other parts of the body. They may occasionally obstruct the excretory gland ducts, thus causing inflammation of the gland (comedones); their agglomeration in the meibomian glands sets up inflammation of the margins of the eyelids. There are generally only a few specimens in a gland. According to some statements Demodex occurs in 5o per cent. of mankind and even in children; they survive the death of their hosts by several days.

The variety living in the dog (Dem. folliculorum, var. canis) is smaller than the variety living in man, and produces a skin disease resembling scabies in these animals. According to Zürn they may also live on man ; nevertheless, no other investigator has recorded a similar observation, and attempts at artificial infection have proved negative. ${ }^{1}$

Simon, G., "Sur les acares vivant dans les follicules pileux de l'homme" (Arch. de médec. comp., 1843, i., p. 45); Leydig, F., "Ueb. Haarsackmilben u. Krätzmilben" (Arch. f. Naturg., 1859, xxv., p. 338); Landois, L., "Ueb. d. Haarbalgparas. d. Menschen" (Greifswald. med. Beitr., I863, i., p. I7); Stieda, L., "Ueb. d. Vork. d. Haarbalgparas. an den Augenlidern" (Centralbl. f. prakt. Augenhlkde., I89o, July, p. 193); Thudichum, J. S. W., "On the Dem. foll. as the Par. Caus. of the Mange of Dog and its Transfer upon Man":(Med. Press and Circ., 1894, p. 103); Majochi, D., "Int. al Dem. foll. nelle ghiand. meib.," Bologna, I 897 (C. f. B., P. u. I., xxv., p. 784); Ivers, K., "Demod. s. Ac. foll. u. seine Bez. z. Lidrandentzdg." (D. med. Wochschr., I899, p. 220) ; Raehlmann, E., "Ueb. Blepharitis acarica" (Kl. Monatsb. f. Augenhlkde., r 899, xxxvii., p. 33 , ref. in C. f. B., P. u. I., xxvi., p. 40).

${ }^{1}$ [This mite causes what we know in England as Red Mange in dogs.-F. V. T.] 


\section{Order Linguatulide (Tongue Worms).}

Arachnoidea greatly altered in consequence of their parasitic manner of life ; for a long time they were regarded as Helminthes. The body is elongated, vermiform, flattened or cylindrical, and more or less distinctly annulated. The head, thorax, and abdomen are not defined from each other (fig. 249). The elliptical mouth, surrounded by a chitinous ring, is situated at the anterior end, on the ventral surface, and the intestine leading straight through the body opens at the posterior end. Two hooks, retractile into grooves, are set at both sides of the mouth (fig. 250); these are usually considered to be the terminal joints of two pairs of legs, but it appears to be more correct to regard them as the remains of the antennæ and palpi (Stiles). According to this opinion, the legs in the adult state would be completely degenerated.

The nervous system is reduced to an œsophageal ring. No organs of sense are recognisable except the papillæ at the anterior end. There are neither organs of circulation nor respiration. ${ }^{1}$

The sexes are distinct. In the small male the sexual orifice is situated ventrally in the anterior part of the body; in the female it is placer near the anus. The Linguatulida lay eggs, and from each egg, after being conveyed into an intermediate host, a four-legged larva, with rudimentary mouth parts, hatches out. It goes through a series of metamorphoses, and passes through a second larval condition, which, however, possesses the essential characteristics of the fully developed form. Sooner or later it migrates during this stage, and reaches its final host, mammal or reptile, in the nostrils or lungs of which the adult Linguatulida live.

\section{Linguatula rhinaria (Pilger), I802.}

Syn.: Tania rhinaria, Pilger, 1802; Polystoma tanioides, Rud., I810 ;

Linguatula tanioides, Lam., I816.-Pentastoma tanioides, Rud., I819.'

The male is white in colour, $18-20 \mathrm{~mm}$. in length, anterior portion $3-4 \mathrm{~mm}$. in breadth, posterior part $0.5 \mathrm{~mm}$. in breadth. The female is of a yellowish colour, 8 , I0, or $13 \mathrm{~cm}$. long, anterior part 8 - $\mathrm{Io} \mathrm{mm}$. and posterior part $2 \mathrm{~mm}$. wide. The brownish eggs can be seen in the median line. The body is elongated. rather flat, and exhibits about ninety rings or segments and crenellated borders. The hooks round the mouth are strongly curved and are articulated to a basilar support. Eggs oval, 0.09 in length, 0.07 in breadth.

Linguatula rhinaria, in the adult condition, lives in the nasal cavity and frontal sinus of the dog, wolf, fox, horse, goat, and occasionally of man; it causes severe catarrh, epistaxis and suppuration.

1 What are designated as stigmata in the Linguatulides are the orifices of sebaceous glands. 
Development. - The ova which are found in masses in the nasal mucus already possess an embryo; they are expelled with the nasal secretion, and are swallowed by herbivorous mammals with their food, mostly by hares and rabbits, but also by sheep, goats, oxen, horses, antelopes, fallow deer, pigs, cats, and occasionally also by human beings. The young larvæ hatch out in the stomach; they possess a thickened anterior body with rudimentary mouth parts and two pairs of limbs; the

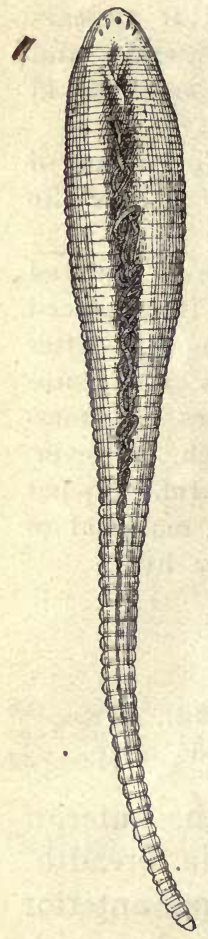

FIG. 249.-Linguatula rhinaria, female, natural size. body gradually tapers to a short tail.

The larvæ of the Linguatulida bore through the intestinal wall and reach the liver, more rarely the mesenteric glands, \&c.; they

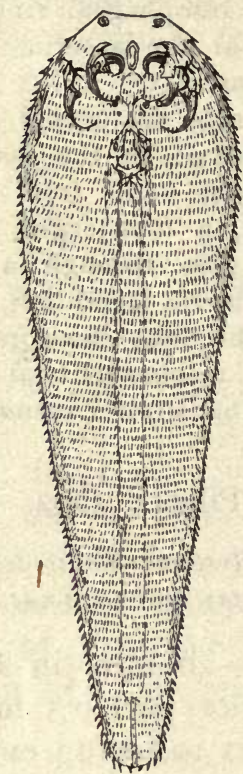

FIG. 250.- Larva of Linguatula rhinaria (Pentastoma denticulatum.) (After Leuckart). Enlarged. here become encysted and enter a sort of pupal stage in which they lose their limbs; after several moultings ånd gradual growth the second larval stage, having the appearance of the adult Linguatula, sets in. About five to six montlis after infection the creatures have become $4-6$ $\mathrm{mm}$. long, possess eighty to ninety rings, which have a series of fine points on their-posterior border; the mouth and intestine are formed, the sexual organs mature and the two pairs of hooks are near the mouth. This larval stage (fig. 250) has been known for a long time, but it was regarded as an independent species of animal, and therefore had a separate name (Linguatula serrata, Fr., Pentastoma denticulatum, Rud., \&c.).

The further course of these Linguatula-larvæ is only peculiar in so far as they make efforts to leave their hosts, and this can only take place by active movements; they abandon the cysts that harbour them, and according to their situation in the abdominal or pleural cavity, they reach either the bronchi or the intestine, and thence finally reach the open; here they are sniffed up by dogs, \&c., and settle themselves in the nasal cavities. But these 
migrations are not essential for further development; it is probable that some of the larvie reach the nasal cavity direct by way of the trachea, thus infecting herbivorous animals direct. In other cases the infection of dogs, wolves, foxes, beasts of prey, takes place through their devouring mammals or parts of them (liver, lungs) which harbour the larval form; it may be conjectured that at all events most of the larvæ are thus first imported into the stomach of their hosts, and thence, having bored through the intestinal wall and diaphragm, invade the lungs, and by way of the bronchi, trachea, \&c., finally find their way to the nasal cavities; possibly also some larvæ find their way to the nasal cavities from the mouth while the food is being masticated. After becoming stationary another moulting takes place, the cuticle with the pointed edges is discarded, and the parasites become adult after six or seven weeks.

Linguatula rhinaria has been observed in man in the adult as well as in the larval condition (Pentastoma denticulatum). Zenker first called attention to the occurrence of the larva in man, having found it nine times in the liver in 168 autopsies. Heschl found it twice in Vienna in 20 autopsies, Virchow found it in Würzburg and Berlin, Wagner in Leipzig (Io per cent.), and Frerichs in Breslau five times in 47 autopsies. The parasite is much less frequent in Switzerland. According to Klebs, one case occurs in 900 autopsies, and according to Zaeslin two cases occurred in Basle to I,9I4 autopsies. In the seamen's hospital in Kronstadt Pentastoma denticulatum has been found six times in 659 autopsies. It was almost always the liver that contained one or a few specimens. The parasite was very rarely found in the kidney or spleen, or encysted in the intestinal wall. The adult Linguatula rhinaria is far more rarely observed in man.

A case reported by Landon that related to a blacksmith of Elbing is particularly interesting. This man accompanied the campaign of I870; he soon, however, fell ill with pains in the liver, accompanied by icterus and intestinal disorders. Soon after the war, and after the symptoms were reduced to icterus and weakness, bleeding of the nose set in and continued with slight intermissions for seven years; an unpleasant sensation of pressure in the left nasal cavity set in with inflammatory swelling of the mucous membrane. At last, in the summer of 1878 , when the pressure in the nose had considerably increased, a Linguatula was expelled from the nose with a violent attack of sneezing, and lived for three days longer in water. The bleeding of the nose then ceased, and the patient soon recovered. There can be no doubt that the first illness was connected with the invasion in the liver of numerous larvæ of Pentastoma; and disappeared after their encystment; one or a few of these must subsequently have found their way to the nose and settled there.'

${ }^{\prime}$ Schubart, T. D., "Entw. v. Pent. tanioides" (Z. f. w. Z., 1852, iv., p. I 16).Zenker, F. A., "Ueher einen neuen thier. Paras. d. Mensch." (Zeitschr. f. rat. Med. 


\section{Porocephalus constrictus (v. Siebold), 1852.}

\section{Syn.: Nematoideum hominis, Diesing, I 85 I ; Pentastomum constrictum, v. Sieb., I852; Porocephalus constrictus, Stiles, 1893.}

Porocephalus is distinguished from Linguatula by its cylindrical body and by certain internal structures. Porocephalus constrictus is as yet only known in its larval stage. It is milk-white in colour with golden-yellow hooklets. Number of rings, twenty-three. Length $13 \mathrm{~mm}$., breadth $2 \cdot 2 \mathrm{~mm}$. There are no prickles on the posterior border of the annulations of the body.

This species was first discovered by Pruner encysted in the livers of two negroes in Cairo. Bilharz reported two further cases in which the parasites were encysted in the liver and in the mucosa of the intestine; a few other observations have been made by Fenger, Aitken, Giard and Chalmas. Aitken's report deals with soldiers of the British Colonies in Africa. The parasites were discovered in the liver as well as in the lung, and appear to have been the cause of death in one case (pneumonia, peritonitis).

Pruner has found the same parasite also in the liver of the giraffe.

\section{B. Myriapoda.}

\section{See Text of Braun, p. 3 I4 (footnote 2).}

\section{Insecta (Hexapoda).}

Three separate divisions can always be distinguished in the body of insects, namely, the head, thorax and abdomen. The HEAD is a roundish unsegmented capsule and possesses four pairs of appendages. The first pair

I854, v., p. 212); “Id. Pent. dent. in der Niere" (Arch. f. phy. Hlkde., 1856, xv., p. 581); "Id. Pent. i. d. Milz" (Arch.f. Hlkde., I862, iii., p. 478).-Virchow, R., "Helminthol. Notizen I." (Arch. f. p. An., I857, xi., p. 81).-Leuckart, R., "Bau u. Entwickelungsgesch. d. Pentast., Lpzg., 1860.-Colin, In Bull. soc. méd. vét., r861, v., p. I 25 ; I 863 , vii., p. $22 ;$ I 864 , viii., p. I08.-Welch, F. H., "The presence of an encysted Echinorhynchus in Man" (The Lancet, 1872, ii., p. 703).-Landon, "Ein casuistischer Beitr. z. Etiol. d. Nasenblut." (Berl. kl. Wchschr., 1878, xv., p. 730).-Lohrmann, E.,

"Unters. ub d. anat. Bau d. Pentast." (Arch. \%. Naturg., 1889, lv., i., p. 303).-Stiles, C. W., "Bau u. Entw. v. Pent. proboscideum u. P. subcylindricum" (Z. †. w. Z., I891, lii., p. 85.)-Rátz, St. "v. V. d. activ. Wanderung d. Pent. denticulatum " (C. f. B. u. P.. I 892, xii., p. 329).-Shipley, A. E., " An Attempt to Revise the Family Linguatulida," (Arch. de parasit., 1898, i., p. 52).-Kulagin, N., " Z. Naturgesch. d. Pent. denticul." (C. f. B., P. u. I., 1898, xxiv., pp. 489 and 525 ).

${ }^{1}$ Pruner, Krankheiten des Orients, Erlange, I847, p. 249.-Bilharz, "Ein Beitrag zur Helminthogr. humana" (Z. f. w. Z., 1852, iv., p. 65).-Bilharz, "Uebers. ub. d. $i$. Agypten beob. Eingeweidewirmer" (Z. d. Ges. d. Erzte, Wien., I858, i., p. 447).Aitken, W., "On the Occurrence of Pent. const. in the Human Body as a cause of painful Disease and Death " (Science and pract. of Medicine, 4th edit., London, I 865).Giard, A., "Pent. constr., par du foie des nègres" (C. R. soc. biol., Paris, I896, iii., p. 460; Ref., C. f. B., P. u. I., xxiii., p. I098).-Chalmers, A., "Case of Pent. constr." (The Lancet, I899, June 24); Ref., C. f. B., P. u. I., xxvi., p. 5 18.-Neumann, G., "Sur les Poroceph. du chien et de quelq. mammit." (Arch. de Paras., i 899, ii., p. 356). 
are the various shaped feelers (antennæ) which are placed on the superior surface of the head next to the eyes; then more ventrally placed a pair of upper jaws (mandibles) without palpi and without articulations; they are powerful masticatory organs. ${ }^{1}$ The first pair of lower jaws (maxillæ) are jointed and bear a palpus (palpus maxillaris); the second pair of maxillæ are soldered together and form the lower lip (labium), and likewise carry a palpus labialis on each side. The upper lip (labrum) as well as a few other pieces, which, however, are only appendages, belong to the mouth, which is really formed of a number of closely-united pieces. The mouth parts undergo manifold metamorphoses according to the functions required of them. Coleoptera, Neuroptera and Orthoptera have biting or masticatory mouth parts which conform with the scheme described above. In the licking mouth parts of the hymenoptera the maxillæ and under lip are considerably elongated, while the mandibles retain their form and are used for triturating the food: in the Lepidoptera nearly all the mouth parts are shortened except the maxillæ, which form a long and sometimes spirally rolled suctorial proboscis; the Diptera and Rhynchota have piercing and sucking mouth parts. The mandibles and maxillæ are metamorphosed into a needle-like organ, while the suctorial apparatus is formed by the labrum (compare p. 97).

The thorax consists of three segments which are frequently completely united; ventrally it carries three pairs of legs, which consist of a definite number of articulated pieces joined one to the other. Their form also changes according to their function, so that legs for running, walking, digging, swimming, jumping, and preying are seen. A pair of wings are respectively joined to the last and last but one thoracic rings, and these may be traced back, not to metamorphosed appendages, but to tracheal branchia. They are composed of chitinous membranes supported by branched structures (veins or ribs). Their size and formation vary; they are seldom of equal size and form (Neuroptera); often the posterior wings are larger than the anterior wings, the former then only serving as protective coverings for the latter (Coleoptera), or the anterior wings are larger (Lepidoptera), or the posterior wings are shortened, or are entirely absent (diptera); and finally there are insects in which both pairs of wings are lacking. ${ }^{2}$

The abdomen retains its segmentation, but, with the exception of a few groups related to the primitive forms of insects, has no appendages in the imago condition; the abdomen usually consists of ten segments, on the last of which the anus is situated.

We need only observe the following points in considering the anatomy of insects.

The EPIDERMIS consists of the chitinous cuticle, which is separate from the cellular layer beneath (hypodermis); the various appendages are supported by the chitinous layer.

1 [The mandibles are only powerful masticatory organs in biting-mouthed insects (Mandibulata); in the sucking or piercing-mouthed insects they may be absent or in the form of needle-like styles (Haustellata).-F. V. T.]

2 [As in the order Aptera, which includes the Thysanura and Collembola, and also exceptions in other orders, as the fleas amongst Diptera; the Mutillas and ants amongst Hymenoptera.-F. V. T.] 
The INTESTINAL CANAL usually consists of the anterior, median and terminal intestine, and as a rule passes straight through the body; a number of salivary glands discharge into the anterior part, and, in some cases, yield a stiffening secretion which serves for spinning webs; numerous or scanty hepatic tubes are appended to the median intestine, while on the border between the median and terminal intestine open four to six long tubes (vasa malpighiana), which act as urinary organs. Finally the end portion of the intestine carries various glands (anal and rectal glands, \&c.)

The CENTRAL NERvous SYSTEM agrees in structure with that of the annelids, but is more highly developed. The pharyngeal ring surrounds the front part of the intestine; the sensory nerves originate from its SUPERIOR PHARYNGEAL GANGLIA and are the seat of the higher psychical functions; the INFERIOR PHARYNGEAL GANGLIA govern the mouth parts, and in addition appear to regulate the movements (cerebellum of the vertebrates).

The chain of GANGLiA lying on the ventral side of the abdomen consists primitively of pairs of ganglia corresponding to the twelve segments, which are connected by longitudinal and transverse commissures. But many changes in the ganglia may be seen in insects caused by partial or entire amalgamation of single ganglia, so that in a few cases only one abdominal ganglion is present. In conclusion, a definite INTESTINAL NERvous SYSTEM is always present.

Of the organs of sense the FACETTED EYES, situated at the sides of the head, deserve special mention, as do also the ORGANS OF TOUCH and SMELL, situated on the antennæ, and the ORGANS OF HEARING and taste, or finer sensations, situated at the mouth and in the buccal cavity.

The sounds emitted by insects are as a rule produced by the friction or beating of certain chitinous parts, but sounds are also produced in breathing (flies).

The ORGANS OF RESPIRATION, the so-called tracheæ, are highly developed; there are openings (stigmata) at the sides of the body which draw in air by means of the active participation of the muscles of the body. The number of stigmata varies between two and ten pairs; the trachea themselves branch off from the trunks in the most varied manner, and carry air to the internal organs.

The colourless BLOOD circulates between the tissues and organs, and is kept circulating by the contraction of a chambered dorsal vessel provided with ostia, and which terminates in a short aorta opening at the anterior end.

Insects are SEXUALLY DISTINCT; their sexual glands are in pairs and have a tubular structure, but the testicular tubules are united together by a capsule into an oval testicle; exceptionally, also, the excretory canals are double, as also the sexual orifices; usually the paired canals unite into a single oviduct or spermatic duct which terminates at the posterior end of the body after receiving the products of various glands.

As to the HISTORY OF THE DEVELOPMENT of insects, all that is necessary to mention here is that the young hatched from eggs only exceptionally (as in apterygota) resemble the addult parent (insecta ametabola); as a rule they differ from them not only in the shape of the body, but also more or less by their manner of life, and only attain the form of the parent through 
METAMORPHosis. This is a gradual process (insecta hemimetabola) in the Rhynchota and Orthoptera, or a sudden one with a stage of inanition (insecta metabola) in the other orders. This stage of rest or inanition, the PUPA, concludes the larval life (caterpillar, maggot, \&c.); during the pupal stage no nourishment at all is taken, but the internal organs undergo changes; in some forms the rest is not absolute, as voluntary local movements may take place (pupæ of gnats).

The insects are divided into numerous orders according to the form of the mouth parts, the structure of the wings, as well as the manner of the development; with the exception of the lowest group (Apterygota), which is most nearly related to the ancestors of the insects, and which has no wings and undergoes no metamorphosis, all the remaining orders, which are termed Pterygota, have wings on the thorax, though there are, of course, a few species and families of this order which have secondarily lost their wings.

The Pterygota include :-

(1) Orthoptera.-Biting mouth parts, anterior wings leathery, posterior wings thin, folded longitudinally; metamorphosis incomplete (Grasshoppers, Crickets, Cockroaches).

(2) Pseudoneuroptera.-Biting mouth parts, wings of equal size, thin, not folded up (Dragon-flies, Hair and Feather Lice, Termites).

(3) Rhynchota or Hemiptera.-Mouth parts formed for puncturing and sucking; wings alike, or the anterior wings may be thickened, parchment-like (Plant-lice, Cicadæ, Bugs anc! True Lice).

(4) Neuroptera.-Biting mouth parts; wings alike, thin ; metamorphosis complete (Ant-Lions, Lace-Wing-Flies, \&c.).

(5) Trichoptera.-Iicking mouth parts; anterior wings narrow, posterior wings longitudinally folded, both ornamented with little hairs: the larvæ are worm-like in form, live in water, and breathe through tracheal gills (May-flies, \&c.).

(6) Lepidoptera.-Suctorial mouth parts; wings covered with scales (Butterflies).

(7) Coleoptera.-Biting mouth parts: anterior wings thickened; they differ in colour, appearance and function from the thin. folded posterior wings (Beetles).

(8) Hymenoptera.-Mouth parts for licking or biting: the wings alike, membranous (Ichneumon flies, Ants, Wasps, Bres, Humble Bees).

(9) Diptera.-Mouth parts formed for puncturing, sucking or licking; posterior wings degenerated (Gnats, Flies, Gadflies, Fleas.)

(10) Strepsiptera-Anterior wings shortened: the femals without wings and living parasitically (Fan-wings).

The parasites of man occur amongst the Rhynchota, Coleoptera, and amongst the Diptera.

[The most usual and recent classification of the Hexapoda is the following :-

(I) Aptera.-Wingless insects; scarcely any metamorphosis.

(2) Neuroptera.-Four membranous wings, frequently with much network; the front pair not much, if at all, harder than the under pair; the latter with but little or no fan-like action in closing; mandibulate; metamorphosis variable, but rarely complete. 
(3) Orthoptera.-Four wings; front pair coriaceous or leather-like, usually smaller than the other pair, which are of more delicate texture and contract in repose like a fan; mandibulate; metamorphosis complete.

(4) Thysanoptera.-Four very narrow fringed wings; mouth imperfectly suctorial; metamorphosis slight.

(5) Hemiptera.-Four wings; the front pair either all transparent or with the basal half leathery; mouth suctorial; metamorphosis slight.

(6) Diptera.-Two membranous wings only; mouth suctorial, very varied; metamorphosis complete.

(7) Lepidopteva.-Four large wings covered with scales; mouth suctorial; metamorphosis great.

(8) Hymenoptera.-Four membranous wings ; front pair larger than hind, which do not fold up in repose; mandibulate mouth, sometimes with a tubular proboscis; metamorphosis complete.

(9) Coleoptera.-Four wings, the front pair hard and horny (elytra), meeting in a line over the back and covering the delicate hind pair; mouth mandibulate; metamorphosis complete.

There are two other well known arrangements, namely, Packards ${ }^{1}$ and Brauers, ${ }^{2}$ of recent date, but the one given here, which is based on Linnæus' grouping by Dr. Sharp, is by far the simplest.-F. V.T.]

\section{Rhyncota. ${ }^{3}$}

The lower lip forms a long thin tube that can be turned back (rostrum), and within which the setaceous mandibles and maxillæ are situated; the first thoracic segment is not united with the two posterior ones; the anterior wings are usually leathery as far as the centre.

(a) Rhynchota aptera s. parasitica.

Fam. Pediculide (Lice).

The lower lip is transformed into a projecting rostrum provided with barbed hooklets in which the hollow extensile sucker (maxillæ and mandibles) is situated; no wings; no metamorphosis; only simple eyes; the antennæ are five-jointed, the feet possess hook-like terminal joints; the barrel shaped eggs (nits) are deposited on the hair of the host.

1 American Naturalist, xx., p. 808, 1886.

2 “Syst. Zool. Studien," S. B. Ak. Wien., xci., 1885, Abth. i., p. 374.

${ }^{3}$ [Usually known as Hemiptera. There are two sub-orders, Heteroptera and Homoptera. The former have the base of the front wings coriaceous; the latter have all four wings membranous. The Homoptera are Aphides or Plant Lice and Scale Insects (Coccida), none of which attack man.-F. V. T.] 
I. Pediculus capitis, De Geer, 1778 .

Male $\mathrm{I}-\mathrm{I} .5 \mathrm{~mm}$. in length, female $\mathrm{I}^{\circ} 8-2^{\circ} \mathrm{O} \mathrm{mm}$. in length. The colour varies from light grey to black according to the colour of the hair of the human race upon which they are parasitic. The abdomen has eight segments, of which the six central ones are each provided with a pair of stigmata. The thorax is as broad as the abdomen. Eggs $0.6 \mathrm{~mm}$. in length; about fifty are deposited by a female Head Louse. The young can propagate when eighteen days old.

The head louse lives especially in the hairy parts of the head of human beings; more rarely it is found $\mathrm{cn}$ other hairy parts of the body. It is spread over the entire surface of the globe, and was present in America before the arrival of Europeans. Quite exceptionally it is said that it bores itself deep into the epidermis and can live in ulcers.

Fig. 251.-Mouth parts of Pediculus vestimenti. After Denny (enlarged).

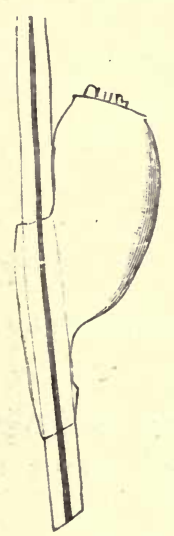

Fig. 252.-Ovum of the head louse, $70 / 1$.

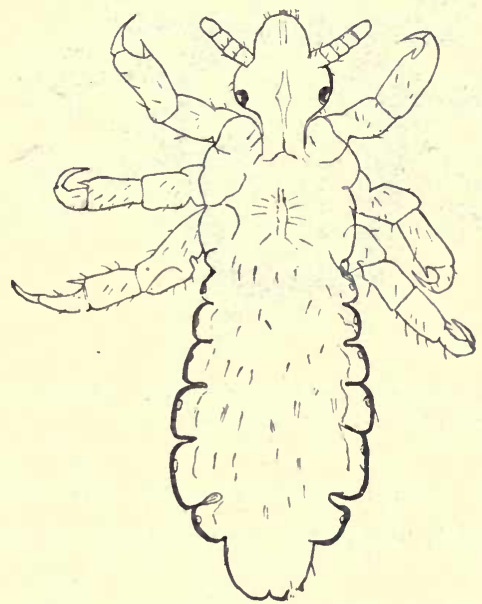

FIG. 253.-Head louse, male, 15/1.

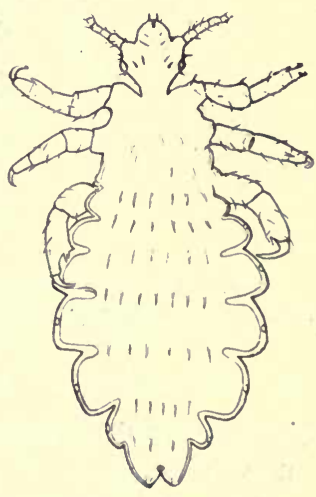

FIG. 254.-Pediculus vestimenti, Burm. I5/1. Adult female.

that of its host. In West Africans nearly black, in Hindoos dark and smoky, on Chinese and Japanese yellow, on Hottentots orange, on South American Indians dark brown (Murray).-F. V. T.] 


\section{Pediculus vestimenti, Nitzsch, $18 \mathrm{I} 8$.}

The head in front is somewhat rounded. Antennæ longer than in the head louse; $2-3.5-4 \mathrm{~mm}$. in length; whitish-grey; the abdomen is broader than the thorax; stigmata as in $P$. capitis. Eggs $0.7-0.9 \mathrm{~mm}$. in length; about seventy are deposited.

Pediculus vestimenti lives on the neck, throat and trunk of persons, and the clothing next the body, in which also the eggs are deposited. The louse of so-called pedicular disease (Pediculus tabescentium) is, according to Landois' researches, only the usual Pediculus vestimenti; moreover, many cases of phthiriasis are attributable to mites or fly maggots.

[This parasite has often been a great pest amongst soldiers during long campaigns, especially amongst the Russians during the Crimean War.F. V. T.]

3. Phthirius inguinalis, Redi, 1668.

Syn.: Pediculis pubis, L.

Male $0.8-\mathrm{I} \cdot 0 \mathrm{~mm}$. in length; female $\mathrm{I} . \mathrm{I} 2 \mathrm{~mm}$. in length; colour greyish-white; form sub-quadrate; the two posterior pairs of legs are strong; the abdomen has nine segments and six pairs of stigmata; and still another pair of stigmata is situated between

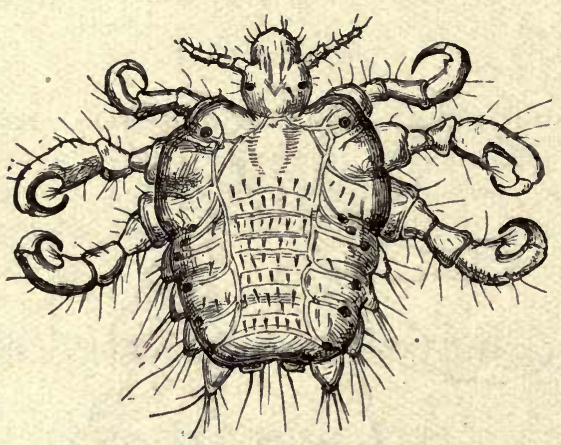

Fig. 255.-Phthirius inguinalis, Leach (enlarged). They are distinguished by the larger tracheal trunks originating from the stigmata.

the two anterior limbs. Eggs pear-shaped, $0.8-0.9 \mathrm{~mm}$. in length, $0.4-0.5 \mathrm{~mm}$. in breadth, and are deposited in rows of about ten on the hairs.

Pediculus pubis, which is found almost exclusively in the Caucasian race, lives on hairy parts of the body, but hardly ever on the skin of the head; the pubic region is its favourite place of abode.'

${ }^{1}$ Literature of the Pediculida. Landois, L., "Unters. üb. d. a. d. Mensch. schmarotzend. Pediculinen" (Z. $f$. w. Z., I864, xiv.-xv., p. I; 1865, pp. 32 and 494).-Graber, V., "An.-phys. Stud. über Phthirius inguinalis" (ibid., I872, xxii., p. I 57).-Giebel, C. G., "Insecta epizoa, Lpzg., 1874.- -Piaget, E., Les pédiculines. Leide, 1880; Suppl Letde, 1885.-Artauld de Vevey, St., "Deux cas de pediculose accid. et intermitt. chez l'homme" (C. R. soc. biol., Paris, 1895, No. 29, p. 684). 
[This species reproduces more rapidly than other lice, and is communicated much more freely. The eggs are often laid singly attached to the hairs near their apex.-F. V. T.]

\section{(b) Rhynchota hemiptera.}

\section{Fam. Acanthiada.}

Body flattened, antennæ four-jointed, rostrum three-jointed, wings atrophied. [In hot countries some bugs acquire wings.-F. V. T.]

\section{Cimex lectularius, Merrett, I667.}

1 Syn. : Acanthia lectularia, Fabricius, I794.

It measures $4-5 \mathrm{~mm}$. in length, $3 \mathrm{~mm}$. in breadth; brownish-red ; eight abdominal segments. The female deposits fifty whitish eggs at a time (I.I2 mm. in length) three or four times a year; the entire development up to complete maturity takes about eleven months.

The bed bugs live in the cracks and fissures of human habitations, under carpets, behind pictures, in furniture, bedsteads, \&c.; hidden during the day. they attack persons at night to suck their blood. The alkaline

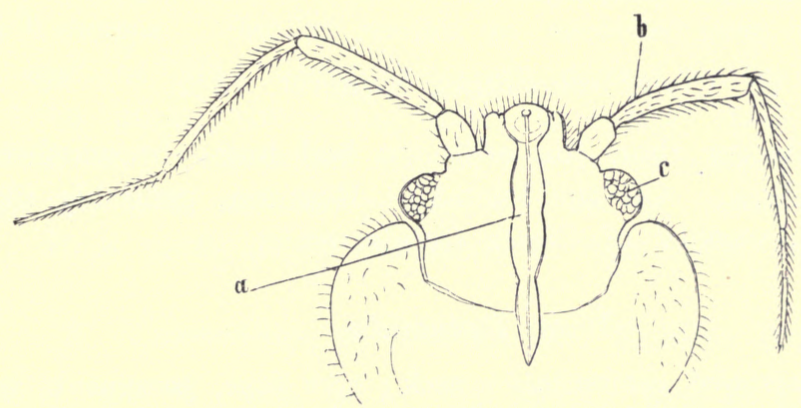

FIG. 256.- - Head of the bed bug from the ventral surface: $a$, the rostrum; $b$ the antenna; and $c$, the eyes. $70 \mathrm{I}$.

secretion of the salivary glands dropped into the wound around the separate bites causes the so-called "wheals."

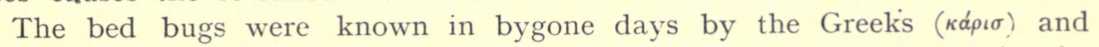
the Romans (cimex). They were firct mentioned from Strasbourg in the Eleventh Century, and England about I500.

[The bed bug, can migrate from one house to another; this especially takes place when a house is uninhabited. They escape from windows and pass along walls, water pipes and gutters, and so reach adjoining houses. This noxious pest accompanies man wherever he goes; ships and trains become infested, especially the former. 
A characteristic feature in this animal is the peculiar odour it produces, like many others in the same group of insects. This odour comes from a clear, oily, volatile liquid secreted by glands in various parts of the body. Although the normal food is man's blood, the bed bug can subsist upon moist wood, dust and dirt that collects in crevices in floors, walls, furniture, \&c. The puncturing mouth consists of a fleshy under lip, within which lie four thread-like hard filaments which pierce the flesh, the blood being drawn up through the beak.

The eggs are oval, white, with a projecting rim around one end ; they are laid in cracks and crevices in batches of from twelve to fifty. The egg stage lasts from seven to ten days. The larval stage so gradually passes into the adult that one scarcely notices the change; during its growth the skin is cast five times, and at the change the little, wingpads are seen, showing that the adult stage is reached. The young larvæ are at first pale yellowish-white. Although eleven weeks is said to be necessary for their development, the stages may be gone through much more rapidly; Howard and Marlatt ${ }^{2}$ give seven weeks in some instances. It seems pretty certain that these Cimex only take one meal of blood between each moult and another preceding egg laying.-F. V. T.]

\section{Cimex ciliatus, Eversmann, I84I.}

$3.3 \mathrm{~mm}$. in length, yellowish-red, thickly covered with hair; indigenous in Russia (Kasan).

\section{Cimex rotundatus, Signoret, $\mathbf{I} 852$.}

Somewhat larger than the ordinary bed bug; brownish-red in colour, legs yellow. On the Island of Reunion, probably like the former, only a variety of Cimex lectularius. ${ }^{2}$

\section{Fam. Reduviida.}

Head long, narrowed behind into a neck; eyes large, prominent; rostrum thick and curved; antennæ moderately long, slender at the tip; legs long and stiff ; carnivorous.

\section{[7. Conorhinus sanguisuga, Lec. (the Blood-sucking Cone-nose).}

This bug is also known as the Texas or Mexican Bed Bug, also as the .Big Bed Bug. It is particularly troublesome in the Mississippi Valley in bedrooms. The bite is very severe and

1"Household Insects." Howard and Marlatt, Bull. No. 4 (N.S.) U.S. Dept. A griculture, p. $37, \mathrm{I} 896$.

"Landois, L., "Anat. v. Cimex lectularius" (Z. f. w. Z., I 868, xviii., p. 206; I 869, xix., p. 206).-Eversmann, E., "Qucedam insectorum species nova" (Bull. soc. Imp. d. natur. Moscou, 184I, xiv., p. 351).-Signoret, V., "Notice sur quelq. hëmipt. nouv." (Ann. soc. entomol., France, I852, x., p. 539). 
results in more pronounced swelling and inflammation than that of the Cimex. Normally this genus feeds upon the blood of mammals and insects. Its fondness for human blood appears to be quite a new habit, and appears limited to the mature insect only. It is nearly an inch long, flat, head very narrow and long, the rostrum short and thick. In colour it is dark brown with pink markings. They are fully winged when adult, and they fly with ease, entering houses on the wing, especially being attracted by lights in windows; they also run swiftly. Like the bed bug they conceal themselves during the day and come out at night and bite the sleeper. The effect of the bite is very varied, but as a rule a sore, itching wound, accompanied by burning pain and swellings, which may extend over a good deal of the body, occur. A specific poison is undoubtedly injected into the puncture; but no doubt serious results are also due to the beak being contaminated through the insects feeding upon foul carrion. Mr. Lembert, when bitten by a Conorhinus sp. (?) on the Pacific Slope, exhibited the following symptoms: An itching sensation extending up the leg, large blotches manifesting themselves on the upper part of the limb and extending up to the hands and arms; his lips swelled and the itching and swelling extended over the head; there was also much nausea. Similar results are recorded from other regions. ${ }^{1}$

The eggs of the $C$. sanguisuga are at first white, then become yellow, then pink; the young hatch in twenty days. There are two larval and two pupal stages, the latter showing wing-pads. The eggs are laid and the young feed out of doors, chiefly upon insects. It is particularly abundant in April and May indoors.

\section{Conorhinus, sp. novum (the Monster Bug).}

Another species; acts in a very similar way in California, the bite being very poisonous.

\section{Conorhinus rubrofasciatus, De Geer ${ }^{2}$ (the Malay Bug).}

This large "bug attacks man in Malay. It is recorded as inflicting "a very nasty sting, which is done by the huge proboscis." Acute pain and inflammation follow in a few minutes. In one case the whole leg became swollen. This species occurs in Madagascar, Sierra Leone, Ceylon, India, China, Philippines, \&c.

I “Household Insects," p. 42.

2 First Report Economic Zoology, p. I 30, 1903.-F. V. T. 
Io. Conorhinus renggeri, Herr-Schäff (the Great Black Bug of Pampas).

This large black bug is mentioned by Darwin, ${ }^{1}$ who states as follows: "At night I experienced an attack (for it deserves no less a name) of the Benchuca, a species of Reduvius, the Great Black Bug of the Pampas. It is most disgusting to feel soft wingless insects, about an inch long, crawling over one's body. Before sucking they are quite thin, but afterwards they become round and bloated with blood, and in this state are easily crushed. One which I caught at Iquique (for they are found in Chili and Peru) was very empty. When placed on a table, and though surrounded by people, if a finger was presented, the bold insect would immediately protrude its sucker, make a charge and, if allowed, draw blood. No pain was caused by the wound. It was curious to watch its body during the action of sucking, as in less than ten minutes it changed from being flat as a wafer to a globular form. This one feast, for which the Benchuca was indebted to one of the officers, kept it fat during four whole months; but after the first fortnight it was quite ready to have another suck." Mr. Kirby ${ }^{2}$ also refers to this species.

\section{Conorhinus variegatus (Variegated Cone-nose).}

Occurs in Florida in houses, and chases bugs (Cimex) and flies; not definitely known to bite man.

\section{I2. Conorhinus nigrovarius.}

This species occurs in South America. It is one of the forms known as Bichuque. Its bite makes a troublesome swelling.

I3. C. protractus also attacks man in Utah. ${ }^{3}$ It has been called the "Big Bed Bug."

I4. Reduvius personatus, Linné; Reduvius personatus, Leconte, I855.

European, but also found in the United States. The bite causes intense pain. It bites when caught or handled, but does not seem to do so voluntarily. Swelling and irritation result which may last

1 “A Naturalist's Voyage" (Voyage of the Beagle), p. 330, I888, Charles Darwin.

2 "Text book of Entomology," p. 205, I 885.

* 3 "The Big Bed Bug of the Far West," Bull. is (N.S.), I898, p. Ior, U.S. Depart ment Agriculture. 
a week and may even cause death. ${ }^{1}$ In I 899 it was very abundant at Washington and elsewhere; other species occurred, and so no definite opinion existed as to the actual biter, but some people took $R$. personatus actually biting. It was first described as a parasite of man in America by Walsh and Riley. ${ }^{2}$

A popular name for this bug is the Wheel or Masked-bug-a black insect, three-fourths of an inch long. The larva of this bug is carnivorous and covers its body with dust so as to conceal itself from its prey. The adult is active on the wing.

\section{I5. Coriscus subcoleoptratus, Kirby, I837.3}

Nabicula subcoleoptrata, Kirby, 1837 ; Nabis subcoleoptratus, Reuter, 1872; Coriscus subcoleoptratus, Stål, I 873 .

N. United States. Howard was bitten by one between the fingers-the pain was intense, like a needle prick, but the swelling was small. No other case known.

\section{I6. Rasahus biguttatus, Say, I83I.}

Pirates biguttatus, Stål, I862 ; Callisphodrus biguttatus, Stál, I866 ; Rasahus biguttatus, Stål, I 872 .

Common in S. United States, and found in Cuba, Panama and Para, \&c. Known as the Two-spotted Corsair on account of the great spot on the hemielytra. Frequently found in houses where it chases the bed bug. It also bites man frequently. From I869 Walsh and Riley placed it amongst the parasites of man. In United States Davidson ${ }^{4}$ is of opinion that all cases attributed to spider bites are due to this insect.

I7. Melanolestes morio, Erichson (I848), Non-Walker.

Pirates morio, Erichson, I848; Melanolestes morio, Stál, I866; Pirates picipes, Herrich-Schäffer, I848; Melanolestes picipes, Howard, 1900.

Guiana and Mexico and E. and S. United States. Length 20 mm.; hides under stones and logs during daylight and flies at

1 " Insects to which the name 'Kissing-bug' became applied during the summer of 1899," Bull. No. 22 (N.S.), p. 24, 1900, U.S. Department Agriculture.

2 American Entomologist, i, p. 84-88, I869.

3 "Sur la Piqûee de quelques Hémiptères," Arch. d Parasitologie, p. I45, 1902, R. Blanchard.

4 "So-called Spider Bites and their treatment," Therapeutic Gazette, February 19, 1875 . 
night. Attracted by lights into houses. Very abundant in 1899 at Washington. Howard cites cases where it was proved to bite man.

I8. Melanolestes abdominalis, Herrich-Schäffer (1848).

Pirates abdominalis, Herrich-Schäffer; Melanolestes abdominalis, Uhler, 1875.

Allied to the former; some say similar, but can be told by the shorter wings on the female. It occurs in the same localities as $M$. morio.

Fam. Lygaida.

Scutellum short; antennæ four-jointed; ocelli present; membranous part of hemielytra with never more than five nervures. Nearly all vegetable feeders. A few are recorded here as biting man.

19. Lyctocoris campestris, Fabricius.

Acanthia campestris, Fabricius.

(Lyctocoris domesticus.)

Rare in habitations, lives on human blood. Found by Blanchard in a bed at an hotel at Liverpool. The bite is undoubtedly worse than that of Cimex. Cosmopolitan. In colour it is ferruginous, shining, legs testaceous; hemielytra slightly shorter and narrower than the abdomen; membranous portion transparent, the apex broadly fuscous. Length 3.8 to $4.8 \mathrm{~mm}$.

20. Rhodinus prolixus, Stål, I859.

Sometimes attacks man, and the bite is very painful. It is $25 \mathrm{~mm}$. long and $8 \mathrm{~mm}$. broad, and occurs in Colombia. It is found also in Cayenne and Venezuela. This like other species is known in South America as Bichuque or Benchuca.

A few other unimportant species are also recorded as biting man, such as Harpactor cruentas, in the South of France; Eulyes amona, from Borneo and Java; Arilus carinatus (Forster), from Brazil. The latter appears to be the same as the Acanthia serratus, Fabricius.-F. V. T.] 


\section{Coleoptera.}

The larvæ of beetles, similarly to those of some other Arthropoda (myriapods and the larvæ of gnats), have sometimes been observed in man as purely accidental guests. In one case or another, such accounts may have originated through a decided mistake of the observer. Thus English doctors report the presence of the larvæ of Blaps mortisaga in the stools of human beings, Sandberg of the larvæ of Agrypnus murinus in his ten-year-old son, and Blanchard mentions the larva of a beetle that was vomited by a child. All these cases, however, do not represent actual parasitism, although there are beetles living parasitically. ${ }^{1}$

[Silvanus surinamensis, Linnæus (the Saw-toothed Grain Beetle).

Taschenberg records this beetle as having invaded some sleeping apartments adjoining a brewery where stores were kept, and annoying the sleepers at night by nipping them when in their beds.

This beetle is common in many parts of the world amongst groceries, corn, meal, seeds, dried fruits, \&c. ' It is about onetenth of an inch long, much flattened and chocolate-brown in colour. The thorax has two shallow grooves and bears six minute teeth on each side. The jaws are strong, but the bite cannot be very serious. - F, V. T.]

\section{Diptera.}

\section{(a) Aphaniptera (Fleas).}

Wingless, the thoracic rings not amalgamated; antennæ three-jointed; legs very powerful; abdomen with nine segments. The mandibles transformed into serrated puncturing organs, which are situated in the split sheath of the rostrum, originating from the labrum; the maxillæ are laminated and have palpi.

\section{Pulex irritans, L., I758.}

Males $2-2.5 \mathrm{~mm}$. in length, females about $4 \mathrm{~mm}$.; reddish or dark brown; head without bristles; thoracic and abdominal rings

1 [Dr. Daniels has sent me a small coleopterous larva found in an abscess on a man in British Guiana.-F. V. T.]

"Cobbold, T. Sp., "On Blaps mortisaga as a Human Parasite" (Brit. Med. Journ., 1877, i., p. 420). - Sandberg, G., "Et tilfolde at Coleopterlarvers tilhold $i$ tarmkanalen hos et menneske" (Entom. Tidskrift., Stockh., I890, p. 77; C. f. B. u. P., I890, viii., p. 182).-Blanchard, R., "Sur une larve de Coléoptère vomie par un enfant au Sénègal" (Bull. soc. entom., France, 1893, p. 156).-Brandes, G., "Ueb. paras. Käfer" (C. f. B., P. U. I., 1896, xx., p. 297). 
of bristles on the dorsal aspect, and small hairs directed backwards at the posterior margin. The barrel-shaped white eggs are deposited in cracks in the boards, sweepings, spittoons, \&c.; they produce legless larvæ consisting of fourteen segments, which, after about eleven days, are transformed into pupæ; after another eleven days the flea emerges.

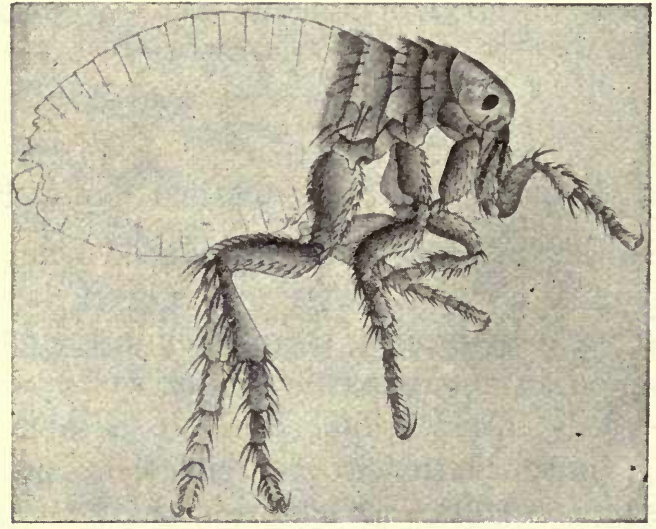

FIG. 257.-Pulex irritans. 14/I.

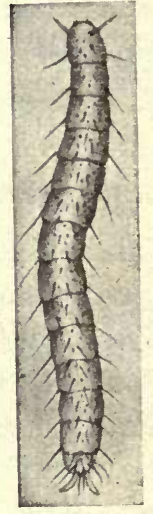

FIG. 258. - Larva of flea, enlarged. (After Railliet.)

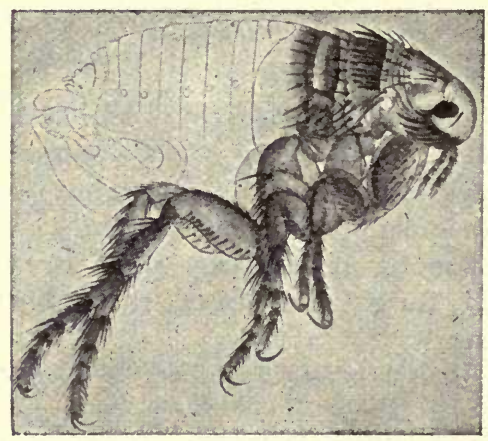

FIG, 259.-Pulex serraticeps. 22/I.

Fleas live in human dwellings all over the worid, and periodically pass on to persons to suck their blood. They may deposit their eggs on very uncleanly individuals, and even undergo development, therefore it is possible to find larvæ and pupæ on such persons.

The dog flea, Pulex serraticeps, is easily distinguished from the flea of man by the large thick bristles on the posterior margin of the first thoracic ring (fig. 259). 


\section{Sarcopsylla penetrans (L.), I758 (Jigger, Chigoe).}

About I-I.2 mm. in length; brown in colour. The males only occasionally visit man to bite; the fertilised female, on the other hand, bores into the skin with her head. particularly about the toes of the host, and then attains considerable dimensions. The eggs develop on the soil with a metamorphosis similar to that of the common flea.

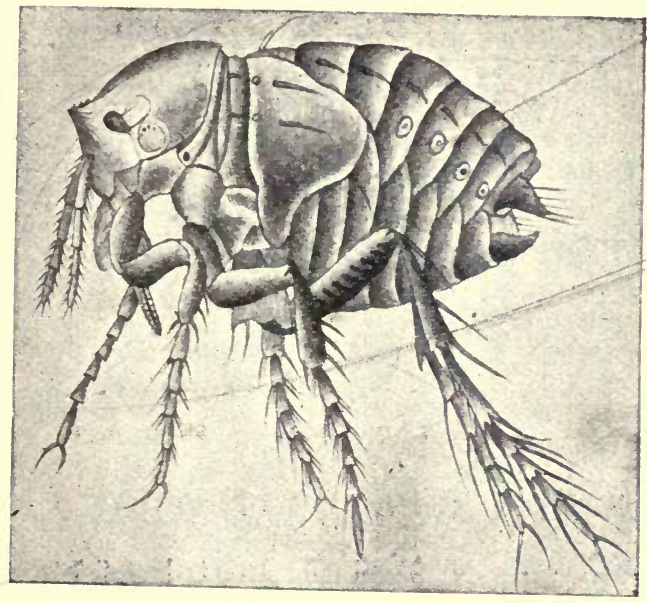

FIG. 260.-Sarcopsylla penetrans, young female, highly magnified. (After Moniez.)

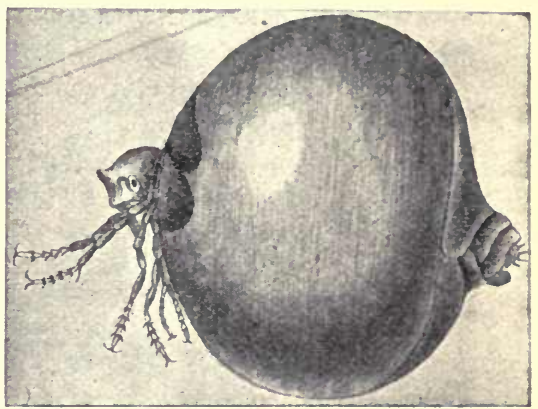

FIG. 261.-Sarcopsylla penetrans, older female, enlarged. (After Moniez.)

The sand-flea (nigua) particularly infests Central and South America, and, in 1873 , was carried by ships from Brazil to the West Coast of Africa. In a comparatively short time it has become disseminated throughout Africa and has also appeared in Madagascar; recently also it has been reported from China.

Besides attacking man it also settles on mammals, for instance, on dogs, pigs, \&c. According to Jullien the wound or little swelling caused by the female has no particular significance, as children infested with ten or eleven sand-fleas quietly proceeded with their games. It will be understood, however, that the wound easily affords the opportunity for the setting up of inflammation or even septic processes, as is the case in any kind of wound. ${ }^{1}$

"Taschenberg, O., "Die Flöhe . . . monogr. dargestellt.," Halle, I880.-Bergh, R., “Die Flohlarve als Psendoparasit d. Mensch." (Monatsh. $f$. pr. Dermatologie, 1885, iv., p. 209).- - Jullien, J., " La chique sur la cîte occidentale d'A frique" (Bull soc. zool., France, I889, p. 93).- Blanchard, R., "Quelq. mots sur la Chique" (Bull. soc. zocl. de France, I 889, xiv., p. 95).- Blandfoord, W. H. F. "The Chigoe in Asia " (Enlomol. Monthly Mag., I 894, v., p. 228).-Blanchard, R., Prés. de la chique a Madagascar" (Arch. de Paras., I899. ii., p. 627). 
[The chief genera and species of British Pulicida may be tabulated as follows :-

(I) Pulex: Eyes distinct.

(2) Hystrichopsylla : Densely spinose cheeks and clypeus. No eyes, or eyes indistinct.

(3) Typhlopsylla: Body narrow and elongated. No eyes, or eyes indistinct.

(1) Pulex.

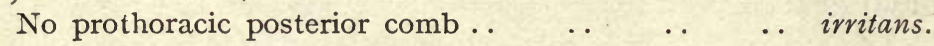

Posterior comb present.

Head without black spines.

Prothoracic comb with twenty-six teeth $\quad . \quad \ldots \quad$.. gallina.

Prothoracic comb with eighteen teeth $\quad$.. $\quad$.. fasciatus.

Head with black spines.

Cheeks, \&c., with six or seven black spines on each side canis.

(2) Hystrichopsylla.

Cheeks and clypeus densely spinose $\quad$.. $\quad$. $\quad$ obtusiceps.

(3) Typhlopsylla.

Comb only on posterior margin of pronotum.

$\begin{array}{lllllll}\text { Four genal spines } & \text {. } & \text {. } & \text {.. } & \text {.. } & \text {. } & \text { musculi. }\end{array}$

$\begin{array}{lllllll}\text { Three genal spines } & \ldots & \ldots & \ldots & \ldots & \ldots & \text { assimilis. }\end{array}$

3. Sarcopsylla gallinacea, Westwood (The Chigoe of Fowls).

This flea is a native of Ceylon and N. America. It lives on the fowl chiefly, attacking the neck and around the eyes. Specimens were sent me from Texas, where they not only attack poultry but also children, the latter somewhat severely. It also occurs on cats.

\section{Pulex serraticeps, Gervaise (The Common Cat and Dog Flea).}

In the eastern cities of America the cosmopolitan dog flea is the species that overruns houses. Man is badly bitten by this species in most parts where it occurs. The eggs are deposited amongst dust, clothes, \&c., and hatch out in fifty hours amongst the dogs' and cats' hairs. As they are not fastened to the hairs they fall off. The larvæ live seven days and then spin a cocoon amongst the dust and dirt. They remain in the cocoons eight days. The times are variable, however, for Howard and Marlatt show that the eggs hatch in one day and the larvæ commence to spin in from seven to fourteen days after hatching, and the flea appeares five days later. The changes thus observed in Washington agree with those observed by Simmons in Calcutta. 


\section{Pulex fasciatus, Bosc.}

This flea is also found on the rat and will attack man. It has eighteen teeth on the prothoracic comb and no black spines on the head.

\section{Pulex pallipes is another species found on the rat and man.}

\section{Typhlopsylla musculi, Duges (The Rat Flea).}

In the genus Typhlopsylla the body is narrow and elongated, and on the under side of the head are numerous chitinous bristles, and also on the pronotum. This rat flea is also found on the vole; it is dark yellowish-brown and the body attenuated in front, and there is a distinct comb on the posterior margin of the pronotum; the legs have very few hairs, femora bare and curved; tibiæ with black bristles; four spines on the genæ.

An allied species, T. assimilis, Taschenberg, occurs on mice, shrews, moles, and voles; it has only three genal spines.-F. V. T.]

\section{Systematic, Anatomical, and Biological Remarks on Mosquitoes.}

Mosquitoes Nematocera form one of the four sub-orders of the Diptera, and are divided into numerous families, of which, however, only the Culicidee are of interest to us here. The head is small, the facetted eyes are placed laterally, but there are no accessory eyes (ocelli). In front of the eyes are situated the comparatively long antennæ, the differences of which strongly mark the distinction of sex.'

The antennæ are composed of fifteen or sixteen segments. In the male they are covered with long whorl-like hairs, while in the female the antennal hairs are short-differences that are perceptible even with the naked eye. ${ }^{2}$ The proboscis, which is longer than the antennæ, protrudes from the inferior aspect of the head and is composed of the following parts (figs. 264 and 265): Two grooved half tubes, facing one another, of which the upper one is the upper lip (labium), and the lower one the lower lip (labrum), which represents a pair of coalesced maxillæ. Within the tube formed by the labrum and labium are the mandibles and maxillæ, transformed into instruments for piercing, and a single puncturing organ, the hypopharynx. On the right and left, next to the proboscis, are placed the straight five-

1 [This is by no means always the case; in the genera Deinocerites, Wyeomyia, Limatus, Theobald, and in Sabothes, Robineau Desvoidy, they are nearly the same in both sexes.-F. V. T.]

2 [This is not always the case, vide previous note.-F. V. T.1 
jointed palpi, the final joint of which is thickened in the male. ${ }^{1}$ In biting, the labrum, which is swollen at its free end, is not introduced into the wound like the other mouth-parts, but is bent backwards. The labium and hypopharynx push direct into the skin; the maxillæ and mandibles, however, which are needle-like and serrated at the tips, penetrate with a

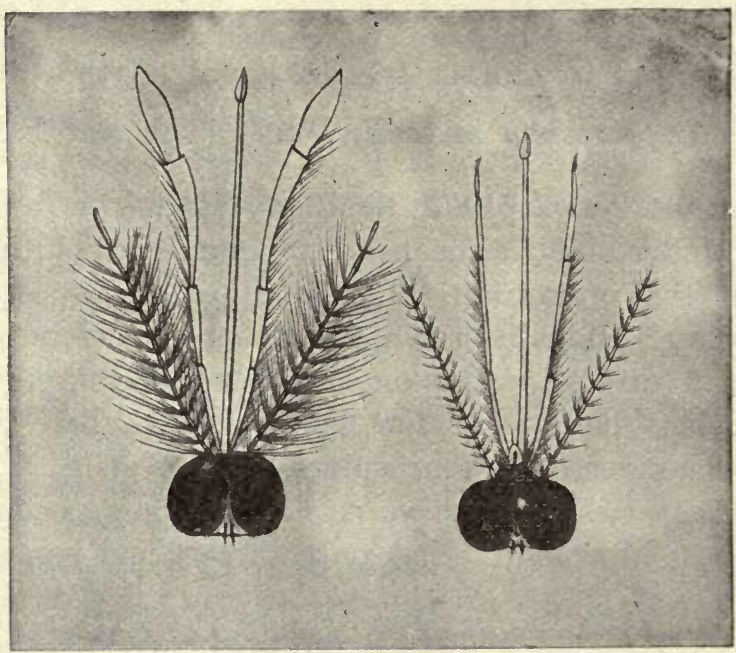

Fig. 262.- - Head of a male $(a)$ and of a female $(b)$ Anopheles; slightly enlarged. (After Giles.)

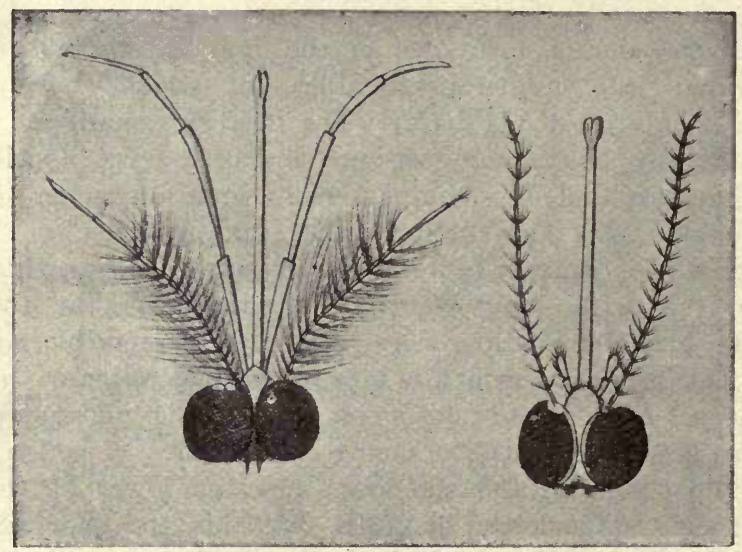

Fig. 263.- Head of a male $(a)$ and of a female $(b)$ Culex. (After Giles.)

saw-like movement. [The swollen free end of the labrum really means the labella, two articulated pieces, supposed by some to be the labial palpi. In most species the mandibles are not serrated at their ends.-F.V.T.] The

' [This is only so in Anophelina and in the genus Theobaldinella, Neveu-Lemaire, Grabhamia, Theobald, Acartomyia, Theobald, \&c. In true Culex and many other genera the male palpi are pointed. -F. V. T.] 
saliva is introduced into the wound through the lumen of the hypopharynx, while the blood is sucked up by the mosquito in the groove of the labium.

The three thoracic segments are soldered together. The central one

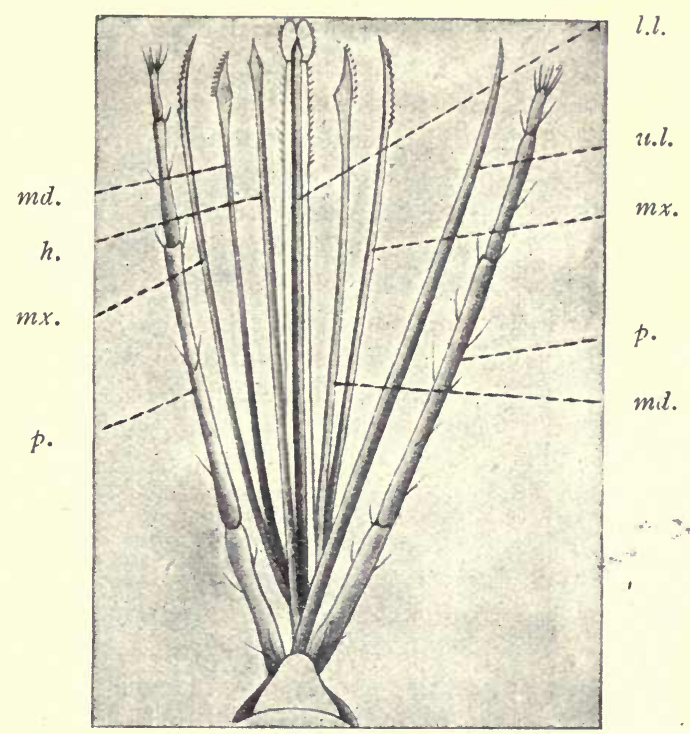

FIG. 264.-Mouth-parts of Anopheles claviger' (after Grassi); h., hypopharynx ; $m d$. , mandible; $m x$., maxilla : $u . l$., upper lip; l.l., lower lip ; p.. palpi.

$$
h y . \quad h \text {. } \quad \text {. }
$$

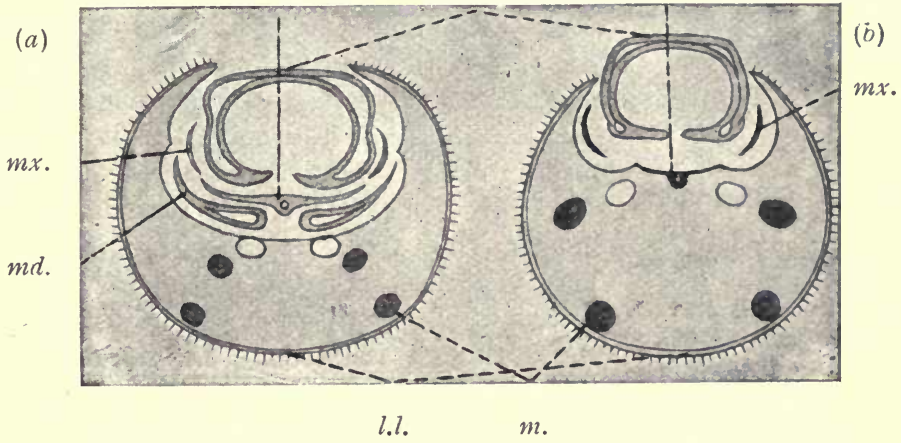

FIG. 265.-Anopheles maculipennis (after Nuttall and Shipley). Transverse section through the proboscis of a female $(a)$ and a male $(b)$; hy., hypopharynx, with duct of the salivary gland; $m$., muscles; $m d$., mandibles; $m x$., maxillæ; l., labium ; l.l., labrum.

carries the membranous wings on the sides of the dorsal surface; the posterior somite carries the small halteres (rudimentary posterior wings). There are three pairs of long slender legs on the lower side.

'TThis should read Anopheles maculipennis, Meig. ; there was no type of A.claviger. -F. V. T.] 
The abdomen has no limbs, is composed of eight distinct segments; the sexual and anal orifices are at the posterior end, the stigmata on the sides. The intestinal canal. (fig. 266) is composed of three principal divisions; the anterior part reaches as far as the front pair of legs, and consists of the osophagus, which is provided with two small lateral diverticula. [At the commencement of the œsophagus are usually three diverticula, which vary in size; they contain air, food and bacteria.-F. V. T.] The mid-gut reaches as far as the fifth and sixth abdominal ring; in front it is thin,

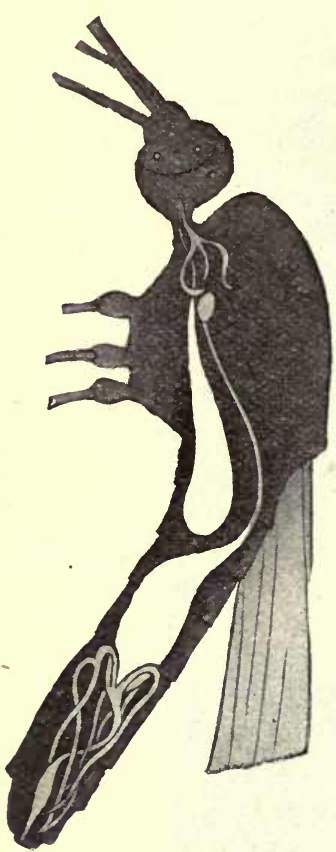

FIG. 266.-Longitudinal section of an Anopheles, showing alimentary canal (after Grassi). In the forepart of the thorax is the salivary gland consisting of three tubules; ventrally, the suctorial stomach extending into the abdominal cavity; the stomach, and at the posterior end of the abdomen the Malpighian vessels. Anopheles. [This cannot be said to be a character by which an Anopheline may be can a genera as Cellia and Nyssorhynchus we get pienty of scales on the abdomen, and glia ; the posterior part is, however, more dilated. Five Malpighian tubes, the excretory organs, discharge at the place where the mid-gut passes into the terminal gut.

The pair of salivary glands have one common excretory duct leading in to the hypopharynx.

The glandular body, situated in the thorax, consists of three slightly serpentine tubules at each side, the dorsal and ventral tubes being long, the central one shorter. The above-named characteristics apply to both genera Culex and Anopheles. The difference consists in various peculiarities in form. The genus Culex is smaller, Anopheles larger. [In Anopheles the ends of the ducts in the lobules are dilated, whilst in most of the genera the ducts are the same size all along. The lobules may bifurcate, and in Psorophora there are five lobules. -F. V. T.] The legs of the genus Culex are about the same length as the whole body; in Anopheles they are double that length. ${ }^{1}$ In Anopheles the palpi and proboscis are of equal length; in Culex the condition is different, according to sex. In the male the palpi are longer than the proboscis; in the female considerably shorter and the number of joints diminished. The venation of the wings exhibits further points of differentiation, as also their adornment, though this last sign is not by any means always conclusive ; most species of the genus Culex have unspotted wings, whilst those of Anopheles are spotted. More important is the fact that in Culex the abdomen is decorated with small scales, similar to those on butterflies, whereas there are small bristles on the abdomen of and has numerous small supra-œsophageal gan-

' [This is certainly not always the case.-F. V. T.] 
in Aldrichia as complete a scaly coat as any Culicine.-F. V. T.] An experienced observer can, however, differentiate the two genera by the difference in size and their manner of resting. When settled they either touch the resting place with all the legs or only with the four anterior legs. In consequence of the different length of the legs, the body of Culex approaches the resting place more closely ; moreover, Culex holds the abdomen parallel to, or at an acute angle to, the resting surface ; whereas $A n$;pheles carries the abdomen directed upwards (at an

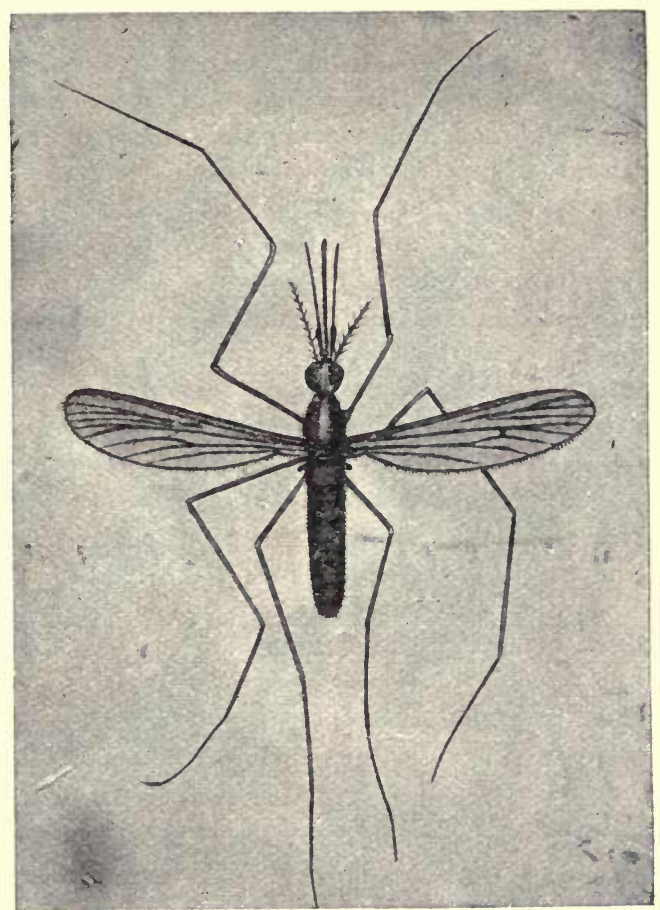

FIG. 267.-Anopheles maculipennis, Meigen (enlarged). (After Grassi.)

angle of about $145^{\circ}$ ) and holds the head down. Both genera, however, usually only rest on the four anterior legs, and then, as has long been known, Culex carries the third pair directed towards the dorsum, while those of Anopheles hang down.

In regard to the differentiation of the species, I must refer you to the special literature, and content myself by observing that about I 50 species of Culex and about 50 species of Anopheles have been described, of which 50 about four are found in Europe. [The number of known Anophelines now is at least 90 species, of other Culicidæ about 580.-F. V. T.] According to our present knowledge it appears that the entire genus Anopheles can transmit malaria to man; this observation has been confirmed in Anopheles claviger, Fabr.; A. maculipennis, Meig. ; A. bifurcatus, L. ; A. superpictus, Grassi ; A. pseudopictus, Gr., all of which are found in Italy,'

1 Compare Ficalbi, E., “Venti spec. di zanzare (Culicida) ital. . ." (Bull. soc. entom. ital., I899, 'xxxi.; ref. in Centr. f. Bakt., Paras. u. Inf., 1900, xxviii., p. 397 . 
Germany, \&c., as well as in the Tropics. Moreover, in A. costalis, Loew ; A. funestus, Giles (Africa); A. quadrimaculatus, Say (North America), and $A$. rossii, Giles; the latter is perhaps identical with $A$. superpictus, Gr., as well as with $A$. culicifacies (India). [Anopheles maculipennis and A. claviger are the same. Certainly neither maculipennis nor bifurcatus have been found in the Tropics. Anopheles quadrimaculatus, Say, is the same as A. maculipennis. There is no evidence that all Anophelines carry malaria, but there is much to show that certain species only are capable of so doing; Rossii will not do so.-F. V. T.].

Everyone is aware that mosquitoes swarm at sunset in fine weather, and at that time seek out human beings and other warm-blooded animals to take food. In this regard, however, the sexes differ, in so far as that it is almost without exception that the females only suck blood, while the males subsist on the juices of plants (blossoms or fruits '). After sucking, and when night has fallen, the mosquitoes find a place of refuge, for which purpose they utilise the grasses or foliage of trees and bushes, or inhabited or uninhabited rooms of houses, also cellars, stables, verandahs, $\& c$., where they also pass the day.

[Some mosquitoes bite in the daytime-Stegomyia and some Anophelines; some bite right into the night, as Culex fatigans and C.pipiens.-F. V. 'Г.].

The period required for digestion varies according to the temperature. It takes two days in summer, and may take up to ten days or more in cool weather. After digestion is complete more food is taken up, this being necessary for the maturing of the sexual products.

It is still unknown under what circumstances copulation takes place? in any case, sooner or later the females are fecundated, and when the ova have become mature, and the season is not too far advanced, they seek a suitable place in which to deposit them. ${ }^{3}$ These are larger or smaller, permanent or temporary, collections of standing water, pools, puddles, lakes, pits, water in rain-water barrels, basins, \&c. Nevertheless, certain kinds prefer certain waters; thus Anopheles (claviger) maculipennis and several of the Culices seek stagnant water overgrown with swamp vegetation and decomposing vegetable matter; $A$. bifurcatus and certain Culices, clear water with some vegetation (such as fountains and the lakes in gardens and parks); Culex pipiens has a preference for rain-water barrels, even though the water be dirty and evil-smelling. [I have found the larvæ of Anopheles bifurcatus living in great numbers in ponds and lakes completely overgrown with floating water-weeds, and those of Culex pipiens in liquid manure.

Sexual Organs of the Mosquito.- The female has a pair of ovaries, opening into a single tube, by the ovariars tubes; into the single tube opens a duct coming from the spermathecæ, and also a mucous gland. The spermathecæ

${ }_{1}$ Both males and females may be kept alive in captivity for a long time if given fruits, or even only sugar and water.

2 The female Culex has three receptacula seminalis, while the female Anophele has one receptaculum seminis.

${ }^{3}$ It is certain that the females perish immediately after depositing the ova; but this dces not always hold good, as a part of them survive for a few days. The males die soon after copulation. 
store up the male cells. The male organs consist of two testes joined by ducts (vasa deferentia) to the ejaculatory duct formed by their union. Each vas deferens is joined by a short tube with the sac-like vesicula seminalis.-F. V. T.].

There is also a difference in the manner in which Culex and Anopheles deposit their ova. Culex deposits two to three hundred eggs in compact heaps that float on the water, and in which the eggs stand perpen. dicularly one next the other; whereas Anopheles maculipennis deposits only three or four up to twenty eggs, united in short rows that float horizontally on the water; the eggs of $A$. bifurcatus, again, are arranged in star-like groups. The eggs are about $0.75 \mathrm{~mm}$. in length, and assume a dark hue

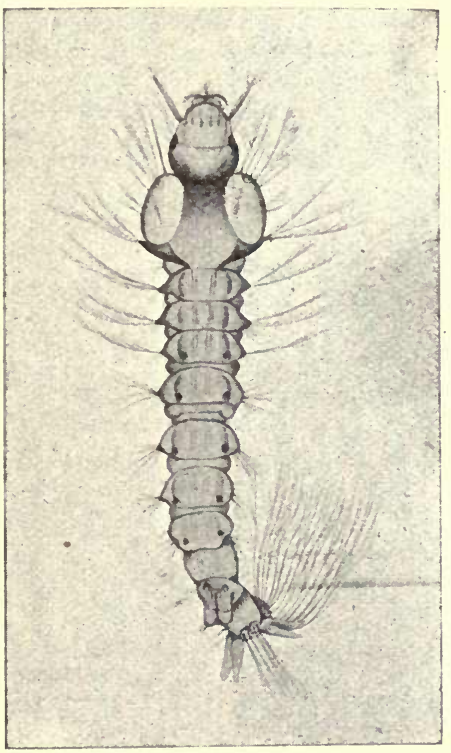

Fig. 268.-Larva of Anopheles maculipennis, Fabr. (enlarged.) (After Grassi.)

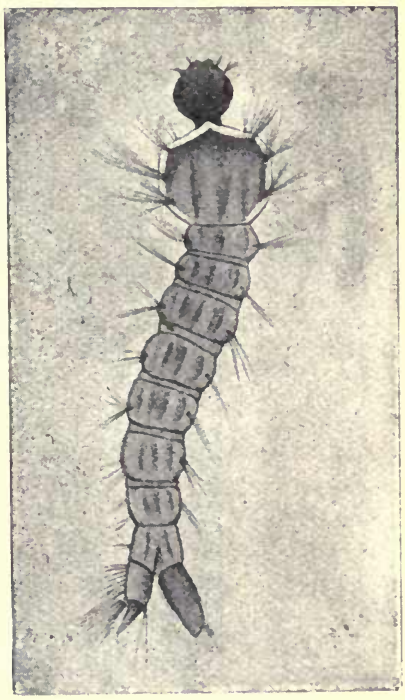

FIx. 269.-Larva of Culex (enlarged.) (After Grassi.)

soon after being laid. The development only occupies a few days. The hatched-out larvæ grow rapidly, changing their integument several times; the larvæ also differ in the various genera, though they are very similar in form (figs. 268 and 269).

The long legless larva has a flattened head, a fairly broad, rectangular, or trapeziform thorax, on which there are bristles, and an abdomen distinctly segmented, and on the segments of which there are also lateral bristles. The situation of the stigmata marks the difference between the two genera. Though in both genera the stigmata are at the posterior end and on the dorsal surface, they are in Anopheles close to the surface of the body; in Culex, however, they are on the free end of a long tube (syphon).

The position of the larva in the water also differs. The larva of Anopheles lies almost horizontally beneath the surface of the water, the posterior border of the penultimate abdominal segment, upon which the stigmata are situated, 
being on the surface; whereas the larva of Culex hangs head downwards perpendicularly in the water, the point of the syphon only touching the surface.

In about a fortnight the larva is fully grown and becomes a pupa. The pupa (fig. 270), which carries out the most remarkable jerky movements, remains in the water, but partakes of no food. In shape it somewhat resembles a tadpole, that is to say, it consists of a bulky anterior portion on the surface of which the head, with its appendages, is recognisable, and a more slender segmented abdomen. Above, on the thorax, there are two small open breathing tubes for the conveyance of air to the tracheal system. After three or four days the perfect mosquito hatches out, remains a short time on the surface of the water until its chitinous integument is hardened, and then flies away.

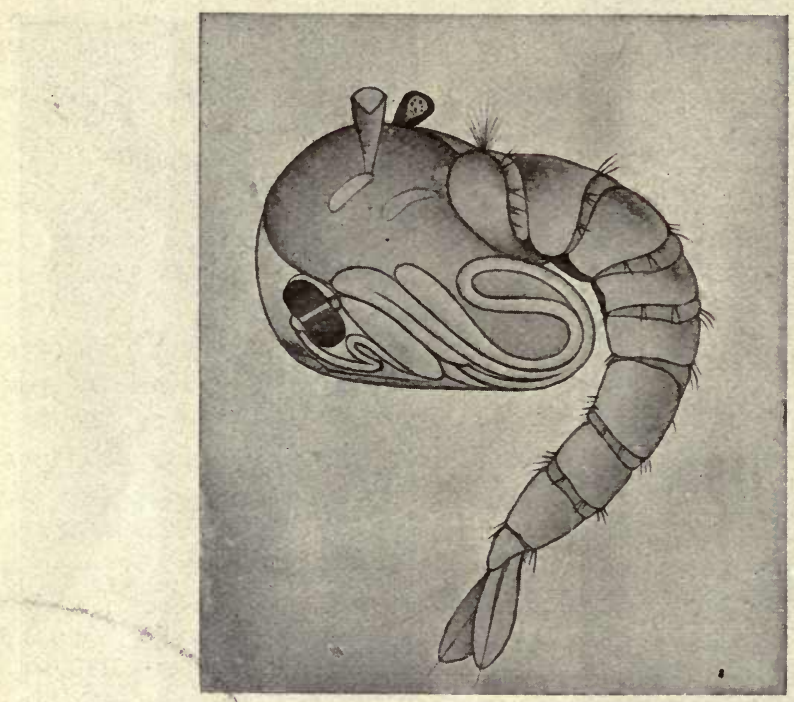

FIG. 270.-Pupa of Anopheles maculipennis, Meig. (enlarged). (After Grassi.)

The females that are fertilised in the autumn hibernate in sheltered spots in the open air, or in houses, cellars, under stairs, in stables, barns, \&c., and are the progenitors of the first generation of the following year.

In accordance with the climate of a country, or the kind of weather of a year, the conditions in regard to the manner of life and the duration of the development of the mosquito varies. At all events, the lifehistory of the mosquito elucidates many points relating to malaria which were hitherto not understood.

[The length of the egg, larval and pupal, life varies so much that it is not possible to give an account of any value here. Frequently the eggs may incubate in two days, whilst I have had Stegomyia fasciata eggs from Cuba that have hatched out under abnormal circumstanccs more than two months after they were laid ("Mono. Culicid.," vol. iii., p. 6). Some larvæ, as Anopheles bifurcatus, live for months during the winter. Some mosquitoes therefore hibernate as larvæ. The larvæ and pupæ of the different genera present very 
marked characters, mainly in regard to the structure of the syphons. Specific differences may be found in the frontal hairs of Anopheline larvæ and in the number and arrangement of a group of spines at the base of the syphon in Culicines.-F. V. T.]

\section{LITERATURE.}

FABRicius, J. C. Syst. antliatorum. Braunschw., I805-06.

Meigen, J. W. Syst. Beschr. d. bek. europ. zweifl. Ins. 7 vols. Hamm, 1818-38.

WALKer, F. Insecta Britann. : Diptera. London, 1851-56.

Schiner, J. R. Fauna Austriaca. Die Fliegen (Diptera). Wien, i 860-64.

Nuttall, G. H. F., and A. E. Shipley. Studies in Relation to Malaria. Structure and Biology of Anopheles (Journ. of Hyg., 1901, i., p. 451).

Giles, G. M. A Handbook of the Gnats and Mosquitoes. 2nd edit. (Systematic part abridged from Theobald). London, I902.

Theobald, F. V. A Monograph of the Culicidæ of the World. 3 vols. London, 1902 Revision and Appendix of same, I vol., 1903.

Theoвald, F. V. Family Culicidæ, genera Insectorium. Brussels, 1905.

Theobald. F; V. A Catalogue of Culicidæ in the National Museum of Hungary. Budapest, I905.

Theobald, F. V. New Culicidæ from Ceylon. Bombay, 1905.

Blanchard, R. Les Moustiques: Hist. Nat. et Med. Paris, 1905.

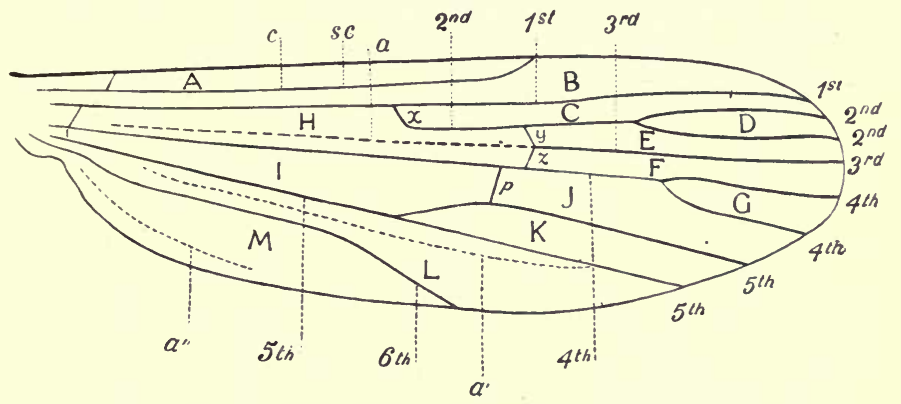

Fig. 271.-Neuration of Wing (Theobald).

Explanation of Wing, Veins and Cells.-A, Costal cell; $B$, sub-costal cell; $C$, marginal cell ; $D$, first sub-marginal cell (= first fork cell) ; $E$, second submarginal cell; $F$, first posterior cell; $G$, second posterior cell (= second fork cell); $H$, first basal cell; $I$, second basal cell; $J$, third posterior cell; $K$, anal cell; $L$, auxiliary cell; $M$, spurious cell; $c$, costal vein; 1 st-6th, first to sixth longitudiual veins; $a, a^{\prime}$ and $a^{\prime \prime}$, incrassations ( $a^{\prime}$ called by Austen the sixth vein, $a^{\prime \prime}$ the eighth vein); $y$, supernumerary cross vein; $z$, mid cross vein; $p$, posterior cross vein.

\section{Culicide or Mosquitoes.}

\section{By F. V. Theobald.}

The importance of these insects to man is very great, greater than all the other partially parasitic animals. They not only produce painful bites, which may become inflamed and give rise to a considerable amount of œdema, but they are more important on account of the part they play in the distribution of various diseases. Culicidæ not only carry disease germs, but act as intermediate hosts for certain parasites, such as some of the Anophelina for malarial parasites, Culex for Filariæ, and Stegomyia for yellow fever; the last-named is in any case the distributor of that fatal disease. It is therefore very necessary to know the life-history, habits and characters of these pests.

Mosquitoes exist in almost all parts of the world from the Arctic circle 

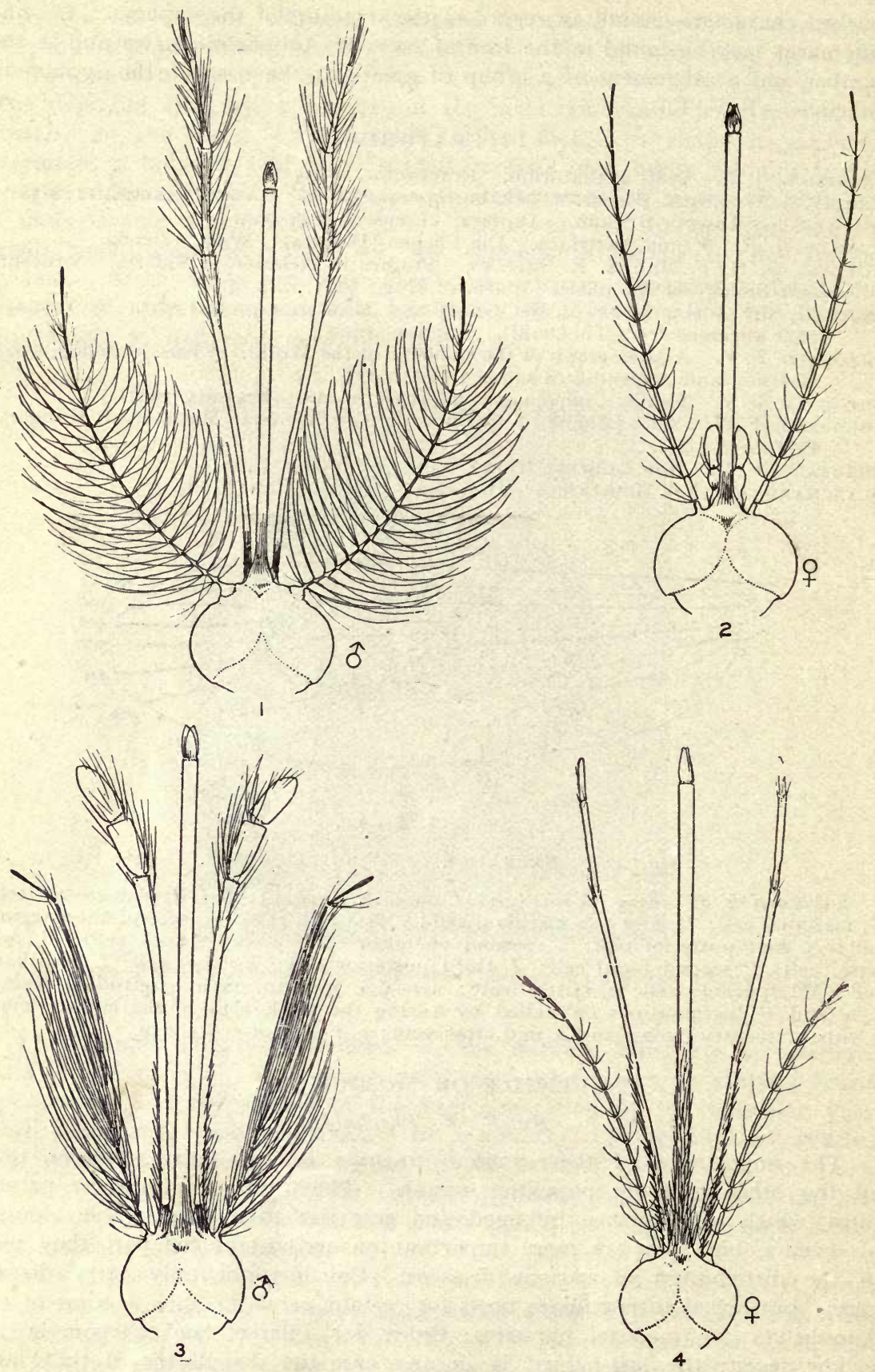

Fig. 272.- (I) Heads of Culex and Anopheles: (I) Culex male; (2) Culex female ; (3) Anopheles male; (4) Anopheles female. (After Danicls.) 
to the tropics; temperate regions suffer from them less than the two extremes, but even there they form not only a source of great annoyance but of danger, as malaria and possibly now and again yellow fever carriers. A few years ago comparatively few'species were known, now some 580 have been described. Their number will probably not stop far short of I,ooo. Some are purely domestic, others entirely sylvan; the former, as we might expect, often have a very wide distribution, having been taken from place to place in boats and trains. The more rapid transport becomes, the greater becomes the possibility of this wide distribution of many species increasing, and the spread of other species from their natural home to foreign parts by sea and then by trains further inland.

All Culicidæ are aquatic in their larval and pupal stages. Almost all small collections of water, both natural and artificial, may form breeding

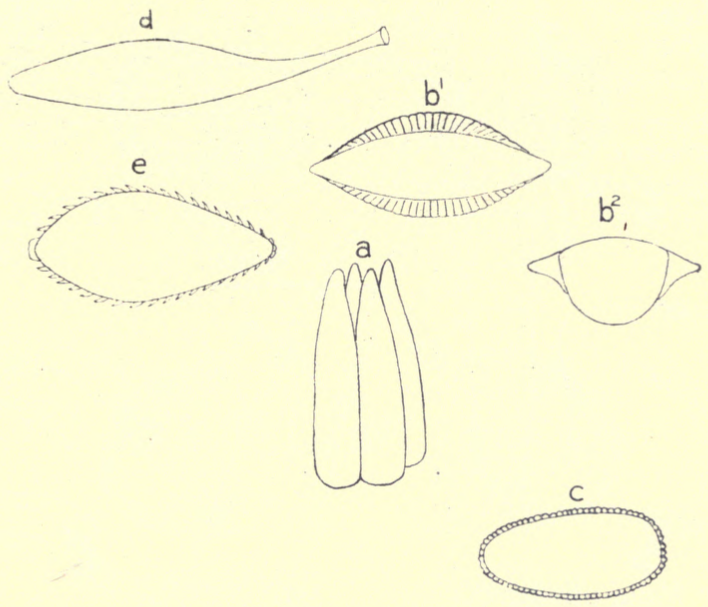

FIG. 273 .

$a$, Eggs of Culex; $b^{1} b^{2}$, Eggs of Anopheles; $c$, Egg of Stegomyia; $d$, Egg of Mansonia; E, Egg of Psorophora.

grounds for these pests. The favourite resorts for the larvæ of Anophelina are small, natural collections of water, such as puddles, ditches and small pools around swamps; certain species ( $A$. maculipennis, \&c.) live in rain barrels as well. They may also occur in the sluggish water at the edges of rivers or even in mid river, where the flow is checked by masses of water weeds (Myzomyia funesta, \&c.). The Stegomyias prefer artificial collections of water, but also occur in natural pools. The yellow fever species (S. fasciata) prefers small collections, such as in barrels, pots, jars, \&c. Culex occur in all manner of places-rain barrels, tanks, cisterns, ponds and ditches. Some of the South American species of Culex, Wyeomyia, Joblotia, $\& c .$, breed in the collections of water at the base of Bromelia leaves.' Very few Culicid larvæ live in salt water except in Australia, where Dr.

1 "Wald mosquitoes und Wald malaria," Dr. Lutz, Centralbt. f. Bakt., Evc., i. Abt. Originale, Bd. xxxiii., No. 4. 
Bancroft has found them in salt water of specific gravity 10,40 (Mucidus alternans, Culex annulirostris and $C$. marinus, \&c.). The food of the larvæ is very varied; the majority appear to feed upon confervæ, small

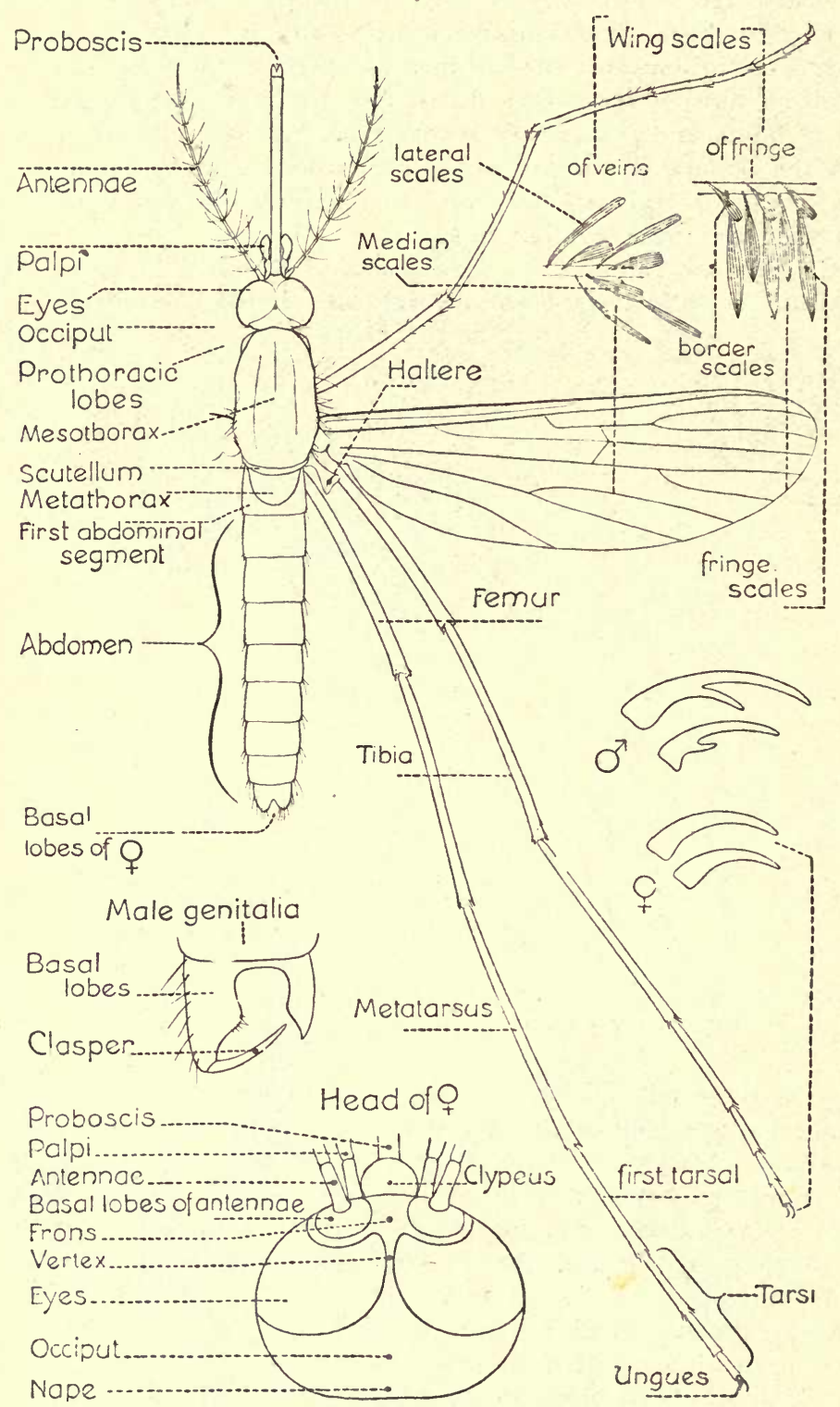

FIG. 274--Diagram showing the structure of a typical mosquito (Theobald).

crustacea and insects; some are cannibals, readily devouring others of their own kind. The larger larvæ of Megarhinus, Psorophora, Toxorhynchites and Mucidus are extremely ravenous and devour one another. 
There are two main types of larvæ, the Anopheline and Culicine; in the former there is no respiratory siphon, in the latter the siphon is long or moderately long. The head offers certain marked peculiarities which are of specific value, this especially applies to the Anophelina, in which the frontal
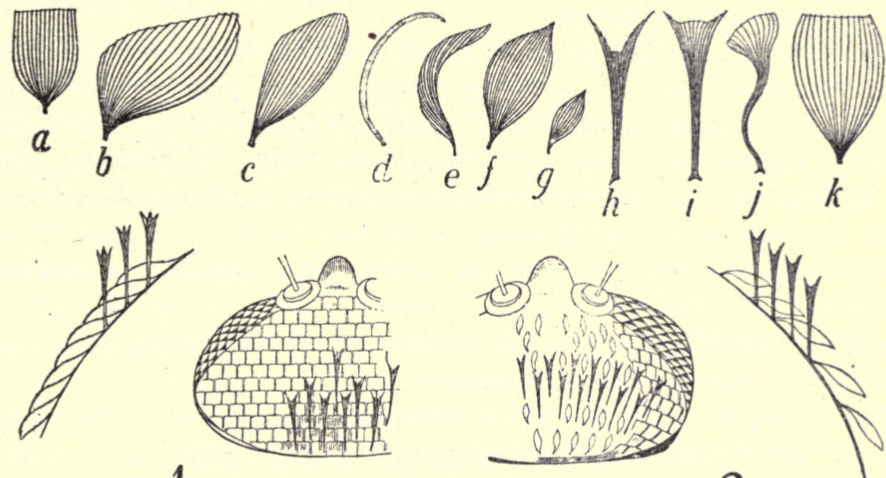

1
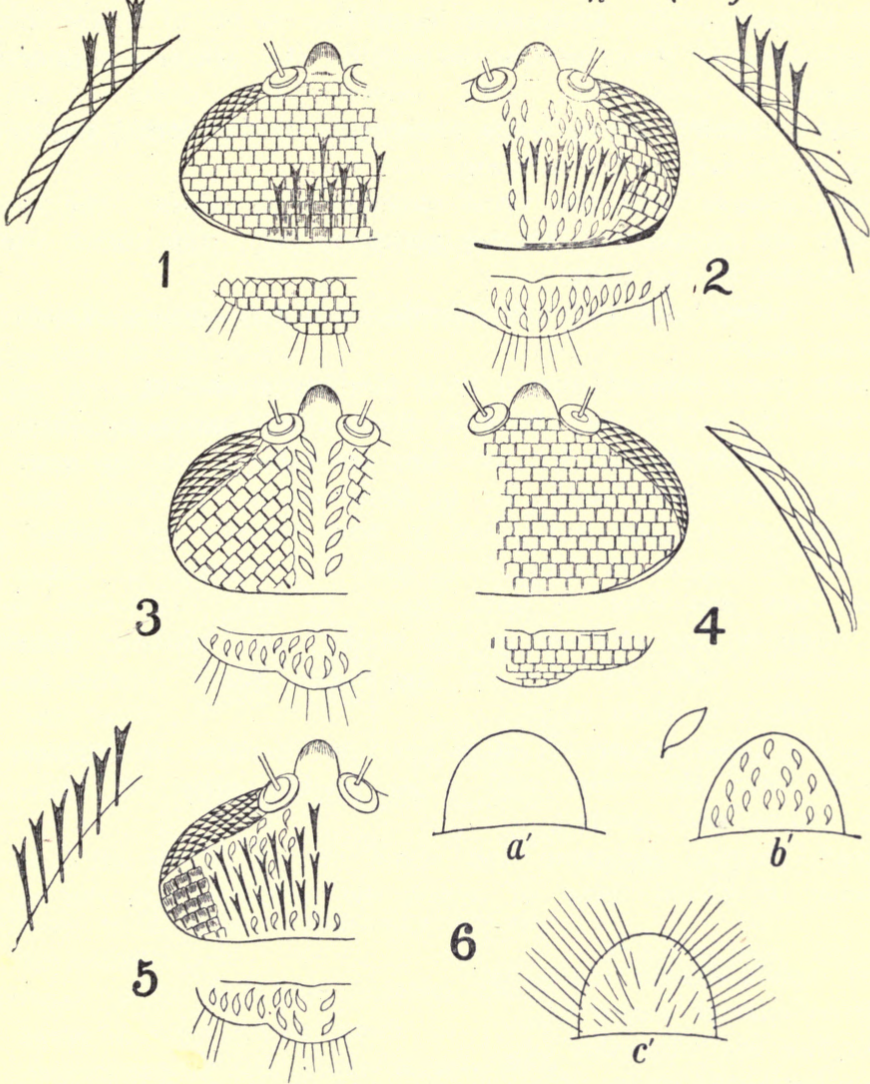

6

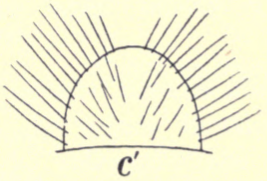

FIG. 275 .

Types of scales, $a$ to $k$; head and scutellar ornamentation, I to 5 ; forms of clypeus, 6 (Theobald).

I, Head and scutellum of Stegomyia, \&c.; 2, of Culex and Mansonia; 3, of Howardina, Ades, \&c.; 4, of Megarhinus and Toxorhynchites, \&c. ; 5, of Cellia and some other Anophelines ; $6 a^{\prime}$, clypeus of Culex; $b^{\prime}$, of Stegomyia; $c^{\prime}$, of Johlotia. 
hairs are of great service in distinguishing the larvæ, ${ }^{1}$ whilst in Culex the number and position of the spines at the base of and on the siphon are characteristic. The position assumed by the larvæ in the water also varies in the different-groups; most of the Anophelines lie horizontally, most of the Culicina and Ædeomyina hang head downwards. The pupæ also vary, but not to the same extent; the chief differences to be noticed are in the form of the two respiratory trumpets.

The eggs, which may be laid separately ( $\dot{A}$ nopheles maculipennis, Stegomyia fasciata, Joblotia nivipes, \&c.), or in rafts (Culex pipiens, C. fatigans), or in chains (Ticniorhynchus fasciolatus), present a great variety of forms. The most peculiar are shown in fig. 273 (Mansonia, Culex, Stegomyia, Anopheles).

As in all insects they differ very materially in each species of one genus. Those best known are the Anopheline eggs.

The eggs always float on the surface of the water; immersion soon destroys them.

Characters of Adult Culicida. - The chief characters by which true mosquitoes or Culicida are known are the following :-

(I) Wings always with the veins covered with scales; the longitudinal veins usually six in number (in one genus seven); the costal vein carried round the border of the wing.

(2) Head, thorax and abdomen usually, but not always (Anopheles, \& $c_{\text {. }}$ ), covered with scales.

(3) Mouth parts formed into a long piercing proboscis.

As a rule the males may be told from the females by their antennæ being plumose, whilst in the females they are pilose (vide fig. 272 ), but this does not invariably hold good, for in Deinocerites. Theobald, and Sabethes, Desvoidy, and others, they are pilose in both sexes. The labial palpi are very variable in regard to their form and the number of joints; in the Anophelina they are long in both sexes, as long or nearly so as the proboscis, more or less clubbed in the males; in Culicina, Joblotina and Heptaphlebomyia, they are long in the males, short in the females; in Edeomyina, short in both sexes.

Scnles.-The most important structural peculiarities in Culicida are the scales, which form the chief and most readily observed characters for separating genera and species.

The head, thorax, abdomen and wings are in nearly all cases clothed with squamæ of varied form, of which the following are the main types (fig. 275):-

(I) Flat, spade-shaped scales (a).

(2) Narrow-curved scales (e).

(3) Hair-like curved scales (d).

(4) Spindle-shaped scales ( $f$ ).

(5) Small spindle-shaped scales (g).

(6) Upright forked-scales ( $h$ and $i$ ).

(7) Twisted upright scales (j).

${ }^{1}$ Recent infcrmation sent me by Dr. Grabham shows this statement to be not quite correct, as the frontal hairs may vary in different stages of the same larva. This he has shown in Cellia albipes, Theo., and I have ncticed it in a Nyssorhynchus from Africa. 
(8) Inflated or pyriform scales $(k)$.

(9) Mansonia scales (b).

(Io) Small broad asymmetrical scales (c).

Various other varieties are found on the wings, such as :-

(I) Narrow linear lateral scales.

(2) Narrow lanceolate scales:

(3) Broad lanceolate scales.

(4) Elongated, broad, truncated scales (= Taniorhynchus-like scales).

(5) Pyriform scales.

(6) Asymmetrical broad or Mansonia scales.

(7) Flat spade-like scales. ${ }^{1}$

The wings have a series of scales along the middle line of the veins, and also lateral scales to all or nearly all the veins. The wing is also fringed by a series of scales (fig. 274) which, however, are of little systematic importance ; the so-called "border-scales" (b.s.) vary, however, to some extent, and are useful characters in separating some of the Mansonias.

\section{The Classification of Culicid}

Section A.-Proboscis formed for piercing; metanotum nude.

A. Palpi long in the male.

a Palpi long in both sexes.

First submarginal cell as long or longer than the second posterior cell .. . . Anophelina.

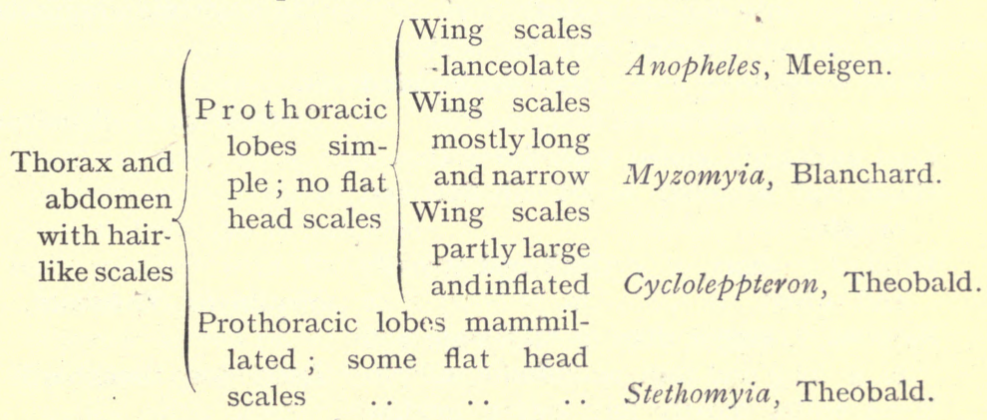

Thorax with some narrow-curved scales; abdomen hairy .. $\quad \ldots \quad \ldots \quad \ldots \quad \ldots$ Pyretôphorus, Blanchard.

Thorax with hair-like curved scales, some narrow-curved ones in front; abdomen with apical lateral scale tufts, scaly venter; no ventral tuft $\quad$.

Thorax with hair-like curved scales; abdominal scales on venter only with a distinct ventral apical tuft ... ..

Much as above, but abdomen with long spine-like dense lateral tufts .. $\quad . . \quad$ Chrystia, Theobald.

\footnotetext{
${ }^{1}$ Heart-shaped scales occur on the wings of Etoileptiomyia.
} 


\section{Abdominal scales as lateral dorsal patches of small flat scales ; thoracic scales narrow and curved, or spindle}

Thorax and shaped .. $\quad . . \quad$.. abdomen Abdomen nearly completely withscales covered with irregular scales and with lateral tufts .. .. ..

Abdomen completely scaled with large flat scales, as in Culex .. .. ..

First submarginal cell much smaller than the second posterior cell; proboscis

Palpi long in both sexes : . .

B Palpi short in the female...

First submarginal cell longer than the second posterior cell .. $\quad$. . $\quad$..

Legs more or less densely scaly; head not entirely clothed with flat scales; all the legs densely scaly.

Wings with large pyriform scales

Wings with narrow scales.

Hind legs only densely scaled

Head entirely clothed with flat scales.

Wing scales long and rather thick; hind legs of $\delta$ with apical scaly paddle ..

Legs uniformly scaled with flat scales.

Head and scutellar scales all flat and broad.

Palpi of $q$ short, of $\delta$ thickened apically and tufted

Palpi of $q$ longer than in Stegomyia and in $\delta$ long and thin, acuminate, simple

Head scales mostly flat, but a median line of narrow curved ones; scutellar scales flat on mid lobe, narrow-curved on lateral lobes and palpi longer than proboscis.. $\quad . . \quad$. $\quad$.

Head scales mostly flat irregular, narrowcurved ones behind; mid lobe scutellum with flat scales, lateral with narrow-curved; $\delta$ palpi shorter than proboscis. .

Head scales mostly flat, but a few narrowcurved ones in middle in front; scutellar scales all flat .. $\quad$. $\quad$..

Head scales all fiat; scutellar scales all narrow-curved
Nyssorhynchus, Blanchard.

Cellia, Theobald.

Aldrichia, Theobald.

\section{Megarhinina.}

Megarhinus, Rob. Desvoidy.

Toxorhynchites, Theobald.

Culicina.

Mucidus, Theobald.

Psorophora, Rob. Desvoidy.

Ianthinosoma, Arribalzaga.

Eretmapodites, Theobald.

Stegomyia, Theobald.

Desvoidea, Blanchard.

Macleayia, Theobald.

Catageiomyia, Theobald.

Scutomyia, Theobald.

Skusea, Theobald. 
Head with flat scales, except a small median area of narrow-curved ones; scutellar scales all narrow-curved ...

Head with all flat scales except a thin line of narrow-curved ones behind; scutellar scales all narrow-curved ] .

Head with small flat scales over most of surface, with median line and line around eyes of narrow-curved ones; scutellar scales bluntly spindle or club$\begin{array}{llllll}\text { shaped } & . & \ldots & \ldots & \ldots & \ldots\end{array}$

Head and scutellar scales narrow-curved.

Wing scales long, narrowly lanceolate, collected in spots; palpi clubbed in $\delta$; five-jointed and rather long in $q .$.

Wing scales (lateral) long and narrow, and $q$ palpi three-jointed, $\delta$ not clubbed and hairy $\quad . \quad \ldots \quad \ldots$

Wing scales at apex of veins dense and rather broad, femora swollen; small dark species $\quad . \quad \ldots \quad \ldots \quad \ldots \quad$..

Wings with short, thick, median scales and short, broadish lateral ones on some of the veins; scales mottled; fork-cells rather short .. . . ..

Wings with dense, broadish, elongated. truncated scales.. $\quad$. $\quad \ldots \quad$..

Wings with broad, short, asymmetrical scales $\quad \ldots \quad$.. $\quad$. . $\quad$. .

Head covered with rather broad flat, spindle-shaped scales; scutellum with small flat scales to mid lobe .. ..

Head clothed with flat, irregularly disposed scales all over, with patches of narrow-curved ones; $\delta$ palpi clubbed

Abdomen with projecting flat lateral scales with deeply dentate apices; wings not ornamented.. .. ..

Wings ornamented; scutellum with flat and narrow-curved scales $\quad . \quad \ldots$

$\gamma$ Palpi short in $\delta$ and $q \quad \ldots \quad \ldots \quad \ldots$

Wings unornamented.

Antennæ pilose in $\delta$ and $q$; second joint very long .. $\quad \ldots \quad \ldots \quad \ldots$

Antennæ plumose in the $\delta$.

Head clothed with narrow-curved and flat scales.

Mid lobe of scutellum with six borde:bristles.

Scutellum with narrow-curved scales.

Palpi in $q$ four-jointed, in $\delta$ two-jointed
Howardina, Theobald.

Danielsia, Theobald.

Hulecoetomyia, Theobald

Theobaldinella, Blanchard.

Culex, Linnæus.

Melanoconion, Theobald.

Grabhamia, Theobald.

Taniorhynchus, Arribalzaga.

Mansonia, Blanchard.

Gilesia, Theobald.

Acartomyia, Theobald.

Lasioconops, Theobald.

Finlaya, Theobaild.

Ædeomyina.

Deinocerites, Theobald. 
Mid lobe of scutellum with four borderbristles.

Scutellum with flat scales.. . . . .

Head clothed with flat scales only.

Fork-cells normal length.

Mid lobe of scutellum with four borderbristles,

Palpi of $q$ two-jointed . . . . . . Verallina, Theobald.

Palpi of $q$ five-jointed, metallic .. .. Hamagogus, Williston.

Fork-cells very small or small.

Scutellar scales flat.

First sub-marginal cell longer than the second posterior cell; no flat scales on mesothorax .. $\quad . . \quad \ldots \quad$..

First sub-marginal cell smaller than the second posterior cell; flat scales on mesothorax

Scutellar scales narrow-curved.

First sub-marginal cell as in Uranotania

Wings ornamented with Mansonia-like scales $\quad . . \quad \ldots \quad \ldots \quad \ldots \quad \ldots \quad \ldots$

Secrion B.-Metanotum ornamented with chætæ, squamæ or both.

a With chætæ only.

Proboscis longer than whole body; lateral

Wing scales Taniorhynchus-like ... ..

Proboscis as long as whole body in $q$; frons drawn out into a prominence; wing scales rather broad and long ...

Proboscis not as long as the whole body; lateral vein-scales narrow ..

Proboscis not as long as whole body, swollen apically; wing scales long and broad .. $\quad . . \quad \ldots \quad$..

B Metanotum with squamæ and chætæ.

Palpi short in $\delta$ and $q$.

Proboscis straight in $q$ and $\delta$; legs with scaly paddles $\quad . \quad$.. $\quad$.. ..

Venation like Sabethes.

Legs simple $\quad$. $\quad$.. $\quad$.. $\quad$.. Sabethoides, Theobald.

Venation like Culex $\quad . . \quad \ldots \quad$.. Goèldia, Theobald.

Proboscis in $\delta$ elbowed, with two scaly tufts

Palpi long in $\delta$, short in $q \quad$.. . . Jóblotina, Blanchard,

II. Wings with seven scaled longitudinal veins : Culex type .. ... ..

Section C.-Proboscis short, not formed for piercing .. $\quad$.. $\quad$.. $\quad$.. $\quad$..

Mctatarsus longer than first tarsal joint. .

Metatarsus shorter than first tarsal

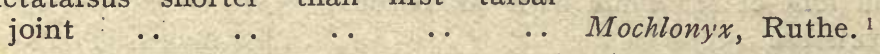

${ }^{1}$ Since this went to press many new genera have been created; these will be found in my catalogue of Culicidæ in the Nat. Mus, Hongrois, in Family Culicidæ, genera Insectorum, and in New Cúlicidæ from Ceylon. 


\title{
Notes on the Different Genera.
}

\author{
Sub-family Anophelina.
}

Genus I. Anopheles, Meigen.

[Syst. Beschr. Europ. Zwei. Ins. I., ii., 2 (1818). Meigen; Mono. Culicid., i., p. 191, and iii., p. 17, 1903.-Theob.]

This genus contains a few large species found either in temperate climates or in hills and mountains of warm climates. The type is the European and North American A. maculipennis.

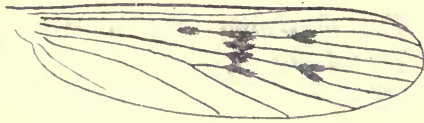

FdG. 276.-Wing of Anopheles maculipennis, Meigen.

Anopheles maculipennis, Meigen. This species and A. bifurcatus are malaria carriers. True Anopheles only occur in Europe, North America, the North of Africa and in the Mountains of India, and one has recently been found by Bancroft similar to A. bifurcatus in Queensland. They are easily told by the absence of scales on thorax and abdomen, and by the rather densely scaled wings with lanceolate scales.

Genus 2. Myzomyia, Blanchard; Grassia, Theobald.

[Comp. Rend. Heb. Soc. Biolog., No. 23, p. 795 (Blanchard); Mono. Culicid. iii., p. 24.-Theob.]

This genus occurs in Asia, Africa and South America, Europe and East Indies. The type is $M$. funesta, Giles, found in Central and West Africa. Some fifteen species occur in this genus. Although structurally there is not much difference between this genus and Anopheles, they differ greatly in appearance, and there are usually a few narrow-curved thoracic scales projecting over the head, whilst the wing scales are much smaller in proportion, and the wings more uniformly spotted, always so along the costa. Funesta is undoubtedly a malaria bearer.

\section{Genus 3. Cycloleppteron, Theobald.}

Mono. Culicid., ii., p. 312, 1903 .

Two species only occur in this genus, C. grabhamii, Theob., from Jamaica, and $C$. mediopunctatus, Theob. (Lutz., ms.), from South America. The chief character is the presence of large black inflated pyriform scales on the wings. The palpi are densely scaled. Neither have been shown to be malaria bearers. 


\section{Genus 4. Stethomyia, Theob.}

Mono. Culicid., iii., p. $13,1903$.

Two species occur in the marked genus-one $S$. nimba, Theob., from British Guiana and Para, another S. fragilis, Theob., from the Malay States.

The former may be a malarial carrier, for Dr. Low says, "Malarial fever is got amongst the Indians and often of a severe type. In that connection it is interesting that in the interior, at a place called Corato, I got an entirely new Anopheles in large numbers." The genus is easily told by its unornamented wings, flat head scales, mammillated prothoracic lobes and long thin legs.

\section{Genus 5. Pyretophorus, Blanchard; Howardia, Theobald.}

Compt. Rend. Hebdom. Soc. d. Biolog., 23, p. 795 ; Blanchard, Journ. Trop. Med., v., I8I, and Mono. Culicid., iii., I3, I903, Theobald.

Ten species come in this genus, of which Anopheles costalis, Loew, is the type.

This genus is found in Africa, India, Europe and in Australia. Two species are proved malaria bearers, namely, $P$. costalis, Loew, and $P$. chantdoyei, Theob. Members of this genus can be told by having narrow-curved thoracic scales, hairy abdomen, and much spotted wings.

Genus 6. Arribalzagia, Theobald.

Mono. Culicid., iii., pp. 13 and 81, 1903.

A single species only occurs, found in South America. The thorax and abdomen have scales and hairs respectively, as in Pyretophorus, but the abdomen has in addition prominent lateral apical scale tufts to the segments and a scaly venter. Wings with membrane tinged in patches and wing scales bluntly lanceolate and very dense. The type is $A$. maculipes, Theobald.

Genus 7. Myzorhynchus, Blanchard; Rossia, Theobald.

Comp. Rend. Heb. Soc. Biologie, No. 23, p. 795, 1902 ; Blanchard, Journ. Trop. Med., p. 181, 1902, Theobald.

A very marked genus of large dark, densely scaled species, found in Europe, Asia, Africa and Australia. The thorax with hair-like curved scales; the abdomen with ventral and apical scales, and a median ventral apical tuft, and with very densely scaled palpi in the $q$, and densely scaled proboscis. It seems to be mainly an Asiatic and East Indian genus, but three species occur in Africa and one in Australia. They are mostly sylvan species and bite severely.

Genus 8. Nyssorhynchus, Blanchard; Laverania, Theobald.

Mono. Culicid:, iii., p. I4, Theobald; Compt. Rend. Hebd. Soc. Biologie, No. 23, p. 795 , Blanchard.

A group of small, closely allied species found in India, Africa and Australia. It appears to be essentially an Indian genus-seven out of the twelve 
species coming from India and another (maculipalpis, Giles) is apparently common to India and Africa.

The thorax is covered with narrow-curved and spindle-shaped scales, abdomen with small, flat or narrow-curved dorsal scales, especially on the apical segments or in patches; the legs are always banded or spotted with white, and the tarsi have as a rule one or more pure white segments. (This banding and spotting is of no generic value, however.)

The species show considerable seasonal variation. The type of the genus is $N$. maculatus, Theobald.

\section{Genus 9. Cellia, Theobald.}

Mono. Culicid., iii., p. I4.

Very marked Anophelines, with densely scaly abdomens, the scales irregularly disposed on the dorsum and forming dense lateral tufts; thorax with flat spindle-shaped scales.; palpi densely scaled and also the wings.

The type of the genus is the African C. pharoensis, Theob. It is represented in Asia by C. kochii, Dönitz; in West Indies and South America by C. argyrotarsis, Desvoidy, and C. bigotii, Theob., in Africa by C. squamosa, Theob., \&c.

C. argyrotarsis, Desvoidy, and C. alpibes, Theobald, are undoubtedly malaria bearers, also $C$. pharoensis.

\section{Genus ro. Aldrichia, Theobald.}

Mono. Culicid., iri., p. 353, 1903.

A single species only occurs, represented by one specimen in the British Museum:1 The abdomen is completely covered with large, flat over-lapping scales, as in Culex; the thorax with very narrow-curved scales, almost hairlike, and the prothoracic lobes with outstanding flat scales. The single species, Aldrichia error, Theob., was taken in India and placed by Giles amongst his types! of rossii

\section{Sub-family Megarhinina.}

Genus II. Megarhinus, Robineau-Desvoidy.

All large brilliant mosquitoes with long palpi in both sexes and, as a rule, with a caudal fan of scales; the proboscis is long and bent. They are all sylvan species, and are not so far recorded as biting man.

Genus I2. Toxorhynchites, Theobald.

Mono. Culicid., i., p. 244, 1901.

Differs from the former genus in that the $q$ palpi are short.

The Elephant mosquito of India (Toxorhynchites immisericors), Walker, bites very severely. They are sylvan species.

\section{Sub-family Culicina.}

Genus Mucidus, Theobald.

Mono. Culicid., i., p. 268, г90т.

This genus is so far confined to Australia, West and Central Africa, East Indies and Malay Peninsula. They are all large mosquitoes, easily 
told by the whale body being more or less covered with long twisted scales, giving them a mouldy appearance, and the legs densely scaled with outstanding scales; the wings with large parti-coloured scales. The Australian $M$. alternans, Walker, occurs in larval forms both in fresh and salt water. The adults bite man.

\section{Genus Psorophora, Robineau-Desvoidy.}

This genus is confined to the Americas and the West Indies. Four species exist which can easily be told from Mucidus by the absence of long twisted scales and the narrower wing scales. The legs are densely scaled and the thorax ornamented with flat spindle-shaped scales.

Psorophova ciliata, Robineau-Desvoidy, occurs in both North and South America, and bites man.

\section{Genus Janthinosoma, Arribalzaga.}

Hind legs only densely scaled; some of the hind tarsi are always white. The venation is as in Culex. The abdomen is metallic and iridescent. They all bite man and occur only in the Americas and West Indies.

\section{Genus Stegomyia, Theobald.}

After Anopheles this is the next most important genus, on arcount of the connection of $S$. fasciata with yellow fever. This genus is easily told by the head and scutellum being entirely clothed with flat scales. They are mostly black and white mosquitoes, and are known in India as tiger mosquitoes. The best known species is S. FAsciata; it is found in all parts of the world between $40^{\circ} \mathrm{N}$. and $\mathrm{S}$. It is a most vicious biter both by day and night, and breeds in small artificial collections of water, such as barrels, puddles, cisterns, and even in such small receptacles as sardine tins. The character by which this species is told is the ornamentation on the thorax, which has a curved silvery line on each side and two dull yellow parallel ones in the middle; but it is subject to much variation, some specimens (variety mosquito) having no median thoracic stripes.

\section{Stegomyia scutellaris, Walker.}

A vicious biter, found in India, China, Malay, and East Indies, Fiji and Ceylon. The thorax has one median silvery stripe, and so can easily be told from $S$. fasciata.

A number of nearly allied genera occur here (vide synoptic table).

\section{Genus Theobaldinella, Blanchard=Theobaldia, Neveu-Lemaire.}

Includes several large Culicines, of which $T$. annulata, Meigen, is the type. The wings are usually spotted (annulata, infidens, \&c.), but may be nearly plain (spathipalpis). The $\delta$ have the palpi swollen apically, and the of have long five-jointed palps.

Several of these are vicious biters. 


\section{Theobaldinella annulata, Meigen.}

This large gnat ( $6 \mathrm{~mm}$. long) can be told by its wings having five large spots of dark scales and by its legs having broad basal white bands to the tarsi. The larvæ occur in rain barrels and small pools. It is essentially a domestic form, occurring in houses and privies. Its distribution is Europe generally and North America. The bite is very severe, and in some districts gives rise to painful œdema.'

Theobaldia spothipalpis, Rondani, occurs in Italy, Mediterranean Islands, Palestine, the Himalayas, Khartoum, and in South Africa. It is about the same size as $T$. annulata, but is yellowish-brown in colour, with striped-thorax and mottled and banded legs. It occurs in privies and bites very severely.

\section{Genus Culex, Linnæus.}

This large genus still contains many forms which should be excluded. The species normally have narrow-curved median head-scales, and similar

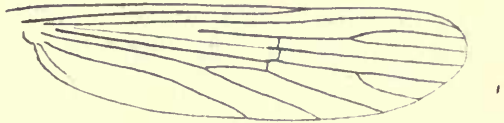

Fig. 277.-Wing of a Culer.

ones on the scutellum; the $q$ palpi are shorter than in the former genus and the male palpi are pointed; the lateral vein-scales are narrow and linear.

The type is Culex pipiens, Linn., the common gnat of Europe. The thorax is covered with narrow-curved golden-brown scales, the abdomen has basal pale bands to the segments and the legs and proboscis are unbanded. The stem of the first submarginal cell is always less than onefifth the length of the cell. It lays its eggs in rafts, in water butts, \&c., and even in the foulest water. They are first deposited in England in June and July and again soon after hatching in August. In some districts this gnat bites man viciously, in others not at all.

The common tropical gnat (Culex fatigans, Wied). This resembles the European Culex pipiens, but can always be told by the stem of the first submarginal cell always being much longer than it is in C. pipiens. This is one of the species that has been proved to transmit Filariæ to man, \&c. Varieties of it occur in almost every country between $40^{\circ} \mathrm{N}$. and S., having a very similar range to $S$. fasciaia. In all countries it appears to be con. nected with the transmission of Filariasis:

\section{Genus Melanoconion, Theobald.}

Mono. Culicid., iii., p. 238, I903.

This genus is composed of eight species, most of which are small black gnats which bite viciously and which occur in swamps and jungles. They can at once be told from Culex by the veins of the wings having dense broadened 
scales on their apical areas and along the upper costal border. The femora and apices of the tibiæ are swollen.

The black mosquito, Melanoconion atratus, Theob. This small gnat is a very troublesome pest in swamps in the West Indies. The female bites both by day and by night, and the bite causes severe irritation. The larvæ live in permanent ponds. It is almost black in colour, but sometimes presents a dull coppery-sheen; each segment has small lateral basal white spots. Length $2 \cdot 5$ to $3 \mathrm{~mm}$.

It occurs in Para and British Guiana as well as in the West Indies.

Ordinary mosquito netting is no use for keeping off this pest.

\section{Genus Grabhamia, Theobald.}

Mono. Culicid., iii., p. 243, I903.

Allied to Culex, but separated by the wings having short fork-cells, mottled scales, the median ones thick and also some of the lateral ones short and broad; the last two joints of the male palps are very slightly swollen. The eggs are laid singly, not in rafts, and the larvæ have short, thick siphons. Ten species occur and are found in Europe, N. America, West Indies and Natal. G. dorsalis, Meigen, bites severely in Europe. G. sollicitans, Walker, is a great scourge along the New Jersey Coast and at Virginia summer resorts and in Florida. It breeds in brackish water, and is the most common mosquito of the Atlantic seaboard.

\section{Genus Taniorhynchus, Arribalzaga.}

Differs from the former in having the whole wing veins clothed with dense, broadish elongated scales. They occur in South America ( $T$. fasciolatus, Arri.; $T$. fulvus, Wied.); in Africa ( $T$. tenax, Theob.); in Asia ( $T$. conopas, Frau ; $T$. aurites, Theob., \&c.), in Europe (T. richardii, Ficalbi).

A yellowish species, $T$. fuscopennatus, Theob., with black apices to some of the tarsi, occurs in Uganda, both in the forest and indoors in great numbers. Dr. Loew found filariæ in the thoracic muscles of this species.

\section{Genus Mansonia, Blanchard; Panoplites, Theobald.}

Compt. Rend. Hebd. Soc. d. Biol., 37, iii., p. I046, I901 ; Mono. Culicid., ii., p. 173, 1901.

A very marked genus easily told by the broad asymmetrical wing scales. It occurs in Africa ( $M$. uniformis and $M$. major, Theob.); in Asia ( $M$. uniformis, Theob.; M. annulipes, Walker, \&c.); and in Australia ( $M$. australiensis); in the Americas and West Indies ( $M$. titillans, Walker). The eggs (fig. $273, d$ ) are peculiar in form and are laid separately; the larva has not been described; the pupa has long curved siphons. They mostly occur along rivers, in swamps and forests, and bite very severely. They also enter houses ( $M$. titillans). $M$. uniformis is most troublesome during the rains. The saliva is strongly acid. 


\section{Genus Acartomyia, Theob.}

Mono. Culicid., 111., p. 25I, 1903.

A single species, A. zammtii, Theob., only known, which occurs in large numbers, breeding in salt pans along the shore line in Malta. It bites severely.

The genus differs from Grabhamia, to which it is nearest related, by having irregular flat scales over the head, not closeiy applied as in Stegomyia, but loose and irregular. It is possible that there is a connection between this species and Mediterranean fever.

Several of the $\mathbb{E}$ deomyina bite, especially the small Uvanotcenias. They are all sylvan species, seldom entering houses. They need not therefore be referred to here.

For full details of the Culicid genera and species the reader is referred to my Monograph,' and my recent work in genera Insectorum (1905).

\section{Other NEMATOCERA.}

Other Nematocerous flies are midges, daddy-long-legs and sand-flies. The ones which cause annoyance to man besides Culicide are the following :-

Sand-flies, Simulide; certain Midges, Chironomide, and a few Owl midges, Psychodida.

The Nematocera have long thread-like jointed antennæ and their pupæ are, as a rule, naked; the larvæ have a distinct head and can thus be told from the next section (Brachycera).

\section{Sand-flies or Simulida.}

[These flies are also known as black flies, buffalo gnats, and sometimes are wrongly called mosquitoes. One genus only exists, viz., Simulium. They occur from Iceland to the Tropics and often swarm in damp places. Their bite is very severe and produces intense pain both in animals and man. They are all dark coloured, small flies, stoutly built, with largish wings; the first, second and third veins dark, the rest pale; legs stout and compressed, unarmed.

The larvæ are aquatic and hold on to stones, grass and water weeds, twigs and roots. When young they are transparent, usually later becoming grey or brown; they prefer running water to still, attaching themselves by a number of hooklets on the posterior part of the body; they thus hang head downwards and collect food by the aid of a pair of fan-like scoops upon either side of the head; on the ventral surface of the thorax is a kind of proleg used for movement, the larva progressing much after the manner of a "canker-worm " or "looper-larva." They have also the power of forming a silken cord, with the aid of which they drop slowly down the stream until a fresh foothold is secured.

The pupal stage is passed in a small shoe-shaped cocoon open at one end,

1 "A Monograph of the Culicidx of the World," 2 vols. and atlas, 1901, and vol. 3 and plates, 1903. British Museum (Nat. Hist.). 
which is formed by the larva of a silky substance. The pupa enclosed in this brown cocoon is bright brown with crimson eye spots (in some species); on the front of the pupa are four-branched respiratory filaments on either side; these and the head of the pupa project from the cocoon. The flies are most restless, and even when stationary continually move their legs about, moving them like feelers. They are gregarious.

Simulium columbaschensis is a great plague to man and beasts in parts of Hungary, \&c It is known as the "Kolumbatz fly." It derives its name from an old Servian castle in the district of Poshararatz, where it abounds in damp marshy lands along the Danube. It is abundant in Austria and Moravia as well, and is most numerous after inundations from the Danube. They sometimes appear in such swarms that it is impossible to breathe without getting them into one's mouth, and white animals become quite black. There are instances of children being lkilled by these flies, which swarm over them when left by their mothers on the ground when they are occupied in the fields.

\section{Simuilium maculatum, Meigen.}

Female bluish-grey with three black stripes on the thorax; abdomen with three black spots above; male dusky black with the sides of the

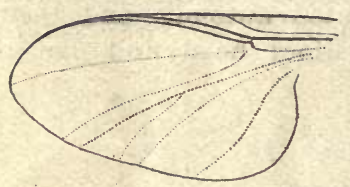

Fig. 278.-WING or Simulium.

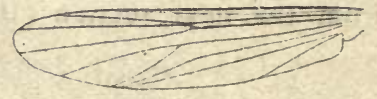

FIG. 279.-WING of Chironomus.

thorax yellowish in front and the base of the abdomen yellow on each side. Length 2 to $2.5 \mathrm{~mm}$.

This so-called spotted Simulium now and again attacks man in Europe, but especially horses and cattle.

Other species, as S. reptans, Linn., and S. cinerum, Mac., are very annoying to man in Great Britain and Europe, biting very ficicely and causing painful wounds.

S. reptans $\mathrm{s}^{1}$ is 2 to $3 \mathrm{~mm}$. long; the female is grey, the male dark and velvety with grey sides to the thorax; base of wings and balancers yellow and legs with white rings.

S. cinerum, Mac., is dark grey with three dark thoracic lines and three dark lines on the thorax; antennæ and legs black. Length 3 to $3.5 \mathrm{~mm}$.

S. damnosum, Theob.," a small sand fly, known as the "Jinja Fly," is found forming a "fly belt" from the shores of Victoria Nyanza northwards along the right bank of the Nile, for twelve or fifteen miles or more, and about three to four miles wide. At certain seasons it swarms in such numbers and is such

1 "An Account of British Flies," vol. i., p. 167. Theobald.

2 Proc. Royal Soc., "Sleeping Sickness Report." ii., I 903. 
a plague that the natives leave their plantations. On nearing the sphere of influence of the Jinja fly the porters stop and break off branches to use as fly swishes, then collect together and travel at an increased speed. The fly is $3 \mathrm{~mm}$. long, of a general black colour, with bright deep golden hairs on the thorax, and the metatarsi of the hind legs with a median pale yellow band.

Numerous other undescribed species have been sent me from the Tropics, where they are known under a variety of names, such as black-fly, brûlots, sand-flies, \&c.

\section{Family Chironomida.}

The Chironomidæ or midges are not only frequently mistaken for mosquitoes, but some are undoubtedly very annoying to man by biting him as mosquitoes do. They are easily distinguished from true mosquitoes (Culicide $)$ by the following characters: (I) head small, often retracted under the cowl-like thorax; (2) no scales to the wings or body and (3) the different arrangement of veins on the wings (fig. 275).

One genus only is important as annoying man, namely, Ceratopogon. The larvæ are either aquatic, both fresh water and marine, and help to

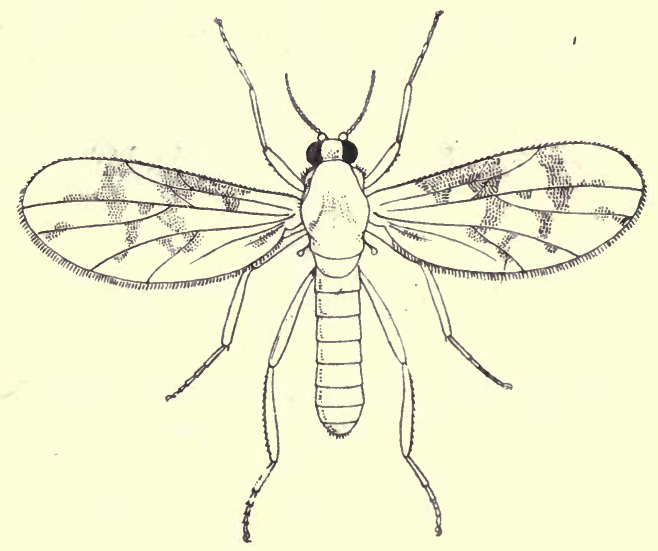

FIG. 276. -A Ceratopogon or Midge (greatly enlarged).

make the former foul' according to Slater, or may as in Ceratopogon live beneath the bark of trees. The pupæ are very varied and also the lifehistories of the different genera.?

\section{Genus Ceratopogon.}

Body small, pilose or bare; head produced into a short rostrum : proboscis with fleshy labium, labrum horny; maxillæ long and horny; wings mostly mottled. The thorax is not produced as a cowl over the head. Abdomen composed of eight segments, hairy. The larvæ are

1 “Entomologist," p. 89, 1879.

2"An Account of British Flies," vol. i., Theobald, p. 172. 
terrestrial and often dwell beneath the bark of decaying trees and even in manure. They are cylindrical white grubs with the anterior part slightly enlarged; head small and retractile, segments deeply constricted, with appendages on the prothorax and on the anal segment. The pupæ are much shorter than the larvæ and are broadest in front with two short lateral appendages; some have long filiform appendages on the back of the thorax. This group of midges are known in America as "punkies." They are most troublesome in the Tropics, but cause great annoyance by their bites in many countries with temperate climates. Little or nothing is known of the exotic species.

\section{Psychodida, or Owl Midges.}

These small flies are easily told by their extremely hairy wings and bodies and general moth-like appearance. The proboscis is usually short, but in some exotic genera (Phlebotomus, \&c.), it is elongated and horny, and

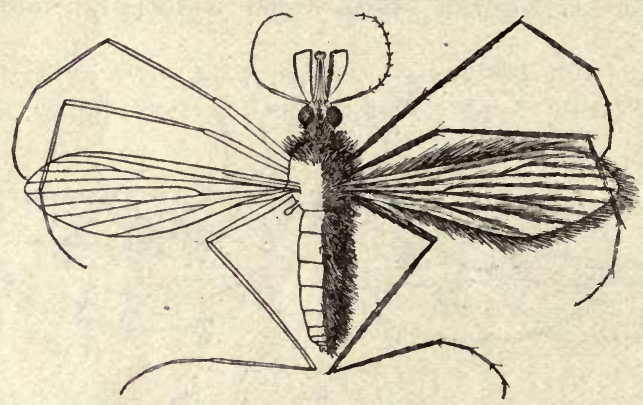

Fig. 277.-An Owl Midge, Phlebotomus, sp., greatly enlarged.

(From Giles' "Gnats or Mosquitoes.")

these are vicious blood suckers. The larvæ live in water, in rotting vegetable substances; they are more or less cylindrical with a short terminal stigmatic tube. The pupæ have two long tube-like anterior stigmata.

The genus Phlebotomus occurs widely over tropical climes; specimens have been received by me from India, West and Central Africa and South America. They frequently occur on windows in houses.-F. V. T.]

\section{(b) Brachycera (Flies).}

The antennæ as a rule have three joints, and are usually shorter than the head. The first joint of the antennæ is frequently very small, and the third one is generally the largest, and sometimes possesses a terminal annulated bristle. The palpi have from one to three joints; the mandibles are covered by the labium. The three thoracic rings are coalesced; wings are almost always present, the posterior ones being rudimentary and covered with a little scale. From the ova legless maggots are hatched, which as a rule have not a distinct head, but occasionally possess two 
or four claw-like hooklets. These maggots live in decomposing organic matter: they rarely live in water, and some of them are parasitic. They either become barrel-shaped pupæ within the last larval integument, or, after casting it, are transformed into pupæ. The larvæ of numerous Brachycera have been observed in man, some in ulcers, or on mucous membranes, others in the skin, or in the intestine, \&c. In many cases the report only mentions the presence of the larvæ of flies; in other cases the species has been determined; whilst in still other cases the corresponding adult creature is unknown. We must, therefore, confine ourselves to describing the most common varieties.

\section{Phora rufipes, Meig.}

The larvæ of the "hump-backed fly" live in rotting potatoes, mushrooms, radishes, \&c., and when accidentally introduced into the intestine of man can, like other larvæ, live there twenty-four hours, and even more, and may set up serious gastric disturbances.

[The larvæ of the Phoride also live in decaying animal matter. Some forms have been found breeding in dead bodies (Howard).

$P$. rufipes is the same as $P$. pallipes, Latr.-F. V. T.]

\section{Piophila casei (L.).}

Cheese flies. The larvæ live in ripe cheese, with which they are sometimes introduced into human beings (Meschede).

[The larvæ of the cheese flies (Piophila casei) may pass through the alimentary canal of human beings alive, and have been occasionally referred to in cases of internal myiasis. It also breeds in dead bodies in adipose tissue. Howard records it on human excrement. it is thus possible that some of the recorded cases of this pest being passed alive may be due to eggs deposited on human færes.-F. V. T.]

\section{Teichomyza fusca, Macq.}

Syn.: Scabella urinaria.

These larvæ live in the urine of privies, and are said to have been repeatedly observed in the fæces or vomit of persons.(Davaine, Rogers, Pruvot, \&c.).

\section{Anthomyia canicularis, Meig.}

Syn.: Scalaris, Fabr., and manicata, Meig. The larvæ live in vegetables, cabbage, \&c.), and are beset with feathered bristles. They frequently invade the intestine of persons, and produce alarming symptoms until vomited up or passed with the fæces (Dubois, Wacker, Kohn, Lampa, Finlayson, \&c.).

[This species is known as Homalomyia canicularis, Linn. It is common to Europe and North America, and is an abundant house-fly. It is the small house fly so often seen on windows. Besides living on vegetable matter, they have also been found in the nests of the humble bee. Larvæ of this species were sent to the British Museum, taken from the fæces of a 
woman suffering from cancer..$^{1}$ They were found at Shrewsbury. Hagen" reports the larvæ of this fly as occurring alive in the urethra of a patient. -F. V.T.]

\section{Homalomyia scalaris, Fabri.}

[This is not a synonym of the above, but a distinct species.

H. manicata, Meigen, is alsc distinct.-F. V. T.]

\section{Musca domestica, L.}

and $M$. (Calliphora) vomitoria, L. and allied species; the larvæ have been repeatedly found in the intestine and nose of man (Mankiewicz, \&c.). ${ }^{3}$

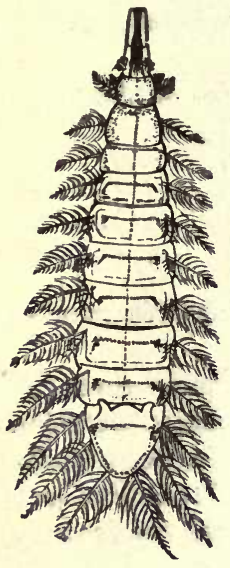

FIG. 278.-Larva of Anthomyia Canicularis (enlarged).

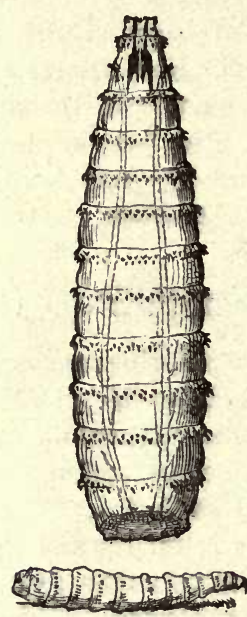

FIG. 279.-Larvæ of Musca vomitoria (enlarged).

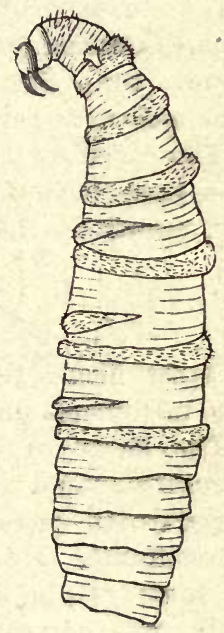

FIG. 280. - Larva of Lucilia macellaria. (After Conel.) 4/I.

\section{Lucilia macellaria (Fabricius), I794.}

Syn.: Luc. hominovorax, Coq., I858 ; Calliphora infesta, Phil., I86I ; Cailiphora anthropophaga, Conil, I878.

An American fly which deposits its eggs on ulcers, in the auditory canal or in the nostrils of persons who may be sleeping in the open air. The larvæ (screw worms), which are provided

1 “First Report Economic Zoology," p. 55, Brit. Mus. (Nat. Hist.), Theobald.

"Hagen, Proc. Bost. Soc., N.H., xx., 107.

${ }^{3}$ Larva of a Musca, probably $M$. corvina, were passed in numbers per rectum by a child in Liverpool with Homalomyia larvæ.- "Second Report Economic Zoology," p. 16, 1903, Theobald. 
with strong spines, work themselves into the nasal and frontal sinus, into the pharynx, larynx, \&c., perforate the mucous membranes and even the cartilage, and may cause the death of their host (Coquerel, Philippi, Francius, Humbert, \&c.).

[This species, the screw worm fly, is known as Compsomyia macellaria, F. It attacks animals as well as man, especially laying its eggs on wounds formed by barbed wire. It may also be found on dead flesh. Dr. St. George Gray sent me specimens from St. Lucia, from the nose

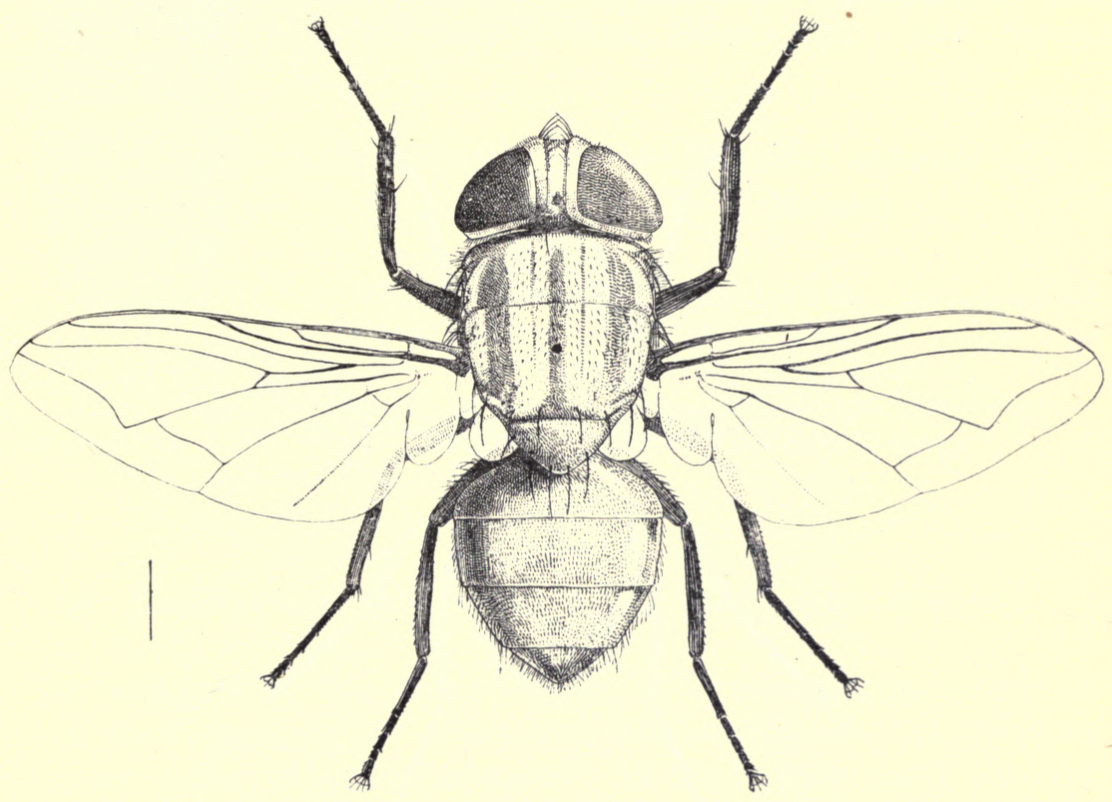

FIG. 281.-The Screw Worm Fly (Compsomyia macellaria).

and mouth of a patient in Victoria Hospital. Others were found in the vagina of another patient. Out of the four patients attacked two occupied the same bed, one after the other, and a third the next bed to it. The other case was in a more remote part of the hospital.-F. V. T.]

\section{Lucilia nobilis, Meig.}

The larvæ were observed by Meinert in Copenhagen in the auditory meatus of a person who, after taking a bath, fell asleep in the open air, and on waking felt singing in the ears, and had a sensation as if there were water in the auditory canal. During the next days severe pains set in, and there was a discharge of blood and pus from both ears, as well as from the nose. On washing out the meatus the maggots made their appearance. 


\section{Lucilia casar, Linn.}

[This golden-green fly usually lays its eggs on decomposing organic matter; now and again it lays its eggs in wounds on man.-F. V. T.]

\section{Io. Sarcophaga carnaria (L.), I758.}

The larva of this common fly has been repeatedly observed in the nasal cavity, the conjunctiva, the external meatus, on the prepuce and anus, in the vagina, in ulcers and in the intestine of man (Guyot, Grube Legrand, \&c.).

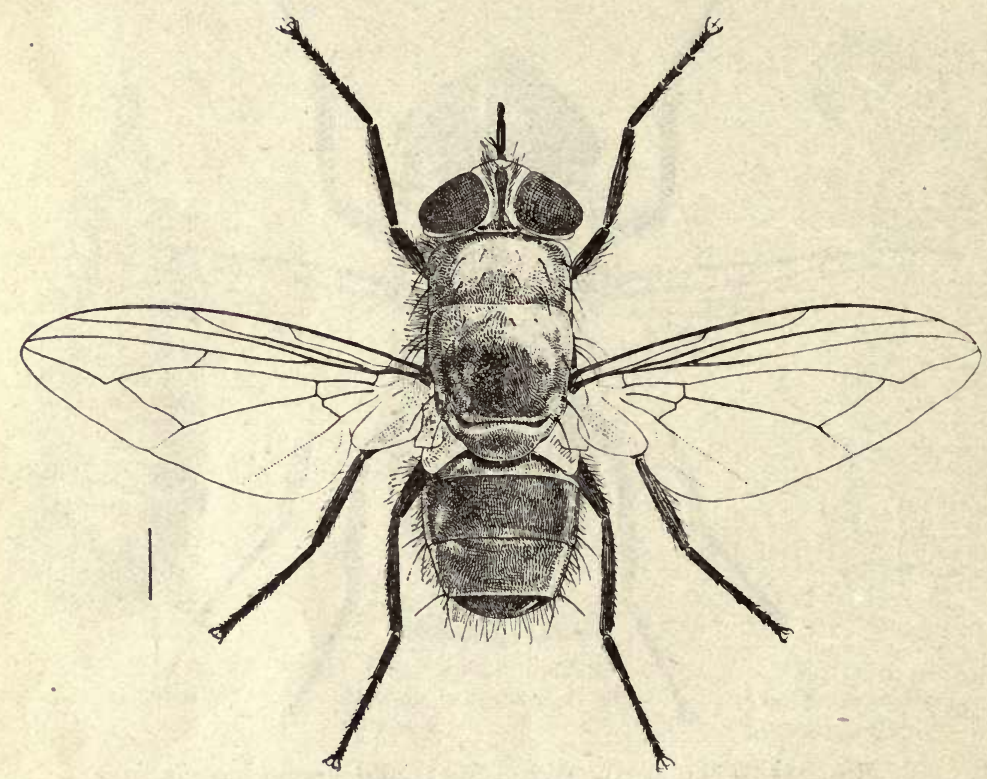

Frg. 282.-The Green Bottle Fly (Lucilia casar, Linn.).

II. Sarcophaga magnifica, Schiner, I862.

Syn. : Sar. wohlfahrti, Portschinsky, 1875.

Spread over the whole of Europe, but is particularly frequent in Russia. The larvæ live in ulcers and the canals and cavities of man that are directly accessible from the exterior. In these situations they cause symptoms similar to those set up by Lucilia macellaria. Little children are especially attacked in the Protectorate of Mohilew (Wohlfahrt, Gerstäcker, Portschinski, \&c.).

[This fly is viviparous. The fly varies from 10 to $30 \mathrm{~mm}$. in length, and is of a general ash-grey colour; the thorax with three dark stripes, the abdomen light grey with three black spots on each segment; legs black; base of wings yellow. It alsn attacks animals and birds, especially geese.-F. V. T.] 


\section{Ochromyia anthropophaga, E. Blanch.}

This fly is frequent in the south of Senegal, especially in Cayor; the larva (ver du Cayor) develop in the skin of man, dogs, cats, jackals, \&c. A closely-related form occurs in the

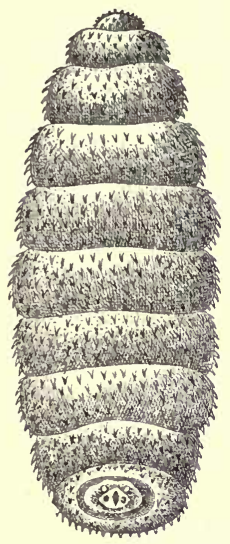

FIG. 283.-Ochromyia larvæ on the skin of man, South Africa. (After Blanchard.) 3/1. south-east of Africa. In consequence of their manner of life these larvæ were usually mistaken for the larvæ of Oestrida until $\mathrm{R}$. Blanchard recognised their real nature; they are the larvæ of Muscidae (Bérenger-Férand, Lenoir and Railliet, Blanchard).

[13. Auchmeromyia (Bengalia) depressa (The Maggot Fly of Natal.:)

This fly, which belongs to the Sarcophagidæ, produces serious cutaneous myiasis. It occurs from Delagoa Bay to Natal and into Rhodesia. It is common in Natal, from the Tugela downwards. (Vide "Second Report on Economic Zoology," p. II2. -F. V. T.]

\section{[14. Auchmeromyia luteola, Fabr. (The Congo Floor Maggot).}

The maggots of this muscid fly occur in numbers in the native huts in the Congo region. They get into crevices, \&c., of the mud floors and under the sleeping mats. At night they crawl out and suck the blood of sleepers and then return to their shelter. The fly is thickset and about the size and build of a blue-bottle. Length Io- $12 \mathrm{~mm}$. Tawny in colour with small black hairs covering its body, giving it a smoky appearance. The flattened thorax has longitudinal black and brown stripes; the abdomen has a dark line in the centre of the second segment which meets a dark line in its posterior border, the dark brown third segment has a narrow yellow anterior line; the fourth is also dark with a paler posterior border. The legs are buff, with black hairs and bristles. The fifth tarsal joint is jet black. After a feast of blood the maggots become reddish.-(Vide Mem. xiii. Liv. Sch. Trop. Med., p. 40, "The Congo Floor Maggot," by Dutton, Todd, and Christy.) —F. V. T.] 


\section{I5. Hypoderma bovis (De Geer), I776.}

Ox hypoderma, ox gad fly, or warble fly. The female deposits her eggs on the skin of cattle; the young larvæ bore deep into the subcutaneous connective tissue, where they give rise to characteristic tumours, which may attain the size of pigeons' eggs. When the larva has reached its full size it again casts its skin and leaves its host to become a pupa on the ground. The larva has also repeatedly settled in the skin of man (Spring, Joseph, \&c.). ${ }^{1}$

\section{Hypoderma diana, Brauer, I858.}

The larvæ live in the skin of deer and roedeer; they have also, in three cases, been observed in man (Boithen, Joseph, Völkel.)

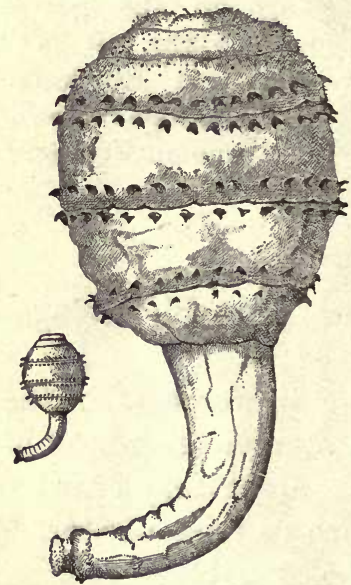

Fig. 284.-Larva of Dermatobia cyaniventris in its natural size and magnified. (After Blanchard.)

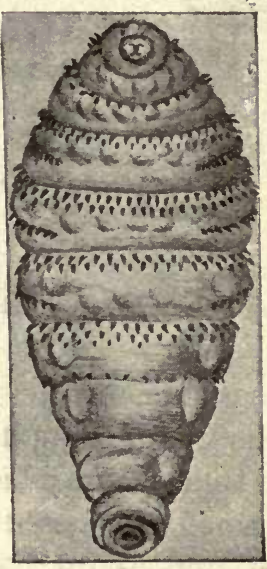

Fig. 285.-Larva of Der. matobia cyaniventris, enlarged. (After Blanchard.)

\section{- I7. Gastrophilus, sp.}

The larvæ of some species of Gastrophilus live in the stomach as well as in the duodenum of horses. When they have become mature they leave the intestine by the natural channel to become puparia in the ground. Cholodkowsky states that the "little worms" observed by Samson and Sokolew

'This species has frequently been confused with $H$. lineata, Villiers (vide Second Rep. Sco. Zool. 1903.)-F. V. T. 
(Wratsch, [895. Nos. 48 and 57), that bore fine canals in the epidermis of human beings are the young larvæ of a Gastrophilus. ${ }^{1}$

\section{I8. Dermatobia cyaniventris (Macquart), I840.}

Syn.: Cuterebra noxialis, Goudot, I845; Dermatobia noxialis, Brauer, I 860 .

The Dermatobia flies in tropical America take the place of our species of Hypoderma, and their larvæ live in the skin of mammals, as well as of human beings. In Mexico they are called "Moyoquil," in Guiana "Macaque," in Venezuela "Torcel," and in Brazil "Berne." They were formerly, at least as regards their occurrence on man, considered to be the larvæ of various species, till R. Blanchard was able to demonstrate the fact that the different forms are only consecutive stages of the same species (Dermatobia cyaniventris).

Sangalli (I893) also identified this species in Italians returned from Brazil.

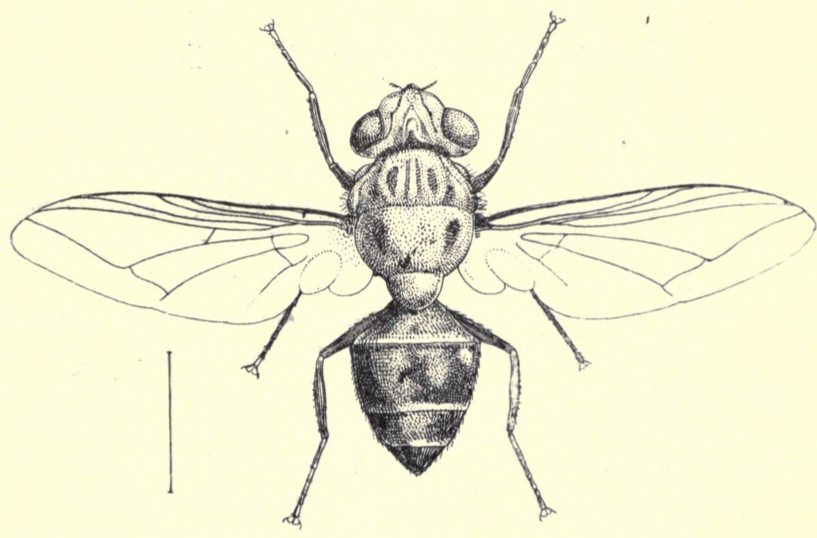

FIG. 286.-Dermatobia noxialis, Goudot.

I9. Dermatobia noxialis, Goudot.

[Dermatobia cyaniventris, Macquart, 1843 , is not the same as noxialis (vide Brauer, p. 266). It is known by various other names, as Nuche or Gusano in New Grenada; the Ura in Brazil, and the Macaw fly in Cayenne. It occurs from Mexico to Brazil. According to Goudot the fly is found in great numbers on the borders of large woods and lands covered with underwood.

The cattle worm, or founzaia ngómbe, is the name given to a larva which

" Ueb. einig selt biem Mensch vork. Paras." (Stzgzb. d. St. Petersb. naturf. Ges s 897 , p. $185 ;$ Wratsch, 1896, No. $3 ; 1897$, No. $7 ;$ i898, No. 2). Compare also Arch. f. Dermat. u. Syph., xli., p. 367. 
develops beneath the skin of oxen and men in Central Africa, especially amongst the natives and stock of Unyamonezi. According to P. Dutrieux, ${ }^{1}$ the egg is laid by a large fly that accompanies cattle. It is unknown between the central plateau or the Ugogo and the East Coast.-F. V. T.]

\section{Biting-mouthed Brachycera.}

By F. V. Theobald.

[Amongst the division Brachycera (as meant in this work) we get several groups of flies which like the fleas and mosquitoes are partially parasitic on man, the adults, mainly in the female sex, being provided with a piercing mouth with which they extract the blood of man and animals. The importance of these parasites is not the mere fact that they feed upon our blood, but that they in all probability often carry germs from man to man (Tsetse flies and Trypanosomosis, Tabanidæ and Anthrax). Amongst the most important bitingmouthed diptera in this section are the following: Tabanida, or Gad Flies, Glossina, or Tsetse flies; and certain other Muscida. Some of the exotic Asilida and a few Leptida also bite man.

\section{Family Tabanida or Gad Flies.}

The Tabanidæ have a broad, rather flattened body and a large head; eyes united in the male. The antennæ have the third joint composed of five to eight annuli. The proboscis is projecting, and sometimes much elongated. The legs are moderately stout. The venation of the wings is shown in the figure 287.

This family of Gad, or Horse flies, contains a great number of genera, all of which bite animals and man more or less severely. The female alone is blood sucking, the males feed upon the juices of flowers. The females deposit their spindle-shaped eggs on leaves, stems of plants that either overhang or stand in water, and amongst rushes; they are at first white, but become brown or black. The eggs are laid in convex masses composed of layers one upon the other. The larvæ are carnivorous, feeding upon snails, other larvæ, \&c., and have a distinct head; they are composed of eleven segments, the last with a vertical breathing pore, or the last two segments may form a breathing tube. The majority taper to a point at each end, in colour shining white or dull grey, many of the larger specimens banded with dark brown or black. The young larvæ burrow into any soft substance, animal or vegetable; they live both in the water and under damp soil surrounding water, also in damp earth generally. The larvæ are not only carnivorous, but they are cannibals, frequently devouring their own species. They may take more than a year to mature.

The pupæ are found close to the surface of mud and earth, and are mostly dull yellowish in colour with rows of spines at the apical third of

1 "Apercu de la pathologie des Européans dans l'Afrique intertropicalc," These de Paris, p. 60, 1885 . 
each abdominal segment, and there are also denticles at the apex of the abdomen.

A habit common to the adults of most of the Tabanidæ of consider-

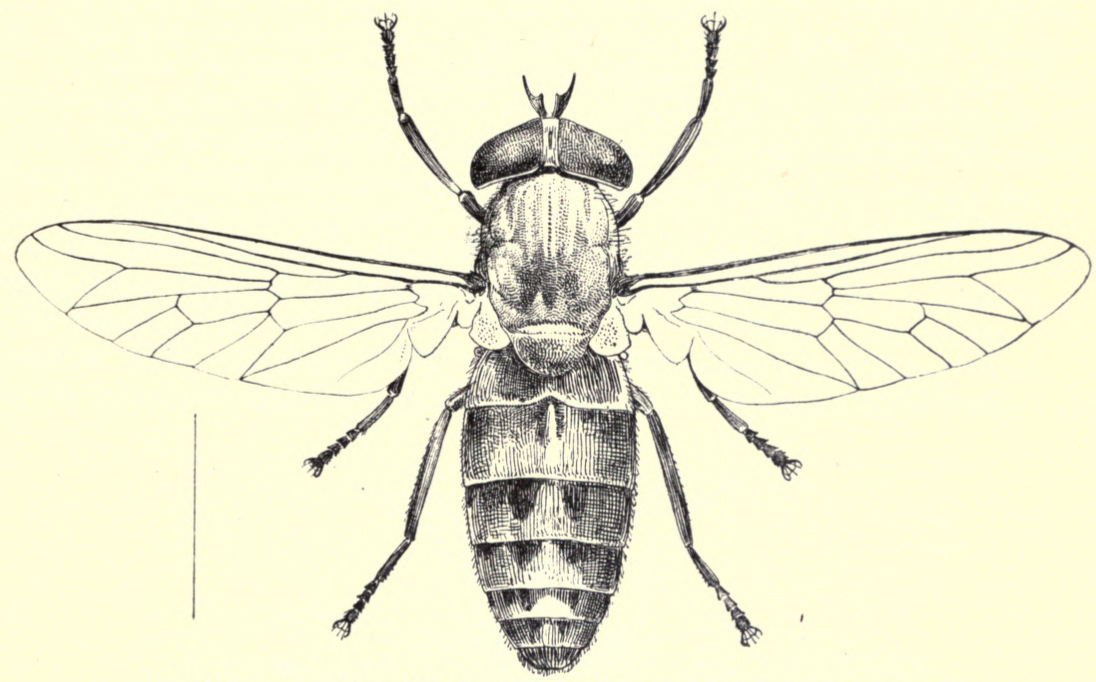

FIG. 287.-The Ox Gad Fly (Tabanus bovinus, Linn.).

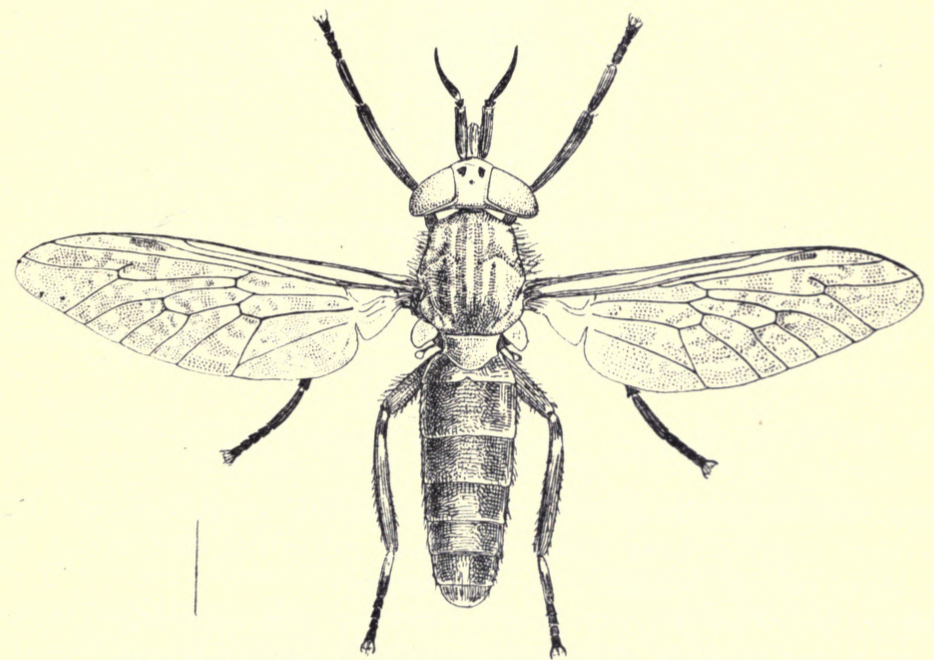

FIG. 288.-The Brimp (Hamatopota pluvialis, Linn.).

able economic importance is that of the adults coming to water to drink. Porchinski $i^{1}$ has found that by applying kerosene to the pool they frequent that the adults are killed, and Hine ${ }^{2}$ that the same oil kills the larvæ that fall into the water from eggs laid on plants above.

1 Vide Bull. 20 N. Sc. U. S. Division, Ento, U.S.A.

" Tabanida of Ohio, Ohio State University. Bull, I9, Sc. 7, p. I4, 1903. 
There are two main sections (I) Pangonince in which the hind tibiæ have spurs at the tip, and (2) the Tabanine in which the hind tibiæ have no spurs.

The chief annoying genera are told by the following characters:Proboscis very long; hind tibiæ with spurs at the tip .. .. Pangonia. Proboscis short; wings with dusky markings; ocelli present .. Chrysops. Hind tibiæ without spurs; thorax and abdomen with irri-

descent tomentum; all tibiæ dilated $\quad . \quad \ldots \quad \ldots$ Hadrus.

Thorax and abdomen without tomentum ; third joint of anten-

næ without well developed basal process; wings mottled

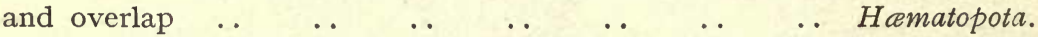

Eyes bare ; last joint of antennæ notched in crescent form .. Tabanus. Eyes pubescent; a small ocelligerous tubercle present.. . . Therioplectus.

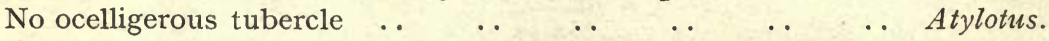

Great numbers of these flies bite man in all climates. The Pangonia can pierce even through thick clothing. Chrysops and Hematopota pro-

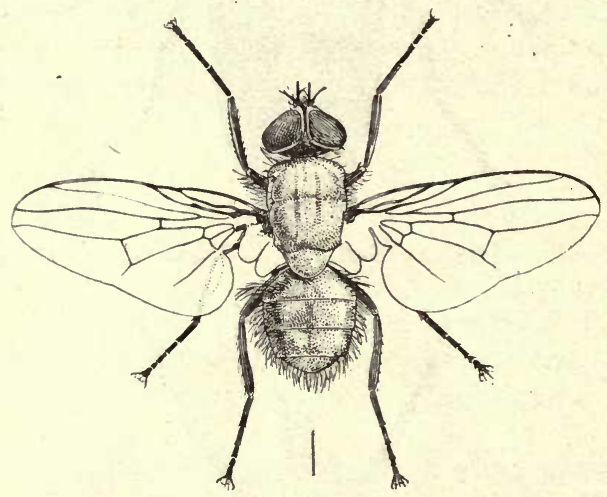

FIG. 289.-The Stinging Fly (Stomoxys calcitrans, Linn.).

duce most pain in man when biting. A common Hæmatopota is $H$. pluvialis or the 'Brimp' found in Europe. It bites men severely. H.crassicornis is also sometimes annoying. ${ }^{\mathrm{I}}$

\section{Family Asilida or Wolf Flies.}

These flies are of little importance in regard to the subject dealt with in this book; but I have had notes sent concerning the biting habits of one or more species belonging to this family..

Asilida, or Wolf-flies, are easily told by the following characters :Large or moderate sized flies, thickly hairy; head separated from thorax by a narrow neck; eyes separated in both sexes; proboscis firm and horny, adapted for piercing; abdomen long, pointed, and composed of eight segments. Legs strong and bristly, of moderate length. Wings sometimes mottled, lying parallel over the abdomen when at rest. There are nearly 3,00 species. They live mostly upon insects, but some are said to bite animals and man. They are, however, of little importance in this respect.

' Second Report Economic Zoology, p. I5, 1903, Theobald. 


\section{Family Muscida (in widest sense).}

This large group of flies contains a host of varied forms; such insects as the house fly may be taken as an example. Some have been referred to in this book as being parasitic during larval life (Compsomyia macellaria, Sarcophaga magnifica, \&c.) ; there are others, however, not referred to here which must be mentioned, namely, Stomoxys, Glossina, Hamatobia, Hydrophoria, Hydrotaea, and Aricia.

The Stomoxys, or Stinging Flies, have a solid elongated proboscis, bent near its base, extending beyond its head; its palpi are shorter'than the proboscis. They are also known as cattle or stable flies. One of the chief species is S. calcitrans - a fly which is common to Europe and North America; has a wide distribution. The larvæ live in horse manure, the adults upon the blood of animals. It has a superficial resemblance to the

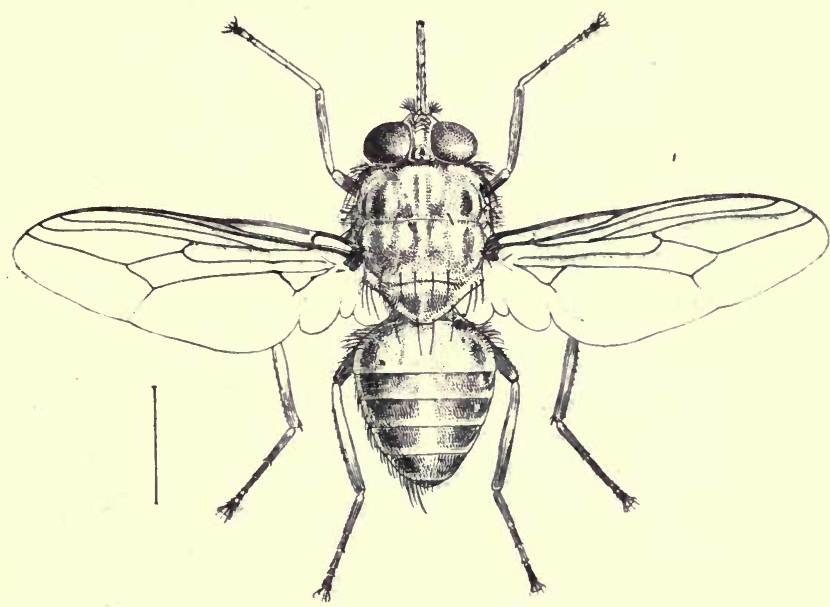

FIG. 290.-The Tsetse Fly (Glossina morsitans, Westwood).

common house fly, but can at once be told by the projecting proboscis. They bite man viciously even through thick clothing. Various species occur in the Tropics. It is noticed that this fly invades houses and stables prior to a storm of wind and rain.

The Horse Fly (Hamatobia irritans, L.) attacks cattle chiefly, but now and then man is bitten. The different species can be told from Stomoxys by the palpi being nearly as long as the proboscis.

Hydrotaea meteorica, L. (the Meteoric Fly). This fly attacks man as well as animals. They especially bite around the eyes and nostrils of animals, but are not so particular with man; the head, however, is usually chosen. Linnæus called it the Meteoric Fly, because it often forms clouds around horses' heads at the approach of rain. The Hydrotaas come in the family Anthomyide, and are usually black or blue-black in colour with bare eyes and simple abdomen, the front femora peculiarly constructed

The genus Hydrophoria, Desvoidy, also bites man. 


\section{Glossina (Tsetse Flies).}

Eight different species of Tsetse fly are known.' They all bite animals and man. They occur only in Africa. The so-called N'gana of horses, \&c., is distributed by one of these flies. The bite is not very painful to man, but their importance lies in the fact that they carry the Trypanosome of sleeping sickness and other species.

The following is Austen's revised synopsis of the species of Glossina 2:-

"1. Hind tarsi dark, or at least all the joints more or less dark (in the $q$ of Glossina tachinoides, the basal half of the first joint and the extreme base of the following joints are usually pale.. ..

" Hind tarsi not entirely dark; last two joints alone dark, remainder pale $\quad$. $\quad \ldots$.. $\quad$.

" 2. Ground colour of abdomen ochraceous buff, with interrupted dark brown deep transverse bands and sharply defined pale hind borders to the segments; a very conspicuous square or oblong pale area in the centre of the second segment ; small species, not exceeding $8 \mathrm{~mm}$. in length (exclusive of proboscis); the males considerably smaller

2.

"Abdomen not so marked, very dark or for the most part uniformly brown, hind borders of segments if lighter extremely narrow and cinereous; pale area in centre of second segment usually triangular with the apex directed backwards and continued into a cinereous median stripe ; larger species _. $\quad$.. $\quad \ldots \quad$..

“ 3. Third joint of antennæ dusky brown to cinereous black

"Third joint of antennæ pale (orange buff) ..

" 4. Large species: length at least in mm., wing expanse measured from tip to tip when wings are set at right angles to body, at least $25 \mathrm{~mm}$. ․ 7 .

"Smaller species: length rarely reaching I I $\mathrm{mm}$., often considerably less; wing expanse not exceeding $25 \mathrm{~mm}$.

" 5. Last two joints of front and middle tarsi without sharply defined dark brown or black .. . .

"Last two joints of front and middle tarsi without sharply defined dark brown or black tips, front and middle tarsi entirely yellow, or last two joints of former faintly tipped with pale brown

Tachinoides, Westw.

Pallidipes, Austen.

1 "Monograph Tsetse Flies," E. Austen, British Museum, Nat. Hist., 1903.

2 "Supplementary Notes on the Tsetse Flies," Mem, XIII. Liv. Sch. Trop. Med., p. III, 1904 . 
" 6. Generally distinctly larger; head wider; front darker and narrower in both sexes, sides parallel in the $\delta$; abdominal bands deeper, leaving hind margins of segments only narrowly pale ; hypopygium in $\delta$ smaller, darker, and more hairy ; tip of $\delta$ abdomen more thickly clothed laterally with short black hair, bristles on sixth segment finer and less prominent $\quad$. . .

"Usually smaller; head narrower; front paler and wider; eyes in $\delta$ as well as in $q$ distinctly converging towards vertex; abdominal bands less deep; pale hind margins of segments therefore deeper; hypopygium in $\delta$ larger, paler, somewhat more oval in outline, and clothed with fewer fine hairs; tip of $\delta$ abdomen less hairy laterally; bristles on the sixth segments in $\delta$ stouter and more conspicuous .. $\quad$. $\quad$.. Morsitans, Westwood.

" 7. Dorsum of thorax with 4 sharply-defined small dark-brown oval spots, arranged in a parallelogram, 2 in front of and 2 behind transverse suture ; bulb at base of proboscis brown at the

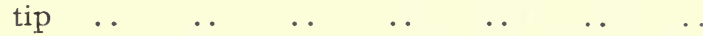

Longipalpis, Wied.

Longipennis, Corti.

"Dorsum of thorax without such spots, though with more or less distinct longitudinal stripes ; bulb at base of the proboscis not brown at tip .. Fusca, Walker."

The most important species is Glossina palpalis of Robineau-Desvoidy, as it acts as the carrier of the Trypanosomes of man (Trypanosoma gambiene). Brumpt considers that the Tsetse disease of domesticated animals is carried by at least five species of Tsetse Flies, and his investigations lead him to suppose that sleeping sickness may be carried by several species. Other diptera also carry Trypanosomes, such as Storm Flies (Stomoxys).

\section{Pupipara or Eproboscidæ.}

The pupipara are all blood-suckers, the majority occurring as parasites on mammals and birds. Occasionally some may attack man. They all produce their young fully formed as puparia. The puparia are large and when passed out may contain a nearly mature pupa. One puparium is passed at a time. They are mostly flat, louse-like flies which may or may not be winged. The winged forms have a short quick flight, and when disturbed will seek shelter in man's hair or beard. Two main families occur (I) the Hippoboscida and (2) the Nycteribida. The former occur on animals and birds, the latter on birds only, but may invade man. Two other families are known-the Braulide (bee parasites) and the Strebbida (bat parasites).

The mouth of the Hippoboscidee is long and sharp, forming a proboscis. Thorax and abdomen are flat and leathery. The legs are stout and strong and terminate in large dentate claws and other structures of use in holding on to the hair or feathers of their host when blood-sucling. 
Two wings are present in the true Hippoboscas, Hippobosca equina (of the horse), $H$. camelina (of the camel), H. maculata (of oxen), and $H$. canis (of dogs), or absent in Melophagus, the Sheep Tick or Ked Fly ( $M$. ovinus).

In one genus, Lipotena, wings are at first present, but are lost as soon as the fly finds its permanent host.

As recently suggested, these parasites may have some connection with the spread of Trypanosomiasis (vide Journal of Pathology, 1904, Theiler).-F. V. T.]

The following is the most important literature on Diptera in general:-Meigen, J. W., Syst. Besch. d. bek. eurr.p. zweiflügligen insecten., 7 vols., Hamm., 1818-1838; Brauer, F., Monographie der Estriden, Wien., I86.3; “Idem, Nachtr. hierzu" (Wien. entom. Ztg., I887, vi., pp. 4, 7I); Schiner, J. R., Fauna austriaca, die Fliegen., Wien., 1860-64; Löw, Fr., "Ueber Myiasis und ihre Erzenger" (Wien. med. Wchnsıhr., I 882, xxii., p. 247 ; 1883 , xxxiii., p. 972 ; Joseph, G., "Ueb. Fliegen als Schädlinge und Parasiten des Menschen" (Dtsch. med. Ztg., I885, i., p. 37 ; 1887, iii., pp. 713 and 725); Peiper, E., Fliegenlarven als gelegentl. Paras. d. Mensch., Berlin, 1900; Theobald, F. V. "Monograph of the Culicidæ of the World," 3 vols, and I atlas, plates, I90I-1903; Austen, E., "A Monograph of Glossina Tsetse Flies," I vol., roo3. The full special literature will be found in Peiper as well as in Huber's Bibliografhie $d$. klin. Entomol., I 899, vol. 3, Jena. 


\section{INDEX.}

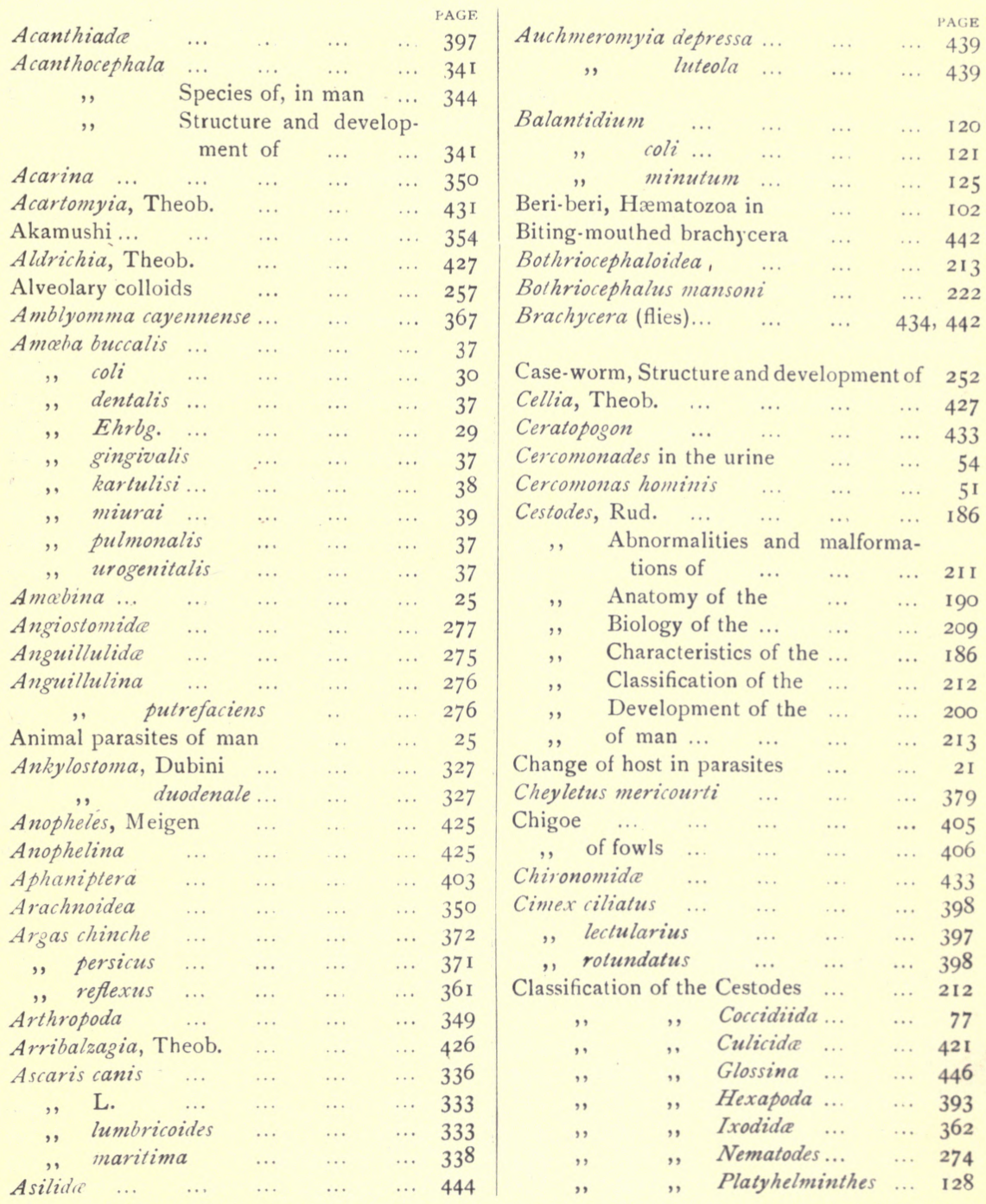


Classification of the Prolozoa

, ", Trematodes

Coccidia of dura mater ...

Cocciliida.

, Classification of the..

,, Development of the

, History of the

, Occurrence of the ..

, The, observed in man

Coccidioides immitis

Coccidium bigeminum

$$
\begin{aligned}
& \text {, cuniculi } \\
& \text {, Doubtful species of ... } \\
& \text {, hominis }
\end{aligned}
$$

Coleoptera...

Conorhinus nigrovarius...

$$
\begin{aligned}
& \text { protractus ... } \\
& \text { renggeri ... } \\
& \text { rubrofasciatus } \\
& \text { sanguisuga ... } \\
& \text { sp. novum } \\
& \text { variegatus }
\end{aligned}
$$

Coriscus subcoleoptratus ...

Cotylogonimus heterophyes

Culex, Linnæus ...

Culicidx or mosquitoes ...

Culicina

Cycloleppieron, Theob. ...

Cysticercus acanthotrias..

Davainea asiatica

$$
\begin{array}{lll}
, & \text { madagascariensis } & \ldots \\
, & \text { R. Blanch. ... }
\end{array}
$$

Derivation of parasites

Dermacentor reticulatus... $\quad$.. $\quad$.. 368

$\begin{array}{llllll}\text { Dermanyssus gallina } & \ldots & \ldots & \ldots & 358\end{array}$

$$
\begin{array}{lllll}
\text { hirundinis } & \ldots & \ldots & 35^{8}
\end{array}
$$

Dermatobia cyaniventris $\quad \ldots \quad$... $44 \mathrm{I}$

$$
\text { , noxialis ... ... ... 44I }
$$

Development of the Acanthocephala ... 34 I

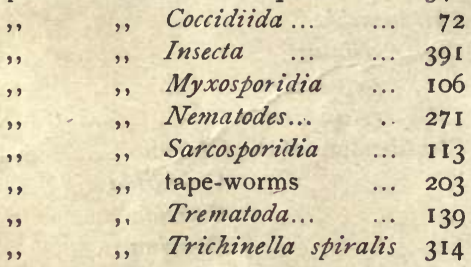

$\begin{array}{lllll}\text { Dibothriocephalus } & \ldots & \ldots & \ldots & \mathbf{2} \mathbf{I} 3\end{array}$

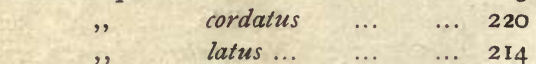

Dicrocrelium, Dag.
PAGE

Dicrocalium lanceatum ... $\quad . . \quad \ldots \quad \ldots \quad 174$

Diplogonoporus grandis ... $\quad$... $\quad \ldots \quad 22$ I

$\begin{array}{cllll}\text {,, Lönnbrg. } & \text {.. } & \text {... } 22 \text { I }\end{array}$

$\begin{array}{lllllll}\text { Diptera } & \ldots & \ldots & \ldots & \ldots & \ldots & 403\end{array}$

$\begin{array}{lllll}\text { Dipylidium caninum } & \ldots & \ldots & \ldots & 223\end{array}$

$\begin{array}{lllll}\text {, } & \text { R. Leuck. .... } & \ldots & \ldots & 223\end{array}$

Distomum rathouisi $\quad \ldots \quad$... $\quad \ldots \quad 159=$

Doubtful species of Coccidia $\quad$... $\quad$.. $\quad 82$

Echinococcus multilocularis $\quad \ldots \quad \ldots \quad 257$

", Structure of $\quad \ldots \quad \ldots \quad 252$

$\begin{array}{lllll}\text { Echinorhynchus gigas } & \ldots & \ldots & \ldots & 344\end{array}$

,, hominis... $\quad \ldots \quad$... 344

," moniliformis ... ... 345

$\begin{array}{lllll}\text { Eimeria hominis... } & \ldots & \ldots & \ldots & 82\end{array}$

$\begin{array}{llllllll}\text { Entozoa } & \ldots & \ldots & \ldots & \ldots & \ldots & 2\end{array}$

$\begin{array}{llllllll}\text { Epizoa } & \ldots & \ldots & \ldots & \ldots & \ldots & 2\end{array}$

$\begin{array}{llllll}\text { Eproboscida } & \ldots & \ldots & \ldots & \ldots & 447\end{array}$

$\begin{array}{lllllll}\text { Eupodide ... } & \ldots & \ldots & \ldots & \ldots & 357\end{array}$

Eustrongy!us, Dies. $\quad \ldots \quad$... $\quad \ldots \quad 322$

$$
\begin{array}{lllllll}
, & \text { gigas } & \ldots & \ldots & \ldots & 322
\end{array}
$$

Fasciola hepatica :.. $\quad \ldots \quad \ldots \quad$ 150, 156

$\begin{array}{lllllll}\text {," } \quad \text { L. } & \text {.. } & \ldots & \text {.. } & \text { I } 49\end{array}$

Fasciolide, Raill.... $\quad \ldots . \quad \ldots . \quad \ldots \quad$ I49

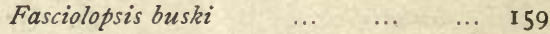

$\begin{array}{lllllll} & \text { L } & \text { Looss } & \ldots & \ldots & \ldots & \text { I58 }\end{array}$

$\begin{array}{llllll}\text { Filaria bancrofti... } & \text {.. } & \ldots & \ldots & 288\end{array}$

$\begin{array}{llllll}\text {, conjunctive } & \ldots & \ldots & \ldots & 303\end{array}$

$\begin{array}{llllll}\text {,, demarquayi } & \ldots & \ldots & \ldots & 296\end{array}$

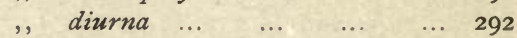

$\begin{array}{lllllll}\text {,, equina } & \ldots & \ldots & \ldots & \ldots & 305\end{array}$

$\begin{array}{llllll}\text {, hominis oris } & \ldots & \ldots & & & \\ & \text {.. } & 305\end{array}$

$\begin{array}{lllllll}\text {, immitis } & \ldots & \ldots & \ldots & \ldots & 285\end{array}$

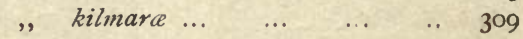

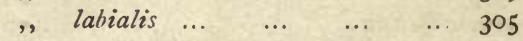

$\begin{array}{lllllll}\text {, } & \text { loa } & \ldots & \ldots & \ldots & \ldots & 300\end{array}$

$\begin{array}{llllll}\text {," magalhãesi } & \text {... } & \text {.. } & \text {... } & 299\end{array}$

$\begin{array}{llllll}\text {," medinensis } & \ldots & \ldots & \ldots & 282\end{array}$

$\begin{array}{llllll} & \text {, occuli humani } & \ldots & \ldots & \ldots & 302\end{array}$

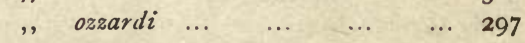

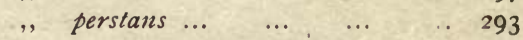

$\begin{array}{lllll}\text {,, romanorum-orientalis .. } & \text {.. } & 307\end{array}$

$\begin{array}{llllllll}\text {,, } & \text { sp. } & \ldots & \ldots & \ldots & \ldots & 309\end{array}$

$\begin{array}{lllllll} & \text {, volvulus } \ldots & \ldots & \ldots & \ldots & 307\end{array}$

Flagellata (Mastigophora) $\quad$... $\quad \ldots \quad$ 4 I

$\begin{array}{llllll}\text { Flat-worms } & \ldots & \ldots & \ldots & \ldots & \mathbf{1 2 7}\end{array}$

$\begin{array}{lllllll}\text { Fleas } & \ldots & \ldots & \ldots & \ldots & \ldots & 403\end{array}$

Flies $($ Brachycera) $\quad$.. $\quad \ldots \quad \ldots 434$

$\begin{array}{lllllll}\text { Gad-flies } & \ldots & \ldots & \ldots & \ldots & \ldots & 442\end{array}$

$\begin{array}{llllllll}\text { Gamasida ... } & \ldots & \ldots & \ldots & \ldots & 358\end{array}$

$\begin{array}{llllll}\text { Gastrodiscus hominis } & \ldots & \ldots & \ldots & \text { I } 49\end{array}$

$\begin{array}{llllll}\text { Gastrophilus, sp. ... } & \text {.. } & \ldots & \ldots & 440\end{array}$ 
General characteristics of the Protozoa... $\quad 25$

$\begin{array}{llllllll}\text { Glossina } & \ldots & \ldots & \ldots & \ldots & \ldots & 446\end{array}$

$\begin{array}{llllll}\text { Glyciphagus buski } & \ldots & \ldots & \ldots & 377\end{array}$

$\begin{array}{llllll}\text {,, } & \text { prunorum } & \ldots & \ldots & \ldots & 377\end{array}$

Gnathostoma, Owen $\quad \ldots \quad \ldots . \quad \ldots \quad$ 28 I

$\begin{array}{llllll}\text { Gnathostomide } & \ldots & \ldots & \ldots & \ldots & 28 \text { I }\end{array}$

$\begin{array}{llllll}\text { Gordiacea ... } & \ldots & \ldots & \ldots & \ldots & 340\end{array}$

Grabhamia, Theob. $\quad \ldots \quad \ldots \quad$... 430

$\begin{array}{lllllll}\text { Gregarinida } & \ldots & \ldots & \ldots & \ldots & 63\end{array}$

$\begin{array}{llllll}\text { Guinea-worm } & \ldots & \ldots & \ldots & \ldots & 282\end{array}$

$\begin{array}{lllllll}\text { Hamadipsa } & \ldots & \ldots & \ldots & \ldots & 348\end{array}$

$\begin{array}{llll}\text { Hamamabe in leucæmia } \quad \ldots & \ldots & \text { I03 }\end{array}$

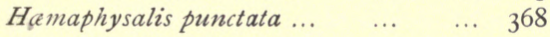

Hamatozoa in beri-beri ... $\quad \ldots \quad \ldots \quad \ldots \quad$ IO2

$\begin{array}{lllllll}\text { Hamentaria } & \ldots & \ldots & \ldots & \ldots & 348\end{array}$

$\begin{array}{lllllll}\text { Hamosporidia } & \ldots & \ldots & \ldots & \ldots & 84\end{array}$

Jigger

Jointed-limbed animals

$\begin{array}{lllllll}\text { Kedani } & \ldots & \ldots & \ldots & \ldots & \ldots & 354\end{array}$

$\begin{array}{lllll}\text { Lamblia, Blanch. } & \ldots & \ldots & \ldots & 48\end{array}$

$\begin{array}{llllll}, \text { intestinalis } & \ldots & \ldots & \ldots & 48\end{array}$

$\begin{array}{llllllll}\text { Leeches } & \ldots & \ldots & \ldots & \ldots & \ldots & 345 \\ & \text { with jaws } & & & \end{array}$

$\begin{array}{llllll}\text { " } & \text { with jaws } & \ldots & \ldots & \ldots & 347\end{array}$

$\begin{array}{llllll}\text {, with rostrum } & \ldots & \ldots & \ldots & 348\end{array}$

$\begin{array}{llllll}\text { Leptus autumnalis } & \ldots & \ldots & \ldots & 35 \mathrm{I}\end{array}$

Leucæmia, Hæmamœba in $\quad \ldots \quad$... 103

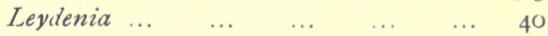

$\begin{array}{llllllll}\text { Lice } & \ldots & \ldots & \ldots & \ldots & \ldots & 394\end{array}$

$\begin{array}{lllllll}\text { Limnatis .. } & \ldots & \ldots & \ldots & \ldots & 348\end{array}$

$\begin{array}{llllll},, & \text { nilotica } & \ldots & \ldots & \ldots & 348\end{array}$

$\begin{array}{lllll}\text { Linguatula rhinaria } & \ldots & \ldots & \ldots & 387\end{array}$

$\begin{array}{lllllll}\text { Linguatulide } & \ldots & \ldots & \ldots & \ldots & 387\end{array}$

$\begin{array}{llllll}\text { Liver fluke } & \ldots & \ldots & \ldots & \ldots & \text { I } 50\end{array}$

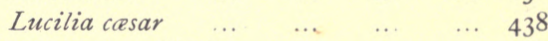

$\begin{array}{llllll}\text { Helminthes } & \ldots & \ldots & \ldots & \ldots & 2\end{array}$

$\begin{array}{llllll}\text { Hermaphroditism } & \ldots & \ldots & \ldots & 4\end{array}$

$\begin{array}{lllllll}\text { Hexapoda ... } & \ldots & \ldots & \ldots & \ldots & \ldots & 390\end{array}$

Hirudinea, sp. Discophora $\quad \ldots \quad \ldots \quad \ldots 345$

$\begin{array}{llllll}\text { Hirudo, L. } & \ldots & \ldots & \ldots & \ldots & 347\end{array}$

$\begin{array}{llllll}\text {, } & \text { medicinalis } & \ldots & \ldots & \ldots & 347\end{array}$

$\begin{array}{llllll},, & \text { troctina ... } & \ldots & \ldots & \ldots & 347\end{array}$

$\begin{array}{lllll}\text { Histiogaster spermaticus... } & \ldots & \ldots & 378\end{array}$

Holothyrus coccinella $\quad \ldots \quad \ldots \quad \ldots \quad \ldots \quad 359$

$\begin{array}{llllll}\text { Homalomyia scalaris } & \ldots & \ldots & \ldots & 436\end{array}$

$\begin{array}{lllll}\text { Hyalomma agyptium } & \ldots & \ldots & \ldots & 367\end{array}$

$\begin{array}{lllll}\text { Hymenolepis diminuta } & \ldots & \ldots & \ldots & 229\end{array}$

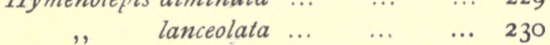

$\begin{array}{llllll}\text {,, macellaria } & \ldots & \ldots & \ldots & 436\end{array}$

$\begin{array}{llllll}\text {,, nobilis } & \ldots & \ldots & \ldots & \ldots & 437\end{array}$

$\begin{array}{lllll}\text { Lyctocoris campestris } & \ldots & \ldots & \ldots & 402\end{array}$

$\begin{array}{lllllll}\text { Lygaida } & \ldots & \ldots & \ldots & \ldots & \ldots & 402\end{array}$

Malaria plasmodia, Sporogony of $\quad \ldots \quad 95$

,, Prophylaxis of ... $\quad \ldots \quad$...

$\begin{array}{llll}\text { Man, animal parasites of } & \ldots & \ldots & 25\end{array}$

$\begin{array}{lllll}\text { Mansonia, Blanch. } \quad \ldots & \ldots & \ldots & 430\end{array}$

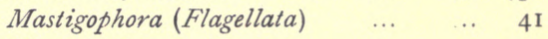

$\begin{array}{llllll}\text { Megarhinina } & \ldots & \ldots & \ldots & \ldots & 427\end{array}$

$\begin{array}{llllll}\text { Megarhinus } & \ldots & \ldots & \ldots & \ldots & 427\end{array}$

Melanoconion, Theob. $\quad \ldots \quad \ldots \quad \ldots \quad \ldots 430$

$\begin{array}{llll}\text { Melanolestes abdominalis } & \ldots & \text {... } & 402\end{array}$

$\begin{array}{llllll},, & \text { nana } & \ldots & \ldots & \ldots & 226\end{array}$

$\begin{array}{llllll} & \text {, } & \text { Weinland } \ldots & \ldots & \ldots & \mathbf{2 2 5}\end{array}$

$\begin{array}{llllll}\text { Hypoderma bovis... } & \ldots & \ldots & \ldots & \ldots & 440\end{array}$

$\begin{array}{llllll}, & \text { diana } & \ldots & \ldots & \ldots & 440\end{array}$

Incidental and pseudo-parasites

Influence of parasites on the host

Infusoria ...

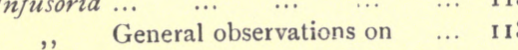

$\begin{array}{lllllll}\text { Insecta } & \ldots & \ldots & \ldots & \ldots & \ldots & 390\end{array}$

, Structure, development and classification of... $\quad \ldots \quad \ldots \quad 39 I$

$\begin{array}{lllllll}\text { Itch mites... } & \ldots & \ldots & \ldots & \ldots & 379\end{array}$

$\begin{array}{llllll}\text { Ixodes hexagonus... } & \ldots & \ldots & \ldots & 366\end{array}$

$\begin{array}{lllllll},, & \text { reduvius } & \ldots & \ldots & \ldots & \ldots & 364\end{array}$

$\begin{array}{llllllll}\text { Ixodide } & \ldots & \ldots & \ldots & \ldots & \ldots & 360\end{array}$

$\begin{array}{lllll}\text {,, Classification of ... } & \ldots & \ldots & 362\end{array}$

," $\begin{array}{lllll}\text {, Genera of } \quad \ldots & \ldots & \ldots & 360\end{array}$

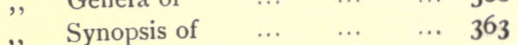

Janthinosoma, Arribalzaga

428

$\cdots+\cdots+\cdots$

Microsporidia $\quad \ldots \quad \ldots \quad$... $\quad \ldots \quad$ I 10

$\begin{array}{llllllll}\text { Mites } & \ldots & \ldots & \ldots & \ldots & \ldots & 350\end{array}$

$\begin{array}{llllll}\text {,, of the hair follicles } \quad . . & \ldots & 385\end{array}$

$\begin{array}{llllll}\text { Monas pyophila } & \ldots & \ldots & \ldots & \ldots & 54\end{array}$

$\begin{array}{llllll}\text { Monocystide gregarines ... } & \ldots & \ldots & 84\end{array}$

$\begin{array}{llllll}\text { Mosquitoes } & \ldots & \ldots & \ldots & \ldots & 407\end{array}$

Acartomyia, Theobald $\quad \ldots \quad$... 43 I

$\begin{array}{llll}\text { Aldrichia, Theobald } \quad \ldots & \ldots & 427\end{array}$

Anopheles, Meigen ... ... ... 425

Anophelina (sub-family) $\quad \ldots \quad \ldots \quad$... 425

Arribalzagia, Theobald ... $\quad$... 426

$\begin{array}{lllll}\text { Cellia, Theobald } & \ldots & \ldots & \ldots & 427\end{array}$

$\begin{array}{llll}\text { Classification of Culicida } & . . . & \ldots & 42 \mathrm{I}\end{array}$

$\begin{array}{lllll}\text { Culex, Linnæus } \quad \ldots & \ldots & \ldots & 429\end{array}$

$\begin{array}{llllll}\text { Culicida } & \ldots & \ldots & \ldots & \ldots & 4 \mathrm{I} 5\end{array}$

$\begin{array}{lllll}\text { Culicina (sub-family) } \quad \ldots & \ldots & 427\end{array}$

Cycloleppleron, Theobald ... $\quad \ldots \quad 425$ 
Mosquitoes - continued.

Grabhamia, Theobald

Janthinosoma, Arribalzas

... 430

Megarhinina (sub-family) ... $\quad$.. $\quad 427$

Megarhinus (Robineau-Desvoidy)... 427

Melanoconion, Theobald ... $\quad$... 429

Mucidus, Theobald... $\quad \ldots \quad \ldots \quad$... 426

Myzomia, Blanch. ... $\quad \ldots \quad \ldots \quad 425$

Myzorhynchus, Blanch. $\quad \ldots \quad \ldots \quad 426$

Nyssorhynchus, Blanch. ... $\quad$... 426

$\begin{array}{llllll}\text { Psorophora ... } & \ldots & \ldots & \ldots & 428\end{array}$

Pyretophorus, Blanch. ... $\quad \ldots \quad 426$

$\begin{array}{lllll}\text { Stegomyia scutellaris } & \ldots & \ldots & 428\end{array}$

$\begin{array}{llll}\text { Stegomyia, Theobald } & \ldots & \ldots & 428\end{array}$

Stethomyia, Theobald _.. $\quad \ldots \quad 426$

7 aniorhynchus $\quad \ldots \quad$... $\quad \ldots \quad 430$

$\begin{array}{lllll}\text { Theobaldinella annulata } & \text {.. } & \text {... } & 429\end{array}$

Theobaldinella, Blanch. $\quad \ldots \quad \ldots \quad$.. 428

$\begin{array}{llll}\text { Toxorhynchitis, Theobald ... } & \ldots & 427\end{array}$

Mosquitoes or Culicidæe ... $\quad \ldots \quad \ldots \quad 4$ I 5

Mucidus, Theob.... $\quad \ldots \quad$... $\quad \ldots \quad 426$

$\begin{array}{llllll}\text { Musca domestica } & \ldots & \ldots & \ldots & \ldots & 436\end{array}$

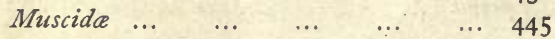

$\begin{array}{llllll}\text { Mutualists ... } & \ldots & \ldots & \ldots & \ldots & 6\end{array}$

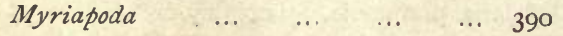

$\begin{array}{llllll}\text { Myxosporidia } & \ldots & \ldots & \ldots & \ldots & \\ \end{array}$

,, History of $\quad \ldots \quad \ldots . \quad 106$

, Structure and Develop$\begin{array}{llll}\text { ment } \text { of } \ldots & \text {... } & \ldots & 108\end{array}$

$\begin{array}{lllll}\text { Myzomia, Blanch. } & \ldots & \ldots & \ldots & 425\end{array}$

$\begin{array}{lllll}\text { Myzorhynchus, Blanch. ... } & \ldots & \ldots & 426\end{array}$

Nematocera

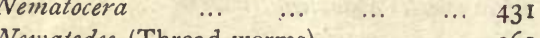

Nhread-worms) $\quad . . \quad \ldots \quad 26 r$

$\begin{array}{lllll}\text {,, Anatomy of the } & \ldots & \ldots & 262\end{array}$

," Classification of the... ... 274

,, Development of the ... 271

observed in man .... ... 275

$\begin{array}{lllll}\text { Nephrophages sanguinarius } & \ldots & \ldots & 384\end{array}$

Notes on different genera of mosquitoes 425

$\begin{array}{llllll}\text { Nyctotherus faba } & \ldots & \ldots & \ldots & \ldots & 126\end{array}$

$\begin{array}{llllll} & \text { Leidy... } & \ldots & \ldots & \ldots & 126\end{array}$

Nyssorhynchns, Blanch.... $\quad \ldots \quad \ldots 426$

Occasional and permanent parasitism ... I I

Ochromyia anthropophaga $\quad$... $\quad \ldots \quad 439$

Opisthorchis noverca $\quad \ldots \quad \ldots \quad \ldots \quad \ldots .170$

$\begin{array}{llllll}\text {, sinensis } & \ldots & \ldots & \ldots & 168\end{array}$

$\begin{array}{lllll}\text { Origin of parasites } & \ldots & \ldots & \ldots & \text { I0 }\end{array}$

Ornithodorus mégnini $\quad \ldots \quad \ldots \quad \ldots \quad \ldots .374$

$\begin{array}{llllll} & \text {, savignyi } & \ldots & \ldots & \ldots & 372\end{array}$

$\begin{array}{llllll},, & \text { taleji } & \ldots & \ldots & \ldots & 373\end{array}$

$\begin{array}{llllll}\text {,, tholozani } & \ldots & \ldots & \ldots & 373\end{array}$

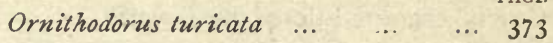

$\begin{array}{lllllll}\text { Owl midge } & \ldots & \ldots & \ldots & \ldots & 434\end{array}$

$\begin{array}{lllll}\text { Oxyuris rudolphi } & \ldots & \ldots & \ldots & 338\end{array}$

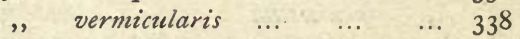

Paragonimus, Braun _.. $\quad$... $\quad . . \quad 160$

. $\quad$ zestermani $\quad \ldots . \ldots \quad \ldots \quad$ I60

$\begin{array}{llllll}\text { Paramphistomida } & \ldots & \ldots & \ldots & \mathbf{1} 49\end{array}$

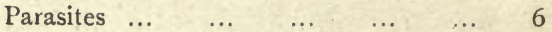

," Derivation of ... ... ... 20

, Incidental and pseudo. $\quad \ldots \quad 6$

, Influence of, on the host ... 8

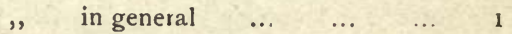

, Origin of $\quad$... $\quad \ldots . \quad \ldots \quad$ do

$\begin{array}{lllll}\text { Pediculoides ventricosus ... } & \ldots & \ldots & 356\end{array}$

Permanent and occasional parasitism ... I

$\begin{array}{lllllll}\text { Phora rufipes } & \ldots & \ldots & \ldots & \ldots & 435\end{array}$

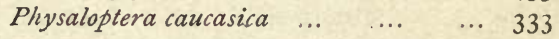

$\begin{array}{lllllll}\text {,, } & \text { Rud. } & \ldots & \ldots & \ldots & 332\end{array}$

$\begin{array}{lllllll}\text { Piophila casei } & \ldots & \ldots & \ldots & \ldots & \ldots & 435\end{array}$

$\begin{array}{lllllll}\text { Placobilella } & \ldots & . & \ldots & \ldots & \ldots & 348\end{array}$

Plasmodium, Doubtful species of $\quad$... 95

$\begin{array}{llllll}\text {, } & \text { malaria } & \ldots & \ldots & \ldots & 92\end{array}$

$\begin{array}{lllllll}\text {, } & \text { sp. ... } & \ldots & \ldots & \ldots & 94\end{array}$

$\begin{array}{llllll},, & \text { vivax } & \ldots & \ldots & \ldots & 93\end{array}$

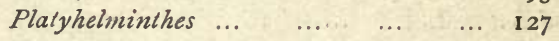

$\begin{array}{lllllll}\text { Polymastigina } & \ldots & \ldots & \ldots & \ldots & & \\ \end{array}$

Porocephalus constrictus ... $\quad$... $\quad$.. 390

Prophylaxis of malaria $\ldots . \quad \ldots \quad$...

$\begin{array}{lllllll}\text { Protomonadina } & \ldots & \ldots & \ldots & \ldots & 5 \text { I }\end{array}$

$\begin{array}{llllllll}\text { Prolozoa } & \ldots & \ldots & \ldots & \ldots & \ldots & \ldots & 25\end{array}$

$\begin{array}{llllll}\text {," Classification } & \text {... } & \ldots & \ldots & 27\end{array}$

" General characteristics of ... 25

$\begin{array}{llllll}\text { Pseudo-parasites ... } & \ldots & \ldots & \ldots & 6\end{array}$

$\begin{array}{lllllll}\text { Psorophora } & \ldots & \ldots & \ldots & \ldots & 428\end{array}$

$\begin{array}{llllll}\text { Psorosperm cysts ... } & \ldots & \ldots & \ldots & 84\end{array}$

$\begin{array}{llllll}\text { Psychodida } & \ldots & \ldots & \ldots & \ldots & \\ \end{array}$

$\begin{array}{llllll}\text { Pulex fasciatus } & \ldots & \ldots & \ldots & \ldots & 407\end{array}$

$\begin{array}{lllllll}\text {, irritans } & \ldots & \ldots & \ldots & \ldots & 403\end{array}$

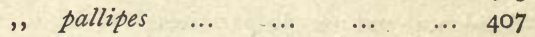

$\begin{array}{lllllll}\text {,, penetrans ... } & \ldots & \ldots & \ldots & 405\end{array}$

$\begin{array}{lllllll}\text { Pupipara } & \ldots & \ldots & \ldots & \ldots & \ldots & 447\end{array}$

Pyrelophorus, Blanch. ... $\quad \ldots \quad$... 426

Rasahus biguttatus $\quad$... $\quad \ldots \quad$... 401

$\begin{array}{lllllll}\text { Reduviide } & \ldots & \ldots & \ldots & \ldots & 398\end{array}$

Reduvius personatus $\quad$... $\quad$.... $\quad$... 400

Rhabdutis, Dujardin $\quad \ldots \quad \ldots . \quad \ldots \quad 275$

$\begin{array}{llllll}\text {," } & \text { niellyi... } & \ldots & \ldots & \ldots & 276\end{array}$

$\begin{array}{lllllll} & \text { " pellio ... } & . & \ldots & \ldots & 275\end{array}$

$\begin{array}{lllll}\text { Rhipicephalus sanguineus } & \ldots & \ldots & 369\end{array}$

$\begin{array}{llll}\text { Rhizoglyphus parasiticus } & \ldots & \ldots & 378\end{array}$

$\begin{array}{rrrrrrr}\text { Rhizopoda ... } & \ldots & \ldots & \ldots & \ldots & \ldots & 29\end{array}$

$\begin{array}{lllll}\text { Rhodinus prolixus } & \ldots & \ldots & \ldots & 402\end{array}$

$\begin{array}{llllll}\text { Rhynchobdellida } & \ldots & \ldots & \ldots & \ldots & 348\end{array}$ 
Rhynchota aptera s. parasitica ... PAGE

$\begin{array}{llll} & & & \\ & & \end{array}$

$\begin{array}{llllll}\text {," hemiptera } & \ldots & \ldots & \ldots & 397\end{array}$

$\begin{array}{llllllll}\text { Ryncota } & \ldots & \ldots & \ldots & \ldots & \ldots & \ldots & 394\end{array}$

Running mites $\quad \ldots \quad \ldots \quad \ldots \quad \ldots, 35 \mathrm{I}$

Sand-flies or Simulidæ $\ldots \quad \ldots \quad \ldots \quad 43$ I

$\begin{array}{llllll}\text { Sarcophaga carnaria } & \ldots & \ldots & \ldots & 438\end{array}$

$\begin{array}{llllll}\text {, } & \text { magnifica } & \ldots & \ldots & \ldots & 438\end{array}$

$\begin{array}{lllll}\text { Sarcopsylla gallinacea } & \ldots & \ldots & \ldots & 406\end{array}$

$\begin{array}{llllll}\text {,, penetrans } & \ldots & \ldots & \ldots & 405\end{array}$

Sarcoptes minor $\ldots \quad \ldots \quad \ldots \quad \ldots . \quad \ldots \quad 383$

$\begin{array}{llllll}, & \text { scabiei... } & \ldots & \ldots & \ldots & 380\end{array}$

$\begin{array}{lllllll}\text { Sarcoptide } & \ldots & \ldots & \ldots & \ldots & 379\end{array}$

$\begin{array}{llllll}\text { Sarcosporidia } & \ldots & \ldots & \ldots & \ldots & \text { I I } 2\end{array}$

, $\quad$ History of the $\quad \ldots \quad \ldots \quad$ I 2

,, Structure and develop-

ment of the ... ... II 3

,, The, observed in man ... I 6

$\begin{array}{llllll}\text { Schistosomide } & \ldots & \ldots & \ldots & \ldots & \text { I76 }\end{array}$

$\begin{array}{lllll}\text { Schistosomum hamatobium } & \ldots & \ldots & \mathbf{1} 76\end{array}$

,, japonicum $\quad \ldots \quad \ldots \quad$ I 8 I

Severi's monocystide gregarines $\quad \ldots \quad 84$

$\begin{array}{llllll}\text { Silvanus surinamensis } & \ldots & \ldots & \ldots & \ldots & 403\end{array}$

$\begin{array}{lllllll}\text { Simulida } & \ldots & \ldots & \ldots & \ldots & \ldots & 43 \text { I }\end{array}$

Simulium maculatum $\quad \ldots \quad \ldots \quad \ldots \quad \ldots \quad 432$

$\begin{array}{llllll}\text { Spiders, mites } & \ldots & \ldots & \ldots & \ldots & 350\end{array}$

Sporogony of malaria plasmodia $\quad$.. 95

$\begin{array}{llllllll}\text { Sporozoa } & \ldots & \ldots & \ldots & \ldots & \ldots & 63\end{array}$

$\begin{array}{llllll}\text { Stegomyia scutellaris } & \ldots & \ldots & \ldots & 428\end{array}$

$\begin{array}{lllll}\text { Stegomyia, Theob. } & \ldots & \ldots & \ldots & 428\end{array}$

Stethomyia, Theob. $\quad \ldots \quad \ldots . \quad \ldots \quad 426$

$\begin{array}{llllll}\text { Strongylide } & \ldots & \ldots & \ldots & \ldots & 322\end{array}$

Strongyloides, Grassi__... $\quad \ldots \quad \ldots \quad \ldots \quad 27 \%$

$\begin{array}{llllll}\text { Strongylus apri } & \ldots & \ldots & \ldots & \ldots & 324\end{array}$

$\begin{array}{lllll}, y & \text { O. F. Müller } & \ldots & \ldots & 324 \\ & \text { subtilis }\end{array}$

$\begin{array}{llllll}\prime, & \text { subtilis } & \ldots & \ldots & \ldots & 326\end{array}$

Systematic, anatomical, and biological

remarks on mosquitoes $\quad \ldots \quad \ldots 407$

$\begin{array}{lllllll}\text { Tabanide } & \ldots & \ldots & \ldots & \ldots & \ldots & 442\end{array}$

$\begin{array}{lllllll}\text { Tania } & \ldots & \ldots & \ldots & \ldots & \ldots & 233\end{array}$

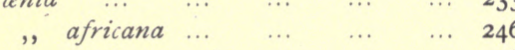

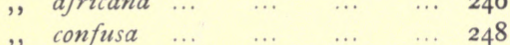

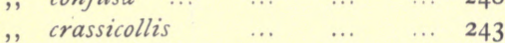

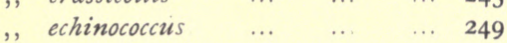

,, hominis ... $\quad \ldots \quad$... $\quad \ldots \quad 26 \mathrm{I}$

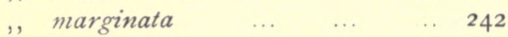

,, saginata ..
Tania serrata

PAGE

$\begin{array}{lll}\ldots & \ldots & \\ \ldots & & \end{array}$

$\begin{array}{llllll}, \text {, solium } & \ldots & \ldots & \ldots & \ldots & 234\end{array}$

$\begin{array}{llllllll}\text { Taniida } & \ldots & \ldots & \ldots & \ldots & \ldots & \ldots & 223\end{array}$

$\begin{array}{lllllll}\text { Taniorhynchus } & \ldots & \ldots & \ldots & \ldots & 430\end{array}$

$\begin{array}{lllllll}\text { Tape-worms } & \ldots & \ldots & \ldots & \ldots & \text { I } 86\end{array}$

,, Biology of the $\quad$... ... 209

,, Development of the ... 200

$\begin{array}{lllllll}\text { Tarsonemide } & \ldots & \ldots & \ldots & \ldots & 356\end{array}$

$\begin{array}{llllll}\text { Tetranychide } & \ldots & \ldots & \ldots & \ldots & 355\end{array}$

Tetranychus molestissimus $\quad \ldots \quad$... 355

$\begin{array}{lllllll} & \text {, } & \text { telarius } & \ldots & \ldots & \ldots & 355\end{array}$

$\begin{array}{llllll}\text { Thread-worms } & \ldots & \ldots & \ldots & \ldots & 26 \mathrm{I}\end{array}$

$\begin{array}{llllllll}\text { Ticks } & \ldots & \ldots & \ldots & \ldots & \ldots & 360\end{array}$

$\begin{array}{lllll}\text { Theobaldinella annulata ... } & \text {... } & \text {.. } & 429\end{array}$

$\begin{array}{lllll}\text { Theobaldinella, Blanch. ... } & \ldots & \ldots & 428\end{array}$

Toxorhynchitis, Theob. ... $\quad \ldots \quad$... 427

$\begin{array}{llllll}\text { Transmigrations } & \ldots & \ldots & \ldots & \ldots & 6\end{array}$

$\begin{array}{lllll}\text { Trematoda, Rud.... } & \ldots & \ldots & \ldots & \text { I } 29\end{array}$

$\begin{array}{lllll}\text { Trematodes, Biology of } \ldots & \ldots & \ldots & \mathbf{I} 45\end{array}$

$\begin{array}{llll}, & \text { Classification of } \ldots & \ldots & \text { I } 47 \\ ,, & \text { Development of the } & \ldots & \text { I39 } \\ \text { observed in man } \ldots & \ldots & \text { I49 } \\ \text {,, } & \begin{array}{l}\text { Structure and development } \\ \end{array}\end{array}$

$\begin{array}{lllll}\text { of } \ldots & \ldots & \ldots & \ldots & \text { I } 29\end{array}$

Trichinella, Railliet $\quad \ldots \quad \ldots . \quad \ldots \quad$ 3I I

$\begin{array}{lllllll},, & \text { spiralis } & \ldots & \ldots & \ldots & 3 \mathbf{I} \mathbf{I}\end{array}$

," ,, Development of ... 3I4

$\begin{array}{lllll}\text { Trichocephalus, Goeze } & \ldots & \ldots & \ldots & 309\end{array}$

$\begin{array}{ccccc}\text { Trichomonas, Donné } & \text { trichiuris } & \ldots & \ldots & 309 \\ \end{array}$

$\begin{array}{lllll}\text {,, } & \text { intestinalis... } & \ldots & \ldots & 44\end{array}$

$\begin{array}{lllll}\text {,, } & \text { pulmonalis } & \ldots & & \\ \end{array}$

$\begin{array}{llllll}\text {,, } & \text { vaginalis } \ldots & \ldots & \ldots & 43\end{array}$

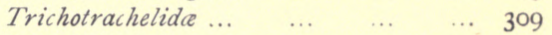

$\begin{array}{lllllll}\text { Trombidiide } & \ldots & \ldots & \ldots & \ldots & 35^{\mathbf{I}}\end{array}$

$\begin{array}{lllll}\text { Trombidium tlalsahuate ... } & \ldots & \ldots & 353\end{array}$

$\begin{array}{llllll}\text { Trypanosoma } & \ldots & \ldots & \ldots & \ldots & 57\end{array}$

$\begin{array}{llllll}\text {, } & \text { Gruby } & \ldots & \ldots & \ldots & 56\end{array}$

$\begin{array}{lllllll}\text { Tsetse-flies } & \ldots & \ldots & \ldots & \ldots & 446\end{array}$

$\begin{array}{lllllll}\text { Tydeus molestus } & \ldots & \ldots & \ldots & \ldots & 357\end{array}$

$\begin{array}{lllll}\text { Typhlopsylla musculi } & \ldots & \ldots & \ldots & 407\end{array}$

$\begin{array}{lllllll}\text { Tyroglyphide } & \ldots & \ldots & \ldots & \ldots & 374\end{array}$

$\begin{array}{llllll},, & \text { farine } & \ldots & \ldots & \ldots & 375\end{array}$

$\begin{array}{llllll}\text {, } & \text { longior } & \ldots & \ldots & \ldots & 375\end{array}$

$\begin{array}{lllllll}, \text {, } & \text { siro } & \ldots & \ldots & \ldots & 375\end{array}$

$\begin{array}{llllll}\text { Uncinaria americana } & \ldots & \ldots & \ldots & 33 \mathrm{I}\end{array}$

$\begin{array}{lllllll}\text { Wolf-flies } & \ldots & \ldots & \ldots & \ldots & \ldots & \ldots\end{array}$ 






\section{UNIVERSITY OF CALIFORNIA LIBRARY \\ BERKELEY}

Return to desk from which borrowed.

This book is DUE on the last date stamped below.

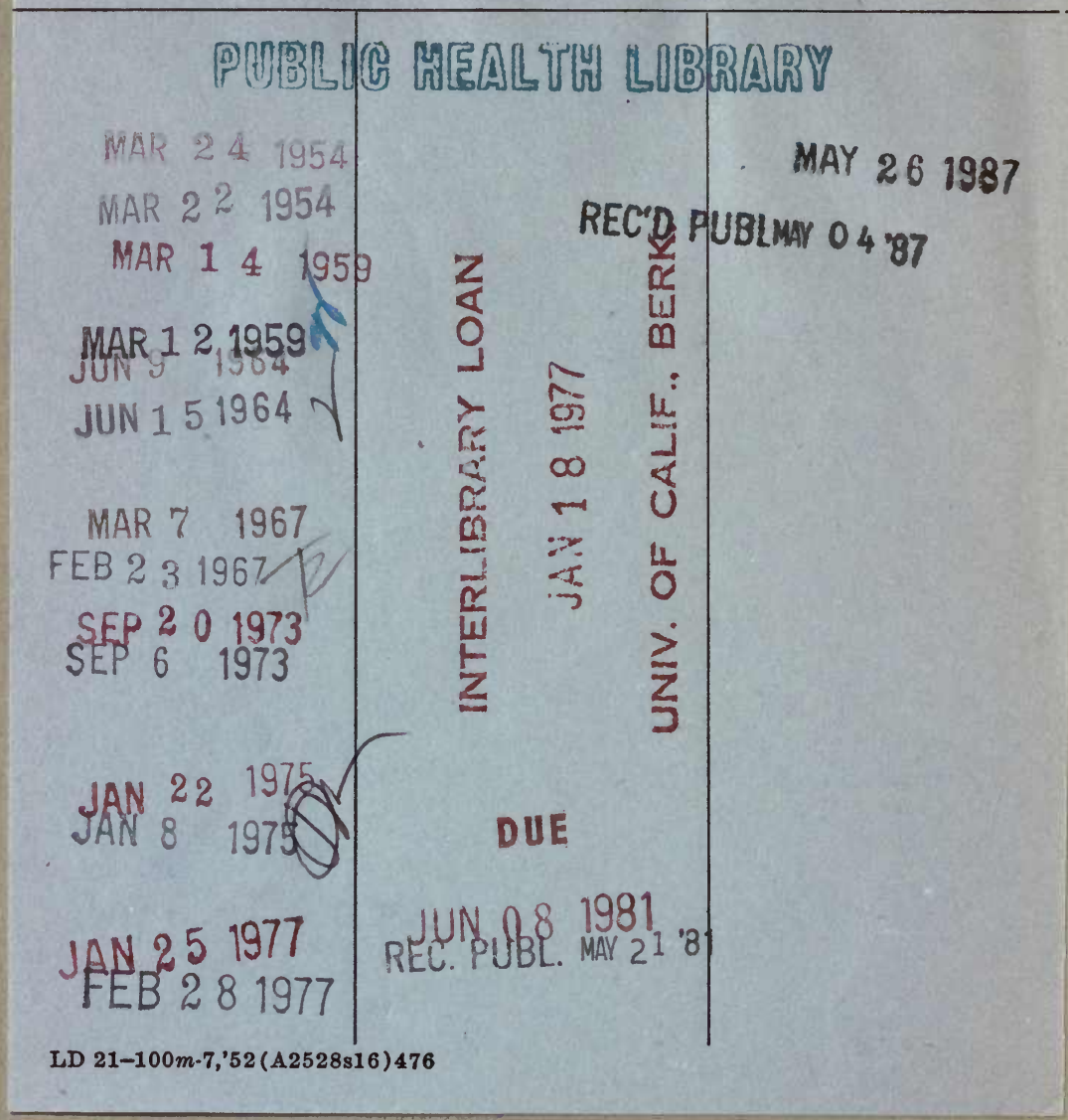


m 638661

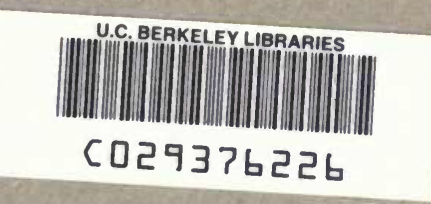


